Slavistische Beiträge · Band 424

(eBook - Digi20-Retro)

\title{
Hella Reese
}

\section{Ein Meisterwerk im Zwielicht}

Ivan Bunins narrative Kurzprosaverknüpfung

"Temnye allei"

\section{zwischen Akzeptanz und Ablehnung - eine Genrestudie}

Verlag Otto Sagner München · Berlin · Washington D.C.

Digitalisiert im Rahmen der Kooperation mit dem DFG-Projekt „Digi20“

der Bayerischen Staatsbibliothek, München. OCR-Bearbeitung und Erstellung des eBooks durch den Verlag Otto Sagner:

http://verlag.kubon-sagner.de

( $)$ bei Verlag Otto Sagner. Eine Verwertung oder Weitergabe der Texte und Abbildungen, insbesondere durch Vervielfältigung, ist ohne vorherige schriftliche Genehmigung des Verlages unzulässig. 


\title{
SLAVISTISCHE BEITRÄGE
}

\author{
Herausgegeben von \\ Peter Rehder
}

B eirat:
Tilman Berger $\bullet$ Walter Breu $\bullet$ Johanna Renate Döring-Smirnov
Walter Koschmal $\bullet$ Ulrich Schweier $\bullet$ Miloš Sedmidubsky $\bullet$ Klaus Steinke

BAND 424 


\section{Hella Reese \\ Ein Meisterwerk im Zwielicht:}

Ivan Bunins narrative Kurzprosaverknüpfung Temnye allei zwischen Akzeptanz und Ablehnung - eine Genrestudie

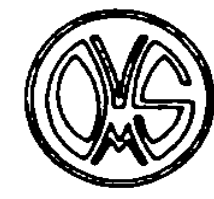

VERLAG OTTO SAGNER MÜNCHEN 2003 


\section{PVA}

2003.

2258

ISBN 3-87690-870-1

(1) Verlag Otto Sagner. München 2003

Abteilung der Firma Kubon \& Sagner

D-80328 München

Gedrucks auf alierungsbeständigem Papier

Bayerische
Staatsbibllotheh
Munctien 
Die vorliegende Studie wurde am 12. Juni 2003 von der Philosophischen Fakultät I der Universităt Potsdam als Dissertation angenommen. Betreut wurde die Arbeit von Frau Prof. Dr. Herta Schmid (Universität Potsdam), der ich für ihre freundliche Unterstützung, ihre wertvollen Anregungen und ihre unermüdliche Geduld meinen herzlichen Dank aussprechen möchte. Herm Prof. Dr. Reinhard Ibler 'Philipps-Universităt Marburg) gilt mein Dank für die Erstellung des Zweitgutachtens sowie für wichtige Hinweise für die Druckfassung. Die Ermutigung zur intensiven Auseinandersetzung mit dem gewăhlten Thema verdanke ich Herm Prof. Dr. Klaus-Dieter Seemann ( +2000$)$. Herm Prof. Dr. Peter Rehder bin ich für die Aufnahme dieser Studie in die Reihe Slavistische Beitrage dankbar.

Ein Kurzzeitstipendium des Deutschen Akademischen Auslandsdienstes ermöglichte es mir dankenswerterweise, 1996 bei einem Aufenthalt in Nordengland wichtiges Material im Leeds Russian Archive einzusehen und die notwendige Grundlage für eine umfassende Auseinandersetzung mit Ivan Bunins Temmye allei zu schaffen. Mein besonderer Dank gilt hier Herm Dr. Richard Davies, der mir in großzügiger Weise Zugang zu den in Leeds verwahrten Ivan Bunin and Vera Bunina Collections gewährte, mich mit dem Material vertraut machte und wichtige Impulse und Hintergrundinformationen gab. Weiteres wertvolles bibliographisches Material hătte nicht berücksichtigt werden können ohne die tatkräftige Hilfe zahlreicher Mitarbeiter in verschiedenen Archiven und Bibliotheken, von denen die wichtigsten stellvertretend alphabetisch genannt sein sollen: Bakhmeteff Archive, Butler Library, Columbia University, New York; Edinburgh University Library, Special Collections Department; Institut mirovoj literatury imeni Gor'kogo, Moskau; Gosudarstvennyj literaturnyj muzej, Moskau; Nordelbisches Kirchenarchiv, Kiel; Rossijskaja gosudarstvennaja biblioteka, Moskau; Rossijskij gosudarstvennyj archiv literatury i iskusstva, Moskau. Für die Erlaubnis zur Publikation bislang unveröffentlichten Materials sei den entsprechenden Institutionen an dieser Stelle herzlich gedankt.

Zum Gelingen dieser Arbeit trugen ferner viele Menschen bei, die kleine und große Fragen beantwortet haben. Ich möchte zudem meinen Eltern und Freunden danken, die mich in unterschiedlichster Weise unterstutzt haben und viel Geduld und Verständnis für mich hatten, ganz besonders Bernhard Richelmann. 


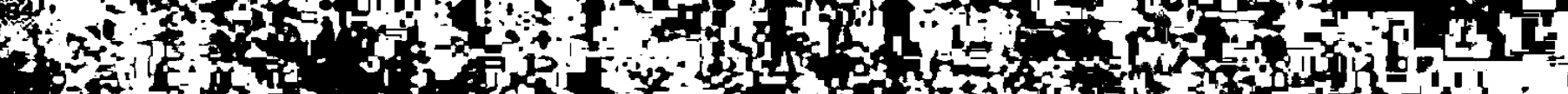

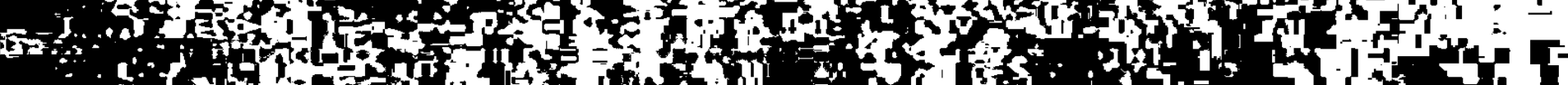
$\therefore$ (n)

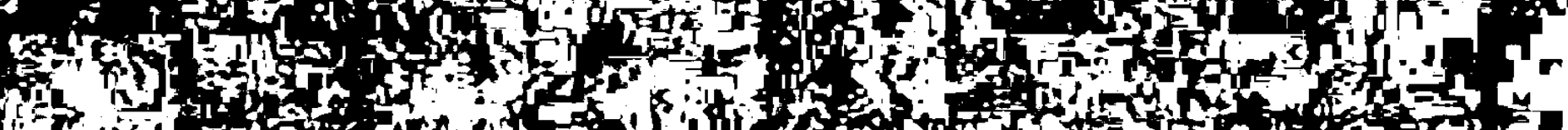

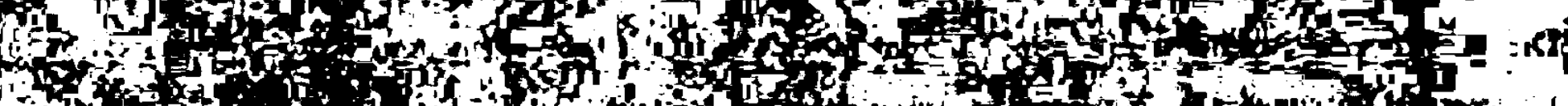

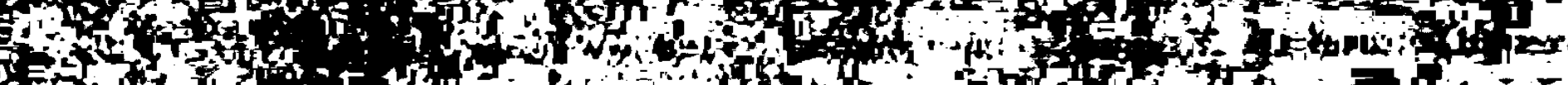

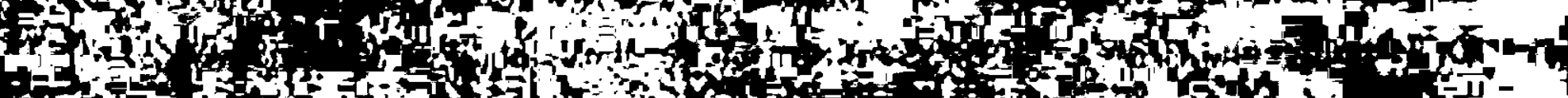
Fi

ing

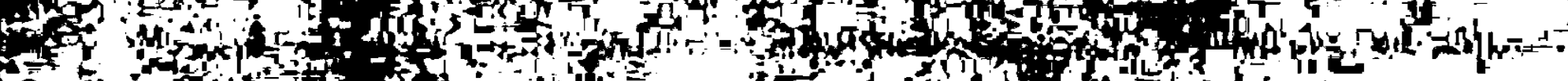
1.

4. (3)

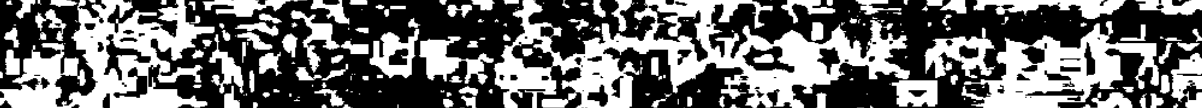

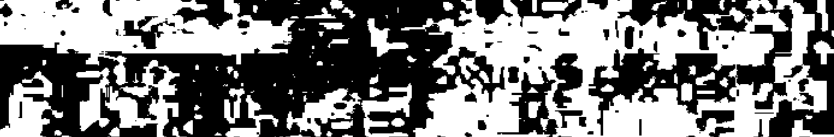

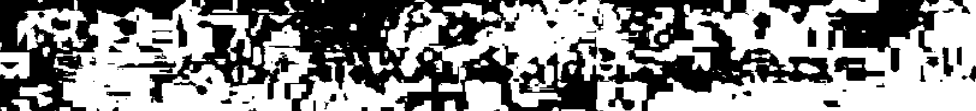
ISx-3

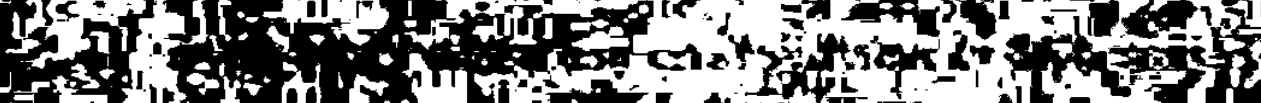

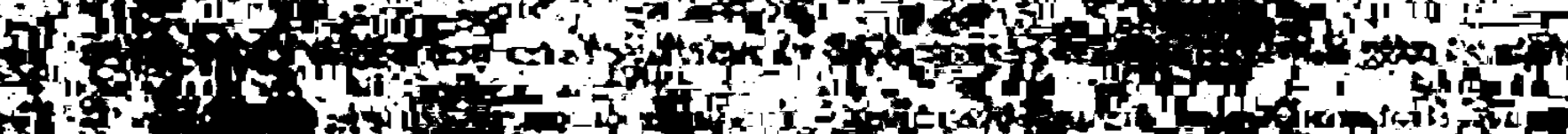

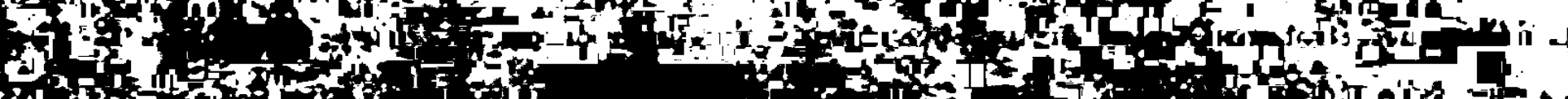

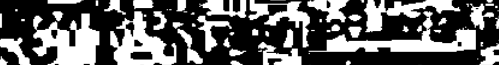

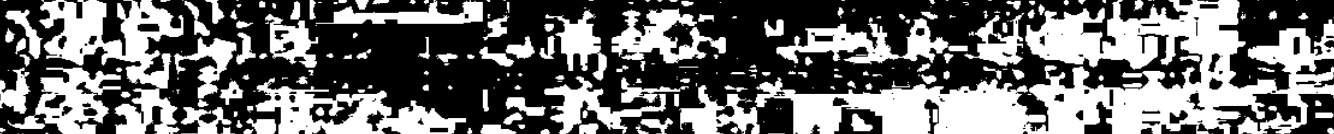

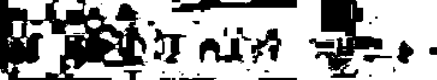
5 s.

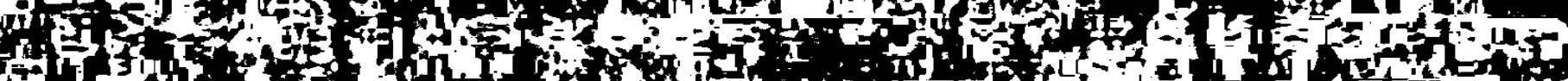

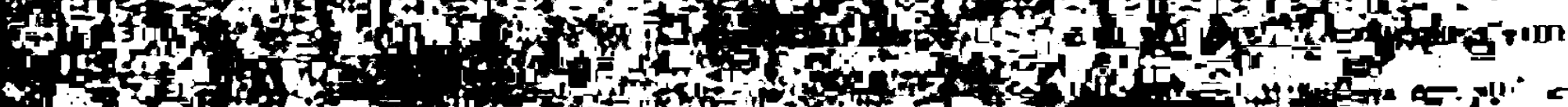

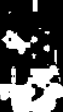

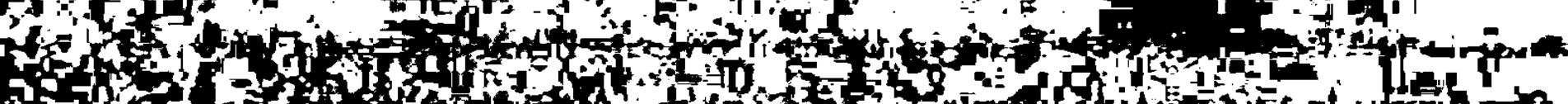

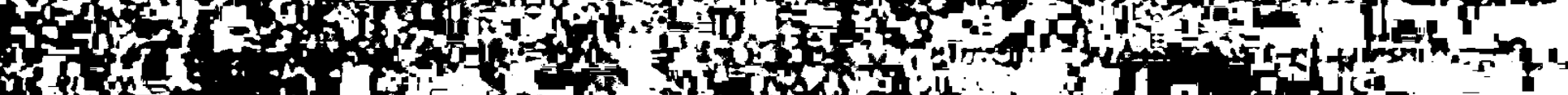
$\Rightarrow$ Phe ato

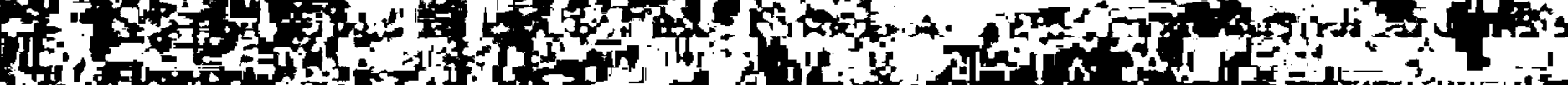

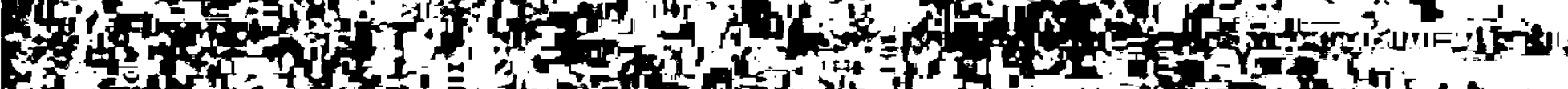

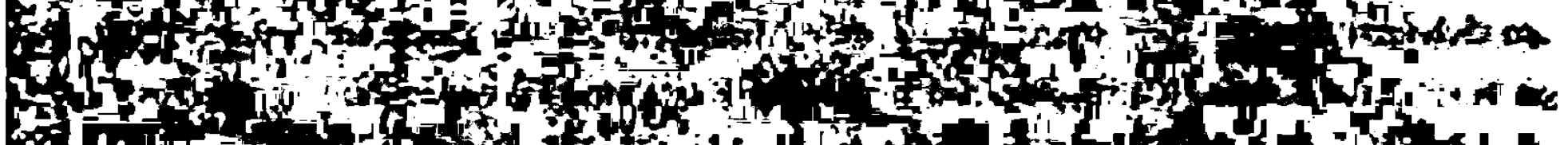
F, 30 , Flow

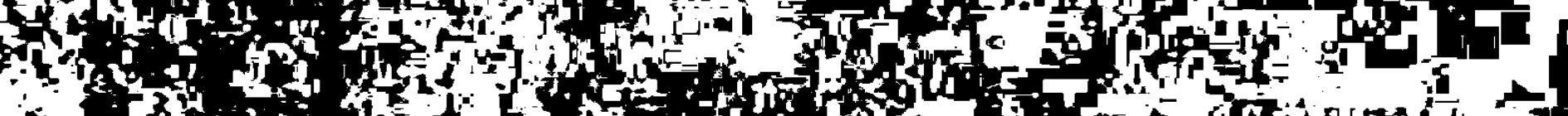

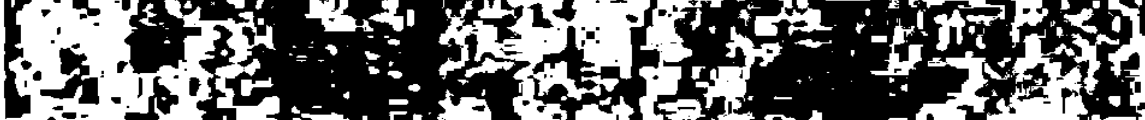
F. - 
1.1 Fragestellungen, Ziele und Aufbau der Arbeit ................................................................................15

1.2 Die Temmye allei im Spiegel der Wissenschaft und des offentlichen Interesses ...................................18

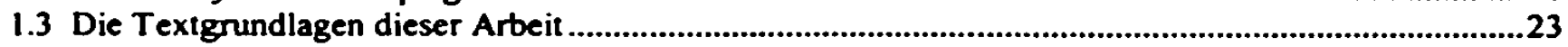

2 ZUR VERKNUPFUNG VON NARRATIVER KURZPROSA

2.1 Annahenungen an eine Definition von narrativen Kurzprosaverknupfungen des

20. Jahrhunderts und die Suche nach einer adaquaten Genrebezeichnung .........................................30

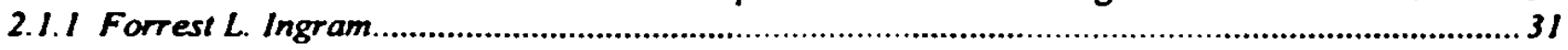

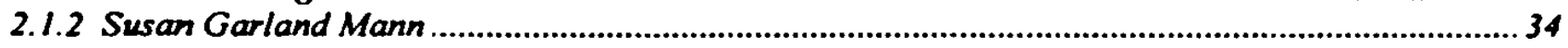

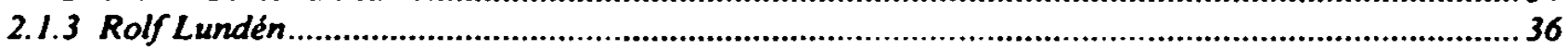

2.2 Kriterien zur Bestimmung von narrativen Kurzprosaverknapfungen ..................................................38

2.2.1 Extratextliche Verknüpfungen - die Anlage der Kurzprosaverknüpfung .....................................38

2.2.2 Intratextliche Verknüpfungen auf struktureller bzw. stilistischer Ebene......................................40

2.2.3 Intratextliche Verknüpfungen auf thematischer Ebene; ihre Umsetzung und ihre Wirkung.......... 41

2.3 Die Temnye alle $i$ als Cluster von Erzahlungen ...................................................................................41

3 DIE ENTSTEHUNGSGESCHICHTE DER SPÄTEN ERZĀHLUNGEN

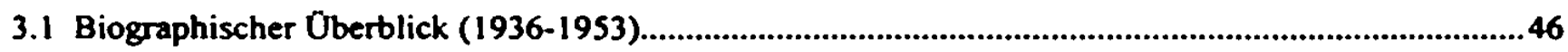

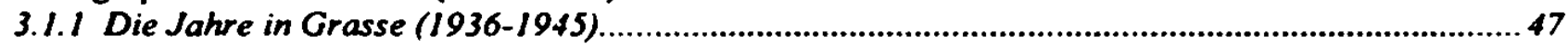

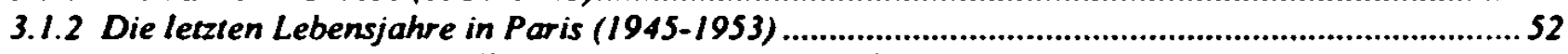

3.2 Zur Genese der die Temnye allei konstituierenden Erzahlungen ............................................................56

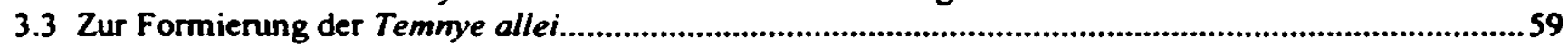

3.4 Weitere veroffentlichte und unveroffentlichte Erzahlungen aus dem Entstehungszeitraum der Temmye allei

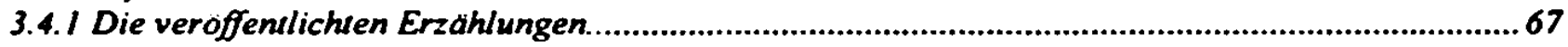

3.4 .2 Bis heute urveroffentlichte Erzahlungen ......................................................................................68

3.5 Zeitgleich entstandene Erzahlungen: Affinitaten und Diskrepanzen zu den Erzahlungen der Temmye allei .............................................................................................................................................73

3.5.1 Erzahlungen mit starker Affinitat zu den Erzahlungen der Temme allei ........................................74

3.5.2 Erzählungen ohne Bezüge zu den Erzählungen der Temme allei.................................................. 79

3.5.3 Erzählungen, die eine neue Tendenz im Schaffen Bunins ankündigen ..........................................8I

3.6 Exkurs: Blick in die Werkstatt - Notizsammlungen, Entwarfe, Skizzen ...............................................84

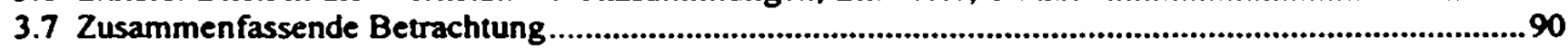

4 EXTRATEXTLICHE VERKNUPFUNGEN: DER ÄUSSERE AUFBAU DER TEMNYE ALLEI ...93

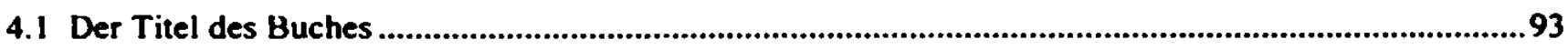

4.2 Die Anordnung der Erzahlungen - eine Bestandsaufnahme ...................................................................99

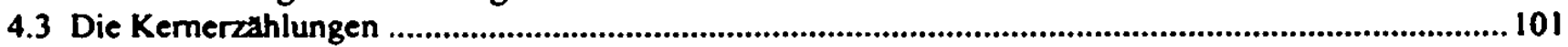

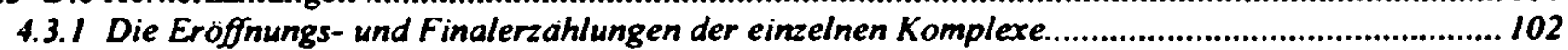

4.3.2 Die Kernerzählungen im Innern der einzelnen Komplexe.............................................................105

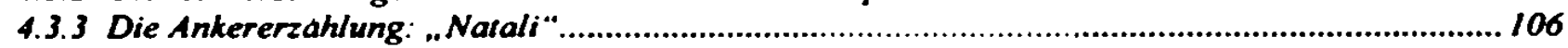

4.4 Die Satelliten- und Randerzahlungen .....................................................................................................112

4.4.1 Satellitenerzahlungen in den Temme allei................................................................................. 112

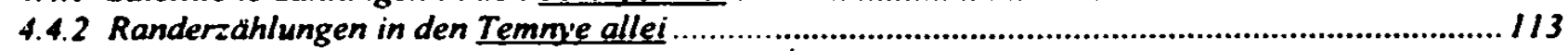

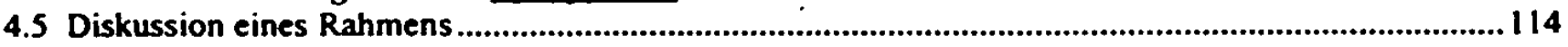

4.6 Zusammenfassende Betrachtung ............................................................................................................. 119

5 INTRATEXTLICHE VERKNÜPFUNGEN IN DEN TEMNYE ALLEI (I): STRUKTUR ............... 121

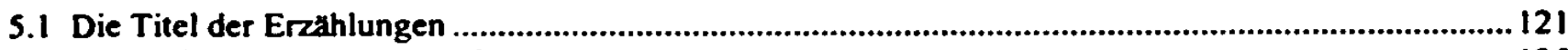

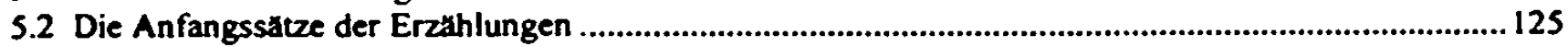

5.3 Typische Arten der Handlungsfuhrung ................................................................................................129

5.3.1 Eindringen der Vergangenheit in die Gegernwart .................................................................. 131

5.3.2 Die Gegenwart als Auslöser des Rückblicks ..................................................................... 132

5.3.3 Die Gegenwart als formaler Rahmen des Erinnerungsberichts............................................... 132

5.3.4 Schilderung einer Handlung in der Vergangenheit ohne Einbeziehung von Erinnerungen......... 133

5.3.5 Momensaufnahmen ......................................................................................................... 134

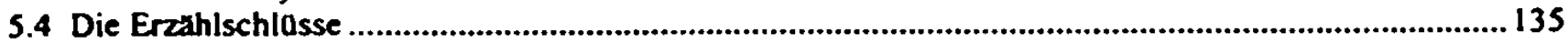

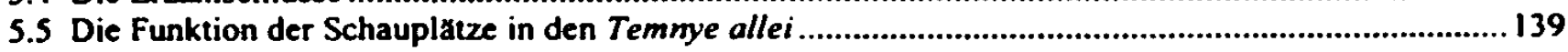


S.S.I Der AuBenraum: Norw versus Stads.

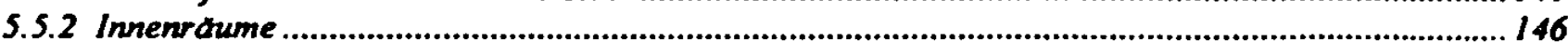

5.6 Der Kontrast ais bevoraugte Gestaltungstechnik ............................................................................... 148

5.6.I Prophetische bew. irrefiuhrende Zukunfisvorausdeutungen ........................................................ 149

5.6.2 Kontrastierendes Erzahltempo.......................................................................................... I52

5.7 Zusammenfassende Betrachtung ....................................................................................... 155

6 INTRATEXTLICHE VERKNOPFUNGEN IN DEN TEMNYE ALLEI (II): STIL............................

6.1 Doppelungen und Wiedertholungen............................................................................................. 160

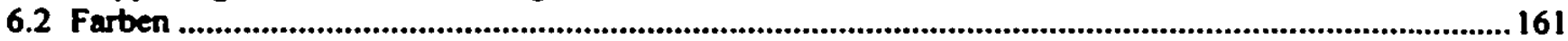

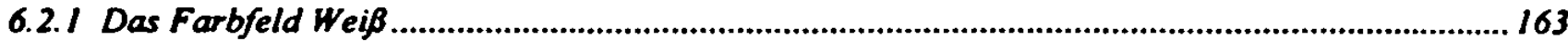

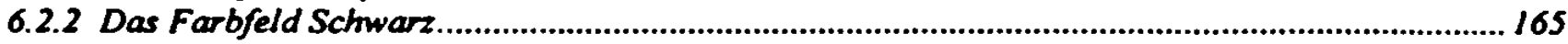

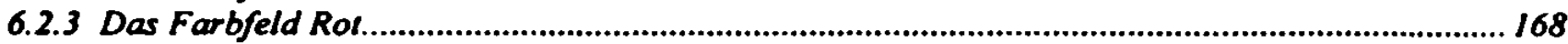

6.2.4 Das Farbfeld Gran............................................................................................................ I7I

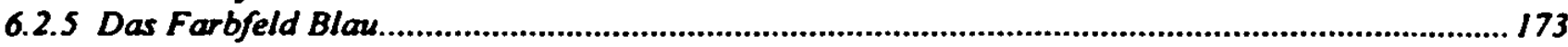

6.2.6 Das Farbfeld Braun ................................................................................................................. 174

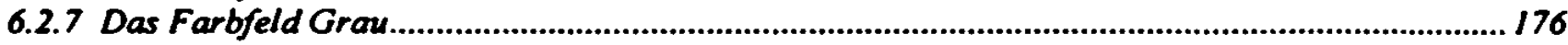

6.2.8 Das Farbfeld Gelb ........................................................................................................................ 177

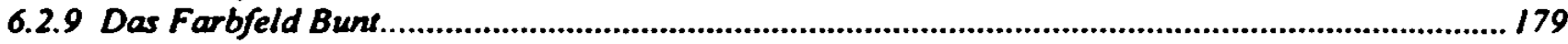

6.2.10 Das Farbfela Lila.............................................................................................................. 180

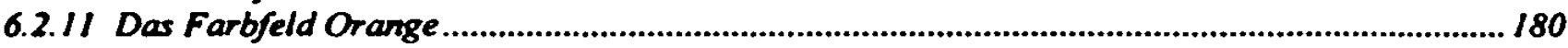

6.3 Helligkeit und Dunkelheit; Glanz .................................................................................... 182

6.3.I Helligkeit ................................................................................................................................ I82

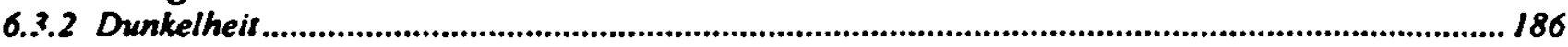

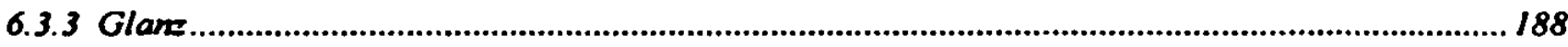

6.4 Eingefugte Fremdtexte ....................................................................................................... 192

6.4.I Auszüge aus Gedichten und Volksliedern; Redewendungen. Sprichworter und Volksweisheillen 193

6.4 .2 Zitate aus religiosen und weltlichen Werken .............................................................................. I98

6.4.3 Zitalhaft venwendete Auberungen von Protagonisten der Erzdhlungen....................................... 200

6.5 Zusammenfassende Betrachtung .............................................................................................203

7 DIE ZENTRALEN FIGUREN DER TEMNYE ALLEI

7.1 Zur Charakterisierung der zentralen Figuren .......................................................................205

7.2. Die Darstellung der Frau ....................................................................................................213

7.2.I Die weibliche Bloße .......................................................................................................... 215

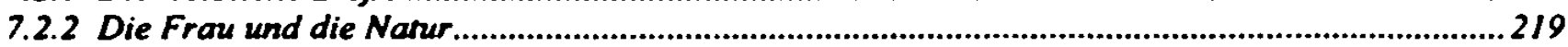

7.3 Die Figurenkonstellationen ...............................................................................................224

7.4 Speisen und Getranke als Sinnbilder der Lebenslust und des Lebenshungers ...................................226

7.5 Zusammenfassende Betrachtung ............................................................................................230

8 DIE ZENTRALEN THEMENKREISE: LIEBE - TOD - ERINNERUNG ......................................

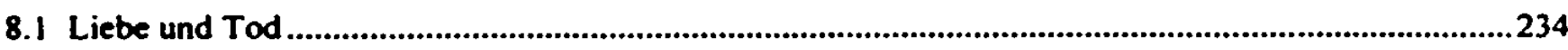

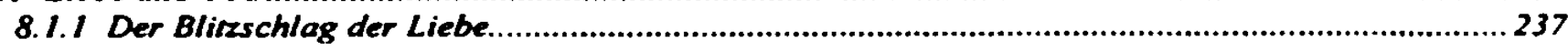

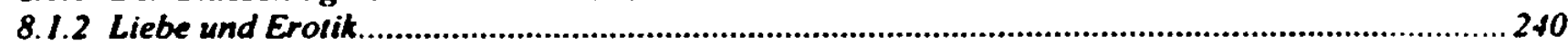

8. 1.3 Der metaphysische .4spekt der Liebe .................................................................................244

8. I.4 Eros und Reisen .................................................................................................................. 25I

8. I.5 Der Tod als Gegenkraft und Gegenspieler der Liebe ................................................................ 255

8. 1.6 Erinnerung: Reisen in die Vergangenheit........................................................................257

8.2 Erinnerung........................................................................................................................................260

8.2.I Der Tod des alten RuBland-Requiem fur eine verlorene Heimat............................................. 262

8.2.2 Ratselhaftes RuBland - RuBland zwischen Europa und Asien ................................................. 264

8.2.3 Abrechmung und Hommage: Kunst und Literatur im vorrevolutionären RuBland...................... 27I

8.3 Zusammenfassende Betrachtung ..........................................................................................274

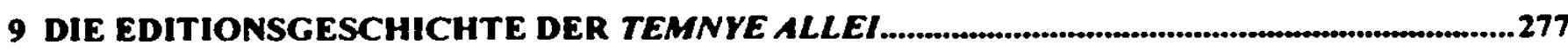

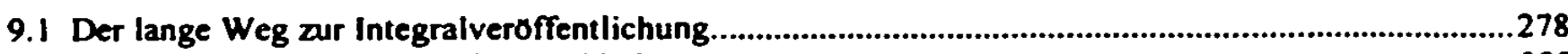

9.I.I Die New Yorker Ausgabe von 1943.................................................................................280

9.1.2 Die Pariser Ausgabe von 1946.......................................................................................285

9.2 Weitere russischsprachige Ausgaben der Temnye allei..................................................................287

9.2.1 Publikationsversuche der Temmye allei zu Bunins Lebzeilen................................................. 287 
9.2.2 Russischsprachige Ausgaben der Temnye allei nach Bunins Tod.

9.3 Franzosisch-, englisch- und deutschsprachige Ausgaben der Temnye allei ........................................295

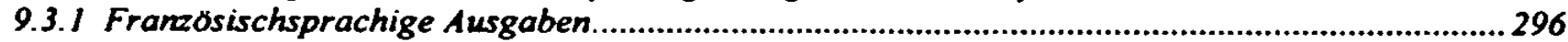

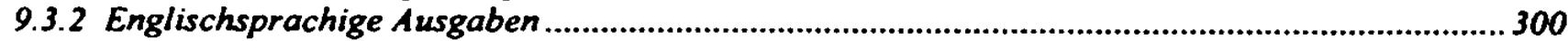

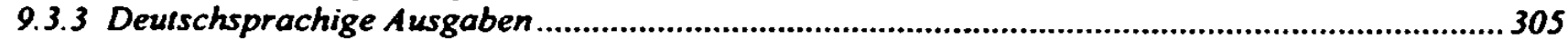

9.4 Zusammenfassende Betrachtung......................................................................................314

10 DIE REZEPTIONSGESCHICHTE - DIE TEMNYE ALLEI IM KREUZFEUER

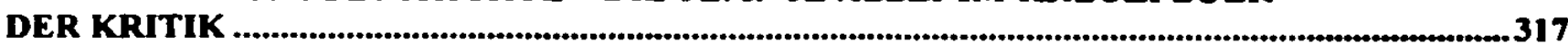

10.1 Zeitgen $\delta s s i s c h e$ Reaktionen ........................................................................................................318

10.1.1 Direkte Reaktionen aus dem Freundes- und Bekanntenkreis vor der Buchpublikation ............. 318

10.1.2 Reaksionen nach Erscheinen des Buches ......................................................................... 325

10.1.3 Rezensionen im Feuilleton nach der Veroffentlichung der Pariser Ausgabe von 1946 ............ 331

10.1.4 Exkurs: Rezensionen der deutschen Übersetzung: 1959-1961 versus 2001............................... 334

10.2 Vor-bzw. Nachworte von Ausgaben der Temmye allei in der Sowjetunion bzw. in RuBland,

Frankreich, England und Deutschland ...........................................................................................338

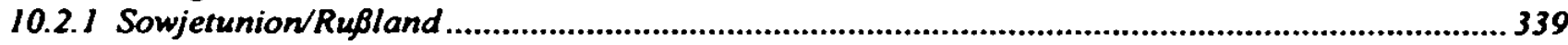

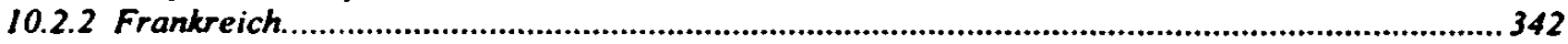

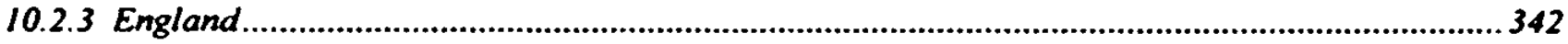

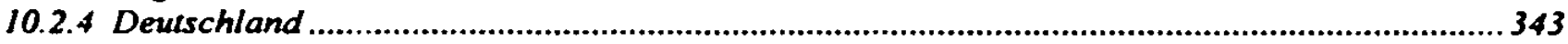

10.3 Literaturwissenschaftliche Bewertungen ............................................................................... 344

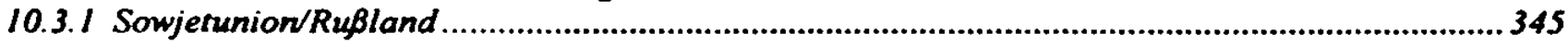

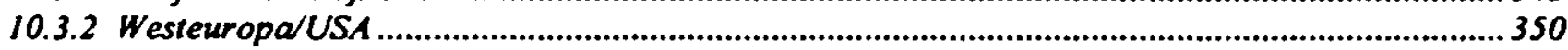

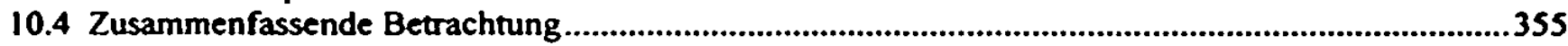

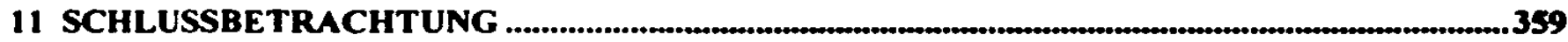

12 QUELLEN- UND LITERATURVERZEICHNIS .

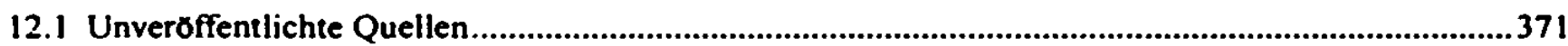

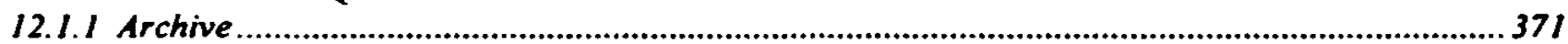

12.I.2 Personliche Gespröche/Korrespondenz ......................................................................37I

12.2 Primărliteratur Ivan Bunin ..............................................................................................372

12.2.I (Integral-)Ausgaben der Temme allei in russischer Sprache/Ausgewahlte Veröfentlichungen einzelner Erzdhlungen aus den Temmye allei in chronologischer Ordnung.............................. 372

12.2.2 Insegralausgaben der Temme allei in frandosischer SprachelAusgewahlte Veroffentlichungen einzelner Erzahlungen aus den Temmye allei in chronologischer Ordnung..............................375

12.2.3 Ausgaben der Temmue allei in englischer Sprache/Ausgewahlse Veroffentlichungen einzelner Erzahlungen aus den Temmye allei in chronologischer Ordnung ........................................... 375

12.2. Ausgaben der Temme allei in deulscher Sprache/Ausgewahlie Veroffentlichungen einzelner Erzahlungen aus den Temmye allei in chronologischer Ordmung ............................................. 376

12.2.5 Autobiographisches. Interviews, weitere Erzdhlungen bzw. Prosatexte von Ivan Bunin........... 376

12.3 Erinnerungen, Tagebücher, Korrespondenzen, Kritik, Stimmen zu den Temmye allei.....................378

12.4 Sekundarliteratur zu Ivan Bunin und seinem Werk .................................................................38 I

12.5 Zitierte Primărliteratur anderer Autoren..............................................................................390

12.6 Nachschlagewerke, Handbucher, Zeitgeschichtliches, Literaturtheorie, Genrestudien ....................393

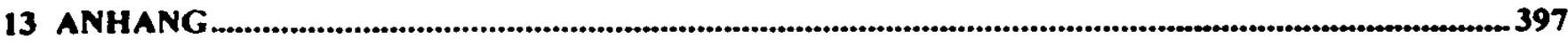

13.1 Anhang 1: Alphabetische Übersicht uber alle zwischen 1936 (,Molodost' i starost'“) und 1949 (..Legenda") entstandenen Erzahlungen sowie aber die in der vorliegenden Arbeit erwăhnten Entwäre, Skizzen und Notizen.

13.2 Anhang 2: Übersicht aber den Formierungs- und Modifikationsprozeß der Temnye allei (1941-1953). 


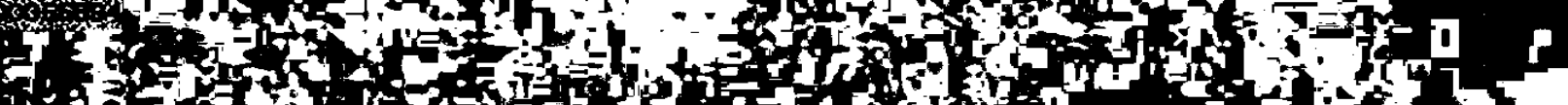

(20)

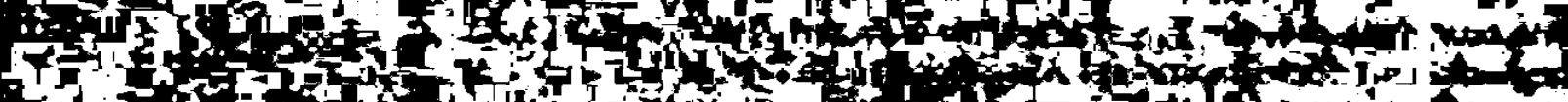

14

20.

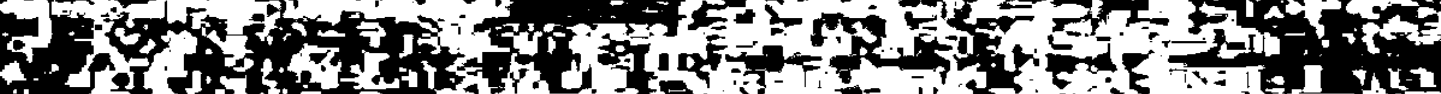

5

int

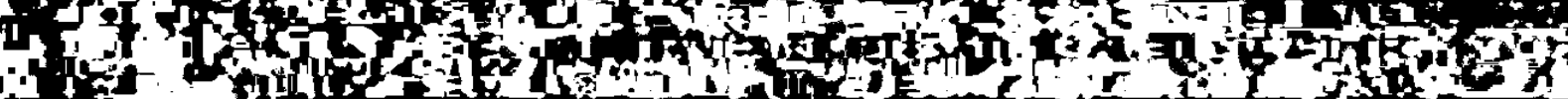

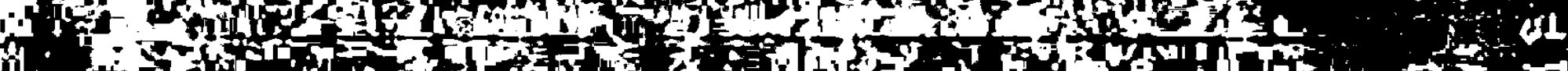

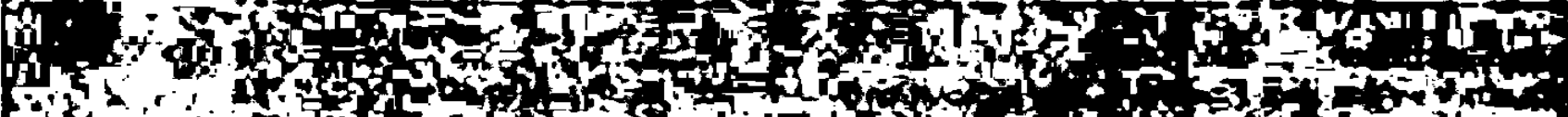

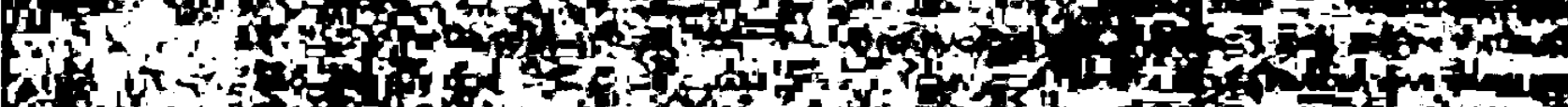

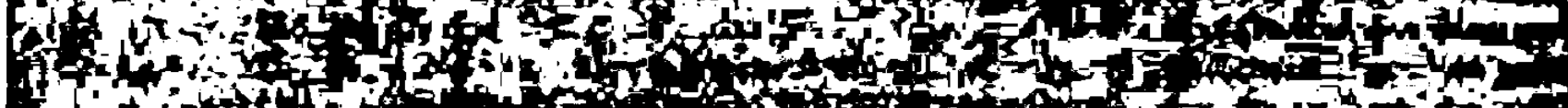

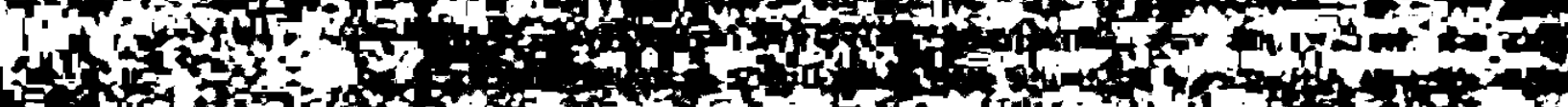

(y)

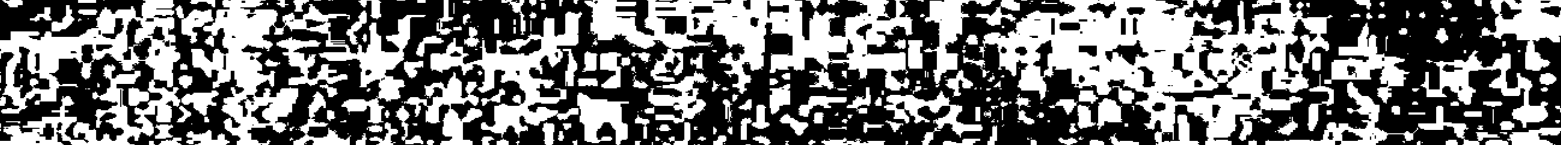

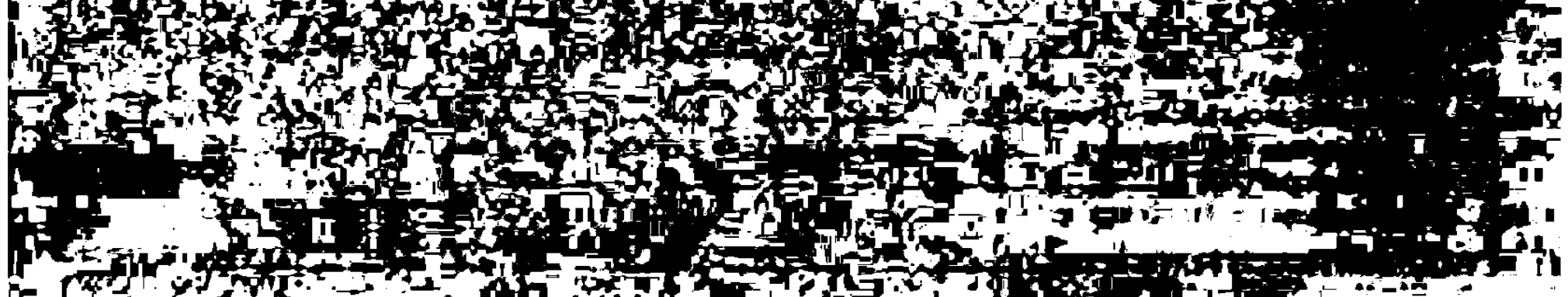

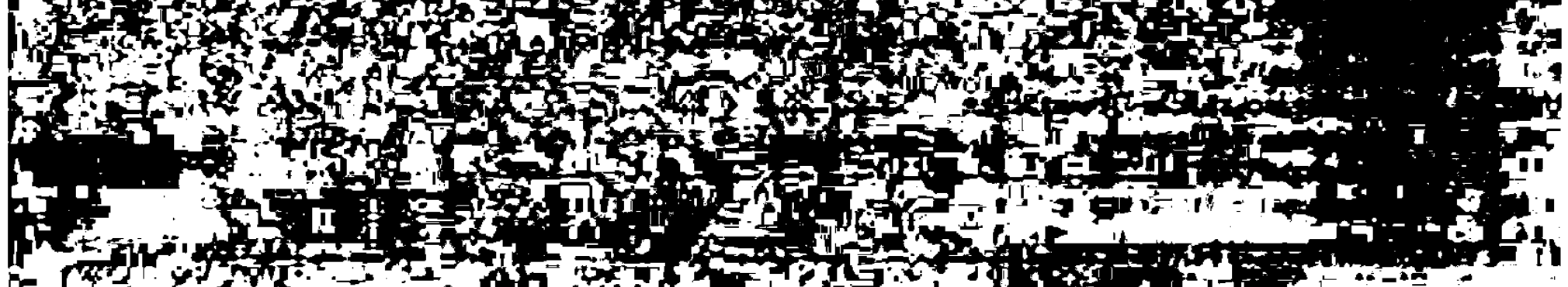

5.

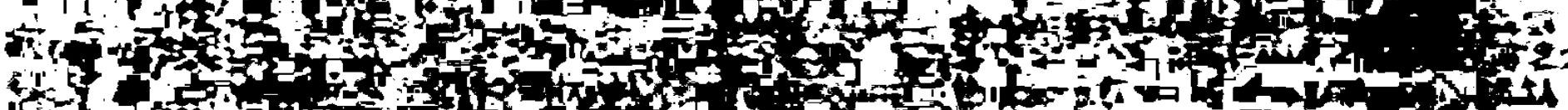

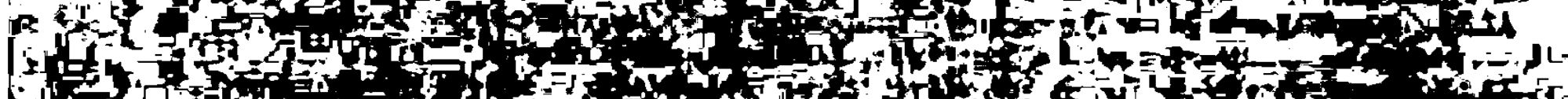
\%

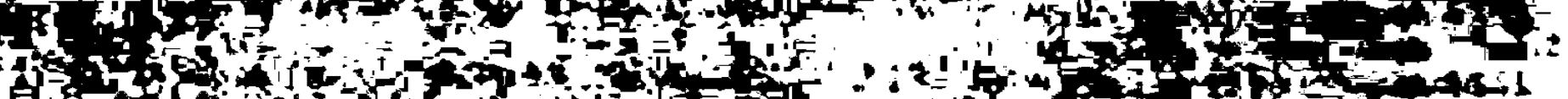

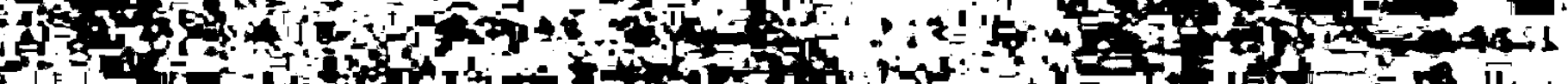

(1)

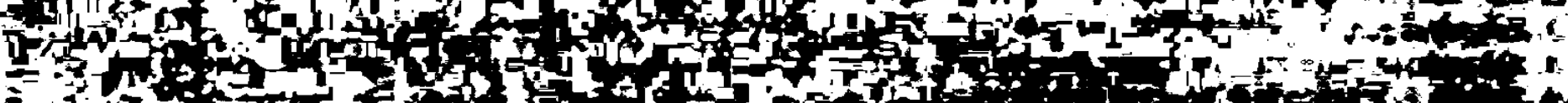

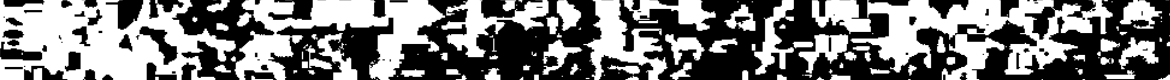

040 for

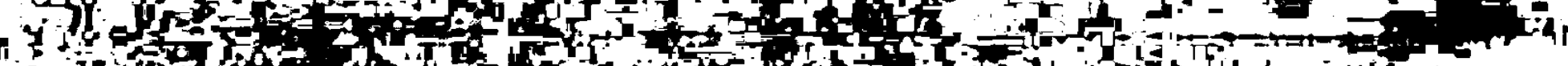

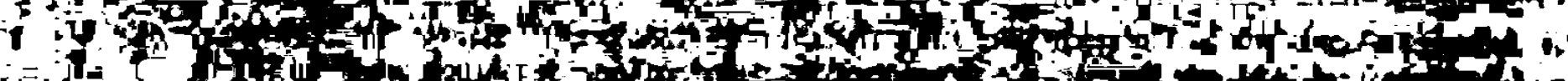

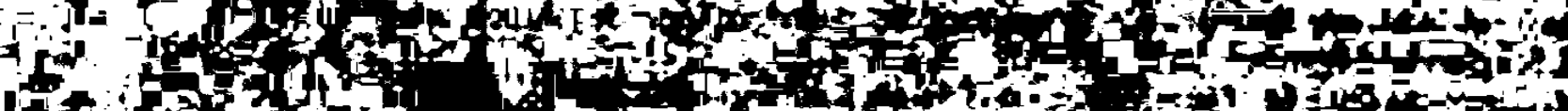

fyl

H.

$=3$

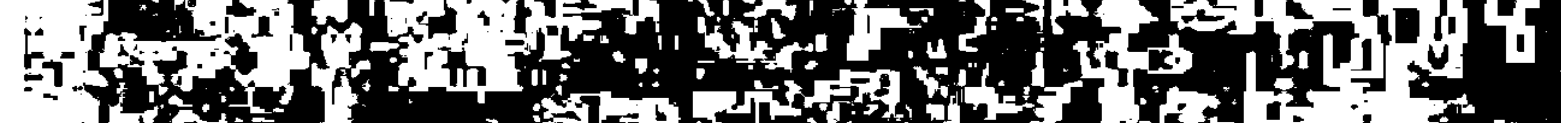

$=x_{1}$

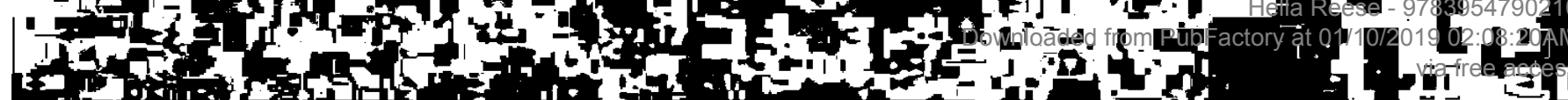




\section{EDITORISCHE VORBEMERKUNGEN}

- Es werden folgende Abkürzungen verwendet:

IMLI: Institut mirovoj literatury imeni Gor'kogo, Moskva

LN: Literaturnoe nasledstvo. Ivan Bunin

LRA: Leeds Russian Archive, University of Leeds

NEK-Archiv, 15.05.01 Nr. 16: Nordelbisches Yirchenarchiv, Bestand 15.05.01 (Nord-

elbische Kirche/Ev. Presseverband Nord e.V. - Verlage Wittig und Steinkopf) Nr. 16

NZ: Novyj zurnal

RGALI: Rossijskij gosudarstvennyj archiv literatury $\mathrm{i}$ iskusstva, Moskva

RGB: Rossijskaja gosudarstvennaja biblioteka, Moskva

SS: Sobranie sočinenij

UB: Ustami Buninych. Dnevniki v trech tomach

- Hervorhebungen in Zitaten:

Sofern nicht anders gekennzeichnet, wurden alle Hervorhebungen als solche aus den Originalquellen übernommen.

- Datierung:

Die Datienung folgt dem julianischen Kalender; Daten wurden - sofern nicht anders gekennzeichnet - entsprechend angepaßt.

- Fremdsprachige Quellen:

Alle Quellen werden in der Originalsprache zitiert.

- Orthographie in russischsprachigen Quellen:

In der vorliegenden Arbeit wird dem heutigen Usus folgend die nach 1917 eingefuhrte, sogenannte neue Orthographie verwendet; Quellen in der alten Orthographie wurden entsprechend angepaßt.

- Transliteration kyrillischer Zeichen:

Es wird die in der Slavistik üblicherweise gebräuchliche wissenschaftliche Transliteration verwendet, etwa für die Titel von Erzählungen, Zeitschriften oder Büchern. Von 
dieser Regel wird abgewichen, wenn der entsprechende Terminus im Deutschen gebrauchlich ist oder in der zitierten Quelle eine andere Schreibweise verwendet wird. Längere Zitate werden in Kirillica wiedergegeben.

- Verweise auf das Referenzwerk Temnye allei:

Die Verweise auf die Sobranie socinenij v vos'mi tomach (6.Bd. Moskva, 1999), das für die vorliegende Dissertation verwendete Referenzwerk, werden folgendermaßen abgekurz: (6: Seitenzahl). Wahrend der Buchtitel im Text kursiviert erscheint, werden die Titel der Erzählungen in Anfühnungszeichen wiedergegeben. 
[...] Темные Аллеи, которую считаю, может быть, самой лучшей моей книгой в смысле сжатости, живости и вообще литературного мастерства.'

Dieses Fazit uneingeschränkter Wertschätzung für sein 1946 in der französischen Emigration erschienenes, 38 Erzăhlungen umfassendes Buch Temnye allei ${ }^{2}$ zog Ivan Alekseevic Bunin (1870-1953) wenige Monate vor seinem Tod. Von seinen Zeitgenossen wurde sein Enthusiasmus in der Regel jedoch nur unter Vorbehalt geteilt; daß die Kohărenz des Buches selten wahrgenommen wurde, lag weniger an den vorangegangenen Einzelveröffentlichungen etlicher Erzählungen in Zeitungen und Zeitschriften, sondern vor allem an einer Rezeption, die sich auf die als erotisch bzw. pornographisch empfundenen Passagen einzelner Erzăhlungen konzentrierte. Auch nachfolgende Editionen in der Originalsprache oder als Übersetzungen waren aus unterschiedlichen Gründen-zensorischen Motiven, moralischen Erwägungen oder schlicht editorischer Nachlässigkeit-von Kürzungen betroffen ${ }^{3}$, so daß einem breiten Publikum die Möglichkeit zur Auseinandersetzung mit dem Meisterwerk des ersten russischen Nobelpreisträgers furr Literatur ${ }^{4}$ verwehrt blieb und nicht zuletzt die Publikation weiterer später Erzahlungen vereitelt wurde.

In den Jahren 1936 bis 1949 entstanden 76 Erzählungen (vgl. die alphabetische Obersicht in Anhang 1) - 55 davon allein in den produktivsten Jahren 1940, 1943 sowie 1944 -, die in vielfältigen Variationen die Bipolarităt von Liebe und Tod zum Inhalt haben und vor allem von der Spannung zwischen Erotik und Todesthematik leben. Diese Beschäftigung mit elementaren emotionalen Grenzsituationen in allen Facetten hat sich in Bunins Prosa-

1 Brief Bunins an Edward Wasiolek vom 24.07.1953. Zit. in: E. Wasiolek. „The Fiction of Ivan Bunin: a Critical Study". [Masch.schr.] Diss. Harvard, 1954: 306.

2 1. Bunin. Temmye allei. Paris, 1946.

3 Nach der Erstveroffentlichung 1946 in einer Auflage von 3.000 Exemplaren vergingen aber 40 Jahre, bevor das Buch potentiellen Lesem als Integraldruck im Rahmen einer in den Jahren 1987 bis 1989 erscheinenden sechsbăndigen Werkausgabe wieder zugänglich war (I. Bunin. SS v Sesti tomach. S.Bd. Moskva, 1988).

4 Der Nobelpreis wurde Bunin fur seine Kunst des Schreibens in der Tradition der klassischen Prosa verliehen. In der Verleihungsrede heißt es unter anderem: ..Die Bedeutung Ivan Bunins für die Literaturgeschichte seines Landes wird seit langer Zeit diskussionslos anerkannt. Er hat die große, glanzende Tradition des 19. Jahrhunderts fortgesetza, indem er ihr zu jeder moglichen Weiterentwicklung verhalf. Straftheit und Ausdrucksreichtum vereinen sich bei ihm zu einer beinahe einzigartigen, bis zur Vollendung entwickelten Genauigkeit der Beobachtung. In seiner unerbittlichen Kunst ist er der Versuchung, dem Zauber der Worte nachzugeben, nie unterlegen. Obwohl von Natur aus Lyriker, hat er doch das Erschaute nie beschonigt, sondern mit unbedingter Treue aufgedeckt. Seine schlichte Sprache umgab er mit einem Zauber, der, wie seine Landsleute bezeugen, aus ihr einen Trank bereitet. wovon jeder Tropfen ein Genuß ist, einem Zauber, den man selbst in den Öbersetzungen manchmal noch verspür. Hierin liegt die wesentliche und geheime Gabe, die jedes seiner Bucher zu einem Meisterwerk werden laßr" (Per Hallstrom. „Verleihungsrede“. Zit. in: I. Bunin. Dunkle Alleen. Zurich, 1969: 23). 
schaffen seit Mitte der 1920er Jahre mit Erzăhlungen wie „Mitina ljubov"“ (1924) und „Solnexnyj udar“ (1925), also erst in der Emigration, zunehmend intensiviert und offnet sein Werk bei weiterhin deutlich spürbarer russischer Prägung endgültig der Weltliteratur.

Über die Hălfte dieser Erzăhlungen wurde in das Buch Temnye allei ${ }^{5}$ aufgenommen, das im allgemeinen falschlicherweise als Schlußpunkt des Erzăhlwerks Bunins angesehen wird. Ein Teil der übrigen Erzăhlungen war ursprünglich ebenfalls für die Aufnahme in die Temmye allei vorgesehen; ein unseliges Zusammenspiel politischer, wirtschaftlicher und moralisch-gesellschafticher Faktoren führte jedoch dazu, daß Bunin sie zu guter Letzt nicht integrierte und das Buch nicht in der von ihm gewinschten Form erschien. Diese Erzăhlungen, denen bislang die gebührende Aufmerksamkeit verwehrt blieb und deren Bezug zu den Temmye allei als ursprilnglicher oder potentieller Bestandteil bisher nicht herausgearbeitet wurde, wurden teils zu Bunins Lebzeiten, teils postum in verschiedenen Zeitungen und Zeitschriften publiziert, neun Erzăhlungen (einige von ihnen unvollendet) sind bis heute unveroffentlicht.

Eine Reihe von ihnen weist verblüffende strukturelle und thematische Ähnlichkeiten mit den Erzählungen der Temnye allei auf, andere unterscheiden sich jedoch in einigen Punkten gravierend von ihnen und zeugen gerade darin von einer künstlerischen Weiterentwicklung Bunins noch im hohen Alter. Im Rahmen einer umfassenden Analyse der Temnye allei müssen sie daher unbedingt berucksichtigt werden, denn nicht zuletzt vor ihrem Hintergrund treten die semantischen Aussagen des Buches profiliert hervor.

Als einen fruhen Versuch Bunins, narrative Kurzprosatexte miteinander zu verknüpfen. könnten 11 in den Jahren 1907 bis 1911 entstandene, unterschiedlich lange Reiseberichte gewertet werden, die Bunin als „putevye poemy“ bezeichnete und unter dem Titel „Ten' pticy“ zusammenfaßte. Auch in den 1930 verfaßten „Kratkie rasskazy“ (36 skizzenhafte, „anekdotenartige Schnappschüsse ${ }^{\text {(6) }}$ ) bemühte sich Bunin um die Schaffung einer unauflösbaren Fusion von Form und Inhalt in Prosa, in der die Erzahltechnik dem Inhalt optimal angepaßt ist. Dieses Streben nach Kongruenz und Konzision, das sich unter anderem durch

5 Spătere Editionen enthalten hăufig zusăzzlich zu den 38 Erzahlungen der Pariser Ausgabe von 1946 die beiden Erzahlungen ..Nocleg“" und „Vesnoj, v ludee”. In seinem persónlichen Exemplar dieser Ausgabe hatte Bunin den Wunsch vermerkt, diese beiden Erzahlungen in kanftige Ausgaben aufzunehmen (dieses Exemplar wird im Moskauer IMLI verwahrt; vgl. Kap. 3.3); die erste, kriegsbedingt unvollständige Edition der Temnye allei war mit II Erzahlungen bereits 1943 in New York erschienen (vgl. Kap. 9.1.1).

6 O. Peschl. "Die künstlerische Entwicklung von Ivan Bunins Prosastil”. [Masch.schr.] Diss. Wien, 1954: 139. Diese 36 Skizzen und kurzen Erzahlungen wurden 1930 in verschiedenen Ausgaben der russischsprachigen Pariser Tageszeitung Poslednie novosfi veroffentlicht. 
bloße Prăsentation der Ereignisse ohne Einblicke in die Psyche der Figuren oder Kommentare seitens des Erzählers auszeichnet, sollte für zahlreiche späte Erzählungen, darunter auch einige aus den Temnye allei, bestimmend werden. ${ }^{7}$ Die optimale Verschmelzung von Form und Inhalt war auch die Leitlinie bei der Auswahl und Zusammenstellung der Erzählungen zu einem Buch, dessen mehrschichtige Kompositionsweise sich erst auf den zweiten und dritten Blick erschließt. Heute ist in der Literaturwissenschaft zwar die hohe literarische Qualität des Buches unumstritten, seir.e strukturelle Gestaltung sorgt jedoch für Unsicherheiten bei der Genrezuordnung und ist bislang nur unzureichend erforscht.

Die vorliegende Arbeit will daher die Temnye allei, die einen Meilenstein und Wendepunkt in Bunins schriftstellerischer Evolution markieren, erstmals im Wirkungsgeflecht äußerer Bedingungen und künstlerischer Intention betrachten, unter Berücksichtigung aller zeitgleich entstandenen und teilweise bis heute unveröffentlichten Erzählungen sowie diverser Entwürfe, Skizzen und Notizen. Im Mittelpunkt des Interesses steht hierbei die bis heute nicht erfolgte Bestimmung der Genrezugehörigkeit des Buches, die eine kritische Beleuchtung der Entstehungs-, Editions- und Rezeptionsgeschichte einschließt. Auf diese Weise soll die vorliegende Dissertation nicht nur einen Beitrag zur Erforschung eng miteinander verknüpfter Kurzgeschichten bzw. Erzählungen in der russischen Literatur leisten, sondern gleichzeitig einen Wandel in Bunins Poetik der spăten Jahre dokumentieren.

\subsection{Fragestellungen, Ziele und Aufbau der Arbeit}

Die Grundlage für eine Analyse der Genrezugehörigkeit der Temnye allei bildet die theoretische Auseinandersetzung mit dem Stand der Erforschung eng miteinander verknüpfter Kurzprosa sowie das Herausarbeiten eines praktikablen Fragenkatalogs, der hinreichend flexibel ist, um die Besonderheiten der Temnye allei abzubilden, und gleichzeitig verbindlich genug, um nicht beliebig zu wirken (Kap. 2).

7 Mit Bezug auf die Temnye allei schreibt Bunin am 11.11.1943 an Boris Zajcev: ..Paccka3ы 3ти большей частью в лист, но есть и в одну страничку, это меня последнее время очень заннмает самая крайняя сжатость, хотя я и всегда был на зтом довольно помешан“ (zit. in: ..Pis'ma l. Bunina k B. Zajcevu“*. In: $N \pm 137$ [1979]: 125).

Und mit Verweis auf eine Besonderheit der japanischen Dichtkunst, das dreizeilige Haiku. notien er 1944: „Bот так и надо писать. Целый рассказ в несколько строк“ Notebook Nr. 2 [Zapiski. zametki]. LRA. MS. 1066/548). 
Da sich die slavistische Literaturwissenschaft der Erforschung dieses Genres bislang nur in geringem Maße gewidmet hat ${ }^{8}$, werden zu diesem Zwecke hauptsächlich Arbeiten aus dem angloamerikanischen Sprachraum herangezogen, in dem die Forschung auf Grund der dortigen Verbreitung von Short-Story-Verbindungen weiter fortgeschritten ist - in ihren Grundzagen sind diese Ergebnisse auf Kurzprosaverknüpfungen aller Sprachen abertragbar. In der Sekundärliteratur herrscht Uneinigkeit bezäglich der Genrezugehörigkeit der Temnye allei: So reichen die Bezeichnungen von einem bloßen Sammelband mit Erzăhlungen bis hin zu einem Zyklus, gemeinhin ohne die verwendeten Termini zu definieren. Fur eine umfassende Interpretation des Buches ist jedoch eine eindeutige Bestimmung der Genrezugehörigkeit unabdingbar.

Die praktische Auseinandersetzung mit den für die Temnye allei verknüpfungsrelevanten Faktoren erfolgt in drei Blöcken:

- Beleuchtung des entstehungsgeschichtlichen Hintergrunds der spăten Erzăhlungen sowie ihre Kategorisierung

- Analyse der maßgeblichen extra- und intratextlichen Verknupfungen im strukturellen. stilistischen und thematischen Bereich

- Kritische Auseinandersetzung mit der Editionsgeschichte und der Rezeptionsgeschichte.

Den Ausgangspunkt für eine Analyse der Genrezugehörigkeit der Temnye allei bildet eine Übersicht uber die bewegte Entstehungsgeschichte der späten Erzahlungen (Kap. 3), da diese Rückschlüsse auf die geplante Anlage des Buches ermoglicht. In diesem Zusammenhang werden auch die zeitgleich entstandenen veroffentlichten und unveroffentlichten Erzăhlungen vorgestellt und ihre Affinităten bzw. Diskrepanzen zu den die Temnye allei konstituierenden Erzăhlungen diskutiert. Ein Blick in die „Werkstatt“ Bunins rundet diesen

8 Erst in jungster Zeit ist ein wachsendes Interesse zu registrieren, das jedoch vornehmlich auf die Erforschung von Zyklusbildung in der Lyrik zielt; vgl. die Erarbeitung eines Handbuchs des russischen Gedichtzyklus am Institut fur Slawische Philologie der Philipps-Universitat Marburg unter der Leitung von Prof. Dr. Reinhard Ibler oder das interdisziplinăre Projekt zur Erforschung des Gedichtzyklus in den europaischen Literaturen in Fribourg (Schweiz). Die zunehmende Aufmerksamkeit dokumentiert auch die große Teilnehmerzahl an der zu diesem Themenbereich durchgefuhrten internationalen Konferenz. die vorm 18. bis 20. Mărz 1997 an der Onto-von-Guericke-Universităt Magdeburg stattfand (s. hierzu auch den Konferenzband Zyklusdichrung in den slavischen Literaturen. Hg. R. Ibler. Frankfurt/Main, 2000). Auch hier dominiert die Lyrik: 32 Beitragen aus diesem Bereich stehen lediglich 9 Beiträge aus dem Bereich der Epik gegenuber. Außerdem bleibt festzustellen, daß die Forschung beim Terminus .Zyklus" verhart, der jedoch fur die einzelnen Erscheinungsformen miteinander verknupfter literarischer Werke viel zu allgemein ist. 
Überblick ab: Beispielhafte Skizzen, Notizen und Entwürfe (teilweise in der New Yorker Zeitschrift Novyj zurnal veröffentlicht) werden vorgestellt und geben Aufschluß über die künstlerischen Fragestellungen, die Bunin in jenen Jahren bewegten.

Auf dieser Basis kann die Untersuchung der Genrezugehörigkeit der Temnye allei beginnen, die sich dem Buch zunächst von außen nähert und das Prinzip der Anordnung der Erzählungen erhellt (Kap. 4). Es schließt sich eine Analyse der entscheidenden intratextlichen strukturellen, stilistischen und thematischen Verknüpfungen an (Kap. 5, 6 und 8). Zentrale Aspekte sind hierbei etwa die typischen Arten der Handlungsfuhrung, die Schauplatzgestaltung und die bevorzugten Stilmittel. Ein gesondertes Kapitel ist der Darstellung der Protagonisten gewidmet (Kap. 7), da sich in Bunins Suche nach der überzeugenden und authentischen Schilderung von Frauen eine zentrale künstlerische Herausforderung jener Jahre widerspiegelt. Die Auseinandersetzung mit den dominierenden Themenkreisen Liebe, Tod und Erinnerung schließlich trägt der inhaltlichen Vielschichtigkeit des Buches Rechnung.

Eine kritische Zusammenschau der Editions- und Rezeptionsgeschichte (Kap. 9 und 10) erhellt die unterschiedlichsten Akzeptanzprobleme bei der Wahrnehmung des Buches als Kurzprosaverknüpfung. Die in der vorliegenden Dissertation erstmals dokumentierte Historie der verschiedenen Editionen der Temmye allei (im Original ebenso wie in Übersetzungen) in der Sowjetunion bzw. in Rußland, Frankreich, England bzw. den USA sowie im deutschsprachigen Raum illustriert nicht nur die Abhängigkeit des Verlagswesens von wirtschaftlichen und politischen Bedingungen sowie der herrschenden Moral, sondem veranschaulicht auch das bewußte oder unbewußte Ignorieren der Übereinstimmung von künstlerischer Intention und formaler Gestaltung. Letzteres zeigt sich auch in der ebenfalls erstmals durchleuchteten Rezeptionsgeschichte des Buches: Von der Reaktion der ersten Leser aus dem privaten Umfeld Bunins auf einige Erzählungen bzw. das gesamte Buch über die Beurteilung der Temnye allei im Feuilleton bis hin zu literaturwissenschaftichen Analysen gibt diese Resonanz beredten Aufschluß sowohl über die moralischen Empfindlichkeiten der Zeitgenossen Bunins und die daraus folgenden Konsequenzen für die Publikationen als auch über die Unsicherheit bei der Frage der Genrezuordnung. Editions- und Rezeptionsgeschichte machen zudem deutlich, daß das Buch unter günstigeren Umständen, vor allem in einem moralisch liberaleren und politisch friedlicheren Umfeld, eine andere Zusammensetzung und damit eine differenziertere Aussage hätte haben können als die 1946 publizierte Fassung, die deutliche Zeichen unfreiwilliger Kompromisse trägt - einen anderen Schluß läßt das vorliegende Material nicht zu. 
1.2 Die Temnye allei im Spiegel der Wissenschaft und des 8 ffentlichen Interesses

Angesichts der hohen Wertschătzung, die Bunin seinen spăten Erzłhlungen entgegenbrachte, ist der geringe Umfang der Forschungsliteratur und die zumeist oberflächliche, partielle oder schlicht summarische Auseinandersetzung mit den Temmye allei nachgerade erstaunlich, entspricht jedoch det allgemeinen literaturwissenschaftlichen Vemachlăssigung von Bunins literarischem Schaffen in der Emigration - ganz im Gegensatz zu der Beachtung, die sein vorrevolutionăres Werk fand. $\mathrm{Zu}$ Bunins Lebzeiten von Presse und Wissenschaft gleichermaßen weitgehend ignoriert, wurde das Buch erstmals 1954 in einer US-amerikanischen Dissertation' erwähnt. Ein verstärktes, tiefergehendes Interesse laßt sich indessen erst seit etwa zehn Jahren ausmachen - in Ost wie in West.

In der Sowjetunion wurden Bunins in der Emigration entstandenen Prosawerke nach dem 2. KongreB des Schriftstellerverbandes $1954^{10}$ zwar wieder akzeptiert und auszugsweise gedruckt, in der sowjetischen Literaturwissenschaft war es aus politischen Gründen jedoch opportun, sich vor allem mit Bunins vor der Oktoberrevolution erschienenen Werk zu befassen: die nüchterne Beschreibung des rückstăndigen Lebens auf dem Lande (wie z.B. in Derevnja, 1910) oder die Darstellung degenerierter Adliger (wie etwa in Suchodol, 1911) fügten sich besser ins kommunistische Wertesystem als das individuelle Liebeserlebnis unpolitischer Menschen, die hilflos den Elementarkraften des Lebens ausgeliefert sind." So wurde das Schaffen Bunins in der Emigration von der sowjetischen Literaturwissenschaft zuruckhaltend und entweder ausgesprochen selektiv oder schlicht summarisch zum Gegenstand der Analyse erhoben. ${ }^{12}$

9 E. Wasiolek. . The Fiction of Ivan Bunin..... op.cit.

10 Den entscheidenden Anstoß zu Bunins allmahlicher Rehabilitation scheint die dort gehaltene Rede Konstantin Fedins gegeben zu haben: „Недостало сил вернуться домон Ивану Бунину - русскому класснку рубежа двух столетия, который оставался реалистом и в прозе и в поззин тоЯ поры, когда господствовала мода на декаданс. Не следует, по-моему, отчуждать Бунина от нсторнн русской литературы, и все ченное [Hervorhebung H. Reese] из ето творчества долхно прнналлехать чнтателю ..." (K. Fedin. „Rexi na s"ezdach“. In: ders. Pisaleli, iskussrva, vremja. Moskva, 1980'). Vgl. hierzu auch I. Sokolov-Mikitov: „Slovo o Bunine“. In: LN. 84. Bd. (2) Moskva, 1973: 158: L. Rakovskij im Artikel .Iz otzyvor sovets-kich pisatelej o Bunine". In: $L N$. 84.Bd. (2) op.cit.: 371; W. Kasack. Lexikon der russischen Literatur ab 1917. Stuttgart, 1976: 73.

11 Stellvertretend sei hier die von A. Sokolov vertretene Meinung aufgefuhr, die den Tenor der sowjetischen Kritik gut wiedergibt: „Буннн замкнулся в интимных лирических воспомннаннях о молодости, в переживаниях прошлого" (A. Sokolov. "Zametki o chudožestvennom masterstve I. Bunina". In: Russkij jozyk za rubezom I [1971]: 95).

12 Eine Reihe von sowjetischen Dissertationen und Artikeln befassen sich im Rahmen der Analyse von Bunins Sparwerk bevorzugt mit politisch unverfanglichen Themen wie dem Stil oder den Naturdarstellungen (vgl. Kap. 10.3.1). 
Die wissenschaftiche Auseinandersetzung mit den Temnye allei wurde zudem durch bruchstückhafte Publikationen erschwert: Selbst im Rahmen der ersten umfangreichen Gesamtausgabe in neun Bänden erschien das Buch mit Kürzungen ${ }^{13}$; der erste integrale Abdruck in der Originalsprache in Bunins ehemaliger Heimat erfolgte erst 1988, wieder im Rahmen einer Gesamtausgabe. 1973 wurden in der von der Akademie der Wissenschaften und dem IMLI herausgegebenen Reihe Literaturnoe nasledstvo zwei Bände dem Leben und Werk Bunins gewidmet; erstmals wurden auch einige der zuvor zensierten späten Erzählungen ${ }^{14}$ abgedruckt und auf diesem Wege der sowjetischen Öffentlichkeit zugänglich gemacht.

Die großen russischsprachigen Monographien lassen es bis in die 1990er Jahre hinein zumeist bei einem Überblick über die wichtigsten biographischen Fakten und Veröffentlichungen bewenden ${ }^{15}$ und streifen die Temnye allei lediglich. Beinahe alle Autoren lassen durchblicken, daß das einst gefeierte und verehrte Akademiemitglied Bunin, seiner Verbindung zur Heimat beraubt, nicht in der Lage war, sein hohes schriftstellerisches Niveau zu halten, geschweige denn auszubauen. Eine bahnbrechende Ausnahme bildet lediglich die gründlich recherchierte Monographie von Jurij Mal'cev ${ }^{16}$, die 1994 erschien und bei der Erörterung der Temnye allei erstmals einige der bislang unveröffentlichten späten Erzählungen in Analyse und Bewertung einbezieht.

Die politischen Veränderungen in der ehemaligen Sowjetunion ermöglichten die Publikation zahlreicher ehemals verbotener Texte Bunins ${ }^{17}$, die auf lebhaftes Interesse stießen, deren editorische Qualităt allerdings in manchen Fällen fragwürdig ist. In den vergangenen zehn Jahren erschienen zudem zahlreiche Ausgaben der Temnye allei, im Rahmen von Gesamtausgaben ebenso wie als Einzelveröffentlichungen (vgl. Kap. 12.2.1). Die veränderten Rahmenbedingungen schlagen sich im übrigen auch nieder in der durchweg positi-

13 I. Bunin. SS v devjati tomach. 7.Bd. Moskva, 1966. Es fehlen die Erzahlungen „Gost““, „Baryšnja Klara" und „Zeleznaja Serst"“.

14 Es handelt sich hierbei um die folgenden Erzăhlungen: „Riv'era“, „Alja“, ..,Kogda ja vpervye ..."“. "Zeleznaja Serst"“. "Modesr" und „Krem Leodor".

I5 V. Afanas'ev. I. A. Bunin. Ocerk Norcestva. Moskva, 1966; entstanden auf Basis seiner Dissertation (bemerkenswert an Afanas'evs Studie ist die Erwăhnung der Erzahlung „Zeleznaja Serst'“, die bis dahin in der Sowjetunion noch nicht veroffentlicht war); A. Volkov. Proza Ivana Bunina. Moskva. 1969; O. Michajlov. Ivan Bunin. Ocerk Norcestva. Moskva, 1967; ders. Strogij talant. Ivan Bunin. Zizn: sud'ba. rvorcestvo. Moskva, 1976; ders. I. A. Bunin. Zizn' i vorcestvo. Tula, 1987; V. Nefedov. Cudesmyj prizrak. Bunin - chudoznik. Minsk, 1990; L. Smirnova. Ivan Alekseevic Bunin. Zizn ${ }^{\circ}$ i rvorcesroo. Moskva, 1991.

16 Ju. Mal'cev. Bunin. 1870-1953. Frankfurt am Main, 1994. (Die Erstveroffentlichung erfolgte sieben Jahre zuvor unter dem Titel Ivan Bunin. La vita e l'opera: 1870-1953. Milano, 1987.)

17 In erster Linie sind in diesem Zusammenhang die Okajannye dni (Berlin, 1935), auf seinen privaten Aufzeichnungen beruhende Tagebuchnotizen aus den Jahren 1918/19, zu nennen. 
ven Beurteilung der Temnye allei in den derzeit zahlreich erscheinenden Handbüchern zur russischen Literatur im allgemeinen und in der Emigration im besonderen. ${ }^{18}$

Zeitgleich verstärkte sich auch das populärwissenschaftliche Interesse an Bunins Leben. Die romanhaften Bunin-Biographien aus der Feder Valentin Lavrovs, Cholodnaja osen' (Moskva, 1989) sowie die erweiterte Fassung Katastrofa. Istoriceskij roman (Moskva. 1995), und Ivan Bunin von Michail Rosxin (Moskva, 2000) sollen in diesem Zusammenhang nicht unerwăhnt bleiben, obwohl sie eine ernsthafte Auseinandersetzung mit Bunins Werk vermissen lassen und statt dessen Fakten mit Fiktion vermengen: Auf einen Anmerkungsapparat oder Quellenangaben verzichten die Autoren, spielen aber mehr oder weniger virtuos mit zahlreichen Versatzstücken aus bereits veröffentlichten Quellen wie etwa der Korrespondenz und den Tagebüchern Bunins sowie den Erinnerungen verschiedener Zeitgenossen, nicht ohne dabei von ihrer schriftstellerischen Freiheit Gebrauch zu machen. Eine vergleichbare Biographie, wenngleich wissenschaftlich fundierter, aber ebenfalls ohne Angabe von Quellen, legte der langjährige Buninforscher Oleg Michajlov jüngst vor (Žizn' Bunina. Liš̀' slovu žizn' dana .... Moskva, 2001).

Gemeinsam mit einer wachsenden Zahl von Fernseh- und Radiobeitrăgen sowie Kinofilmen ${ }^{19}$ dokumentieren die genannten Bücher jedoch beispielhaft das neu erwachte Interesse der russischen Öffentlichkeit an Bunin ebenso wie ein Versuch der Regenbogenpresse, die unveröffentlichten (und selbstverständlich unverkăuflichen) Erzăhlungen, die im LRA an der University of Leeds verwahr werden, zu einem hohen Preis zu erwerben vermutlich, weil man sich von dem vermeintlich pornographischen Inhalt eine auflagensteigemde Wirkung versprach. Die Enthüllung verschiedener Denkmäler ${ }^{20}$, das Anbringen

18 Z.B. O. Michajlov. Literatura russkogo zarubez'ja. 1920-1940. Moskva, 1993; ders. Literatura russkogo zarubez'ja. Moskva, 1995; ohne Verfasserangabe. Russkoe zarubez e. Zolotaja kniga emigracii. Moskva, 1997; ohne Verfasserangabe. Literaturnaja enciklopedija russkogo zarubeż ja (1918-1940). Moskva, 1997; ohne Verfasserangabe. Enciklopedija dlja detej. Moskva, 1999; ohne Verfasserangabe. Enciklopedija mirovoj literatury. Sankt-Peterburg. 2000.

19 Hierzu gehoren unter anderem: "The Meshcherskies“" (Regie: Boris Yashin), basierend auf den drei Erzăhlungen "Natali“, „Tanja" und „V Pariže" (Teilnahme am Moscow Film Festival, 18.-27.07.1995) und A. Ucitel', Regie. Dnevnik ego Łeny. Spielfilm (104 Min.). Pyramid Home Video, 2000. Der Filmtitel mit dem werbenden Zusatz „Иван Буннн хотел любвн, но получил только Нобелевскую премию" gibt bereits AufschluB uber das Niveau des Films, der sich auszeichnet durch zahlreiche verfalschte Informationen zu Bunins Leben in der Emigration (so starb Bunin nicht im Zug nach Italien, sondern in seiner Pariser Wohnung) und insbesondere seine Beziehung zu Galina Kuznecova in den Fokus ruckt.

A. Razina verweist in ihrem Essay zur Verfilmbarkeit von Bunins Erzahlungen auf weitere Verfilmungen von Erzahlungen aus den Temmye allei: „Natali“ (1988). „Cholodnaja osen “" (1990) und „Temnye allei“" (1991, unter dem Titel „Dva golosa“). Vgl. A. Razina. „Kinematografiénost" - kak stilevaja osobennost' tvorkeskogo pocerka Ivana Bunina". In: I. A. Bunin i russkaja literatura XX veka. Moskva. 1995: 263.

20 So beispielsweise in Orel (1992) und Voronez (1995). Vgl. A. Rogacevskij. „Review Article. Bunin Reincarnate". In: The Slavonic and East European Review 3 (Juli 2002): 489. 
von Plaketten an Häusern, in denen sich Bunin aufgehalten hat ${ }^{21}$, und die Einrichtung von Museen unter anderem in Orel, Elec und Efremov sowie der vielfach geäußerte Wunsch, den Leichnam Bunins vom nahe Paris gelegenen Friedhof Sainte-Geneviève-des-Bois in russische Erde umzubetten, sind ebenfalls Zeugnisse dieses Wandlungsprozesses.

Auch in den westlichen Gesamtdarstellungen ${ }^{22}$ erschöpft sich der kritische Umgang mit den Temnye allei in der zusammenfassenden Witdergabe einzelner Erzăhlungen in stark differierendem Umfang, ohne die unveröffentlichten Erzählungen in die Analyse einzubeziehen: Die Verfasser der drei großen US-amerikanischen Monographien ${ }^{23}$ nähern sich dem Spätwerk zwar deutlich vorbehaltloser als ihre sowjetischen Kollegen, betrachten Bunins Schaffen jedoch in seiner Kontinuität, ohne den Auswirkungen der Revolution von 1917 und der nachfolgenden Emigration auf Bunins Kreativität und Poetik in ausreichendem Maße Rechnung zu tragen.

Die deutschsprachige Forschungsliteratur weist nur wenige - und schon gar keine aktuellen - Monographien zu Bunins spätem Erzählwerk auf. Zu nennen sind in erster Linie zwei unveröffentlichte, das ganze Prosawerk Bunins umfassende Dissertationen ${ }^{24}$, von denen sich jedoch keine in wünschenswertem Maße mit den späten Erzählungen auseinandersetzt $^{25}$ : Während Otto Peschl zwar konstatiert, daß Bunin mit den Temmye allei einen

21 Beispielsweise in der ulica Povarskaja, Moskau.

22 Berucksichtigt werden Studien aus dem angloamerikanischen, deutschen und franzosischen Sprachraum.

23 S. Kryzytski. The Works of Ivan Bunin. The Hague/Paris, 1971; J. Woodward. Ivan Bunin. A Study of His Fiction. Chapel Hill, 1980; J. Connolly. Jvan Bunin. Boston, 1982. Eine weitere Studie, die unveroffentlichte Dissertation von E. Wasiolek (..The Fiction of Ivan Bunin ...“. op.cit.), berucksichtigt zwar wenn auch nur auf zwei knappen Seiten - die Temmye allei, erteilt der künstlerischen Qualitat des Buches jedoch eine klare Absage (n... low water of his artistic achievement". S. 306). Ein ahnlicher Randplatz wird den Temmye allei in einer weiteren Dissertation zugewiesen: K. Sheridan Tiffany. ..Ivan Bunin: A Poet in Prose". [Masch.schr.] Diss. Columbia University, 1986. Hingewiesen werden soll in diesem Zusammenhang auch auf die kompilative Arbeit von T. Marullo, der mit dem Titel Ivan Bunin: Twilight of .. Emigre" Russia (1934-1953). A Portrait from Diaries, Letters, and Fiction (Chicago [IIlinois], 2002) den dritten Teil einer Trilogie uber Bunins Leben auf Grundlage authentischer Dokumente vorlegte. Ähnlich wie Roscin liefert er keine neuen Erkenntnisse, darf sich aber zugute halten, zuvor nur in der russischen Sprache vorhandene Texte dem interessierten englischsprachigen Leser in einem biographischen Kontext zugănglich zu machen.

24 O. Peschl. „Die künstlerische Entwicklung von Ivan Bunins Prosastil“. [Masch.schr.] Diss. Wien. 1954; B. Kirchner. „Die Lebensanschauung Ivan Alekseevið Bunins nach seinem Prosawerk“. Inaugural-Diss. Ludwigsburg, 1968.

25 Lediglich die vor 1917 entstandenen Erzahlungen sind Gegenstand einer umfassenden Monographie: A. Elbel. Die Erzahlungen Ivan Bunins 1890-1917. Eine systematische Studie uber Form und Gehalt. Gießen, 1975. Mit der bewußten Wahl dieses Zeitraumes scheint die Autorin die Zasur im Prosawerk Bunins zwar durchaus wahrgenommen zu haben, halt jedoch ihre Ergebnisse fur ubertragbar auf die in der Emigrationszeit entstandenen Erzahlungen, so daB auch sie offensichtlich eine Entwicklung ausschließt (s. ebd. S. 5). Auf großeres Interesse stoBt in der deutschsprachigen slavistischen Forschung die Lyrik Bunins, die in zwei jüngeren Dissertationen unter verschiedenen Aspekten beleuchtet wird: A. Meyer. Die Sonelldichiung Ivan Bunins. Wiesbaden, 1990 und S. Klover. Farbe. Licht und Glanz als dichterische Ausdrucksmittel in der Lyrik Ivan Bunins. Munchen, 1992. Den Einsatz metaphorischer Stilelemente analysiert I. Zielke in ihrer Dissertation Text und Metapher. Studien zur Prosa Ivan Bunins. Hamburg, 2001. Eine Dissertation zu den literarischen, publizistischen und dokumentarischen Diskursen Bunins im Exil befindet sich derzeit in Vorbereitung (D. Riniker, Universitat zu Basel). 
allerletzten Höhepunkt in seinem Werk erreicht habe, aber die Verbindungen zwischen den Erzählungen allein im thematischen Bereich sieht, stehen in Baldur Kirchners Studie oberflächliche Nacherzăhlungen im Vordergrund, die eine nuancierte Analyse vermissen lassen. Auch in den einschlägigen deutschsprachigen Handbüchern werden die Temnye allei nur am Rande gestreift oder gar nicht erst erwähnt - als repräsentativ mögen hier das Lexikon der russischen Literatur des 20. Jahrhunderts (1992) von Wolfgang Kasack gelten, der zwar in seinem Artikel zu Bunin einen Hinweis auf die Temnye allei gibt, aber nicht näher auf das Buch eingeht, oder aber auch das Handbuch desselben Autors, Die russische Schriftsteller-Emigration im 20. Jahrhundert (1996), das nicht einmal einen eigenen Artikel zu Bunin enthält. Selbst das neueste Handbuch, die Geschichte der russischen Literatur von Reinhard Lauer, bietet nur unvollständige Informationen $\mathrm{zu}$ den Temnye allei, wobei jedoch nicht verschwiegen werden soll, daß die künstlerische Qualität des Buches klar herausgestellt wird. 26

Der entscheidende Impuls zu einer Neubewertung und zur differenzierten Auseinandersetzung mit den Temnye allei ging von der französischen Slavistik aus: 1980 wurde eine Dissertation angefertigt, die sich ausschließlich mit den Temnye allei beschäftigt. ${ }^{27}$ Rosa Fedoulova liefert aufschlußreiche biographische Details und zeigt Gemeinsamkeiten zwischen den Erzählungen auf; dabei stützt sie sich jedoch einzig auf die Pariser Edition und läßt die entscheidenden Umstände der Formierung des Buches ebenso außer acht wie seine originelle Struktur und die Existenz weiterer Erzählungen sowie den Einfluß der ersten Rezipienten. Eine weitere, 1993 erschienene Dissertation ${ }^{28}$ ist dem gesamten Prosaschaffen Bunins in der Emigration gewidmet und stellt erstmals das Frühwerk qualitativ dem Spätwerk gleich. In diesem Zusammenhang bildet die Analyse der Temnye allei zwar nur einen Teilbereich, dennoch gelingt es Claire Hauchard, auf die Wechselbeziehungen der strukturellen und thematischen Verknüpfungen hinzuweisen.

Das deutlich gestiegene Interesse am Emigrationsschaffen Bunins zeigt sich zudem in einer wachsenden Zahl von internationalen Konferenzen ${ }^{29}$ und Sammelbänden ${ }^{30}$. Seither

$26 \mathrm{Vgl}$. R. Lauer. Geschichte der russischen Literatur. Munchen, 2000: 564.

27 R. Fedoulova. „Les allées sombres d'Ivan Bounin“. [Masch.schr.] Diss. Paris. 1980.

28 C. Hauchard. "La Prose de 1. A. Bounine de 1920 a 1953: La Reconstruction d'une cuvre". [Masch.schr.] Diss. Paris. 1993.

29 1. A. Bunin i russkaja literatura XX veka. Moskva, 1995. In seinem einleitenden Artikel weist der langjathrige Buninforscher $O$. Michajlov nachdrucklich auf die innovatorische Qualitat der Temmye allei hin. mit denen Bunin eine neue Seite in der Literatur aufgeschlagen habe (,Mirovoe znacenie Bunina“: 5): Tvorcestvo I. A. Bunina i russkaja literatura $X I X-X X$ vekov. $\mathrm{Hg}$. Belgorodskij gosudarstvennyj universitet. Belgorod, 1997. Im letzigenannten Titel findet sich unter insgesamt 47 Beitragen allerdings nur ein Artikel zu den Temnye allei.

30 Izvestija Voroneżskogo gosudarstvennogo pedagogičeskogo instituta. 114.Bd. Voronez, 1971; Bounine revisité. Hg. C. Hauchard. Paris, 1997. 
haben auch in der Fachliteratur Artikel zugenommen, die sich mit ausgewähiten Aspekten des Spătwerks und zunehmend mit den Temnye allei auseinandersetzen (vgl. Kap. 10.3). ${ }^{31}$ Unter strukturellen Aspekten haben sich bislang allerdings nur zwei Arbeiten mit den Temnye allei beschäftigt: Wăhrend sich Natalija Evstafeva in ihrer 1989 erschienenen Dissertation $^{32}$ den verschiedenen Genreformen innerhalb des Buches widmet, vertritt M. Stern in ihrer umfangreichen Monographie zur Prosa Bunins in den 1930er und 1940er Jahren ${ }^{33}$ die These, daß die Temnye allei ein lyrisches Buch in Prosa seien. Die Frage nach der Genreeinordnung des Buches als Ganzes indessen lassen beide Studien offen. Ebenso fehlt eine umfassende Auseinandersetzung mit der Editions- und Rezeptionsgeschichte sowie eine vorbehaltlose Berücksichtigung der erotischen Schilderungen innerhalb des Buches - diese Lücke möchte die vorliegende Studie schließen.

\subsection{Die Textgrundlagen dieser Arbeit}

Der vorliegenden Dissertation dient als zentrales Referenzwerk für die spăten Erzăhlungen der 1999 erschienene sechste Band der jüngsten Sobranie socinenij ${ }^{34}$ in acht Bänden. Dieser Band enthălt sowohl die Temnye allei auf Grundlage der Pariser Ausgabe von 1946 unter Berücksichtigung der von Bunin in seinem persönlichen Exemplar vorgenommenen Änderungen ${ }^{35}$ als auch eine Reihe weiterer, einzeln veröffentlichter später Erzählungen. Ergänzend werden Veröffentlichungen in den New Yorker Emigrantenzeitschriften Novyj zurnal und Novosel'e herangezogen sowie Manuskript- und Typoskriptfassungen aus verschiedenen Archiven (vgl. die tabellarische alphabetische Übersicht in Anhang 1).

31 Z.B. B. Briker. "Time, History, and Fairy Tale in Ivan Bunin's, A Cold Autumn"“. In: Canadian Slavonic Papers 1-2 (1998): 125-136; V. Greenev. „Cikl rasskazov I. Bunina .Temnye allei`. (Psichologiceskie zametki)“. In: Russkaja literatura 3 (1996): 226-235; L. lezuitova. „V poiskach ,samogo glavnogo, samogo podlinnogo, cto est' $v$ nas' - ,Scast'ja Zizni““. In: Russkaja literatura 3 (1996): 214 226; O. Slivickaja. „Celovek Bunina kak kosmos i lienost"“. In: Slavic Almanach. The South African Year Book for Slavic. Central and East European Studies. 4 (1997): 69-80.

32 N. Evstafeva. „Svoeobrazie zanrovych form $v$ knige I. A. Bunina .Temnye allei“". Avtoreferat. Charkov, 1990.

33 M. Stem. V poiskach utracennoj garmonii (proza I. A. Bunina 1930-1940-ch gg.): Monografija. Omsk, 1997.

34 I. Bunin. SS v vos'mi romach. 6. Bd. Moskva, 1999.

35 Der überwiegende Teil dieser quantitativ geringfugigen Änderungen ist stilistischer Natur; in der Regel handelt es sich um den Austausch einzelner Worter; von erheblich großerer Tragweite ist der von Bunin auf den ersten Seiten des Buches niedergeschriebene Wunsch, in künftigen Publikationen der Temm'e allei an die bislang letże Erzahlung .Casovnja” zusłatzlich die Erzăhlungen „Nocleg” und .Vesnoj, v ludee" anzuhăngen (vgl. Kap. 3.3 und 4.5). 
Von entscheidender Bedeutung für die vorliegende Arbeit sind die größtenteils unveroffentlichten Materialien aus Bunins sogenanntem „Pariser Archiv“, das im LRA an der University of Leeds ${ }^{36}$ verwahrt wird. Es umfaßt den Großteil der Zeugnisse des literarischen und publizistischen Schaffens Bunins in den Jahren der Emigration ebenso wie weite Teile seiner Korrespondenz, Tagebücher, Notizen, Zeitungskritiken, Fotoalben, Gästebücher etc. ${ }^{37}$ Eine immens wertvolle Quelle bilden denn auch die unveröffentlichten Erzählungen und Entwüre, die dort in Manuskript- bzw. Typoskriptform einsehbar sind. Eine Reihe weiterer Manuskripte bzw. Typoskripte befinden sich darüber hinaus in russischen Archiven. ${ }^{38}$

Von besonderem Interesse für die Erhellung der Entstehungs- und Rezeptionsgeschichte sind die Tagebuchaufzeichnungen Bunins jener Jahre ebenso wie die seiner Frau Vera Nikolaevna, die nur in gekürzter Form ${ }^{39}$ veröffentlicht sind, sowie Erinnerungen verschiedener Zeitgenossen. Es muß jedoch darauf hingewiesen werden, daß Bunins private Aufzeichnungen mit Vorbehalt zu bewerten sind, da er große Teile seiner Tagebücher auszugsweise abgeschrieben und die Originale im Anschluß verbrannt hat (vgl. z.B. seine Tagebuchnotiz vom 3. April $1940^{40}$ ). Sein ausdrücklicher Hinweis in seinem literarischen Vermächtnis, daß er gegen die postume Veröffentlichung seiner Tagebücher nichts einzu-

36 Bunins Archiv aus den Jahren der Emigration hat eine bewegte Geschichte: Anfang der 1950er Jahre spielte Bunin mit dem Gedanken, sein Archiv der Butler Library an der Columbia University New York zu vermachen bzw. zu verkaufen, zog sein Angebot jedoch zuruck. Nach seinem Tod ging das Archiv in den Besitz seiner Witwe Vera Nikolaevna uber, die es ihrerseits dem seit Jahren im Hause der Bunins lebenden Schriftsteller Leonid Fedorovic Zurov vermachte (sie starb 1961). Zurov hinterließ es wiederum 1971 der in Edinburgh lebenden Milica Eduardovna Greene (1908-1998), einer Bekannten der Bunins. Diese ubergab das Material in Form einer Schenkung zwischen 1985 und 1991 - und damit noch zu Lebzeiten - dem LRA, Teil der Special Collections der Brotherton Library der University of Leeds, unter Leitung von Dr. R. Davies (vgl. A. Heywood. Catalogue of the I. A. Bunin. V. N. Bunina. L.F. Zurov and E. M. Lopatina Collections. Leeds, 2000; der umfangreiche Katalog ist dem Gedenken an Milica Greene gewidmet). Seither wurden in der Sowjetunion bzw. in Rußland immer wieder Stimmen laut, die die Übergabe des Archivs an RuBland forderten - mit teilweise recht dubiosen Argumenten: 1997 etwa zweifelte der Publizist A. Baboreko die Rechtmaßigkeit des Erbverlaufs an Zurov an, da er Vera Bunina mutmaBlich unter Druck gesetza habe, um sich des Nachlasses zu bemăchtigen (ders. ..Archiv Bunina dol'zen byt' v Rossii“. In: Literaturnaja gazela 6 [1997]: 12). Vgl. auch V. Lavrov. ...V mire kruga zemnogo'. Za strokoj avtografov I. A. Bunina“. In: Al'manach bibliofila 19 (1985): 214-235; M. Ul'janov et. al. „Pecal'naja sud'ba archiva Bunina. Otkrytoe pis'mo Prezidentu Rossijskoj Federacii V. V. Putinu“. In: Literaturnaja gazela 48 (2000): 1; N. Ivanova-Gladilscikova. „Detektivnaja istorija s otkrytym finalom. Kak vernut' v Rossiju archiv Ivana Bunina". In: Izvestija (12.01.2001); A. Andreeva et. al. "Necego $v$ gosti po plac, esli doma navzryd". In: Izvestija (01.02.2001); N. Ivanova-Gladilscikova. „Sorok odin recept vmesto archiva“. In: Izvestija (01.02.2001).

37 A. Heywood. Catalogue of the I. A. Bunin .... op.cit.

38 RGALI und RGB, otdel rukopisej, beide Moskau. Von Regierungsseite bestand bereits wenige Jahre nach Bunins Tod ein ausgeprägtes Interesse an seinem literarischen Nachlaß; die Witwe Vera Bunina obergab sowjetischen Regierungsvertretem zwischen 1956 und 1961 verschiedene Materialien.

39 Ustami Buninych. Dnevniki v trech tomach. Hg. Milica Grin [Greene]. Frankfurt am Main, 1.Bd. 1977, 2.Bd. 1981 , 3.Bd. 1982.

40 „Перепнсываю аневниковые клочкн предыдущих лет. Многое рву н жrу“ (zit. in: UB. 3.Bd. op.cit.: 41). 
wenden habe, weckt zudem Zweifel an der Unmittelbarkeit eines Teiles der dort festgehaltenen Impressionen. ${ }^{41}$

Höchste Bedeutung bei der Rekonstruktion der Entstehungs-, Publikations- und Rezeptionsgeschichte kommt der umfangreichen Korrespondenz Bunins zu, da sich Bunins Verhăltnis zu Verlegern, Kritikern und Lesepublikum zum Teil sehr deutlich darin widerspiegelt. $^{42}$ Ein Großteil der Briefe an Bunin aus den Jahren der Emigration (teils auch Durchschläge seiner Briefe an den jeweiligen Adressaten) befindet sich ebenfalls im LRA, einiges in dem Special Collections Department in der Edinburgh University Library und im Bakhmeteff Archive in der Butler Library der New Yorker Columbia University, anderes wurde in verschiedenen Zeitschriften publiziert. Ergänzt wurden diese Informationen durch Recherchen im Nordelbischen Kirchenarchiv, in diversen Verlagsarchiven sowie persönliche Gespräche oder Briefwechsel mit Verlegern, literarischen Agenten und Zeitzeugen. Die Durchsicht diverser Rezensionen sowie die Sichtung entsprechender Handbücher, Monographien, Artikel etc. runden die Nachforschungen ab.

41 Die Bedeutung seiner Tagebalcher versucht er zu schmălem in seinem 1951 verfaßten „literarischen Vermachtnis": „Дневники мон тоже, по-моему, мало интересны. [...] Да и уничтожил я очень бальшое количество этих записей" (zit. in: "Literaturnoe zavescanie I. A. Bunina". In: Nz 66 [1961]: 172).

42 Vermutlich nicht zuletzt aus diesem Grunde wendet sich Bunin bereits 1942 ("K moemu zavescaniju“) gegen die postume Veroffentlichung seiner Briefe: „Bсе мои письма [...] не печатать, не издавать“, eine Bitte, die er 195 I wiederholt (,K moemu literatumomu zavescaniju“): „... ^ чрезвычайно прошу не печатать нх ...“- beide Zitate in: „Literatumoe zavescanie I. A. Bunina“. op.cit.: 169 bzw. 172 . Im Gegensatz zur Veroffentlichung seiner (hăufig uberarbeiteten) Tagebuchaufzeichnungen sprach sich Bunin nachdrucklich gegen eine Publikation seiner Briefe aus, spielte jedoch gleichzeitig vorwegnehmend deren Bedeutung herunter. 


\section{ZUR VERKNÜPFUNG VON NARRATIVER KURZPROSA}

Das künstlerisch-integrative Verfahren der Verknüpfung verschiedener autonomer narrativer Kurzprosatexte zu einer umfassenden Einheit und damit zu einer neuen, eigenständigen Kompositionsform geht mutmaßlich auf orale Erzähltraditionen zurück und ist bereits seit vorchristlicher Zeit Bestandteil literarischen Schaffens in aller Welt. ${ }^{43}$ In der westeuropäischen Literatur erreichten diese soge.zannten zyklischen oder mehrgliedrigen Rahmenerzählungen $^{44}$ mit Boccaccios Decamerone (1349-1353) einen einflußreichen künstlerischen Höhepunkt. Ihr heutiges Erscheinungsbild erhielt diese Erzähltechnik, deren breites Spektrum von Sammelbänden nicht miteinander vernetzter Erzählungen bis hin zu romanähnlichen Verknüpfungen reicht, aber erst im Laufe des 19. Jahrhunderts mit der wachsenden Zahl kürzerer Erzählprosatexte und dem zunehmenden Verzicht auf den Kunstgriff des alle Einzelteile verbindenden Rahmens.

In der altrussischen Literatur finden sich Prosatexte mit verknüpfenden Strukturen erstmals im kirchenslavischen Schriftum; dominierendes Ordnungsprinzip dieser Zusammenstellungen kirchlicher Texte (z.B. Psalter, Horen, Chroniken) war das Kalendarium; seltener sind Textsammlungen, die einem rein thematischen oder auktorialen Ordnungsprinzip gehorchen - in der Regel ist ein Zusammenspiel verschiedener Prinzipien zu beobachten. ${ }^{45}$ Allen Sammlungen gemein ist indessen die nachträgliche Zusammenstellung der Texte. Die Verknüpfung von Erzählprosatexten läßt sich hingegen erst in der russischen Romantik feststellen, bedingt durch das - im Vergleich mit der Entwicklung in Westeuropa spăte Auftreten von Erzählungen in der russischen Literatur, die sich nur allmählich gegen

43 Als Beispiele fruher Erzăhlprosaverknupfungen seien das zwischen dem ersten und sechsten Jahrhundert n. Chr. entstandene indische Pañcatantra, die von Ovid zwischen I v. Chr. und $10 \mathrm{n}$. Chr. verfaßten Metamorphosen und die seit dem achten Jahrhundert durch mehrere Jahrhunderte hindurch weiterentwickelten Geschichten aus 1001 Nacht genannt.

44 Gero von Wilpert unterscheidet im Sachwörterbuch der Literatur $\left(1979^{\circ}\right)$ zwischen der zyklischen Rahmenerzăhlung (im folgenden „mehrgliedrige Rahmenerzahlung“ genannt) und der gerahmten Einzelerzahlung: Wahrend der Rahmen der gerahmten Einzelerzahlung zum einen der Einfuhrung eines Erzahlers und zum anderen der Unterstreichung der Glaubwürdigkeit bzw. der Objektivităt des Rahmeninhalts durch eine ..fingierte Quelle“ (S. 652) dient, hat der Rahmen der mehrgliedrigen Rahmenerzathlung daruber hinaus die Aufgabe, „eine groBere Anzahl von inhaltlich zusammengehorigen Einzelerzahlungen zu einer in sich geschlossenen [...] Einheir“ (S. 652) zusammenzufassen. In beiden fallen hat der Rahmen in der Regel keine selbstandige Funktion; vgl. hierzu auch B. Tomasevskij: „Bо всех трех случаях [Kniga Kalily i Dimmy, Skazki I00I noci, Dekameron] мы имеем простеЯшия прнем связывания новелл - при помоши обракегеия, т.е. новеллы (обычно мало развитой, поскольку она не имеет самостоятельной функции новеллы, а вводится лищь как обрамление иикла), однн нз мотнвов которой является рассказывание“" (Teorija literatury. Poetika. New York, 1967: 195).

$45 \mathrm{Vgl.} \mathrm{R.} \mathrm{Marti.} \mathrm{„Zyklisierung} \mathrm{im} \mathrm{alteren} \mathrm{kirchenslavischen} \mathrm{Schriftum".} \mathrm{In:} \mathrm{Zyklusdichtung} \mathrm{in} \mathrm{den} \mathrm{slavi-}$ schen Literaturen. op.cit.: 319-338. 
das dominierende Versmedium durchsetzten. Ihren Anfang nahm die Entwicklung dieses Genres in Rußland mit mehrgliedrigen Rahmenerzăhlungen wie Puškins Povesti pokojnogo Ivana Petrovica Belkina und Gogol's Vecera na chutore bliz Dikan'ki (beide 1831). Ob Ivan Belkin oder Rudij Pan'ko, in beiden Fällen bildet die im Rahmen enthaltene Geschichte des Erzählers die Klammer, die nicht nur für die Authentizität des Rahmeninhalts bürgen soll, sondern vor allem für die Einheit des Buches verantwortlich ist und die Verknüpfung der voneinander völlig unabhängigen Erzählungen motiviert und legitimiert. Auch Vladimir Odoevskij verwendete für seine in den 1830er Jahren entstandenen, aber erst 1844 publizierten Russkie noci die mehrgliedrige Rahmenerzählung: Die im Verlauf von neun Nächten stattfindenden Treffen vierer philosophisch interessierter Freunde bilden in diesem Fall den Rahmen, in den die verschiedenen Erzählungen unterschiedlichen Typs integriert sind.

Einer anderen verknüpfenden Technik bedienten sich Lermontov und Turgenev in ihren Prosawerken Geroj našego vremeni (1840) und Zapiski ochotnika (1847-1851). Beide verzichteten auf den kompositorischen Kunstgriff des Rahmens und stellten die Verknüpfung auf eine weniger offensichtliche Weise her - Lermontov durch die umfassende Darstellung seines Protagonisten Pecorin über Innen- und Außensicht, Turgenev über den im ganzen Buch präsenten Ich-Erzähler. Dadurch erzielten sie eine wesentlich stärkere Kohärenz.

Während im Realismus der Roman die dominierende Stellung unter den Gattungen einnimmt, gewinnt die kleine Erzählform erst in der nachfolgenden Epoche der russischen Moderne mit Čechovs Erzählungen der 1880er Jahre erneut an Bedeutung. Der Verknüpfungsgrad seines vornehmlich in Sammelbänden edierten Erzählwerkes ist jedoch wesentlich lockerer ${ }^{46}$ als jener der romanähnlichen Prosawerke Lermontovs oder Turgenevs, da die Zusammenstellung von Sammelwerken überwiegend anhand thematischer Kriterien nach Abschluß des Schreibprozesses erfolgt; eine bewußte globale Konzeption durch den Autor kann demzufolge ausgeschlossen werden.

Für narrative Kurzprosaverknüpfungen des 20. Jahrhunderts verliert der extratextliche Kunstgriff des Rahmens an Bedeutung und wird abgelöst durch starke intratextliche Bezuge - vor allem im thematischen, aber auch im strukturellen und stilistischen Bereich -, die keinen Zweifel an der Zusammengehörigkeit der Erzählungen aufkommen lassen. Als Beispiele können Kurzprosaverknüpfungen wie die Rasskazy Nazara Il'ica gospodina Sinebrjuchova (1921) von Michail Zošenko und Konarmija (1926) von Isaak Babel’

$46 \mathrm{Vgl}$. L. Ljapina. „Puti i principy cikloobrazovanija v lirike, èpike i drame“. In: Zyklusdichtung in den slavischen Literaturen. op.cit.: 287-297. 
angeführt werden. Während Zošcenkos Buch seine Verknüpfung durch die Ich-Erzählperspektive des titelgebenden Protagonisten erfährt, kommt in Konarmija über den IchErzăhler hinaus ein komplexes System von thematischen und motivischen Verflechtungen zum Tragen. Babel's Odesskie rasskazy (1921-1924) hingegen werden vornehmlich durch die Beibehaltung des Schauplatzes (das Odessaer Judenviertel Moldavanka) zusammengehalten und sind dadurch ungleich offener gestaltet.

Golosa, Vladimir Makanins 1980 erschienene Collage aus Kurzgeschichten und Skizzen $^{47}$, das 1993 veröffentlichte Buch Archiv $i$ drugie istorii von Dmitrij Dobrodeev ${ }^{48}$ und die Publikation verschiedener Erzählbände der Autorin Viktorija Tokareva ${ }^{49}$ in den vergangenen Jahren machen deutlich, daß das Genre auch an der Wende zum 21. Jahrhundert nicht an Aktualităt eingebüßt hat. Als jüngstes Beispiel wäre der Titel Taiga Blues von Aleksandr Ikonnikov zu nennen, der in dieser Form bislang nur in der deutschen Übersetzung vorliegt. ${ }^{\text {so }}$

Die Erforschung dieses Genres in der russischen Literaturwissenschaft findet bis heute in einer Art Niemandsland statt, obwohl Einzelstudien zu verschiedenen narrativen Kurzprosaverknüpfungen in der russischen Literatur vorliegen. ${ }^{51}$ Zwar haben sowohl Boris Tomaševskij als auch Viktor Sklovskij auf die mehrgliedrigen Rahmenerzählungen als Sonderfall der Erzählliteratur hingewiesen ${ }^{52}$, ihre Überlegungen jedoch weder in ausreichendem Maße auf rahmenlose Kurzprosaverknüpfungen ausgedehnt noch eine entsprechende Sensibilisienung bewirkt, obgleich eine analytische Betrachtung von Kurzprosaverknüpfungen unter formalistischen bzw. strukturalistischen Aspekten naheliegend erscheint. Nach wie vor konzentriert sich die russische Literaturwissenschaft bei der Erforschung von Kurzprosaverknüpfungen auf die Literatur des 19. Jahrhunderts. ${ }^{53}$ Dieser Still-

47 Z.B. enthalten in:'ders. Laz. Moskva, 1998.

48 D. Dobrodeev. Archiv i drugie istorii. Moskva, 1993.

49 Z.B. die folgenden Titel: Korrida. Moskva, 1997; Gladkoe liciko. Povesti i rasskazy. Moskva, 1999; Lilovyj kostjum. Moskva. 1999.

50 A. Ikonnikow. Taiga Blues. Übs. A. Nitschke. Berlin, 2002.

51 Z.B. D. Ward. "The Structure of Pushkin's .Tales of Belkin"". In: Slavonic and East European Review 14 (1955): 516-517; N. Belova. „Zanrovoe novatorstvo Turgeneva v ,Zapiskach ochotnika"”. In: Ucemye zapiski Saratovskogo universiteta 67 (1959): 41-62; A. Neminusxij. Povesti i rasskazy (1894) v kontekste sbornikov prozy A. P. Cechova. Riga. 1989; M. Schreurs. Procedures of Montage in Isaak Babel's .Red Covalry". Amsterdam u.a., 1989.

52 B. Tomasevskij. Teorija literatury. op.cit.: 195ff. und V. Sklovskij. „Neskol'ko èmpiriceskich zamecanij o sposobach soedinenija novell". In: Povesti o proze. Razmyslenija i razbory. Moskva, 1966: 104ff.

53 Vgl. z.B. die folgenden Arbeiten: A. Januskevic. „Russkij prozaiceskij cikl kak ,forma vremeni‘" In: Istoriceskie puli i formy chudotestvennoj ciklizacii v poezii i proze. Hg. M. Darvin. Kemerovo, 1992: 18-35; Ju. Lebedev. „Stanovlenie èposa v russkoj literature $1840-1860$ gg. (Problemy ciklizacii)“. Avtoreferat doktorskoj dissertacii. Jaroslavl, 1975; L. Ljapina. Ciklizacija v russkoj literature 1840-60-ch gg. Sankt-Peterburg, 1995; dies. Ciklizacija v russkoj literature XIX veka. Sankt-Peterburg, 1999; dies. "Puti i principy cikloobrazovanija v lirike, èpike i drame“. In: Zyklusdichtung in den slavischen Literaturen. op.cit.: 287-297; 1. Pospisil. . The Cycle as Undercurrent in the Development of Prose: the Example of

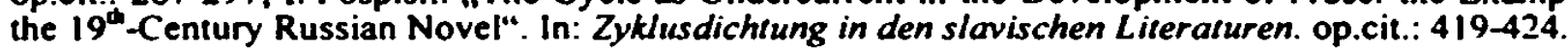


stand im narrativen Bereich steht im krassen Gegensatz zu der Erforschung von Lyrikzyklen in der russischen Literatur. ${ }^{54}$

Es verwundert nicht, daß in der US-amerikanischen Literaturwissenschaft rahmenlose Verknüpfungen kürzerer Prosatexte bzw. Short Stories schon seit gut 30 Jahren Gegenstand einer lebhaften gattungstheoretischen Diskussion sind, da sich dieses Genre seit Beginn des 20. Jahrhunderts wachsender Beliebtheit bei angloamerikanischen bzw. anglokanadischen Schriftstellem erfreut. Die wichtigsten Arbeiten auf diesem Gebiet stammen von Forrest L. Ingram (1971), Susan Garland Mann (1989) und Rolf Lundén (1999) ${ }^{55}$, deren induktiv gewonnene Ergebnisse auch auf Kurzprosaverknüpfungen anderssprachiger Literaturen übertragen werden können. Die zentralen Fragestellungen und Definitionsansätze dieser drei umfangreichen Genrestudien sollen daher im folgenden komparativ vorgestellt und erörtert werden, bevor abschließend die Leitfragen für eine Analyse der Temnye allei unter genrespezifischen Gesichtspunkten entwickelt werden.

\subsection{Annäherungen an eine Definition von narrativen Kurzprosaverknüpfungen des}

20. Jahrhunderts und die Suche nach einer adäquaten Genrebezeichnung

Die gattungstheoretische Diskussion ist gekennzeichnet durch heterogene Definitionen für Verknüpfungen narrativer Kurzprosa und eine terminologische Vielfalt der Genrebezeichnungen. ${ }^{56}$ Sie hat eine Reihe typologischer Studien ${ }^{57}$, aber auch Analysen und

S4 Vgl. Fußnote 8 in Kap. 1.1 und die diesbezugliche Gewichtung in: $\mathrm{R}$. Ibler (Hg.). Zyklusdichtung in den slavischen Literaruren. op.cit.: XIIff.

55 F. L. Ingram. Representative Short Story Cycles of the Twentieth Century. Studies in a Literary Genre. The Hague/Paris, 1971; S. G. Mann. The Short Story Cycle. A Genre Companion and Reference Guide. Westport/Connecticut, 1989; R. Lunden. The United Stories of America. Studies in the Short Stony Composite. Amsterdam u.a., 1999.

56 Die Bezeichnungen schwanken in auffalliger Weise zwischen den beiden Extremen dieses Genres: romanăhnlichen Verknupfungen und der Sammlung von Erzăhlungen. Rolf Lundén hat in seiner Genrestudie eine Vielzahl verwendeter Termini zusammengetragen und diskutiert, von denen an dieser Stelle einige beispielhaft aufgefuhrt werden sollen: Story Novel, Storied Novel, Collective Novel, Fragmentary Novel, Para-Novel oder Rovelle (zusammengesetzt aus „Roman“" und ..Novelle“) versus Integrated Short-Story Collection, Blended Work, Short Story Compound, Short Story Ensemble. Short Story Cluster, Short Story Sequence oder Short Story Cycle (R. Lunden. op.cit.: 12ff.).

57 Z.B. J. G. Kennedy. „Toward a Poetics of the Short Story Cycle“. In: Journal of the Short Story in English 11 (Herbst 1988): 9-25; ders. (Hg.). Modern American Short Story Sequences: Compositc Fictions and Fictive Communities. New York, 1995; K. Lubbers. Typologie der Kurzgeschichte. Darmstadt. 1977; P. L. Reed 111. „The Integrated Short-Story Collection: Studies of a Form of Nineteenth- and Twentieth-Century Fiction". [Masch.schr.] Diss. Indiana University. Dissertation Abstract Index (DAI) 35 (1975): 6730A; 1. Reid. The Short Story. London, 1977; R. Silverman. „The Short Story Composite: Forms, Functions, and Applications“. [Masch.schr.] Diss. University of Michigan, 1970. DAI 31: 12 (1970): 6622A. 
Interpretationen einzelner Kurzprosaverknüpfungen ${ }^{58}$ hervorgebracht. Literaturwissenschaftliche Nachschlagewerke sind bei der Beschäftigung mit dieser Problematik nur bedingt hilfreich, da die in ihnen enthaltenen Definitionen sehr allgemeiner Natur (die Anerkennung von Kurzprosaverknüpfungen als eigenständiges Genre steht noch aus) und von dem Bestreben gekennzeichnet sind, alle Gattungen umfassen zu wollen. ${ }^{59}$

Eine allgemeingültige Definition zu Kurzprosaverknüpfungen gibt es bislang nicht, ja kann es möglicherweise auch gar nicht geben, da Verknüpfungsgrad und -form alle denkbaren Variationen aufweisen können. Dieser Umstand erschwert die Suche nach einer eindeutigen und gleichzeitig flexiblen Genrebezeichnung. Die entscheidenden Impulse gehen hierbei von den bereits erwähnten drei großen Genrestudien aus, deren definitorische Ansätze in der Folge vorgestellt und diskutiert werden.

\subsubsection{Forrest L. Ingram}

Den ersten Versuch, eine allgemeingültige Definition für narrative Kurzprosaverknüpfungen zu erstellen sowie auf ihre spezifischen Eigenheiten hinzuweisen, unternahm Forrest L. Ingram 1971 mit seiner einflußreichen Studie Representative Short Story Cycles of the Twentieth Century. Studies in a Literary Genre. Dabei prägte er den Terminus „Short Story Cycle", der seitdem am häufigsten zur Bezeichnung narrativer Kurzprosaverknüpfungen und in undifferenzierter Weise verwendet wird ${ }^{60}$ - suggeriert doch der Begriff ,Zyklus“61

58 Hierzu gehoren z.B. J. V. Creighton. „.Dubliners" and, Go Down, Moses": The Short Story Composite“. [Masch.schr.] Diss. University of Michigan, 1969. Dissertation Abstract Index (DAl) 31: 4 (1970); K. El-Hassan. Kurzgeschichtenensembles. Formen der Verknüpfung anglokanadischer Short-Stories. Bochum, 1991; F. Weltz. „Vier amerikanische Erzahlzyklen“. [Masch.schr.] Diss. Munchen, 1953.

59 Vgl. beispielsweise die Eintragungen unter dem Stichwort „Zyklus“ bzw. „cikl“ im Sachworterbuch der Literatur (op.cit.) bzw. in der Kratkaja literaturnaja enciklopedija (Moskva, 1975). Uberlegungen zu Verknupfungsformen in Lyrik und Drama werden in der vorliegenden Arbeit nicht berucksichtigt. da Vergleiche nur in eingeschrănktem Maße moglich sind.

60 Diese Feststellung gilt im ubrigen auch fur die slavistische Literaturwissenschaft.

61 In Deutschland verwendete F. Weltz als einer der ersten Literaturwissenschaftler in seiner 1953 vorgelegten Dissertation „Vier amerikanische Erzahlzyklen“ den Terminus „Zyklus“ zur Bezeichnung von Kuraprosaverknupfungen und macht damit deutlich, daß er diese Erscheinungsform als eigenstandiges Genre auffaßt. Im Zuge der vergleichenden Analyse der einzelnen Werke gelangt er zu der Feststellung. daß in Erzahlzyklen eine Reihe "selbstwertiger Erzăhlungen in mehr oder minder enger Beziehung" zueinander stehen, deren Glieder ,thematisch oder motivisch auf eine gemeinsame Mitte bezogen [sind], die aber erst aus dem Zusammenwirken all dieser Teile entstehr" (S. 92). Wichtig ist ihm dabei. $\mathrm{da}$ jeder Bestandteil seinen festen und unverruckbaren Platz innerhalb des Zyklus hat. Das asthetische Grundprinzip des Zyklus besteht Weltz zufolge in „wechselseitiger Bedeutungssteigerung, durch die das Ganze immer mehr Aussagekraft besitzt als die Summe der Einzelglieder" (S. 92). Auf die Erstellung eines allgemeingultigen Profils von Erzahlzyklen verzichtet Weltz jedoch. 
eine Zirkularităt, eine innere Geschlossenheit, eine Rückkehr an den Beginn, die vielen Kurzprosaverknüpfungen trotz einer engmaschigen intratextlichen Vernetzung nicht eignet.

Forrest L. Ingram stellt zunächst fest, daß sich die Short Story Cycles des 20. Jahrhunderts von den mehrgliedrigen Rahmenerzählungen der vorangegangenen Jahrhunderte vor allem im kompositorischen Bereich unterscheiden, da sie zumeist auf das verbindende Strukturelement des Rahmens - dessen Funktion bei rahmenlosen Kurzprosaverknüpfungen im übrigen hăufig von der ersten und letzten Erzählung übernommen wird ${ }^{62}$ - verzichten und somit rein äußerlich nicht mehr auf den ersten Blick als Erzăhlprosaverknüpfungen zu erkennen sind. Für moderne Short Story Cycles schlägt er folgende Definition vor:

[...] a book of short stories so linked to each other by their author that the reader's successive experience on various levels of the pattern of the whole significantly modifies his experience of each of its component parts. ${ }^{63}$

Das zyklische Kompositionsprinzip bewegt sich demnach zwischen drei Koordinaten: zum ersten muß die Publikation der zum Short Story Cycle gehörenden Erzählungen geschlossen, das heißt im Rahmen eines Buches, erfolgen, zum zweiten muß die ordnende Instanz bezuglich der Reihenfolge der Erzählungen in der Person des Autors und nicht etwa in einem Herausgeber bestehen, und zum dritten soll die fortschreitende Wahrnehmung des zugrunde liegenden Musters bei der sukzessiven Lektüre den Blick des Lesers auf die einzelnen Erzählungen verändern, wodurch diese neben der ihnen bereits innewohnenden eigenständigen Bedeutung noch einen darüber hinausweisenden Sinngehalt bekommen, der wiederum den ihnen zugewiesenen Platz innerhalb des Buches rechtfertigt. Das entscheidende Charakteristikum des Short Story Cycle sieht Ingram in der Formulierung einer aus allen Erzählungen entstehenden übergeordneten Aussage, die über eine bloße Summierung der Einzelteile hinausgeht und zu der jede Erzăhlung ihren spezifischen Beitrag leistet, ohne dabei ihre Identität zu verlieren - wenn auch ihre eigene Bedeutung im Rückblick und in der Gesamtschau eine Modifikation erfahren könnte.

Diese semantische Aussage entsteht laut Ingram aus dem Zusammenwirken der statischen und der dynamischen Muster ${ }^{64}$ des jeweiligen Short Story Cycle. In den statischen Bereich fält die Anlage des Buches, die äußere Struktur, während sich die komplexeren dynamischen Muster durch die Wiederkehr verschiedener Elemente entfalten, die die Ent-

62 Vgl. F. Weltz. op.cit.: 106.

63 F. L. Ingram. op.cit.: 19.

64 Vgl. F. L. Ingram. Op.cit.: 20-24. Er verwendet die Begriffe „Static Pattem“ und „Dynamic Pattern”. 
wicklung der Gesamtaussage vorantreiben. Solche wiederkehrenden und verbindungsstiftenden Elemente können beispielsweise Motive, Symbole, handelnde Personen oder gar einzelne Wörter sein, sollten aber über bestimmte Gemeinsamkeiten, die das Werk eines jeden Autors durchdringen, hinausgehen. Diese Verbindungselemente kehren in modifizierter Form oder in einem anderen Kontext wieder, so daß die originäre Verwendung eine zusătzliche Dimension erfăhrt oder im Rückblick gar eine ganz neue Bedeutung erhält. Durch ihr mehr oder minder regelmäßiges Wiedsrauftreten setzen sie einen Proze $B^{65}$ in Gang, der den thematischen Kern des Short Story Cycle ausdehnt und vertieft und dadurch den Grad der Bindung zwischen den Erzählungen bestimmt.

Das Spektrum von Short Story Cycles reicht Ingrams Meinung zufolge von der reinen Sammlung nicht miteinander verbundener Erzăhlungen an dem einen Ende bis zu dem Roman nahestehenden Formen am anderen. ${ }^{66}$ Zwischen diesen Extremen sieht er unzählige Varianten, die sich auf drei Grundformen reduzieren lassen: den „Composed Cycle“, den "Completed Cycle“ sowie den "Arranged Cycle“67 Der Arranged Cycle stellt Ingram zufolge die loseste Form dar. Die Auswahl aus einer Reihe bereits fertiggestellter Erzăhlungen triff der Autor entweder allein oder gemeinsam mit dem Herausgeber. Als maßgebliche und leitende Kriterien sind hierbei in erster Linie die variierte Wiederholung eines einzigen Themas, aber auch die Dominanz eines einzelnen oder mehrerer ähnlicher Protagonisten in allen Erzăhlungen zu nennen. Eine weniger lose Form zeigt sich in dem Completed Cycle, der ursprünglich nicht als Zyklus angelegt wurde, dessen zyklische Elemente sich dem Autor aber im Verlaufe des Schreibvorganges offenbaren und von ihm bewußt weitergefuhrt werden.

Die festesten Strukturen weist der Composed Cycle auf, der von Anfang an als Zyklus konzipiert wurde und dem Autor erlaubt, sich mit Beginn der ersten Erzählung von seinem zugrunde liegenden Plan leiten zu lassen und alle Möglichkeiten zur Zyklisierung auszuschöpfen. Ingrams Kategorisierung bietet eine gute Ausgangsbasis für eine grobe Orientierung innerhalb der vielgestaltigen Erscheinungsformen narrativer Kurzprosaverknüpfungen. Durch die hohe Bedeutung, die er den Absichten des Autors zumißt, beruhen seine

65 Zur Bezeichnung der Wiederholung bei gleichzeitiger Fortentwicklung der semantischen Aussage verwendet Ingram den Schlusselbegriff „Recurrent Development“ (vgl. F. L. Ingram. op.cit.: 20ff.). Zur Verdeutlichung vergleicht er diesen Proze $B$ mit der Bewegung eines Rads: Die Speichen, d.h. die wiederkehrenden Elemente, kreisen um die Felge, d.h. das thematische Zentrum. Wahrend dieser Vorwartsbewegung dehnt und vertieft sich der thematische Kern in dem Maße, in dem sich die Elemente in verschiedenen Kontexten wiederholen.

67 Vgl. F. L. Ingram. op.cit.: $17 f f$. 
Klassifizierungen jedoch auf nur begrenzt nachprüfbaren Annahmen und lassen sich daher schwerlich objektivieren.

\subsubsection{Susan Garland Mann}

In ihrer 1989 erschienenen kompilativen Studie The Short Story Cycle. A Genre Companion and Reference Guide knüpft Susan Garland Mann an den von Ingram begonnenen Versuch an, einen Merkmalskatalog für narrative Kurzprosaverknüpfungen zu erstellen und diesen anhand verschiedener Beispiele zu illustrieren. Darüber hinaus verfolgt sie die Entwicklung dieser Erzăhltechnik in ihrem literaturhistorischen Kontext (überwiegend im angloamerikanischen Sprachraum) und fuhrt in einem umfangreichen Anhang beispielhafte Kurzprosaverknüpfungen aus dem 20. Jahrhundert auf.

Die Beibehaltung des von Ingram geprägten Terminus Short Story Cycle ${ }^{68}$ deutet bereits an, daß Mann mit der von ihm vorgeschlagenen Definition von Kurzprosaverknüpfungen weitgehend konform geht, auch wenn sie die äußeren Merkmale wie Herausgeber und Editionsform, auf die sie in der Folge noch hinweist, zunächst unberücksichtigt läßt und nur das ihrer Ansicht nach wesentliche Charakteristikum eines Short Story Cycle hervorhebt: „[...] the stories are both self-sufficient and interrelated" ${ }^{\circ 69}$, wobei der Leser vor der Wahl stehe, die jeweilige Erzählung als autonome Einheit zu rezipieren oder sie in Bezug zu den übrigen Erzählungen zu setzen. Damit betont auch sie die Eigenständigkeit der einzelnen Erzăhlungen sowie ihre Interdependenz im Hinblick auf die Kohärenz der semantischen Aussage des Short Story Cycle, während sie analog zu Ingram autorspezifische Kennzeichen ausklammert, die auch in anderen seiner Publikationen zum Tragen kommen: „[...] that is, the places the author knows, or the historical period in which the author lives, including certain social, economic, or political realities. “70

Bei ihren Überlegungen vernachlässigt sie indessen das Kriterium der sukzessiven Bedeutungsvertiefung und bleibt damit zu allgemein, denn eine gewisse intratextliche Vernetzung läßt sich schließlich auch in mancher Sammlung von Erzählungen konstatieren.

68 Ebenso wie Ingram läßt auch Mann offen, welche Gronde sie dazu bewogen haben, den verhăltnismåßig engen Terminus des Zyklus zu verwenden.

69 S. G. Mann. op.cit.: 15.

70 S. G. Mann. op.cit.: 16. 
ohne daß das von Ingram betonte Element des „Recurrent Development“ bei ihrer Rezeption von Bedeutung wäre.

Ebenso wie Ingram weist auch Mann darauf hin, daß der Short Story Cycle des 20. Jahrhunderts im Vergleich zu den mehrgliedrigen Rahmenerzählungen fruherer Jahrhunderte über spezifische Besonderheiten verfügt, die sie im Gegensatz zu Ingram aber nicht allein im kompositorischen, sondern vielmehr im thematischen Bereich ansiedelt. Sie unterscheidet im großen und ganzen zwei vielfach variier:e Typen moderner Short Story Cycles, deren semantische Aussage durch die Verwendung einer verknüpfenden Erzăhlweise plastischer als beispielsweise in einem Roman gestaltet werden könne, da sie die Beleuchtung des jeweiligen Erzăhlgegenstandes von mehreren Seiten erlaube: Während bei personenbezogenen Short Story Cycles das Erleben bzw. die Entwicklung eines oder mehrerer Protagonisten im Vordergrund stehe, konzentrierten sich die themenbezogenen auf die Illustration zeitgenőssischer gesellschaftlicher Probleme wie beispielsweise die Isolation des einzelnen oder die Veranschaulichung zwischenmenschlicher Kommunikationsbarrieren. ${ }^{71}$ Im Unterschied zu Ingram weist Mann den Leerräumen zwischen den Erzählungen eine Bedeutung zu, die sie in der Folge indessen nicht präzisiert. Dennoch deutet sie damit an. daß eine Analyse der verbindungsstiftenden Elemente allein nicht ausreichen könnte:

Along with this sense of isolation, the lack of continuity (or the gaps that exist between the stories in cycles) is used by some writers to emphasize the fragmentary nature of life, especially in the twentieth century. ${ }^{72}$

Mit der Feststellung, daß sich der modeme Short Story Cycle vomehmlich mit den Themen des Zerfalls des Gewohnten und der Unbestimmtheit der Zukunft beschăfigt, das heißt mit Problemstellungen, die den Menschen des 20. Jahrhunderts in stärkerem Maße bewegten als seine Vorfahren, vertritt sie daher eine ăhnliche Meinung wie Friedrich Weltz, der schon $1953 \mathrm{zu}$ dem Schluß kam, daß dieses Genre nicht von ungefăhr, zzum typischen Ausdruck unserer um ein neues Weltbild ringenden Zeit“"73 wurde. Im Gegensatz zu Ingram stützt sich Mann bei ihrer Kategorisierung vornehmlich auf die inhaltlichen Komponenten-zur Identifizierung narrativer Kurzprosaverknüpfungen ist diese Vorgehensweise jedoch zu oberflächlich und einseitig.

71 Vgl. S. G. Mann. op.cit.: 8 bzw. 11.

72 S. G. Mann. op.cit.: 12.

73 F. Weltz. op.cit.: 133. 


\subsubsection{Rolf Lundén}

1999 erschien eine weitere umfassende und wegweisende kritische Auseinandersetzung mit dem Genre, wiederum konzentriert auf Kurzprosaverknüpfungen aus dem angloamerikanischen Raum, aber mit einem gänzlich neuen Ansatz: Die Studie The United Stories of America. Studies in the Short Story Composite von Rolf Lundén ist in erster Linie theoretisch ausgerichtet (verzichtet also auf umfangreiche Beispielanalysen) und in dieser Form die umfassendste ihrer Art. Auf der Suche nach einem allgemeingültigen Oberbegriff fulr Verknüpfungen narrativer Kurzprosatexte rückt er demonstrativ von der Verwendung des Terminus „Short Story Cycle“ ab und plädiert für die Verwendung des Terminus „Short Story Composite“, da dieser flexibel genug sei, alle denkbaren Variationen aufzunehmen und gleichzeitig neutral genug, um keine spezifischen Assoziationen zu wecken. Anders als Ingram und Mann, die bei der Analyse der verschiedenen beispielhaften Kurzprosaverknüpfungen ausschließlich nach einheitsstiftenden Elementen Ausschau halten, hebt Lundén als Spezifikum des Short Story Composite die gleichermaBen wichtige Bedeutung der Spannung auf verschiedenen Ebenen hervor, der bislang nicht genügend Aufmerksamkeit gewidmet worden sei: „[...] between variety and unity, separateness and interconnectedness, fragmentation and continuity, openness and closure [...]."74 Die Existenz einer Spannung zwischen verschiedenen Konstituenten einer Kurzprosaverknüpfung haben zwar sowohl Ingram („between the one and the many ${ }^{\text {"75) }}$ ) als auch Mann („between separateness and interdependence“76) registriert, maßen dieser aber offensichtlich keine ausschlaggebende Bedeutung bei. Während Ingram nicht näher darauf eingeht, bricht Mann ihre diesbezulglichen Überlegungen ab mit einem Hinweis auf den nur schwer nachzuvollziehenden Prozeß der Auseinandersetzung mit der Spannung im Laufe der Lektüre. Indessen ist eines der markantesten Charakteristika von Kurzprosaverknüpfungen ihre Doppelwesenheit (eins und viele), die in der Spannung zwischen den Einzelerzăhlungen in ihren vielfaltigen Beziehungen zum Gesamtkomplex zum Ausdruck kommt. So lautet denn Lundéns Definition folgendermaßen:

The short story composite, then, is a form of narrative consisting of interlocking, autonomous stories, a narrative consciously constructed around the tension between simultaneous separateness and cohesion. [...] each individual story takes part in a cumulative process of meaning. ${ }^{77}$

74 R. Lundén. op.cit.: 12.

75 F. L. Ingram. op.cit.: 19.

76 S. G. Mann. op.cit.: 18-19.

77 R. Lundén. op.cit.: 33-34. 
Mit letzterer Feststellung verweist auch Lundén auf die sukzessive Formulierung der semantischen Aussage, vernachlässigt dabei allerdings die zum Verständnis gegebenenfalls zwingend notwendige sequentielle Lektüre - im Unterschied zur Lektüre in beliebiger Reihenfolge bei Sammlungen von Erzählungen.

Wăhrend Ingrams und Manns Studien somit unter dem Postulat der Einheit stehen, hebt Lundén die Relevanz der separierenden Elemente hervor. Seiner Ansicht nach laßß sich ein Short Story Composite nicht ausschließlich nach dem Grad seiner Verknüpfungsdichte beurteilen; es sollte vielmehr eine Analyse der Art des Zusammenwirkens zentripetaler und zentrifugaler narrativer Kräfte in den Mittelpunkt gestellt werden. Den einheitsstiftenden zentripetalen Kräften, die für Kohärenz und Geschlossenheit sorgen, stehen die zentrifugalen Kräfte gegenüber, die für die offenen Charakterzüge verantwortlich sind-dieses Spannungsfeld modelliert das unverwechselbare Profil einer Kurzprosaverknüpfung.

Die Kategorisierung von Kurzprosaverknüpfungen nimmt Lundén sowohl auf formaler als auch auf inhaltlicher Basis vor. Er unterscheidet vier Arten von Short Story Composites: den Zyklus, die Sequenz, den Cluster und die Novella. ${ }^{78}$ Während der Zyklus zirkulär aufgebaut sei und eine Rückkehr an den Anfang impliziere, folge die Sequenz einem rein additiven Aufbau, der nicht zwangsläufig einheitlich und geschlossen sein müsse. Der Cluster hingegen sei wesentlich loser und offener strukturiert; charakteristische Merkmale seien eine fragmentarische Struktur, Diskontinuität sowie hăufig eine durchbrochene Chronologie. Als Novella bezeichnet Lundén die mehrgliedrige Rahmenerzăhlung, die lediglich durch den Rahmen mit seinem wiederkehrenden Erzähler zusammengehalten werde. Die Eckpunkte dieses breiten Spektrums sieht er demzufolge in Übereinstimmung mit Ingram und Mann in der Sammlung am einen und romanähnlichen Prosawerken am anderen Ende. Mit dieser ganzheitlichen und flexibilisierten Betrachtungsweise wird Lundén der Ausdrucks- und der Inhaltsebene gleichermaßen gerecht - und damit dem individuellen Profil einer Kurzprosaverknüpfung -, ohne ins Schematische abzugleiten. Daher bilden seine Überlegungen die Grundlage für die im folgenden zusammengestellten Kriterien zur Bestimmung von narrativen Kurzprosaverknüpfungen. 


\subsection{Kriterien zur Bestimmung von narrativen Kurzprosaverknüpfungen}

So verschiedenartig die methodischen Ansätze auch sein mögen, Einigkeit besteht bei allen Forschem in dem Punkt, daß bei der Analyse einer narrativen Kurzprosaverknüpfung keine allgemeingültige Schablone gestalterischer Grundmuster angelegt werden kann, sondern vor allem jene Aspekte herausgearbeitet werden sollten, die das individuelle Profil maßgeblich mitbestimmen.

Dabei sollte man nicht allein textimmanent vorgehen, sondern auch außerliterarische Faktoren, wie etwa die Entstehungs-, Editions- und Rezeptionsgeschichte des jeweiligen Buches, miteinbeziehen: Während die Entstehungsgeschichte verdeutlicht, welche Faktoren die Konzeption der jeweiligen Kurzprosaverknüpfung beeinflußt haben, geben die Editions- bzw. Rezeptionsgeschichte Auskunft daruber, ob sie als solche erkannt und akzeptiert wurde bzw. wird. Flankiert von diesen Faktoren erfolgt die Annăherung an die Kurzprosaverknüpfung sinnvollerweise von außen, über eine Analyse der extratextlichen Verbindungen, wie sie sich etwa in der Anordnung der Erzählungen zeigt. Die textimmanente Betrachtung einer Kurzprosaverknüpfung konzentriert sich in der Folge auf die maßgeblichen intratextlichen Verknüpfungen auf struktureller, stilistischer und thematischer Ebene. Der folgende Merkmalskatalog, der auf der Grundlage der Arbeiten von Ingram, Mann und Lundén erstellt wurde, enthält Richtlinien, die diesen Anforderungen gerecht werden wollen.

\subsubsection{Extratextliche Verknüpfungen - die Anlage der Kurzprosaverknüpfung}

Die ersten, oberflächlichen Hinweise auf das Vorliegen einer Kurzprosaverknüpfung finden sich vielfach bereits im Titel, in einer gegebenenfalls vorhandenen Einleitung oder auch im Klappentext des jeweiligen Buches. Im Unterschied zu einer bloßen Sammlung von Erzählungen, die generell nach der ersten oder-seltener-der letzten Erzählung betitelt wird und im Titel häufig den Zusatz „und andere Erzählungen“ aufweist, pflegen die Titel von Kurzprosaverknüpfungen im allgemeinen zentrale Elemente wie zugrunde liegende Ideen oder den Schauplatz anklingen zu lassen. ${ }^{79}$ Auch dem Buch vorangestellte Zitate oder Mottos verdienen eine besondere Beachtung, da sie Schlüsselideen andeuten

79 Vgl. S. G. Mann. op.cit.: 14. 
können. ${ }^{80}$ Ferner ist davon auszugehen, daß im Falle einer Kurzprosaverknüpfung die Autorschaft von einer einzelnen Person getragen wird; ein Autorenkollektiv tritt nur in Ausnahmefallen auf.

Der Aufbau eines gegebenenfalls vorhandenen Inhaltsverzeichnisses gibt eine erste Auskunft über die Art der Anordnung der Erzählungen, die in der Regel einem bestimmten, etwa einem chronologischen oder thematischen, Muster folgt oder sich als symmetrisches bzw. asymmetrisches Gefüge präsentiert. Im Zuge der weiteren Analyse wird sich herausstellen, welche Bedeutung die Position der jeweiligen Erzăhlung innerhalb der globalen Konzeption des Buches hat. Ein besonderes Augenmerk ist hierbei auf die erste und die letzte Erzählung zu richten, die in Kurzprosaverknüpfungen des 20. Jahrhunderts häufig die Funktion eines Rahmens übernehmen. Bei mehrgliedrigen Rahmenerzählungen sind die Verwendung von Rahmenhandlungen, die die einzelnen Erzählungen voneinander trennen, sowie das Vorhandensein von Prologen und Epilogen genauer zu betrachten.

Im allgemeinen sind Kurzprosaverknüpfungen - im Gegensatz zum Roman und selbst im Gegensatz zu den sie konstituierenden Erzăhlungen - weder end- noch rückwärtsorientiert. $^{81}$ Retrospektiv sind sie nur in dem Maße, in dem die Lektüre fortschreitet und der Rückblick auf vorangegangene Erzählungen den Lesehorizont erweitert und erhellt. Daher ist eine Analyse der Anlage des Buches sowie der Art der Sukzession der einzelnen Erzăhlungen von nicht zu unterschätzender Bedeutung. Unter Bezugnahme auf Roland Barthes hat Lundén im Zuge seiner Strukturuntersuchungen festgestellt, daß Kurzprosaverknüpfungen in der Regel einige Kernerzählungen („Kernel Stories") aufweisen, die die Stützpfeiler des Buches bilden und die Hauptaussagen enthalten. ${ }^{82}$ Viele Kurzprosaverknüpfungen besitzen darüber hinaus noch eine sogenannte Ankererzählung („Anchor Story"), die sich im allgemeinen in der Mitte oder am Ende des Buches befindet und die von einer Dominanz und Lănge ist, daß sie die anderen Erzăhlungen zumindest zeitweilig zu überschatten droht. Flankiert werden die Kernerzählungen von Erzăhlungen mit geringerer Bedeutung für das Ganze, den Satellitenerzählungen (,Satellite Stories“). Eine extreme Form der Satellitenerzăhlungen stellen Erzählungen dar, die sich auf den ersten Blick scheinbar gar nicht in das Gefüge der Kurzprosaverknüpfung eingliedern lassen, da sie keine offensichtlichen intratextlichen Verbindungen mit den übrigen Erzählungen aufweisen - Lundén nennt sie Randerzählungen („Fringe Stories“). Bei einer einseitig ausge- 
richteten Suche nach einheitsstiftenden Elementen würden diese Erzählungen nicht angemessen berücksichtigt - dabei sind gerade sie es, die den Leser für die genrespezifische Inkohärenz sensibilisieren und ihn herausfordern, sich mit dem offenen Charakter einer Kurzprosaverknüpfung auseinanderzusetzen.

\subsubsection{Intratextliche Verknüpfungen auf struktureller bzw. stilistischer Ebene}

Die intratextlichen Verknüpfungen (nicht notwendigerweise Analogien) können von mannigfaltiger Ausprägung und auf jeder Textebene zu finden sein. Die folgenden Bereiche sind dabei für eine Bestimmung der Genrezugehörigkeit der Temnye allei von besonderer Relevanz hinsichtlich ihres Einflusses auf die Verknüpfungsdichte: Titel, Anfang und Schluß der Erzählungen, die Arten der Handlungsführung, die Schauplatzgestaltung, das Figurensystem und seine Besonderheiten sowie die maßgeblichen Gestaltungstechniken und auffallige stilistische Eigenarten. ${ }^{83}$

Der Frage nach den Verbindungslinien zwischen den Figuren sollte besondere Aufmerksamkeit gewidmet werden. Zunächst einmal ist festzustellen, ob eine einzelne Figur in der Kurzprosaverknüpfung eine dominante Rolle spielt oder aber jede Erzählung ihre eigene(n) zentrale(n) Figur(en) aufzuweisen hat: Wird die Aufmerksamkeit auf nur eine Figur gelenkt, so geht es dem Autor gewöhnlich um die Nachzeichnung des Entwicklungsbzw. Reifeprozesses einer meist jugendlichen Persönlichkeit. Werden hingegen viele handelnde Personen eingesetzt, sollte ermittelt werden, ob und welche Parallelen zwischen den einzelnen Figuren bestehen. Sie können in einer wie auch immer gearteten Gemeinschaft zusammenfließen, die als eigentliche zentrale Figur der Kurzprosaverknüpfung zu betrachten ist und von Mann als „Composite Personality“ ${ }^{84}$ bezeichnet wird. Sofern einige Figuren in mehreren, aber nicht in allen Erzählungen auftreten, sollte darauf geachtet werden, ob sie eine bestimmte Entwicklung durchlaufen oder ihre Funktion wechseln. Unter Umständen lassen die Figuren durch eine kontrastierende oder parallele Anordnung gar eine Einflußnahme auf die Anlage der Erzählungen innerhalb der Kurzprosaverknüpfung erkennen. Und letztlich muß die Frage nach der Darstellungsweise der Figuren beantwortet

83 Vgl. auch F. L. Ingram. op.cit.: $44 f$.

84 S. G. Mann. op.cit.: 10. 
werden: Sind bzw. wirken sie realistisch oder werden sie als Träger bestimmter Allegorien oder Symbole, weltanschaulicher Überlegungen oder Ideen verwendet?

\subsubsection{Intratextliche Verknüpfungen auf thematischer Ebene; ihre Umsetzung und ihre Wirkung}

Häufig werden die thematischen Schwerpunkte in einer narrativen Kurzprosaverknüpfung als ausschlaggebend für die Wahrnehmung der Verbindungsdichte empfunden. Bei einer Analyse der Entfaltung dieser Schwerpunkte ist beispielsweise von Interesse, ob im Verlauf der Kurzprosaverknüpfung verschiedene Haltungen einem bestimmten Thema gegenüber eingenommen werden oder ob eine Entwicklung spürbar wird. Weiterhin sollte untersucht werden, ob sich aus den Themen der einzelnen Erzählungen ein anderes, neues Gesamtthema ergibt und ob im Rückschlußverfahren die Aussage der Kurzprosaverknüpfung nachträglich weitergehende Deutungen der einzelnen Erzählungen ermöglicht und ihnen eine zusătzliche Bedeutungstiefe verleiht. Zudem sollte analysiert werden, ob untergeordnete Themen oder Motive einzelner Erzählungen in anderen eine größere Bedeutung erlangen. Besondere Aufmerksamkeit sollte hierbei den Abschlüssen der einzelnen Erzählungen gewidmet werden, da sie häufig die Essenz der in den Erzählungen getroffenen Aussagen enthalten. Sollte das zentrale Thema in allen Erzählungen dasselbe sein, kann eine Analyse der Anordnung der Erzählungen aufschlußreiche Muster zutage fordern. Wechselnde Schwerpunktthemen deuten darauf hin, daß das Interessenzentrum der Kurzprosaverknüpfung als Ganzes sich von den Schwerpunkten der einzelnen Erzählungen unterscheidet.

\subsection{Die Temnye allei als Cluster von Erzählungen}

Die in der Sekundärliteratur häufig anzutreffenden Bemerkungen zum „Zykluscharakter" der Temnye alle $i$ werden in der Regel mit dem Hinweis auf die thematischen Analogien der Erzählungen begründet. Derartige Beurteilungen bewegen sich allerdings insofern an der Oberfläche, als sie lediglich auf die thematische Dominanz der Antipodenstellung von 
Liebe und Tod hinweisen. In den meisten Fällen wird weder analysier, ob uber die thematische Ähnlichkeit hinaus weitere Verbindungen zwischen den einzelnen Erzählungen bestehen oder sich gar eine weitere inhaltliche Ebene in der Gesamtheit aller Erzăhlungen verbirgt, noch wird auf ein mögliches zugrunde liegendes Schema hingewiesen. ${ }^{85}$ Diese vagen Äußerungen tragen nur bedingt zum Verständnis des Buches bei; sie unterstreichen vielmehr das Unbehagen über die Schwierigkeit bei der Bestimmung der Genrezugehörigkeit der Temnye allei, sind aber gleichzeitig Beleg dafür, daß die Integrationsdichte des Buches intuitiv wahrgenommen wurde.

Wenn man unter einem Cluster die aus der Kernphysik übernommene Definition als eine „als einheitliches Ganzes zu betrachtende Menge von Einzelteilchen“86 versteht, so zeigt sich, daß diese sich als Ausgangspunkt auch für literaturwissenschaftiche Öberlegungen zu narrativen Kurzprosaverknüpfungen anbietet. Dieser Gedanke mag auch Lundén dazu bewogen haben, den Cluster als vierten Verknüpfungstyp narrativer Kurzprosa neben den Zyklus, die Sequenz und die Novella zu stellen. Dem methodischen Ansatz Lundéns folgend sind die Temnye allei als Cluster zu kategorisieren, da sie weder die innere Geschlossenheit des Zyklus, noch die reihende Verknüpfung der Sequenz oder gar die Merkmale der Novella, wie eine Rahmenhandlung und/oder einen in allen Erzăhlungen identischen Erzähler, aufweisen. Der Clustertypus hingegen ist Lundén zufolge gekennzeichnet durch eine vergleichsweise lose und offene Struktur,

[...] in which stories seem to be striving in various directions; in which chronology is not strictly adhered to; in which the gaps between the stories are wide; and in which some stories are not easily integrated into a coherent whole. [...] in many cases the interconnections between the stories are not obvious, but will have to be constructed by readers, often with a constricting result. While there definitely is a measure of unity in these clusters, discontinuity and fragmentation emerge as the by far more characteristic features. ${ }^{87}$

In der Tat wird in der Folge zu klären sein, in welchem Maße die Temnye allei offen sind für andere Erzählungen (ohne dabei die Gefahr zu unterschätzen, die Auswahl der Erzählungen beliebig wirken zu lassen), welche Absicht sich hinter der durchbrochenen Chronologie in der Anordnung der Erzăhlungen verbirgt und welche Erzählungen sich aus

85 Ausnahmen bilden die Monographien von J. Woodward (Ivan Bunin. A Study of His Fiction. Chapel Hill, 1980) und J. Connolly (Ivan Bunin. Boston, 1982) sowie die Dissertation von C. Hauchard (,La Prose de 1. A. Bounine de 1920 à 1953 ... “. Paris, 1993). Wahrend Woodward und Connolly hauptsachlich auf thematische Bez0ge abheben und bei der Enwahnung einiger Parallelen zwischen den einzelnen Erzahlungen stehenbleiben, spannt Hauchard den Bogen weiter, indem sie die Gesamtkonzeption des Buches in ihre Betrachtung einbezieht.

86 Duden. Das Fremdworterbuch. S.Bd. 6., verb. und erw. Auflage. Mannheim u.a., 1997: 156.

87 R. Lundén. op.cit.: 38. 
welchen Gründen auf den ersten Blick nicht integrieren lassen. Die Lücken zwischen den Erzăhlungen sind - darauf kann hier bereits hingewiesen werden - groß, dennoch gibt es vernetzende Fäden zwischen den einzelnen Erzăhlungen. Hierbei ist die Beantwortung der folgenden Fragen von besonderer Relevanz:

- Außerliterarische Faktoren: Läßt sich anhand der Entstehungsgeschichte eine bewußte globale Konzeption des Buches nachweisen? Oder war Bunin nur daran gelegen, überhaupt einige der Erzăhlungen zu veröffentlichen? Welchen Stellenwert hatten - sofern nachweisbar - die politischen, finanziellen bzw. moralischen Randbedingungen bei der Publikation? Welche Faktoren führten zu den differierenden Zusammensetzungen verschiedener Publikationen? Welchen Anteil hat die Editionsgeschichte an der Unsicherheit bezüglich einer Genrezuordnung des Buches? Wie wurden die Temnye allei vom zeitgenössischen, aber auch späteren Lesepublikum aufgenommen? War bzw. ist den Rezipienten die globale Konzeption des Buches bewußt?

- Extratextliche Verknüpfungen: Welche Funktion hat der Titel des Buches? Welchem Ordnungsprinzip folgt die Anlage der Erzählungen? Wie ist das Verhältnis von Kernund Randerzählungen? Auf welche Weise wird ein äußerer Zusammenhalt hergestellt?

- Intratextliche Verknüpfungen auf struktureller und stilistischer Ebene: Bestehen Parallelen im Aufbau der Erzählungen? Welche Arten der Handlungsfuihrung wurden bevorzugt verwendet? Welche Funktion haben die Schauplätze? Welche Gestaltungstechniken dominieren? Welche stilistischen Merkmale zeichnen die Temnye allei aus? Welche Funktion kommt den zentralen Figuren zu?

- Intratextliche Verknüpfungen auf thematischer Ebene: Wie werden die übergreifenden Themen entfaltet und welche Rolle spielen sie bei der Konstituierung von Ganzheitlichkeit? Welcher Art ist ihr Zusammenspiel?

Die schrittweise Beantwortung dieser und einiger weiterer, sich daraus ergebender Fragen ist notwendig, um zum einen der thematischen, inhaltlichen und formalen Komplexität der Temnye allei gerecht zu werden und zum anderen die Leistung Bunins angemessen zu würdigen, dem es gelang, die Erzähltradition des 19. Jahrhunderts in einer Kompositionsform des 20. Jahrhunderts lebendig zu erhalten. 
(

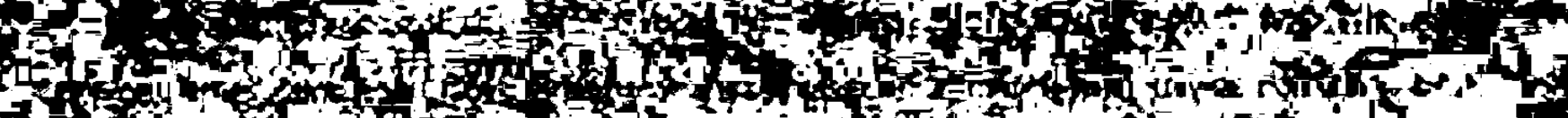
Tite

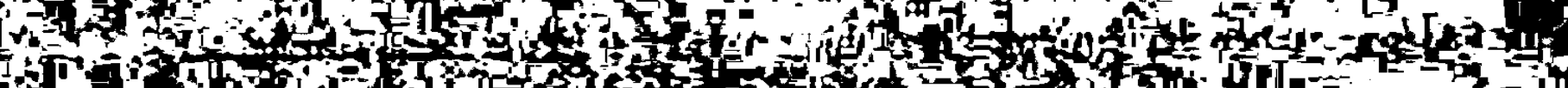
1.5

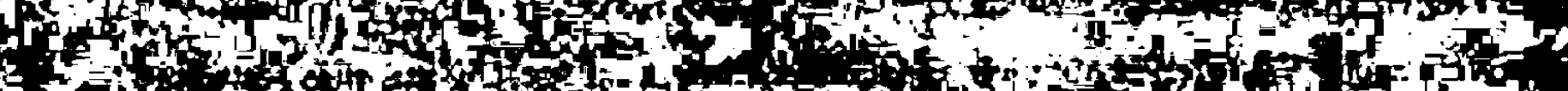

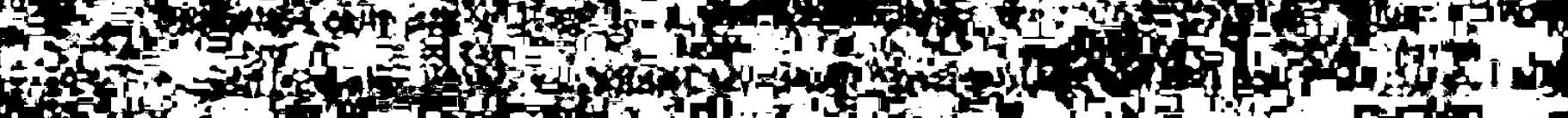

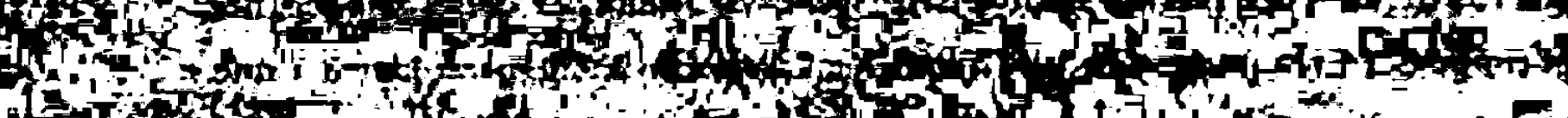

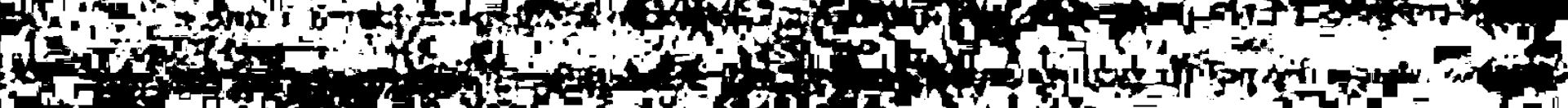
$2+\frac{1}{20}$

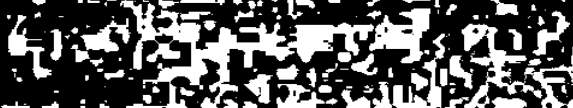

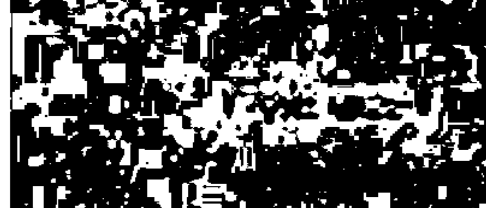

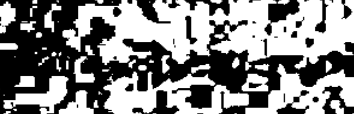

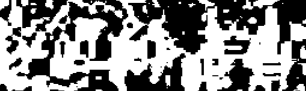
and

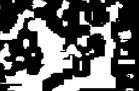
of Ton the

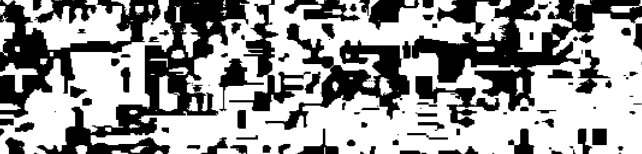

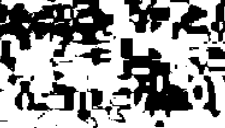

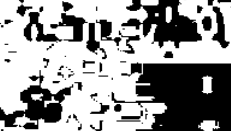
. tats

rist? s. in to ,

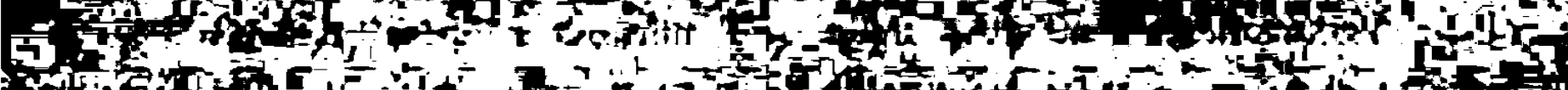

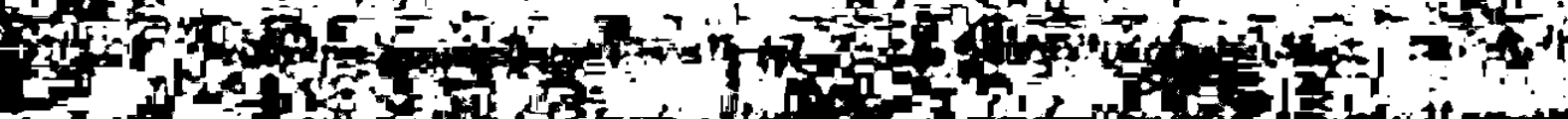

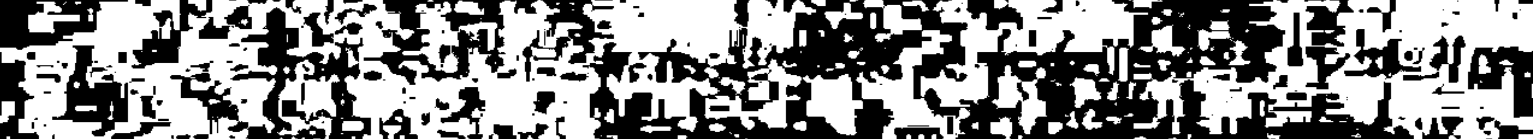
1.

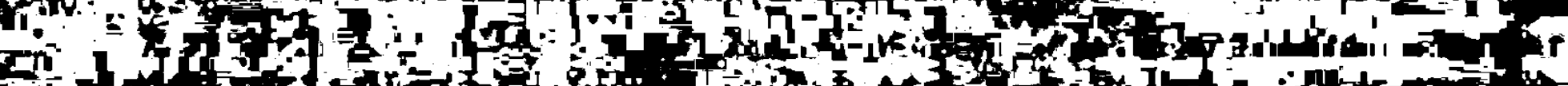
$5{ }^{2}$.

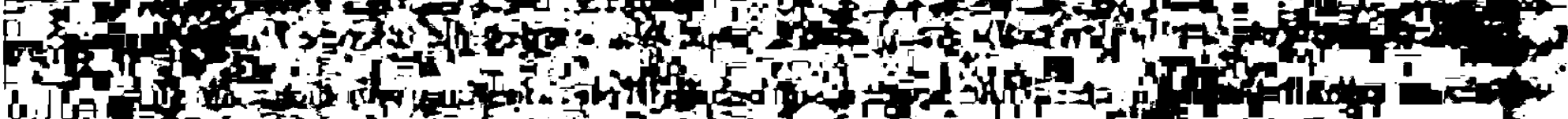
d J

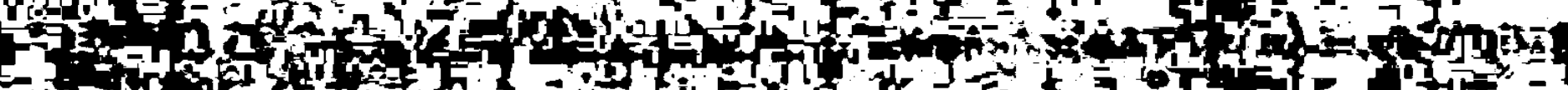

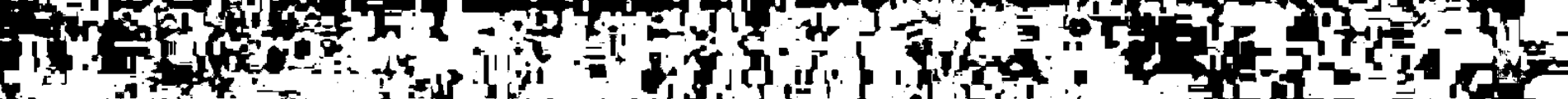
(1)

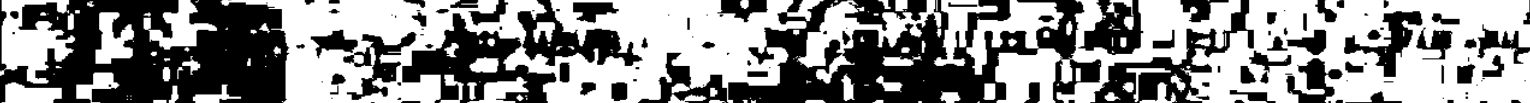
fre

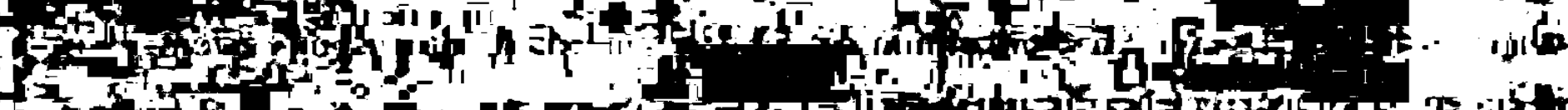

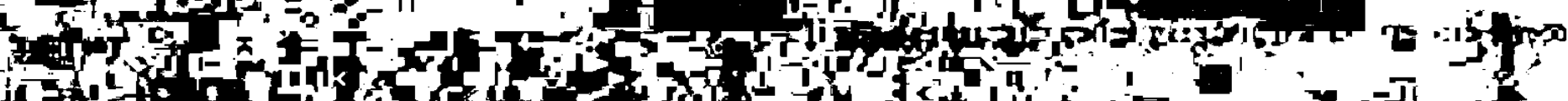
1) Fif

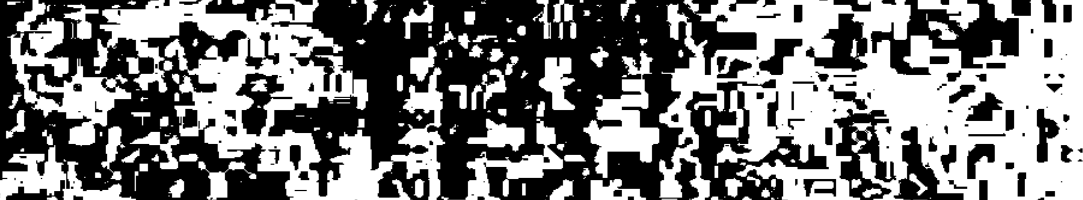

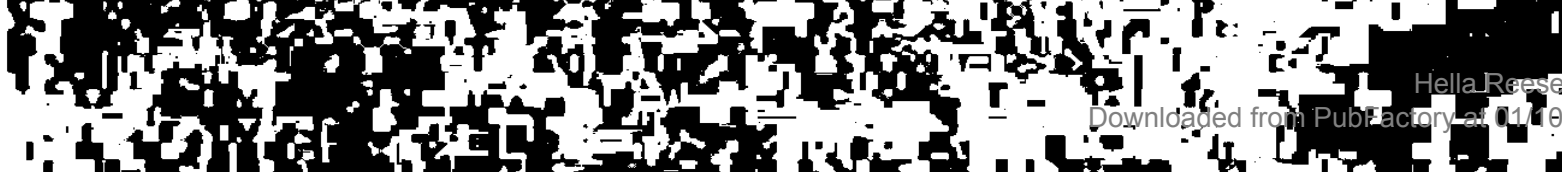




\section{DiE ENTSTEHUNGSGESCHICHTE DER SPÄTEN ERZÄHLUNGEN}

Im Jahr 1946 überreichte Bunin Zinaida Sachovskaja ein Exemplar der Temnye allei mit folgender Widmung: „,Декамерон' написан был во время чумы. ,Темные Аллеи“ в годы Гитлера и Сталина - когда они старались пожирать один другого.“88 Der Vergleich mit dem Decamerone gibt nicht nur Aufschluß über Bunins eigene hohe Meinung von den Temnye allei als seinem Meistenwerk, sondern zeigt zudem, daß Bunin sein Buch in der Tradition der großen zyklischen Rahmenerzählung sieht. Zudem wirft diese Widmung daruber hinaus ein Schlaglicht auf seine problematische persönliche Situation im Entstehungszeitraum der Temnye allei, die vor dem Hintergrund des Zweiten Weltkriegs gekennzeichnet war von finanzieller und materieller Not, gesundheitlichen Problemen, emotionaler Isolation, Betroffenheit und Sorge über die politischen Geschehnisse, Ungewißheit über sein weiteres Dasein als Schriftsteller (möglicherweise ohne Lesepublikum), Heimweh nach Rußland sowie quälenden Gedanken an das unausweichliche Ende alles Irdischen. Um so bemerkenswerter ist die Tatsache, daß Bunin, für den die Arbeit an den Erzählungen auch einen wichtigen geistigen Zufluchtsort vor der bedrückenden Realität bedeutete, unter derartig widrigen Bedingungen in der Lage war, zu einer schöpferischen Höchstleistung zu gelangen. ${ }^{89}$

Dieses Kapitel wird nach einem biographischen Überblick über die Lebensumstände Bunins in den Jahren 1936 bis 1953 die Genese der die Temnye allei konstituierenden Erzählungen sowie den Prozeß der Formierung zu einem Buch - soweit möglich - nachzeichnen. Des weiteren werden die im gleichen Zeitraum entstandenen, zum Teil unveröffentlichten Erzählungen, von denen ursprünglich ebenfalls einige zur Aufnahme in das

88 Z. Sachovskaja. „Bunin“. In: Kontinent 3 (1975): 280.

89 Einen thnlichen Vergleich zog Bunin in einem Brief an Boris Zajcev vom 11.11.1943. Des Zwiespalts zwischen der fiktiven Welt seiner Erzahlungen und der vom Krieg dominierten Realitat war sich Bunin bewuBt: fast scheint es, als wUrde er den Vergleich auch zur Rechtfertigung seines schriftstellerischen Tuns heranziehen: „И вот еще что - нынешней осенью все хотелось писать и писал что-ннбудь милое, пустяковое, веселое из любовных делишек - что ж все думать о смерти и дьявольских делах в мире! Бокачио написал ,Декам[ерон]' во время чумы, а я вот ,Темные Аллеи“.” (zit. in: „Pis'ma 1. Bunina k B. Zajcevu“. In: NZ 137 [1979]: 125). Ein Bedürfnis nach Rechtfertigung klingt auch aus den folgenden Zeilen aus einem Brief an Téffi vom 19.05.1944: ,[...] возьмите еще 5 из монх последних [...] рассказиков - совершенно диких по своему несоответствио особенно тем последним дням, что дошли до нас, но, может быть, вполне законных по тему, вндно, вечному, что бывает в чуму н во все семь казней египетских, о чем говорит Тот, с кем в мире несравнимый [...]” (zit. in: „Perepiska Teffi s I. A. i V. N. Buninymi 1939-1948“. In: Diaspora II [2001]: 514). Mit letzerer Bemerkung spielt Bunin an auf Puskins Pir vo vremja cumy, eine der vier ..kleinen Tragodien". und bezieht sich damit auf die. ahnlich schweren Entstehungsumstănde. denn dieses Einaktdrama (nach dem dramatischen Poem The City of the Plague von John Wilson) entstand im Herbst 1830, den Puskin wegen der in Moskau herrschenden Choleraepidemie in Boldino verbrachte. 
Buch vorgesehen waren, vorgestellt und ihr Bezug zu den Erzählungen der Temnye allei diskutiert. Ein Exkurs zu den Skizzen und Notizen jener Jahre rundet diese Übersicht ab und gewährt Einblick in Bunins künstlerische Entwicklung. Anhand der auf diese Weise gewonnenen Erkenntnisse wird sich eine erste Aussage machen lassen hinsichtlich der Art der Konzeption des Buches, da Bunin seine Auswahl aus einer Fulle von Erzählungen treffen konnte: In welchem Maße folgte er einem festen Plan bzw. welche Rolle kommt Faktoren zu, die außerhalb der vom Autor beeinflußbaren Sphäre lagen?

\subsection{Biographischer Überblick (1936-1953)}

Seit 1923 verbrachten Vera Nikolaevna und Ivan Alekseevic Bunin den Großteil des Jahres in der südfranzösischen Stadt Grasse. Ihre Pariser Wohnung in der Rue Jacques Offenbach Nr. 1 im 16. Arrondissement nutzten sie lediglich in den kulturell lebhafteren Wintermonaten. Nach zwei Jahren in der Villa Mont-Fleuri ${ }^{90}$ siedelten sie 1925 in die etwas hőher gelegene Villa Belvédère' ${ }^{91}$ über. Als der Mietzins 1939 für die Bunins unerschwinglich wurde und sich besser betuchte Mieter fanden ${ }^{92}$, waren sie gezwungen, sich nach einer neuen Bleibe umzusehen. Ende Oktober 1939 bezogen sie die an der Route Napoléon gelegene Villa Jeannette ${ }^{93}$, die sie, bedingt durch den Ausbruch des Zweiten Weltkriegs, günstig von der in ihre Heimat zurückkehrenden Witwe eines englischen Kapitäns mieten konnten ${ }^{94}$ und die sie bis zum Ende des Krieges bewohnten. In ihre Pariser Wohnung, die sie während der Kriegsjahre untervermietet hatten, kehrte das Ehepaar Bunin erst am 1. Mai 1945 zuruck. Hier starb Ivan Bunin am 8. November 1953.

90 G. Simonoff. „La Vie des Bounine à Grasse pendant la deuxième guerre mondiale“. In: Bounine revisité. op.cit.: 147.

911973 ließ die Stadt Grasse anlaßlich des 50. Jahrestages der Ankunft Bunins am Weg zur Villa eine Gedenktafel anbringen. Die nicht ganz korrekte Inschrift lautet wie folgt: "Ce chemin mène a la Villa Belvédère où demeura pendant seize ans Ivan Bounine, écrivain russe, 1870-1953, Prix Nobel.“

92 Tagebucheintrag Vera Buninas vom 02.08.1939. Zit. in: UB. 3.Bd. op.cit.: 30.

93 Tagebucheintrag G. Kuznecovas vom 01.10.1940. Zit. in: dies. Grasskij dnevnik. Moskva, 1995: 301.

94 Tagebucheintrag Vera Buninas vom 18.09.1939. Zit. in: UB. 3.Bd. op.cit.: 34. 


\subsubsection{Die Jahre in Grasse (1936-1945)}

Die Bunins waren indes nicht die einzigen Bewohner der Villa Jeannette: Die zahlreichen Gäste aus der Vorkriegszeit blieben zwar während der Kriegsjahre aus, jedoch hatten sich verschiedene Personen für unterschiedlich lange Zeitrăume bei ihnen niedergelassen. Seit dem Frühjahr 1927 weilte die Schriftstellerin Galina Nikolaevna Kuznecova (1900-1976) unter ihrem Dach, deren Bekanntschaft Bunin im Juli 1925 gemacht hatte. Mit der jungen Schriftstellerin, die offiziell als seine Schülerin galt, verband ihn eine längere Liebesaffäre. Diese endete Mitte der 1930er Jahre, nachdem Galina Kuznecova im Anschluß an die Nobelpreisverleihung in Stockholm im Dezember 1933 uber Weihnachten gemeinsam mit dem Ehepaar Bunin in Dresden einem Freund Bunins, dem Schriftsteller und Literaturkritiker Fedor Avgustovic Stepun (1884-1965), einen Besuch abgestattet und dort dessen Schwester, die Sängerin Margarita Avgustovna Stepun (1897-1972), kennengelernt hatte, die ihre zukünftige Lebensgefährtin werden sollte. Bunin litt sehr unter dem Bruch. ${ }^{95}$ Dennoch hatte er offenbar nichts dagegen einzuwenden, daß Margarita Stepun sich gemeinsam mit Galina Kuznecova 1934 und 1935 besuchsweise, mit Kriegsausbruch ständig in der Villa aufhielt, bevor die beiden Frauen im April 1942 das Haus endgültig verließen. ${ }^{96}$

Ein weiterer Mitbewohner war der Schriftsteller Leonid Fedorovix Zurov (1902-1971), der am 23. November 1929 aus Tallinn anreiste ${ }^{97}$ und vor allem Vera Bunina bis zu ihrem Tode 1961 eng verbunden blieb. Mit Ausnahme einiger zeitlicher Unterbrechungen, die verschiedenen Aufenthalten in Sanatorien geschuldet waren, lebte er dauerhaft in Bunins Haushalt.

95 Noch Ende 1941 qualen ihn Erinnerungen an diese Romanze: „Все вспоминастся почему-то и вся моя несчастная история с Г[алиноһ]" (Tagebucheintrag Bunins vom 26.11.1941. Zit. in: UB. 3.Bd. op.cit.: 120), und auch die endgoltige răumliche Trennung im Fruhjahr 1942 bringt keine Erleichterung: ..[..] и все тоска, боль воспоминаний о несчастных веснах 34,35 годов, как отравила она (Г[алина)) мне жизнь - и до сих пор еще отравляет! 15 лет!" (Tagebucheintrag Bunins vom 18.04.1942. Zit. in: UB. 3.Bd. op.cit.: 133).

96 Trotz der problematischen Beziehungsverhaltnisse war der Wegzug der beiden Frauen ein schwerer Schlag fur Bunin (vgl. den Tagebucheintrag Bunins vom 01.04.1942, dem Tag des Auszugs: „Конеu. Почти 16 лет тому назал узнал ее. [...] Против воли на душе спокойно и тяжело трустно." Zit. in: UB. 3.Bd. op.cit.: 131). Die restlichen Kriegsjahre verbrachten Galina Kuznecova und Margarita Stepun in Sudfrankreich und ab Mai 1943 in Dresden (vgl. den Brief Bunins an Teffi vom 24.09.1943. Zit. in: .Perepiska Teffi s 1. A. i V. N. Buninym 1939-1948“. op.cit.: 497), wo sie die schweren Bombardierungen miterlebten. Auch nach dem Krieg hielten sie sich in Deutschland auf, vornehmlich in Munchen, bevor sie 1949 gemeinsam in die USA auswanderten. 1952/53 ubernahmen Galina Kuznecova und Margarita Stepun auf Bunins Wunsch die Korrekturarteiten an den vom in New York ansässigen russischen Verlag Izdatel'stvo imeni Cechova herausgegebenen Bunin-Publikationen. Ende der 1950er Jahre kehrten sie ubber die Schweiz nach München zuruck. Der Kontakt zu Bunin bestand bis zu dessen Tod, und ungeachtet der fraheren persönlichen Differenzen wurden sie eines seiner wichtigsten Sprachrohre bezuglich der Redaktion und Veroffentlichung seiner Originaltexte bzw. verschiedener Übersetzungen.

97 Tagebucheintrag Vera Buninas vom 23.11.1929. Zit. in: UB. 2.Bd. op.cit.: 211. 
Neben diesen langjährigen Hausgenossen nimmt sich der vierjăhrige Auénthalt von Aleksandr Vasil'evic Bachrach (1902-1985) im Anschluß an seine Demobifisierung im Oktober 1940 geradezu bescheiden aus. ${ }^{98}$ Seinen eigenen Angaben zufolge sabe er gar nicht so lange bleiben wollen; sein Verweilen bis Oktober 1944 habe er dem ausdruicklichen Wunsch Bunins zu verdanken, der jeden Abreiseversuch durch hartnäekige Überredungskunste vereitelt habe.

Wie nicht zuletzt die Tagebuchnotizen Vera Buninas bezeugen ${ }^{99}$, war die Atmosphäre im Haus zeitweilig von starken emotionalen Spannungen gekennzeichnet, de Bunin in zunehmende Isolation trieben. ${ }^{100}$ Von nicht $\mathrm{zu}$ unterschätzender Bedeutung für ihn waren daher seine zahlreichen Korrespondenzpartner, als deren wichtigste Mark Aleksandrovic Aldanov (eigentlich Landau, 1886-1957) ${ }^{101}$ und das Ehepaar Cetlin, Michail Osipovic (1882-1945) und Mar'ja Samojlovna (1882-1976), in den USA sowie Boris Konstantinovič Zajcev (1881-1972) und Nadežda Aleksandrovna Téffi (eigentlich Bucinskaja, 1872-1952) in Paris genannt werden müssen.

Wahhrend des Krieges waren allerdings sowohl der innerfranzösische als auch der transatlantische Postverkehr zwischen 1940 und $1942^{102}$ bzw. zwischen 1942 und 1944 unterbrochen bzw. mit erheblichen Schwierigkeiten verbunden, so daß in jenen Jahren die Tagebuchaufzeichnungen für Bunin an Bedeutung gewannen. Die noch erhaltenen Notizen müssen jedoch mit Vorsicht betrachtet werden, da Bunin zahlreiche Niederschriften vernichtet und die solcherart entstandenen Lücken mit zusammenfassenden Betrachtungen gefullt oder Passagen neu verfaßt hat. ${ }^{103}$ Eingang in seine Notizen finden der Verlauf der

98 In verschiedenen Publikationen (u.a. V. Antonov. „I. A. Bunin vo Francii v gody vojny". In: Inostrannaja literatura 9 [1956]: 251; A. Baboreko. „Bunin v gody vojny [1943-1944]". In: Daugava 10 [1980]: 119; A. Kolonickaja. ."Vse cisto dlja cistogo vzora". (Besedy s Irinoj Odoevcevoj). Moskva, 2001: 119) ist zu lesen, daB er als judischer Flachtling von Bunin in der abgelegenen Villa versteckt wurde. In seinen Erinnerungen an jene Jahre (vgl. A. Bachrach. Bunin v chalare. Moskva, 2000: 21-26) bestreitet er dies: Er habe sich nach seiner Demobilisierung ganz legal unter seinem eigenen Namen in Grasse aufgehalten.

99 Vgl. z.B. die Tagebucheintrage Vera Buninas vom 25.08.1938 und 14.04.1944 sowie die Anmerkung zu einem Tagebucheintrag Bunins vom 01.01.1942. Zit. in: UB. 3.Bd. op.cit.: 25, 163 bzw. 212.

100 Vor allem das Verhaltnis zwischen Bunin und Zurov war phasenweise denkbar schlecht, wie ein Brief Bunins an Bachrach vom 25.01.1945 beispielhaft illustriert: „C 29 декабря обедаю н завтракаю у се6я в комнате, чаще всего с Верой Ник[олаевной], Зуров вижу раз в неделю, случайно встретясь с ним где-нибудь на ходу, н твердо решил больше не разговарнвать с этим мерзавцем вовеки" (A. Bachrach. Bunin v chalate. op.cit.: 232).

101 Die umfangreiche Korrespondenz entstand in einem Zeitraum von 33 Jahren: Wahrend Bunins Briefe aus den Jahren 1920-1939 zusammen mit Aldanovs Archiv im Zuge einer Durchsuchung der Wohnung Aldanovs verlorengingen, nachdem das Ehepaar Aldanov Paris verlassen hatte, blieben zahlreiche Briefe aus den Jahren 1940-1953 erhalten; Teile dieser Korrespondenz, die in verschiedenen Archiven verwahn werden, sind vor allem im Novyj Zurnal veroffentlicht worden.

102 Bis November 1942 gehorte Grasse zur sogenannten freien Zone.

$103 \mathrm{Vgl}$. hierzu den folgenden Tagebucheintrag: „Переписываю дневниковые хлочки предыдущих лет. Многих рву и жrу" (03.04.1940). Zit. in: UB. 3.Bd. op.cit.: 41. 
Kriegsereignisse (vor allem nach dem Einmarsch der deutschen Wehrmacht in die Sowjetunion), Naturimpressionen, Klagen über körperliche Gebrechen, Notizen zu Krankheiten, Arzbesuchen und Medikamenteneinnahmen sowie Bestandsaufnahmen des fortschreitenden Alterungsprozesses. Als roter Faden ziehen sich bedridckende Gedanken an den Tod und zum unaufhaltsamen Fortschreiten der Zeit sowie Klagen über seine innere Einsamkeit durch die Tagebücher, wie etwa in den Einträgen vom 29. Juli 1940 („А у меня все одно, одно в глубине души: тысячу лет вот так же будут сиять эти дни, а меня не будет. Вот-вот не будет.“) und vom 6. Маі 1942 („Очень грустно и скучно - погибаю в одиночестве. Ни души даже знакомой. И все воспоминания, воспоминания."). ${ }^{104}$ Auch Erinnerungen an unwiederbringlich Vergangenes quälten ihn: „И опять, опять боль - о счастливых моих, невозвратньх днях. Все кончено для меня.“105

Der Ausbruch des Zweiten Weltkriegs markiert zudem das endgültige Ende von Bunins Reisetătigkeit, die ihn noch Ende der 1930er Jahre unter anderem nach Deutschland (1936), uber die Schweiz und Italien nach Jugoslawien (1937) und in die baltischen Staaten (1938) gefuhrt hatte. Die Kriegsjahre verbrachte er ausschließlich in Grasse, mit Ausnahme kurzer Aufenthalte in Paris im Januar und im Mai 1940 sowie einer unfreiwilligen mehrwöchigen, den politischen Umständen geschuldeten Reise in den Südwesten Frankreichs im Juni/Juli 1940 nach dem Einmarsch der deutschen Wehrmacht. ${ }^{106}$ Danach blieben ihm lediglich seltener werdende Ausflugsmöglichkeiten nach Cannes und Nizza.

$\mathrm{Zu}$ den persönlichen Problemen gesellten sich finanzielle und materielle, denn die Stockholmer Prämie für den Nobelpreis war von dem großzügigen und hilfsbereiten Bunin rasch ausgegeben worden ${ }^{107}$, und die ohnehin nicht zahlreichen Publikationsmöglichkeiten

$104 \mathrm{Zit}$ in: UB. 3.Bd. op.cit.: $56 \mathrm{bzw}$. 135. In einem Brief an den Joumalisten Andrej Blok bekennt er gar: ..Напрасно Вы думзете, что а не беседую с хрысами - их теперь у нас очень немного, почти все подохли с голоду, но с оставшимися я порой беседую- больше мне не с кем беседовать - одиночество ужасное!“” (zit. in: „Dva pis'ma I. A. Bunina k A. G. Bloku“. In: Nz 120 [1975]: 163-166).

105 Unveroffentlichter Tagebucheintrag Bunins vom 16.06.1943 (LRA. MS.1066/535).

106 Nach dem Kriegseintritt Italiens im Juni 1940 verließen die Bunins gemeinsam mit Galina Kuznecova, Margarita Stepun sowie Elena Zirova samt Tochter Ol'ga fluchtartig Grasse, auf der Suche nach einem sicheren Aufenthalisort in der allgemeinen Panik, den sie für knapp drei Wochen in Lafrançaise in der Năhe von Montauban fanden. (In Montauban befand sich der Bauernhof von E. Zirovas Mann; Plâne, dort Schutz zu suchen, existierten seit Ausbruch des Krieges [vgl. Tagebucheintrag Vera Buninas vom 08.09.1939. Zit. in: UB. 3.Bd. op.cit.: 33\}.) Ausloser der uberstarzten Abreise war vor allem die Befurchtung. Margarita Stepun könne auf Grund ihres deutschen Passes interniert werden, zumal bereits von den zustăndigen franzosischen Stellen die Aufforderung an sie ergangen war, das Département Alpes-Maritimes umgehend zu verlassen (Tagebucheintrag Bunins vom 25.07.1940. Zit. in: UB. 3.Bd. op.cit.: 53ff.; R. Fedoulova. „Les Allees sombres d'Ivan Bounin“. op.cit.: 26).

107 Bereits im Jahr 1935 soll das Geld aufgezehrt gewesen sein. Vgl. N. Vinokur. „Novoe o Buninych“. In: Minunsee 8 (1989): 286. Boris Zajcev außerte sich in einem Interview mit Jurij Kazakov folgendermaßen zu Bunins Verhaltnis zum Geld: „Иван Алексеевнч был человек, конечно, очень такой стародворянской замашки: когда деньтн есть, спускал мгновенно, а потом вот на бобах" (J. Kazakov. ..Beseda v Parize". In: Literaturnaja gazeta 30 [1990]: 4). 
im Netzwerk der Emigrantenpresse versiegten gänzlich, als im Mai/Juni 1940 die Institutionen und Strukturen des "russischen Paris“ zusammenbrachen. ${ }^{108}$ Seit jenen Jahren war Bunin zunehmend auf finanzielle bzw. materielle Unterstützung von Freunden, wie vor allem dem Ehepaar Cetlin ${ }^{109}$, sowie verschiedenen Gönnern bzw. Wohltătigkeitsorganisationen wie dem Tolstoj-Fonds ${ }^{110}$ in den USA angewiesen. In welchem Maße Nahrungsmittelknappheit und fehlendes Heizmaterial den Alltag der Bunins und ihrer Mitbewohner beeinträchtigten, illustrieren Auszüge aus Briefen Bunins an das Ehepaar Cetlin (24. Januar 1941) und an Mark Aldanov (20. März 1941):

[...] и что мы находимся в положении совершенно катастрофическом-доживаем последние гроши, в полном голоде и адском холоде. Помогите через кого-нибудь ради Бога."

От одной брюквы с одной солью и горячей водой (супом!), без капли масла, я становлюсь худ как Ганди, а у В[еры] Н[иколаевны] летағот „мухи“ перед глазами. Дом ледяной, мы его не топим, для кухни осталось сто полен - дров покупать нам не на что. ${ }^{112}$

Zu einem möglichen Ausweg aus dieser Notlage, der Emigration in die Vereinigten Staaten, konnte sich der mittlerweile ubber Siebzigjăhrige nicht entschließen, obwohl er am 9. August $1940 \mathrm{im}$ Zuge des Abschiednehmens von emigrierenden Freunden und Bekannten (wie beispielsweise die Ehepaare Aldanov, Cetlin, Višnjak, Sedych [Cvibak]) in seinem Tagebuch notierte: „Твердо решил уехать в Америку“1/3 und ihm vor allem der Abschied von Mark Aldanov, der Frankreich Ende 1940 verließ, zu schaffen machte. ${ }^{114}$

Noch während Aldanov in Südfrankreich auf die endgültige Bewilligung der Ausreise und später in Lissabon auf das Auslaufen des Schiffes wartete, versuchte er in seinen Briefen, Bunin von der Notwendigkeit der Emigration in die USA zu überzeugen. Nach seiner Ankunft in New York kümmerte er sich um die notwendigen Formalitäten, warb vor Ort um Unterstützung für Bunin und wirkte in seinen Briefen mal beschwörend, mal sanft drängend auf den Freund ein. ${ }^{115}$ Doch Bunin zögerte, auch als seine Frau und er 1941 im

108 R. Johnston. „Paris: Die Hauptstadt der russischen Diaspora“. In: Der große Exodus. Die russische Emigration und ihre Zentren 1917 bis 1941. Hg. K. Schlogel. Munchen, 1994: 277.

109 Vgl. N. Vinokur. "Novoe o Buninych". op.cit.: 285, 287.

110 Fond Tolstogo; der Korrespondenz mit Aleksandra L'vovna Tolstaja zufolge erhielt Bunin von 1941 bis 1947 finanzielle Zuwendungen (LRA. MS.1066/5557-5560).

111 Zit. in: N. Vinokur. „Novoe o Buninych“. op.cit.: 297.

112 Zit. in: „Perepiska I. A. Bunina s M. A. Aldanovym“. In: Nż 150 (1983): 161.

113 Zit. in: UB. 3.Bd. op.cit.: 57.

114 Aleksandr Bachrach zitien Bunin mit den folgenden Worten: „Tеперь здесь А уже совсем один остался" (ders. Bunin v chalate. op.cit.: 161).

115 Vgl. z.B. Briefe Aldanovs an Bunin vom 13.09.1940, 13.12.1940, 03.02.1941, 21.03.1941, 15.04.1941, 02.08.1941, 29.06.1942 (Edinburgh University Library. Special Collections Department). 
Besitz eines Nansen-Passes sowie Tickets für die Überfahrt waren ${ }^{116}$ : „Виза, билетыхорошо, но чем-же, чем буду я существовать? ${ }^{117} \mathrm{Er}$ fürchtete, auf die Mildtätigkeit fremder Leute angewiesen $\mathrm{zu} \operatorname{sein}^{118}$, und wich in seinen Briefen einer klaren Stellungnahme aus. Über die möglichen Konsequenzen seines Zauderns war er sich im klaren: „Тем, что я не уехал с Ц[етлиными] и А[лдановыми] в Америку, я подписал себе смертный приговор. Кончить дни в Грассе, в нищете, в холоде, в собачьем голоде!“119 Seine Befürchtungen scheinen sich bewahrheitet zu haben, wie die Schilderung seiner sich verschlechternden Lebensumstände vom 4. März 1942 illustriert: „Нищета, дикое одиночество, безвыходность, голод, холод, грязь-вот последние дни моей жизни. И что впереди? Сколько мне осталось? И чего? Верно, полной погибели. “'20

Unter den sich zunehmend verschlechternden Lebensbedingungen scheint Bunin sich im Juli 1942 doch für die Reise in die USA entschieden zu haben, denn er bat Aldanov, seine Bemühungen um Visa für sich und seine Frau zu verstärken: „Très cher ami, je vous prie de faire tout possible pour obtenir visas pour moi et Véra.“ ${ }^{121}$ Im August trafen die nötigen Papiere ein ${ }^{122}$; in diesen Zusammenhang sind möglicherweise auch die zeitgleichen Bemühungen Bunins zu stellen, aus finanziellen Gründen die Pariser Wohnung aufzulösen. ${ }^{123}$ In den verfügbaren Unterlagen findet sich kein Hinweis darauf, zu welchem Zeitpunkt sich Bunin dann doch definitiv gegen eine Emigration in die USA entschied. Möglicherweise wurde ihm die Entscheidung abgenommen durch die deutsche Besetzung Südfrankreichs im November 1942. Kriegsbedingt brach der Briefwechsel zwischen Bunin und Aldanov zu diesem Zeitpunkt ab, der nächste Brief Aldanovs erreichte Bunin erst Ende 1944, nach der Libération Frankreichs.

I16 A. Heywood. Calalogue of the I. A. Bunin .... op.cit.: XXII.

117 Brief an Aldanov vom 11.04.1941. Zit. in: „Lettres d'Ivan Bunin à Mark Aldanov“. In: Cahiers du monde russe et soviétique 4 (1981): 473.

118 Am 06.05.194I schrieb Bunin an Aldanov: „Но - как решиться ехать! Доехать, как Вы говорнте, мы можем. Но олять, олять: что дальше? Вы пишите: ,погибнуть с голоду Вам не дадут.' Да, в буквальном смысле слова ,логибнуть с голода', м[ожет] б[ыть], не дадут. Но от нищеты, всяческого мнзера. унижений, вечной неопределенности? Месяца два-три будут помогать, заботиться, $a$ daпьисе бросят. забудут - в этом я твердо уверен. [...] И рассказы. кннги я не могу печь без конца - главное же, продавать их“ (zit. in: .Lettres d'Ivan Bunin a Mark Aldanov“. op.cit.: 474).

119 Tagebucheintrag Bunins vom 28.12.1941. Zit. in: UB. 3.Bd. op.cit.: 145.

120 Tagebucheintrag Bunins vom 04.03.1942. Zit. in: UB. 3.Bd. op.cit.: 129.

121 Brief an Aldanov vom 28.07.1942. Zit. in: „Perepiska I. A. Bunina s M. A. Aldanovym.“ In: Nz 150 (1983): 168.

122 Tagebucheintrag Vera Buninas vom 23.08.1942. Zit. in: UB. 3.Bd. op.cit.: 139.

123 Postkarte Bunins an Mar'ja Kallas vom 10.08.1942 (LRA. MS. 1066/3040). 
Die Rückkehr nach Paris, die bereits für November 1944 geplant war, gestaltete sich schwierig, da sich einerseits die Untermieter in der Rue Jacques Offenbach weigerten, die Wohnung vor April 1945 zu răumen, andererseits die Vermieterin der Villa Jeannette im Frühjahr nach Grasse zurückzukommen plante. ${ }^{124}$ Erst am 1. Mai 1945 kehrte Bunin gemeinsam mit seiner Frau und Leonid Zurov nach Paris zurilck.

\subsubsection{Die letzten Lebensjahre in Paris (1945-1953)}

1945 war die kleine Wohnung in der Rue Jacques Offenbach uberbelegt: Neben dem Ehepaar Bunin und Leonid Zurov lebten dort auch noch Elena Žirova und ihre Tochter ${ }^{125}$, letztere bis März 1948. ${ }^{126}$ In dieser räumlichen Enge waren Bunins letzte Lebensjahre überschattet von materieller Not, schweren Krankheiten, Einsamkeit und Verbitterung.

Auch nach dem Krieg war Bunin weiterhin auf Unterstützung angewiesen. Neben Mar'ja Cetlina (bis 1947) war vor allem Aldanov der wichtigste Organisator: Gemeinsam mit Andrej Sedych [Jakov Moiseevic Cvibak, 1902-1994] erwirkte er beispielsweise 1948 eine regelmäßige monatliche Zahlung durch den Strumpffabrikanten S. S. Atran, die mit dessen Tod 1951 endete. ${ }^{127}$ Es erfolgten aber auch einmalige Zahlungen von verschiedenen Personen, wie etwa von dem „Fund for Intellectual Freedom", einem losen und informellen Zusammenschluß US-amerikanischer Schriftsteller, die vor allem bedürftigen Kollegen im Exil helfen wollten und dem unter anderem Graham Greene, Aldous Huxley und Stephen Spender angehörten. ${ }^{128}$ Ebenfalls 1948 erhielt Bunin das restliche Geld der Mäzenatengruppe, die 1943 die New Yorker Ausgabe der Temnye allei finanziert hatten, möglicherweise als Entschädigung dafür, daß die Fortsetzung wider Erwarten und entgegen der im Buch festgehaltenen Ankündigung nicht gedruckt wurde (vgl. Kap. 9.1.1). ${ }^{129}$

124 Briefe Bunins an Zajcev vom 26.10.1944 bzw. 21.01.1945. Zit. in: „Pis'ma I. Bunina k B. Zajcevu“. In: NE 138 (1980): 156 bzw. 165.

125 T. Murav'eva-Loginova. Pis'ma Buninych (1936-1961) k Murav'evoj-Loginovoj. Paris, 1982: 11.

126 R. Fedoulova. „Les Allees sombres d'Ivan Bounin". op.cit.: 84.

127 N. Vinokur. „Novoe o Buninych“. op.cit.: 321.

128 Brief Arthur Koestlers an Bunin vom 20.04.1951: „We were distressed to hear of your illness and troubles and are grateful for an opportunity to prove in a small, practical way our admiration for the doyen of Russian writers" (LRA. MS.1066/3324).

129 Brief Aldanovs an Bunin vom 24.06.1948. Bakhmeteff Archive (New York), MS Coll. Aldanov. 
Die gesellschaftliche Isolation, in die Bunin nach Ende des Krieges geriet, resultierte im wesentlichen aus seinen Kontakten zu offiziellen Repräsentanten der Sowjetunion ${ }^{130}$ sowie zur prosowjetischen Fraktion der russischen Emigranten in Paris ${ }^{131}$, die sich in den Zeitraum zwischen Mai 1945 und Herbst 1947 einordnen lassen. ${ }^{132}$ Gerüchteweise war die Rede von seiner vermeintlich festen Absicht, in die Heimat zurückzukehren - sei es besuchsweise oder für immer. Vor allem in der sowjetischen Sekundärliteratur wird diese Absicht, die zu haben Bunin stets vehement bes:ritt, oft kolportiert, allein, es fehlen die Fakten. $^{133}$ Das zweifelhafte zentrale Beweisstück ist das vielzitierte Postskriptum aus einem Brief Bunins vom 8. Mai 1941 an Nikolaj Dmitrievic Telešov, seinem langjăhrigen Freund und Dichterkollegen, zu dem er seit seiner Emigration keinen Kontakt mehr hatte: „Я сед, худ, но еще ядовит. Очень хочу домой.“" ${ }^{134}$ Gedanken an eine mögliche Rückkehr haben Bunin zwar beschäftigt (vgl. einen Tagebucheintrag vom 2. April 1943: "Чacto думаю о возвращении домой. Доживу ли? И что там встречу? ${ }^{135}$ ), aber nichts deutet auf konkrete Schritte zur Umsetzung dieses Vorhabens hin, zumal Bunin - wie Mal'cev es treffend formulierte ${ }^{136}$-, von einer Rückkehr nicht in die Sowjetunion, sondern rach Rußland träumte. Über die Unmöglichkeit eines solchen Unterfangens war sich Bunin im klaren: „Просмотрел свои заметки о прежней России. Все думаю, если бы дожить,

130 Zum Vorwurf gemacht wurde Bunin unter anderem, die Einladung des sowjetischen Botschafters Bogomolov im Herbst 1945 angenommen zu haben. Bunin begrundete diesen Besuch mit seiner Absicht, ober die Veroffentlichungsmodalităten von Teilen seines Werkes in der Sowjetunion sprechen zu wollen. Da dies nicht Gegenstand der Unterhaltung gewesen sei, habe er die Botschaft nach sehr kurzer Zeit wieder verlassen (vgl. u.a. O. Michajlov. Zizn' Bunina. Lis' slovu Zizn' dana .... Moskva, 2001: 450).

131 Eine Reihe von Erzahlungen wurde in der prosowjetischen Tageszeitung Russkie novosti publiziert: "Cholodnaja osen"“ (Mai 1945), „Kaceli” und „V odnoj znakomoj ulice“ (beide November 1945), "Voron“ (Dezember 1945), „Vesnoj, v ludee“" (April 1946) sowie „Pamjatnyj bal“ (Januar 1947). In diesem Zusammenhang muB darauf hingewiesen werden, daß es zu diesem Zeitpunkt kaum alternative Publikationsmoglichkeiten gab. Bunin begründete den Abdruck der Erzłhlungen mit seiner finanziellen Notlage (vgl. O. Michajlov. Żizn' Bunina. Lis' slovu tizn' dana ... op.cit.: 450).

132 D. Bethea. "Ivan Bunin and the Time of Troubles in Russian Emigre Literature“. In: Slavic Review 1 (1984): 13. In diesem Artikel findet sich cine detaillierte Schilderung der Grunde, die zu Bunins Austritt aus dem Schriftstellerverband (Sojuz russkich pisatelej i zumalistov v Pariže) und zu seinem Bruch mit Teilen der russischen Emigranten gefuhrt haben.

133 Im Fruhjahr 1945 hat sich Bunin zwar bei Jakov Borisovic Polonskij nach Reisemoglichkeiten in die UdSSR erkundigt; in seinem Antwortbrief vom 06.03.1945 rat dieser inm aber entschieden davon ab, die zu der Zeit verfugbaren Mittel zu nutzen, Bunin solle besser einen eigenen Weg beschreiten (LRA. MS.1066/4660). Im Mai 1946 wird Bunin ein zweiwochiger Moskau-Aufenthalt mit Ruckreisegarantie in Aussicht gestellt, den er jedoch ablehnt (Tagebucheintrag Vera Buninas vom 27.05.1946. Zit. in: UB. 3.Bd. op.cit.: 181). Auch die Versuche des in die Sowjetunion zurtickgekehrten alten Bekannten Nikolaj Jakovlevic Roscin, Bunin zur Ruckkehr zu bewegen mit dem Argument, daß die russischen Emigranten in Frankreich doch bald in Vergessenheit gerieten, wathrend er in der Sowjetunion von vielen Freunden erwartet würde, liefen ins Leere (Brief an Bunin vom 28.11.1946. LRA. MS.1066/4827).

134 Brief an Telešov vom 08.05.1941. Zit. in: $L N$. 84.Bd. (1) op.cit.: 623.

135 Zit. in: UB. 3.Bd. op.cit.: 148.

$136 \mathrm{Vgl}$. Ju. Mal'cev. Bunin. op.cit.: 347. In seinem Tagebuch notierte Bunin am 01.01.1945 Folgendes: .(Необыкновенно глупо: ,Советское отечество"! Уж не говоря о том, что никто там ни с кем не советуется)." Zit. in: UB. 3.Bd. op.cit.: 175. 
попасть в Р[оссию]! А зачем? Старость уцелевших (и женщин, с которыми когда-то), кладбище всего, чем жил когда-то ...“137 In einem Brief vom 23. Januar 1946 teilt er Aldanov entschieden mit: „Ехать „доми“ не собирался и не собираюсь.“138

Als die sowjetische Regienung am 14. Juni 1946 ein Dekret erließ, das es den russischen Emigranten ermöglichte, die sowjetische Staatsbürgerschaft zu beantragen, hielten es viele von ihnen für angebracht, rechtzeitig von dieser Möglichkeit Gebrauch zu machen, anstatt Gefahr zu laufen, zwangsrepatriiert zu werden. ${ }^{139}$ Im November 1947 reagierte der Schriftstellerverband (Sojuz russkich pisatelej $i$ žurnalistov v Pariže) darauf mit dem Ausschluß all jener Mitglieder, die in der Zwischenzeit einen sowjetischen $\mathrm{Pa}$ erhalten hatten. Aus Solidarităt und Sympathie mit den Ausgeschlossenen traten umgehend verschiedene illustre Persönlichkeiten des Verbandes aus, zu denen unter anderem Vera Bunina, Georgij Adamovix und Gajto Gazdanov gehörten; Bunin selbst folgte ihnen gut zwei Wochen später. ${ }^{140}$ Ein offener Brief, den Mar'ja Cetlina Bunin im Dezember 1947 über Boris Zajcev zukommen ließ und in dem sie ihm auf Grund seiner Entscheidung die Freundschaft aufkündigte ${ }^{141}$, führte zum dauerhaften Bruch sowohl mit Mar'ja Samojlovna als auch mit dem Ehepaar Zajcev und illustriert exemplarisch die Spannungen und Spaltungen innerhalb der russischen Emigration der Nachkriegsjahre. Trotz verschiedener Erklärungsversuche sowohl von Seiten Mar'ja Cetlinas als auch Boris Zajcevs zeigte sich der schwer gekränkte Bunin unversöhnlich. ${ }^{142}$ Von diesem Ereignis unbeeinflußt blieben Bunins enge freundschaftliche Beziehungen zu Tèffi und Boris Grigor'evic Pantelejmonov (18881950), den Bunin 1946 kennenlernte und der ein regelmäßiger Gast der DonnerstagsVeranstaltungen der Bunins war. ${ }^{143}$ Auch das Verhältnis zu Aldanov blieb ungetrübt.

137 Tagebucheintrag Bunins vom 20.01.1944. Zit. in: UB. 3.Bd. op.cit.: 161. Nach seiner Ruckkehr nach Paris geriet Bunin angesichts der ungewissen Zukunft doch wieder ins Grubein und teilte Aldanov in einem Brief vom 28.05.1945 mit: „Так что, как ннкак, остается одно: домой. Этого, как слышно, очень хотят н сулят золотые горы во всех смыслах. Но как на это решиться? Подожду, подумаю ... хотя, повторяю, что же делать иначе?“ (zit. in: „Perepiska I. A. Bunina s M. A. Aldanovym". In: Nz 150 [1983]: 172). In seiner Antwort vom 30.05.1945 rat Aldanov Bunin zwar nicht ausdrucklich ab, zeigt ihm jedoch die zahireichen negativen Implikationen und Unsicherheiten eines Entschlusses zur Ruckkehr auf (zit. in: ..Pis'ma M. A. Aldanova k I. A. i V. N. Buninym“. In: Nz 81 [1965]: 120-122).

138 Zit. in: „Perepiska 1. A. Bunina s M. A. Aldanovym“. In: Nz 152 (1983): 155.

139 D. Bethea. op.cit.: 7-8.

140 D. Bethea. op.cit.: 9.

141 Brief Cetlinas an Bunin vom 20.12.1947 (LRA. MS.1066/5659).

$142 \mathrm{Vgl}$. z.B. seinen Briefwechsel mit Tèffi in den ersten Monaten des Jahres 1948. Zit. in: „Perepiska Tèffi s I. A. i V. N. Buninymi 1939-1948“" op.cit.

143 Details zu diesem Freundschafts-Trio finden sich im folgenden Aufsatz: E. Troubilova. „Bunin, Téffi, Pantelejmonov - istorija druzby". In: Bounine revisité. op.cit.: 129-140. 
Bunins letzte Lebensjahre standen im Zeichen des Erinnerns und Ordnens; Erzählungen schrieb er nach dem Krieg nur noch selten und nach 1949 gar nicht mehr. Zu seinen Lebzeiten erschienen noch vier Bücher: seine Erinnerungen (Vospominanija, Paris, 1950) und im New Yorker Verlag Izdatel'stvo imeni Čechova der Roman Žizn' Arsen'eva (1952) sowie zwei Sammelbände mit Erzählungen (Mitina ljubov'. Solnečnyj udar und Vesnoj, v Iudee. Roza lerichona, beide 1953). Ein Manuskript über Cechov blieb unvollendet und wurde erst nach Bunins Tod veröffentlicht ( $O$ Cechove, New York, 1955); ein weiterer Erzählband wurde 1954 ebenfalls in New York publizien (Petlistye uši $i$ drugie rasskazy). Neben der aus gesundheitlichen Gründen nur noch eingeschränkt möglichen künstlerischen Arbeit befaßte sich Bunin mit Ordnungsarbeiten in seinem Archiv, das er ursprïnglich dem Russischen Archiv der Columbia University in New York übergeben wollte; hierfür erhielt er eine finanzielle Aufwandsentschädigung. ${ }^{144}$ In seinem letzten Lebensjahr entschied er sich zum Verkauf des Archivs an die Columbia University, änderte jedoch seine Meinung nach Erhalt des Kaufangebots, das ihm vermutlich zu niedrig erschien. ${ }^{145}$

Vor allem ab 1948 verschlechterte sich Bunins Gesundheitszustand zusehends. Am gesellschaftlichen Leben konnte er nur noch sporadisch teilnehmen. Sein letzter offentlicher Auftritt erfolgte am 21. Juni 1949, im Rahmen einer Abendveranstaltung zu Ehren des 150. Geburtstags Puškins. ${ }^{146}$ Verschiedene Operationen sowie chronische Atemwegserkrankungen (Lungenemphysem, Asthma) zwangen ihn für lange Zeiträume zur Bettruhe. Reisen konnte er keine mehr unternehmen, einzig zu Erholungszwecken fuhr er einige Male in das Sanatorium "Russkij dom“ in Juan-les-Pins (März bis Juni 1947, Januar bis März 1948, Januar bis Mai 1949). ${ }^{147}$ Seine Lebensumstände (und Wünsche für einen erträglichen, ihm aber unmöglichen Lebensabend) schilderte der 82-jährige Bunin gut ein Jahr vor seinem Tod in einem Brief vom 10. Dezember 1952 an Mark Efimovix Vejnbaum folgendermaßen:

Моя старость, моя астма, моя сердечная слабость, мое душевное состояние - все требует жизни на юге, на солнце, на воздухе, в комфорте, но доступно это человеку состоятельному, а не мне с моей несчастной женой, тоже старой и слабой, которая несет все домашние тяготы и весь уход за мной - и все это в дьявольском Парижском климате, при котором я безвыходно сижу в четырех стенах, и при дороговизне тоже дьявольской. ${ }^{48}$

$144 \mathrm{Vgl}$. Empfangsbestătigung, adressiert an Semen A. Bolan, vom 14.11.1951 (LRA. MS.1066/1945).

145 A. Heywood. Catalogue of the I. A. Bunin... op.cit.: XXVIII.

146 R. Fedoulova. "Les Allées sombres d'Ivan Bounin". op.cit.: 88.

147 R. Fedoulova. "Les Allées sombres d'Ivan Bounin“. op.cit.: 2-3, 83 bzw. 87.

148 Zit. in: .Pis'ma I. A. Bunina k M. E. Vejnbaumu”. In: $N \leq 133$ (1978): 185. 
Der Sterbeprozeß vollzog sich langsam und manifestierte sich in einer zunehmenden Einschränkung seines Bewegungsradius: Als die Erholungsreisen nach Südfrankreich zu beschwerlich wurden, konnte Bunin zunächst noch Spaziergänge in Paris untemehmen; nachdem der körperliche Verfall in der Folge ein Verlassen der Wohnung unmöglich machte, war er bald nur noch auf sein Zimmer und schließlich auf das Bett beschrănkt. Die physischen Beschwerden wirkten betäubend selbst auf seine zeitlebends ausgeprägte Făhigkeit, das Leben in aller Intensităt wahrzunehmen. Seine schmerzvolle Verwunderung darüber kommt in seiner letzten datierten Notiz vom 2. Mai 1953 eindringlich zum Ausdruck:

Это все-таки поразительно до столбняка! Через некоторое очень малое время меня не будет - и дела и судъбы всего, всего будут мне неизвестны! [...] И я только тупо, умом стараюсь изумиться, устрашиться! ${ }^{149}$

Ivan Bunin starb am 8. November 1953 und wurde auf dem russischen Friedhof in Sainte-Geneviève-des-Bois in der Nähe von Paris zur letzten Ruhe gebettet.

\subsection{Zur Genese der die Temnye allei konstituierenden Erzählungen}

Vor diesem Hintergrund persönlicher und finanzieller Probleme entstanden zwischen 1936 und 1949 insgesamt 76 Erzählungen (vgl. die tabellarische Übersicht in Anhang 1), von denen die Hälfte in das Buch Temnye allei aufgenommen wurde. In diesen Jahren wurden Phasen fieberhafter Schreibtätigkeit von Phasen quälenden Nichtschaffens abgelöst. Der Entstehungsproze $ß$ der Erzăhlungen läßt sich im großen und ganzen auf drei unterschiedlich lange Zeiträume eingrenzen: Diese Phasen Bunins größter schriftstellerischer Produktivităt lagen im Herbst 1938, im Herbst 1940 sowie im Herbst 1943/Frühjahr 1944; in diesen Monaten schrieb er insgesamt 61 der 76 Erzählungen. Hingegen scheint seine Kreativität in den Jahren 1939 sowie 1941 bis Mitte 1943 fast gänzlich zum Erliegen gekommen zu sein; Ähnliches gilt für die Jahre nach 1944.

Während sich für 1939 weder Hinweise auf die Ursachen für sein Schweigen noch Anzeichen für eine Unzufriedenheit mit der Passivität finden lassen, notierte Bunin am

5. September 1941 in sein Tagebuch: „Ничего не делаю. Беспокойство, грусть.“ ${ }^{150}$ Sein 
Schweigen in den zweieinhalb Jahren von April 1941 bis Oktober 1943 entspricht in etwa jener Phase der deutsch-russischen Kampfauseinandersetzungen, in denen Rußland schwere Niederlagen hinnehmen mußte. Der Überfall der deutschen Wehrmacht auf die Sowjetunion rief ihm die Zeit vor seiner Emigration in Erinnerung: „Страшные бон русских и немцев. Минск еще держится [...] Да, опять ,Окаянные дни“!“'s। In dem genannten Zeitraum haben seine Tagebuchaufzeichnungen über weite Strecken hauptsächlich das Kriegsgeschehen in Rußland zum Inhait, Jas er aufmerksam verfolgte und das ihn sehr bedrückte. In die gleiche Zeit fallen seine schwankenden Überlegungen bezüglich einer Emigration in die Vereinigten Staaten sowie die Besetzung auch Südfrankreichs; diese unsichere persönliche Lage mag sich blockierend auf seine Kreativităt ausgewirkt haben. Im Herbst 1942 äußerte er gar erstmals Zweifel an seinem Schreibvermőgen: „Да и сам на себя дивлюсь - как все это выдумалось - ну, хоть в ,Натали“. И кажется, что уж больше не смогу так выдумать и писать.“\$2 Im Februar 1943 hingegen schien er sich selbst wieder Mut machen zu wollen: „Я был умен и еще умен, талантлив, непостижим чем-то божественным, что есть моя жизнь, своей индивидуальностью, мыслями, чувствами - как же может быть, чтобы это исчезло? Не может быть!“153 Im September 1943 nahm er die Arbeit wieder auf und konnte im April/Mai 1944 eine besonders intensive Schaffensphase verzeichnen. Nach 1944 entstanden nur noch vereinzelt Erzählungen; Gründe hierfür kőnnen sowohl in seinem sich verschlechternden Gesundheitszustand liegen als auch in der Verstimmung über die kühle bis ablehnende Reaktion auf einige Erzählungen der Temnye allei (vgl. Kap. 10.1).

Als Motivation für das Schreiben der Erzăhlungen in jenen Jahren gab Bunin Boris Zajcev gegenüber in einem Brief vom 14. Juli 1944 folgende Erklărung: "Quand nous sommes seuls longtemps nous peuplons le vide de fantomes [sic]' - выдумываю рассказики больше всего поэтому. "154 Darüber hinaus verwies Bunin mehrfach beharrlich auf die Tatsache, daß alle Erzăhlungen seiner Imagination entstammen, wie beispielsweise in einem Brief an Mark Aldanov vom 23. August 1947: „И опять, опять твержу [...]: как $9 / 10$ всего написанного мною на 99 процентов выдумано [...].“15s In einer von ihm zusammengestellten Übersicht mit dem Titel „Proischoždenie moich rasskazov“ erlăutert Bunin am Beispiel verschiedener Erzählungen, unter anderem aus den Temnye allei, den

151 Tagebucheintrag Bunins vom 01.07.1941. Zit. in: UB. 3.Bd. op.cit.: 101 .

152 Tagebucheintrag Bunins vom 20.09.1942. Zit. in: $U B$. 3.Bd. op.cit.: 141 .

153 Tagebucheintrag Bunins vom 24.02.1943. Zit. in: UB. 3.Bd. op.cit.: 147.

154 Zit. in: „Pis'ma I. Bunina k B. Zajcevu“. In: $N \geq 137$ (1979): 140.

155 Zit. in: ..Perepiska I. A. Bunina s M. A. Aldanovym". In: Nz 152 (1983): 182. 
jeweiligen Schreibanstoß: So sei etwa die Erzählung „Vizitnye kartocki“ zurückzufuhren auf die Erinnerung an eine gemeinsam mit seinem Bruder Julij unternommene Schiffsfahrt auf der Wolga im Juni 1914, während der er mit einer Verehrerin ins Gespräch gekommen sei. ${ }^{156}$ Der Inhalt der Erzählung spiegele indessen nicht die Realität wider, sondern sei lediglich der Auslöser für seine Imagination gewesen - im Gegensatz zu seinem Schaffen in jüngeren Jahren, als es ihm schwerfiel, ein Sujet zu ersinnen. ${ }^{157}$ Dieser schöpferische Umgang mit seinen Erinnerungen war möglicherweise auch eine wirksame Methode, die ihn hăufig quälenden Rückblicke in seine Vergangenheit produktiv zu nutzen (vgl. Kap. 8.2.1).

Von der Tatsache abgesehen, daß in Bunins Tagebuch bei weitem nicht alle Erzählungen erwähnt werden, finden sich darüber hinaus nur wenige detaillierte Notizen zum Entstehungsproze $B$ der einzelnen Erzählungen. Eine Ausnahme bildet der Eintrag vom 7. Mai 1940, in dem er sich zu den Erzählanlässen einiger der 1938 verfaßten Erzählungen äußert. ${ }^{158}$ In der Regel erwähnt er - wenn überhaupt - lediglich die Fertigstellung bzw. Überarbeitung einer Erzählung. In diesem Zusammenhang läßt sich die nicht erklärliche Feststellung machen, daß mit Ausnahme der Erzählungen „Ivolga“ und „Tri rublja“ in seinem Tagebuch nur Erzählungen aufgeführt werden, die in der Folge auch veröffentlicht wurden, wie beispielsweise „Genrich“ (10. November 1940), „Nacalo“ (23. Oktober 1943) oder „Kamarg“ (23. Mai 1944). Einen Eindruck von der Bedeutung des schriftstellerischen Schaffensprozesses für Bunin vermittelt eine Notiz während des Verfassens der Erzählung "Čistyj ponedel'nik":

Час ночи. Встал из-за стола-осталось дописать неск[олько] строк „Чистого Понед[ельника]“. Погасил свет, открыл окно проветрить комнату-ни малейш[его] движения воздуха; полнолуние, ночь неяркая, вся долина в тончайшем тумане, далеко на горизонте неясный розоватый блеск моря, тишина, мягкая свежесть молодой древесной зелени, кое-где щелкание первых

156 .Proischoždenie moich rasskazov““. LRA. MS.1066/665. Einige dieser Texte wurden in die neunbăndige Werkausgabe aufgenommen: I. Bunin. SS v devjati tomach. 9.Bd. Moskva, 1967: 368-373.

157 In einem Brief an Aldanov vom 02.09.1947 schildert er diese Entwicklung, die wie eine zur Veroffentlichung bestimmte Erklarung klingt: „A потом случилось нечто уднвнтельное: воображенне у меня стало развиваться, не по дням, а по часам', как говорится, выдумка стала необыкновенно легка, один Бог знает, откуда она бралась, когда я брался за перо, очень, очень часто еше совсем не зная. что выйдет из начатого рассказа, чем он кончится (а он очень часто кончался соверщенно неожиданно для меня самого, каким-ннбудь ловким выстрелом, какого я и не чаял): как же мне после зтого, после такой моей радости н гордостн, не огорчаться, когда все думают, что я пишу с такой реальностью и убеднтельностью только потому, что обладаю, ,необыкновенной памятью", что я все пншу ,с натуры', то, что со мной самнм было, или то, что я знзл, вндел!“” (zit. in: „Perepiska I. A. Bunina s M. A. Aldanovym". In: NE 152 [1983]: 185).

158 Zit. in: $U B$. 3.Bd. op.cit.: 48-49. 
соловьев ... Господи, продли мои силы для моей одинокой, бедной жизни в этой красоте и в работе! ${ }^{159}$

Außergewöhnlich viel Aufmerksamkeit (und Platz) widmete Bunin der Erzählung „Natali“ in seinem Tagebuch: Entgegen seiner sonstigen Gepflogenheit erwähnte er bereits den Beginn der Arbeit an der Erzählung am 18. März 1941. ${ }^{160}$ Nachdem er „Natali“" nach Tagen intensiven Schreibens am 4. April 1941 für abgeschlossen erklärte, nahm er bereits am 11. April Korrekturen am Ende des letzten Kapitels vor. ${ }^{161}$ Auch in den Folgemonaten setzte er sich immer wieder mit der Erzählung auseinander, wie unveröffentlichte Tagebuchnotizen vom 15. April, 6. bzw. 19. Juni und 18. November 1941 belegen. ${ }^{162}$ Diese intensive Überarbeitung deutet bereits auf die Sonderstellung hin, die dieser „kleine

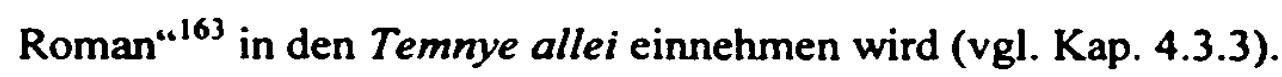

Inhaltlich wertend äußerte sich Bunin in seinem Tagebuch lediglich zu der Erzählung "Cholodnaja osen'“:

Очень самого трогает „Холодная осень“. Да, „великая октябрьская“, Белая армия. змиграция ... Как уже далеко все! И сколько было надежд! Эмиграция, новая жизнь - и, как ни странно, еще молодость была! В сушности, удивительно счастливые были дни. И вот уже далекие и никому не нужные. ${ }^{164}$

Lassen sich zur Genese der einzelnen Erzählungen nur in begrenztem Umfang Informationen finden. so ist die Formierung der Erzählungen zu einem Buch im großen und ganzen besser dokumentiert.

\subsection{Zur Formierung der Temnye allei}

Im Hinblick auf die Frage nach der Formierung des Buches bilden Bunins Tagebuchnotizen sowie seine Korrespondenzen mit Mark Aldanov, Tèffi, Boris Zajcev, Nikolaj Telešov und Fedor Stepun die hauptsächlichen Quellen (vgl. Übersicht über den Formierungsproze $B$ in Anhang 2). Vorwegnehmend muß auf den Umstand hingewiesen werden,

159 Tagebucheintrag Bunins vom 09.05.1944. Zit. in: UB. 3.Bd. op.cit.: 164-165.

160 Unveroffentlichter Tagebucheintrag Bunins. LRA. MS.1066/533.

$161 \mathrm{Vgl}$. die entsprechenden Tagebucheintrăge Bunins. Zit. in: UB. 3.Bd. op.cit.: 90 bzw. 91 .

162 LRA. MS.1066/533 bzw. MS.1066/534.

$163 \mathrm{Vgl}$. Brief Bunins an Zajcev vom 08.11.1943. Zit. in: „Pis'ma I. Bunina k B. Zajcevu“. In: Nz 136 (1979): 139.

164 Tagebucheintrag Bunins vom 01.01.1945. Zit. in: UB. 3.Bd. op.cit.: 174-175. 
$\mathrm{da} ß$ weder den verfugbaren privaten Aufzeichnungen Bunins noch den einsehbaren Briefwechseln Details zum Prozeß der Zusammenstellung zu entnehmen sind; auch scheint Bunin keinem von vornherein feststehenden konkreten strukturellen „Bauplan“ gefolgt zu sein (Näheres zur Natur der Anordnung der Erzählungen in Kap. 4). Auf den Tag genau låß sich nicht feststellen, wann in Bunin der Entschluß gereift ist, seine Erzählungen in Buchform herauszugeben - zumal Ende der 1930er Jahre bereits einige der Erzählungen, die spăter in das Buch aufgenommen wurden, in der russischsprachigen Pariser Tageszeitung Poslednie novosti erschienen sind. ${ }^{165}$ Daher wird im folgenden von einer Formierung ab dem Zeitpunkt ausgegangen, an dem Bunin erstmals von einem geplanten Buch mit dem Titel Temnye allei spricht.

Bereits im Frühjahr 1940 scheint Bunin eine Veröffentlichung als Integraldruck intendiert zu haben, wie der Tagebucheintrag vom 7. Mai 1940 belegt: „Перечитал свои рассказы для новой книги. Лучше всего ,Поздний час', потом, м[ожет] 6[ыть], ,Степа', ,Баллада'“"166 Zu diesem Zeitpunkt existierten lediglich acht Erzählungen aus den Jahren 1936-1938, die fast alle in spätere Veröffentlichungen der Temnye allei aufgenommen wurden.

Eine gewichtige Rolle sowohl beim Formierungsproze $B$ als auch bei der Editionsgeschichte spielte die bereits erwähnte unsichere Publikationssituation. Da es Anfang der 1940er Jahre für Bunin unmöglich schien, in absehbarer Zeit in Europa etwas zu veröffentlichen, geschweige in seiner Muttersprache, war seine Hoffnung auf Mark Aldanov in den USA gerichtet, der eine russischsprachige Zeitschrift (das spätere Novyj žurnal) zu grinden beabsichtigte und dem er offenbar auch zutraute, die Temnye allei in der von ihm gewünschten Form zu publizieren.

Im Januar 1941 erwähnte Bunin Mark Aldanov gegenüber erstmals ein fertiges neues Buch mit 25 nicht namentlich aufgeführten Erzählungen, von denen $9^{167}$ bereits veröffentlicht worden seien und das nach der ersten Erzählung den Titel Temnye allei trage. ${ }^{168}$ Auf

165 Hierzu gehoren mit Ausnahme der Erzahlung „Temnye allei“ alle Erzăhlungen des spateren ersten Komplexes: „Aprel”“, „Ballada“, „Kavkaz“, „Muza“, „Pozdnij Cas“, „Stepa“ sowie in der Zeitschrift IIljustrirovannaja Rossija "Molodost' i starost" unter ihrem urspringlichen Titel "Pro obez'janu“ (vgl. Anhang 2).

166 Zit. in: UB. 3.Bd. op.cit.: 48. Es ist erstaunlich, daß die titelgebende Erzahlung „Temnye allei“ weder im Tagebuch erwahnt noch einzeln veroffentlicht wurde und dennoch eine derart wichtige Position im Buch erhielt. Es ist nicht auszuschließen, daß Bunin ihr von Anfang an eine besondere Bedeutung als Auftakterzahlung fur das geplante Buch beimaß und sie deshalb zuruckhielt.

167 Nachweisen laßßt sich jedoch nur die Veroffentlichung der folgenden sieben Erzahlungen: „Molodost' i starost”" (unter ihrem ursprünglichen Titel „Pro obez'janu“), "Kavkaz". „Ballada“, „Aprel”., „Stepa“, "Muza“ und „Pozdnij Cas" (vgl. auch Anhang 1).

168 Brief an Aldanov vom 08.01.1941. Zit. in: „Lettres d'Ivan Bunin à Mark Aldanov“. op.cit.: 472. 
Grund der ungewissen Beforderungssituation durch die Post habe er sich jedoch dazu entschlossen, Aldanov vorerst keine Kopien zur Aufbewahrung zu schicken. In den folgenden Monaten scheint Bunin sich bezüglich der Zusammenstellung anders entschieden zu haben: Ein Paket mit nur noch 21 Erzählungen ${ }^{169}$ (vgl. Anhang 2, Stand Frühjahr 1941) ließ er Aldanov durch den nach Amerika reisenden Pianisten Sergej Nikolaevix Barsukov uberbringen; in einem Brief an Aldanov vom 10. April 1941 beschreibt er erstmals konkrete Vorstellungen von der formalen Zusamminsetzung des Buches, das sich in drei Abschnitte gliedern sollte und bei dessen Zusammensetzung Bunin sich zu diesem Zeitpunkt am Veröffentlichungsstatus der einzelnen Erzählungen zu orientieren scheint:

[...] нынче отправляется Вам совсем готовая к печати книга моих новых рассказов под общим заглавием (по первому рассказу) „Темные аллеи“ (вся о любви) в трех отделах: 1. Семь рассказов, напечатанных в газетах, 2. Тринадцать еще не напечатанных, 3. Один рассказ тоже напечатанный,- всего 230 страниц напечат[анных] на машинке. ${ }^{170}$

Seinen Wunsch, diese Erzăhlungen als Integraldruck zu veröffentlichen, unterstrich Bunin in einem weiteren Brief, den er am 11. April 1941 an Aldanov verfaßte. Im Falle von Einzelveröffentlichungen der Erzăhlungen in der geplanten Zeitschrift bat er den Freund, den Abdruck um den Zusatz „из книги ,Темные аллеи““ zu ergänzen. ${ }^{171}$ Gut einen Monat später erläuterte er Aldanov nochmals detailliert seine Gründe für die Übermittlung des Manuskripts und erteilte ihm eine Vollmacht hinsichtlich möglicher (Einzel-)Veröffentlichungen:

Повторяю: эту книгу я послал Вам прежде всего потому, что мне часто приходит в голову: „мало ли что может со мной случитьсья, пусть будет один экземпляр моей новой (и, верно, последней) книги в сохранности, в надежных руках - для потомства." А на печатание ее теперь, даже частично, я мало надеюсь [...] Словом, я послал Вам книгу и в этом смысле на всякий случай. ${ }^{172}$

169 Im Nachlaß Mark Aldanovs fand sich ein Paket mit Typoskripten von Erzahlungen aus den Temmye allei. Dabei handelt es sich mutmaßlich um das Paket, das Bunin durch den Pianisten Barsukov an Aldanov geschickt hat; der Umschlag des Pakets ist mit dem folgenden Text versehen: „Le manuscrit 192 pages. C'est mon nouveau livre des contes. Pour la Traduction [sic] et l'édition en Amérique. Ivan Bounine (Ivan Bunin). Ecrivain, Prix Nobel 1933“ (RGB, fond 429, karton 3, edinica chranenija 21 ).

170 Zit. in: "Lettres d'Ivan Bunin a Mark Aldanov". op.cit.: 472. Anfang Mai 1941 uberarbeitete Bunin bereits den ersten Teil in nicht naher bekannter Weise (vgl. Tagebucheintrag vom 02.05.1941. Zit. in: UB. 3.Bd. op.cit.: 92). Es bleibt unklar, ob er Aldanov diese Veranderung mitgeteilt hat.

171 Zit. in: „Lettres d'Ivan Bunin a Mark Aldanov". op.cit.: 473. Dieser Zusatz findet sich jedoch bei keiner der von Aldanov verantworteten Einzelveroffentlichungen von Erzahlungen.

172 Brief an Aldanov vom 06.05.1941. Zit. in: „Perepiska 1. A. Bunina s M. A. Aldanovym“. In: Nz IS0 (1983): 164. 
Trotz seiner Schaffenskrise befaßte sich Bunin im Winter 1942 mit dem Manuskript, bevor er am 2. Mărz 1942 feststellte: „Кончил ,Темн[ые] ал[леи]“ и отложил до поры до времени. Есть еще кое-где фразы неприятные.“173 Auch gegenüber der Dichterin Alla Sergeevna Golovina äußert er sich ähnlich und gibt als Grund fur seine Unkreativităt mangelnde Motivation als Folge eines fehlenden Lesepublikums an: „[...] я написал целую книгу новых рассказов (теперь не пишу,- для кого, зачем?). “174 Abgeschlossen ist das Buch indessen noch nicht, und so ließ Bunin, nachdem seit Ende 1944 wieder Briefkontakt nach Übersee bestand, in einem Brief vom 17. Januar 1945 seinen Freund Aldanov in einem Nachsatz wissen, daß er inzwischen den zukünftigen dritten und letzten Teil der Temnye allei fertiggestellt habe, jedoch ohne die betreffenden Erzăhlungen namentlich aufzulisten: „J'ai écrit encore un livre (comme ,Les allées sombres'). “175 Die Formulierung als Vergleich bezieht sich vermutlich auf den Titel des 1941 an Aldanov geschickten Manuskripts; von der 1943 in New York herausgegebenen gekürzten Fassung (vgl. Anhang 2, New Yorker Ausgabe) erfährt Bunin erst im Sommer 1945 (vgl. Kap. 9.1.1).

Auch Tèffi ließ Bunin am Entstehungsprozeß der Temmye allei teilhaben, so etwa im Frühjahr 1943 mit einem Hinweis auf die Arbeit an einem neuen Buch; gleichzeitig berichtete er von seiner derzeitigen Schaffenskrise, die ihn zu dem Schluß kommen ließ, daß sein Buch bereits abgeschlossen sein könnte:

[...] еще год, полтора года тому назад мог без устали писать часов восемь в день (и тогда написал целую книгу новых рассказов), а вот теперь и двух часов не пропишешь. Да и думаешь все одно: к чему, для чего. И все не мило, все постыло..${ }^{176}$

Nachdem Tèffi, die über Boris Zajcev im Frühjahr 1944 Zugang zu einem Teil der Erzählungen der Temnye allei erhielt, sich mehrfach positiv geäußert hatte, bezog Bunin sie in seine weiteren Pläne bezüglich des entstehenden Buches ein. In einem Brief vom 11. April 1944 schickte er ihr eine Übersicht über den Status quo der Zusammensetzung (vgl. Anhang 2, Stand April 1944):

Вообще, если бы вы видели всю эту мою новую книгу, она бы еще немножко вынграла. [...] Список зтот, думаю, вам совсем не нужен. Но что делать-хочется

173 Tagebucheintrag Bunins. Zit. in: UB. 3.Bd. op.cit.: 128.

174 Brief an A. Golovina vom 07.09.1942. Zit. in: „Iz perepiski I. A. i V. N. Buninych s Alloj Golovinoj (1942-1953)“. In: I. A. Bunin i russkaja literatura XX veka. Moskva, 1995: 250.

175 Zit. in: „Perepiska I. A. Bunina s M. A. Aldanovym“. In: Nż 150 (1983): 169.

176 Brief an Teffi vom 25.04.1943. Zit. in: .Perepiska Teffi s I. A. i V. N. Buninymi 1939-1948“. op.cit.: 488. 
поделиться своей последней литературной радостью с таким редким другом, как вы! $!^{177}$

Im November 1943 übersandte Bunin Durchschläge eines Teils der in den Jahren in Grasse entstandenen Erzählungen Boris Zajcev in Paris (im Original und - soweit vorhanden - in französischer Übersetzung), darunter „Natali““178, zur Veröffentlichung durch den Pariser Verleger Sorlot, mit dem Boris Zajcev in Verbindung stand (vgl. Kap. 9.3.1), obwohl er sich keine Illusionen darüber machte, daß in den Verlagen in der Regel Romane den Vorzug vor Erzählbänden erhielten. Aus diesem Grunde gab Zajcev in den Verhandlungen mit Sorlot vor, daß es sich bei Bunins Buch nach der Fertigstellung um eine Art Roman mit verschiedenen Kapiteln handeln würde, die alle eigene Titel tragen würden. ${ }^{179}$ Die Gründe, aus denen heraus Bunin bereits im Dezember 1943 sein Manuskript wieder zurückforderte ${ }^{180}$, bleiben im dunkeln; möglicherweise realisierte er im Zuge der schöpferischen Periode im Herbst 1943, daß das Buch doch umfangreicher ausfallen würde, oder aber er vergegenwärtigte sich die politische Dimension einer Veröffentlichung unter der deutschen Besatzung.

Dennoch fuhr Bunin fort, Duplikate verschiedener Erzăhlungen an Zajcev zu schicken, damit dieser sie „für alle Fälle“ verwahre. Einem Brief an Zajcev vom 14. Juli 1944 fügte Bunin zudem eine Übersicht über die bis zu jenem Zeitpunkt verfaßten Erzählungen bei. die in der Publikation des Briefwechsels im Novyj žurnal indessen nicht aufgefuhrt ist: „Посылаю - на всякий случай - список того, что накопилось в моем ,портфеле‘. Ты из этого ,портфеля“ далеко не все знаешь [...]." ${ }^{181}$ Tatsächlich enthielt diese Übersicht die Titel von 50 Erzählungen, von denen Zajcev bis zu diesem Zeitpunkt lediglich 15 erhalten hatte. ${ }^{182}$ Nach der Anzahl der Erzăhlungen zu schließen könnte diese Liste identisch sein mit einer Aufstellung, die Bunin vermutlich im Mai 1944 angefertigt hatte ${ }^{183}$ und die eine überwiegend chronologisch ausgerichtete Aufstellung von 50 Erzählungen (vgl.

177 Zit. in: „Perepiska Téffi s I. A. i V. N. Buninymi 1939-1948“. op.cit.: S10-511.

$178 \mathrm{Vgl}$. Brief Zajcevs an Bunin vom 17.11.1943. Zit. in: „Pis'ma B. Zajceva I. i V. Buninym“. In: Nż 146 (1982): 121.

179 Brief Zajcevs an Bunin vom 28.I1.1943. Zit. in: „Pis'ma B. Zajceva I. i V. Buninym“. In: $N \dot{z} 146$ (1982): 124.

180 „[...] некоторые обстоятельства, довольно неожиданные, заставляют меня твердо решиться не переводить пока и не издавать ,Темные аллен““ (Brief an Zajeev vom 14.12.1943. Zit. in: „Pis'ma I. Bunina k B. Zajcevu“. In: Nz 137 [1979]: 129).

181 Zit. in: „Pis'ma I. Bunina k B. Zajcevu“. In: Nz 137 (1979): 139.

182 Brief an Bunin vom 25.07.1944. Zit. in: „Pis'ma B. Zajceva I. i V. Buninym“. In: Nż 146 (1982): 39.

183 Da das Original im Bakhmeteff Archive (New York) nicht auffindbar ist, wird die Liste nach einer Fotokopie zitiert, die Rosa Fedoulova ihren Angaben zufolge fur ihre Dissertation anfertigte (vgl. dies. "Les Allees sombres d'Ivan Bounin“. op.cit.: Anhang). 
Anhang 2, Stand ca. Mai 1944) enthält, von denen ein Großteil Eingang in die Endfassung der Temnye allei fand. Die Untergliederung dieser Auflistung in die bereits erwähnten drei Komplexe legt die Vermutung nahe, daß Bunin bei der Erstellung dieser Liste geleitet wurde von seiner Vorstellung von der endgültigen Zusammensetzung der Temnye allei, da die zuletzt genannte Erzählung („Otec Nikon“, 27. Mai 1944) das jüngste Entstehungsdatum trägt (die năchste, in dieser Liste nicht aufgeführte Erzählung mit dem Titel „Mest““ schloB Bunin am 4. Juni $1944 \mathrm{ab}$ ) und sie inhaltlich die Fortsetzung der wenige Wochen zuvor an Téffi gesandten Aufstellung darstellt (vgl. Anhang 2, Stand April 1944). Zudem schickte Bunin mit „Mistral"“184 auch eine Erzählung an Zajcev, die nicht in dieser Liste aufgeführt ist, so daß die Annahme naheliegt, daß diese Aufstellung einem vorläufigen Inhaltsverzeichnis entspricht.

Während der erste und zweite Komplex im Vergleich zum Stand von 1941 im wesentlichen unverändert geblieben waren, begann nun auch der dritte Komplex Gestalt anzunehmen, wenn er auch von seiner endgultigen Form noch weit entfernt war.

Im Zuge von Gesprächen über mögliche Publikationen aus Bunins Werk in der Sowjetunion, die Bunin nach Kriegsende unter anderem über seinen in Moskau ansässigen langjährigen Freund Nikolaj Telešov führte, verwies er auch auf sein letztes Buch, das zu dem Zeitpunkt lediglich in der unvollständigen New Yorker Fassung von 1943 vorlag. Ende 1945 schickte Bunin über Boris D. Michajlov, den Vorsitzenden des Pariser „Sovinformbjuro“, unter anderem eine "Soderžanie“ betitelte Übersicht samt Typoskripten von Erzählungen aus den Temnye allei in die UdSSR (vgl. Anhang 2, Stand Ende 1945; vgl. auch Kap. 9.2.1). ${ }^{185}$ An dieser Aufstellung irritiert die Diskrepanz zur Pariser Fassung von 1946, die als maßgebliche Version gelten darf (da vom Autor imprimiert) und deren endgültige Zusammensetzung zu diesem Zeitpunkt bereits feststand. Auffällig an dieser Liste ist die Tatsache, daß Bunin trotz der bereits feststehenden Zusammensetzung der Pariser Ausgabe bewußt Erzählungen ausgespart hat, die er zuvor integriert hatte, wie zum Beispiel „Baryšnja Klara“ und „Antigona“ (vgl. Anhang 2, Pariser Ausgabe von 1946). Eine offensichtliche Erklärung für diese Modifikationen gibt es nicht.

184 Vgl. Brief Zajcevs an Bunin vom 27.I1.1944. Zit. in: „Pis'ma B. K. Zajceva K I. A. i V. N. Buninym. In: $N z 140$ (1980): 159.

$185 \mathrm{Vgl}$. Ankundigung im Brief an Telesov vom 08.12.1945. Zit. in: $L N$. 84.Bd. (1) op.cit.: 627. Zitiert wird diese Liste nach einer Kopie aus dem LRA, das Origina! wird im Telesov-Museum in Moskau verwahrt. 
Der Stand der Pariser Ausgabe blieb über mehrere Jahre stabil; weitere Modifikationen nahm Bunin erst in seinem letzten Lebensjahr vor: Zu einem nicht genau ermittelbaren Zeitpunkt verfügte er in seinem persönlichen Exemplar der Temnye allei, in künftigen Ausgaben die Erzählungen „Vesnoj, v Iudee“ und „Nocleg“ am Ende des dritten Komplexes abzudrucken (vgl. Anhang 2, Stand 1953; vgl. hierzu auch Kap. 4.5). ${ }^{186}$ Noch im Oktober 1952 legte Bunin einem Brief an Fedor Stepun eine Liste mit dem Titel „Rody moich socinenij" bei, in der er unter anderem einen Großteil seines erzählerischen Werkes bestimmten Kategorien zuordnete: „o narode“, „o ljubvi“, „misticeskie“, „o smerti“, „raznye", "stichi“. Die letzte Rubrik mit dem Titel „Kniga ,Temnye allei"“ entspricht in ihrer Zusammensetzung dem Inhaltsverzeichnis der Pariser Ausgabe von $1946^{187}$, so daß vermutet werden kann, daß die späteren Ergänzungen vornehmlich Bunins Wunsch nach einer Publikation der betreffenden Erzählungen entsprangen. Außer in dieser Sonderrubrik fuihrt Bunin die Temnye allei auch in ihrer Gesamtheit in der Kategorie „o ljubvi“ auf, der auch die beiden Erzăhlungen „Vesnoj, v Iudee“ und „Nočleg“ zugeordnet wurden.

Vermutlich zeitlich nach dieser Liste entstand eine weitere Zusammenstellung von Erzählungen, deren ordnende Richtlinie jedoch unklar bleibt. Milica Greene veröffentlichte sie gemeinsam mit weiteren Archivmaterialien. die im Zusammenhang mit Äußerungen Bunins zu seiner Person und seinem Werk stehen. ${ }^{188}$ Die Entstehung dieser Liste bringt Greene in Verbindung mit Julija Leonidovna Sazonova, die 1953 ein Buch über Bunin vorbereitete und diesen bat, sie mit Material zu unterstutzen. Die Aufstellung ist nicht identisch mit jener, die Bunin an Stepun schickte, und unvollständiger: Unter der Überschrift .,Moi rasskazy i povesti“ führ er lediglich die Rubriken „o ljubvi“ und „o narode“ auf. Zu den Liebeserzählungen zählt er das Buch Temnye allei, dem er zu diesem Zeitpunkt lediglich 38 Erzählungen zuordnet. Des weiteren nennt er unter anderem die Erzählung „Vesnoj, v ludee“, während „Nočleg“ nicht erwähnt wird. Eine Gewichtung nimmt er nicht vor.

186 Das personliche Exemplar Bunins, in dem dieser Ergănzungswunsch enthalten ist, wird im Moskauer IMLI verwahrt. Etwa zeitgleich scheint Bunin eine identische Zusammenstellung einer geplanten englischen Übersetzung erwogen zu haben (vgl. einen Brief Julija Sazonovas an Bunin vom 13.05.1953. LRA. MS.1066/4931 sowie Kap. 9.3.2). Da Bunin in diesem Zusammenhang seine 1953 in New York erschienenen Titel Mitina ljubov: Solnecrnyj udar und Vesnoj, $v$ ludee. Roza lerichona aufnuht, muß er diesen Zusatz in seinem personlichen Exemplar der Temmye allei mutmaßlich kurz vor seinem Tod vermerkt haben.

187 Brief an Fedor Stepun vom 12.10.1952. Zit. in: „Pis'ma I. A. Bunina k F. A. Stepunu“. In: Nz 118 (1975): 126-127.

188 .Bunin o sebe i svoem tvorcestve. Archivnye materialy“. Hg. M. Grin. In: Nz 107 (1972): 168-169. 
3.4 Weitere veröffentlichte und unveröffentlichte Erzählungen aus dem Entstelungszeitraum der Temnye allei

In dem Entstehungszeitraum der Temnye allei verfaßte Bunin eine Reihe weiteer Erzählungen, von denen 14 noch zu seinen Lebzeiten und 15 nach seinem Tode veröffentlicht wurden. Neun Erzählungen wurden bis heute nicht publiziert, sind jedoch in Manuskriptbzw. Typoskriptform im LRA einzusehen. Viele dieser Erzählungen ähneln trematisch, motivisch und/oder strukturell in verblüffender Weise den in die Temnye allei afgenommenen Erzählungen. Allein im produktivsten Jahr 1944 entstanden 31 Erzähluagen, von denen nur 13 in der Fassung der Temnye allei von $1946 \mathrm{zu}$ finden sind, so da3 sich die Fragen aufdrängen, warum Bunin die restlichen nicht ebenfalls integrierte bzw. warum er sie nicht in einem separaten Buch publizierte, zumal der Titel Temnye allei bereits für die Erzählungen des ersten und zweiten Komplexes vergeben war, die 1943 in New York erschienen. Die Erzählungen aus dem Jahr 1944 hätten dem Umfang nach ohne weiteres eine gesonderte Publikation gerechtfertigt. Daß Bunin sich mit einem solchen Gedanken trug, belegt der bereits erwähnte Brief an Aldanov vom 17. Januar 1945, in dem es heißt: „J'ai écrit encore un livre (comme, Les allées sombres'). “189 Was also bewog ihn die Temnye allei um den dritten Komplex zu erweitern, diesen jedoch nur mit ausgewählten Erzählungen zu füllen? Hegte er den Wunsch, die anderen Erzählungen gesondert zu publizieren? Ein Brief an Aldanov aus dem Jahr 1951 legt diesen Schluß nahe: „Сейчас хочу сказать еще только то, что, если будет издательство, о котором Вы пишете, у меня есть небольшая книжка монх рассказов, еще не выходивших отдельным изданием.“"190

Die folgende Übersicht über die zeitgleich entstandenen Erzählungen unter dem Aspekt ihres Bezugs zum Buch in der 1946 publizierten Fassung wird aufschlußreiche Diskrepanzen aufzeigen zwischen den Erzählungen der Temnye allei und jenen. die nicht aufgenommen bzw. aus den Zusammenstellungen wieder entfernt wurden. Die bis heute unveröffentlichten Erzăhlungen werden dabei jeweils mit einer kurzen Inhaltsangabe vorgestellt. Aus dieser vergleichenden Darstellung werden auch erste Gestaltungsprinzipien ersichtlich, denen Bunin bei der Einkleidung seiner Liebeskonzeption in den Temnye allei folgte. 
Ergänzt wird diese Übersicht um einen Exkurs zu Skizzen und Notizen aus demselben Zeitraum.

\subsubsection{Die veröffentlichten Erzählungen}

Zwischen 1936 und 1953 und damit zu Lebzeiten Bunins wurden 14 Erzählungen in verschiedenen Tageszeitungen. Zeitschriften und Sammelbänden publiziert. Mit Ausnahme der Erzăhlungen „Molodost' i starost”“ (1936) und „Aprel”“ (1938) stammen diese Erzăhlungen aus den 1940er Jahren. Fünf Erzählungen erschienen in der seit 1942 in New York, ab 1950 in Paris herausgegebenen literarischen Monatszeitschrift Novosel 'e: "Tri rublja" (1942) ${ }^{191}$, „Krem Leodor“ (1947), „Un petit accident““ (1950), „V Al'pach“ (1950), „,V takuju no丈' ...““ (1950). Die übrigen Erzählungen wurden teils in den Tageszeitungen Poslednie novosti („Aprel’“, 1938), Russkie novosti („Vesnoj, v Iudee“, 1946, und „Pamjatnyj bal“, 1947), teils in den Magazinen Illjustrirovannaja Rossija (,Molodost' i starost““, 1936) und Vozroždenie (,Nočleg“ und „Poludennyj żar“, beide 1949) sowie in den Sammelbänden Vstreča (,Mistral”“, 1945) und Vesnoj, v Iudee („Alupka“ und .Legenda“, beide 1953) publiziert.

Nach Bunins Tod wurden weitere 15 Erzählungen veröffentlicht, die mit wenigen Ausnahmen 1944 entstanden waren: „Lita“ wurde 1943 fertiggestellt, während „Na izvozcike“ und eine titellose Erzählung beide kein Datum tragen. Abgesehen von der titellosen Erzählung erfolgte die Erstpublikation all dieser Erzählungen in der Zeitschrift Novyj żurnal. Zu Lebzeiten Vera Buninas wurde dort nur eine Redaktion der Erzählung „Alja“ (1959) $^{192}$ veröffentlicht; die übrigen in diese Rubrik fallenden Erzählungen ${ }^{193}$ wurden in verschiedenen Ausgaben der Jahrgänge 1961, 1962 und 1964 von Leonid Zurov ${ }^{194}$ sowie 1981 von Milica Grin und 1987 von Jurij Mal'cev publiziert.

191 Die in den Klammem stehende Jahreszahl bezeichnet das Publikationsjahr; vgl. hierzu auch Anhang 1.

192 Die zweite Redaktion wurde 1962 von Leonid Zurov im Nz 69 publiziert.

193 Dazu gehoren die folgenden Erzăhlungen: ...Kogda ja vpervye ....” (1961), „Modest“ (1962), „Riv "era” (1962), "Lita“ (1964), „Achmat" (1981), "Novaja Subka“ (1981), ,Dalekij pozar" (1981), .Na izvozcike“" (1987), „Au secours!" (1987), „Pis'ma“" (1987), „Marija Stjuar" (1987), „Kibitka“ (1987) und „V kanavu!" (1987); vgl. hierzu auch Anhang 1.

194 Zurov zufolge waren alle Texte, die er bzw. Vera Bunina zum Abdruck freigegeben haben, von Bunin imprimien (vgl. die Anmerkung Zurovs anlaßlich des Abdrucks der zweiten Redaktion der Erzahlung .Alja" im Nz 69 [1962]: 15). Diese Aussage muB in Zweifel gezogen werden, da beispielsweise der Abdruck der Erzahlung „Riv'era“" auf Grundlage eines undatierten Typoskripts erfolgte, das Bunins handschriftliche Korrekturen nicht berlucksichtigt. Der Schluß des im Gegensatz zum Typoskript datierten Manuskripts fehlt und wurde laut Zurov von Bunin entfemt (vgl. $L N$. 84.Bd. [1] op.cit.: 124). Da jedoch Bunins Typoskriptkorrekturen nicht ubernommen wurden, die ahnlich erotischen Charakters sind wie der in der Druckfassung fehlende Schluß, scheinen Zweifel an Zurovs Aussage berechtigt. 
Irina Odoevceva zitiert in ihren Memoiren die erwähnte titellose Erzählung, geschrieben in der Manier der Temnye allei, die jedoch von Bunin nicht schriftlich fixiert wurde und auch keine Spuren in den Archiven hinterließ. ${ }^{195}$ Sie beruft sich darauf, daß Bunin ihr diese Erzăhlung 1947 wăhrend eines Aufenthaltes im südfranzösischen Juan-les-Pins als Erlebnis eines Freundes wiedergegeben und sie diese anschließend aus dem Gedächtnis niedergeschrieben habe: Ein Mann auf der Durchreise triff in seinem Übernachtungsort eine Frau, zu der er sich stark hingezogen fühlt und mit der er sich die Zeit bis zu seiner Abreise am nächsten Morgen verkürzen möchte. Seinen Vorschlag, die Nacht mit ihm in seinem Hotelzimmer zu verbringen, lehnt sie jedoch ab und führt ihn statt dessen auf den örtlichen Friedhof. Während er den Beischlaf auf einem Grab in nie gekannter Intensität erlebt und sich der ganzen Schöpfung verbunden fühlt, wünscht er sich, für immer mit ihr zusammenzubleiben. Um so verwirter und schockierter ist er von ihrem hastigen Aufbruch, bei dem sie ihm erklärt, daß er lediglich Mittel zum Zweck war und daß dieses intime Zusammensein auf dem Grab ihres Gatten als Racheakt an dem Verstorbenen zu werten sei.

Durch das Erleben eines einzigartigen Augenblicks erinnert die Erzählung stark an jene der Temnye allei; die zentrale Stellung des Geschlechtsaktes und das emotionale Unbeteiligtsein der Frau sowie die Emüchterung des Mannes in der Folge hingegen rücken sie in den Kreis der bis heute unveröffentlichten Erzählungen, die Bunin vermutlich aus gutem Grund im Manuskript- bzw. Typoskriptstatus beließ (vgl. Kap. 3.5.1).

\subsubsection{Bis heute unveröffentlichte Erzählungen}

Neun weitere Erzählungen, einige von ihnen unvollendet, wurden bis heute nicht veröffentlicht und werden im LRA verwahrt. Drei davon sind undatiert, die übrigen sechs verfaßte Bunin zwischen 1942 und 1944. Mit Ausnahme von "Ivolga" und „Na postojalom dvore" erwăhnte Bunin keine dieser Erzählungen in seinem Tagebuch, Eingang in vorläufige Zusammenstellungen der Temnye allei fanden lediglich „Na postojalom dvore“ und

195 1. Odoevceva. Na beregach Seny. Moskva, 1989: 273-276. Jurij Lotman, der sich im Rahmen einer Analyse des Einflusses Dostojevskijs auf Bunin mit dieser Erzahlung befaßt, hallt Odoevcevas Wiedergabe der Erzahlung fur glaubwurdig, sogar Bunins Stil sei gewahrt worden (vgl. Ju. Lotman. Stat 'i po istorii russkoj literatury: Teorija i semiotika drugich iskusstv: Mechanizmy kul'tury: Mel 'kie zametki. Tallinn, 1993: 172). 
"Otec Nikon". Diese Erzählungen werden im folgenden zusammenfassend in alphabetischer Reihenfolge vorgestellt. ${ }^{196}$

- „Dura“ (LRA. MS.1066/109-110): Die auf den 21. September 1943 datierte Erzăhlung „Dura" liegt in einer Manuskript- und einer Typoskriptfassung vor. Sie schildert in überwiegend szenischer Gestaltung die sexuelle Nötigung einer naiven Bauernmagd durch den Dorfschullehrer. Sie hatte ihn wegen eines schmerzhaften Insektenstiches am Oberschenkel aufgesucht in der Annahme, er könne ihr Linderung verschaffen. Er hingegen nutzt ihre Arg- und Hilflosigkeit aus, nötigt sie, mehr zu zeigen, als ihr recht ist, und macht sich zudem über sie lustig.

- Die unvollendete Erzählung „Ivolga“ (LRA. MS.1066/124-126) schrieb Bunin seinen Tagebuchaufzeichnungen gemäß im Oktober/November 1943 ${ }^{197}$; sie liegt in Manuskript- bzw. Typoskriptform vor (beide mit „Oktober 1943“ gekennzeichnet), ergänzt um verschiedene Notizen (unter anderem eine Reihe französischer Sprichwörter), die möglicherweise in die Erzählung hätten eingefügt werden sollen. Sie hat die bittersüßen Erinnerungen eines Mannes zum Inhalt: Zehn Jahre nach der ersten und schicksalshaften Begegnung eines Jünglings mit einem Mädchen schreibt die mittlerweile verheiratete Frau und Mutter einer Tochter ihrem verflossenen Verehrer und ruft ihm jene unbeschwerten, glücklichen Tage in Erinnerung, die sie auf dem Gut seiner Familie verlebte und während derer er sie „Pirol“ nannte. Nach Erhalt des Briefes erstehen vor dem geistigen Auge des Mannes die Bilder jener Sommertage - und des Kummers, den sie ihm mit ihrer jugendlichen Unbekümmertheit verursachte und den er keineswegs vergessen hat, wie die Schreiberin vermutet. Im Gegenteil erinnert er sich genau und empfindet den vergangenen Schmerz inzwischen als großes Glück.

- Auch die Manuskriptfassung der Erzählung „Knjažna Sajtanova“ (LRA. MS.1066/136) blieb undatiert und unvollendet: Eine verarmte Fürstin, die gezwungen ist, sich ihren Lebensunterhalt als Lehrerin zu verdienen, unterbricht die Reise zu ihrem Einsatzort für einen kurzen Besuch bei ihrer Schulfreundin, die mit ihrem Bruder, einem Offizier, ein Gut bewirtschaftet. Als dieser sie am folgenden Tag ein Stück auf ihrer Weiterreise begleitet, geraten sie in ein Unwetter, das sie in einem verlassenen Bahnwărter-

196 Erstmals referierend hingewiesen wurde auf diese Erzăhlungen (mit Ausnahme von „Skazka pro soldata") von L. lezuitova: „V poiskach vyraženija ...“. op cit.: 214-226.

$197 \mathrm{Vgl}$. Bunins Tagebucheintrage vom 01.11.1943 (.Вечером писал начало ,Иволги' - не знаю. что напишу дальше, пншу наугад.") und 06.11.1943 (..... продолжал ,Кволгу .“). Zit. in: UB. 3.Bd. op.cit.: 157 bzw. 158. 
hăuschen abwarten wollen. Dort kommen sie sich näher; die Erzählung bricht in dem Moment ab, als er sie küßt und sie seine Männlichkeit durch seine Pluderhosen hindurch ertastet. Der weitere Verlauf dieses sexuellen Abenteuers bleibt offen.

- Im Oktober 1943 entstand die Manuskriptfassung der Erzählung "Lizok“ (LRA. MS.1066/165-167), die in der Folge zu zwei Typoskriptvarianten mit handschriftichen Korrekturen ausgearbeitet wurde. Ein Mann mittleren Alters besucht seinen ehemaligen Schulfreund auf dessen Landsitz und hat es sich in den Kopf gesetzt, der halbwüchsigen Tochter den Kopf zu verdrehen. Geschildert wird einer dieser Verfuhnungsversuche wăhrend einer klaren Nacht, in der er versucht, bei dem jungen Mädchen Interesse fur die Astronomie zu wecken und ihr ganz nebenbei körperlich näherzukommen. Sie zeigt sich unbeeindruckt von seinen Annăherungen und kokettierenden Bemerkungen. Es bleibt offen, was im weiteren Verlauf des Abends geschieht. Der in einer frühen Fassung vorhandene Epilog konterkariert in gewisser Weise die Erzählung.

- Am 27. November $1942^{198}$ stellte Bunin die Erzählung "Na postojalom dvore“ (LRA. MS.1066/196-197) fertig, deren Titel in der Sekundärliteratur fälschlicherweise oftmals für den ursprïnglichen Titel der Erzählung „Nočleg“ gehalten wird. Es lassen sich indessen keine Hinweise darauf finden. daß „Noxleg“ jemals einen abweichenden Ursprungstitel trug. Während die Manuskriptfassung den Vermerk „ночь 27 ноября 1942“"199 trăgt, finden sich auf dem Typoskript die beiden ausgestrichenen Daten 27. November 1942 sowie 21. Mai 1946. „Na postojalom dvore“ fugt sich inhaltlich ein in den Reigen der Darstellung sexueller Nötigung von Dienstbotinnen, wie er auch in „Stepa“, „Gost”“, „Tanja“ oder „Durocka“ (zu dieser Erzählung besteht eine starke Ähnlichkeit) thematisiert wird, unterscheidet sich von jenen jedoch durch die profunde und eindringliche Darstellung des unauflöslichen Kontrastes zwischen Liebe und Begierde, wobei im Gegensatz zu der vergleichbaren Problemstellung in „Natali“ der Begierde ungleich größerer Raum eingeräumt wird: Ein junger Fürstensohn wird von seinem Vater mit einem Auftrag zu einem befreundeten Gutsherm geschickt. Diesen trifft er zwar nicht an, wohl aber die Hausherrin und die Köchin, was seine sexuellen Phantasien in Wallung versetzt. Erregt ihn zunächst die Anwesenheit der Köchin, wird

198 Vgl. Bunins Tagebucheintrag vom 27.11.1942: „Кончил ,На пост[оялом] дворе““ (zit. in: UB. 3.Bd. op.cit.: (44). Den ImaginationsprozeB hat er in einem Eintrag vom 24.09 .1942 festgehaiten: „Пот⿰亻⿻コ一心 стал думать о6 зтой кухарке на постохлом дворе. Все вообразил с страшной живостью. Возбуждение - и до того, что уже почувствовал все, что бывает перед концом. Мурашки, стеснение во всей грудной клетке" (zit. in: UB. 3.Bd. op.cit.: 143).

199 LRA. MS.1066/197. 
seine Aufmerksamkeit kurz darauf gefesselt von der - unerreichbaren - Gutsherrin. Er fühlt sich in seinem männlichen Stolz gekränkt, als weder die eine noch die andere Frau erkennbares Interesse an ihm bekundet. In seiner nächtlichen Einsamkeit versucht er den Widerspruch in sich aufzulösen, der resultiert aus der ihn übermannenden tierhaften Gier im Vergleich zu den zärtlichen Gefưhlen, die er bereits für verschiedene junge Mädchen empfunden hat. Die Begierde siegt - in einem plötzlichen Entschluß macht er sich auf den $\mathrm{Weg}$ in die Küche und vergewaltigt die Köchin. Moralische Skrupel plagen weder ihn noch den Autor, denn Bunin stellt diese Vergewaltigung in einem Licht dar, als würde der Jüngling lediglich dem Ruf der Natur folgen. ${ }^{200}$

- Die Erzählung „Otec Nikon“ (LRA. MS.1066/214-216) schloß Bunin am 27. Mai 1944 $\mathrm{ab}$, unterschrieb sie jedoch nicht. ${ }^{201}$ Sie liegt in einer Manuskript-Typoskript-Kombination vor sowie in zwei Typoskriptfassungen mit handschriftlichen Korrekturen. Die vollstăndigste Version dient als Referenzfassung. In dieser Erzählung schildert eine sechzigjăhrige Frau ihr mittlerweile 40 Jahre zurückliegendes kurzes Liebesverhältnis mit einem 25-jährigen Popen. Als junge Witwe von 22 Jahren ist sie fasziniert von seiner Stimme und von seinem heilandähnlichen Aussehen, das dieser geschickt bei alleinstehenden Frauen einzusetzen weiß. Seinen Annäherungsversuchen kann sie nicht standhalten, bis sie ihm völlig verfällt. So willigt sie auch ein, als er ihr eines Tages ein abendliches Stelldichein auf dem Friedhof vorschlăgt, damit sie ganz die Seine werde. Dort erwartet er sie ohne seinen Priesterrock, in einen alten Mantel gehüllt, und seine Silhouette erinnert sie an jene des dorfbekannten Trinkers. Ihre anfängliche Aufregung erfährt eine rasche Entzauberung, zumal der Pope ohne Umschweife zur Tat schreitet. Als er von ihr abläßt, ist ihre Liebe bereits in $\mathrm{Haß}$ umgeschlagen; sie fühlt das plötzliche Verlangen, ihm ein Messer zwischen die Rippen zu stoßen und flieht formlich vom Ort des Geschehens. Weitere Zusammentreffen bleiben ihr zwar erspart, da Vater Nikon überraschend versetzt wird, das Erlebte bleibt jedoch für den Rest ihres Lebens in ihrer Erinnerung präsent.

- Der undatierte und unvollendete Manuskriptentwurf der Erzählung "Raisa“ (LRA. MS.1066/252) hat die Hochzeit eines jungen Mădchens zum Inhalt. Die häßliche und

200 Hingegen laßßt Bunin moglicherweise als Korrektiv der fehlenden Moral in dieser Erzahlung eine mannliche Urangst lebendig werden - die der , vagina dentata“, denn der Jüngling wahnt wăhrend des Koitus im Leib der Kochin etwas Zahnartiges, Kiemenăhnliches wahrzunehmen.

201 In einer begleitenden Anmerkung im Rahmen der Herausgabe mehrerer bis dahin unveroffentlichter Erzahlungen Bunins schreibt Milica Grin [Greene]: „Рассказ ,О[тес] Никон“ Бунин просил не печатать, я соб людаю его просьбу“" - ohne jedoch zu prazisieren, in welcher Form Bunin seine Meinung kundtat (.Neopublikovannye rasskazy I. A. Bunina“. In: Nz 142 [1981]: 5). 
knochige Tochter eines verwitweten Kaufmanns wird für ihren Gang zum Altar zurechtgemacht und fulhit sich mit jedem Kleidungsstück, jedem Schminkstrich hübscher und reiner; gleichzeitig bewegt sie die Frage, wie sie vor ihrem Ehemann in der Hochzeitsnacht verheimlichen soll, daß sie keine Jungfrau mehr ist. Auch während der Trauzeremonie steht diese Besorgnis im krassen Gegensatz zu ihren erhabenen Gefühlen. Doch alles geht gut, der frischgebackene Ehemann hat dem Alkohol in einem Maße zugesprochen, daß ihm die fehlende Unschuld seiner Gattin nicht auffallt, und rasch wird diese in ihre neue Familie integriert. Das Manuskript bricht an der Stelle ab, an der ihr Schwager beginnt, ihr Avancen zu machen, und sich bereits ahnen läßt, daß die hehren Gefuhle ihres Hochzeitstages bereits vergessen sind und sie ihren Ehemann in absehbarer Zeit betrügen wird.

- Die 1943 entstandene Erzăhlung „Skazka pro soldata“ (LRA. MS.1066/269-270) liegt in zwei Typoskriptfassungen mit handschriftlichen Korrekturen vor. Als Referenzfassung dient die von Bunin mit seiner Unterschrift versehene Typoskriptversion. Die Erzăhlung fallt auf Grund der märchenhaften Elemente und der fehlenden Liebesthematik ein wenig aus dem Rahmen der in jenen Jahren entstandenen Erzählungen: Der Protagonist, ein Soldat in alter Zeit, wird während seiner Durchreise durch ein Dorf von den Söhnen eines toten Zauberers gebeten, die Psalmlesung an dessen Grab zu übernehmen. Der Tote, der sich in seiner Ruhe gestört fühlt, schickt daraufhin Teufel nach dem Störenfried aus, die ihn davonjagen. Nach einem weiteren erfolgreich überstandenen Abenteuer erhält er ein junges Mädchen zur Frau, das sich in der Hochzeitsnacht in eine Schlange verwandelt. Daraufhin macht er sich verzweifelt auf den Weg zu kriegerischen Auseinandersetzungen im Kaukasus, die er unbeschadet übersteht, und läßt sich schließlich mit einer christlichen Frau hăuslich nieder, um ruhig bis ans Ende seiner Tage zu leben.

- Die undatierte Manuskriptfassung der gleichwohl geschlossen wirkenden Erzählung „Zamužestvo“ (LRA. MS.1066/298) liest sich wie das Gegenstück zu „Raisa“. Hier stehen ebenfalls die Vorbereitungen einer jungen, in diesem Falle jedoch noch unberührten Braut im Mittelpunkt. Auch dieses junge Mädchen blickt der Hochzeitsnacht mit unruhiger Spannung und romantischer Erregung entgegen. Im Gegensatz zu Raisa weiß sie allerdings nicht, was sie erwartet, und ist emüchtert und angewidert, als der Ehemann gierig nach ihr greift und sich in einen ihr fremden, widerlichen Menschen zu verwandeln scheint: „О до чего он гадок был мне!“ 
Unabhängig davon, ob sie abgeschlossen sind oder nicht, läßt sich zusammenfassend über diese bis heute unveröffentlichten Erzählungen sagen, daß sie mit Ausnahme von "Ivolga“, „Lizok“ und „Skazka pro soldata“ den Geschlechtsakt entweder in den Mittelpunkt rücken oder die Erzählung darauf zulaufen lassen. Liebe wird - im Gegensatz zu den Erzăhlungen in den Temnye allei - reduziert auf die physiologischen Funktionen des Körpers, wobei die teilweise drastischen und nüchternen Beschreibungen des Koitus besonders auffällig sind. Des weiteren stehen alle diese Erzählungen in gewisser Weise im Zeichen der Desillusionierung, des Einbrechens der Realităt in die Träume und Vorstellungen eines Teils der Protagonisten - und unterscheiden sich darin von den Erzählungen der Temnye allei, in denen Liebe und Leidenschaft unverhofft den Alltag der Protagonisten durcheinanderwirbeln. Das Schicksal als entscheidendes Moment im Leben eines Menschen tritt in diesen Erzählungen zurück und macht Platz für eine neue Tendenz im schriftstellerischen Schaffen Bunins: der nüchtemen Abbildung der Realität - eine Tendenz, die sich auch in den zahlreichen unveröffentlichten Skizzen und Entwürfen widerspiegelt (vgl. Kap. 3.6).

3.5 Zeitgleich entstandene Erzählungen: Affinitäten und Diskrepanzen zu den Erzählungen der Temnye allei

16 der 38 im Entstehungszeitraum der Temnye allei verfaßten weiteren Erzählungen hätten sich auf den ersten Blick problemlos in das Buch einfügen lassen; der zweite Blick enthüllt indessen bemerkenswerte Unterschiede, die ihre Nichtaufnahme in das Buch rechtfertigen. Neun dieser Erzählungen wurden zu unterschiedlichen Zeitpunkten veröffentlicht, während die anderen sieben zu den bis heute nicht publizierten Erzählungen gehören. Einige dieser Erzählungen hat Bunin in verschiedenen Zusammenstellungen der Temnye allei aufgeführ (vgl. Anhang 2), bevor er sich letztlich gegen eine Aufnahme entschied. Acht weitere Erzählungen lassen sich aus verschiedenen Gründen nicht in das Buch einpassen, während die restlichen 14 Erzăhlungen von einem thematischen Fokuswechsel Bunins künden. Im folgenden werden diese Erzählungen unter dem Aspekt einer möglichen Zugehörigkeit zu den Temnye allei betrachtet und die möglichen Hintergründe ihrer Nichtaufnahme diskutiert. 


\subsubsection{Erzählungen mit starker Affinität zu den Erzählungen der $\underline{\text { Temnye allei }}$}

Bezüglich der Aufnahme einiger dieser überwiegend in den 1940er Jahren entstandenen Erzählungen in das Buch äußerte sich Bunin verschiedentlich, sei es im Rahmen von vorläufigen Inhaltsverzeichnissen, sei es durch Anmerkungen im Gespräch oder als Notiz; einige dieser Erzählungen blieben jedoch trotz starker Ähnlichkeit zu denjenigen der Temnye allei unkommentiert.

Der umfangreichsten Fassung der vorliegenden vorläufigen Inhaltsübersichten zufolge, der vermutlich im Mai 1944 entstandenen Aufstellung, wollte Bunin die folgenden sechs Erzählungen ursprünglich in die Temnye allei integrieren: „Aprel”“ (fertiggestellt am 9. März 1938), „Tri rublja“ (9. Dezember 1940), „Na postojalom dvore“ (27. November 1942), „Lita“ (23. September 1943), „Pamjatnyj bal“ (29. April 1944) sowie „Otec Nikon“ (27. Mai 1944) (vgl. Anhang 2). Außerdem waren die Erzählung „Riv'era“ (10. Januar 1944) und die titellose Erzählung (undatiert) laut Aussagen Leonid Zurovs ${ }^{202}$ bzw. Irina Odoevcevas $^{203}$ zur Aufnahme vorgesehen. Die beiden Erzählungen „Vesnoj, v Iudee“ (1946) und „Noxleg“ (23. März 1949) fügte Bunin vermutlich erst in seinem letzten Lebensjahr den Temnye allei hinzu; diese nachtrăgliche Ergänzung wird in den Kapiteln 3.3 und 4.5 ausfuhrlich diskutiert. Die Integration der sechs unveröffentlichten Erzählungen „Alja“ (16. März 1944204), „Ivolga“ (Oktober/November 1943) „Knjažna Sajtanova“ (undatiert), „Lizok“ (Oktober 1943), „Raisa“ (undatiert) und „Zamužestvo“ (undatiert) schien Bunin trotz offenkundiger Ähnlichkeiten zu keinem Zeitpunkt erwogen zu haben.

Eine mögliche Erklärung für den späteren Verzicht auf die Aufnahme der Erzählung „Aprel” mag darin bestehen, daß es sich hierbei um die Ausführung einer 1926 im Zusammenhang mit der Arbeit an „Mitina ljubov"“ entwickelten Skizze handelt und Bunin daran gelegen war, eine Wiederholung zu vermeiden, zumal er das Thema des Widerstreits zwischen Liebe und Begierde in der Zwischenzeit mit der 1941 entstandenen Erzählung „Natali“" ungleich eindrucksvoller umgesetzt hatte (vgl. Kap. 4.3.3).

Über seine Beweggründe beim Entfernen der Erzählung „Tri rublja“ kann nur spekuliert werden, da sich vom zentralen Thema Liebe über den blitzartigen Moment der Liebeserkenntnis bis zum abrupten tragischen Ende alle Elemente wiederfinden, die die Erzäh-

202 L. Zurov. „lz archiva l. A. Bunina“. In: Nz 68 (1962): 5.

203 1. Odoevceva. Na beregach Seny. op.cit.: 277.

204 Die Erstveroffentlichung der ersten Redaktion dieser Erzahlung erfolgte erst nach Bunins Tod im Nz 68 (1962): 13. 
lungen der Temnye allei ausmachen. Möglicherweise liegt Bunins Entscheidung in der Ähnlichkeit mit der spăter entstandenen Erzählung ,"Madrid““ (26. April 1944) begründet: Beide Protagonistinnen sind als Prostituierte tătig, wobei jedoch die Persönlichkeit der namenlosen Dime, die vom Erzähler in ein Moskauer Hotelzimmer mitgenommen wurde, origineller ist als die des jungen Mädchens, das sich dem Erzähler in einem Hotel in einer Provinzstadt für drei Rubel anbietet. Auch Bunin selbst hat diese Erzählung sehr hoch geschätzt: „... пиша и про девчонку в ,Мадриде‘ [...], я то и дело умиленно смеялся, чувствовал нечто вроде приступа нежных, радостных слез. ‘205

Die Erzählung „Na postojalom dvore“ eröffnete in den an Tèffi und Zajcev geschickten Inhaltsaufstellungen den dritten Komplex, folgte damit unmittelbar auf die anderthalb Jahre zuvor entstandene Erzählung „Natali“ (auch entstehungsgeschichtlich gesehen) und liest sich wie ein Gegenentwurf zu dieser: Während jedoch der Widerspruch von Liebe und Begierde in „Natali“ aufgelöst wird, sieht sich der Jüngling in "Na postojalom dvore“ dem nächtlichen Ansturm seiner fleischlichen Lust hilflos ausgeliefert und verspürt zudem keinerlei zärtliches Gefühl. Die Beschreibung des Koitus, den Bunin brutal in Szene setzt, und die damit einhergehende Betonung desselben passen ebenfalls nicht in die Temnye allei; so erscheint die Erzählung vielmehr als Ausarbeitung der am 18. September 1940 fertiggestellten Erzählung „Durocka“, in der die quälende Lust nicht so ausfuhrlich dargestellt wird. Vor allem durch die minutiōse Schilderung der aufflammenden Begierde, die den Moment in der Wiedergabe ausdehnt, unterscheidet sich diese Erzählung von jenen der Temnye allei. Diese zeitliche Dehnung nimmt dem Geschehen das unerwartet hereinbrechende Schicksalshafte, das für die meisten Erzählungen der Temnye allei kennzeichnend ist.

In der Erzählung „Lita“ wird der frivole Wortwechsel eines Liebespaares am nächtlichen Meeresstrand eingefangen, in dessen Verlauf die Protagonistin das Spiel der Verführung umkehrt und den aktiven Part übernimmt. In eben diesem Verhalten unterscheidet sie sich von den meisten Frauengestalten in den Temnye alle ${ }^{206}$, die überwiegend in der Passivität verharren. Die Konzentration auf einen kurzen Zeitausschnitt und das abrupte Ende der Erzählung mit dem Schlußsatz „Больше все равно ничего не будет“207 (6: 590) fügt

205 Brief an Zajcev vom 25.05.1944. Zit. in: „Pis'ma I. Bunina k B. Zajcevu“. In: Nะ 137 (1979): 136.

206 Gestutzt wird diese Annahme durch die Analyse von $M$. Le Guevel, der diese Erzahlung in seinem Artikel „Lita et la résurrection d'un mythe" analysiert hat (in: Bounine revisité. op.cit.: 91-98).

207 Dieser Satz weckt Ankläge an den Schlußsatz der im darauffolgenden Jahr entstandenen Erzahlung „V odnoj znakomoj ulice“: „Ничего больше и не было“ (6: 332). Far eine ahnliche Schlußgestaltung entscheidet sich Bunin bei dem im Oktober desselben Jahres entstandenen Manuskript "Lizok“; die Erzahlung endete ursprunglich mit dem folgenden Satz: „Но ничего подобного не было. Было вот 4T0" (LRA. MS.1066/166). 
sich zwar gestalterisch in die Kompositionsprinzipien der Temnye allei ein, das Einbrechen der profanen Realität in ein stimmungsvolles Ambiente bricht jedoch die Darstellung und ironisiert das romantische Dekor in einem Maße, wie es in den übrigen Erzählungen des Buches nicht zu finden ist. „Lita“ ist daher eher als Zwischenstufe in der Entwicklung zu den realistischen Momentaufnahmen zu bewerten.

Ähnlich verhält es sich mit der Erzählung „Pamjatnyj bal“: Auch hier geht es um eine grausame Frau, die ihrem verliebten Verehrer kaltherzig eine Abfuhr erteilt. Die romantische Liebeserklärung, auf die die Erzählung zuzulaufen scheint, ersetż Bunin durch den gefuhlskalten Hinweis der angebeteten Frau, daß sie sich durch ihren Bewunderer belästigt fuhle. Auch hier führt also der Einbruch der Realităt zu einer Desillusionierung - ebenso wie in "Otec Nikon" und in der titellosen Erzählung. Die beiden letzteren Erzählungen sind daruber hinaus noch durch das pikante Detail des Geschlechtsakts auf dem Friedhof miteinander verbunden. Abgesehen von der Emüchterung, die in diesen Erzählungen die verliebte Frau bzw. den entflammten Liebhaber ereilt, dürfte Bunin vor allem aus diesen Gründen von einer endgültigen Aufnahme in die Temmye allei Abstand genommen haben. Bezüglich der titellosen Erzählung soll Bunin sich gegenüber Irina Odoevceva folgendermaßen geäußert haben: „Я хотел этот случай в ,Темные аллеи“ включить, да раздумал. Он бы детонировал. Слишком уж, макаберно', возмутил бы святощ - осквернение могилы. Заклевали бы меня за него.“ ${ }^{208}$ Im vollständigsten Typoskript von „Otec Nikon“ hat Bunin eine vorwegnehmende Rechtfertigung der Niederschrift dieser Erzählung plaziert: „A и то сказать: что же они, не люди что-ли, священники-то, и не имеют права любить ${ }^{209}$ Abgesehen von der unvermutet erfolgenden Entzauberung und Banalisierung der Liebe findet sich in beiden Erzählungen das für die Erzählungen der Temnye allei charakteristische thematische Merkmal: die untrennbare Verbindung von Liebe und Tod, durch den Beischlaf auf dem Grab auf die Spitze getrieben.

Schenkt man der Anmerkung Leonid Zurovs anläßlich der Erstveröffentlichung von „Riv'era“ im Novyj žurnal Glauben, hatte Bunin diese Erzählung ursprünglich in die Temnye allei aufnehmen wollen: „Рассказ „Ривьера' Иван Алексеевич хотел включить в книгу ,Темные аллен', но потом раздумал. Оставил его в пакете с ненапечатанными рассказами. “210 Die Beschreibung eines ehebrechenden Liebespaars, das tagsuber in der Offentlichkeit Distanz hält, um abends im schützenden Dunkel einer Allee seinen sexuel-

208 I. Odoevceva. Na beregach Seny. op.cit.: 277.

209 LRA. MS. $1066 / 216$.

210 L. Zurov. .Jz archiva I. A. Bunina“. op.cit.: 5. 
len Gelüsten nachzugeben, enthält zahlreiche der für die Temnye allei typischen Elemente. Die lakonische Schreibweise, wie sie sich beispielsweise in dem folgenden Zitat zeigt, ist jedoch nicht kennzeichnend für den Ton des Buches: „Он кто-то при каком-то министерстве иностранных дел. Она ждет из Парижа мужа. Оба от чего-то отдыхают“ (6: 591). Sie enthüllt nicht nur die Beliebigkeit des Zusammentreffens dieser gutsituierten Erwachsenen, sondern entlarvt gleichermaßen die Fragwürdigkeit dieser Bindung, der unter der glatten Oberfläche der Doppelinoral jegliches echte Gefühl fehit.

Während diese Beobachtungen eine Nichtaufnahme der genannten Erzählungen rechtfertigen, ist es unerklärlich, aus welchen Gründen Bunin die Integration der Erzählung „Alja“ nicht einmal erwog: Sie schildert eine erwachende keusche Liebe, die jedoch durch den Wegzug des Mädchens ihre Blüte nicht mehr erlebt. Ebenso rätselhaft bleibt die Tatsache, daß Bunin die Erzählung "Ivolga“ nicht in das Buch aufnahm. Während sich ein Großteil der unveröffentlichten Erzählungen durch die zentrale Rolle des Koitus auszeichnet, bildet "Ivolga“ eine Ausnahme von dieser Regel, die jedoch trotz ihres abgeschlossen wirkenden Charakters nicht den Temmye allei zugeordnet wurde. Iezuitova konstatient eine Sujetverwandtschaft mit der zwei Jahre darauf entstandenen Erzählung "Čistyj ponedel'nik“ - ihrer Ansicht nach fliehen beide Frauen vor der Liebe des Mannes. ${ }^{21}$ Diese Annahme trifft indes auf keine der Protagonistinnen zu: Wăhrend die junge Frau aus "Ćistyj ponedel'nik“ sich von Anfang an auf der Suche nach Spiritualität befindet, wobei ihr der Genuß der weltlichen Verlockungen lediglich die Richtigkeit ihres Weges bestätigt, scheint sich das junge Mädchen aus „Ivolga“ der Ernsthaftigkeit der Gefühle ihres jungen Verehrers zum Zeitpunkt ihres Erblühens nicht bewußt gewesen zu sein. Wie auch in der Erzählung „Temnye allei“"klärt sich die Situation-diesmal unter umgekehrtem Vorzeichen - im Rückblick, da ihr erst Jahre später klar wird, was sie mit diesen zauberhaften und unbeschwerten Sommertagen verlor, die sie zum Zeitpunkt des Erlebens nicht einmal bewußt wahrgenommen hatte. "Ivolga“ hătte daher ein eindrucksvolles Gegengewicht zu der Erzählung „Temnye allei“ bilden können; zahlreiche nicht eingearbeitete Notizen zu der Erzählung deuten jedoch darauf hin, daß Bunin mit dieser Fassung noch nicht ganz zufrieden war. ${ }^{212}$

Trotz struktureller Ähnlichkeiten unterscheiden sich die vier bis heute unveröffentlichten Erzählungen „Knjažna Sajtanova“, „Lizok“, „Raisa“ und „Zamužestvo“ von denjeni- 
gen der Temnye allei, da in ihnen pure Begierde oder reiner Eroberungswille otme einen Funken Gefuhl oder gar Leidenschaft dominieren.

In „Knjažna Sajtanova“ sucht man vergeblich nach Anzeichen einer Verliebtıeit oder eines „magischen“ Augenblicks dieses auch für einige Erzăhlungen der Temmye dlei typischen sexuellen Abenteuers während einer Reise. Ähnlich wie in „Riv'era“ brict Bunin die Erzăhlung ab, als es zu den ersten Initimităten kommt, ohne daß dem Leser di: Einzigartigkeit dieses Erlebnisses vor Augen gefuhrt würde.

Die Erzählung "Lizok“ erinnert in Zügen an „Lita“, wenn auch keine bewußte Verkehrung der Verführung ersichtlich wird, die den eigentlichen Verführer zum Opter seiner dunklen Plăne werden läßt. Von besonderem Interesse ist ein ursprünglich hinzagefügter Epilog, der an den Schlußsatz der Erzählung „V odnoj znakomoj ulice“ erinnert (,Больше ничего не помню. Ничего больше и не было“, 6: 332) und den potentiellen Velauf dieses Flirts andeutet:

Всякий подумает: Ну, дальнейшее не трудно угадатъ. Всякнй решит, что в конце концов я влюбил в себя и сделал несчастной, что она погибла, что ее логибель погубила и мою жизнь - и тому подобное. Но ничего подобного не было. Было вот что. .213

Im Unterschied zu den Erzählungen der Temnye allei verblüfft die ironische Brechung der Geschehnisse - vergleichbar der generalisierenden und damit banalisierenden Zeichnung der Protagonisten in „Riv'era“-, spricht doch im Gegensatz zu „V odnoj znakomoj ulice" aus diesen Worten eine gewisse Gekränktheit über die Umkehrung des beziehungsinternen Machtverhältnisses. Auch wird die Liebe in dieser Erzählung nicht als iberwältigende Himmelsmacht dargestellt, sondern vielmehr als kühle Berechnung - und muß möglicherweise aus diesem Grund scheitern, so daß dieses Erlebnis das Leben des Erzählers in keiner Weise beeinflußt.

Berechnung kennzeichnet auch die Beziehungen, die in den Erzählungen „Raisa“ und „Zamužestvo“ eingegangen werden - in diesem zentralen Punkt unterscheiden sie sich trotz motivischer Ähnlichkeiten von den Erzählungen der Temnye allei. Zwar illustrieren auch verschiedene der im Buch enthaltenen Erzăhlungen Bunins Ansicht, daß Liebe und Ehe einander ausschließen - sei es durch den plötzlichen Tod eines der Partner (z.B. „V Pariže“, „Cholodnaja osen'“) oder durch die Darstellung unglücklicher Ehen (z.B. „Kavkaz“, „Dubki““, „Voron“). Diese ehelichen Bindungen stehen jedoch nicht im Zentrum der Aufmerksamkeit, sondern bilden den kontrastierenden Hintergrund für eine lei- 
denschaftliche Liebesbeziehung eines der Ehepartner mit einer außenstehenden Person. Während es Raisa ihren hehren Gefühlen am Tag der Hochzeit zum Trotz voraussichtlich gelingen wird, aus ihrer Ehe auszubrechen, mutet „Zamužestvo“ wie eine Opferung an. Bunins Auffassung der Amoralität und Widernatürlichkeit einer Heirat ohne Liebe spiegelt sich wider in der abstoßenden Darstellung des Ehemanns beim Geschlechtsakt: „Страшный испуг в мннуту соития: у него вдруг раздулись ноздри, с мукой стиснулись в рыжей бороде оскаленные зубь, исказилось лицо, глаза помертвели, закатились как у зарезанного. 214

\subsubsection{Erzählungen ohne Bezüge zu den Erzählungen der Temmye allei}

In diese Kategorie fallen insgesamt acht Erzăhlungen, die zwischen 1936 und 1949 entstanden sind. Während sich die drei Erzăhlungen „Molodost' i starost”“ (1936), „Skazka pro soldata“ (1943) und „Poludennyj zar" (1947) durch ihren gleichnis- bzw. märchenhaften Charakter von den Erzählungen der Temnye allei unterscheiden, zeichnen sich die übrigen fünf Erzählungen durch die Wiedergabe von Reflexionen über das Leben und das menschliche Wesen als solches aus.

Die Erzählung „Molodost' i starost”“ eröffnet unter ihrem ursprünglichen Titel „Pro obez'janu“" den dritten Komplex der 1941 erstellten Übersicht über den Inhalt der Temnye allei, die Bunin mit einer Publikationsvollmacht an Mark Aldanov schickte (vgl. Anhang 2, Stand Frühjahr 1941). In der 1943 erschienenen ersten Druckfassung der Temnye allei findet sie sich allerdings nicht wieder; auch in die späteren Zusammenstellungen wird sie nicht aufgenommen. Möglicherweise wurde Bunin im Laufe der Jahre klar, was Aldanov vermutlich nach Erhalt des Manuskripts erkannte: Das in dieser Erzählung enthaltene Gleichnis über die verschiedenen Entwicklungsstadien im Leben eines Menschen bietet keinerlei Berührungspunkte mit den Themenbereichen der Temnye allei.

Die beiden Erzählungen „Skazka pro soldata“ und „Poludennyj zar" waren zu keinem Zeitpunkt zur Aufnahme in das Buch vorgesehen. Das Märchen "Skazka pro soldata“ gehört einer Gattung an, die in den Temnye allei nur ansatzweise mit der Erzählung „Železnaja Šerst”“ vertreten ist: Während jedoch die märchenhaften Elemente in der unveröffentlichten „Skazka pro soldata“ im Vordergrund stehen, treten sie in „Železnaja 
Šerst"“ zugunsten der Liebesgeschichte in den Hintergrund. Die Begegnung mit dem Übersinnlichen dominiert auch die Erzählung „Poludennyj zar": Die partiell unwahrscheinlich klingende Lebensgeschichte der „durocka Glasa“ erinnert entfernt an die in den Temnye allei enthaltene Erzählung „Ballada“, läßt jedoch wie „Skazka pro soldata“ die Liebesthematik vermissen, die in „Ballada“ ausgeprägter zutage tritt.

Weitere fünf Erzählungen, die allesamt veröffentlicht vorliegen, fügen sich ebenfalls aus inhaltlichen Gründen nicht in die Temnye allei: „Mistral”“ (1944), „V kanavu!“ (12. Dezember 1944), „V Al'pach“ (1949? $\left.{ }^{215}\right)$, „Legenda“ (1949) sowie die undatierte Erzăhlung „Na izvozzike“.

„Mistral"“ knüpft in wesentlich kürzerer Form thematisch an den 1925 publizierten philosophischen Monolog „Nox'““ (ursprünglicher Titel „Cikady“) an: Während der Mistral um das in năchtlicher Dunkelheit liegende Haus tost, denkt der schlaflose Erzăhler, angeregt durch verschiedene religiöse Zitate, über den Sinn und Lauf des Lebens nach. Diese Erzählung, die Bunin zur Aufbewahnung an Boris Zajcev schickte, ohne sie jedoch in eine vorläufige Zusammenstellung des Inhalts der Temmye allei aufzunehmen, veranlaßte den Freund zu höchstem Lob:

Друг, „Мистраль“ - великолепно! „Принадлежит к лучшим партиям гроссмейстера“ (так пишут о шахматах). Нет, серьезно: это даже выше „Холодной осени". Какая-то совершенно особенная, твоя линия, необыкновенно тебе удающаяся ... ${ }^{216}$

Auch die im selben Jahr entstandene kurze Reflexion „V kanavu!“ war nicht zur Aufnahme in das Buch vorgesehen. Bunin kommentiert darin verschiedene typische menschliche Äußerungen und schließt mit der Einsicht: „Более сладострастного создания, чем человек, нет на земле. ${ }^{\text {“217 }}$ Die Impression einer dunklen Herbstnacht, ausgelöst durch den verloren wirkenden Scheinwerferstrahl eines Autos, ist in der kurzen Beschreibung „V Al'pach" festgehalten.

Die undatierte und unvollendete Erzählung „Na izvozzike“ weist zwar einen Handlungsstrang auf, ist aber von dialogischen Reflexionen über die Vergänglichkeit des Lebens und die mogliche Unvermitteltheit des Todes geprägt. Inhaltlich erinnert sie an die 1923 entstandene Erzăhlung „Ogon’ požirajušij“. In seinem Vorwort zur Publikation bis

215 Undatiertes Typoskript in der RGB; Datum enstammt der jungsten Werkausgabe (6: 582).

216 Brief an Bunin vom 27.11.1944. Zit. in: „Pis'ma B. K. Zajceva K I. A. i V. N. Buninym“. In: Nz 140 (1980): 159.

217 Ju. Mal'cev. „Neizvestnye rasskazy I. A. Bunina“. In: Nz 168-169 (1987): 79. 
dahin unveröffentlichter Erzählungen im Novyj zurnal stellt Jurij Mal'cev die These auf, daß Bunin diese Erzählung im Oktober 1939 geschrieben habe, nach einer erneuten Lektüre von Lev Tolstojs Erzählung „Smert' Ivana Il'iła“. Er sieht darin eine polemische Antwort Bunins auf Tolstojs Glauben an die Unsterblichkeit, der er die eisige Kälte des Unglaubens entgegensetzte $e^{218}$, indem er einem der beiden Dialogpartner den folgenden Kommentar zu Tolstojs Erzählung in den Mund legte:

Неплохо написано, а в итоге все-таки ерунда. Ивану Ильичу ужасно было умирать, видите ли, потому, что он как-то не так прожил жизнь. Нет, Лев Николаевич, как ее ни проживи, смерть все равно. Несказанный ужас. ${ }^{219}$

\subsubsection{Erzählungen, die eine neue Tendenz im Schaffen Bunins ankündigen}

14 Erzählungen, die teils zu Bunins Lebzeiten, teils nach seinem Tode veröffentlicht wurden, kündigen einen künstlerischen Wechsel im Schaffen Bunins an, bei gleichzeitiger Rückkehŕ zu den Gestaltungsprinzipien der Anfang der 1930er Jahre verfaßten „Kratkie rasskazy“. Waren jene noch geprägt von kurzen und prägnanten Momentaufnahmen, zeigt sich nun ein Wechsel zu szenischer Gestaltung. Im besonders produktiven Jahr 1944 schrieb Bunin neben 13 Erzählungen, die Eingang in die Temnye allei fanden, weitere 18 Erzählungen, von denen 12 sowohl inhaltlich als auch formal eine neue Tendenz einleiten: „Un petit accident““ (12. Januar), „Achmat“ (18. April), „Au secours!“ (18. April), „Alupka“ (21. April), „Kogda ja vpervye““ (22. April) „Krem Leodor“ (22. April), „Novaja šubka“ (2. Mai), „Dalekij požar“ (4. Mai), „Pis'ma“ (15. Oktober), „Kibitka“ (16. Oktober), „Modest“ (16. Oktober), „Marija Stjuart“ (1944). Einzig die ebenfalls in diese Rubrik fallenden Erzählungen „Dura“ (21. September 1943) und „,V takuju noð’ ...“ (20. September 1943) verfaßte Bunin im Jahr zuvor. In dem vorläufigen Inhaltsverzeichnis, das Bunin 1944 an Boris Zajcev schickte (vgl. Anhang 2, Stand ca. Mai 1944), ordnet er die folgenden Erzählungen dem dritten Komplex zu, entfernt sie spăter jedoch wieder: „,V takuju noc' ...“, „Achmat“, „Au secours!“, „Alupka“, „Kogda ja vpervye““, „Krem Leodor“, „Novaja Šubka“ und „Dalekij požar“. Bei einer Betrachtung der Entstehungsdaten fällt auf, daß sieben dieser Erzählungen im April bzw. Mai 1944 entstanden-leider finden sich

218 Ju. Mal'cev. „Neizvestnye rasskazy I. A. Bunina“. op.cit.: 65.

$219 \mathrm{Ju}$. Mal'cev. „Neizvestnye rasskazy I. A. Bunina“. op.cit.: 72. Mal'cevs Wiedergabe des letzten Satzes dieses Zitats entspricht nicht dem Manuskript. Die entsprechende Passage lautet wie folgt: „Her, ЛeB Николаевич, как ее ни проживи, смерть все равно несказанный ужас" (LRA. MS. 1066/194). 
keine diesbezüglichen erlăuternden Tagebuchaufzeichnungen Bunins, dafür jedoch folgende Notiz vom 28. April 1944:

„Ночевала тучка золотая“, „Белеет парус одинокии““ [...] и т[ак] д[алее]. Разве это не целые рассказы? Почему же пишущим прозой не писать рассказа в 10, 20, 100 строк? Почему скульттор может изваять женщину, девочку, юношу, живописец написать портрет, пейзаж, двух пьяных в кабаке, а я не имею права делать то же самое словами и только этим ограничиваться? ${ }^{220}$

Diese in der Regel nicht mehr als eine gedruckte Buchseite umfassenden Momentaufnahmen geben überwiegend Gespräche zwischen einem Mann und einer Frau wieder. Ausnahmen bilden lediglich die Erzăhlungen ,.Un petit accident'“, „Marija Stjuart“ und "Modest", die reine Beschreibungen ohne Handlung enthalten. „Un petit accident"“ schildert den fließenden Straßenverkehr im abendlichen Paris ${ }^{221}$, der plötzlich ins Stocken gerät: Ein junger Mann ist tot über seinem Lenkrad zusammengebrochen. Interessant ist der urspriingliche Schlußsatz des Manuskripts („Капли ,Sevesexe' [...] оказались слишком сильны, несмотря на еrо молодость. ${ }^{.222}$ ), der der Erzählung eine sexuelle Note verleiht und damit suggestiv den Auslöser für die möglicherweise todbringende Medikamenteneinnahme in den zwischenmenschlichen Bereich verlagert. „Marija Stjuart” und „Modest“ hingegen enthalten Personenbeschreibungen: Wăhrend „Marija Stjuart“ das schonungslose Bild einer alternden und abgehalfterten Schauspielerin zeichnet, die dennoch über diverse Liebhaber verfügt, werden in "Modest“ ein Pferdehändler und seine Geliebte porträtiert. Hierin ähneln sie den Erzählungen „Kamarg“ und „Sto rupij“, die sich ebenfalls nicht so recht in die Temnye allei einfügen (vgl. Kap. 4.4.2), so daß Bunin möglicherweise aus diesem Grund auf die Aufnahme weiterer derartiger Erzählungen verzichtete.

Dic übrigen zu dieser Kategorie gehörenden Erzählungen ähneln sich in ihrem dialogischen Aufbau, unterscheiden sich jedoch graduell durch die Heftigkeit der wiedergegebenen Szene, so daß sie sich in die Kategorien „gewöhnliche Gespräche“ und „Streitgespräche" unterteilen lassen.

Abgesehen von der Erzählung „Achmat", in der ein alter Kaufmann in monologischen Erinnerungen an seine wilden Zeiten als Lüstling schwelgt, bestehen die übrigen genann-

220 Notebook Nr. 2 [Zapiski, zametki]. LRA. MS.1066/548.

221 Die Interpretation Ju. Ivasks, der in dem Sonnenuntergang ein Symbol fur den Niedergang des Westens zu sehen vermeint, ist fragwürdig; bemerkenswert ist jedoch, daB diese Erzahlung zu den wenigen mit einer eindringlichen Stadtbeschreibung gehort (vgl. Ju. Ivask. „Bunin“. In: Nż 99 [1970]: 120).

222 LRA. MS. 1066/305. 
ten, sehr kurzen, teils skizzenhaften, teils szenischen Erzăhlungen hauptsächlich aus einem Dialog zwischen einem Mann und einer Frau: „V takuju nox' ...“" enthält die Wiedergabe des Gesprăchs eines Liebespaares während eines năchtlichen Spaziergangs, „Novaja subka“ gibt einen Dialog zwischen einem Mann und einer kapriziősen Frau wieder, während „Dalekij požar" das Liebesgeflüster eines Paares in der nächtlichen Steppe einfängt, deren philosophisch anmutende Überlegungen zur Vergänglichkeit der Liebe in der an die Erzählung „Temnye allei“ erinnemden Aussage gipfeln: „Bce пройдет“ (6: 597). „Pis'ma“ zeigt ein Liebespaar, das sich gemeinsam über die flehentlichen Liebesbriefe des verflossenen Geliebten der Frau lustig macht, und „Kibitka“ enthält ein kühles Verhandlungsgespräch zwischen einer Zigeunerin und einem Halbwüchsigen, dem sie sexuelle Befriedigung gegen Geld verspricht, um ihn letztlich zu narren. In "Dura“ schließlich wird das scheinbar menschenfreundliche Tun des Dorfschullehrers entlarvt als schamloses Ausnutzen seiner Stellung. ${ }^{223}$

Ein heftigerer Tonfall kennzeichnet die übrigen Erzăhlungen: Während „Alupka“ ein gewöhnliches, streitendes Paar im Urlaub zeigt, wird in der Auseinandersetzung eines Ehepaars in ".Kogda ja vpervye ..."“ bewußt verletzender Zynismus laut. Der Konflikt eines weiteren Paares eskaliert in der Erzăhlung "Au secours!", ohne daß der Anlaß verdeutlicht würde. Auch die Erzählung „Krem Leodor" ist von Disharmonie geprägt. Der Grund für Bunins Interesse am detaillierten Einfangen derartiger Momentaufnahmen kommt in einer lakonischen Bemerkung zum Ausdruck, die er dem Typoskript von „Krem Leodor" beifügte, bevor er es an Sof'ja Pregel' zur Veröffentlichung in der Zeitschrift Novosel'e schickte: „Дорогая Софья Юлевна, вот все, что могу сейчас предложить. Думаю, что это довольно страшная история, одна из тех, которыми переполен мир. Не понравится - не печатайте. ${ }^{.224}$

Zusammenfassend läßt sich zu diesen zeitgleich mit den Temnye allei entstandenen Erzählungen festhalten, daß sie im Unterschied zu den im Buch enthaltenen Erzăhlungen die Protagonisten ernüchtert bzw. berechnend statt verzaubert zeigen und dem Leser ein-

223 lezuitova, die sich bei ihrer Beurteilung der Erzahlung an eine komische Genrestudie im Sinne Cechovs bzw. an ein naturalistisches Bild erinnert fuhlt, dem der ...temnoallejnyj" duch" fehle, muß entschieden widersprochen werden, denn eine solche Einordnung verharmlost diese Darstellung einer sexuellen Notigung in unangemessener Weise. Im Unterschied zu den in den Temmye allei enthaltenen vergleich. baren Erzăhlungen wie „Stepa“ oder „Gost' wäre die Frau selbst im Rockblick nicht in der Lage gewe. sen, zartliche Gefuhle zu entwickeln, da sie des ihr angetanen Unrechts offenbar gar nicht gewahr wurde (vgl. L. lezuitova. „V poiskach vyraženija ...“. op.cit.: 223 ).

224 RGALI. Fond Nr. 44 (1. A. Bunin), opis' Nr. 4, edinica chranenija Nr. 27. 
mal mehr die Unvereinbarkeit von Liebe und Alltag vor Augen fuhren. Diese Momentaufnahmen haben eine deutlich andere Qualität als jene Augenblicke des Glücks, wie sie für die Temnye allei kennzeichnend sind. In diesen Erzählungen deckt Bunin die Abgründe auf, die im Alltagsleben lauern und die die Protagonistin in „Dalekij požar“ vorauszuahnen scheint: „Все пройдет! Все пройдет: и моя любовь, и этот пожар, и эта прекрасная и оттого такая печальная ночь“ (6: 597). In diesem Zusammenhang stellt sich die Frage, ob Bunin auf Grund der ihn in der Entstehungszeit der Erzählungen erreichenden negativen Reaktionen auf einige der späten Erzählungen (vgl. Kap. 10.1.1) beschlossen hat, die Erzählungen mit ausgeprägtem sexuellem Inhalt für ein gesondertes Buch aufzubewahren. Möglicherweise kam Selbstzensur zum Tragen. Eine Gesamtschau der Erzählungen vermittelt den Eindruck, als hätte Bunin das Thema Liebe von allen Seiten beleuchten, sowohl die körperliche als auch die geistige Dimension deutlich machen wollen. So groß der Trennungsschmerz in vielen Erzählungen der Temnye allei auch sein mag, einen bitteren Nachgeschmack hinterläßt keines der amourösen Zusammentreffen; im Gegenteil, im Rückblick gewinnt das Erlebnis in der Regel an Tiefe. Hingegen dominiert in den unveröffentlichten bzw. spăter veröffentlichten Erzăhlungen der Trieb - die dunklen Wege der Liebe werden um die Darstellung ihrer Abgründe (blinde Begierde, Zukunftslosigkeit der Liebe im Alltag) ergănzt, das Bild abgerundet und vervollständigt durch die ebenso dazugehörige physische Komponente. Die dunkle Seite der Liebe, die seelischen Abgründe, die Schicksalsschläge zeigt Bunin zwar auch in den Temnye allei, nach Lektüre dieser Erzählungen und Skizzen stellt sich jedoch die Frage, ob die wahre verhängnisvolle Seite der Liebe nicht vielmehr in den Fallstricken des Alltags lauert.

3.6 Exkurs: Blick in die Werkstatt - Notizsammlungen, Entwilrfe, Skizzen

Die im vorangehenden Kapitel konstatierte neue Tendenz zeigt sich darüber hinaus in weiteren unveröffentlichten Materialien. Nach dem Ende des Krieges ist Bunin nur noch in eingeschrănktem Maße schöpferisch tătig und beklagt in einem Brief an Aldanov vom 23. August 1947 die Einbuße seiner Kreativităt:

И клянусь Вам-никогда я ничего не записывал; последние годы не мало записал кое-чего в записных книжках, но не для себя, а „для потомства“ - жаль, что многое из народного и вообще прежнего языка и быта уже забыто, забывается; есть у меня и много других записей-лица, пейзажи, девочки, 
женщины, погода. сюжеты и черты рассказов-которые, конечно, уже никогда не будут написаны, - я, верно, „уже откупался“. 225

Das LRA verwahrt zahlreiche dieser in Mehrzahl undatierten und unveröffentlichten Notizbücher Bunins sowie Sammlungen loser Blätter, die unmißverständlich verdeutlichen, daß die Gründe für sein diesbezügliches negatives Empfinden schwerlich in mangelnden Ideen oder fehlendem Material zu suchen sind. Aus welchen Gründen auch immer Bunin nur noch wenige Erzählungen fertigstellte, beim Schreiben kam es ihm auf jedes Wort an; ihm waren nicht nur die Detailgenauigkeit und korrektes Zeitkolorit ausgesprochen wichtig, sondern auch der Rhythmus der Wörter, wie er in einem Brief an Boris Zajcev vom 21 . November 1943 mit Bezug auf die Temnye allei erläuterte:

[...] я тебе писал, что почти вся книга есть у моего американского издателя, но в текстах не окончательно исправленных, тогда как теперь я их, мне кажется, уже совсем, совсем исправил (в мелочах, разумеется, но ты ведь знаешь, что порой десять неверных или лишних слов портят всю музыку, как портят ее тупые переводы). ${ }^{226}$

Von diesem Streben nach Präzision zeugen auch die erwähnten Listen mit Zusammenstellungen kleiner Skizzen und kurzer Beschreibungen zu verschiedenen Themenbereichen, die sich zum Teil in Erzählungen der Temnye allei wiederfinden; die Fokussierung auf Beschreibungen von Frauen, Naturbeobachtungen und Notizen zum Tod entspricht dem Gewicht dieser Bereiche im Buch. Einige dieser Beschreibungen wurden auf den Listen ausgestrichen und mit der Randbemerkung „vzjato“ versehen. Zu den umfangreichsten Verzeichnissen gehört die 22 Seiten umfassende Sammlung von Skizzen verschiedener Frauentypen (,Ženšxiny, devuški, devocki“"): Sie enthält zahlreiche konzise Beschreibungen von Mädchen, Nonnen, Schauspielerinnen, Tänzerinnen, Huren, die Bunin in wenigen prägnanten und treffenden Worten lebendig werden läßt, wobei er nicht allein das Aussehen, sondern auch Eigenschaften festhält. Auffallig ist seine Konzentration auf ein genaues Erfassen von Haaren, Augen und Busen - und die vergleichsweise seltenen Darstellungen älterer oder gar alter Frauen. Bunins besonderes Interesse gilt vor allem Mädchen und jungen Frauen, wie in den folgenden Beispielen: „Лет двенадцати. Запавшие грозно печальные глаза, пепельное личико. Похожа на мертвую в гробу“ oder: .В баре. Девушка, похожая на красивого молодого человека типа Байрона. 
Стриженная, в пиджаке. Лицо, шея, волосы-все молодое, благородное“ oder: „Лежит на оттоманке. Ногти крашены кармином.“227

Wer aus dem zahlenmäßigen Überwiegen russischer Schauplätze in den Erzählungen der Temnye allei (vgl. Kap. 5.5) und Bunins Weigerung, in einer anderen als der russischen Sprache zu publizieren, schließen wollte, daß der Schriftsteller sich seiner französischen Umgebung gegenüber indifferent verhielt, wird durch die Lektüre der umfangreichen Skizzenpakete „K Parižu“ (8 Seiten) und "Iug" (30 Seiten, teilweise beidseitig beschriftet) eines Besseren belehrt: Hier finden sich zahlreiche Notizen etwa zu landesüblichen Mahlzeiten und Gebräuchen, Sprichwörter und Hotelnamen sowie Impressionen aus Paris, Südfrankreich und Italien. Der Grund für die Zeichnung überwiegend russischer Protagonisten liegt in der Tatsache begründet, daß ihm die Mentalität der Franzosen fremd blieb, so sehr er sich auch darum bemühte, diese zu verstehen, wie er in einem Gespräch mit Galina Kuznecova bekannte:

Я ведь все-таки, по совести, не могу написать о таком Жозефе или Жанне потому, что не знаю их души. А я ужасно хочу написать о них - ведь Франция для нас теперь вторая родина .... 228

Neben Wetterbeschreibungen („Zimnjaja noč, očen' snežno ...“) sind auch einige Naturskizzen erhalten geblieben, die sich wie Schauplatzanweisungen in einem Drama bzw. Drehbuch lesen und für die Anfänge zahlreicher spăter Erzăhlungen typisch sind (vgl. Kap. 5.2). Dort finden sich lokalisierende Momentaufnahmen wie beispielsweise die folgenden: „Миндальный запах цветущей сирени“, „Ледяной вечер. Поле. Красноапельсинная полоса зари над синевой земли на горизонте“, „Раннее утро, розовый туман, его свежнй, мятный запах “229, aber auch Orts- und Lichtbeschreibungen, die wie hingetuscht wirken: „Абрикосовый цвет спеющей ржи“, „Облака как свинцовые белила“, „Лунные слезы в море.“230

Darüber hinaus hat Bunin auch eine Reihe von Skizzen um das Todesthema angefertigt (,Bol'కoe kladbił̌ce $v$ stenach““231), die Beschreibungen von Friedhöfen, Grabstătten, Trauergottesdiensten und Beerdigungsritualen enthalten. Unter diesen Notizen befinden

227 LRA. MS. 1066/702, 22 Seiten.

228 Tagebucheintrag G. Kuznecovas vom 31.07.1927. In: dies. Grasskij dnevnik. op.cit.: 35.

229 „Vemulcja $v$ usad'bu pozdno ...“. Notes. LRA. MS. 1066/658.

230 "Zimnjaja noz”, ozen' snežno ...“. Notes. LRA. MS.1066/659.

231 Notes. LRA. MS. $1066 / 568$. 
sich auch das Protokoll des Sterbeprozesses eines kleinen Jungen und die Darstellung der tröstlichen „Begegnung“ eines traurigen Mannes mit seinem verstorbenen Vater. In seinem letzten Lebensjahrzehnt beschäftigte Bunin stärker denn je zuvor der unauflösbare Konflikt zwischen der Schönheit des Lebens und der Unausweichlichkeit des Todes, den darzustellen ihm ein besonderes Bedürfnis war:

Все думаю о краткости и ужасах жизни. [...] как скоро пройдет их молодость, начнется увядание, болезни, потом старость, смерть ... До чего несчастны люди! И никто еще до сих пор не написал этого как следует! $!^{232}$

Eine Möglichkeit, diesem Ringen Ausdruck zu verleihen, muß er in der kontrastreichen Gegenüberstellung des blühenden Lebens zum Nichts des Todes gesehen haben, die auch für zahlreiche Erzählungen der Temnye allei charakteristisch ist.

Neben diesen losen Sammlungen blieben verschiedene Hefte erhalten, mit Notizen zu allen möglichen Themenbereichen, die zum Teil in den Temnye allei verwendet wurden. Hierzu gehören beispielsweise Auflistungen von Farbnuancen (vgl. Kap. 6.2), Namen für Protagonisten unterschiedlicher nationaler Herkunft, Fahrtrouten von Zügen im zaristischen Rußland, aber auch Zusammenstellungen veralteter und zunehmend ungebräuchlicher russischer Wörter und frivoler Verse sowie Entwürfe verschiedener Erzählungen.

Nach 1949 schreibt Bunin keine Erzählungen mehr; daher steht zu vermuten, daß die in der Folge vorgestellten Entwürfe und Skizzen in Übereinstimmung mit dem oben erwähnten Brief an Aldanov aus den 1940er Jahren (vermutlich nach 1944) stammen. Zu den wenigen veröffentlichten Skizzen gehört „Spjat $v$ odnoj komnate ${ }^{\text {“233 }}$, die Beschreibung eines inzestuösen Beischlafes zwischen Bruder und Schwester. Der Bruder hatte sich ursprünglich mit der Absicht, seine aus Liebeskummer weinende Schwester zu trösten. zu jener ins Bett gelegt. Die zärtlichen Küsse gehen unmerklich in intimere Liebkosungen über, die Bunin zwar nicht explizit beschreibt, über deren Natur nach der Lektüre des Schlußsatzes beim Leser jedoch keinerlei Zweifel besteht: „[...] и все произошло само собой. с горячей, порывистой нежностью, счастьем и жалостью, горем. Самая прекрасная за всю жизнь любовь. “234 
Der Großteil der unveröffentlichten und in der Regel undatierten (da nicht abgeschlossenen) Skizzen und Entwürfe blieb jedoch unveröffentlicht, wie auch die sechs im folgenden stellvertretend vorgestellten Manuskripttexte:

- Die unvollständige Skizze „Ee chvatilo tol'ko na menja odnogo“ liest sich wie eine Illustration von Bunins Annahme, daß es in der Jugend eines jeden Menschen eine Zeit gäbe, in der ihm alles möglich und eine Ewigkeit vor ihm zu liegen scheint. Die junge Frau in diesem Entwurf erlebte ihre Blüte, ohne sich dessen bewußt zu sein, daß es ihre einzige sein würde - und starb. Der Witwer fuhlt sich durch sein Beteiligtsein an ihrem Schicksal mitschuldig an ihrem Tod-und an ihren betrogenen Hoffnungen auf die Wunder des Lebens.

- Die sechs Skizzen unter dem zusammenfassenden Titel „Ego zapiski“ (zuvor: „Zapiski chudožnika") enthalten knapp gefaßte Beschreibungen weiblicher Körper und Erinnerungen eines namentlich nicht näher bezeichneten männlichen Erzählers an sexuelle Begegnungen mit verschiedenen Frauen.

- Im Mittelpunkt der unvollständigen Erzăhlung „Spal'nja byla v uglovoj komnate ...“ steht eine leidenschaftliche Liebesnacht: Ein junger Mann betrachtet eine junge Frau im gemeinsamen Schlafzimmer mit dem Wissen, daß sich in absehbarer Zeit die sexuelle Vereinigung vollziehen wird. Der Teil des Manuskripts, der die Beschreibung des Koitus enthielt, wurde offensichtlich entfernt; der Erzählfaden wird nach Vollzug wieder aufgenommen, als beide erschöpft auf dem Bett liegen und der Mann die in ihm einkehrende Sanftmut nach der „zverstvo“ genießt.

- Der Entwurf „Stisnuv zuby $v$ poslednjuju minutu ...“ setzt ein nach Beendigung des Beischlafs und gibt die Gedanken des Mannes wieder, der von seiner Geliebten vor die Tür geschickt wurde, damit sie postkoitalen Verrichtungen nachgehen kann. Sein intensives Erleben der ihn umgebenden Nacht weckt in ihm die Sehnsucht nach einer Fortsetzung der intimen Zärtlichkeiten. Nach seiner Rückkehr ins Zimmer läßt er seine von Bunin detailliert beschriebenen Verfuhrungskünste erneut ihre Wirkung tun.

- Die Skizze „Do 15 let vyros oxen' nemnogo ...“ schildert die erwachende Sexualität eines schwerkranken Halbwüchsigen, der eine Leidenschaft für die Heilige Marija Egipetskaja entwickelt. Die Vorstellung, wie diese lediglich von ihren Haaren umhüllt durch die Wüste wandert, laßßt ihn nicht mehr los, und er bittet seine Mutter, ihm ein Buch uber ihr Leben zu besorgen. Seine unruhige und ungeduldige Erwartung ihrer 
Rückkehr hat einen eindeutig sexuell geprägten Hintergrund, den nur der Schlußsatz des Manuskripts enthüllt, während er im Typoskript fehlt: „Уже рукоблудствовал.“235

- Die Miniaturerzählung „Zimnjaja noč”, očen’ snežno ...“ schildert das Schäferstündchen eines Paares während einer Schlittenfahrt durch eine zauberhafte Winterlandschaft. In diesem Fall erfolgt die Beschreibung der sexuellen Nähe indirekt: Der Mann öffnet den Waschbärpelzmantel der Frau, um sich dann zwischen ihre gespreizten Beine zu legen. Mit ihrem glücklichen Lächtin und dem gleichzeitigen Verzicht auf Fragen nach der zukünftigen Entwicklung ihrer Beziehung verwirn sie ihren Liebespartner und läßt damit diese Skizze zu einem Plädoyer für das Leben im Augenblick werden.

Aller Wahrscheinlichkeit nach entstanden diese Texte, nachdem der Großteil der die Temnye allei konstituierenden Erzählungen fertiggestellt war, da sie - ähnlich wie die unveröffentlichten Erzählungen - eine neue Tendenz erkennen lassen, wie Claire Hauchard zutreffend feststellt, wobei ihre Anmerkung, daß diese Erzählungen zunehmend pornographische Züge annehmen würden, einseitig ist und falsche Erwartungen weckt:

Un courant expressioniste se manifeste dans ces derniers récits. Les scènes érotiques. beaucoup plus osées que dans les Allées sombres frôlent la pornographie, allant jusqu'à présenter l'acte de copulation sous une lumière crue. [...] Bounine se tourne vers une esthétique de la laideur, et, sans la moindre émotion apparente, sans le moindre commentaire, il s'attache à représenter les hommes dans leur mesquinerie, leurs mensonges, et leurs instincts les plus bas. ${ }^{236}$

Es ist offenkundig, daß Bunins Blick auf physische Details unbestechlicher geworden ist - die Erzählung „Baryšnja Klara“ mit ihrer unbarmherzigen Beschreibung des alternden Körpers der Kurtisane deutet diese Entwicklung bereits an -, und es läßt sich auch nicht leugnen, da $\beta$ er die Liebe vor allem in ihrer körperlichen Dimension beschreibt und dabei physische Details nicht ausläßt, wobei ihm seine Darstellungen indes weder primitiv noch voyeuristisch geraten (vgl. Kap. 8.1.2). Er begibt sich auf den gefährlichen Drahtseilakt, die rechte Balance zu finden zwischen dem Abgleiten in die Pomographie und der Gefahr, die Darstellung der körperlichen Liebe zu technisch, zu medizinisch geraten zu lassen. Die Frage nach der Natur der körperlichen Liebe beschäftigt Bunin schon seit langem („Coitus - восторг чего? Саморождения? Напряжения жизни? Убийства смерти? ${ }^{4237}$ ), 
doch erst jetzt findet er den Mut, physische Intimität nicht nur anzudeuten (wie in den Erzählungen der Temnye allei), sondern den Versuch zu unternehmen, sie zu beschreiben. $\mathrm{Da}$ er diese Erkundungen nicht mit seinem Publikum teilte, mag zum einen daran gelegen haben, daß er mit seinen Ergebnissen unzufrieden war, zum anderen, daß seine Selbstzensur ihn vor vernichtenden Urteilen warnte (vgl. Kap. 10), wie sie einige Erzählungen der Temnye allei trafen, und er es vorzog, seine tastenden Erforschungen unbehelligt von der Öffentlichkeit durchzufuhren. ${ }^{238}$ Die Diskrepanz zu bzw. der Bruch mit den herrschenden Moralvorstellungen jener Zeit wird um so augenfälliger, je detaillierter die Nuancen der sexuellen Begegnungen herausgearbeitet werden. Bunin zeigt, daß sich Liebe und Begehren nicht nach gesellschaftlichen und moralischen Regeln richten - die elementaren Kräfte des Lebens lassen sich in kein vom Menschen aufgestelltes Schema pressen.

\subsection{Zusammenfassende Betrachtung}

Die bewegte Entstehungsphase der Temnye allei, die eine gewisse Diskontinuităt aufweist, läßt keinen Rückschluß auf eine von vornherein bewußte globale Konzeption des Buches zu. Diese Annahme beruht vor allem auf der Tatsache, daß Bunin das Buch zunächst mit dem zweiten Komplex abschloß und den dritten Komplex erst einige Jahre später hinzufügte. Obwohl unubersehbare thematische, strukturelle und stilistische Parallelen zu zahlreichen Erzăhlungen aus demselben Entstehungszeitraum bestehen, vor allem jedoch zu jenen aus dem Jahr 1944, scheint Bunins Entscheidung. diese nicht in das Buch zu integrieren, aus den erläuterten Gründen gerechtfertigt. Gleichzeitig untermauert diese zeitliche Übereinstimmung die Annahme, daß sich ein Wandel in Bunins Poetik ankündigt.

Vielen dieser Erzahlungen und Skizzen ist gemeinsam, daß sie zunehmend küzer und prägnanter sowie handlungsärmer werden. Dabei konzentriert sich Bunins Fähigkeit der unbestechlichen Abbildung der Realität, die schon in der Darstellung des Niedergangs des russischen Landadels in frühen Werken wie Derevnja (1910) und Suchodol (1911) zum Ausdruck kommt, auf die Veranschaulichung der negativen Seiten des Menschen. Diese kommen vor allem in den dialogisch aufgebauten Erzählungen zum Tragen: Vulgarität,

238 Obgleich auch einige Erzahlungen der Temmye allei in fruhen Manuskriptstadien eindeutige Beschreibungen enthielten, die spater abgemildert wurden, ist nicht zwangslaufig davon auszugehen. daß Bunin aus diesen spăten Manuskripten die sexuellen Darstellungen ebenfalls hatte entfemen wollen. 
Gemeinheit, Verlogenheit in heterosexuellen Beziehungen sowie die Tücken des Alltags werden eindrucksvoll illustriert. Nichts ist so, wie es zu sein scheint - Bunin begibt sich auf die andere Seite des Spiegels und beschreibt, wie es ist. Für die szenisch gestalteten Erzählungen ist weiterhin festzustellen, daß die Erzählerstimme zugunsten der meist namenlosen Protagonisten in den Hintergrund tritt. Auch bricht nicht das Schicksal unerwartet über die Liebenden herein - möglicherweise wird diese Komponente abgelöst durch die Personenkonstellationen; das Schicksal ist keine blinde Macht, wie in zahlreichen Erzăhlungen der Temnye allei dargestellt, vielmehr liegt es im menschlichen Wesen begründet. In diesen Erzählungen wird nicht mehr der ganze Mensch ergriffen von der Macht der Liebe, hier geht es vielmehr um die blinde physische Begierde, und nicht in jeder Erzählung wird deutlich, daß sich durch die körperliche Liebe auch geistige Dimensionen eröffnen (vgl. Kap. 8.1.3).

Während die Erzählungen der Temnye allei auf die Darstellungen der verschiedenen Schattierungen des Gefühls Liebe konzentriert sind, werden die übrigen späten Erzählungen und Skizzen von Darstellungen der physischen Liebe dominiert. Auch wird der häßlich-graue Alltag, der in den Erzählungen der Temnye allei ausgespart ist, thematisiert. Es geht nicht mehr allein um hehre Augenblicke, die bis zum Ende des Lebens in Erinnerung bleiben, sondern teilweise nur noch um die Darstellung des Geschlechtsaktes oder um den quälenden Alltag von Paaren und zermürbende Streitgespräche. Damit setzt Bunin seinen Weg des künstlerischen Einfangens von Momentaufnahmen, den er zu Beginn der 1930er Jahre mit dem Verfassen der „Kratkie rasskazy“ begonnen hatte, in seinen letzten Lebensund Schaffensjahren konsequent fort, in den Temnye allei zudem noch erweitert um die Frage nach der Bedeutung eines intensiv erlebten Augenblickes für das weitere Leben des Menschen. In diesen Erzählungen zeigt er, was von diesem Augenblick im Alltag eines Paares übrigbleibt: nichts.

Bezüglich der in die Temnye allei aufgenommenen Erzählungen wird im folgenden Kapitel eine Diskussion der Leitlinien, denen Bunin bei ihrer Positionierung folgte, einen zusătzlichen Beleg dafür liefern, daß die Auswahl nicht unwillkürlich, sondern im Gegenteil sehr bewußt erfolgte. 
The

$y=1,0,2,190$

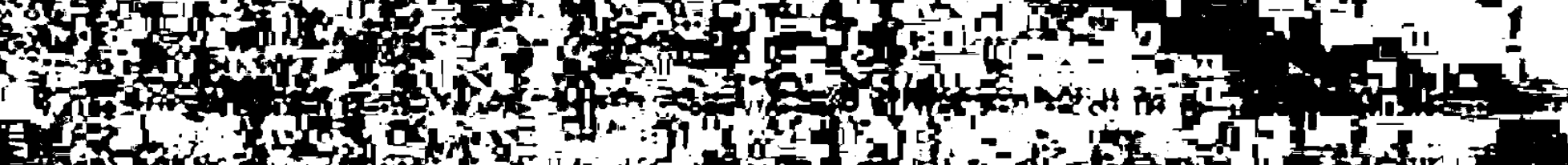

(1)

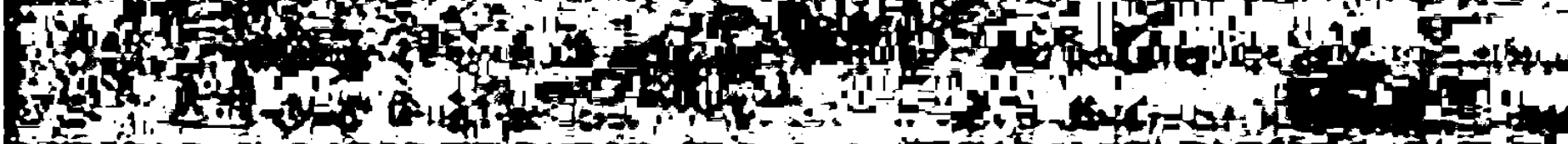

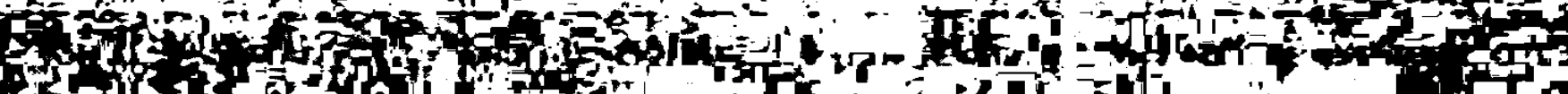

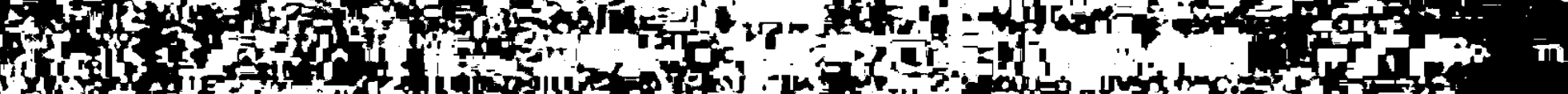

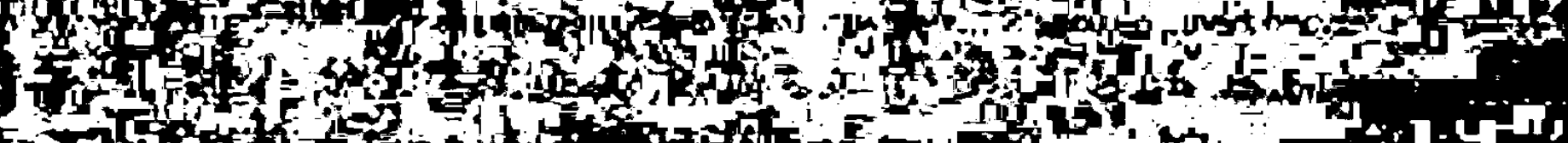

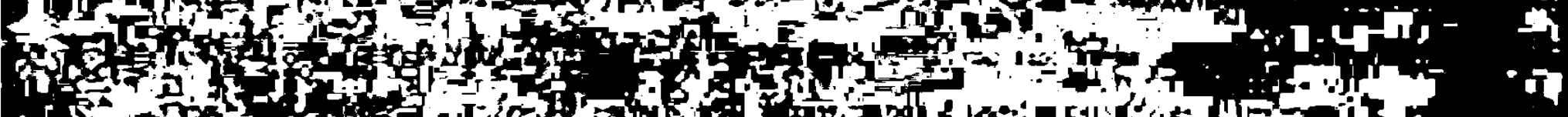

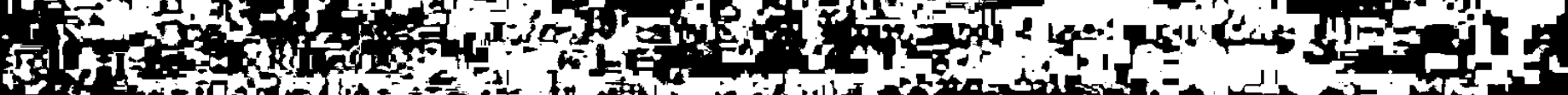
in (1)

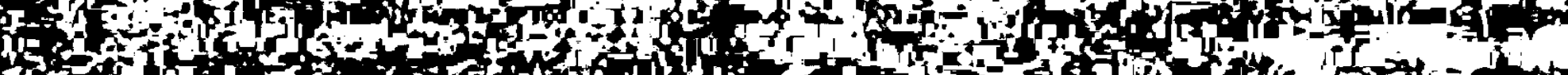
(1) H 2.5 4 1

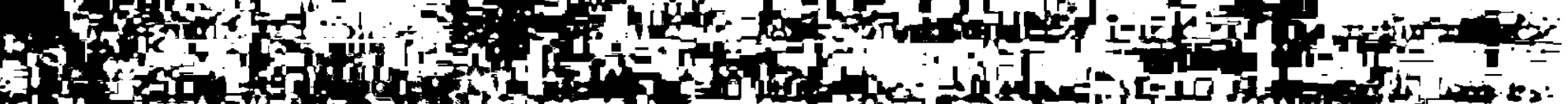
i l in

F

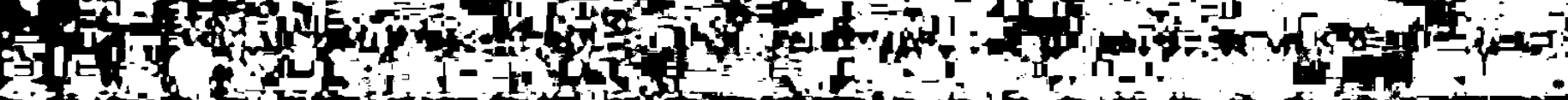

Af

tan

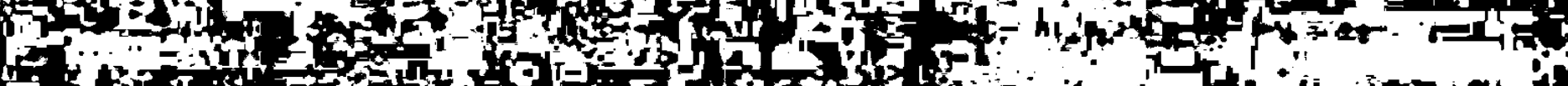

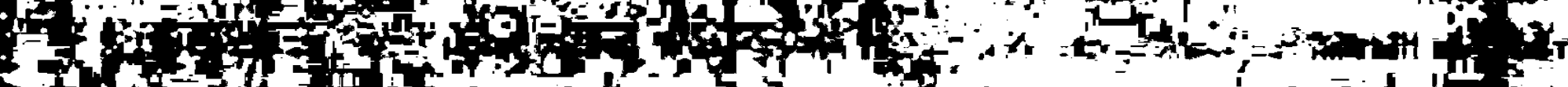

F

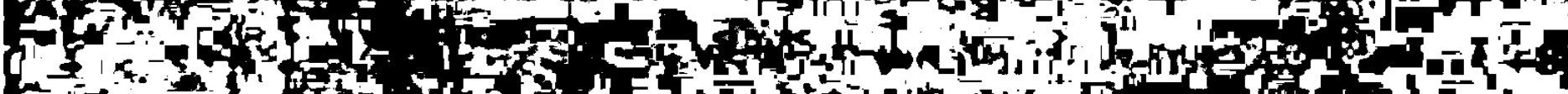
and

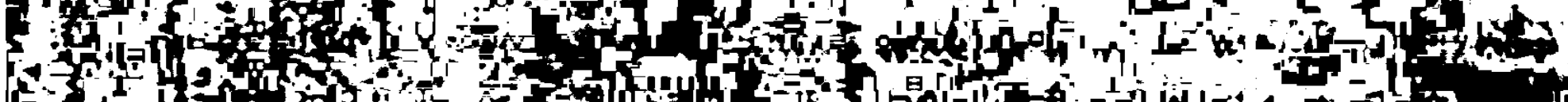
a

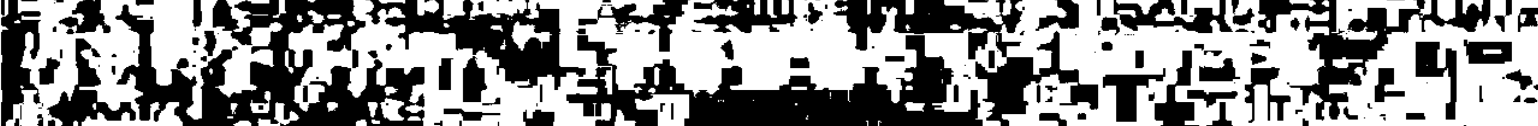

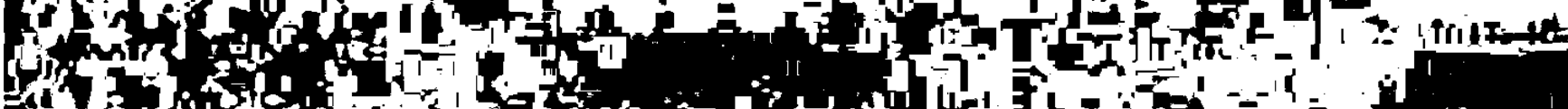

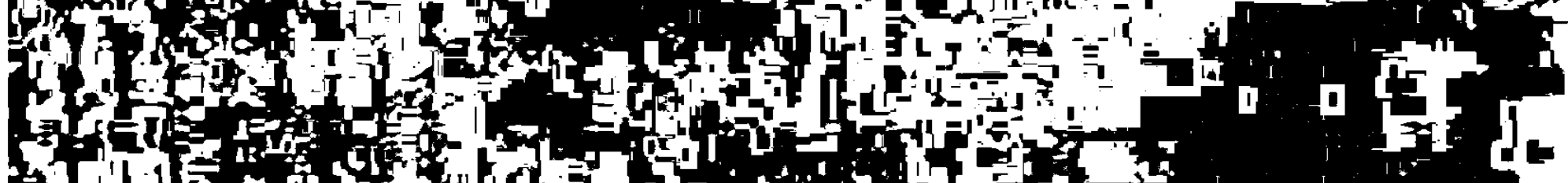
(1) the 
4 EXTRATEXTLICHE VERKNÜPFUNGEN: DER ÄUSSERE AUFBAU DER TEMNYE ALLEI

Die extratextlichen Verbindungen einer Kurzprosaverknüpfung treten vor allem in der Positionienung der Erzählungen und der Art ihrer Sukzession zutage, kommen jedoch auch in der Titelwahl zum Ausdruck (vgl. Kap. 2.2.1). Der individuelle Charakter der Temnye allei läßt sich daher nicht allein durch einen flüchtigen Blick auf das Inhaltsverzeichnis erschließen - dies würde lediglich zu der Fehlinterpretation fuhren, daß es sich um eine aus nicht ersichtlichem Grund in drei unterschiedlich große Blöcke unterteilte Sammlung von Erzăhlungen handelt, ist doch für jene kennzeichnend, daß der Buchtitel der ersten, letzten oder längsten Erzählung entlehnt wird, ohne über diese hinauszuweisen. Nach Kenntnisnahme aller zu den Temnye allei gehörenden Erzählungen wird jedoch die Funktion des Titels bzw. der ersten Erzählung als Motto deutlich, der, vergleichbar einem Romantitel, die zentrale Idee aller Erzählungen in sich vereinigt (vgl. Kap. 4.1).

Eine Klassifizienung der Erzählungen als Kem-, Anker-, Satelliten- und Randerzählungen auf der Grundlage der Genrestudie Rolf Lundéns zu Kurzprosaverknüpfungen ${ }^{239}$ (vgl. Kap. 2.1.3) steht im Zentrum dieses Kapitels. Sie wird erste Hinweise auf die Ordnungsprinzipien liefern, denen Bunin bei der Zusammenstellung der Erzăhlungen folgte - diesbezügliche Aufzeichnungen aus seiner Hand liegen nicht vor. Vorangestellt werden Überlegungen zu Gehalt und Bedeutung des Titels sowie seiner Strahlkraft für das ganze Buch.

\subsection{Der Titel des Buches}

Dem Titel eines Buches, den Lev Vygotskij bezeichnet als „ту доминанту, которая определяет собой все построение рассказа“.240, kommt eine besondere Bedeutung zu unabhăngig davon, ob er einer einzelnen Erzählung oder einem ganzen Buch vorsteht, setzt er doch den ersten Ton, weckt Vorstellungen und Erwartungshaltungen im Leser. Der Titel

239 Lundén zufolge ist es ohne Belang, welche Zusammenstellung Autor oder Herausgeber ursprunglich vorgesehen haben, als Grundlage fur eine Analyse der Genrezugehorigkeit zăhle nur der Text in seiner vorliegenden gedruckten Form (vgl. R. Lundén. op.cit.: 35). Dieser Aussage muß widersprochen werden, da die Art der Zusammenstellung unter Umstănden nicht allein in den Hănden des Autors liegt: Zensur und postume Veräderungen durch den Herausgeber können die strukturelle Dichte einer Kurzprosaverknuppfung erheblich beeintrăchtigen, wie es etwa bei den fruhen sowjetischen Editionen der Temnye allei der Fall war (vgl. Kap. 9.2.2). Außerdem kann es dem Verstăndnis einer Kurzprosaverknupfung zutraglich sein, den Prozeß der Zusammenstellung in die Betrachtung einzubeziehen.

240 L. Vygotskij. .,.Legkoe dychanie` Bunina". In: ders. Psichologija iskusstva. Moskva, 1968: 204. 
der Temnye allei hat darüber hinaus noch Funktionen, die Gero von Wilpert ausschlieBlich den Titeln lyrischer Werke zuordnet: „[Er] dient der Einstimmung in das Werk selbst, bezeichnet oft allein den Gegenstand des lyrischen Sprechens, [...] schildert die răumliche oder zeitliche Ausgangssituation [...] oder verzichtet schließlich auf eigene Aussage und greift die Anfangsworte des Gedichts selbst auf [...].،241

Diese Feststellungen lassen sich übertragen auf Bunins Titelwahl für die erste Erzählung sowie für das gesamte Buch ${ }^{242}$ mit ihrem Bezug auf den Versteil „темньх лип asreł“ aus dem Gedicht „Obyknovennaja povest““243 (1842) von Nikolaj Ogarev. Mit der Doppeldeutigkeit des Titels, der sowohl einen realen Schauplatz als auch im übertragenen Sinn Verwicklungen unklarer Natur bezeichnen könnte, weckt Bunin nicht nur die Neugier des potentiellen Lesers auf mð̈gliche romantische Rendezvous in lauschigen Laubengängen oder gefahrvolle Reisen in die Abgründe der menschlichen Seele, sondern verleiht dem Buch bereits vor der ersten Erzăhlung einen gedämpften, dunklen atmosphărischen Grundton $^{244}$, der sich in vielerlei Variationen durch alle Erzahlungen zieht. Einen hellen Kontrapunkt setzt hingegen der am Schluß der ersten Erzählung zitierte Vers „Кругом шиповник алый цвел“ mit seinem Hinweis auf die rote Heckenrose, dem Symbol der Liebe, die sich vor dem dunklen Hintergrund um so leuchtender ausnimmt. Damit erklingen bereits in der ersten Erzăhlung mit der lyrischen Inszenierung der Antipodenstellung von Liebe und Tod die ersten Töne der Melodie des Buches.

Inhaltlich låßt sich eine wichtige Parallele zu dem Gedicht feststellen: die Nichtwahrnehmung der Einzigartigkeit des Liebesglücks. Sowohl im Gedicht als auch in der Erzählung hat sich bei einer Begegnung Jahre spăter das ehemalige Liebespaar nichts mehr zu sagen, wurden die Gefühle offensichtlich den gesellschaftlichen Konventionen geopfert.

241 G. von Wilpert. Sachworterbuch der Literatur. op.cit.: 840.

242 Das besondere Gepräge dieses Titels unterstreicht zudem die lyrische Färbung. die Bunins vielfach als musikalisch und poetisch empfundene Prosa auszeichnet.

243 In: N. Ogarev. Stichorvorenija i poemy. Leningrad, 1956: 151-152. Die Verse „была чудесная весна“ und „шиповник алый цвел“ zitierte Bunin bereits in der 1924 fertiggestellten Erzahlung „Nadpisi“: Eine russische Reisegruppe erortert wăhrend einer Fahrt an den Rhein den Sinn des Einritzens von Namen in Banke, Gemauer und dergleichen. Wahrend sich eine Dame sehr uber diese vermeintliche Unsitte aufregt, halt ein alter Mann dagegen, indem er Verstăndnis für jene Menschen ăußert, die sich gegen den Strom des Vergessens stemmen wollen, wobei er selbst diese kleinen Auflehnungsversuche in den großen Zusammenhang der Aufzeichnungen aller Zeiten stellt (vgl. I. Bunin. SS v vos'mi romach. 4.Bd. Moskva, 1995: 444-448). Die wiederholte Verwendung von Versteilen aus diesem Gedicht unterstreicht die Symboltrăchtigkeit, die es fur Bunin gehabt haben muß.

244 Konstantin Paustovskij verweist in seinen Erinnerungen auf die Aufzeichnungen von Bunins Neffen Nikolaj Alekseevic Pušešnikov (1882-1939), der ein Gesprăch mit Bunin wiedergibt, worin jener betont habe, wie wichtig es fur ihn sei, vor dem Schreiben einer Erzathlung zunachst den ,richtigen Ton" zu finden: „Бунин говорил, что начиная писать о чем бы то ни было, прежде всего он должен ,найтн звук'. "Как скоро я его нашел, все остальное дается само собоя'“.” (vgl. K. Paustovskij. Naedine s asen 'ju. Portrety, vospominanija, ocerki. Moskva, 1967: 71). 
Eine Parallele besteht ebenfalls zu dem 1847 erschienenen Roman Obyknovennaja istorija Ivan Gončarovs, der die Wandlung des romantischen adeligen Jünglings Alexander in einen abgeklärten jungen Mann unter der sachkundigen Anleitung seines lebenserfahrenen Onkels schildert. Jener weist ihn nicht nur auf die Notwendigkeit pflichtbewußten Arbeitens mit Blick auf die Karriere hin, sondern erschüttert auch die schwärmerische, idealistische Liebeskonzeption seines Neffen mit dem ernüchternden Hinweis: „С Адама и Евы одна и та же история у всех, с маленькими вариантами. ${ }^{245}$ Auch in den Temmye allei findet sich in Variationen die grundsätzlich immer gleiche Geschichte der gegenseitigen Anziehungskraft zweier Menschen - und der Zukunftslosigkeit wahrer Liebe.

Der Bedeutung der Titelwahl war sich auch Bunin bewußt, denn ihr gingen eingehende Überlegungen voraus, wie sich Aleksandr Bachrach, der mehrere Jahre Bunins Gastfreundschaft genoß, erinnert:

Домашние предлагали для будущего сборника различные заглавия, сам он еще ничего не мог придумать, но потом пришел $\mathrm{x}$ завтраку радостный и сказал, что лучше, чем озаглавить весь сборник по одному из рассказов - „Темные аллеи“и не придумать. ${ }^{246}$

Diese Erinnerung wird jedoch zeitlich nicht präzisiert. Daher kann als frühester nachweisbarer Zeitpunkt der Titelfindung der Januar 1941 gelten, als Bunin in einem Brief an Mark Aldanov von einem Buch mit dem Titel Temnye allei sprach (vgl. Kap. 3.3). ${ }^{247}$

Das Prinzip der Titelgebung auf Grundlage der ersten Erzählung änderte sich auch dann nicht, als Bunin zwischenzeitlich einen anderen Titel für die Erzählung „Temnye allei“ erwog. In einem Brief vom 18. August 1947 an Andrej Sedych, in dem er sich nach dem Stand der englischen Übersetzung seines Buches in Amerika erkundigte, äußerte Bunin sich folgendermaßen:

И как же насчет заглавия книги? Я писал вам, - уже давно, предлагал озаглавить первый рассказ „Шиповник“ и, значит, всю книгу тоже „Шиповник“- ведь в конце первого рассказа „герой“ его вспоминает (уже в дороге) стихи: „Кругом

245 In: I. Goncarov. SS v vos'mi tomach. I.Bd. Moskva, 1952: 72.

246 A. Bachrach. Bunin v chalate. op.cit.: 90.

247 Brief an Aldanov vom 08.01.1941. Zit. in: „Lettres d'Ivan Bunin a Mark Aldanov“. op.cit.: 472. Bedingt durch den regen personlichen und brieflichen Kontakt Bunins mit Aldanov ist es wahrscheinlich. daß jener als erster in die neuen Buchplane des Freundes eingeweiht wurde. Da die Briefe Bunins an Aldanov aus den Jahren vor 1940 im Zuge der Durchsuchung der Wohnung der Aldanovs nach ihrer Abreise nach Südfrankreich im Herbst 1940 verlorengegangen sind, muß offen bleiben, ob es diesbezüglich bereits zeitlich fruhere Äußerungen Bunins gegeben hat. 
шиповник алый цвел ...“ Поэтому, думаю, не плохо и заглавие всей книги такое и даже не „Шиповник“, а „Алый шиповник“. ${ }^{248}$

Die Tatsache, daß auch in diesem Fall der Titel der ersten Erzählung gleichzeitig titelgebend für das gesamte Buch hätte sein sollen, stärkt die Annahme, daß der Buchtitel als Motto für alle unter ihm subsumierten Erzählungen fungieren sollte. Gestützt wird diese Hypothese durch das Festhalten an der Verwendung eines Zitats aus demselben Gedicht Ogarevs (gleichfalls bestehend aus Substantiv und präzisierendem Adjektiv) - auffällig an Bunins Überlegung ist das Festhalten am lyrischen Gehalt, der in diesem Falle durch den Wechsel von der Dunkelheit der Alleen zur leuchtenden Lebenskraft der Heckenrose jedoch positivere Assoziationen weckt. Letztlich erschien Bunin offenbar das Düstere als Folie geeigneter, um die kurze, intensive Blüte des Lebens und der Liebe eindringlich zu veranschaulichen, die zugleich die strahlende Farbgebung des Buches zur Geltung bringt (vgl. Kap. 6.2). Die Bedeutung und Tragweite der ersten Erzählung erläutert Bunin in einem Brief an Boris Zajcev vom 11. November 1943 mit den folgenden Worten:

Книга эта называется по первому рассказу „Темные аллеи“- во всех следующих дело идет, так сказать, тоже о темньх и чаще всего весьма жестоких „аллеях любви". ${ }^{249}$

Eine fast wortgleiche Erläuterung findet sich in einem Brief Bunins an Tèffi vom 23. Februar 1944:

Вся эта книга называется по первому рассказу - „Темные аллеи“ - в котором "героиня“ напоминает своему первому возлюбленному, как когда-то он все читал ей стихи про „темные аллеи“ [...] и все рассказы этой книги только о любви, о ее „темных“" и чаше всего очень мрачных и жестоких аллеях. ${ }^{250}$

Gemeinsam ist allen oben zitierten Erläuterungen Bunins zur Titelwahl zum einen die Betonung der ersten Erzählung sowie zum anderen der Hinweis auf das Gedicht „Obyknovennaja povest'“, wobei er die tragende Rolle der Verse „Кругом шиповник алый цвел, стояли темных лип аллеи ....251 hervorhebt. Die folgende nähere Betrachtung der Erzäh-

248 A. Sedych. Dalekie, blizkie. New York, 1979: 217.

Die bluhende Heckenrose hatte offenbar schon Jahre zuvor Symbolcharakter fur Bunin: „Блаженные часы проходят, н на до, необходимо ... хоть что -нибудь сохрани ть, то есть противопоста внть смерти, отиветанию шиповника", notierte er 1924. Zit. in: A. Saakjanc. „Temnye allei". Posiednic gody". In: I. Bunin. Socinenija v trech tomach. 3.Bd. Moskva, 1982: 514.

249 Zit. in: „Pis'ma I. Bunina k B. Zajcevu“. In: Nż 137 (1979): 125.

250 Zit. in: „Perepiska Teffi s I. A. i V. N. Buninymi 1939-1948“. op.cit.: 506.

251 In seinen Briefen ebenso wie in der Erzahlung "Temnye allej" zitient Bunin nicht ganz korrekt: Im Original heißt es ..вблизи" anstatt ..кругом“" 
lung wird die Relevanz veranschaulichen, die Bunin ihr im Hinblick auf das gesamte Buch zugemessen hat.

Geschildert wird in der Erzählung die zufällige Begegnung eines älteren Offiziers mit der Wirtin einer Poststation, in der er Rast einlegt. In der reifen Frau erkennt er die ehemalige Leibeigene Nadežda wieder, mit der ihn etwa 30 Jahre zuvor eine Liebesbeziehung verband, die er nicht eben ehrenhaft beendete. Während der Offizier davon ausgeht, daß die Zeit Nadeždas Liebesschmerz geheilt hat („Все проходит, мой друг“, 6: 177), muß er uberrascht und beschämt zur Kenntnis nehmen, daß sie keineswegs vergessen, geschweige denn ihm verziehen hat („Все проходит, да не все забывается“, 6: 178). Trotz der erlittenen Demütigung hat sie zeitlebens die Erinnerung an diese ihre einzige Liebe bewahrt und sich nach dieser einschneidenden emotionalen Erfahrung nicht wieder gebunden.

Ihrem Gespräch kann der Verlauf jener lang zurückliegenden Liebesbeziehung nur bruchstückhaft entnommen werden; einzig eine Bemerkung des Offiziers (,история пошлая, обыкновенная“, 6:177), die an den Titel des Gedichts gemahnt, erhärtet die Vermutung, daß sich zwischen den beiden eines der üblichen amourösen Abenteuer zwischen einem jungen Gutsherm und einer Leibeigenen abgespielt hat, das der Mann trotz möglicherweise tiefen Empfindens aus rationalen Überlegungen heraus gesellschaftlichen Konventionen zum Opfer gebracht hat, möglicherweise in dem Glauben, daß angesichts seiner Jugend das Beste noch vor ihm liege und dieser Verzicht daher zu verschmerzen sei. Ebenso gewöhnliche Züge trägt der Fortgang der Ereignisse im Leben des Offiziers: Während seine Frau ihn betrogen hat, entwickelte sich sein Sohn zu einem Taugenichts (.Впрочем, все это тоже самая обыкновенная, пошлая история“, 6: 178). Dennoch stellt er seine damalige Entscheidung auch nachträglich nicht in Frage, obwohl ihm bewußt ist, daß er das einzige Glück, das er jemals erlebt hat, Nadežda zu verdanken hat (..Paзвe не правда, что она дала мне лучшие минуты жизни?“, 6: 178).

Bereits in dieser Erzählung finden sich zahlreiche der künstlerischen Stilelemente (vgl. Kap. 6), die Bunin auch in den übrigen Erzählungen verwendete, wie beispielsweise die Wiederholung und der Kontrast. ${ }^{252}$ Letzterer kommt etwa zum Ausdruck in der Gegenüberstellung des ungemütlichen Herbstwetters der erzählerischen Gegenwart mit seinen Konnotationen der Vergänglichkeit und des Lebensabends und den die Vergangenheit charakterisierenden Zeilen des Gedichts, die von einem „wundervollen Frühling“ sprechen und an einen hoffnungsvollen Start ins Leben denken lassen. Deprimierender als das Wis-

$252 \mathrm{Vgl}$. auch N. Evstaf eva. ..Svoeobrazie zanrovych form ...”. op.cit.: 3. 
sen um die unerfüllten Träume der Jugend oder das trübe Wetter zu Beginn der Erzählung wirkt jedoch die fahle Herbstsonne am Ende der Erzählung, die von einem nahenden, freudlosen Lebensabend kündet. Prägnante und vielsagende Kontraste finden sich auch in der Zeichnung der handelnden Figuren, etwa in der strengen schwarz-weiß-grauen Farbgebung, die von roten Farbtupfen wie der Schürze und den Schuhen Nadeždas aufgebrochen wird (vgl. Kap. 6.2.3). Für Dichte hingegen sorgen verschiedene Wiederholungen in der wörtlichen Rede, wie beispielsweise das dreimalige Wiederholen des Ausrufes „Божe мой!“ (6: 176/177), der Feststellung „Все проходит“ (6: 177/178) oder der Erkenntnis „пеняй на себя“ (6:179). Inhaltlich klingen bereits die zentralen Themen Liebe, Tod/Vergänglichkeit und Erinnerung an, verbunden mit dem Motiv des Reisens, das eine Annäherung an die Vergangenheit ebenso ermöglicht wie die (räumliche und geistige) Distanzierung von ihr.

Darüber hinaus kommuniziert die Erzählung durch den in der Erzählung "Temnye allei“ nicht erwăhnten Titel des verwendeten Gedichts „Obyknovennaja povest”“ auf subtile Art und Weise mit den wesentlich später entstandenen Erzählungen „V Pariže“ und „Mest”“, die sich im zweiten bzw. im dritten Komplex befinden, und stellt damit eine intratextliche Kommunikation und thematische Tiefe her, die bloßen Sammelbänden von Erzählungen nicht eignet. Nach der Art des Endes seiner Ehe befragt, gibt der ehemalige General in „V Pariže", der von seiner Frau verlassen wurde, zur Antwort: „История очень обыкновенная“ (6: 277). Dieser Satz bezieht sich auf den folgenden Aphorismus, den er auf französisch zitiert und mit dem er auf die Kurzlebigkeit der Liebe anspielt: „Qui se marie par amour a bonnes nuits et mauvais jours“ (6: 277). In der Erzählung "Mest"“ wiederum wăhlt die von ihrem Liebhaber verlassene Frau zur Umschreibung ihrer Vergangenheit folgende Worte: „Прошлое мое тоже самое обыкновенное“ (6: 392). Mit diesen Worten umreißt sie den typischen biographischen Hintergrund eines russischen Emigranten, der nach der Revolution 1917 seine Heimat verlassen mußte.

Diese drei „gewöhnlichen“ Geschichten bilden als Dreiklang den Hintergrund, vor dem ein Großteil der Erzăhlungen der Temnye allei spielt: gescheiterte Liebesbeziehungen und drohender oder bereits erfolgter Verlust der Heimat. Dieser Exkurs zu ähnlichen Tönen, die an verschiedenen Stellen des Buches erklingen, läßt die mehr als oberflächliche Zusammengehörigkeit der Erzählungen ahnen, die sich bereits im resümierenden Titel ankündigt und auch in ihrer Anordnung deutlich zutage tritt. 


\subsection{Die Anordnung der Erzăhlungen - eine Bestandsaufnahme}

Das Inhaltsverzeichnis läßt auf den ersten Blick keinen Aufschluß über die Leitlinie zu, der Bunin bei der Anordnung der 38 Erzahlungen folgte. Erst eine Zuordnung der Entstehungsdaten scheint hinzuweisen auf eine Unterteilung in drei Komplexe unterschiedlichen Umfangs nach primär chronologischen Gesichtspunkten, die 6, 14 und 18 Erzählungen enthalten. Im wesentlichen entsprechen sie den drei intensiven Schreibphasen, in denen Bunin die meisten der Erzăhlungen verfaßte (Herbst 1938, Herbst 1940 und Herbst 1943/Frühjahr 1944, vgl. Kap. 3.2). Innerhalb der einzelnen Komplexe ist die Chronologie jedoch durchaus nicht durchgängig gewahrt, so daß andere Kriterien die Zusammenstellung beeinflußt haben müssen. Es fällt etwa auf, daß Bunin bei der Wahl und der Positionierung der Eröffnungs- bzw. Finalerzählungen besondere Sorgfalt walten ließ. Diese Vorgehensweise hat unubersehbare Parallelen in der Konstruktion der drei Komplexe zur Folge, die zu deren Verschränkung und somit zu einer inneren Festigung der Kurzprosaverknüpfung führte (vgl. Kap. 4.3.1).

Der ersłe Komplex enthält eine Erzählung aus dem Jahr 1937 („Kavkaz“, 4. September 1937), die allerdings erst an zweiter Stelle aufgeführt wird, obgleich sie in der Chronologie am weitesten vom steht, sowie fünf Erzählungen aus dem Jahr 1938, die gemäß dem Datum ihrer Fertigstellung plaziert wurden. Die am spätesten vollendete Erzählung „Temnye allei“ (20. Oktober 1938) wurde aus dem chronologischen Zusammenhang gerissen und bildet nunmehr die Eingangserzählung. Die Reihenfolge der Erzählungen in diesem Komplex stand seit der ersten Zusammenstellung, die Bunin 1941 Aldanov zukommen ließ (vgl. Anhang 2, Stand Frühjahr 1941), unverändert fest, mit Ausnahme der (sich ebenfalls in die Chronologie einfügenden) Erzählung „Aprel”“ (9. März 1938), die er nach dem Mai 1944 aus dem Kreis der ausgewăhlten Erzăhlungen entfernte, möglicherweise wegen der thematischen Ähnlichkeit mit der im April 1941 abgeschlossenen Erzăhlung "Natali“ (bei gleichzeitig weitaus ausführlicherer und eindringlicherer Darstellung des zentralen Konflikts; vgl. Kap. 3.5.1).

Ähnlich präsentiert sich die Situation im zweiten Komplex, der 13 Erzăhlungen aus dem Jahr 1940 und mit „Natali“ eine Erzăhlung aus dem Jahr 1941 enthält. Er folgt einem chronologischen Ordnungsprinzip - mit nur wenigen Ausnahmen: Die Erzählung "Rusja“ (27. September 1940) wurde von ihrem unter chronologischem Aspekt betrachteten dritten Platz nach vom gezogen. Des weiteren wurden lediglich die Erzählungen „Volki“ (7. Oktober 1940) und „Vizitnye kartocki“ (5. Oktober 1940) gegeneinander ausgetauscht. 
Auch in diesem Komplex nahm Bunin nach seiner Zusammenstellung, die spätestens im Frühjahr 1944 erfolgte (vgl. Anhang 2), bis zur ersten Integralveröffentlichung 1946 keine wesentlichen Änderungen vor, er verzichtete lediglich auf die Aufnahme der Erzăhlung "Tri rublja“" (9. Dezember 1940). ${ }^{253}$

Hingegen erfuhr der dritte Komplex weiter reichende Umstrukturierungen hinsichtlich seiner inneren Chronologie. 13 der 18 Erzählungen entstanden im Jahre 1944. Zudem wurden vier Erzählungen aus dem Jahr 1943 und eine aus dem Jahr 1945 aufgenommen. Die Erzählungen „Rexnoj traktir”, „Kuma“, Načalo“ sowie „Dubki““, die allesamt 1943 entstanden, wurden zwar zu einer Gruppe zusammengefaßt, stehen aber wider Erwarten nicht gemäß der Chronologie am Beginn des Komplexes. Ihnen vorangestellt wurde die Erzählung „V odnoj znakomoj ulice“, die erst im Mai des darauffolgenden Jahres zum Abschluß gebracht wurde. Auch innerhalb dieser Gruppe läßt sich eine Umstellung registrieren: Die Erzählung „Rečnoj traktir“, die dem Datum ihrer Fertigstellung zufolge den vorletzten Platz hätte belegen müssen, wurde an die erste Stelle verschoben. Eine weitere Durchbrechung der Chronologie ergab sich durch die Umstellung von „Kaceli“ (24. September 1943) auf den drittletzten Platz. Die Erzählung „Cistyj ponedel'nik“ (10. Mai 1944) wurde ebenfalls aus der Chronologic herausgenommen und an den vorletzten Platz verschoben, wo sie nun gemeinsam mit „Časovnja“ (2. Juli 1944) den Abschluß des Buches bildet.

Am augenfälligsten sind die Veränderungen, die Bunin zwischen dem Frühjahr 1944 und 1945 bzw. 1946 vorgenommen hat (vgl. Anhang 2). In diesem Zeitraum entfernte er zwölf Erzăhlungen aus der bis dahin bestehenden Zusammenstellung. ${ }^{254}$ Das Vorziehen der Erzählungen „V odnoj znakomoj ulice“ (25. Mai 1944) und „Režnoj traktir“ (27. Oktober 1943) an den Beginn des dritten Komplexes und das Verschieben von „Cistyj ponedel'nik" an die drittletzte Stelle erfolgten vor 1945, während für die Pariser Publikation von 1946 die Erzăhlungen „Čistyj ponedel'nik“ und „Kačeli“ die Plătze tauschten, so daß „Čistyj ponedel'nik“ vor die Schlußerzählung „Casovnja“ rückte.

253 Der Vollstandigkeit halber soll darauf hingewiesen werden, daß Bunin Ende 1945 folgende Erzahlungen aus der fur die Publikation in der UdSSR (vgl. Kap. 9.2.1) vorgesehenen Zusammenstellung entfernte: .Krasavica“, „Durocka“, „Antigona“, „Gost” und .Baryšnja Klara“. Außerdem revidierte er die fur die Pariser Ausgabe von 1946 vorgenommene Änderung der Reihenfolge der Erzathlungen "Volki" und "Vizitnye kartocki" und verănderte erstmals die Reihenfolge der beiden Erzahlungen "Tanja" und "V Parize" (vgl. Anhang 2. Stand Ende 1945). Zudem fehlen in dieser Zusammenstellung die in der nachfolgenden Fußnote genannten Erzăhlungen. Daruber hinaus nahm er keine weiteren Erganzangen vor, so daß davon auszugehen ist, daß Bunin die fur die Pariser Ausgabe von 1946 zu diesem Zeitpunkt bereits imprimierte Fassung im wesentlichen beibehalten wollte.

254 Es handelt sich dabei um die folgenden Erzahlungen: „Na postojalom dvore“, „V takuju nox"“, "Lita“, .Achmar", „Au secours!“”. „Alupka“, ...Kogda ja vpervye“"”, „Krem Leodor", .,Pamjatnyj bal“, .,Novaja subka”, „Dalekij pozar" sowie „Otec Nikon“. Die Erzahlung „Molodost' i starost”“ fand unter ihrem urspronglichen Titel .Pro obez"janu“" lediglich Eingang in den Stand von 1941. 
Unter Zugrundelegung aller von Bunin erstellten Übersichten ubber den møglichen Aufbau seines geplanten Buches (vgl. Anhang 2) läßt sich festhalten, daß die Auswahl der Erzăhlungen trotz der Existenz zahlreicher Alternativen in Form weiterer Erzählungen bewußt erfolgte und die Zusammensetzung weitgehend stabil blieb. Um so größere Aufmerksamkeit muß daher den Umstellungen gewidmet werden. Die Beweggründe Bunins für die Modifikationen innerhalb der Komplexe erschließen sich erst durch eine Gewichtung der Erzăhlungen auf Grundlage des von Lundén vorgeschlagenen Klassifizierungsmodells in Kern-, Anker-, Satelliten- und Randerzăhlungen (vgl. Kap. 2.2.1), die eine bewußte Rahmenkunstruktion sowohl um die einzelnen Komplexe als auch um das Gesamtgefüge mit einem dichten und strahlkräftigen Zentrum zu Tage fordert.

\subsection{Die Kernerzählungen}

Als zentrale oder Kemerzählungen einer Kurzprosaverknüpfung werden Erzählungen bezeichnet, die die Hauptaussagen des Buches enthalten und/oder vom Autor an strategisch bedeutsamen Stellen plaziert wurden. Diese Definition triff auf 19 Erzăhlungen der Temnye allei zu, die zu einem Großteil in der bereits erwähnten Zusammenstellung von Erzählungen nach Rubriken („Rody moich soxinenij“) aufgelistet sind, die Bunin als Anlage zu einem Brief vom 12. Oktober $1952^{255}$ an Fedor Stepun schickte (vgl. Kap. 3.3).

In dieser klassifizierenden Übersicht hebt Bunin das 38 Erzăhlungen umfassende Buch Temnye allei als Sonderkategorie hervor (,Kniga ,Temnye allei“") und kennzeichnet jene Erzăhlungen, die für ihn von besonderer Wichtigkeit sind, mit der Anmerkung „N.B.“. Hierzu gehören die folgenden 16 Erzählungen, die proportional auf die einzelnen Komplexe verteilt sind: „Ballada“, „Pozdnij cas“, „Rusja“, „Vizitnye kartocki“, „Zojka i Valerija“, „Tanja“, „V Pariže“, „Galja Ganskaja“, „Genrich“, „Natali“, „Madrid“", „Železnaja Serst"“, „Cholodnaja osen”“, „Voron“, „Cistyj ponedel'nik“ sowie „Ćasovnja“. Mit einem doppelten „N.B.“ versah er die Erzählungen „Tanja“ und „Natali“. Parallel ordnet er das gesamte Buch zudem der Rubrik „o ljubvi“ zu und hebt dabei die Bedeutung der Erzählung "Pozdnij cas“ mit dem Vermerk „osobenno“ hervor. 
Ergănzend zu der von Bunin vorgenommenen Gewichtung erfullen drei weitere Erzăhlungen die Kriterien einer Kernerzăhlung: „Temnye allei“, „V odnoj znakomoj ulice“ und „Rexnoj traktir ${ }^{256}$ - sei es aus Gründen ihrer Positionierung an Schlüsselstellen des Buches oder weil sie Kernaussagen enthalten.

\subsubsection{Die Eröffnungs- und Finalerzählungen der einzelnen Komplexe}

Die intratextlichen Spannungen bzw. Beziehungen zwischen den Erzăhlungen, die die einzelnen Komplexe eroffnen und abschließen, zeugen von der Sorgfalt, die Bunin bei der Wahl der Eckpfeiler seines Buches walten ließ und die sich bei der Plazierung der Eroffnungserzăhlungen in einer bewußten Durchbrechung der Chronologie manifestiert.

Unter den drei Eroffnungserzählungen nimmt einzig „Rusja“ den ihr gemäßen Platz in der Chronologie der Entstehungsdaten ein. Sowohl „Temnye allei“ als auch „V odnoj znakomoj ulice" wurden weiter nach vorn gezogen. Allen drei Erzählungen ist gemeinsam, $\mathrm{da} B$ in der jeweiligen männlichen zentralen Figur die Erinnerung an eine vergangene Liebesbeziehung während einer Reise bzw. eines Spaziergangs in der erzăhlerischen Gegenwart wachgerufen wird. ${ }^{257}$ Diese Liebe erfährt im Rückblick eine Aufwertung zu einem tiefen Gefühl, das ihr zur Zeit ihrer Blüte nicht in dieser Intensităt innewohnte bzw. nicht in seinem ganzen Ausmaß wahrgenommen wurde. Die gemeinsame Grundmelodie dieser Erzählungen mit den Hauptthemen Liebe und Erinnerung ist die der Trauer über den Verlust unwiederbringlicher Augenblicke einer weit zurückliegenden Vergangenheit.

In der Erzählung „Temnye allei“ erkennt der alternde Offizier im bedauernden Rückblick, daß er in seiner Romanze mit der Leibeigenen Nadežda die schönsten Momente seines Lebens erlebt hat („лучшие мннуты жнзнн“, 6: 178). In „Rusja“ wird die Erinnerung eines Mannes mittleren Alters an eine heimliche Liebesbeziehung in seinen Jugendjahren geweckt, die nach der Aufdeckung durch die Mutter des Mädchens ein jähes Ende fand. Auch dieser Protagonist empfindet die Einzigartigkeit seines Liebesgefühls, als er die

256 Bunin erhielt positive Resonanz auf diese Erzahlung, die 1945 auch als limitierte Sonderausgabe in 1.000 numerierten Exemplaren erschien (vgl. Kap. 9.1.1), zeigte sich jedoch beschamt aber diese Publikation, da er das Opus nicht zu seinen besten zahite: „[...] в нем хое-4то неплохо насчет Волги, воо6ще насчет ,святой Руси', но ведь все-такн зто не лучший ,перл' в моей, короне' [...]" (Brief an Aldanov vom 11.11.1945; zit. in: „Perepiska I. A. Bunina s M. A. Aldanovym. In: NE 150 [1983]: 182).

$257 \mathrm{Vgl}$. auch A. Acatova. "Iz nabljudenij nad liriceskoj prozoj I. A. Bunina“. In: Voprosy literatury. Uzenye zapiski. 83. Bd. Tomsk, 1973: 84. 
Quintessenz in folgenden Worten formuliert: „Amata nobis quantum amabitur nulla“ (6:217). Ähnlich wie in „Temnye allei“ bildet ein unvorhergesehener Reiseaufenthalt den äußeren Anlaß zur Rückbesinnung. Die Erzăhlung „V odnoj znakomoj ulice“ beschreibt die gedankliche Erinnerungsreise eines nicht mehr ganz jungen russischen Emigranten während eines Spaziergangs durch Paris. Ein (im übrigen unkorrekt zitiertes) Gedicht Jakov Polonskijs mit dem Titel „Zatvomica“258 (1846) evoziert den melancholischen Rückblick in das Moskau seiner Jugend, als er eine Liebelei mit dem Bruch eines Versprechens unrühmlich beendete. Ihre innere Spannung bezieht die Erzählung aus der Gegenuberstellung eines Gedichts, dessen Schlußvers dem wahren Ablauf der Ereignisse in der Vergangenheit zuwiderläuft-und damit seine melancholische Erinnerung als Schönfärberei entlarvt.

Zwischen den Eröffnungserzählungen "Temnye allei" und „V odnoj znakomoj ulice“ besteht ein besonders enger Bezug, da beide durch die Einbindung von Gedichten eine bestrickende poetische Doppelgründigkeit erfahren. In „Rusja“ hingegen wird diese doppelte Tiefe auf andere Weise erzielt: Hier fuhrt der Bruch in der Darstellungsweise des Erzählers zu einer Ausdehnung der erinnerten Dimension. Während er seine neugierige Frau mit dem Bericht eines unwahrscheinlichen Endes seiner Liebesbeziehung zum Mădchen Rusja auf Distanz hält und damit weitere teils spöttische, teils eifersüchtige Nachfragen ihrerseits unterbindet (,я застрелился, а она закололась кинжалом“, 6: 210), hängt er im Dunkel der Nacht ungestört seinen Erinnerungen nach, die einen anderen Verlauf der Romanze zutage fördern.

Dominieren die Themen Liebe und Erinnerung die Eröffnungserzählungen, so sind die Finalerzählungen der einzelnen Komplexe (.,Pozdnij Cas“, „Natali“ und „Časovnja“) durch das Todesthema miteinander verbunden. ${ }^{259}$ Es soll festgehalten werden, daß jede Finalerzählung gemäß der Chronologie ihren Platz fand.

Ähnlich wie in „V odnoj znakomoj ulice“ unternimmt der Protagonist der Erzählung „Pozdnij cas ${ }^{460}$ eine Erinnerungsreise in seine vor 19 Jahren $^{261}$ verlassene Heimatstadt,

258 In: Ja. Polonskij. Stichorvorenija. Moskva. 1981: 43-44.

$259 \mathrm{Vgl}$. C. Hauchard. „La Prose de I. A. Bounine ...... op.cit.: 288.

260 In einem Tagebucheintrag vom 07.05.1940 druckt Bunin seine eigene Wertschatzung fur diese Erzahlung aus: „Перечитал свон рассказы аля новой книги. Лучше всего .Поздний час`, потом, м[ожет] 6[ыть], ,Степа', .Баллада“" (zit. in: UB. 3.Bd. op.cit.: 48).

261 Die Kongnuenz des genannten Zeitraums mit der Anzahl von 19 Kernerzahlungen (und demzufolge auch 19 Erzahlungen von minderer Bedeutung for die semantische Aussage des Buches) ist frappierend und ladt ein zu der Spekulation, daß ein Zusammenhang bestehen kơnnte. 
auf der Suche nach Spuren jener Menschen, die er einst liebte, wobei seine Gedanken vor allem um ein junges Mädchen kreisen. Die einzigen Relikte dieser weit zurückliegenden Vergangenheit sind die Grabsteine auf dem Friedhof. Neben diesen Erinnerungen beherrschen Gedanken an seinen nahenden Tod sein Fühlen und Denken.

In „Natali“, der Finalerzählung des zweiten Komplexes, stirbt die gleichnamige Protagonistin, als ihre Wünsche und Sehnsüchte in Erfullung zu gehen scheinen. Eine Schwangerschaft als Kulmination des Glücks bedeutet indessen zugleich ihr Todesurteil, da sie eine Frühgeburt nicht überlebt. Diese Finalerzählung hat auf Grund ihrer Länge sowie ihrer Bedeutung als Schmelzpunkt für die zentralen Themen Liebe, Tod, Erinnerung gleichzeitig die Funktion einer Ankererzählung (vgl. Kap. 4.3.3).

Der Protagonist der Erzählung „Časovnja“, Finalerzählung des dritten Komplexes wie auch des Buches, wird schon gar nicht mehr als Lebender präsentiert - er erscheint lediglich beiläufig als Gesprächsthema fröhlich spielender Kinder als ein noch junger Onkel, der sich auf Grund einer unglücklichen Liebesbeziehung des Leben genommen hat. Die Hypothese, daß Liebe durch physische und/oder psychische Auslöschung des Selbst tődlich sein kann, wird am Ende der Erzählung auf den folgenden doppeldeutigen und generalisierenden Nenner gebracht: „Он был очень влюблен, а когда очень влюблен, всегда стреляют себя" (6: 412).

In allen drei Erzăhlungen wird die Niederlage des Lebens vor dem Tod thematisiert, eines Lebens, das ausgelöscht wird, ohne sichtbare Spuren zu hinterlassen, eines Lebens, das nur noch in der Erinnerung eines Menschen lebendig ist, der eines Tages ebenfalls sterben wird. Die Kulmination dieses Themas und gleichzeitig die dichteste Darstellung der engen Verknüpfung von Liebe und Tod erfolgt in der Erzählung "Časovnja“. Der Tod, das dunkle Nichts, wird meisterhaft symbolisiert durch den kalten Windhauch, der aus der Kapelle weht, in der sich die Sarkophage befinden. Der heiße Sommertag, an dem die Lebendigkeit der Natur besonders intensiv zu spüren ist, bildet einen scharfen Kontrast zu der kühlen Heimstatt des Todes und steht für die thematischen Antipoden des Buches: „И чем жарче и радостней печет солнце, тем холоднее дует из тъмы, из окна“ (6: 412).

Die Spannung der thematischen Klammer Liebe - Tod findet sich über die Eröffnungsund Finalerzählungen hinaus auch in dem alle Erzählungen umschließenden Rahmen, bestehend aus den Erzăhlungen "Temnye allei“ sowie "Cistyj ponedel'nik" und "Casovnja“, so daß nicht nur die einzelnen Komplexe eine äußere Festigung erfahren, sondern darüber hinaus auch alle Komplexe, noch unterstützt durch ihren identischen Aufbau, 
miteinander verschränkt werden (vgl. Kap. 4.4). Die auf diese Weise entstandenen inneren Rahmen wurden mit Erzahlungen unterschiedlicher Wertigkeit in bezug auf die Gesamtkomposition aufgefullt. Ihre Positionierung wird in den folgenden Kapiteln beleuchtet.

\subsubsection{Die Kernerzählungen im Innern der einzelnen Komplexe}

Neben den Eröffnungs- und Finalerzăhlungen lassen sich 13 weitere Kernerzăhlungen ausmachen, die zur Aufrechterhaltung eines strukturellen Spannungsbogens proportional auf die einzelnen Komplexe verteilt, jedoch von unterschiedlicher Wertigkeit sind:

Komplex I: „Ballada“

Komplex II: „Vizitnye kartocki“, „Zojka i Valerija“, „Tanja“, „V Pariže“, „Galja Ganskaja“, „Genrich“

Komplex III: „Rex̌noj traktir", „Madrid“", „Železnaja Serst"“, „Cholodnaja osen"“, „Voron“, „Cistyj ponedel'nik“.

Bei einer Betrachtung der strategischen Verteilung dieser Erzählungen fallt ein Konglomerat am Ende des zweiten Komplexes - und damit in der Mitte des Buches - auf. Diese sechs 1940/1941 entstandenen, aufeinanderfolgenden Erzahlungen stellen die Themen Liebe und Tod in besonders dichter Form dar. Ihre Strahlkraft verglich Claire Hauchard zu Recht mit der einer schwarzen Sonne, möglicherweise in Anlehnung an Bunins Beschreibung der Augen Natalis aus der gleichnamigen Erzăhlung als "черные солнца“ (6: 303):

Chaque nouvelle au sein de cette structure d'ensemble est elle-même une variation sur les thèmes de l'amour et de la mort. [...] La tonalité funèbre s'éclaircit ou s'obscurcit à travers le livre en séquences plus ou moins denses. On remarque par exemple au centre de l'ouvrage une suite éprouvante de dénouements tragiques dans six nouvelles consécutives (Zoé et Valérie, Tania, A Paris, Galia Ganskaia, Heinrich, Nathalie) [...] L'effet accumulatif des six nouvelles forme au centre de cette cuvre tripartite comme un soleil noir diffusant une sourde opacité. La "suite à la Schumann" égrène ainsi d'une nouvelle à l'autre divers „accords" qui vont de la mélancolie légère à l'angoisse tragique. ${ }^{262}$

262 C. Hauchard. .La Prose de I. A. Bounine ...“. op.cit.: 289. Da Hauchard bei ihrer Betrachtung der Temmye allei keine Gewichtung der Erzahlungen vornimmt, ist ihre Wahmehmung dieses Konglomerats als strahlendes Zentrum um so bemerkenswerter. 
Die im Zitat gemachten Feststellungen sind zutreffend, jedoch sollte der Kreis der genannten Erzählungen um „Vizitnye kartocki“ erweitert werden, während „Natali“ von ihm ausgenommen werden sollte, da sie in ihrer Doppelfunktion als Final- und Ankererzählung eine Einzelerscheinung mit Alleinstellungsanspruch darstellt. Alle Erzählungen dieses dunklen Zentrums zeichnen sich über die thematische Verbindung hinaus vor allem durch die in ihnen beschriebenen, einprägsamen Frauengestalten aus. Zudem werden in ihnen wichtige Aussagen zu den zentralen Themen des Buches Liebe, Tod und Erinnenung formuliert (vgl. Kap. 8). Im zweiten Komplex befinden sich im übrigen keine weiteren Kernerzählungen.

Die im dritten Komplex plazierten Kemerzăhlungen sind lockerer verteilt und von nachrangiger Bedeutung, mit Ausnahme der Erzählungen „Rex̌noj traktir“, „Cholodnaja osen”“ und "Čistyj ponedel'nik“. Diese drei Erzählungen enthalten ebenfalls wesentliche Aussagen zu den zentralen Themen; "Čistyj ponedel'nik" darf daruber hinaus gemeinsam mit „Časovnja“ als Schlußakkord gelten. Zusätzlich fallen auch die Erzählungen „Madrid““ und "Voron" in diese Kategorie, denn obwohl sie keine Kernaussagen beinhalten, wurden sie von Bunin als wichtig eingestuft. Durch Zuordnung zu den Kernerzählungen sorgen sie zudem für einen inneren Zusammenhalt des umfangreichen dritten Komplexes, der anderenfalls Gefahr liefe zu zerfasern.

Eine Sonderstellung unter den Kernerzählungen nehmen „Ballada“ (erster Komplex) und „Železnaja Šerst'“ (dritter Komplex) ein, da ihr legenden- bzw. märchenhaft anmutender Charakter mit Verwendung entsprechender Stilelemente sie von den übrigen realistischen Darstellungen abhebt. Ihre Aufnahme in das Buch kann mit Bunins Wunsch nach Berucksichtigung verschiedener Erzählgattungen erklärt werden, um dadurch dem Facettenreichtum von Liebe und Tod umfassenden Ausdruck zu verleihen.

\subsubsection{Die Ankererzählung: "Natali"}

Die dominanten Ankererzăhlungen (Anchor Stories) sind Rolf Lundén zufolge durch ihre besondere Bedeutung für die jeweilige Kurzprosaverknüpfung und ihre Länge gekennzeichnet (,kleiner Roman“), mit der sie andere Erzählungen zumindest zeitweise zu über- 
schatten drohen. ${ }^{263}$ In der Regel positioniert der Autor eine Erzăhlung dieses Typs in der Mitte oder am Ende der Kurzprosaverknüpfung.

Tatsächlich befindet sich die Erzählung „Natali“ an einer strategisch bedeutsamen Stelle: in der Mitte des Buches sowie gleichzeitig am Ende des zweiten Komplexes - und damit an einem zentralen Ort. Darüber hinaus ist sie die umfangreichste Erzählung und verfügt als einzige über sichtbar gemachte Einteilungen in sieben Unterkapitel und einen sehr kurzen Epilog. Die durch diese Unterteilung entstandenen Abstände zwischen den erzählten Zeiteinheiten verdeutlichen einerseits in diesem fortlaufenden Rückblick, welche Ereignisse im Leben des Protagonisten wirklich wichtig waren, und sorgen andererseits für einen Spannungsaufbau beim Leser. ${ }^{264}$ Der Wert, den Bunin „Natali“ beimaß, ebenso wie ihr Alleinstellungscharakter spiegeln sich vor allem in den zahlreichen Korrekturläufen wider, denen er diese Erzählung unterzog ${ }^{265}$, aber auch in den wiederholten Versuchen einer separaten Publikation in französischer Sprache (vgl. Kap. 9.3.1).

Die Handlung wird aus der Sicht des Ich-Erzählers und Protagonisten Mešcerskij dargeboten und setzt ein mit seiner Erinnerung an einen Ferienaufenthalt auf dem Gut seines Onkels. Wild entschlossen, sich in diesem Sommer von seiner physischen Unberührtheit zu befreien („нскать любви без романтики“, 6: 302), stürzt er sich bereits am Abend seiner Ankunft in einen heftigen, heimlichen Flirt mit seiner Cousine Sonja. Ihren Warnungen, daß er sich zweifellos unglücklich in ihre gleichfalls auf dem Gut weilende Freundin Natali verlieben werde, schenkt er keine Beachtung (I). Nach einer ersten flüchtigen Begegnung mit Natali ist er zwar von ihrer Schönheit eingenommen, fühlt aber lediglich eine Art spontaner Verbundenheit mit ihr als potentieller Mitwisserin seines Verhältnisses mit Sonja. Zur Verschleierung ihrer Affäre fordert Sonja Mešcerskij nachdrücklich auf, eine Verliebtheit in Natali vorzutäuschen, wobei sie ihn gleichzeitig davor warnt, sich tat-

$263 \mathrm{Vgl}$. R. Lundén. op.cit.: 124. Vgl. in diesem Zusammenhang auch Bunins eigene Bezeichnung der Erzashlung "Natali" als ..malen'kij roman" in einem Brief an Boris Zajcev vom 08.11.1943 (zit. in: „Pis'ma I. Bunina k B. Zajcevu“. In: Nz 136 [1979]: 139).

264 Es uberrascht nicht, daß Jurij Mal'cev zur Illustrierung der Funktionsweise dieses Spannungsaußbaus einen aus der Musik entlehnten Vergleich heranzieht: ,.[...] зффект подобен тому, хакой имеет пауза в кульмннацнонном моменте музыкального пронзведення" (vgl. Ju. Mal'cev. Bunin. op.cit.: 331).

$265 \mathrm{Vgl}$. die Schilderung der intensiven Arbeit an dieser Erzahlung in Kap. 3.2; vgl. Hinweise auf Überarbeitungen von "Natali" in den Tagebucheinträgen vom 11.04.1941 und 25.09.1941 bzw. 15.04.1941 (zit. in: UB. 3.Bd. op.cit.: 91 und 113 bzw. LRA. MS.1066/533) sowie Belege fur das Versenden bzw. Überbringenlassen überarbeiteter Fassungen dieser Erzahlung an Mark Aldanov, so etwa am 18.04.194I (Brief an Aldanov vom 06.05.1941) und Anfang Juli 1941 (Brief an Aldanov vom 09.07.1941), mit der Bitte, die zuvor geschickten Versionen zu vemichten (beide zit. in: „Perepiska I. A. Bunina S M. A. Aldanovym. In: Nz 150 [1983]: 164 bzw. 166). An Boris Zajcev schickte Bunin am 21.11.1943 eine weitere, die nach eigenem Bekunden endgultige Fassung, erganzt um den Hinweis, daB im Novyj zurnal nicht die Endredaktion publiziert worden sei (zit. in: „Pis'ma I. Bunina k B. Zajcevu“. In: NE 137 [1979]: 127). 
sächlich in diese zu verlieben - nun nicht mehr im Spaß (II). Mešcerskij läßt sich leichtherzig auf diesen Handel ein, findet sich jedoch rasch in einer Zwickmühle wieder, als er sich darüber klar wird, daß er sich unmerklich tatsächlich in Natali verliebt hat. Seine ersten Annäherungsversuche bleiben jedoch erfolglos, zumal er der Begründung ihrer abweisenden Haltung, daß er doch eigentlich Sonja liebe, nur eine Lüge entgegensetzen kann (III). Als Sonja sich für einige Tage aus gesundheitlichen Grinden zurückzieht, setzt Mešcerskij alles daran, Natalis Herz zu erobern. Ein abendlicher Spaziergang, bei dem sie ihm ihre Liebe gesteht, scheint sein Glück zu besiegeln. Sie planen ihre Zukunft: Natali soll am folgenden Tag abreisen, während Mešcerskij ihr in wenigen Tagen folgen würde (IV). Doch die folgende Nacht, in der ein heftiges Gewitter niedergeht, macht alle Pläne zunichte: Natali, die angsterfullt auf der Suche nach Sonja durch das Haus geht, ertappt ihre Freundin und Mešcerskij in einer kompromittierenden Situation auf dem Divan. Damit scheinen alle Hoffnungen auf eine gemeinsame Zukunft zerstört zu sein (V). Diese Vermutung findet ihre offizielle Bestätigung in Natalis Heirat ein Jahr spăter. Dennoch kommt es in der Folge zu zwei Begegnungen zwischen Mešcerskij und Natali. Wenige Monate nach ihrer Hochzeit trifft er sie zufällig auf einem Ball in Begleitung ihres Mannes. Alte Wunden brechen wieder auf, und er verläßt das Fest überstürzt. Anlaß der zweiten Begegnung ist der Tod ihres Ehemannes anderthalb Jahre später. Auf der Trauerfeier trifft Meščerskij zwar mit Natali zusammen, wechselt jedoch über die konventionellen Beileidsbekundungen hinaus kein Wort mit ihr (VI). Als nach Abschluß seiner Studien kurz nacheinander seine Eltern sterben, zieht er sich resignierend auf das Familiengut zuruck und lebt mit einer Bediensteten und dem gemeinsamen Kind zusammen. Die Rückreise von einem Auslandsaufenthalt führt ihn eines Tages in die Năhe von Natalis Gut. Meščerskij, der nichts mehr vom Leben zu erwarten hat, bittet um die Erlaubnis, sie besuchen zu dürfen, und berichtet ihr von seiner unveränderten Liebe, die er nach so vielen Jahren des hoffnungslosen Sehnens für gelăutert und selbstlos hält. Doch auch Natali hat sich ihre Gefuhle für ihn bewahrt; in jener Nacht wird sie seine Geliebte, ohne offiziell seine Frau werden zu können, da die Dienstbotin ihren Selbstmord und die Ermordung des Kindes angekündigt hatte für den Fall, daß Mešcerskij heiraten sollte (VII). Das nach vielen Jahren wiedergefundene Glück ist jedoch nicht von Dauer, da Natali kurze Zeit später an den Folgen einer Frühgeburt stirbt (Epilog).

Die Relevanz dieser Erzählung fưr das Buch allein mit ihrer Länge zu erklären, hieße jedoch, ihrer Bedeutung nicht umfassend gerecht zu werden. Ihre besondere Position wird 
auch dadurch gerechtfertigt, daß sie sich intensiv mit den zentralen Themen Liebe, Tod und Erinnerung auseinandersetzt und über für einen Großteil der Erzählungen der Temnye allei typische Strukturelemente verfügt, wie beispielsweise die Darstellung der Ereignisse im Rückblick, die Schilderung von Momenten bzw. sehr kurzen Zeitabschnitten und das Medium des Reisens als äußere Umsetzung des inneren Unterwegsseins zu einer Frau. Charakteristisch ist zudem die Gestaltung des Schlusses, der in Form eines lakonisch wirkenden zweizeiligen Epilogs zunächst unmotiviert erscheint, gleichwohl ein Paradebeispiel ist für Bunins Verfahren, die menschliche Ohnmacht vor dem unbarmherzigen und unberechenbaren Schicksal sichtbar zu machen.

„Natali“ verfügt durch die oben genannten Merkmale nicht nur über Verbindungen zu einer Vielzahl der übrigen Erzählungen der Temnye allei, sondern stellt über die thematische Ähnlichkeit auch einen Bezug bzw. einen Gegenentwurf zu der 1924 entstandenen Erzählung „Mitina ljubov”“ her. Wie Mitja leidet Mescerskij unter dem Zwiespalt zwischen körperlicher Begierde und reiner Liebe ${ }^{266}$ - im Gegensatz zu „Mitina ljubov““ bietet Bunin in „Natali“ jedoch eine Versöhnung der sich scheinbar ausschließenden Gefühlszustände in einer wenn auch nur kurzzeitigen Erfülung: Wăhrend Mitja zerbricht unter dem Andrang seiner physischen Bedürfnisse, die den Sieg über sein Idealbild von der Liebe davontragen, gelingt es Mešcerskij durch eine glückliche Fügung, den körperlichen und seelischen Aspekt der Liebe auf eine Person zu konzentrieren, nachdem er zuvor gezwungen war, seine körperlichen Sehnsüchte getrennt von seinem Gefühl zu befriedigen. Der Widerstreit spiegelt sich deutlich in der Zweiteilung der Erzählung wider: Deren eine Hälfte beschäftigt sich mit seinem Leiden an der Diskrepanz zwischen physischer Begierde und „körperloser" Liebe, die andere mit seinem Leiden an der Liebe, am Fehlen des Liebesobjekts, an seinem resignierenden Sichhineinbegeben in einen unerwinschten Zustand, welcher deutlich zeigt, daß die körperliche Befriedigung nicht zwangsläufig auch einen zufriedenen Seelenzustand nach sich zieht. Dieser innere Zwiespalt wird in keiner anderen Erzählung der Temnye allei so detailliert beschrieben, und es kann als Ausdruck der Zufriedenheit des Autors mit einer gelungenen Darstellung gewertet werden, daß Bunin die einzige Erzählung mit einer vergleichbaren Thematik, die 1938 entstandene Erzăhlung .Aprel'“, aus der 1944 vorgenommenen Aufstellung eines möglichen Inhaltsverzeichnisses

266 Diesbezuglich gibt Bunin in einem Brief an Boris Zajeev vom 08.11.1943 folgende Erlăuterung: „Bor B .Натали' две любви, как вообще бывают две любви и две ненависти и одна нз ннх иногда вдруг перескливает другую“" (zit. in: „Pis'ma I. Bunina k B. Zajcevu“. In: Nz 136 [1979]: 140). 
wieder entfernte (vgl. Anhang 2), da die dortige Ausgestaltung dieses Themas seinen Ansprulchen möglicherweise nicht mehr genügte (vgl. Kap. 3.5.1).

Die strukturbildende Funktion der Ankererzählung „Natali“ erschöpft sich indessen ebensowenig in ihrer zentralen Positionierung wie in ihrer Länge oder thematischen Ausrichtung. Sie dient darüber hinaus als Bindeglied zwischen der ersten und der vorletzten Erzählung ${ }^{267}$ und sorgt in dieser Funktion für einen strukturellen Zusammenhalt des Buches. Die vermeintliche Dominanz dieser Erzählung relativiert sich bei einer Gesamtschau aller Erzählungen. Anhand ausgewählter Beispiele soll im folgenden verdeutlicht werden, wie eine Fülle von Details und Parallelen auf verschiedenen Ebenen Brücken zwischen diesen drei Erzählungen schlagen:

- In ihren Kernaussagen korrespondiert „Natali“ bezüglich der Vergänglichkeit mit der Erzăhlung „Temnye allei“, hinsichtlich unglücklicher Liebe mit „Čistyj ponedel'nik“: Das „Bce npoxодит“" (6:177) aus „Temnye allei“ findet sich in „Natali“ in folgender Variation wieder: „Ведь все на свете проходит“ (6: 328), während Natalis rhetorische Frage zum Wesen der Liebe, „Хотя разве бывает несчастная любовь?“ $(6: 328)^{268}$, einer ähnlichen Aussage in „Cistyj ponedel'nik“ entspricht: „все-таки счастье, великое счастье“ (6: 403).

- Nur in diesen drei Erzählungen finden zufälige Wiederbegegnungen von ehemaligen Liebespaaren statt, in denen die Vergangenheit lebendig wird. Wăhrend es in „Natali“ jedoch die Gelegenheit zu einem wenn auch nicht dauerhaften Neuanfang gibt, ist diese Möglichkeit in den beiden anderen Erzählungen ausgeschlossen.

- Übereinstimmung läßt sich in der farblich kontrastierenden Ausgestaltung der Protagonisten in jeder der drei Erzählungen registrieren: Während im Äußeren der männlichen Hauptfiguren die Farben schwarz und grau dominieren. heben sich ihre weiblichen Pendants farblich auffallend von ihnen ab, entsprechend dem Stellenwert der Frau in allen Erzählungen der Temnye allei-und entsprechend dem Bild der roten Heckenrose, die vor dem Hintergrund der dunklen Alleen an Leuchtkraft gewinnt.

267 „Cistyj ponedel'nik“ bildet gemeinsam mit „Casovnja“ den abschließenden Zweiklang des Buches (vgl. Kap. 4.5).

268 Julian Connolly stellt fest, daß sich diese Frage und Mešcerskijs Replik - „И ты правду сказала: нет несчастной любви“ (6: 161) - als Motto fur das Buch eignen warden, denn .despite the suffering that love may cause, it still illuminates and transforms one's life" (J. Connolly. Ivan Bunin. op.cit.: 130). Dieser Gedanke hat etwas fur sich; die Wahl der ersten Erzahlung als Motto fur das gesamte Buch hingegen erreicht eine ungleich tiefere, umfassendere und poetischere Dimenșion. 
- Die Protagonistinnen aller Erzăhlungen weisen als besonderes Schönheitsmerkmal einen leichten Flaum auf der Oberlippe auf (in „Natali“ ist dieser Mešcerskijs Cousine Sonja zu eigen).

- In der Erzählung „Natali“ schreiten Mešxerskij und seine Angebetete durch jene dunklen Alleen, die der Eröffnungserzählung „Temnye allei“ ihren Titel gaben; „Natali“ und „Čistyj ponedel'nik“ hingegen sind (gemeinsam mit der Erzählung „Genrich“) durch die Erwăhnung der Menstruation miteinander verbunden.

Während einzelne Strahlen dieser Ankererzählung auch zu anderen Erzählungen reichen $^{269}$, weist "Natali“ jedoch außerdem eine thematische Besonderheit auf, die sie aus dem Kreise der ubrigen Erzăhlungen heraushebt und die ihre Sonderstellung in den Temnye allei weiter untermauert: Sie ist die einzige Erzählung, in der auf der Ebene der Hauptfiguren eine innige Beziehung zwischen zwei Freundinnen dargestellt wird. ${ }^{270}$ In diesem Zusammenhang verdient vor allem die eindringliche, ja geradezu werbende Beschreibung von Natali, die Sonja Mešcerskij gegenüber abgibt, besondere Beachtung und wirft die Frage auf, ob nicht auch sie sich über die reine Freundschaft hinaus von ihrer schönen Freundin erotisch angezogen fühlt. ${ }^{271}$ Dem Rezipienten mag diese Lesartmöglichkeit auf den ersten Blick nicht auffallen, da er die Geschehnisse aus Sicht Mešerskijs verfolgt und dieser es inmitten des hitzigen Flirts mit seiner Cousine nicht wahrnimmt, daß Sonja ihre Freundin auf ungewöhnliche Art und Weise anpreist, geschweige denn dieses Verhalten hinterfragt. In diese Richtung weist auch ihre nur als eifersüchtig zu bezeichnende Reaktion, als sie Mešcerskij jeden verliebten Umgang mit Natali kategorisch untersagt und seine Nähe ganz für sich beansprucht.

Ihre Funktion als Ankererzählung erfüllt „Natali“ somit den obigen Ausführungen zufolge uber rein thematische Ähnlichkeiten hinaus sowohl durch ihre dominante Stellung

269 Mit den Erzahlungen „Duroxka“ und „Krasavica“ etwa ist sie durch die Darstellung von Schwangerbzw. Mutterschaft verbunden (hingegen ist sie die einzige Erzahlung, in der die Protagonistin durch eine Fehlgeburt zu Tode kommt). Mit den Erzahlungen ..Rusja“. „Vtoroj kofejnik" und "Mest" wiederum hat sie die Darstellung von badenden Frauen gemeinsam. Und „Natali“ und „Rusja“ sind die einzigen Erzahlungen, in denen Hochzeit gefeiert wird nicht in einer konventionellen Zeremonie, sondern im Rahmen einer intensiven Liebesnacht. Es ließen sich noch zahlreiche weitere Beispiele anfuhren, die jedoch den Rahmen dieses Kapitels sprengen wüden.

270 Lediglich auf der Ebene der Nebenfiguren wird in der Erzahlung ...Madrid“' auf ein lesbisches Liebespaar hingewiesen (6: 354-355).

27I Im Gegensatz zu Tatyana Mamonova, der zufolge es fur den Autor undenkbar gewesen sei, ,that Sonya could feel an attraction to her [Natali]", sollte eingedenk Bunins eigener Erfahrungen im Hinblick auf lesbische Liebe diese Möglichkeit keinesfalls ausgeschlossen werden (vgl. T. Mamonova. .The Shadowed Paths of Ivan Bunin". In: dies. Russian Women's Studies. Oxford, 1989: 63). 
samt ihren Alleinstellungsmerkmalen und ihrer strukturbildenden Funktion als auch durch ihre Verbindungen zu anderen Erzählungen der Temnye allei.

\subsection{Die Satelliten- und Randerzählungen}

Der offene Charakter von Kurzprosaverknüpfungen bringt es mit sich, daß auch Erzählungen aufgenommen werden können, die von geringerer Bedeutung für die semantische Aussage des Buches sind. Lundén bezeichnet diese als Satellitenerzählungen (Satellite Stories). In ihrer extremen Form scheinen sie auf den ersten Blick über keinerlei Bindungen zu den übrigen Erzăhlungen zu verfügen und fallen damit in die Kategorie der Randerzählungen (Fringe Stories). Wăhrend die Satellitenerzăhlungen jedoch noch deutliche Bezüge zu den Kernerzählungen aufweisen, haben die Randerzählungen eine gănzlich marginale Bedeutung. Es hieße jedoch, diesen beiden Typen von Erzählungen nicht gerecht zu werden, wollte man sie gewaltsam in das Schema der anderen Erzählungen hineinpressen. ${ }^{272}$ Ihre zentrale Funktion besteht darin, den Leser in eine Sackgasse zu fuhren, indem sie seine Erwartungshaltung nach Kohärenz und Geschlossenheit enttäuschen und ihn gerade dadurch zu der Erkenntnis gelangen lassen, daß die gebrochene und offene Struktur ein signifikantes Charakteristikum der Kurzprosaverknüpfung darstellt.

\subsection{Satellitenerzählungen in den Temnye allei}

Wie bei den Kernerzählungen läßt sich auch hier eine ausgewogene Verteilung auf die einzelnen Komplexe feststellen. Folgende 14 Erzählungen sind auf Grund ihres zweitrangigen inhaltlichen Stellenwertes als Satellitenerzählungen zu klassifizieren:

Komplex I: „Kavkaz“, „Stepa“, „Muza“

Komplex II: „Durocka“, „Antigona“, „Gost”“, „Volki“

Komplex III: „Kuma“, „Načalo“, „,Dubki““, „Baryšnja Klara“, „Parochod ,Saratov““, .Mest"“, „Kaceli“. 
In den oben genannten Erzăhlungen lassen sich zwar zahlreiche Analogien zu den Kemerzählungen ausmachen, die thematischer bzw. motivischer oder gestalterischer Natur sind und ihre Zugehörigkeit zu den Temmye allei klar belegen. Die Austauschbarkeit dieser Erzăhlungen ist - im Gegensatz zu den Kernerzăhlungen - indessen nicht von der Hand zu weisen. Dies wird vor allem deutlich bei einer vergleichenden Betrachtung jener unveröffentlichten Erzăhlungen, die im selben Zeitraum wie etliche der Erzăhlungen aus dem dritten Komplex verfaßt wurden (1943/44), von denen ein Großteil sich ohne weiteres in die Temnye allei hätte integrieren lassen (vgl. Kap. 3.5.1); die Gründe, die Bunin zur Aufnahme dieser und jener Erzăhlung bewogen haben mögen, wurden in Kapitel 3.5 erörtert sei es, daß ihn bei einigen Erzählungen die Furcht vor negativen Reaktionen auf den Inhalt abhielt oder die Einsicht, daß Erzăhlungen wie etwa „,Un petit accident ““ sich zu stark von der Struktur der in die Temnye allei aufgenommenen Erzahlungen unterscheiden und eine neue Tendenz in seinem Schaffen ankündigen, oder sei es, daß er Wiederholungen vermeiden wollte, wie sie sich etwa durch die Aufnahme der Erzăhlungen „Aprel”“ (Ähnlichkeit mit „Natali“) oder „Tri rublja“ (Ähnlichkeit mit „Madrid”) ergeben hătten. Möglicherweise erschienen ihm zudem einzelne Erzählungen nicht vollendet genug.

Ohne an dieser Stelle die Analogien jeder einzelnen Satellitenerzählung mit den Kemerzăhlungen diskutieren zu wollen (ausgewăhlte Analogien werden in den Folgekapiteln vorgestellt), sei zumindest darauf hingewiesen, daß die Austauschbarkeit der Erzählungen auf Grund dieser Parallelen und Bezüge keinesfalls mit Beliebigkeit gleichzusetzen ist. Die Aufgabe dieser Erzählungen ist neben den bereits erwähnten darin zu sehen, den Leser für die Variationsbreite der Themen Liebe und Tod zu sensibilisieren und durch die Lektüre von Erzählungen nachgeordneter Bedeutung seinen Blick für die Kernerzählungen zu schärfen. Vergleichbares gilt für die Randerzăhlungen.

\subsubsection{Randerzählungen in den Temnye allei}

In diese Kategorie fallen fünf Erzăhlungen. Sie weisen so gut wie keine Analogien zu den Kernerıăhlungen auf und scheinen zunächst für die Bedeutung des Buches von keiner erkennbaren Relevanz zu sein. Während der erste Komplex keine Randerzählungen enthält, beinhaltet der zweite Komplex zwei (,Krasavica“ und „Smaragd“) und der dritte Komplex drei Erzählungen dieses Typs („Vtoroj kofejnik“, „Kamarg“ und „Sto rupij“) - 
auch bei der Verteilung dieser Erzählungen auf die einzelnen Komplexe wahrte Bunin demzufolge die Proportionalităt. Allen Erzăhlungen ist gemeinsam, daß sie aus dem Buch entfernt werden könnten, ohne daß es dessen Gehalt und Aussagekraft merklich schmälern würde.

Die genannten Erzahlungen zeichnen sich allesamt durch Handlungsarmut aus; in ihnen dominieren Beschreibungen und/oder Dialoge. „Krasavica“ ist die einzige Erzählung, die das Gefühlsleben eines Kindes in den Mittelpunkt stellt, während die titelgebende „Schơnheit" uberhaupt nicht in Erscheinung trith, gleichwohl dennoch präsent ist. „Smaragd“" und „Vtoroj kofejnik“ geben jeweils einen Dialog zwischen einem Liebespaar wieder, weisen aber keine Handlung auf und sind auf Grund dessen jener Kategorie von Bunins Erzăhlungen zuzuordnen, die sich auf unkommentierte Augenblicksausschnitte ohne jegliche Dekoration konzentrieren. „Kamarg“ und „Sto rupij“ wiederum enthalten jeweils lediglich die präzise Beschreibung einer Frau. Dadurch haben sie zwar einen Bezug zu den übrigen Erzăhlungen, in denen der Zeichnung der weiblichen Protagonisten ebenfalls erhöhte Aufmerksamkeit geschenkt wird, verfügen aber im Gegensatz zu jenen über so gut wie keine Aussagekraft. Mit ihrer objektiven Darstellungsweise kündigen diese beiden Erzählungen den künstlerischen Wechsel Bunins zu statischen Momentaufnahmen an oder zu Erzăhlungen mit einem minimalen Handlungsgeschehen.

\subsection{Diskussion eines Rahmens}

$\mathrm{Da}$ in modemen Kurzprosaverknüpfungen im allgemeinen auf eine alle Erzählungen umschließende Rahmenhandlung verzichtet wird, übernehmen häufig-aber nicht zwangsläufig - die erste und die letzte Erzăhlung diese Funktion. Diese Beobachtung triff auch auf die Temnye allei zu, ergänzt um die Besonderheit, daß neben dieser großen Spange drei kleine Klammem existieren, die die einzelnen Komplexe umschließen. Diese entstanden durch die gezielte Plazierung der Eröffnungs- und Finalerzählungen und werden beherrscht vom Spannungsfeld Liebe-Tod/Vergänglichkeit - Erinnerung (vgl. Kap. 4.3.1).

In jedem der drei Komplexe läßt sich eine spezifische Verbindung zwischen der Eröffnungs- und der Finalerzăhlung konstatieren, die über die alle Erzählungen der Temnye allei beherrschende Darstellung der Bipolarität von Liebe und Tod hinausgeht. Die entspre- 
chenden Erzăhlungen des ersten Komplexes, „Temnye allei“ und „Pozdnij cas“, haben beide Erinnerungen an eine viele Jahre zurückliegende Romanze zum Inhalt. Wăhrend jedoch der Protagonist der Eröffnungserzăhlung seine Entscheidung, die Liebesbeziehung den gesellschaftlichen Konventionen zum Opfer zu bringen, nicht bereut, hat der Protagonist der Finalerzählung nicht einmal mehr die Gelegenheit, an die Vergangenheit anzuknüpfen. Das Kopfschütteln des Offiziers bei der Vorstellung, daß er seine damalige Geliebte zur Frau hätte nehmen können, steht in krassem Gegensatz zu der Unmöglichkeit der Rückkehr des Protagonisten der Erzählung „Pozdnij cas“ in eine glückliche Vergangenheit, die offensichtlich ohne sein persönliches Zutun ein jähes Ende fand.

Der zweite Komplex wird eingerahmt von den Erzählungen „Rusja“ und „Natali“. Die von A. Ačatova vertretene Meinung, "Natali“ sei die logische Vollendung von "Rusja“, wirkt auf den ersten Blick nachvollziehbar. ${ }^{273}$ In der Tat schildern beide Erzăhlungen eine aufblühende junge Liebe in der Sommerfrische. Während jedoch in „Rusja“ die Mutter des jungen Mädchens der Liebelei ein Ende setzt und den jungen Mann des Hauses verweist, bringt sich der Protagonist in "Natali“ durch eigene Schuld um die Früchte seines Werbens, die ihm erst nach Jahren der emotionalen Qual doch noch zuteil werden. Zudem lassen sich beide Erzählungen nicht ohne weiteres auf eine Stufe stellen, da die thematischen Dimensionen in „Natali“ ungleich vielschichtiger sind (vgl. Kap. 4.3.3).

Die Spannung zwischen den betreffenden Erzählungen des dritten Komplexes, „V odnoj znakomoj ulice“ und „Casovnja“, speist sich aus dem höchst unterschiedlichen Umgang mit einer Liebesaffäre. Während der Protagonist der Eröffnungserzählung gedankenlos seine Tändelei mit einem jungen Mädchen abgebrochen hat und auch in seiner Erinnerung leichtfertig diese Affäre abtut, gingen die Gefuhle des namenlosen Onkels, der freiwillig aus dem Leben schied, offenbar deutlich tiefer.

Diese Klammern um die einzelnen Komplexe dehnen sich aus auf die große Spange, bestehend aus der ersten Erzăhlung (,Temnye allei“) und den beiden letzten Erzählungen ("Cistyj ponedel'nik" und „Casovnja“). Die besondere Spannung zwischen diesen Erzahhlungen entsteht vor allem bei der Betrachtung des Endes der einzelnen Liebesbeziehungen, die Bunins Liebeskonzeption zufolge ohnehin keine Zukunft haben (vgl. Kap. 8.1.1). Dem schmählichen Abbruch einer offensichtlich tiefgehenden Romanze in "Temnye allei“ ste-

273 A. Acatova. .Pozdnjaja liriceskaja novella I. A. Bunina. (K voprosu o kompozicii)“. In: Izvestija Voronetskogo gosudarsivennogo pedagogiceskogo institufa. 114.Bd. Voronez, 1971: 116. 
hen der Gang ins Kloster ("Čistyj ponedel'nik“) bzw. ein Selbstmord („Casovnja“) gegenuber. Die an Erkenntnis reiche Konsequenz, die sowohl dem Freitod des Protagonisten der Erzăhlung "Časovnja“, der offenbar keine Zukunft für seine Liebe gesehen hat, als auch der Entsagung des weltlichen Lebens der Protagonistin aus „Cistyj ponedel'nik“, die sich vom rein spirituellen Leben mehr Erfullung verspricht, innewohnt, steht in scharfem Kontrast zu der reuevollen und schamerfullten Begegnung zwischen dem Offizier und seiner ehemaligen Geliebten in "Temnye allei“".

In der Schauplatzgestaltung findet das nasse und ungemütliche Herbstwetter der „Temnye allei" seinen Kontrapunkt in der sommerlichen Hitze eines in voller Blüte stehenden Gartens in "Časovnja“ - es ließe sich auch solcherart formulieren, daß die dunklen Alleen der Titelerzählung über die Rotonde in der Ankererzählung „Natali“ direkt in die Gruft fuhren, daß es aller Lebensfreude zum Trotz kein Entrinnen vor dem Tod gibt. Und obwohl in keiner anderen Erzählung so konzis und vielsagend wie in „Časovnja“ der Triumph des Todes über das Leben und das Ende der Liebe beschrieben wird, wobei Bunin es der Phantasie des Lesers überläßt, sich die Vorgeschichte auszumalen, ermutigt diese Erzăhlung in ihrer Darstellung dessen, daß das Leben dem Tode zum Trotz weitergeht, ungleich stärker zum Leben und zur Liebe als das resignierende Fortsetzen einer Lebensweise unter Rückstellung aller emotionalen Bedürfnisse, wie es in der Erzählung „Temnye allei“ thematisiert wird.

Mit der Erzählung "Čistyj ponedel'nik“ hat die Titelerzählung "Temnye allei“" gemein, daß es zu einer direkten Konfrontation der Gegenwar mit der Vergangenheit in Form eines leibhaftigen Wiedersehens des Protagonisten mit seiner ehemaligen Gefährtin kommt eine solche Begegnung findet nur noch in der Erzählung "Natali“ statt, mit dem Unterschied, daß dort die Protagonisten eine zweite Chance bekommen und diese auch nutzen. Während die Sinnlosigkeit eines solchen Zusammentreffens in "Temnye allei" in einem quälenden Gespräch zum Ausdruck kommt, ist in "Čistyj ponedel'nik“ eine Kommunikation schlechterdings nicht mehr möglich - und auch überflüssig, da Vergangenes ohnehin nicht zu neuem Leben erweckt werden kann, denn: „... мертвых с погоста не носят“ (,Temnye allei“, 6: 178). Versinnbildlicht werden die Unaufhaltsamkeit des Fortschreitens der Zeit und die Unmöglichkeit einer nachträglichen Einwirkung auf vergangene Ereignisse durch zwei Zitate, bei denen die Flüchtigkeit und die trügerischen Eigenschaften flieBenden Wassers im Mittelpunkt der jeweiligen Aussage stehen. Dem biblischen Zitat aus dem Buch Hiob in der Erzählung „Temnye allei“ („Как о воде протекшей будешь вспоминать“, 6: 177; Hiob 11, Vers 16) steht ein Zitat aus Tolstojs Vojna i mir in „Čistyj 
ponedel'nik“ gegenüber („Счастье наше, дружок, как вода в бредне: тянешьнадулось, а вытащишь - ничего нету“274, 6: 403).

Nur der Vollständigkeit halber soll am Rande vermerkt werden, daß in den rahmenbildenden Erzăhlungen alle vier Jahreszeiten enthalten sind, die am Anfang und Ende des Buches einander komplementär gegenübergestellt sind: Während "Temnye allei“ im Herbst spielt, sich aber auf einen vergangenen Frühling (im übertragenen Sinne auch auf den des Lebens) bezieht, findet die Handlung in „Cistyj ponedel'nik“ im Winter stat, um dann unvermittelt in der letzten Erzăhlung "Casovnja“ in einen heißen Sommertag überzugehen.

In diesem Zusammenhang soll auch jener Rahmen diskutiert werden. der durch die Hinzufügung der beiden Erzăhlungen „Vesnoj, v ludee“ (1946) und „Nočleg“ (23. März 1949) entstehen würde, die Bunin nach Veröffentlichung der Pariser Ausgabe von 1946 einer undatierten Anmerkung in seinem persönlichen Exemplar zufolge ans Ende der Temnye allei gestellt wissen möchte:

В конце этой книги (следуя хронологии) надо прнбавить „Весной, в Иудее“ и "Ночлег". Текст этих рассказов взять из монх сборников этих же заглавий, изданных „Чеховским издательством“ в Нью-Йорке. ${ }^{275}$

Während dieser Eintrag aller Wahrscheinlichkeit nach 1953, dem Erscheinungsjahr von Vesnoj. v ludee, erfolgte, läßt sich das Aufkeimen dieser Idee zeitlich bedeutend schwieriger eingrenzen. Ein Interview mit der niederländischen Zeitschrift Het Parool anlæßlich seines 80. Geburtstags 1950 scheint darauf hinzudeuten, daß Bunin sich zu diesem Zeitpunkt zumindest bezüglich der übersetzten Ausgaben der Temnye allei für diese Änderung entschieden hat: „Tijdens de Duitse bezetting hier heb ik een bundel novellen geschreven, o.a. ,De Herberg', die straks in England en Frankrijk zal uitkomen. ${ }^{276}$ Auch Julia Sazonova gegenüber, die sich Anfang der 1950er Jahre in den USA um eine englischsprachige Übersetzung bemühte, äußerte er in einem Brief vom 13. Mai $1953^{277}$ den Wunsch, die beiden später entstandenen Erzählungen bei einer Veröffentlichung zu berücksichtigen, obgleich eine offenbar später entstandene, für Sazonova zusammengestellte, aber nicht

274 L. Tolstoj. Vojna i mir. Moskva, 1983: 468.

275 Dieses Exemplar wird im Moskauer IMLI verwahr.

276 Ohne Verfasserangabe. „Iwan Boenin in kamerjas. Gesprek met 80-jarige emigrant-schriver“. In: Het Parool (28.10.1950).

277 LRA. MS. 1066/4931. 
abgeschickte Liste keine der beiden Erzählungen im Zusammenhang mit den Temnye allei nennt (vgl. Kap. 3.3).

Der Sinn dieser Ergänzung bleibt daher nebelhaft, denn beide nachträglich an das Textkorpus angefügten Erzählungen fallen in mehrfacher Hinsicht aus dem Rahmen: Zum ersten zerstört die bloße Addition dieser Erzählungen die Einheit des Buches, die mit der letzten Erzählung „Časovnja“ ihre Abrundung erfăhrt. Zum zweiten sind beide Erzählungen spăter als die übrigen des dritten Komplexes entstanden und fügen sich schon durch die Wahl der Schauplătze (Judãa und Spanien) nicht in die in den übrigen Erzählungen bestehende Konzentration auf Rußland und Frankreich ein. ${ }^{278}$ Zum dritten bezog sich Bunin noch ein Jahr vor seinem Tode, in einem Brief vom 12. Oktober 1952 an Fedor Stepun, im Rahmen einer Aufstellung seiner Erzăhlungen (,Rody moich soxinenij“, vgl. Kap. 3.3) in der Rubrik mit dem Titel „Kniga ,Temnye allei“" auf die Zusammensetzung der Pariser Ausgabe von 1946, ohne auf die Zugehörigkeit der beiden genannten Erzählungen hinzuweisen. In der Rubrik „o ljubvi“ wiederum führte Bunin die beiden Erzählungen neben den Temnye allei auf und versah sie mit der ihre Wichtigkeit kennzeichnenden Bemerkung „N.B.“. ${ }^{279}$ Möglicherweise war ihm in erster Linie daran gelegen, diese beiden als bedeutungsvoll für sein Schaffen klassifizierten Erzählungen zur Publikation zu bringen, denn ursprünglich hatte er zumindest „Noxleg“ nicht unter dem Aspekt der Aufnahme in die Temnye allei geschrieben. In einem Brief an Téffi vom 30. März 1949 berichtet Aldanov von den Hintergründen der Entstehung dieser Erzählung:

Читал его [Бунина] рассказ для книги Рогнедова. [...] Сам он говорит (как и Вы), что рассказ никуда не годится, что он разучился писать и т[ак] д[алее]!!! [...] Впрочем, Рогнедов просил Ивана Алексеевича написать рассказ в духе ,Темных anreй. ${ }^{280}$

In der Sekundärliteratur findet sich einzig in dem Artikel von A. Acatova die Ansicht, $\mathrm{daß}$ diese nachtrăgliche Plazierung logisch und emotional gerechtfertigt $\mathrm{se}^{281}$, da ihrer Meinung nach in dem Vergewaltigungsversuch alle Gewalttätigkeiten kulminierten, die vor allem im dritten Komplex zu finden seien. In der Tat fallt der dritte Komplex durch eine Hăufung von Grausamkeiten auf (z.B. die Morde in den Erzählungen ,,Dubki““,

278 Der Einwand, daß die Erzahlung .Sto rupij“ in Übersee spielt und deshalb ebenfalls weder nussisch noch franzosisch gepragt ist, laßt sich dadurch entkraften, daß sie auf Grund ihrer Gestaltung in die Kategorie der Randerzăhlungen fallt, wăhrend „Vesnoj, v ludee” und „Nocleg“ durchaus den Status einer Kernbzw. Satellitenerzahlung erfullen wurden.

279 Zit. in: „Pis'ma I. A. Bunina K F. A. Stepunu“. op.cit.: 126-127.

280 Zit. in: „Perepiska Teffi s I. A. i V. N. Buninymi 1948-1952“. In: Diaspora III (2002): 582-583.

281 A. ACatova. „Pozdnjaja liriceskaja novella I. A. Bunina ...". op.cit.: 116. 
„Baryšnja Klara“ und „Parochod ,Saratov“")- ebenso wie sich dort eine Häufung von Erzählungen findet, die die Emigration zum Schauplatz haben (z.B. „V odnoj znakomoj ulice“, „Cholodnaja osen"“, „Mest”“). Sonderlich standfest wirkt diese Interpretation dennoch nicht. Die möglichen Deutungen, daß auch Tierliebe mit dem Tod büßen muß (als Ausweitung der Liebeskonzeption), oder eine Illustration der Lektion, daß die Tiere in ihrer Liebe treuer sind als Menschen bzw. daß auch Tiere fühlen können (Bezüge zu den Erzăhlungen „Ballada“ und „Železnaja Šerst““), rnuten ähnlich konstruiert an, lassen sich nicht überzeugend begründen und können daher verworfen werden.

Wesentlich stimmiger und schlüssiger ist der zuerst diskutierte Rahmen, in den sich die übrigen Erzählungen mühelos einfugen lassen: Zwischen der Trennung als Tod der Liebesbeziehung („Temnye allei“) am einen und dem Selbstmord als entschiedenster Umsetzung der Sehnsucht nach der Auflösung des Selbst („Casovnja“) am anderen Ende des Spektrums liegen unzählige Variationen von Liebesgeschichten, in denen der Tod bzw. die Vergänglichkeit als Gegenspieler der Liebe bzw. des Lebens auftritt, um letztlich stets den Sieg davonzutragen - denn selbst die Erinnerung kann Geschehenes nur so lange dem Vergessen entreißen, wie es einen Menschen gibt, der sich erinnern kann.

\subsection{Zusammenfassende Betrachtung}

Bunins häufig als rhythmisch bzw. musikalisch wahrgenommene Prosa legt auch bei der Beurteilung des äußeren Aufbaus der Temnye allei den Vergleich mit einem Musikstück nahe, das die Themen Liebe und Tod in verschiedenen Motiven und Tonarten anklingen läßt. In dieses Vergleichsbild fügt sich der von Julian Connolly konstatierte Refrain des unerwarteten, unverhofften, tief empfundenen und einzigartigen Glücks ein (,unexpected happiness “282 ). Dieser kommt durch das unvermutete Aufflammen der Liebe, die trotz des Risikos eines emotionalen Scheiterns willkommen geheißen wird, in vielen Erzählungen zum Klingen, wie beispielsweise in den folgenden (vgl. hierzu auch Kap. 8.1.1):

Разве неправда, что она дала мне лучшие минуты жизны? (,Temnye allei“, 6: 178); Откуда вдруг такое счастье! („Миzа“, 6: 198); Боже мой, какое это было несказанное счастье! („Pozdnij cas“, 6: 203); [...] подобного счастья не было во всей его жизни. („Rusja“, 6: 210); [...] неожиданное счастье; который должен был довольствоваться редким и всегда неожиданным счастьем только поцелуев [...] 
(„Zojka i Valerija“, 6: 247); [...] неожиданное счастье [...] („Tапја“, 6: 258); Хотя разве бывает несчастная любовь? [...] Разве самая скорбная в мире музыка не дает счастья? („Natali“, 6: 328); [...] вспомнная подробности своего неожиданного счастья. („Кита“, 6: 342); [...] нечто совсем неожиданное [...] („Voron“, 6: 378); [...] все-таки счастье, великое счастье! („Čistyj ponedel'nik“, 6: 403).

Als Fazit laßt sich festhalten, daß eine Analyse der Anordnung der Erzählungen ausreichend Belege für die strukturelle Dichte der Temnye allei liefert. Die Funktion des Titels als Motto und das Gefuge der Erzăhlungen, die um die Kernerzählungen gruppiert wurden, belegen ohne jeden Zweifel, daß es sich bei den Temnye allei um eine Kurzprosaverknüpfung und nicht um eine bloße Erzählsammlung handelt. Drei Binnenrahmen aus den Eröffnungs- und Finalerzählungen der einzelnen Komplexe sowie ein Außenrahmen aus der ersten und den beiden letzten Erzahlungen bilden ein stabiles Gerüst, in das weitere Erzăhlungen unterschiedlicher Wertigkeit eingefügt wurden. Ein Konglomerat von Kernerzählungen in der Mitte des Buches samt einer Ankererzählung, die auch als Scharnier zwischen der ersten und der vorletzten Erzăhlung fungiert, bildet cin aussagekräftiges Zentrum, das in die anderen beiden Komplexe hineinstrahlt und fur zusätzliche Festigkeit sorgt. Eine bewußte strategische Anordnung der Kernerzählungen stellt die strukturelle Ausgewogenheit sicher, die durch den Einsatz von Satelliten- und Randerzählungen sichtbar wird.

Die Leerstellen zwischen den einzelnen Erzählungen, die gattungsbedingten Zwischenrăume zwischen dem Ende der einen und dem Beginn der folgenden Erzăhlung, markieren nicht nur die Grenzen zwischen den einzelnen Strukturelementen einer Kurzprosaverknüpfung, das heißt den Erzählungen, sondem unterstreichen auch die Unvermitteltheit, mit der das Schicksal in ein Leben einbrechen kann - und doch geht das Leben weiter, und doch folgt die nächste Erzählung.

Nach dieser Betrachtung der Anordnung der Erzählungen innerhalb der Temnye allei, die ihre rein willkürliche Zusammenstellung ausschließt, werden die folgenden Kapitel die vernetzenden Fäden sowie die Parallelen in der „technischen“ Gestaltung der Strophen aufzeigen, die um den Refrain des „unverhofften Glücks“ angeordnet sind. 
5 INTRATEXTLICHE VERKNÜPFUNGEN IN DEN TEMNYE ALLE/ (I): STRUKTUR

Jede Kurzprosaverknüpfung weist in Abhängigkeit von ihrer Dichte mehr oder weniger zahlreiche intratextliche Verknüpfungen auf, die dem Leser erst im Laufe der Lektüre oder im Rückblick bewußt werden. Ihre Funktion besteht darin, die sukzessive Entwicklung der thematischen Gesamtaussage auf der strukturellen und der stilistischen Ebene zu stützen.

Im folgenden werden zunächst die relevanten verknüpfungsbildenden Elemente im strukturellen Bereich der Temnye allei vorgestellt, die eine Bestimmung der Genrezugehörigkeit des Buches auch ohne den Einbezug thematischer Ähnlichkeiten ermöglichen. Analysiert werden die Leitlinien bei der Gestaltung der Titel der Erzăhlungen, der Anfangssätze und Erzăhlschlüsse ${ }^{283}$ sowie Parallelen bei der Handlungsfuhrung im Hinblick auf die Gestaltung des Zeitgerüsts innerhalb der einzelnen Erzăhlungen. Eine vergleichende Analyse der Schauplătze und Überlegungen zum Kontrast als bevorzugter Gestaltungstechnik Bunins in den Temnye allei runden dieses Kapitel ab.

\subsection{Die Titel der Erzählungen}

Ebenso wie für den Buch- oder Gedichttitel gilt auch für den Titel einer Erzählung die Feststellung, daß seine exponierte Stellung eine Erwartungshaltung im Leser hervorruft und den ersten Klang setzt (vgl. Kap. 4.1). Bei einer Kurzprosaverknüpfung leistet er zudem einen wichtigen Beitrag zur strukturellen Integration der einzelnen Erzăhlung. Im folgenden wird dargelegt, welche Beziehungen zwischen dem Titel und dem Inhalt der Erzählungen der Temnye allei bestehen und welcher Natur die Ähnlichkeiten zwischen den einzelnen Titeln sind.

Die Titel aller Erzählungen der Temnye allei zeichnen sich durch Kürze und Prägnanz aus - 23 der 38 Titel bestehen aus nur einem Wort, 13 sind aus zwei Wörtern zusammengesetzt und lediglich zwei weisen drei bzw. vier Konstituenten auf (vgl. Inhaltsverzeichnis der Temnye allei); auf Untertitel wird gänzlich verzichtet. Bunin legte bewußt großen Wert

283 Ein weiterer wichtiger Bereich der intratextlichen Verknupfungen, die Gestaltung der Protagonisten und die Beziehungen/Parallelen zwischen ihnen, wird auf Grund des Umfangs in einem separaten Kapitel untersucht (Kap. 7). 
darauf, die Einzeltitel so neutral wie moglich zu gestalten, wie er in einem Gespräch mit Aleksandr Bachrach erläuterte:

Заглавия рассказов не должны ничего объяснять, [...] это дурной тон. С какой стати давать читателю сразу же ключ, пускай он хоть немного поломает себе голову над заглавием. ${ }^{284}$

$\mathrm{Da} B$ Bunin dariber hinaus der Wahl eines treffenden Titels erhebliche Bedeutung zumaß, belegen die nachträglichen Änderungen von neun Titeln der die Temnye allei konstituierenden Erzăhlungen, die sich anhand der Manuskriptfassungen in den verschiedenen Archiven nachweisen lassen ${ }^{285}$ und die vomehmlich Erzählungen aus dem zweiten Komplex betreffen. Im ersten Komplex änderte Bunin lediglich den Titel „Božjj zver”“ in „Ballada“, im dritten Komplex wurden „Rečnoj restoran“ in „Rečnoj traktir" und „Nemezida“ in „Mest”“ umbenannt. Zwei Drittel der Titeländerungen im zweiten Komplex betreffen die am Anfang plazierten Erzählungen „Krasavica“, „Duroðka“, „Antigona“ und "Gost'“, die mit Ausnahme von „Gost”" nach der Änderung Verweise auf die zentralen weiblichen Figuren der Erzählungen im Titel enthalten und damit - wie zahlreiche weitere Einzeltitel des Buches - auf die Bedeutung der Frau in den Temnye allei verweisen. ${ }^{286}$ Stand in der Erzählung „Krasavica“ bei dem ursprünglichen Titel „Mamin sunduk“ noch der wichtigste und kostbarste Gegenstand im Besitz des einsamen kleinen Jungen im Vordergrund, entschied Bunin sich später dafür, die beiden für das Schicksal des Jungen wichtigen schonen Frauen im Titel hervorzuheben: Mutter und Stiefmutter. Eine vergleichbare Fokusänderung ist bei der Modifizierung des Titels „Po ulice mostovoj“ (nach einem in der Erzăhlung gesungenen Lied) in „Duročka“ festzustellen: Auch hier wird die Erzählung nach der Protagonistin benannt. Der Umbenennung in „Antigona“ gingen umfangreiche Überlegungen voraus, wie die ursprünglichen Titel „Anekdot“, „Flora“ sowie „Flora i Fauna" dokumentieren. Auch bei dieser Änderung wird die zentrale weibliche Figur in den Vordergrund gerückt und damit ihre Bedeutung für das Leben des Protagonisten nach-

284 A. Bachrach. Bunin v chalate. op.cit.: 93.

285 Nachträgliche Umbenennungen von Erzahlungen sind in Bunins Werk keine Seltenheit. Die Erzahlung "Solnexnyj udar" beispielsweise trug ursprunglich den Titel "Slucajnoe znakomstvo“" bzw. „Ksenija“", wahrend .Mitina ljubov"w zunachst "Aprel'" bzw. "Dozd”“ betitelt wurde. Auch in einigen der zeitgleich entstandenen Erzăhlungen nahm Bunin Titelânderungen vor (in Klammern stehen die ursprunglichen Varianten): „Dura" („V rabocuju poru“, "Sancta Simplicitas"), „Krem Leodor" („Razgovory“). „Modest" („Na jarmarke“), „Molodost” i starost”“ („Pro obez'janu“), „Riv'era“ (,Rendez-vous“, ..Hótel des Palmiers", .,Hótel des Palmiers et de la Plage“), .,Un petit accident"“ (..Zimnij zakat”, "Accident"), "Vesnoj, v ludee“" (,Noc'“, „Kozyj syr").

286 Eine Randbemerkung wert ist der Zufall, daß Bunin just diese vier Erzahlungen aus der Zusammenstellung von fur die Publikation in der Sowjetunion bestimmten Erzahlungen entfernte (vgl. Anhang 2, Stand Ende 1945). 
drücklich unterstrichen. Die Ausnahme von dieser Regel bildet der Titel der Erzählung „Gost'“. In der Manuskriptform lautet der Titel noch „Pasa“ nach der Protagonistin; während aus Paša im Laufe der Arbeit an der Erzählung Saša wurde, paßte Bunin nicht etwa den Titel entsprechend an, sondern lenkte nunmehr die Aufmerksamkeit des Lesers auf den Protagonisten, der dem unbedarften jungen Mädchen zum Verhängnis wird.

Marginaler Natur hingegen sind die Modifikationen, die Bunin an den Titeln der Erzählungen „Galja Ganskaja“ und „Natali“ vornahm, die ursprünglich „Ganja Ganskaja“ und „Natali Stankevic“ lauteten. Während der Wechsel von „Ganja“ zu "Galja“ rein phonetischer Natur ist, mag das Streichen von Natalis Nachnamen mit Bunins Streben nach einer überindividuellen Darstellungsweise der zentralen Figuren zusammenhängen (vgl. Kap. 7).

In bezug auf die Titelgebung der einzelnen Erzählung hat Bunin seine Absicht der neutralen Gestaltung erfolgreich umgesetzt; bei einer gesamthaften Betrachtung aller Titel enthüllen sich jedoch aufschlußreiche Beziehungen. Die Mehrzahl der Titel läßt sich in die folgenden vier Kategorien einordnen:

1. 17 Titel (und damit fast die Hälfte der Erzählungen) bestehen aus den Namen der Protagonisten oder aus einem auf sie referierenden Substantiv, das ihrer Bezeichnung dient. Hierbei überwiegen die Namen der entsprechenden Protagonistinnen, die 13 Erzählungen vorstehen und damit bereits den Stellenwert ankündigen, den die Darstellung von Frauen in den Temnye allei innehat (vgl. Kap. 7.2): „Stepa“, „Muza“, „Rusja“, „Krasavica“, „Durockka“, „Antigona“, „Zojka i Valerija“, „Tanja“, „Galja Ganskaja“, „Genrich“, „Natali“, „Kuma“ und „Baryšnja Klara“. Im Gegensatz zu den weiblichen Protagonisten figurieren nur zwei männliche Protagonisten in den Titeln es sind der unheimliche Besucher der Erzählung "Gost"“ und der nicht minder furchterregende Vater des eingeschüchterten Jünglings aus der Erzählung „Voron“, der durch seine Kleidung an einen Raben erinnert und dräuend über dem heimlichen Glück des jungen Liebespaares schwebt. Dieser Art von Titeln können auch jene zwei Erzählungen zugeordnet werden, in denen Tiere aufgeführt werden: „Volki“ und „Železnaja Serst'“. Obwohl sie nicht die zentralen Figuren der Erzählungen bezeichnen, stehen sie doch in enger Beziehung zu ihnen, da sie inhaltlich eine entscheidende Rolle spielen: Während das plötzliche Erscheinen der Wölfe in der Erzählung „Volki“ indirekt zu einer harmlosen Verletzung der Protagonistin führ, die sie zeit ihres Lebens an jene Kutschfahrt mit ihrem jungen Kavalier erinnern wird, trägt der Bär namens „Železnaja 
Šrst"“ durch sein Vergehen an der Braut des Protagonisten eine Mitschuld an ihrem spăteren Selbstmord, den er ebenso wie der unglückliche Witwer betrauert.

2. Eine ähnlich große Bedeutung wie der Bezeichnung der zentralen weiblichen Figuren kommt geographischen Angaben zu: Insgesamt neun Titel weisen auf jenen Schauplatz hin (vgl. Kap. 5.5), der im Verlauf der Erzählung die Arena für die zentralen Ereignisse darstellt oder für einen der Protagonisten eine besondere Bedeutung gewinnt (,Kavkaz“, „V Pariže“, „Rexnoj traktir“, „Dubki““, „Madrid““, „Parochod ,Saratov““, „Kamarg“, „Kaceli“ und „Casovnja“). Auffälig ist die Konzentration derartiger Titel im dritten Komplex, in dem sich die Zahl der Erzählungen, die in der Emigration spielen, verdichtet; gleichzeitig wird dort besonders intensiv das Bild des alten Rußland beschworen (vgl. Kap. 8.2.1).

3. Vier Titel enthalten eine mehr oder minder genaue Zeitangabe: Während der Titel der Erzăhlung „Pozdnij Cas“ konkret auf eine Tageszeit hindeutet und „Čistyj ponedel'nik“ einen religiosen Feiertag bezeichnet, sind die Titel „Nacalo“ und „Vtoroj kofejnik“ vielmehr im übertragenen Sinne zu verstehen. Der eine zeigt den Anbruch eines neuen Lebensabschnitts an, der andere markiert einen Einschnitt im Tagesablauf - beide Zeiteinschnitte sind für die jeweilige Hauptfigur der Erzählung von Bedeutung.

4. Drei der Titel sind Gedichten entnommen, die im Erzählungsinneren auszugsweise wiedergegeben werden: „Temnye allei“, „V odnoj znakomoj ulice“ und „Cholodnaja osen'“. Die von Bunin verwendeten Auszüge sind übrigens in keinem einzigen Fall korrekt zitiert. Auch die Erzählung „Ballada“ ist trotz der scheinbaren Wahl einer Genrebezeichnung dieser Kategorie zuzuordnen, da die Protagonistin Maša aus einer Ballade zitiert, die einen engen Bezug zum Inhalt herstellt.

Einzig die vier Titel „Smaragd“, „Vizitnye kartocki“, „Sto rupij“ und „Mest”“ lassen sich in keine dieser Kategorien einordnen und repräsentieren den offenen Charakter der Kurzprosaverknüpfung. Die metaphorische Aufladung des Titels „Smaragd“ hebt diesen in gleicher Weise aus der Gesamtheit der übrigen Titel heraus wie die Benennung der Erzählung „Mest”“ nach einem Abstraktum. Bedeutungstragende Konkreta erhalten titelgebende Funktion in den beiden übrigen Erzählungen: Während die Protagonistin aus „Vizitnye kartocki" davon träumt, eines Tages im Besitz von Visitenkarten zu sein, die für sie die Zugehörigkeit zu einer bestimmten Gesellschaftsschicht symbolisieren, führt der Betrag von „Sto rupij“ zur Desillusionierung des Erzählers, als ihm klar wird, daß die von ihm bewunderte Schönheit zu diesem Preis kăuflich ist. 
Die Tatsache, daß in weit über der Hallfte aller Titel (26) eine zentrale Figur oder der Schauplatz in den Mittelpunkt gerückt werden, zeugt von der Wichtigkeit, die Bunin diesen handlungstragenden Elementen beigemessen hat (vgl. Kap. 5.5 und 7). Darüber hinaus wirkt diese Vorgehensweise der ähnlich motivierten Titelgestaltung verbindend und leistet einen wichtigen Beitrag zur Wahmehmung der Temnye allei als Kurzprosaverknüpfung. Bei den Erzählanfängen lassen sich vergleichbare Beobachtungen machen.

\subsection{Die Anfangssätze der Erzählungen}

Dem ersten Satz einer Erzählung maß Bunin richtungweisende Bedeutung zu, so daß eine vergleichende Betrachtung der Anfangssätze der Erzählungen der Temnye allei lohnend erscheint; 1929 notierte er in der Selbstauskunft „Kak ja pisu“:

Да, первая фраза имеет решающее значение. Она определяет, прежде всего, размер пронзведения, звучание всего пронзведения в целом. И вот еще что. Если этот изначальный звук не удается взять правильно, то неизбежно или запутаешься и отложишь начатое, или просто отбросишь начатое, как негодное ... ${ }^{28}$

Die Anfangssätze einer Erzählung setzen jedoch nicht nur den thythmusgebenden Eingangsakkord für die Entfaltung der Handlung, sondern enthalten im Falle der meisten Erzăhlungen der Temnye allei wichtige Angaben zu den Protagonisten bzw. zur Positionierung der jeweiligen Erzählung in Zeit und Raum. In bezug auf den Rhythmus bzw. auf die Dynamik kann zwischen epischen und dramatischen Erzählanfängen unterschieden werden ${ }^{288}$ : Während ein epischer Erzählanfang sich durch statische Anfangssätze auszeichnet, die beispielsweise aus beschreibenden Einführungen handelnder Personen bestehen, beinhaltet ein dramatischer Erzăhlanfang Sătze, die eine Handlung wiedergeben bzw. eine Bewegung übermitteln. Auch eine Anrede an den Leser oder ein Ausruf sind als dramatischer Erzählungsbeginn zu werten.

Eine diesbezügliche Analyse aller Erzăhlanfänge der die Temnye allei konstituierenden Erzählungen hat eine gleichmäßige Gewichtung von jeweils 19 Erzählungen mit epischen bzw. dramatischen Anfangssätzen zum Ergebnis. ${ }^{289}$ Während im ersten Komplex die

287 I. Bunin. „Kak ja pisu“. In: ders. SS v devjati tomach. 9.Bd. op.cit.: 375.

$288 \mathrm{Vgl}$. in diesem Zusammenhang Hans Halms Untersuchung "Titel und Anfangssatz in Cechovs Erzahlungen". In: Wiener Slavistisches Jahrbuch 10 (1963): 5-10.

289 Epische Anfangssatze weisen die folgenden Erzahlungen auf: „Ballada“, „Krasavica“, „Smaragd”,

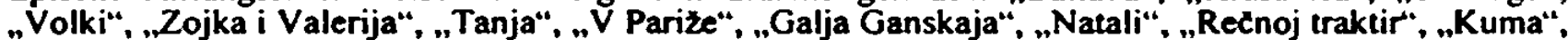
„Baryšnja Klara“, „Vtoroj kofejnik“, „Cholodnaja osen”“, „Parochod ,Saratov“", „Voron”, "Mest"“, ..Kaceli" und „Casovnja“. Die ubrigen Erzăhlungen haben dramatische Anfangssăzé. 
dramatischen Anfange uberwiegen, sind im zweiten bzw. dritten Komplex beide Kategorien relativ gleichmäßig verteilt. Innerhalb der Gruppe der dramatischen Erzählanfänge setzen einzig die vier Erzăhlungen „Pozdnij cas“, „Nacalo“, „Dubki““ und „Železnaja Šrst” mit einem Ausruf oder einer Anrede des Lesers ein. Während „Pozdnij cas“ als Selbstgespräch konzipiert ist („АX, как давно я не был там, сказал я себе“, 6: 202), richten sich die Anfänge der ubbrigen drei Erzăhlungen an einen imaginären Zuhörer bzw. Leser:

А я господа, в первы раз влюбился, или, вернее, потерял невинность, лет двенадцати. („Načalo“, 6: 343); Шел мне тогда, друзья мои, всего двадцать третий год ... („Dubki““, 6: 346); Нет, я не инок, ряса моя и скуфья означают лишь то, что я грешный раб Божий, странник, сушею и водами ходящий вот уже шестой десяток лет. (,Železnaja Šrst’”, 6: 364).

Die Konzentration derart gestalteter Erzählanfänge im dritten Komplex verwundert nicht, ist sie doch einer Auflockerung innerhalb des vergleichsweise großen Konglomerats von Erzăhlungen forderlich.

Bei einer năheren Betrachtung der Erzăhlanfänge epischen Charakters wiederum fallen ebenfalls vier Erzählungen auf, die durch das Fehlen von Verben im Anfangssatz an eine Bühnen- bzw. Regieanweisung erinnern:

Ночняя синяя чернота неба в тихо плывуших облаках, везде белых, а возле высокой луны голубых. („Smaragd“, 6: 230); Тьма теплой августой ночи, еле видны тусклые звезды, кое-где мерцаюшие в облачном небе. („Volki“, 6: 234); Дачи в сосновых лесах под Москвой. („Кита“, 6: 340); Летний жаркий день, в поле, за садом старой усадъбы, давно заброшенное кладбище, - бугры в высоких цветах и травах и одинокая, вся дико заросшая цветами и травами, крапивой и татарками, разрушающаяся кирпичная часовня. („Саsovnja“, 6: 412).

Indessen läßt erst eine differenzierte Betrachtung der inhaltlichen Konstituenten die Hintergründe für Bunins Gestaltung der Anfangssătze erkennen. Öber die Hälfte der Erzăhlungen (22) 290 weisen bereits im ersten Satz sowohl Orts- als auch Zeitangaben auf. Weitere zehn Erzählungen ${ }^{291}$ enthalten nur eine oder auch keine dieser Angaben, tragen

290 In diese Kategorie fallen die folgenden Erzahlungen: „Temnye allei“, „Ballada“, ..Stepa“, „Muza“, "Pozdnij cas", .Rusja“, „Durocka“, „Antigona“, „Vizitnye kartozki", „Zojka i Valerija“, "Genrich“, "V odnoj znakomoj ulice“, „Rexnoj traktir", .,Dubkj““, „Baryšnja Klara“, ...Madrid““, .Cholodnaja

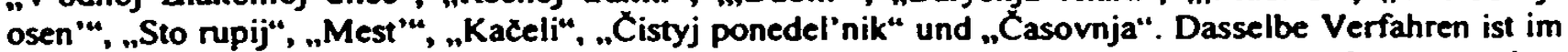
ubrigen auch in den 38 zeitgleich entstandenen Erzahlungen zu konstatieren. 23 Erzahlanfange enthalten Hinweise auf die temporare und lokale Einordnung der Handlung; 13 Erzahlanfange gleichen Bohnenanweisungen bzw. Regiebemerkungen; 24 Erzahlanfange sind episch, 14 dramatisch.

291 Hierzu gehøren die folgenden Erzahlungen: „Kavkaz", „Volki“, „Tanja“, „Galja Ganskaja“, Natali”,

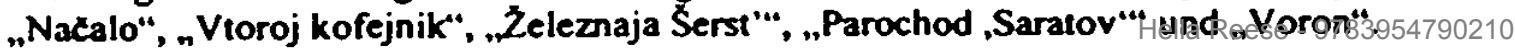


diese Information jedoch ergänzend im zweiten Satz nach. In den Erzählungen „Kuma“ und „Kamarg“ wird lediglich der Ort năher bezeichnet, in der Erzăhlung „Smaragd“ wiederum findet sich nur eine deiktische Zeitangabe in Form einer Beschreibung des nächtlichen Himmels („Ночняя синяя чернота неба в тихо плывуших облаках, везде белых, а возле высокой луны голубых“, 6: 230). Die Nennung der Angaben erfolgt entweder so präzise wie in der Erzählung „Rusja“ („В одинадцатом часу вечера скорый поезд Москва - Севастопол остановился на маленькюй станции за Подольском ...“, 6: 208) oder so nebulös wie in „Genrich“ („В сказочный морозный вечер с сиреневым инеем В садах ...“, 6: 290). Die auffällige Tatsache, daß bei 23 Erzählungen die Angabe der Zeit vor jener des Ortes erfolgt, läßt sich mit der Relevanz des Zeitfaktors in den Temnye allei erklären, der vor allem in der kontrastiven Gegenüberstellung von augenblicksorientiertem Erleben und der Thematisierung einer fernen Vergangenheit zum Ausdruck kommt und sich auch in der Gestaltung der Handlungsfuhrung widerspiegelt (vgl. Kap. 5.3). ${ }^{292}$

Den offenen Charakter der Kurzprosaverknüpfung Temnye allei unterstreichen die drei Erzählungen „Krasavica“, „Gost”“ und „V Pariže“, die keinerlei Fixierung im Zeit-RaumKontinuum aufweisen, sondern mit einer Personen- bzw. Zustandsbeschreibung einer zentralen Figur einsetzen:

Чнновник казенной палаты, вдовец, пожилой, женился на молоденькой, на красавице, дочери воинского начальника. („Krasavica“, 6: 218); Гость позвонил раз, другой - за дверью тихо, никакого ответа. (,Gost'“, 6: 232); Когда он был в шляпе,- шел по улице или стоял в вагоне метро,- и не видно было, что его коротко стриженные красноватые волосы остро серебрятся ... („V Pariže“, 6: 272).

In 27 Erzählungen werden darüber hinaus mindestens einer, meistens mehrere Protagonisten bereits im ersten Satz eingeführ, wenn auch in der Regel ohne spezifizierende Beschreibungen. ${ }^{293}$ Somit enthalten weit über die Hälfte der 38 Erzählungen nicht nur Informationen zu Zeitpunkt und Schauplatz des Geschehens, sondern auch zu einem oder mehreren zentralen Handlungsträgern. Daraus läßt sich der Schluß ziehen, daß es fur Bunin von Wichtigkeit war, die Handlung von vornherein in ein festes Koordinatensystem einzubinden, das einem Bild gleich vor dem Auge des Lesers ersteht, der auf diese Weise zum in

$292 \mathrm{Vgl.} \mathrm{hierzu} \mathrm{auch} \mathrm{1.} \mathrm{Figurovskijs} \mathrm{Arikel} \mathrm{„O} \mathrm{sintaksise} \mathrm{prozy} \mathrm{Bunina.} \mathrm{Sintaksiceskaja} \mathrm{dominanta} \mathrm{.Tem-}$ nусh allej““. In: Russkaja rec” S (1970): „По-видимому, зто обьясняется тем, что многие новеллы содержат повествование о давнем прошлом ..." (S. 64).

293 Es sind dies die folgenden Erzahlungen: „Kavkaz”, „Stepa“, „Muza“, „Pozdnij cas", „Krasavica”. "Durocka”, „Antigona“, „Gost”“, „Zojka i Valerija“, „Tanja“, .. $\vee$ Parize”, „Galja Ganskaja”, „Genrich”, "Natali", „V odnoj znakomoj ulice“, „Nacalo", ...Dubki"“., .Baryšnja Klara“, ...Madrid”“, „Vtoroj kofej-

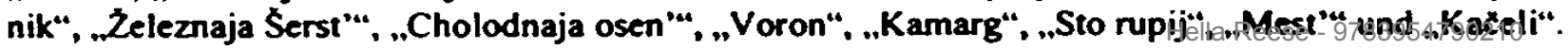


die Szene eingebundenen Betrachter wird. ${ }^{294}$ In ihrem Tagebuch notierte Galina Kuznecova die Zusammenfassung eines Gesprächs mit Bunin, in dem dieser die Initialphase seines Schreibprozesses erlăuterte: „У И[вана] А[лексеевича] это начинается почти всегда с природы, какой-нибудь картины, мелькнувшей в мозгу, часто обрывка. ${ }^{295}$ Diese Vorgehensweise des Einfangens eines Bildes ist nicht nur in engem Zusammenhang mit Bunins langjährigem Interesse an der Malerei zu sehen (vgl. Kap. 6.2), sondern auch seiner Begeisterung für den Film zuzuschreiben. Die Gründe für seine häufigen Kinobesuche präzisiert Bunin im Rahmen einer Umfrage in einem Brief an den Journalisten Andrej Blok vom 12. November 1935:

„Une fenêtre est ouverte ...“ Правильно, и это одна из главньх причин, почему я много ходнл и хожу в синема- „страсть $\mathrm{K}$ обозрению мира“, говоря словами Саадн, всегда была и есть у меня в очень большой, даже редкой мере. Есть и другие причнны. Я, например, люблю откровенную мелодраму,- то что так редко (в смысле откровенности-то) в театре (который я, кстати сказать, всегда выносил с большим трудом). ${ }^{296}$

Bunins Faible für unmittelbar erfahrbare, atmosphärisch dichte Szenen offenbart sich in den Temnye allei von den ersten Sătzen einer Erzählung an, seien sie nun dramatischen oder epischen Charakters. Die auffallend proportionale Verteilung der beiden Kategorien bis hinein in ihre Besonderheiten belegt nicht nur, daß zur künstlerischen Umsetzung der von Bunin gewăhlten thematischen Schwerpunkte beide Arten von Erzählanfängen gleichermaßen geeignet sind. Vor allem trägt sie zu einer Ausgewogenheit in der strukturellen Gestaltung bei, die auch bei der Handlungsfuhrung zum Ausdruck kommt.

$294 \mathrm{Vgl}$. in diesem Zusammenhang auch A. Razina. „Kinematografixnost' kak stilevaja osobennost” tvorteskogo pocerka Ivana Bunina“. op.cit.: „Н в каждом своем произведенин на русском материале [...], он преодолевал пространственно-временное удаление, прнближал прошлое, проживал его вновь. В определенном смысле он был интерпретатором своето прошлого, поскольку воскрешенне как творческия акт, преображало воскрешаемое, накладывало на него отсвет настоящего, придавало ему современное звучание" (S. 261).

295 Tagebucheintrag G. Kuznecovas vom 08.08.1927. Zit. in: dies. Grasskij dnevnik. op.cit.: 35.

296 Zit. in: „Dva pis'ma I. A. Bunina k A. G. Bloku“. op.cit.: 163-164. Auf die Frage, welche seiner Erzahlungen er sich als Filmadaptionen vorstellen köne, nannte Bunin unter anderem „Gospodin iz SanFrancisko" und "Syn“, regte aber auch an, bei der Verfilmung seiner Erzahlungen und Skizzen neue Wege zu beschreiten: „Нз прочих [...] мохно составнть ряд картин, ряд мнниатюр - на целыЯ час. Было бы ново и прекрасно, художественно и поэтично!" 


\subsection{Typische Arten der Handlungsfuhrung}

Innerhalb der Temnye allei lassen sich verschiedene Typen von Erzählungen ausmachen ${ }^{297}$, deren Klassifizierung auf Basis ihrer Genrezugehörigkeit jedoch im Rahmen einer Analyse der verknüpfungsbildenden Faktoren des Buches unerheblich ist. Zudem ist die dadurch suggerierte Vielfalt trügerisch, denn zum einen werden mit Ausnahme von „Cholodnaja osen'“ alle Erzählungen aus einer männlichen Erıählperspektive berichtet, und zum anderen folgt Bunin bei der Gestaltung der Handlungsführung nur zwei Grundmustern, die er mehrfach variiert verwendet. ${ }^{298}$ Während eine Analyse der Erzählperspektive für die Ermittlung verknüpfungsbildender Faktoren unabhängig von der Erzählsituation ${ }^{299}$ jedoch lediglich die Rolle der Frau als Objekt auch in der strukturellen Umsetzung unterstreicht (vgl. Kap. 7.2), ist eine Betrachtung der Handlungsführung unter dem Aspekt der temporăren Kontraste ungleich zielfürender, denn Bunin gelingt es, die Bedeutung der Zeit nicht nur im thematischen Teilbereich der Erinnerung aufzuzeigen, sondern sie auch über die Struktur sichtbar zu machen.

Im ersten Schritt lassen sich die Erzählungen klassifizieren in einen Typus mit eindimensionalem und einen weiteren Typus mit zweidimensionalem Handlungsverlauf. Dem ersten Typus können 24 Erzählungen ${ }^{300}$ zugeordnet werden: Sie verlaufen chronologisch linear und verzichten auf kommentierende oder philosophische Digressionen. Diese Art der Komposition bevorzugt Bunin bei Erzählungen, die sich auf ein einzelnes Orientierungszentrum konzentrieren, wie beispielsweise kürzere Zeit- bzw. Lebensausschnitte, aber auch Erzählungen statischen Charakters, wie beschreibende kurze Portrăts einer Person sowie L.andschaftsbilder.

$297 \mathrm{Vgl}$. zu diesem Thema die Dissertation von Natalija Evstaf eva (..Svocobrazie zanrovych form v knige 1. A. Bunina ,Temnye allei“". op.cit.) sowie ihre vergleichende Analyse der Erzahlungen „Kavkaz" und "Rusja" in dem Artikel „Novella i rasskaz - vedusčie zanrovye formy v knige I. A. Bunina ,Temnye allei"“ (in: Voprosy russkoj literafury 1 [1986]: 94-100). Sie unterscheidet im wesentlichen zwischen der .novella" mit einem versteckten Subtext als Trager der philosophischen Anschauungen des Autors, der erst am Ende der Erzahlung zutage trete (z.B. „Kavkaz"), der „rasskaz". die den Subtext an der Oberfache transportiere (z.B. „Rusja“) und lyrischen Miniaturen ohne Subtext (z.B. „Kamarg“). Der Erzahlung .Natali“ billigt sie auf Grund ihrer Lănge eine Sonderstellung zu.

$298 \mathrm{Vgl}$. hierzu auch die Ubereinstimmenden Beobachtungen Otto Peschls im gesamten Alterswerk Bunins („Die kunstlerische Entwicklung von Ivan Bunins Prosastil“". op.cit.: 148ff.).

299 Das Verhaltnis der Erzahlsituationen ist relativ ausgewogen: 16 Erzahlungen mit einer Ich-Erzahlsituation stehen 22 Erzahlungen mit personaler bzw. auktorialer Erzăhlsituation gegenuber, wobei darauf hingewiesen werden soll, daß sich in den Erzahlungen mit Rahmenkonstruktion beide Typen finden.

$300 \mathrm{Zu}$ diesem Kreis von Erzahlungen gehoren "Temnye allei“, „Stepa“, „Pozdnij cas", "Krasavica“,

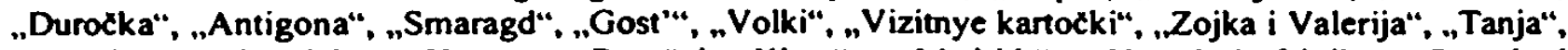
"V Parize“, „Genrich", „Kuma“, „Baryšnja Klara“, .,Madrid”", „Vtoroj kofejnik“. "Parochod

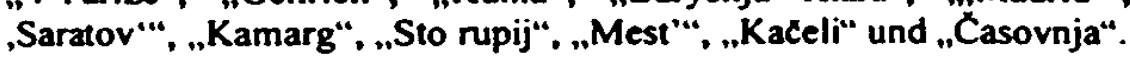


Der zweite Typus folgt einem anderen Kompositionsprinzip: Ein bestimmtes Objekt bzw. Ereignis dient als Anlaß, um das Interesse auf eine andere, bereits vergangene Handlung zu lenken. Auf diese Weise entsteht bei einem Teil der verbleibenden Erzählungen („Ballada“, „Rusja“, „Galja Ganskaja“, „V odnoj znakomoj ulice“ und „Rečnoj traktir") ein zweidimensionaler Handlungsverlauf, der in Form einer Rahmenerzählung mit einer eigenstăndigen Nebenhandlung und einer in den Rahmen eingebetteten Binnenerzählung, die als Kemhandlung den eigentlichen Erzăhlgegenstand bildet, gestaltet ist. Die übrigen Erzählungen weisen zwar keine Rahmenhandlung auf, sind aber insofern trotzdem von einem Rahmen umgeben, als sie in ihrer Form als Erinnerungsberichte von der Gegenwart in die Vergangenheit und wieder zurück in die Gegenwart führen. In diese Kategorie fallen die folgenden neun Erzählungen: „Kavkaz", „Muza“, „Natali“, „Načalo“, „Dubki““, „Železnaja Serst”“, „Voron“, „Cholodnaja osen'“ und „Cistyj ponedel'nik“.

Eine feinere und in bezug auf die thematische Schwerpunktsetzung höchst aufschlußreiche Unterteilung der Erzählungen läßt sich im zweiten Schritt erreichen durch eine Analyse des Verhältnisses von erzählerischer Gegenwart und erzählter Vergangenheit, die die Bedeutung der Erinnerung für Bunin gerade durch die Weise ihrer Verwendung auch als grundlegendes strukturbildendes Element klar herausstellt. Den Ausgangspunkt für diese Analyse bildet die von Ljudmila Foster vorgenommene Kategorisierung der die Temnye allei konstituierenden Erzählungen im Hinblick auf ihre zeitliche und räumliche Distanz zum Leser:

События и действующие в них лица отдалены от читателя либо во времени, либо В пространстве. Причем, тот или иной тип косвенной передачи связан с сюжетностью. В рассказах с динамичной сюжетностью, $\mathrm{T}[\mathrm{o}] \mathrm{e}[\mathrm{crъ}]$ с установкой на действие, отдаление может быть и во времени (воспоминания) и в пространстве (от лица какого-то рассказчика). В рассказах же более статичных, с установкой на набросок портрета или мимолетной сценки, отдаление только в пространстве. ${ }^{301}$

Die räumliche Distanz zum Leser ist durch die Person des Erzählers immer gegeben und bedarf keiner weiteren Analyse. Mehr Aufmerksamkeit hingegen verdient die Gestaltung des Kontrastes zwischen der Ebene des Erzählvorgangs und der Ebene, auf der sich die Handlung entfaltet; die Erinnerung als thematischer Teilaspekt (vgl. Kap. 8.1.6 und 8.2) übernimmt dabei eine wichtige strukturbildende Aufgabe. Bei vier Kompositionstypen und somit bei der Mehrzahl der Erzählungen werden die Ebene des Erzählvorgangs, die stets in der erzählerischen Gegenwart liegt, und jene der erinnerten Vergangenheit einander kon- 
trastiv gegenübergestellt, um durch diesen Bruch die zeitliche Entfernung zum Leser hervorzuheben. Der füfte Kompositionstyp verzichtet auf diese temporale Kontraststellung und steht nur in räumlicher Distanz zum Leser.

\subsubsection{Eindringen der Vergangenheit in die Gegen.vart}

Bei diesem Kompositionstyp stehen sich die Ebene des Erzählvorgangs in der Gegenwart und die Ebene des in diese eindringenden Ereignisses aus der Vergangenheit kontrastiv gegenüber. Die Kernhandlung verläuft in der erzählerischen Gegenwart, die Vergangenheit dringt über die in Dialogform übermittelten vergangenen Ereignisse in die Gegenwar ein. Dabei stellen die beiden Erzählungen „Vtoroj kofejnik“ und „Kuma“ mit ihrem an das Drama angelehnten Aufbau die ausgeprägteste Umsetzung des dialogischen Bauwillens dar. Vor allem der Erzählbeginn von „Kuma“ gemahnt durch die knappe Schilderung des Schauplatzes unter Verzicht auf den Einsatz von Verben an die Bühnenanweisung eines Dramas oder an Regieanweisungen eines Films:

Дача в сосновых лесах под Москвой. Мелкое озеро, купальни возле топких берегов.

Одна из самых дорогих дач недалеко от озера: дом в шведском стиле, прекрасные старые сосны и яркие цветники перед обширной террасой. (6: 340).

Neben diesen beiden Erzählungen gehören auch die Titelerzählung "Temnye allei“ sowie „Pozdnij čas“, „V Pariže“, „Madrid““ und „Mest”“ zu diesem Typus. Die genannten Erzählungen gleichen sich darin, daß durch die Verwendung der Dialogform die erzählerische Gegenwart einen breiten, selbständigen Raum einnimmt, während inhaltlich die Vergangenheit im Fokus steht. Die Sonderstellung der Erzählung „Pozdnij cas“ zeigt sich in ihrer Gestaltung als Erinnerungsmonolog, der jedoch in der erzählerischen Gegenwart stattfindet. Gemeinsam ist ihr mit der Erzählung „Mest”“ die Ich-Erzählsituation, die eine mehr oder minder ferne Vergangenheit übermittelt. Auch der folgende Kompositionstyp rückt die Vergangenheit in das erzählerische Zentrum, drängt dabei aber - im Gegensatz zu diesem Typus - die Gegenwart zurück. 


\subsubsection{Die Gegenwart als Auslöser des Rückblicks}

Die Gegenwart ist bei diesem Kompositionstyp lediglich in einer ereignisarmen Rahmenhandlung präsent, deren rein formale Funktion darin besteht, dem in der Binnenhandlung auftretenden Ich-Erzăhler den Anstoß für die Rückbesinnung auf vergangene Ereignisse zu bieten. Diesem Typus sind die Erzăhlungen „Ballada“, „Rusja“, „Galja Ganskaja“, „V odnoj znakomoj ulice" und „Rexnoj traktir" zuzuordnen.

Unterschiedlich sind lediglich die Anlasse, die die Erinnerung evozieren: Ebenso wie in "Ballada“ ist in "Galja Ganskaja" die Jahreszeit das auslösende Moment, während in „Rusja“ die Ortlichkeit, in „V odnoj znakomoj ulice“ die Atmosphäre der năchtlichen Pariser Straßen und in „Rexnoj traktir" ein zufalliges Zusammentreffen mit dem Dichter Brjusov entweder konkret oder assoziativ den AnstoB zur Rückbesinnung geben. Variationen lassen sich auch hinsichtlich der Erzăhlsituation feststellen: Während die Rahmenhandlung in „Galja Ganskaja“ und „Rusja“, in die der Erinnerungsbericht eines Ich-Erzăhlers eingebettet ist, von einem unbeteiligten personalen Erzăhler wiedergegeben wird, werden in „Ballada“ und „Rexnoj traktir" sowohl Rahmen- als auch Binnenerzählung von jeweils unterschiedlichen Ich-Erzăhlern getragen. Nur in der Erzăhlung „V odnoj znakomoj ulice“ ist der Ich-Erzăhler der Rahmenerzăhlung mit jenem der Binnenerzăhlung identisch. Durch die Konstruktion der Binnenerzăhlung als Erinnerungsmonolog năhert sie sich bereits dem folgenden Kompositionstyp an.

\subsubsection{Die Gegenwart als formaler Rahmen des Erinnerungsberichts}

In den Erzăhlungen, die diesem Kompositionstyp angehören, bildet die Gegenwart nur den formalen Rahmen der Erinnerungsubergabe durch einen Ich-Erzăhler an ein nicht năher bezeichnetes Auditorium und weist keinen eigenen Handlungsstrang auf: Der Ich-Erzähler stellt den Bezug zur Vergangenheit mit Hilfe von Verben der Vergangenheit oder adverbialen Bestimmungen der Zeit her, verdeutlicht damit seinen Standort in der Gegenwart und weist gleichzeitig auf den Kontrast der zwei zeitlichen Ebenen hin. Die folgenden neun Erzählungen fallen in diese Kategorie: „Kavkaz“, „Muza“, „Natali“, „Načalo“, „,Dubki““, „Železnaja Serst”“, „Cholodnaja osen”“, „Voron“ und „Čistyj ponedel'nik“. 
In einigen dieser Erzählungen enthält bereits der erste Satz einen Hinweis auf die Hinwendung zur Vergangenheit, wie beispielsweise in „Nacalo“: „A я, господа, в первый paз впюбился [Hervorhebungen H. Reese], или, вернее, потерял невинность, лет двенадиати“ (6: 343) oder in „Dubki'“: „Шел мне тогда, друзья мои, всего двадиать третий год ...“ (6: 346). In diesen beiden Erzăhlungen ebenso wie in „Železnaja Šerst”“ wird gleichzeitig deutlich, daß sich die Erzählung an ein nicht näher bezeichnetes Publikum richtet. Den Erzăhlungen „Muza“, „Natali“, „Cholodnaja osen”“ und „Voron“ fehlt eine derartige Anrede, ohne daß dadurch unklar zu werden droht, daß ein monologisierter Erinnerungsbericht vorliegt, da der jeweilige Ich-Erzähler bereits in den Eingangssätzen durch die Verwendung von Zeitadverbien oder mit Hilfe adverbialer Bestimmungen der Zeit deutlich macht, daß die geschilderten Ereignisse der Vergangenheit angehören: „Я был mогда [Hervorhebungen $H$. Reese] уже не в первой молодости ...“ („Мuza“, 6: 196); „В то лето я впервые надел студенческий картуз ...“ („Natali“, 6: 302); „В июне того года он гостил у нас в имении ...“ („Cholodnaja osen'“, 6: 367); „Отец мой похож был на ворона. Мне пришло это в голову, когда я был еще мальчиком ...“" ("Voron“, 6: 377).

Anders verhält es sich in den Erzählungen „Kavkaz“ und „Čistyj ponedel'nik“, in denen präzise Angaben zur Vergangenheit fehlen. In diesem Falle ist es allein die Person des Erzählers, die deutlich macht, daß von vergangenen Geschehnissen die Rede ist, da diese folglich nur von einem späteren Stand der Ereignisse aus berichtet werden können. Ähnlich ist auch der folgende Kompositionstyp konstruiert, der einen eindimensionalen Handlungsverlauf in der Vergangenheit aufweist, aber im Gegensatz zu den drei vorangegangenen Typen weder auf Erinnerungen basiert noch diese in den Handlungsverlauf integriert.

\subsubsection{Schilderung einer Handlung in der Vergangenheit ohne Einbeziehung von Erinnerungen}

Der Aufbau dieses Kompositionstyps gleicht vom Prinzip her jenem der drei anderen, da hier ebenfalls, wenn auch nicht so ausgeprägt, ein Kontrast in der Chronologie provoziert wird: Der zeitliche Abstand wird in diesem Falle unter Zuhilfenahme von Zeitadverbien, aber auch temporaler Angaben in Verbindung mit Demonstrativpronomen, wie beispielsweise „в ту далекую пору“, oder einer Hinwendung zur Gegenwart am Ende der Erzăh- 
lung realisiert. Auf diese Weise entsteht ein wenn auch fragmentarischer zeitlicher Rahmen, den der jeweils personale Erzăhler mit der Schilderung der betreffenden Ereignisse fullt. Diesem Aufbau folgen die acht Erzählungen „Stepa“, „Antigona“, „Vizitnye kartoxkj“, „Zojka i Valerija“, „Tanja“, „Genrich“, „Baryక̌nja Klara“ und „Parochod ,Saratov'“. In diesen Erzählungen werden zwar nicht explizit die Erinnerungen einer der zentralen Figuren wiedergegeben; durch die Schilderung vergangener Ereignisse jedoch bietet sich eine Lesart als Erinnerungsbericht an.

Der folgende Kompositionstyp fügt sich durch das Fehlen eines chronologischen Kontrastes nicht in das Raster der vorangegangenen Typen ein, realisiert die Distanz zum Leser jedoch auf eine andere Weise.

\subsubsection{Momentaufnahmen}

Die Erzăhlungen des füften und letzten Kompositionstyps zeichnen sich durch textliche Kürze und Unmittelbarkeit der Darstellung aus und sind auf Grund des in ihnen gestalteten kurzen Zeitausschnittes am treffendsten als Momentaufnahmen zu bezeichnen. In diese Kategorie fallen die folgenden neun Erzählungen: „Krasavica“, „Durocka“, „Smaragd“, „Gost'“, „Volki“, „Kamarg“, „Sto rupij“, „Kaceli“ und „Casovnja“. Das Fehlen eines zeitlichen Kontrastes suggerien Unmittelbarkeit. In diesen Erzählungen wird mit der erzăhlerischen Gestaltung eines Augenblicks oder einer nur kurzen Zeitspanne ein Vorgehen offenbar - von Andreï Makine treffend als ,instantisation“ ${ }^{302}$ bezeichnet -, mit dem Bunin sich bereits im Rahmen der "Kratkie rasskazy" befaßte und das ihn auch in den 1940er Jahren stark beschăftigte. So schreibt er am 11. November 1943 in einem Brief an Boris Zajcev: „Рассказы эти большей частью в лист, но есть и в одну страничку, это меня последнее время очень занимает - самая крайняя сжатость, хотя я и всегда был на этом довольно помешан. “303

Innerhalb dieses Typus lassen sich zwei Untergruppen registrieren. Die Miniaturen „Krasavica“, „Durozka“, „Smaragd“, „Gost”“, „Volki“, „Kačeli“ und „Casovnja“ werden von einem personalen Erzähler übermittelt, wăhrend die Frauenporträts aus „Kamarg“ und

302 A. Makine. „La Prose de I. A. Bounine. La Poétique de la nostalgie“. [Masch.schr.] Diss. Paris, $1991: 417$.

303 Zit. in: „Pis'ma I. Bunina k B. Zajcevu“. In: NZ 137 (1979): 125. 
„Sto rupij“ von einem Ich-Erzähler gezeichnet werden. Trotz unterschiedlicher Erzăhlsituationen ist ihnen neben der Kürze des Textes gemeinsam, daß sie auf das strukturbildende Element der Erinnerung verzichten, so daß demzufolge auch hier die Erinnerungen nur implizit enthalten sind.

Wăhrend sich eine zahlenmäßig relativ gleichmäßige Verteilung aller Arten zeitlicher Kontrastierung mit dem Ziel der Strukturbildung unter den 38 Erzählungen feststellen läßt ${ }^{304}$, ergibt eine Betrachtung der 19 Kernerzählungen (vgl. Kap. 4.3) unter diesem Aspekt eine andere Gewichtung: Die ersten vier Typen sind ebenfalls ausgewogen verteilt $^{30}$, dem fünften Typus gehört lediglich die Erzählung „Časovnja“ an. Die zahlenmäßige Uberlegenheit der Zugehörigkeit zu den Kompositionstypen eins bis drei unterstreicht bereits in der formalen Umsetzung nachdrücklich die Bedeutung der Erinnerung als eines gleichberechtigten Themas neben den zentralen Themen Liebe und Tod (vgl. Kap. 8.2). Die Vergangenheit bzw. die Wiedergabe des Erinnerten nehmen dementsprechend in den Erzählungen dieser Kompositionsarten stets größeren Raum ein als die Gegenwart. Gemeinsam ist fast allen Erzählungen zudem eine überwiegend einheitliche SchluBgestaltung.

\subsection{Die Erzählschlüsse}

Analog zur Gestaltung der Anfangssätze und der Handlungsführung lassen sich auch bei den Erzählschlüssen zwei Kategorien feststellen, die sich hinsichtlich ihrer Motivierung unterscheiden, sich jedoch nicht immer ganz sauber voneinander trennen lassen: Während die Erzähschlüsse des ersten Typus gänzlich unmotiviert erscheinen, lassen sich jene des zweiten Typus zumindest auf den ersten Blick auf mangelnde Charakterfestigkeit des Protagonister. zurückführen.

Der Großteil der Erzählungen in den Temnye allei ist durch abrupte, in der Regel unerwartete und dadurch überraschende Erzählschlüsse gekennzeichnet, deren Kausalităt aus menschlicher Sicht willkürlich erscheint, weil jenseits der Beeinflussungsmöglichkeiten

304 Dem esten Typus folgen sieben Erzahlungen, dem zweiten funf, dem dritten neun, dem vierten acht und dem finften wieder neun.

305 Zum esten Typus gehoren vier Erzahlungen, zum zweiten funf, zum dritten funf und zum vierten wieder vier Erzahlungen. 
der Protagonisten liegend, jedoch die Existenz kosmischer Gesetze spürbar macht. ${ }^{306}$ Der nüchtern konstatierende Tonfall der letzten Sătze dieser Erzählungen mit tragischem Ausgang verschärft den Kontrast zum vorangegangenen Handlungsverlauf nachdrücklich und läßt sie wie Epiloge wirken. Der geschlossene Charakter dieser Erzählenden liegt begründet in der uberwiegend unwiderruflichen Natur der Handlungswendungen, die etwa in der endgültigen, angesichts des gemeinsamen Glücks widersinnig wirkenden Trennung eines Liebespaares oder im Tod eines der Partner besteht. Derartige Schlüsse finden sich vornehmlich in Erzählungen mit einer Ich-Erzăhlsituation (z.B. „Kavkaz", „Natali“, „Dubki““, „Cistyj ponedel'nik“), zu denen auch die Binnenerzählungen der Rahmenerzăhlungen zu rechnen sind (z.B. „Ballada“, „Rusja“), sowie in allen Erzählungen im Mittelteil des Buches. ${ }^{307}$ Auch wenn der Kunstgriff des Rahmens dem Erzähler die Moglichkeit zu einem kurzen Kommentar der Ereignisse bietet, trifft das tragische Ende den Leser in beiden Gestaltungsformen mit unverminderter, aber durchaus beabsichtigter Wucht, denn diese Unvermitteltheit konzipierte Bunin bewußt, um die blinde und unkalkulierbare Macht des Schicksals zu veranschaulichen.

Am Ende des zweiten Komplexes konzentrieren sich die unvermittelten und ausgesprochen tragischen Erzählschlüsse (mit Ausnahme von „Vizitnye kartocki“) in den Erzählungen der „schwarzen Sonne“ (vgl. Kap. 4.3.2): „Zojka i Valerija“, „Tanja“, „V Pariže“, „Galja Ganskaja“, „Genrich“ und „Natali“. Der Überraschungseffekt in diesen Erzählungen resultiert vor allem aus der Technik der in die Irre leitenden Zukunftsvorausdeutungen im Verlauf der jeweiligen Erzählung (vgl. Kap. 5.6.1): So kündigt Levickij (,Zojka i Valerija“) seine baldige Abreise an, um sich tatsächlich in selbstmörderischer Absicht vor einen fahrenden Zug zu werfen (die Wahl seines vermeintlichen Reiseziels, Mogilev ${ }^{308}$, könnte allenfalls den sensibilisierten Leser wegen seiner semantischen Ähnlichkeit mit dem Substantiv „mogila“ stutzig machen); Tanja aus der gleichnamigen Erzählung trăumt bereits von sommerlichen Rendezvous und wartet doch vergebens auf die Rückkehr ihres Geliebten; den Protagonisten in „V Pariže“ trifft der Tod gänzlich unerwartet, da er sich durch

306 Vgl. hierza auch O. Slivickaja. „Fabula - kompozicija - detal' buninskoj novelly". In: Buninskij sbornik. Orel, 1974: 100.

307 Die folgenden 19 Erzahlungen bzw. Binnenerzahlungen haben einen dem Schicksal geschuldeten tragischen Ausgang: „Kavkaz”, „Ballada“, ..Pozdnij cas“, „.Rusja“, „Vizitnye kartocki“, „Zojka i Valerija“, „Tanja“, .,V Parize“, „Galja Ganskaja“, „Genrich“, .Natali“, „Recnoj traktir“, „Nacalo“, „Zelez-

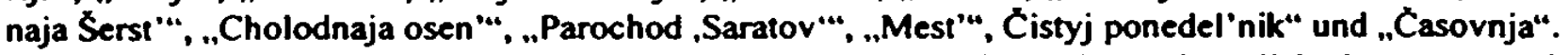

308 For die gezielte Wahl dieses Ortes spricht die Tatsache, daß Bunin nachtraglich das urspronglich gewăhlte Reiseziel Voronež durch Mogilev ersetzze (vgl. die Liste mit Korrekturvorschlägen, aber auch verbindlichen Änderungen, die Bunin am 06.05.1941 an Aldanov schickte; RGB, fond 429, edinica chranenija 21, karton 3). 
seine Liebe zur jungen Kellnerin belebt und verjüngt gefühlt hatte - die Regelung seiner persönlichen Angelegenheiten schien eine reine Formsache zu sein; in "Galja Ganskaja“ vertraut der Protagonist darauf, daß die erboste Galja sich schon wieder beruhigen würde, und zieht nicht einmal in Erwägung, daß sie sich das Leben nehmen könnte; die Journalistin Genrich aus der gleichnamigen Erzählung wiederum prognostiziert ihrem derzeitigen Liebhaber eine unproblematische Trennung von ihrem bisherigen Gefährten und ein baldiges Wiedersehen, das indessen auf Grund ihrer Ermordung durch den düpierten Partner nicht zustande kommt (auch in dieser Erzählung gibt Bunin mit der Schilderung eines Eifersuchtsanfalls des Wiener Konkurrenten nicht nur einen Hinweis auf ein mögliches anderes Ende); in der Ankererzählung „Natali“ schließlich scheinen sich die Verwicklungen der Vergangenheit in der Aussicht auf eine friedliche Zukunft aufzulösen, bevor der Tod der Protagonistin durch eine Frühgeburt alle frohen Erwartungen zunichte macht.

In „Natali“ findet diese von J. Woodward als "terrible pause“309 bezeichnete Technik der Atempause vor einem abrupten Ende ihre eindrucksvollste und nachhaltigste Umsetzung in dem von der Erzählung deutlich abgesetzten Epilog. ${ }^{310}$ Das Innehalten im Erzählfluß jedoch nicht nur der Retardationsspannung vor der Katastrophe; Bunin setzt dieses aus kontrastierender Zeitraffung und Zeitdehnung kombinierte Verfahren auch inmitten von Erzählungen ein, um dem dramatischen Auf und $A b$ der Inhaltsebene auch auf der gestalterischen Ebene Ausdruck zu verleihen (vgl. Kap. 5.6.2), entsprechend seiner Überzeugung, daß Literatur einen unmittelbaren, starken Eindruck beim Leser hinterlassen soll: „Между тем цель литературы заключается именно в непосредственном, эмоциональном воздействин.“"'1 Darüber hinaus fordern die abrupten Erzählschlüsse zu einem sinnsuchenden, wenn auch rationalem Denken nicht zugänglichen Rückblick auf. Gleichzeitig unterstreichen sie die Bedeutung der Erinnerung als strukturbildendes Element und thematischer Teilaspekt innerhalb der Temnye allei.

309 J. Woodward. „Narrative Tempo in the Later Stories of Bunin“. In: Die Welt der Slaven 16 (1971): 393.

310 In bezug auf die Erzăhlung ..Natali“ beschreibt J. Woodward dieses Verfahren so: „Thus a dénouement that would have been fully motivated is replaced by one that is simply appended, and it is precisely this lack of motivation, which is Bunin's aesthetic correlative of irremediable human impotence, that strikes the note of horror" (J. Woodward. Ivan Bunin. A Siudy of His Fiction. op.cit.: 211).

311 ,Interv'ju“. In: Odesskie novosti (01.03.1912). Zit. in: 1. Bunin. SS v devjati lomach. 9. Bd. op.cit.: 542. Woodward fuhrt dieses Bestreben auf Bunins eigene Erfahrungen zuruck, die ihn als Kind Zeuge des Ruins seiner Familie und des Zusammenbruchs der traditionellen Lebensweise werden und inn zu der Überzeugung kommen ließen, ,that man is utterly powerless, that his destiny is govemed by irrational forces which subvert and defy all his efforts to control it, and his consciousness of the power of such forces in life, which lies at the basis of all his art, explains the term that he used to describe it" (J. Woodward. Ivan Bunin. A Study of His Fiction. op.cit.: 146). 
Abgesehen von den beiden Momentaufnahmen „Kamarg" und „Sto rupij" bergen die Erzählschlüsse der übrigen 17 Erzăhlungen zwar ebenfalls tragische Momente in sich; diese lassen sich jedoch oftmals rein vordergriindig auf menschliche Charakterschwäche zurickfuhren, die unterschiedlichen Triebfedern geschuldet ist. Den gesellschaftlichen Konventionen zum Opfer gebracht wurden die Liebesbeziehungen in den Erzählungen "Temnye allei“ und „Durockka“; eine ähnliche Entwicklung steht für die sich anbahnende Liebesgeschichte der Erzählung ,"Madrid““ zu befürchten. Die Morde in den Erzählungen „,Dubki““ und „Baryšnja Klara“ lassen sich auf Eifersucht bzw. auf aus triebhaftem Verlangen genährten $\mathrm{Haß}$ zurückführen. Vorsätzliche Täuschung zur Beruhigung der Frau nach erzwungenem oder freiwillig gewährtem Beischlaf liegt den einseitigen Trennungen in den Erzählungen „Stepa“, „Gost"“, „V odnoj znakomoj ulice“ und „Kuma“ zugrunde, in denen der jeweilige Protagonist eine Fortsetzung der Beziehung in Aussicht stellt, obwohl er sich in dem Moment bereits sicher ist, daß er die Frau keinesfalls wiedersehen wird. Mangelnde Willensstärke der jeweiligen zentralen männlichen Figur läßt die Liebesbeziehungen in den Erzählungen „Antigona“ und „Voron“ scheitern: Während der Protagonist in „Antigona“ nicht den Mut aufbringt, entgegen seiner ursprünglichen Träumereien öffentlich zu seinen Gefühlen für die Krankenschwester zu stehen, vermag sich der junge Mann in „Voron“ nicht gegen die Autorität seines Vaters durchzusetzen. Fehlende Emsthaftigkeit im Umgang mit zärtlichen Gefühlen ist den Protagonisten der Erzählungen "Smaragd“, „Volki“ und „Vtoroj kofejnik“ anzulasten: Während in „Volki“ sowohl Mann als auch Frau in Übereinstimmung einen lockeren Umgang miteinander pflegen, macht sich in den beiden anderen Erzählungen der Mann auf Kosten der Frau lustig. Dieser Spieß wird umgedreht in den Erzählungen „Muza“, „Krasavica“ und „Kačeli“, in denen Frauen zu Lasten des Mannes die Spielregeln der Liebe bestimmen.

Trotz ihrer Ähnlichkeit mit den Erzählungen der neuen Tendenz im Hinblick auf die Darstellung boshaften menschlichen Verhaltens (vgl. Kap. 3.5.3) unterscheiden sich die Erzählschlüsse des zweiten Typus von jenen durch das Element des Schicksalhaften: Menschliches Versagen ist hier nicht Auslöser, sondern nur Ausdruck eines vom Schicksal vorbestimmten Scheiterns, dessen Ursachen außerhalb der menschlichen Einflußsphäre liegen: Der Mensch ist seiner eigenen Natur ebenso ohnmächtig ausgeliefert wie den ihn umgebenden Naturgewalten (vgl. Kap. 5.5). ${ }^{312}$ Die Protagonisten werden von einer

312 Von den Erzahlungen, die der neuen Tendenz in Bunins Schaffen zuzuordnen sind, unterscheiden sich diese Erzahlungen in erster Linie durch ihre Einbindung in die Natur. Zudem sind sie fast ausschließlich dialogisch aufgebaut und lassen jegliche emotionale Verzauberung vermissen, derer die Protagonisten der Temnye allei in der einen oder anderen Form in der Regel teilhaftig werden. 
Begierde uberwăltigt, die sich jeglicher rationalen Steuerung entzieht, und so können sie auch für die daraus resultierenden verwerflichen Verhaltensweisen nicht zur Rechenschaft gezogen werden. Ihre Handlungsunfähigkeit erleben sie zwar teilweise bewußt (z.B. „Antigona“), sind aber unfähig, sich dagegen zur Wehr zu setzen und lassen sich von der Entwicklung der Ereignisse treiben, werden zum Spielball außerhalb ihrer Person liegender Kräfte.

Die unvermittelten Erzählschlüsse - ganz gleicì ob auf menschliches Versagen oder auf das Schicksal zurückfuhrbar -, die in einer Kurzprosaverknüpfung dicht aufeinander folgen, unterstreichen mit ihrer Ballung nicht nur die stets drohende Unvermitteltheit, mit der das Schicksal in ein Menschenleben einbrechen kann, sondern symbolisieren gleichzeitig den Fortgang des Lebens, denn auf das Ende einer Erzählung folgt die nächste Erzählung, trotz eines Schicksalsschlags geht das Leben weiter. In den Erzählungen, die im gleichen Zeitraum wie die Temnye allei entstanden und starke Ähnlichkeiten zu diesen aufweisen, lassen sich vergleichbare Beobachtungen machen. Anders verhält es sich mit den Erzählungen, die der neuen Tendenz zuzuordnen sind: Hier tritt nicht das Schicksal als blindwütige Macht auf; es ist vielmehr das menschliche Wesen, das seine Banalität bzw. Boshaftigkeit zeigt.

\subsection{Die Funktion der Schauplätze in den Temmye allei}

Der Schauplatzgestaltung in den Temnye allei kommt bereits bei der isolierten Betrachtung der einzelnen Erzählung eine wichtige strukturbildende Funktion zu. Doch erst bei einer Gesamtschau aller Erzăhlungen des Buches fallt auf, daß die Schauplatzgestaltung nach einheitlichen Prinzipien bei gleichbleibenden Intentionen erfolgte. Oberflächlich betrachtet kommt dies zunächst durch die restriktive Wahl von russischen Schauplätzen zum Ausdruck: 29 Erzählungen spielen ausschließlich im vorrevolutionären Rußland, nur 3 haben Frankreich zum Schauplatz („V Pariže", „Kamarg“, „Mest"“), ebenfalls 3 sind zwar im Frankreich der 1930er Jahre lokalisiert, die übermittelten Ereignisse hingegen spielen im vorrevolutionären Rußland („Pozdnij cas“, „Galja Ganskaja“, „V odnoj znakomoj ulice“), während "Genrich" und "Cholodnaja osen"“ von Rußland nach Frankreich führen. Eine Ausnahme stellt einzig die zeitlich nicht fixierte, in Asien angesiedelte Erzählung "Sto 
rupij“ dar. ${ }^{313} \mathrm{Daß}$ Bunin der Verwendung rein russischer Schauplätze nicht bedurfte, um seine Themen angemessen zu gestalten, zeigte sich schon in früheren Erzählungen wie beispielsweise „Brat'ja“ (1914) und „Gospodin iz San-Francisko“ (1915). In einem Gespräch mit Valentin Kataev, der angesichts der nichtrussischen Schauplätze einiger Erzählungen Erstaunen bekundete, legte Bunin die Gründe hierfur dar:

Почему вас удивляет, что я написал такие „не русские“ рассказы? Я не давал клятвы всю жизнь описывать только Россию, изображать лишь наш, русский быт. У каждого подлинного художника, независимо от нащиональностн, должна быть свободная мировая, общечеловеческая душа; для него нет запретной темы; все сущее на земле есть предмет искусства. ${ }^{3 / 4}$

Um so mehr überrascht die fiktive Rückkehr in das vorrevolutionäre Rußland in den späten Erzählungen, zumal das französische Umfeld zur Zeit der Entstehung der Temnye allei bereits seit zwei Jahrzehnten zu Bunins Alltag gehörte. Eine Füle diesbezüglicher Details, wie zum Beispiel die Erwăhnung historischer Personen und Ereignisse, Zeitschriften, tatsächlich existenter Hotels etc., bürgt für eine authentische russische Schauplatzgestaltung (vgl. Kap. 8.2.2). Dennoch stellt sich die Frage, wie real dieses Rußland ist, zumal es zum einen definitiv untergegangen ist und zum anderen für die Einkleidung der universellen Themen Liebe und Tod nicht zwingend ist. ${ }^{315}$ Abgesehen von den Namen großer Städte wie Moskau, Sankt Petersburg oder Odessa fehlen konkrete Ortsangaben. Darüber hinaus fällt auf, daß Örtlichkeiten und ihre Bewohner nicht mehr so negativ wie in den Erzählungen vor der Emigration gezeichnet werden, sondern wie von der Erinnerung verzaubert erscheinen. Ivan Bunins Rußlandbild der 1940er Jahre scheint der Wirklichkeit entrückt; einen kritischen Blick auf Niedergang und Verfall, wie etwa in Derevnja (1910) und Suchodol (1911), gibt es nicht mehr, selbst die schmuddelige Schenke in der Erzählung „Rečnoj traktir“ erscheint pittoresk. Bunins Rußland existiert nur noch in der Erinne-

313 Die Tatsache, daß tropische Gefilde in jedem der drei Komplexe erwăhnt werden, verdient festgehalten zu werden, da auch dieses Detail verbindende Funktion hat: In der Erzahlung ..Kavkaz" geht die Reise an die kaukasische Koste (..B rорных лжунглях, у тропического моря“, 6: 180), in ..Muza“ erinnert die Datschenregion nahe Moskau an die Tropen („B парке усааьбы деревья были так велики, что дачн, кое-где построенные в нем, казались под ними малы, как жилища под деревьями в тропических странах“, 6: 199), in „Rusja“ das Wetter (..Кажется, дождливый период наших тропических мест кончился“, 6: 211), wăhrend die Erzahlung ..Sto rupij“" gleich ganz in den Tropen spielt.

314 Zit. in: V. Kataev. Trava zabvenija. In: ders. SS v desjati lomach. 6.Bd. Moskva, 1984: 308.

$315 \mathrm{Vgl}$. J. Woodward. Ivan Bunin. A Study of His Fiction. op.cit.: 23-24: .....] and even though the Russian setting was restored to its former dominance in the works written in emigration, its relevance to the thematic content is unusually minimal. The reasons for its restoration were not thematic, but personal and aesthetic." 
rung - der des Protagonisten bzw. des Erzählers ebenso wie der des Autors -, er schafft sich sein persönliches gedankliches Refugium, sein ,univers nostalgique “316.

Über diese geographische Lokalisierung hinaus zeigt eine Analyse der in Außen- und Innenräume unterteilten Schauplätze bei unterschiedlicher Trägerfunktion von Bunins weltanschaulichen Überlegungen interessante Parallelen zwischen den einzelnen Erzăhlungen, die im folgenden beleuchtet werden.

\subsubsection{Der Außenraum: Natur versus Stadt}

In den Temnye allei stehen ländliche und städtische Außenräume in Opposition zueinander, wobei den Landschaftsbeschreibungen eine klar dominierende Stellung zukommt ${ }^{317}$, was A. Ter-Abramjanc zu folgender Feststellung veranlaßte: „И. Бунин - один из последних русских писателей, в творчестве которых природа занимает важнейшее место. Без нее немыслим лирический строй его поэзии и прозы. ${ }^{\text {“318 }} \mathrm{Zu} \mathrm{dem} \mathrm{Kreis} \mathrm{der} \mathrm{Erzählun-}$ gen mit akzentuierten, bedeutungsvollen Naturbeschreibungen gehören im übrigen alle Kernerzählungen der Temnye allei.

In einem Gespräch mit Irina Odoevceva erläuterte Bunin die seiner Meinung nach für den Menschen hohe Bedeutung der Natur, der er sich zeit seines Lebens eng verbunden fühlte:

Для меня природа так же важна, как человек. Если не важнее. [...] Я писал о природе гораздо больше, чем о людях, с которьми сталкивался. Я любил, я просто был влюблен в природу. Мне хотелось слиться с ней, стать небом, скалой, морем, ветром. ${ }^{319}$

Von dieser engen Bindung zeugen auch verschiedene einschlăgige Tagebuchaufzeichnungen, die belegen, daß Bunin selbst in den schweren Kriegsjahren noch offenen Sinnes war für Naturerscheinungen:

316 A. Makine. „La Prose de I. A. Bounine ..... op.cit.: 438.

317 In 20 Erzahlungen des Buches finden sich ausfuhrliche und eindringliche Landschaftsbeschreibungen. Ihnen gegenuber stehen zehn Erzăhlungen mit Stadtbeschreibungen (.,Muza“, .,Pozdnij cas", „V Parize“, "Galja Ganskaja“, „Genrich“, „V odnoj znakomoj ulice“, „Barysnja Klara“, ...Madrid“", „Voron“ und "Cistyj ponedel'nik") sowie acht Erzahlungen ohne Beschreibungen des Außenraumes (.Krasavica".

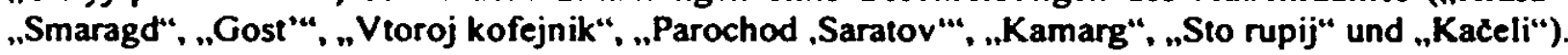

318 A. Ter-Abramjanc. "Sozvezdija Ivana Bunina". In: 1. A. Bunin i russkaja literatura XX veka (obra-y zvezdnogo neba v ivorcestve Bunina. Moskva, 1995: 109.

319 I. Odoevceva. Na beregach Semy. op.cit.: 283. 
Долина синевато туманится. Море слабо белеет. Над ним сизо, над сизым чуть румянится. Прелестно синеет Эстерель. За ним, правее, чуть смугло снизу, бруснично, выше чуть желтовато, еще выше зеленовато [...]. К Марселью горизонт в сизой мути, выше мутно-кремовато, еще выше - легкая зелень. (06.11.1941);

Летний день. Деревцо на нижней площадке - розовые цветы, коричн[евые] листья. Зацвело грушевое дерево, яблоня - самое прелестное. (03.04.1943);

Туман, к вечеру легкий дождь. Закричали как следует лягушки - с опозданием против обыкновенного чуть не на два месяда. (05.04.1944). ${ }^{320}$

Die meisten Erzählungen der Temnye allei enthalten symbolträchtige Landschaftsbeschreibungen (in Ausnahmefällen, wie etwa in der Erzählung „Vtoroj kofejnik“, wird gar auf die Leinwand gebannte Natur bemüht), denen dabei nicht nur die intensive Darstellungsweise gemeinsam ist, in der Bunins Detailfreude hinsichtlich der Wiedergabe von Farben, Schattierungen, Gerüchen, Geräuschen etc. zum Ausdruck kommt (vgl. z.B. Kap. 6.2), sondern auch die ihnen innewohnende enge Beziehung zu den Protagonisten der Erzăhlungen, die der Natur gleichermaßen ausgeliefert wie in sie eingebunden sind. ${ }^{32 !}$ Die sprachlich dichten, höchst anschaulichen Landschaftsbeschreibungen in den Temnye allei sind jedoch nicht Selbstzweck oder bloße Hintergrundmalerei, sondern aktiver Teil des Erzählten ${ }^{322}$ mit einem bedeutungsvertiefenden Charakter - die Polyfunktionalität ihrer Suggestivkraft manifestiert sich hauptsächlich in drei Bereichen ${ }^{323}$ :

1. Spiegel oder Opposition des Seelenzustandes des Protagonisten

2. Verbindung unterschiedlicher zeitlicher Ebenen

3. Vorwegnahme bzw. Vorbereitung der Sujetentwicklung.

Diese Funktionen setzt Bunin in unterschiedlicher Frequenz ein; eine Musterbildung im Laufe des Buches läßt sich jedoch nicht konstatieren. Der erstgenannte Funktionsbereich ist in den Temnye allei schwerpunktmäßig vertreten und trägt in erheblichem Maße dazu bei, Bunins Konzeption von der engen Verbundenheit alles Irdischen zu transportieren; mit

$320 \mathrm{Vgl}$. die entsprechenden Eintrage in UB. 3.Bd. op.cit.: 118, 148 und 164.

321 Bunins philosophische Oberlegungen bezoglich des Eingebundenseins des Menschen in die Schopfung kommt am nachdracklichsten in der Relation Mensch - Kosmos im Rahmen von Himmelsdarstellungen zum Ausdruck (vgl. Kap. 8.1.3).

322 A. Acatova sieht die Bedeutung der Landschaftsdarstellungen gar auf einer Stufe mit jener der Protagonisten: „B лирнческих пронзведениях Бунина природа [...] дает человеку высшую радость. высшее наслаждение своей гармониеи, светом, запахом или, наоборот, свонм равнодушием $k$ судьбам м ира она заста вляет челове ка ис пытать горь кое ч увство од иночества. покинутости" (dies. „Iz nabljudenij nad liriceskoj prozoj I. A. Bunina“. op.cit.: 86).

$323 \mathrm{Vgl}$. E. Sirina. „Idejno-chudozestvennye funkcii pejzaza v cikle rasskazov $\mathrm{I}$. A. Bunina ,Temnye allei““. In: Tvorcesno I. A. Bunina i russkaja literatura XIX-XX vekov. Belgoroülel|9988.9 198.83954790210 
fortschreitender Lektüre des Buches wird der Leser sensibilisiert für diese Kongruenz von psychischer Verfassung und Naturdarstellung. Naturdeskriptionen mit dieser Funktion können den Seelenzustand des Protagonisten einerseits vertiefen, ihn von den Bürden des Alltags befreien, ihn öffnen für die Schönheit der ihn umgebenden Natur und ihm eine andere Dimension des Daseins aufzeigen (vgl. Kap. 8.1.3), wie etwa in der Erzählung „Tanja“:

И все вокруг как-то странно в своем ночном существовании, отрешенном от всего человеческого, бесцельно сияющее. И странно еще потому, что будто в первый раз видит он весь этот ночной, лунной осенний мир. (6: 257).

Die Natur kann andererseits aber auch in einem krassen Gegensatz zum Empfinden einer Figur stehen. Dieses Verfahren verwendet Bunin beispielsweise in der Erzăhlung „V Pariže“:

Когда она, в трауре, возвращалась с кладбища, был милый весенний денъ, коегде плыли в мягком парижском небе весенние облака, и все говорило о жизни юной, вечной - и о ее, конченной. $(6: 281)$.

Getragen wird diese Sensibilisierung des Rezipienten durch die subjektive Schilderung der Naturerscheinungen, das heißt aus der Wahrnehmungsperspektive des Protagonisten, was unwillkürlich dazu anregt, Gemütsverfassung und Naturerscheinung in eine Wechselbeziehung zu setzen. ${ }^{324}$ In anderen Erzählungen wiederum steht die Natur dem aufgeregten menschlichen Treiben ruhig gegenüber, wie zum Beispiel in der Erzăhlung „Casovnja“, in der sonnendurchströmtes Leben und eisiger Tod kommentarlos nebeneinander gezeigt werden.

Der zweite genannte Funktionsbereich, die Verbindung unterschiedlicher zeitlicher Ebenen, ist kleiner und hinsichtlich der Verknüpfungsleistung von geringerer Bedeutung. Besonders deutlich kommt diese Wirkweise in der Erzählung "Rusja“ zum Ausdruck: Während eines außerplanmäßigen Aufenthalts seines Zuges fuhlt sich der Protagonist bei der Betrachtung der Landschaft zurückversetzt in jenen lang zurückliegenden glücklichen Sommer seiner ersten Liebe, den er ganz in der Nähe der Bahnstation verbracht hat (6: 208). Auch in der Erzählung "Ballada" ist die Winterzeit, die die Pilgerin Maša auf dem Gut verbringt, eigentlicher Auslöser des Erzählten, denn ohne ihr dortiges Verweilen wäre die Geschichte nicht zutage gekommen; Vergleichbares gilt für die Erzählung „Galja 
Ganskaja", in der ein herrlicher Pariser Frühlingstag den Erzähler in Gedanken in seine Vergangenheit zuruckfuhrt und Erinnerungen an eine Liebesaffäre in Odessa evoziert.

Der dritte Funktionsbereich, die in den Naturschilderungen verborgene Sujetentwicklung, unterstützt in einer Reihe von Erzählungen der Temnye allei den erstgenannten Funktionsbereich insofern, als die angekündigte Katastrophe auch die Seele des Protagonisten berühren wird; in der Regel sind diese Ankündigungen verhängnisvoller Natur und enthalten sprachliche Anspielungen auf den Tod. In der Erzählung "Tanja“ etwa blickt der Protagonist während seiner năchtlichen Kontemplation auf „снеговые мертвые [Hervorhebungen H. Reese] ropы“ (6: 257). In „Genrich“ gibt die Schilderung einer Abendstimmung einen versteckten Hinweis auf die dramatische Entwicklung der Ereignisse in Wien, von der der Protagonist nichts ahnen kann: „Был морозный, первозданно-непорочный, чнстый, мертвенно алевщий и синевший к ночи вечер на каком-то перевале ...“ (6: 298). Darüber hinaus können Naturschildenungen einen zukunftsweisenden Symbolcharakter haben, dessen sich der jeweilige Protagonist nicht bewußt sein muß, wie beispielsweise in der Erzählung „Temnye allei“: Die blasse Sonne, die über den abgeernteten Feldern untergeht, als der Offizier die Poststation verläßt, kündet vom nahen Ende seines leeren Lebens. Der Hahn, der in der Erzählung „Rusja“ das heimliche Liebespaar mit seinem plötzlichen Erscheinen erschreckt, ist ebenso dieser Kategorie zuzuordnen wie das zunächst drohende und dann hereinbrechende Unwetter in "Stepa“, das Gewitter in „Natali“ oder das schimmernde Mondlicht in "Cholodnaja osen"“. Personifizierende Naturbeschreibungen im Zuge einer allumfassenden, sensuellen Wahmehmung der Umgebung in zahlreichen Erzählungen tragen zudem zur Perzeption der Schöpfung als einem unteilbaren Ganzen bei: „... точно какое-то дивное существо, пристально [Hervorhebungen H. Reese] смотрела поздняя луна“ (,Kavkaz“, 6: 183); „Ночью осторожно и старательно пели в парке соловьи ...“ (,Аntigona“, 6:225); „... радостней печет солнце“" („Casovnja“, 6: 412).

Beschreibungen des Stadtlebens sind von minderer Dichte und wirken deutlich negativer als Landschaftsbeschreibungen, in denen selbst ein heftiges Unwetter seinen Reiz hat (vgl. etwa "Stepa“, 6: 190). Als Schauplätze dienen überwiegend russische Städte: Moskau („Muza“, „Tanja“, „Genrich“, „V odnoj znakomoj ulice“, „Zojka i Valerija“, „Madrid““, „Vtoroj kofejnik“ und „Čistyj ponedel'nik“), Sankt Petersburg („Gost”“, „Baryšnja Klara“ und „Voron“), Odessa („Galja Ganskaja“) und zwei namentlich nicht näher bezeichnete Provinzstädte („Pozdnij čas“ und „Voron“). Paris erscheint nur in den Erzählungen 
„Pozdnij Cas“, „V Pariže“, „Galja Ganskaja“ und „V odnoj znakomoj ulice“. Andere europäische Städte wie Warschau, Wien und Nizza finden lediglich in der Erzăhlung „Genrich“ kurze, beschreibende Erwähnung.

Die Funktionsweise der (überwiegend Moskauer) Stadtschilderungen entspricht im wesentlichen jener der Naturbeschreibungen, wenn auch in deutlich verminderter Ausprägung, zumal die Städte seltsam unbewohnt-wenngleich nicht unbelebt - wirken; die Moskauer Einwohner scheinen fast inexistent zu sein, und auch die Protagonisten selbst gehören nicht dauerhaft in die Stadt: Sie sind Künstler oder Reisende ohne festen Wohnsitz (vgl. Kap. 7.1) und blicken gewissermaßen von außen, ohne Gefuhlsbeteiligung auf die Metropole. Zudem bildet Moskau mit Ausnahme der Erzählungen ,"Madrid““ und „Čistyj ponedel'nik", in der die Hauptstadt ihren größten Auftritt hat, in der Regel lediglich den Ausgangspunkt einer Handlung, die ihre Fortsetzung in der Natur findet - die Stadt ist schmutzig, laut und ungemütlich, man flieht sie: So reisen die Protagonisten der Erzählungen "Kavkaz" und „Genrich“ von Moskau aus in südliche Gefilde, die Liebesgeschichte in „Muza“ nimmt ihren verhängnisvollen Verlauf nicht im Hotel der ersten Begegnung, sondern in einem Datschengelände nahe Moskau. Auf der Datscha weilt auch die untreue Ehefrau in „Kuma“, deren abwesender Mann in Moskau arbeitet, das Restaurant „Praga“ bildet in „Rečnoj traktir“ den Rahmen für die innerliche Ruckkehr des Militărarztes in eine provinzielle Pfahlbauschenke an der Wolga, während in "V odnoj znakomoj ulice“ die gedankliche Reiserichtung umgekehrt in den verschneiten Moskauer Vorort Presnja fuhrt. Auch in "Cholodnaja osen"“ ist Moskau nur Durchreisestation für die Protagonistin, die dort ihre letzten Habseligkeiten verkauft.

Die Stadtbeschreibungen, insbesondere die von Moskau, zeichnen sich durch eine enge Verbindung zu Naturerscheinungen aus und werden stets jahreszeitlich eingeordnet: Moskau im Winter geht einher mit Frost und dem fröhlichen Geklingel von Schlittenglöckchen, typisch für den Herbst ebenso wie für das Frühjahr sind Regenschauer (im Frühjahr ergänzt um den Glanz des jungen Laubs), im Sommer treibt die trockene Hitze die Menschen von den staubigen Straßen. ${ }^{325}$ Neben den Wetterbeschreibungen spielen Lichterglanz bzw. Reflexionen, der nächtliche Stemenhimmel und Geräusche ${ }^{326}$ eine entscheidende Rolle, wie aus den folgenden Beispielen ersichtlich ist:

325 O. Oboukhova. „Moskva - moskovskij tekst u Bunina émigrantskogo perioda“. In: Bounine revisité. op.cit.: 107-114.

326 Kennzeichnend für die stădtische Gerauschkulisse ist nicht nur der Verkehrslärm, sondern auch die Musik, die von verschiedenen Interpreten intoniert wird, wie Z.B. von einem Ballorchester (.Natali“" 6: 323), einem portugiesischen Streichorchester (..Recnoj traktir“, 6: 333) oder einem Balalaikaspieler (...Madrid“" 6: 360). 
В Москве шли холодные дожди, похоже было на то, что лето уже прошло и не вернется, было грязно, сумрачно, улицы мокро и черно блестели раскрытыми зонтами прохожих и поднятыми, дрожащими на бегу верхами извозчичьих пролеток. („Kavkaz“, 6: 181);

И, отвернувшись, подошел $\mathrm{x}$ окну и торопливо закурил. За двойньми стеклами, снизу замерзшими, бледно светили в месячном свете фонари, сльшно было, как, гремя, неслись мимо, вверх по Тверской, бубенцы на „голубках“... („.Madrid““, 6: 358);

Темнел московский серый зимний день, холодно зажигался газ в фонарях, тепло освещались витрины магазинов - и разгоралась вечерняя, освобождающаяся от дневных дел московская жизнь: гуще и бодрей неслись извозчичьи санки, тяжелей гремели переполненные, ныряющие трамваи,-в сумраке уже видно было, как с шипением сыпались с проводов зеленые звезды ... („Čistyj ponedel'nik“, 6: 398).

Im Vergleich mit den Naturdeskriptionen läßt sich feststellen, daß Bunin dem städtischen Lebensraum mit weitaus größerer Distanz begegnet. Deutlich wird dies vor allem in der Erzăhlung „Čistyj ponedel'nik“, in der der Protagonist seine Liebe zur Protagonistin und sein Verhältnis zu Moskau auf den folgenden kurzen Nenner bringt: „Странная любовь!‘ - думал я [...] ,Странный город!“ говорил я себе ...“ (6: 402). Die Natur der Stadt als Werk von Menschenhand kommt zum einen in den Anthropomorphisierungen ihrer Darstellung zum Ausdruck: in Paris fließt aus luftiger Höhe die Reklame wie Blut auf die Stadt herab (6: 279), und die Mauern des Moskauer Novodevizij-Klosters sind von einem blutigen Ziegelrot (6: 404). Zum anderen fălt auf, daß im Gegensatz zu Schauplätzen in der Provinz die Musik in der Geräuschkulisse einen wichtigen Platz einnimmt, in öffentlichen Răumen (z.B. „Genrich“, „Natali“) ebenso wie in Privatwohnungen (z.B. „Čistyj ponedel'nik“). Über diese Beobachtungen hinaus beeinflussen diese eingeflochtenen Beschreibungen den Rhythmus der Erzählung, etwa als Ruhepol nach einem Dialog oder einer Handlung, der zur Kontemplation des Vorangegangenen einlädt, oder als Vorbereitung auf eine bevorstehende Katastrophe.

\subsubsection{Innenräume}

Auf den ersten Blick bietet sich dem Leser eine breite Palette an überdachten Schauplätzen, die, der Darstellung der Protagonisten vergleichbar, in höchst verschiedenartiger 
Ausgestaltung präsentiert werden (vgl. Kap. 7.1), sich jedoch auf wenige Grundtypen reduzieren lassen: Güter des Provinzadels, Bauernkaten, Hotels, Landgasthöfe, Poststationen, Restaurants - dabei fällt auf, daß im städtischen Umfeld nur wenige Wohnungen darunter sind („Baryšnja Klara“, „Parochod ,Saratov““), was der Unbehaustheit der meisten Protagonisten entspricht. Gemeinsam ist allen diesen Schauplätzen, daß sie zumindest von den männlichen zentralen Figuren nicht dauerhaft bewohnt werden, da diese sich entweder auf der Durchreise befinden oder aber für einen mehr oder minder langen Zeitraum in einem Hotel abgestiegen sind bzw. als Gast auf einem Landgut weilen, in jedem Fall fern ihres üblichen Alltags sind (vgl. Kap. 8.1.4). Den Schenken, Restaurants bzw. Frühstücksräumen von Pensionen kommt zudem eine vermittelnde Rolle zu, denn sie erlauben es Bunin, ohne Erklärungsnot Angehörige verschiedener gesellschaftlicher Schichten zusammentreffen zu lassen, und ermöglichen zufallige Begegnungen wie in den Erzählungen „Temnye allei“, „V Pariže“, „Rexnoj traktir" und „Mest”“. Für Lokalkolorit sorgen Beschreibungen der Gäste etwa in "Rexnoj traktir" und "Cistyj ponedel'nik“. Darüber hinaus schafft dieses Umfeld durch sein Ambiente in Erzählungen wie „Galja Ganskaja“ und „Reěnoj traktir" erst Rahmen und Gelegenheit fur die Berichterstattung

Diesen statischen Innenrăumen sind eine Reihe beweglicher Schauplătze beigeordnet, wie etwa der Zug in „Kavkaz" und "Genrich“, das Schiff in "Vizitnye kartocki“ oder die Kutsche in „Volki“. War der Zug in früheren Erzăhlungen Bunins häufig ein Symbol für die durch den Fortschritt ausgelösten machtvollen Veranderungen in der Provinz ${ }^{327}$, steht er in den späteren Erzählungen ebenso wie die anderen Fortbewegungsmittel vor allem für Mobilität, begleitet von einer besonderen Empfanglichkeit fur Sinneseindrücke und intensive Begegnungen mit Angehörigen des anderen Geschlechts, die im Alltag aus verschiedenen Gründen nicht möglich wären (z.B. „Načalo“ und „Genrich“). Darüber hinaus ist diese Gestaltungsweise des Aufeinandertreffens in einem unbestimmten, nicht dauerhaft bewohnten Raum, sei er nun beweglich oder statisch, eine konsequente Umsetzung von Bunins Liebeskonzeption als einer zeitlich begrenzten Angelegenheit (vgl. Kap. 8.1.1). Nicht zuletzt erlaubt die ephemere Situation des Reisens Bunin, alles für die Aussage der Erzählung Irrelevante, wie etwa die alltäglichen Lebensumstände der Protagonisten, auszuklammern. ${ }^{328}$

327 D. Richards. „Comprehending the Beauty of the World: Bunin's Philosophy in Travel". In: The Slavonic and East European Review 52 (1974): 518.

$328 \mathrm{Vgl}$. J. Woodward. Ivan Bunin. A Study of His Fiction. op.cit.: 214. 
Die Funktion der Innenräume kann nur in ihrer Oppositionsstellung zu den Außenräumen gesehen werden, was sich nicht zuletzt in ihrem beständigen Wechselspiel mit dem sie umgebenden endlosen Raum bzw. der Natur zeigt, unabhängig ob lăndlich oder städtisch, der in der Regel durch das Fenster zu den Protagonisten dringt; teilweise wird der Kontakt von ihnen bewußt gesucht: Hierzu gehören Blicke nach draußen (z.B. „Rusja“, „Madrid“") ebenso wie das hereindringende Geräusch des Regens (z.B. „Kavkaz“, „Parochod ,Saratov“"), Vogelgezwitscher (z.B. „Antigona“) oder der hereinströmende Geruch von Blumen und Bäumen (z.B. „Natali“, „Rečnoj traktir"). In einigen Erzählungen wird die Natur in die Räume hineingetragen: Muza Graf gelüstet es nach Äpfeln (,Muza“), der junge Verehrer in "Čistyj ponedel'nik“ läßt seiner Angebeteten regelmäßig Blumen zustellen, und auch der Maler aus "Galja Ganskaja“ kauft dem jungen Mädchen einen Strauß Veilchen, bevor die beiden in sein Atelier gehen. Desgleichen zieht es die Protagonisten zu einem Stelldichein oder nach einer intimen Begegnung aus den beengten Räumen in die Weite, wie beispielsweise in „Rusja“ und „Tanja“. Unabhängig von der Art des Kontaktes mit der Natur wird diese jeweils mit allen Sinnen wahrgenommen und ihre enge Verbindung mit dem Menschen dadurch nachdrücklich unterstrichen. Diese kontrastive Darstellungsweise weist zudem auf die Relevanz des Kontrastes als eine von Bunin bevorzugte Gestaltungstechnik zur Profilienung seiner Aussagen hin - nicht nur in den Temnye allei.

\subsection{Der Kontrast als bevorzugte Gestaltungstechnik}

In verschiedenen Untersuchungen zu den grundlegenden Strukturprinzipien in Bunins Prosa wird die Bedeutung des Kontrastes in der erzähltechnischen Gestaltung hervorgehoben. ${ }^{329}$ Jedoch wies erst 1997 O. Slivitskaia [Slivickaja] darauf hin, daß es sich bei den von Bunin verwendeten Gegenüberstellungen nicht um scharfe, einander ausschließende Kontraste im westlichen Verständnis handelt, sondern vielmehr um eine Bipolarität im Sinne des östlichen Yin und Yang, die sich zwar voneinander unterscheiden, gleichwohl aber

$329 \mathrm{Vgl}$. z.B. A. Kocetkov. „Sredstva vyrazenija èmocional'nosti i èkspressivnosti $v$ jazyke I. A. Bunina. (Sbornik, Temnye allei ${ }^{\circ}$ ". In: Iavestija Voronesskogo pedagogiceskogo institula. 114.Bd. Voronez, 1971: 130; J. Woodward. "The Symphonic Art of Ivan Bunin". In: The Short Stony in Russia. Hg. N. Luker. Nottingham, 1991: 153. 
feste Bestandteile eines Ganzen sind. ${ }^{330}$ Auch in den Temnye allei bedient sich Bunin dieser Gestaltungstechnik, die nicht nur in der Gegenüberstellung der Themenbereiche Leben/Liebe - Tod sowie Gegenwart - Vergangenheit zum Ausdruck kommt, sondern ihre Entsprechung auch auf der gestalterischen wie der stilistischen Ebene findet und dadurch die thematischen Aussagen nachdrücklich profiliert. Für die meisten Erzählungen dieses Buches gilt somit Lev Vygotskijs abschließende Feststellung anläßlich seiner Analyse der Buninschen Erzählung „Legkoe dychanie“ (1916):

Мы прнходим как будто к тому, что в художественном произведении всегда заложено некоторое противоречие, некоторое внутреннее несоответсвие между материалом и формой, что автор подбирает как бы нарочно трудный, сопротивляющийся материал, такой, который оказывает сопротивление своими свойствами всем стараниям автора сказать то, что он сказать хочет. ${ }^{331}$

Bei der Suche nach der optimalen bzw. passenden Verbindung von Form und Inhalt ging es Bunin nicht um eine offensichtliche, oberflächliche Harmonie; viel entscheidender ist ein gewisses $\mathrm{Maß}$ an Diskrepanz (nicht zwangsläufig in Form von Widersprüchen), mit deren Hilfe er um so konturierter seine Aussagen herausarbeiten konnte.

Anhand zweier Beispiele kontrastiver Techniken auf der strukturellen Ebene, die in beinahe jeder Erzählung der Temnye allei zum Einsatz kommen und daher als typisch zu betrachten sind, soll dieses Verfahren illustriert werden: die Technik der prophetischen bzw. irrefuhrenden Zukunftsvorausdeutungen und die Gestaltung des Erzähltempos.

\subsubsection{Prophetische bzw. irreführende Zukunftsvorausdeutungen}

Die Technik der prophetischen bzw. irrefuhrenden Zukunftsvorausdeutungen wendet Bunin in zahlreichen Erzählungen der Temnye allei an. Während die erste Variante lediglich der erzählerischen Gegenwart kontrastiv gegenübersteht, steht die zweite darüber hinaus in Opposition zur geplanten Zukunft. Diese Vorausdeutungen beziehen sich in der Regel auf die jeweilige Liebesbeziehung in einer Erzählung: Mit mehr oder minder deutlichen Hinweisen suggeriert Bunin die mögliche Entwicklung der Romanze in der Zukunf,

$330 \mathrm{Vgl}$. O. Slivitskaia [Slivickaja]. ..Psichologija kak ontologija. O rasskaze ,V nocnom more'“. In: Bounine revisite. op.cit.: 64 .

331 L. Vygotskij. Psichologija iskusstva. op.cit.: 208. 
um den erwarteten Verlauf schließlich mit einem gănzlich unerwarteten Ereignis zu konterkarieren. ${ }^{332}$

Die prophetischen Vorausdeutungen unheilvoller Wendungen kleidet Bunin in der Regel in Details, die den Leser bei der ersten Lektüre einer Erzăhlung noch nicht unbedingt mißtrauisch werden lassen bzw. ihn auf eine falsche Fährte setzen, weil sie ganz unauffallig in den Text integriert sind (vgl. auch Kap. 5.4) und zunächst nicht mit der geschilderten Liebesbeziehung in Verbindung gebracht werden; erst der wissende Rückblick ermöglicht eine entsprechende Interpretation. Bei fortschreitender Lektüre des Buches lassen derartige Hinweise den solcherart sensibilisierten Rezipienten entweder Ungutes ahnen oder erschüttern zumindest die im Text suggerierte Sicherheit der von den Protagonisten oder vom Erzähler geäußerten Zukunftsvorstellungen.

In der Erzăhlung "Muza“ etwa spielt der zunächst harmlos erscheinende Wunsch der Protagonistin nach Äpfeln auf den Sündenfall im Paradies an und läßt ahnen, daß Muza den jungen Künstler ins Verderben stürzen wird. Der Peitschenknall in „Genrich“ („крутой выстрел бича“, 6: 300), den der ungeduldig auf die Ankunft seiner Geliebten wartende Protagonist vernimmt, erscheint im nachhinein wie ein Widerhall des Schusses, mit dem Genrich kurz zuvor in Wien von ihrem bisherigen Liebhaber ermordet wurde. In verschiedenen Erzählungen übernimmt ein feuerähnlicher Schein am Himmel die Funktion der Vorankündigung, so in den Erzählungen „Pozdnij cas“ (Brand), „Cholodnaja osen”“ (Mondlicht) und „Voron“ (Gewitter, Brand). Auch Fauna und Flora spielen beim Einsatz dieser Technik eine wichtige Rolle: in der Erzählung „Rusja“ nimmt das plötzliche Erscheinen eines Hahns, der die beiden heimlich Liebenden aus einer innigen Umarmung aufstört, das weitaus folgenreichere Ertapptwerden durch die Mutter des jungen Mädchens vorweg. In „Natali“ wiederum erschreckt eine Fledermaus den Protagonisten beim Betreten seines Zimmers. Selbst die samtige Rose, die Sonja bei ihrem ersten heimlichen Rendezvous im Zimmer ihres Cousins aus dem Haar fallt und die vielsagend in der Schreibtischschublade verwelkt, wirkt im nachhinein symbolträchtig. Dem gemeinsamen Klosterbesuch in „Cistyj ponedel'nik“ kommt eine Bedeutung zu, derer der junge Verehrer erst im wissenden Rückblick gewahr werden kann. Und der Offizier aus der Erzählung „Kavkaz“, der ankündigt, vor nichts zurückzuschrecken, um seine Ehre zu retten, wird nicht - wie man annehmen könnte - zu einer Bedrohung für den Geliebten seiner Ehefrau, sondern scheidet freiwillig aus dem Leben und gibt damit seinen eingangs der Erzählung zitierten Worten einen neuen Sinn. 
Eine Ansammlung prophetischer sowie irrefuhrender Vorzeichen findet sich in der Erzählung „Parochod ,Saratov““. Auf ganz unerklärliche Weise fuhlt sich der junge Offizier an einem frischen Frühlingstag zu allem bereit („в счастливое чувство готовности на все что угодно“, 6: 373) - daß diese Bereitschaft auch einen Mord einschließen könnte, liegt nicht auf der Hand, da kommende fröhliche Ereignisse suggeriert werden. Der Fußtritt jedoch, den der Offizier einer Puppe seiner Geliebten versetzt, deutet das Gewaltpotential an, das er in sich trägt und das nach ihrer Ank:indigung, ihn zu verlassen, nach außen drängt. Die Realisierung ihrer Absicht, zu ihrem vorherigen Partner zurückzukehren, wird jedoch durch ihre Ermordung verhindert, so daß sich ihre Zukunftsvorausdeutung als irreführend erweist.

Dieses Beispiel veranschaulicht bereits die ungleich größere Komplexităt der Technik der irreführenden Zukunftsvorausdeutungen; eine Konzentration findet sich in den Erzählungen der "schwarzen Sonne“ am Ende des zweiten Komplexes (vgl. Kap. 5.4). In der Regel drehen sich diese Vorausdeutungen ums Wegfahren und Wiederkommen: in "Stepa“ und „Gost'“ kündigt der jeweilige Protagonist seine Rückkehr ebenso wider besseres Wissen an wie der heuchlerische Gast in „Kuma“, der seiner Geliebten und Frau seines Freundes einen gemeinsamen Urlaub vorgaukelt, während er längst beschlossen hat, die Frau nicht wiederzusehen. Auch die gemeinsam geschmiedeten Fluchtpläne in „V odnoj znakomoj ulice“ und "Kaceli“" werden nicht realisiert und stellen sich als substanzlose Träumereien heraus. Die feste Absicht, den Konventionen zu trotzen, haben die Protagonisten der Erzăhlungen „Antigona“ und „,Dubki'“: Wăhrend der junge Mann aus „Antigona“, dessen Langeweile verheißender Anstandsbesuch bei Onkel und Tante sich zu einer aufregenden Romanze entwickelt, die gekündigte Krankenschwester nach Aufdeckung ihres Liebesverhältnisses im Gegensatz zu seinen kämpferischen Vorstellungen tatenlos davonfahren läßt, muß der Protagonist aus „,Dubki““, dem ein Leben auf dem Lande gemeinsam mit seiner Geliebten vorschwebte, erschüttert die Nachricht von ihrer Ermordung durch den eifersüchtigen Ehemann vernehmen. Auch der Eindruck des jungen Mannes in der Erzählung "Čistyj ponedel'nik“, daß die gemeinsam verbrachte Nacht der Auftakt für eine glückliche Zukunft sein würde, stellt sich als Trugschluß heraus.

Wie bei den prophetischen Zukunftsvorausdeutungen ermöglicht erst die sukzessive Lektüre eine zunehmende Sensibilisierung des Lesers für unerwartete Wendungen. Die parallele Verwendung beider Techniken macht es dem Leser indessen bei der Erstrezeption nahezu unmöglich, die Natur der jeweiligen Vorausdeutung verläßlich einzuschätzen, und verhindert so eine Berechenbarkeit des Inhalts und damit eine Abnutzung des Über- 
raschungseffekts. Der wissende Rückblick hingegen schafft die nötige Distanz zum Text und erlaubt schließlich eine aktive Auseinandersetzung mit der Technik und der dahinter liegenden Intention.

\subsubsection{Kontrastierendes Erzähltempo}

„Каждый рассказ имеет свой ритм.“333 ${ }^{33}$ Diese von Vera Bunina gegenüber Leontij Rakovskij zitierte Aussage Bunins bezüglich der Erzählungen der Temnye allei verweist auf dessen Vermögen der situations- und themengerechten Gestaltung des Erzähltempos, das in der einzelnen Erzählung vielfach variiert wird und jeder Erzählung ihren spezifischen Rhythmus verleiht. Es liegt nicht zuletzt an dieser Rhythmisienung, daß Bunins Prosa als lyrisch empfunden wird, wobei Bunin in diesem Punkt keinen Unterschied zwischen seiner Lyrik und seiner Prosa machte: „Свои стихи, кстати сказать, я не отграничнваю от своей прозы. И здесь, и там одна и та же ритмика ... - дело только в той или иной силе напряжения ее. ${ }^{.334}$

Verallgemeinemd läßt sich feststellen, daß Bunin zwischen dem szenischen Aufbau der Dialoge und ausgedehnten Beschreibungen der Umgebung bzw. der Protagonisten hin und her wechselt, wobei die Beschreibungen oftmals die Funktion einer Aufforderung zum Innehalten übernehmen, sei es zum Reflektieren des Vorangegangenen, sei es zum Durchatmen vor dem Hercinbrechen der Katastrophe. ${ }^{335}$ Eine Ausnahme bilden lediglich die Unmittelbarkeit suggerierenden Momentaufnahmen, die häufig im Präsens übermittelt werden und dadurch zusătzlich für das Empfinden einer zeitlichen Verdichtung sorgen.

Exemplarisch wird der Einsatz dieses Verfahrens anhand einer diesbezüglichen Analyse der Erzählung .,Dubki““ veranschaulicht, die, wie viele andere Erzählungen der Temnye allei auch, als Erinnerungsbericht mit einer Ich-Erzählsituation konzipiert ist: Ein alter

333 Zit. in: N. Sedovoj. „Iz otzyvov sovetskich pisatelej o Bunine“. In: LN. 84.Bd. (2) op.cit.: 371.

334 I. Bunin. „Kak ja piš". op.cit.: 375.

$335 \mathrm{Vgl}$. hierzu die detaillierte Analyse J. Woodwards zum Einsatz der betreffenden Technik in der Erzahlung ..Muza“: ,Narrative Tempo in the Later Stories of Bunin“. op.cit.: 383-396. In diesem Zusammenhang ist auch die Untersuchung der verschiedenen Zeitebenen in der Erzahlung „Cholodnaja osen ““, die Boris Briker auch im Hinblick auf die Auswirkungen auf das Erzahltempo durchfuhrie, von Interesse: „Time, History, and Fairy Tale in Ivan Bunin's ,A Cold Autumn'w. op.cit.: 125-136. Einem vergleichbaren Aspekt widmet sich I. Karpenko in seiner Analyse der Erzăhlung .Pozdnij cas“: „.Problemy dinamiceskogo i staticeskogo v proze I. A. Bunina". In: Izvestija Voroneżskogo pedagogičeskogo instiIuta. I14.Bd. Voronez, 1971: 106-114. 
Mann entsinnt sich jener lang zurückliegenden Winterferien, die er auf dem elterlichen Gut verbrachte. Dort begegnete er der schönen jungen Frau des Dorfältesten, in die er sich verliebte. Sie erwiderte seine Liebe und ermunterte ihn zu einem heimlichen Stelldichein in Abwesenheit ihres Mannes, der jedoch vorzeitig nach Hause zuruckkehrte und die beiden ertappte. Seine Rache war fürchterlich, denn noch in derselben Nacht ermordete er seine Frau. Die folgende Analyse soll illustrieren, auf welche Weise Bunin Spannung durch das Wechseln zwischen einem stockenden bzw. zügigen Erzählfluß erzeugt.

Die Erzăhlung setzt ein mit einer umfangreichen Beschreibung, die der Lokalisierung der Begebenheiten in Zeit und Raum dient. Während Bunin jedoch zunächst die Zeitangabe recht vage hält („Шел мне тогда, друзья мои, всего двадиать третий год ...“, 6: 346), verwendet er viel Mühe auf die rảumliche Situierung, über die wiederum eine Präzisierung des Zeitraums möglich ist: die Mitteilung über die Beförderung des Protagonisten im Militärdienst sowie der Verweis auf das Gut erlauben eine zeitliche Einordnung in das 19. Jahrhundert oder um die Jahrhundertwende. Die kondensierte Beschreibung der Örtlichkeiten mit Hilfe eines Chiasmus läßt jedoch bereits auf der ersten Seite das Heraufziehen eines dramatischen Kammerspiels ahnen: „Дика [Hervorhebungen H. Reese] и поныне русская деревня, зимой пуце всего, а что ж было в мои времена! Таково дико было и Петровское с этой пустовавмей усадьбой ...“ (6:346). Es schließen sich Beschreibungen der beiden weiteren zentralen Figuren an: während der Dorfalteste Lavr mit seinem ziegelroten Gesicht an einen Atamanen erinnert, ăhnelt seine junge Gattin Anfisa einer Spanierin. Nach diesen Beschreibungen, die den Rahmen für die kommenden Ereignisse abstecken, faßt der Erzähler den typischen Ablauf seiner Ferientage, die er wegen Anfisa unter verschiedenen Vorwänden mit Vorliebe in der Hütte des Dorfältesten verbringt, zusammen. Dieser Zeitfluß gerät ins Stocken mit der Mitteilung seiner nahenden Abreise: „Анфиса [...] опустила вдруг [Hervorhebung H. Reese] шитье на колени ...“ (6: 347). Das Adverb „вдруг“ dient Bunin in zahlreichen Erzăhlungen der Temnye allei als typisches Mittel zur Ankündigung eines Wechsels (vgl. Kap. 8.1). In diesem Fall leitet die nun von Anfisa ausgesprochene Einladung furr den kommenden Tag, an dem ihr Ehemann nicht im Haus sein würde, sowohl die eigentliche Handlung als auch die Wendung zur Katastrophe ein. Diese kurze, unmittelbare Darstellung geht wieder uber in eine Beschreibung des folgenden Tages, der dem ungeduldig auf den Abend wartenden jungen Mann schier endlos erscheint. Dieser Eindruck wird nachdrücklich übermittelt durch lange Aufzählungssätze. Diese Dehnung der Zeit scheint der Kürze eines Wintertages entgegenzustehen: „... я до самого утра то трубку курил, то ром пил, нимало не пьянея, все 
разгораясь в своих безрассудных мечтах,-прошел и короткий зимний день, стало темнеть, а на дворе - прежестокий буран“ (6: 347). Die anschließende Beschreibung des wütenden Schneesturms und der bedrohlichen Dunkelheit der Scheune entsprechen dem Gefuhlsaufruhr im Innern des jungen Mannes und stehen gleichzeitig in scharfem Kontrast zum Glanz und der Wärme, die den jungen Mann in der Hütte erwarten - dieser Augenblick des ersten Eindrucks wird im Präsens festgehalten, als hătte die Zeit stillgestanden, Zeit und Raum verdichten sich spürbar: Das knistemde, funkensprühende Feuer, der Glanz der Augen Anfisas, ihres seidenen Sarafans, ihrer silbernen Ohrringe spiegeln in sich all das Glück des Augenblicks. Der Zeitfluß setzt erneut ein mit dem erfreuten Aufspringen Anfisas beim Anblick des Eintretenden und wird wieder unmittelbar im kurzen szenischen Gespräch zwischen den beiden Liebenden, deren Umarmungen abermals von einem „вдруг“ (6:348) unterbrochen werden. Dieser Wechsel markiert die Ankunft Lavrs und somit die Wendung zur Katastrophe. Jener hat auf Grund des Schneesturms seine Reise abgebrochen und kehrt unerwartet früh nach Hause zurück („Вот тут он и взошел ...“, 6: 348). Eine erneute Beschreibung des Äußeren Lavrs, mit wiederholter Hervorhebung seines ziegelroten Gesichts, läßt dahinter nicht eine natürliche Gesichtsfarbe, sondern kochenden Zom vermuten. Des weiteren wird mit Hilfe dieser im Präsens übermittelten Schilderung die lăhmende Anspannung der beiden Liebenden sichtbar gemacht. Diese löst sich erst, als schließlich Lavr dem jungen Mann dringend empfiehit, sich zu verabschieden. Nachdem dieser das Haus verlassen hat, erfolgt ein Zeitsprung zum folgenden Morgen. In der epilogisch wirkenden Wiedergabe eines weiteren szenischen Dialogs, der sich noch in der Nacht zugetragen hat, kommen die grausamen Geschehnisse in der Hütte des Dorfältesten ans Tageslicht, während Lavr erfolglos versucht, den Mord an seiner Frau als Selbstmord auszugeben. Übergangslos wird der letzte Satz mit einem kurzen Ausblick an die Erzählung gehängt: „Был он бит плетьми и отправлен в Сибирь, в рудники“ (6: 349). Dieses epilogische Segment hat eine ähnliche Funktion wie die ausfuhrlichen Beschreibungen, wirkt jedoch durch das Fehlen eines Übergangs ungleich stärker nach.

Eine besondere Rolle beim Aufbau der in der Erzählung herrschenden Spannung kommt der Beschreibung des Schneesturms zu, der mehrere Funktionen übernimmt: Zum ersten spiegelt er den Aufruhr der Gefuhle im Innem des Protagonisten wider, zum zweiten unterstützt er das Gefühl des Abgeschnittenseins von der restlichen Welt, zum dritten illustriert er nachdrücklich das Ausgeliefertsein des Menschen an die Kräfte des Schicksals, und zum vierten liefert er die realistische Motivierung für Lavrs vorzeitige Heimkehr. 
Zusammenfassend läßt sich feststellen, daß lange Sătze mit ausführlichen Beschreibungen abwechseln mit kurzen dialogischen Sătzen. Die beiden erwähnten Passagen im Präsens stehen fưr die beiden Momente, die sich dem Protagonisten am stärksten eingeprägt haben. Dieser unvermittelte Wechsel ins Präsens hat dreierlei Funktionen: Zum einen tritt der Protagonist in diesen Augenblicken aus dem Zeitfluß heraus, und zum anderen wird auf diese Weise die Intensität der Erfahrung hervorgehoben. Nicht zuletzt entspricht dieser plötzliche Wechsel Bunins Konzeption von der Liebe als einem jăh und heftig hereinbrechenden Gefühl.

Die Statik der von Bunin gezeichneten Bilder erfährt vor allem durch die Dialoge eine Dynamisierung, die jedoch die zuvor gezeichneten Bilder nicht ins Wanken bringt. Die ständigen Wechsel zwischen Beschleunigung und Verzögerung dienen jedoch nicht nur dem Spannungsaufbau, sondern führen auch zu der segmentarischen Struktur zahlreicher Erzählungen, die die Bedeutsamkeit des Augenblicks gestalterisch im selben Maße hervorhebt wie sie die Vielfalt des Lebens sichtbar macht.

\subsection{Zusammenfassende Betrachtung}

Eine zusammenfassende Betrachtung der in den vorangegangenen Abschnitten untersuchten strukturellen Merkmale im Hinblick auf ihre verknüpfungsbildenden Funktionen

für die Erzählungen der Temnye allei resultiert in der Feststellung zahlreicher Parallelen bei der Gestaltung der einzelnen Erzăhlungen, die auf Grund des von Bunin verwendeten Variantenreichtums für unaufdringliche Verbindungen der Erzählungen in unterschiedlichen Festigkeitsgraden sorgen.

Bereits die Titel der Erzăhlungen lassen die Bedeutung der Protagonisten (mit besonderer Betonung der Frau) und der Schauplätze bei der Umsetzung der thematischen Schwerpunkte erahnen, die sich in den entsprechenden Analysen bestätigt. Eine vergleichende Betrachtung der Anfangssătze und der Gestaltung der Handlungsführung in den einzelnen Erzăhlungen fordert zudem die Relevanz des zeitlichen Aspekts zutage, der sich in dem hohen Stellenwert zeigt, den Bunin der Erinnerung beimißt. Die Erinnerung ist somit als grundlegendes Gestaltungskonzept zu werten und gleichberechtigt neben die Schwerpunktthemen Liebe und Tod zu stellen. Eine Zusammenschau der häufig abrupten Erzählschlüsse, teilweise mit kurzen Epilogen versehen, zeigt schließlich die konsequente 
gestalterische Umsetzung von Bunins Liebeskonzeption als einem zwar intensiven, aber höchst kurzlebigen Gefühl sowie die Macht des unvermittelt hereinbrechenden Schicksals.

Des weiteren lassen sich frappierende Ähnlichkeiten zwischen den Schauplätzen feststellen, deren hauptsächliche Funktionen darin bestehen, den Seelenzustand der Protagonisten zu spiegeln bzw. zu konterkarieren und den Allzusammenhang der Schöpfung zu verdeutlichen. Mit der bevorzugten Wahl temporärer Behausungen als Schauplatz, wie etwa Hotels, vermittelt Bunin eindringlich sowohl die Rastlosigkeit der männlichen zentralen Figuren als auch die schicksalhafte Kürze der Liebeserfahrungen, die so ihre Entsprechung auf der lokalisierenden Ausdrucksebene finden.

Als grundlegende Gestaltungstechnik und zugleich als Rhythmusgeber in den Temnye allei darf der Kontrast gelten, mit dessen Hilfe Bunin die verschiedenen thematischen Bipolaritäten herausarbeitet. Auf der strukturellen Ebene fallen zwei Methoden besonders auf: die Technik der prophetischen bzw. irrefuhrenden Zukunftsvorausdeutung und der gezielte Einsatz eines kontrastierenden Erzăhltempos. Der Technik der prophetischen bzw. irrefuhrenden Zukunftsvorausdeutungen kommt hierbei die Aufgabe zu, das Ausgeliefertsein des Menschen an Mächte außerhalb seines Einflußbereiches zu verdeutlichen. Mit dem Einsatz eines auffallig variierenden Erzähltempos erzeugt Bunin Spannung. Der Kontrast als Gestaltungsmittel unterstreicht nachdrücklich das Mißverhältnis zwischen der Kürze des leidenschaftlichen Liebesaugenblicks und dem langen Zeitraum, der von der nicht immer tröstlichen, sondern auch höchst quälenden Erinnerung ausgefullt wird.

Im stilistischen Bereich finden sich gleichfalls ausgeprägte Parallelen zwischen den Erzählungen, die im folgenden Kapitel vorgestellt werden. 
6 INTRATEXTLICHE VERKNÜPFUNGEN IN DEN TEMNYE ALLEI (II): STIL

Bunins Detailfreude und seine Fähigkeit, komplexe und plastische Bilder zu schaffen, werden in beinahe jeder Äußerung zu seiner Kunst hervorgehoben. ${ }^{336}$ In einer undatierten Notiz äußert sich Bunin selbst zu den Anmerkungen eines Kritikers:

„Как удивительно помнит Бунин пережитое им - лица, пейзажи, звуки, запахн, краски!" - и т[ак] д[алее]. Но мое существо сильно воспринимает, запоминает не частности, а нечто общее, а из этого создает вынысль, любит только „лгать“. И с годами во мне развилась способность „лгать“ так убедительно, что [например], чуть не все любовные истории, написанные мною, не только мои читатели, но даже и критики, считали и считают мною самым пережитыми. ${ }^{337}$

Bunins ausgeprägter Sinn fürs Detail spiegelt sich im übrigen auch in den Korrekturen, die er in Manuskripten und Typoskripten durchfuhrte - diese betreffen in der Regel häufig nur einzelne Wörter, wie sich auch in seinem Autorenexemplar der Temmye allei in der Ausgabe von 1946 zeigt. Diese auffällige Betonung scheinbarer Kleinigkeiten zeugt gleichermaßen von Lebensfreude und von Bunins Bestreben, uber Details mit Symbolkraft die untergegangene Heimat wieder lebendig werden zu lassen. ${ }^{338}$

So ist Bunins Prosa nicht nur rhythmisch und lyrisch, sondern gleichermaßen sehr sinnlich, so daß Iezuitovas Klassifizierung von Bunin als „самый чувственный писатель всех времен “339 als nicht übertrieben erscheint: Das Aussehen von Personen, der Anblick von Landschaften spielen eine ebenso gewichtige Rolle wie Beschreibungen von Geräuschen (z.B. Tosen des Windes, Kirchenglocken, nahende Schritte, Ohrfeigen), Gerüchen (z.B. feuchte Blătter nach einem Regenguß, dampfendes Essen, billiges Parfum), Tastimpressionen (z.B. Weichheit von Pelzen, erhitzte Wangen) und Geschmacksempfindungen (z.B. Essen, Haut). Sein Streben nach verbaler Plastizităt liegt in seiner Art der Lebenswahr-

336 Vgl. u.a. I. Gazer. „O svoeobrazii lirizma v novellach Bunina“. In: Voprosy russkoj literatury 16 (1971): 60; A. Sokolov. „Zametki o chudožestvennom masterstve I. Bunina“. op.cit.: 100; T. Bonami. .K poetike rasskazov I. A. Bunina. (Funkcional'noe znacenie zvukovych i muzykal'nych obrazov)“. In: I. A. Bunin i russkaja literatura XX veka. Moskva, 1995: 92.

337 LRA. MS. 1066/466.

$338 \mathrm{Vgl}$. auch S. Hutchings. „Myth, Plot Transformation and Iteration in Ivan Bunin's Fiction". In: Forum for Modern Language Studies 30 (1994): „Bunin's penchant for the ,blind pursuit“ of detail was linked to his strategy of projecting the negativised random contingency of the present into the value-laden past, thus making it ripe for resurrection as ,present-but-absent", and simultaneously dissolving the past/present dichotomy. We can now perceive more easily the other, related aspect to the sometimes choking detail of Bunin's descriptive technique. By writing in this manner Bunin implicitly demonstrates how the realms of narrative and memory blur the difference between what is specific and contingent and what is general and permanent. Through the pseudo-mythic, transformative action of narrative/memory the specific is automatically eternalised and the etemal acquires specificity" (S. 60-61).

339 L. lezuitova. „V poiskach vyraženija ...“. op.cit.: 215. 
nehmung begründet; am 22. Januar 1922 notiert er in seinem Tagebuch: „Я всегда мир воспрннимал через запахи, краски, свет, ветер, вино, еду - н как остро, Боже мой, до чего остро, даже больно! “340

Bei seiner sehr überlegten Wortwahl schöpft Bunin aus einem reichen und differenzierten Wortschatz, ohne auf Hilfsmittel zurückzugreifen, wie er nicht ohne Selbstgefalligkeit in einer undatierten Notiz feststellt: „Откуда мое такое удивительное, огромное богатство знания русского языка? Я даже Даля' никогда в жизни не держал в pyкax. ${ }^{341}$ Bunin verwendet ein klassisches hochsprachliches Russisch, im Vergleich zu seinem Fruhwerk hat die Verwendung dialektaler Formen spürbar nachgelassen, die er nur noch gezielt zur Schaffung von authentisch wirkendem Lokalkolorit einsetzt. ${ }^{342}$

Kennzeichnend für den Einsatz sprachlicher Mittel sind in den Temnye allei die auffallende und überlegte Verwendung von Epitheta, häufig in gedoppelter Form (z.B. „c чеpными беспокойными глазами“, „Rečnoj traktir", 6: 338) oder in ungewöhnlichen Verbindungen $^{343}$, vor allem im farblichen Bereich (z.B. „мрачно-цветисто“, „Mеst”“, 6: 388; vgl. Kap. 6.2), die die Individualität einer Erzählung sicherstellen. ${ }^{344}$ Weiterhin erregt die Hăufung von Zeitadverbien Aufmerksamkeit (z.B. „вдруг“, „тогда“) - diese Verwendung ist erklärbar mit der Bedeutung der Zeit in dem Buch. Letzteres spiegelt sich auch in der gehäuften Verwendung von Verben in der unvollendeten Zeitform wider, mit deren Hilfe Bunin zeigt, daß das alte Rußland noch lebendig ist-und sei es auch nur in der Erinnerung. ${ }^{345}$

Unterstützt wird die Musikalität der Prosa durch Wörter aus dem poetischen Bereich etwa in „Dubki““ (,ланнты“, 6: 348), aber vor allem durch den Einsatz von Stilmitteln, die üblicherweise in der Lyrik verwendet werden, wie etwa die Anapher in der Erzählung

340 Zit. in: UB. 2.Bd. op.cit.: 75.

341 LRA. MS. 1066/550.

342 O. Peschl. „Die kunstlerische Entwicklung von Ivan Bunins Prosastil“. op.cit.: 164 und A. Kocetkov. „Sredstva vyrazenija emocional'nosti ...”. op.cit.: 125. Vgl. hierzu „Ballada“ und ...Madrid“.”.

343 Eine Besonderheit stellen anthropomorphisierende Adjektive und Adverbien dar, wie sie beispielsweise zu finden sind in „Genrich" (,моря [...] печально пропадающег“", 6: 300) oder „Cistyj ponedel'nik“" (.зловещие [...] волосы“, 6: 399), deren Funktion haufig in der atmosphărischen Einstimmung auf kommende dramatische Ereignisse zu sehen ist.

$344 \mathrm{Vgl}$. R. Fedoulova-Touja. „O nekotorych osobennostjach jazyka I. Bunina“. In: Revue des études slaves 4 (1983): 567-575 und G. Stulz. .Une Approche de Bunin: Etude des qualificatifs". In: Cahiers du monde russe et soviétique 3-4 (1987): 347-360. Die SchluBfolgerung, die Stulz aus ihrer Analyse der Verwendung von Adjektiven in Bunins einzigem Roman Żizn'Arsen'eva (1927-1939) zieht, trifft auch auf die Temnye allei zu: „Tous ces exemples amenent à une conclusion paradoxale: ce luxe d'adjectifs est concision!" (S. 359). Mit verschiedenen Beschreibungstechniken in Bunins Prosa befaBt sich Robert Roudet in seinem Aufsatz "Quelques Particularités de la technique d'Ivan Bunin“ (in: Revue des études sloves 4 [1995]: 665-673), in dem er ebenfalls auf die Pradominanz des Adjektivs hinweist.

$345 \mathrm{Vgl}$. A. de Yackovlev. ..Bunin's Prose Writing in Exile“. [Masch.schr.] Diss.Rd967: \$8854790210 
"Temnye allei“ („Ax, как хороша [Hervorhebungen H. Reese] ты была! - сказал он, качая головой. - Как горяча, как прекрасна! Какой стан, какие глаза! Помнншь, как на тебя все загладывались?“, 6: 177), die Alliteration, wie beispielsweise in „Natali“ und „Dubki““ („После ужина улан уходил спать ...“, 6:311; „сказал улан бодро, с одобрительным намеком“, 6: 315; „стремительно-страстно“, 6: 347), leicht abgewandelte Epiphorä, wie zum Beispiel in „Mest”“ (,Да, знаю, вы жсивописеч. / Да, а вы живописны“, 6: 389) oder den Einsatz eines Ciniasmus, wie zum Beispiel in „Temnye allei“ („Сама, значит, держишь?/ Так точно. Сама“, 6: 176). Gehäuft verwendete Bunin diese Mittel in der Erzählung „Pozdnij Cas“, wie das folgende Zitat verdeutlicht:

За мостом я поднялся на взгорье, пошел в город мощеной дорогой. В городе не было нигде ни единого огня, ни одной живой души. Все было немо и просторно, спокойно и печально - печалью русской степной ночи, спящего степного города.“ (6: 203).

Auch spielt die Bildhaftigkeit in den Temnye allei eine große Rolle, die vor allem bei den Naturdarstellungen zum Ausdruck kommt. ${ }^{346}$ In der Regel greift Bunin hierbei auf die Vergleichsform (как, похоже на, точна, подобный etc.) oder den Instrumental zurück. Dadurch können höchst ungewöhnliche und originelle Wortverbindungen entstehen, wie etwa in „Pozdnij cas“ („... рыбъим блеском блестит крыша дома“, 6: 205), in „Tanja“ bzw. „Dubki““ („белая тьма“, 6: 263 bzw. 347), in „Natali“ („черные солнца“, 6: 303), in „Antigona“ („с веселой ненавистью“, 6:223) oder in „V odnoj znakomoj ulice“ („грудь с твердевшим недозрелой земляникой острием“, 6: 332).

Im folgenden werden typische stilistische Merkmale, die über die genannten Stilmittel hinaus in eklatanter Weise allen Erzählungen der Temnye allei gemeinsam sind, anhand ausgewählter Beispiele vorgestellt: hierzu gehören die Technik der Doppelung bzw. Wiederholung einzelner Laute und Wörter sowie die farbliche Ausgestaltung der Erzählungen mit einer schier unerschöpflich scheinenden Farbpalette unter Berücksichtigung der prominenten Bedeutung von Licht, Glanz und Schatten. Als weitere stilistische Besonderheit zahlreicher Erzählungen des Buches dürfen die intertextuellen Bezüge mittels Fremdzitaten unterschiedlicher Provenienz gelten, die Bunin auffälig häufig verwendet und die unter anderem eine enge Bindung zur russischen, nicht nur literarischen Vergangenheit herstellen. 


\subsection{Doppelungen und Wiederholungen}

Analog zur Ausdrucksverstärkung auf der strukturellen Ebene mit Hilfe des Kontrastes verwendet Bunin auch im lexiko-semantischen Bereich bevorzugt eine gestalterische Technik, die die innere Struktur einer Erzählung festigt, aber auch zu einer Rhythmisierung und Emotionalisierung fuhrt: die Technik der Wiederholung von Lauten und Wörtern findet sich in allen Erzählungen der Temnye allei.

Zu den Verfahren der Lautwiederholung gehört der gezielte Einsatz sowohl von Assonanzen als auch von klanglich ähnlichen Wörtern, die in der Regel in unmittelbarer Nähe zueinander stehen. Vokalwiederholungen bzw. die überwiegende Verwendung bestimmter Vokale tragen nicht zuletzt zu dem Eindruck bei, daß Bunins Prosa lyrische Züge trägt. So ist etwa die Erzählung „Temnye allei“ von dem Vokal „o" geprägt, während in „Časovnja“ der Vokal „a" dominiert. Interessante Assonanzen finden sich beispielsweise in "Galja Ganskaja“ (фиалки, вуалка, чулки; неожиданно вбегает она однажды [6:288]; отправлюсь-отравилась [6: 288-289]), in „Mest““ („.... как я был удивлен, когда увидал ..." [6: 392]) und in "Cholodnaja osen"“, in Anlehnung an das Zitat aus Fets Gedicht „Kakaja cholodnaja osen'“347 (1847): „Посмотри, как совсем особенно, поосеннему светят окна дома“ (6:368); überdies sorgt das Gedichtzitat für zusătzliche poetische Tiefe.

Doppelungen oder gar Verdreifachungen sind in der Regel in der wörtlichen Rede zu finden, bilden rhythmische Ankerpunkte und wirken hrchst emotionalisierend. In der Erzählung „Temnye allei" verwendet Bunin diese Technik unter anderem, um dem resignativen Lebensgefühl des alternden Offiziers Ausdruck zu verleihen: „Все проходит, мой друг, [...] все, все. [...] С годами все проходит“ (6: 177). Einen komischen Effekt erzielt Bunin in der Erzählung „Mest"“ in folgendem Dialog, der sich entspinnt, als die Protagonistin herauszufinden versucht, warum der Protagonist sie verfolgt und am Strand beobachtet hat: „Да, знаю, вы живописец.“- „Да, а вы живописны.“ (6: 389). In besonders eklatanter Weise setzt Bunin dieses Stilmittel in der Erzählung „Cistyj ponedel'nik“ ein, wie das folgende Beispiel eines Dialogs zwischen den jungen Liebenden über die Zukunft ihrer Beziehung zeigt [Hervorhebungen $\mathrm{H}$. Reese]:

- Нет, в жены я не гожсусь. Не гожсусь, не гожусь. [...]

- Да, все таки это не любовь, не любовь ...

Она ровно отозвалась из темноты:

- Может быть. Кто же знает, что такое любовь? 
- Я, я знаю! - воскликнул я. - И буду ждать, когда и вы узнаете, что такое любовь, cuacmbe!

- Счастье, счастье ... „Счастье наше, дружок, как вода в бредне: тянешь надулось, а выташишь - ничего нету“.

- Это что?

- Это так Платон Каратаев говорил Пьеру. (6: 402-403).

Leitmotivische Funktion mit dem Ziel der inneren Strukturierung einer Erzählung und möglicherweise Neubewertung kommt der zwei- oder mehrfachen Wiederholung von Wörtern innerhalb einer Erzählung zu. Diese Aufgabe hat etwa in der Erzählung „Duroxka“ das Adjektiv „блестящий“, das viermal in höchst unterschiedlichem Kontext erwähnt wird: es glänzen Wasser und Augen, der Sohn des Diakons hat sein Examen mit „glänzend“" bestanden und blickt einer strahlenden Zukunft entgegen, deren einziger Schandfleck der aus dem kurzen Verhältnis mit dem Küchenmädchen hervorgegangene Sohn ist. Ähnlich verhält es sich in der Erzählung "Smaragd“ mit dem Vergleich des Aussehens eines Sterns mit dem Edelstein; daruber hinaus wird durch den Vergleich des Sterns mit einer Träne am Anfang der Erzählung („золотая слеза звезды“, 6: 230) eine Verbindung zum Ende hergestellt, als die Protagonistin nur mit Mühe ihre Trănen zurückhalten kann. Vergleichbares läßt sich in der Erzăhlung „Parochod ,Saratov““ feststellen, die sich um das Substantiv „Hоra“ zu drehen scheint. Zu Beginn und am Ende der Erzăhlung stehen jeweils die Füße des Offiziers im Mittelpunkt, zunächst in neue Stiefel gekleidet, auf dem Sträflingsschiff mit Fesseln zusammengebunden. Seine besondere Aufmerksamkeit gilt den Füßen seiner Geliebten, die in Pantoffeln stecken, und einer Puppe versetzt er einen effektvollen Fußtritt. Als weitere ausgewählte Beispiele lassen sich das Adjektiv „белы ““ in "Tanja“ und "Genrich“, das Substantiv „6apxar" in "Nacalo“ oder die Substantive „встреча“" und „история" in „V Pariže“" anführen.

\subsection{Farben}

Bunins sprachliches Vermögen und seine Freude am Detail kommen nicht zuletzt in einer reichen und sehr nuancierten Farbgestaltung mit keineswegs rein attributiver Funktion zum Ausdruck. Auf Grund seines virtuosen Umgangs mit einer erstaunlich breit gefächerten Farbpalette kann man Bunin mit Fug und Recht als literarische Ausnahmeerscheinung bezeichnen: „Внимание Бунина к миру красок, его мастерство в передаче тонов и 
оттенков - явление исключительное в русской литературе. “348 Mit der Welt der Farben war er schon als Kind in Berührung gekommen, durch seinen Hauslehrer Nikolaj Osipovix Romałkov, der sich selbst mit Malerei beschäftigte. ${ }^{349}$ In einer autobiographischen Notiz erinnert Bunin sich an diese Zeit:

Он играл на скрипке, рисовал акварелью, а с ним вместе иногда по цельм дням не разгибался и $я$, до тошноты насасываясь с кисточки водой, смешанной с красками, и на всю жизнь запомнил то несказанное счастье, которое принес мне первыи коробок этих красок: на мечте стать художником, на разглядывании неба, земли, освещения у меня было довольно долгое помещательство. ${ }^{350}$

Prägend für Bunins intensive Auseinandersetzung mit Farben war darüber hinaus der enge Kontakt mit verschiedenen Malem der Odessaer Künstlervereinigung „Tovarißcestvo južnorusskich chudožnikov" in den letzten Jahren des 19. Jahrhunderts, denen er mit der Erzăhlung „Galja Ganskaja“ ein Denkmal zu setzen scheint. Die grőßte Bedeutung kommt hierbei seiner Freundschaft mit Petr Nilus (1869-1943) zu. ${ }^{351}$ Letzterer fühlte sich zu Beginn seiner künstlerischen Laufbahn den Peredvižniki verbunden, setzte sich in der Folge jedoch verstärkt mit dem Farbe und Lichteffekte betonenden Impressionismus auseinander und hebt den Einfluß der südrussischen Maler auf Bunin sowie dessen Aufenthalt in Odessa in einem undatierten Aufsatz hervor:

Среди своих друзей-художников Бунин особенно живо понял, что небо и море не только голубого цвета, что есть теплые и холодные тона, что небо отражается не только на крышах и в воде, не облекает все предметы свонм отражением, что луна бывает серебряной и золотой и красноватой, а ночное небо зеленоватым и розоватым и золотистым, и что солнце и луна насыщают светом испарений воздух, землю...[...] Я глубоко уверен, что без Одессы он был бы писателем другого оттенка, характера. 352

Die Begeisterung für eine möglichst detailgenaue Wiedergabe von Farben verliert sich auch nicht in den Jahren des Exils, im Gegenteil, in den Temnye allei fällt der gezielte Einsatz von Farben bei der Beschreibung des Äußeren der zentralen Figuren (vor allem der weiblichen) oder zur Übermittlung von Naturerscheinungen auch in unkonventionellen Kombinationen mit Gespür für die Atmosphäre des jeweiligen Augenblicks bzw. für einen bewußten Bruch mit der Stimmung auf. Dieses Verfahren erzeugt eine überraschende Pla-

348 A. Saakjanc. ... Temnye allei". Poslednie gody". op.cit.: 517.

$349 \mathrm{Vgl}$. hierzu auch Silke Klovers Studie: Furbe. Licht und Glanz als dichterische Ausdrucksmittel in der Lyrik Ivan Bunins. Munchen, 1992. Im Rahmen des biographischen Überblicks widmet sie der Entwicklung des Farbempfindens Bunins im Laufe seines Lebens besondere Aufmerksamkeit.

350 I. Bunin. „Avtobiograficeskaja zametka“. (10.04.1915). In: ders. SS v devjati tomach. 9.Bd. op.cit.: 257.

351 I. Bazinov. „Bunin i Nilus“. In: $L N$. 84.Bd. (2) op.cit.: 424-428.

352 P. Nilus. „Iv[an] Bunin i ego tvorkestvo". In: $L N$. 84.Bd. (2) op.cit.: $430-431$ und 435 
stizităt und hinterläßt einen tiefen emotionalen Eindruck beim Leser. Darüber hinaus dient der Farbeinsatz auch der Wiedergabe bestimmter Stimmungen von Personen, vor allem bei Beschreibungen der Gesichtsfarbe.

Eine Zählung und Kategorisierung der in den Temnye allei verwendeten Farben erbringt interessante Ergebnisse: Es finden sich 1.083 relevante Farbwörter aus den Farbfeldern WeiB, Schwarz, Rot, Grün. Braun, Blau, Grau, Gelb, Bunt, Lila und Orange (vor allem Adjektive, aber auch Verben und Substantive), die eine an Nuancen und Halbtönen reiche Farbpalette sichtbar machen. Die gewünschte Farbgebung wird überwiegend durch den Einsatz von Epitheta (auch als Komposita), aber auch mit Hilfe von Verben in unterschiedlicher Präfigierung sowie von Substantiven realisiert. In der Folge wird die Verwendung der Farben gemäß der Häufigkeit ihres Auftretens in den drei Komplexen des Buches dokumentiert. Ergänzt werden die Anmerkungen zu dem einzelnen Farbton durch eine Tabelle im Anschluß an jeden Abschnitt, die Auskunft sowohl über die eingesetzten Farbwörter als auch über deren Frequenz gibt. Letztere wurde errechnet, indem die Gesamtzahl der ermittelten Wörter durch die Anzahl der Seiten des jeweiligen Komplexes dividiert wurde (I: 32 Seiten, II: 119 Seiten, III: 79 Seiten). Die adjektivischen Komposita, die Bunin zahlreich verwendet (und nur selten wiederholt), werden gesondert vorgestellt, da in die Zählung lediglich der zweite und somit determinierende Bestandteil einfloß.

\subsubsection{Das Farbfeld Weiß}

Die dominierenden Farben in den Erzählungen der Temnye allei sind Weiß, Schwarz und Rot, wobei Weiß mit 253 Nennungen und einem Anteil von 23,4 Prozent an allen Farbwörtern die Spitzenstellung einnimmt. ${ }^{353}$ Rein rechnerisch verwendet Bunin diesen neutralen Farbton im Schnitt einmal pro Seite, so daß Weiß wie eine Leinwand erscheint, auf der er die Farben zum Leuchten bringt.

Den größten Anteil am Farbfeld Weiß hat das Adjektiv „белый“ mit 108 Nennungen. Mit Abstand folgen „снег“ (48), „бледный“ (18), „белеть“(16) und „белизна“ (11). Die weiteren Tönungen werden vereinzelt und sehr gezielt eingesetzt, so zum Beispiel 
„известковый als nähere Beschreibung von Vogelexkrementen („Natali“, 6: 314) oder ein die Farbe Weiß implizierender Instrumentalvergleich von Schnee mit Puderzucker („точно сахарной пудрой“, „Тапја“, 6: 262).

Komposita mit Weiß als zweitem Bestandteil verwendet Bunin überwiegend zur Präzisierung von Naturphänomenen und Hauttönen. Darüber hinaus ist festzustellen, daß der nuancierende Farbton mehrheitlich Blau ist, nur eine einzige Wiederholung vorkommt und sich der Einsatz derartiger Komposita mit einer Ausnahme auf die Erzählungen der „schwarzen Sonne“ beschränkt: „сахарно-белың“ (Chalat, „Zojka i Valerija“, 6: 242), „сизо-белый“ (schneebedeckte Felder, 2x, „Тапја“, 6: 262), „синевато-меловой“ (Lichtbündel des Projektors im Kino, „V Pariže“, 6: 278), „голубовато-бледный“ (Hautfarbe, „Genrich“, 6: 293), „голубовато-мелово һ“ (Hautfarbe, „Natali“, 6: 308), „дымчатобелы ““ (Wolken, „Natali“, 6: 320), „мертвенно-бледны ““ (Mond, „Natali“, 6: 320), „розово-белыи“" (Hautfarbe, „Voron“, 6: 377).

In beinahe jeder Erzählung der Temnye allei setzt Bunin Weiß in Kombination mit Schwarz in vielerlei Variationen zur Illustrierung eines Kontrastes ein, der nicht selten beim Rezipienten unheilvolle Vorahnungen weckt, wie beispielsweise in der Erzählung „Genrich":

[...] он [...] выходил на набережную, к смоляной черноте [Hervorhebungen H. Reese] моря, глядел на драгоценное ожерелье его черного изгиба, печально пропадаюшего вдали направо [...]. Возвратясь в отель, он, белый как мел, в белом галстуке, в белом жилете, в чилиндре, важно и небрежно подошел к портье, бормоча мертвеющими губами: Pas de télégrammes? (6: 300).

Tabelle 1, Farbfeld Weiß

\begin{tabular}{|l|l|l|l|}
\hline & Komplex I & Komplex II & Komplex III \\
\hline Adjektive & & & \\
\hline белый & 9 & 70 & 29 \\
\hline белоснежный & 2 & - & - \\
\hline бледный & 3 & 9 & 6 \\
\hline жемчужный & - & - & 2 \\
\hline нзвестковый & - & 1 & - \\
\hline кремовый & - & 3 & - \\
\hline
\end{tabular}

354 Die in dieser und den folgenden Tabellen mit einem Sternchen gekennzeichneten Worter stellen den Übergang zum Wortfeld Glanz dar. 


\begin{tabular}{|c|c|c|c|}
\hline меловой & - & 2 & 1 \\
\hline млечный & - & 1 & 1 \\
\hline молочный & - & 1 & - \\
\hline опаловый & - & 1 & - \\
\hline рисовый & 1 & - & - \\
\hline снежный & 3 & 5 & 4 \\
\hline снеговой & - & 2 & - \\
\hline фарфоровый & - & 2 & - \\
\hline \multicolumn{4}{|l|}{ Verben } \\
\hline белеть & 6 & 6 & 4 \\
\hline бледнеть & 2 & 2 & 2 \\
\hline блекнуть & - & 1 & - \\
\hline снежить & - & - & 1 \\
\hline \multicolumn{4}{|l|}{ Substantive } \\
\hline белизна & 1 & 7 & 3 \\
\hline белок, яичный & - & 1 & - \\
\hline бледность & 1 & 2 & 1 \\
\hline лебедь & - & 1 & - \\
\hline мел & - & 1 & 1 \\
\hline млечность & - & 2 & - \\
\hline пудр, сахарный & - & 1 & - \\
\hline сливки & - & 1 & - \\
\hline снег & 7 & 16 & 25 \\
\hline Gesamt & 35 & 138 & 80 \\
\hline Frequenz & 1,09 & $\longdiv { 1 , 1 5 }$ & 1,01 \\
\hline
\end{tabular}

\subsubsection{Das Farbfeld Schwarz}

Nach Weiß weist die Farbe Schwarz mit 234 Nennungen einen Anteil von 21,6 Prozent an allen Farbnennungen auf. Mit Ausnahme von „Krasavica“ ist sie in jeder Erzählung vertreten; die höchste Frequenz läßt sich im ersten Komplex konstatieren. In der Verwendung 
des Farbfeldes Schwarz erweist Bunin sich in zweierlei Hinsicht als Purist: Zum einen verwendet er nur ein Kompositum mit Schwarz als Determinante („черно-смолисто“ zur

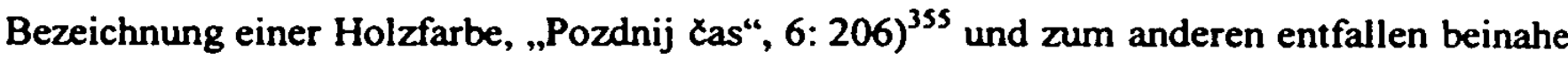
zwei Drittel aller Nennungen auf das Adjektiv „черный“. Aus derselben Wortfamilie sind darüber hinaus das Verb „чернеть“ (17 Erwähnungen, mit verschiedenen Präfigierungen) und das Substantiv „чернота“ (21) anzutreffen. Dieser düstere Ton, der Assoziationen an Tod und Trauer weckt, gestaltet das neben dem Thema der Liebe im Buch vorherrschende Todesthema auch optisch aus und wird dabei unterstützt durch an den Tod gemahnende Adjektive wie „гробовой“ und „траурный. Bei den Adjektiven unterscheidet Bunin insgesamt elf Nuancen, von denen er zehn sehr sparsam einsetzt, wie etwa bei der einmaligen Verwendung von ,смородинный“ zur Wiedergabe einer Augenfarbe (,Zojka i Valerija“, 6: 243). Die Augen der Protagonisten sind im übrigen häufig schwarz, wie etwa auch die rußfarbenen Augen von Mešerskijs Geliebter Gasa („глазами цвета сажи“, „Natali“, 6: 326), analog zu dem von Bunin bevorzugten dunklen Haut- und Haartyp vor allem bei den weiblichen Figuren (vgl. Kap. 8.2.2).

Wie bereits erwăhnt, verwendet Bunin die Antonyme Schwarz und Weiß hăufig gemeinsam, um einen Kontrast schärfer herauszuarbeiten; bei Personenbeschreibungen tritt Schwarz jedoch auch pur und gehăuft auf, wie beispielsweise bei der Beschreibung des Äußeren der Protagonistin in der Erzählung „Čistyj ponedel'nik“: „... великолепные и несколько зловещие в своей густой черноте [Hervorhebungen H. Reese] волосы, мягко блестящие, как черный соболий мех, брови, черные, как бархатный уголь, глаза (6: 399-401). Dieser Wille zur Kontrastbildung fuht bis zur Veränderung des in der Erzählung "Cholodnaja osen'“ zitierten, von Afanasij Fet stammenden Gedichts „Kakaja cholodnaja osen”“356 (1847). In den Versen „Смотри: из-за дремлющих сосен / Как будто пожар восстает“ ersetzt Bunin die Elemente „из-за дремлющих“ durch „меж чернеющих“ (6:368) und erzielt damit einen farblich und atmosphärisch ungleich dramatischeren und effektvolleren Gegensatz.

355 In der Edition der Temnye allei von 1999 und einer Ausgabe aus dem Jahr 1990 findet sich zwar die aufgeloste Schreibweise „черно, смолисто“ (206), in der von Bunin imprimierten Ausgabe von 1946 jedoch das Kompositum "черно-смолисто“" (50), so daß in den jungeren Ausgaben von einem Editionsfehler ausgegangen werden kann.

356 In: A. Fet. Polnoe SS. op.cit.: 455. 
Tabelle 2, Farbfeld Schwarz

\begin{tabular}{|c|c|c|c|}
\hline & Komplex I & Komplex II & Komplex III \\
\hline \multicolumn{4}{|l|}{ Adjektive } \\
\hline гробный & 1 & - & - \\
\hline гробовой & 1 & - & - \\
\hline дегтярный & - & 1 & 2 \\
\hline смолистый & 1 & - & - \\
\hline смольный & - & - & 3 \\
\hline смоляной & 1 & 1 & 1 \\
\hline смородинный & - & 1 & - \\
\hline траурный & 3 & - & - \\
\hline угольный & 1 & 1 & 1 \\
\hline черный & 23 & 67 & 58 \\
\hline черненький & - & 1 & - \\
\hline \multicolumn{4}{|l|}{ Verben } \\
\hline чернеть & 5 & 7 & 5 \\
\hline \multicolumn{4}{|l|}{ Substantive } \\
\hline вакса & - & - & 1 \\
\hline ворон & - & - & 7 \\
\hline маслина & - & 1 & - \\
\hline сажа & - & 1 & - \\
\hline смоль & 1 & - & - \\
\hline траур & - & 2 & - \\
\hline уголь & - & 1 & 1 \\
\hline фрак & - & 6 & 3 \\
\hline цилиндр & - & 4 & - \\
\hline чернота & 3 & 14 & 4 \\
\hline Summe & 40 & 108 & 86 \\
\hline Frequenz & 1,25 & 0,91 & 1,09 \\
\hline
\end{tabular}




\subsubsection{Das Farbfeld Rot}

Den dritten Platz unter den Farben in den Temnye allei nimmt mit 220 Nennungen ${ }^{357}$ und einem Anteil von 20,3 Prozent die Farbe Rot ein. Im zweiten Komplex ist die Frequenz mit im Schnitt einer Nennung pro Seite am höchsten und bildet einen interessanten farblichen Kontrast zum eher düsteren Inhalt der Erzăhlungen. Im Vergleich mit den ebenfalls stark vertretenen Farben Weiß und Schwarz erweist sich das Vitalităt symbolisierende Farbfeld Rot als ungleich produktiver und enthălt mit Abstand die meisten Abstufungen aller im Buch verwendeten Farben. Allein im adjektivischen Bereich unterscheidet Bunin 21 Nuancen, und die zu „красның“ gehorende Wortfamilie wird proportional seltener erwăhnt als ihre Äquivalente aus den Wortfamilien „черны ““ und „белы““. Die Abstufung Rosa findet sich mit 24 Nennungen, in der Regel bevorzugt Bunin ein sattes, intensives und leuchtendes Rot, das pure Lebensfreude ausstrahlt.

Ungewöhnlichere und im allgemeinen entsprechend seltener verwendete Bezeichnungen für Rot entnimmt Bunin den verschiedensten Bereichen, unter anderem den chemischen Elementen („очки цвета иода“358, „Кrasavica“, 6: 218) und Gemüse („полньх колен цвета свеклы“, „Stepa“, 6: 233), wobei er sich auch nicht scheut, sie in einem kurzen Abschnitt mit entsprechend spektakulărer Wirkung zu vereinen:

Но и без малороссийского наряда она была очень хороша: крепкая, ладная, с густыми темными волосами, с бархатными бровями, почти сросшимися, с грозными глазами чвета черной крови [Hervorhebungen H. Reese], с горячнм темным румянцек на загорелом лице, с ярким блеском зубов и полными вищкевыни губами. (,Zojka i Valerija“, 6: 244).

Ähnlich originell ist die Beschreibung eines Spiegelungseffektes von Feuer in den Augen lauemder Wolfe: „как горячий сироп варенья из красной смородины“ („Volki“, 6: 235).

Die Farbe Rot wird wie Weiß vor allem als Kontrapunkt zu Schwarz eingesetzt, wie dies beispielsweise bei dem in der Erzăhlung "Temnye allei" gezeichneten Wechselspiel zwischen Schwarz bzw. Grau und Rot bei der Beschreibung der beiden zentralen Figuren

357 Würden zadem alle Erwăhnungen von Feuer und Flammen hinzugezăhlt, die in der vorliegenden Arbeit dem Lichtbereich zugeordnet werden, kame man auf 66 zusătzliche Erwahnungen der Farbe Rot. Eine derartige Zahlung würde dieser vomehmlich mit Lebensfreude assoziierten Farbe die dominierende Stellung zuweisen und stunde vollkommen im Einklang mit dem Eindruck intensiver Lebenslust, den die Erzahlungen allen tragischen Geschehnissen zum Trotz vermitteln.

358 Diese ungewohnlich anmutende Farbbezeichnung einer Brille findet sich im abrigen bereits in einem Tagebucheintrag Bunins vom 03.J16.08.1923. Zit. in: UB. 2.Bd. op.cit.: IIS $\|_{l l}$ Reese - 9783954790210 
besonders eindringlich erfolgt und zudem emotionalisierende Wirkung hat, da innere Prozesse zum Ausdruck kommen:

... стройный старик военный в большом картузе и в николаевской серой [Hervorhebungen H. Reese] шинели с бобровым стоячим воротником, еще чернобровый, но с бельми усами, которые соединялись с такими же бакенбардами ... (6: 175).

Приезжий [...] с устальм видом провел бледной худой рукой по голове-седые волосы его с начесами на висках к углам глаз слегка курчавились, красиво удлиненное лицо с темными глазами ... (6: 176)

Тотчас [...] вошла темноволосая, тоже чернобровая и тоже еще красивая не по возрасту женшина [...] с темным пушком на верхней губе и вдоль щек [...] с большими грудями под красной кофточкой, с треугольным [...] животом под черной шерстяной юбкой. [...] Приезжий мельком глянул на ее округлые плечи и на легкие ноги в красных поношенных татарских туфлях ... [...] Он быстро выпрямился, раскрыл глаза и покраснел ... (6: 176).

Потом остановился и, краснея сквозь седину, стал говорить ... (6: 177).

Femer verwendet Bunin den roten Farbton, um Akzente zu setzen. Bei den Figuren können dies etwa rote Haare, ein roter Bart oder - wie in der Titelerzählung - ein plötzliches heftiges Erröten sein, in den Räumlichkeiten eines Hauses finden sich häufig rote Lampenschirme ${ }^{359}$ oder Vorhänge, in der Natur hingegen etwa blutrote Felsen. Auch Feuer, Wein und Kaviar werden mit der Farbe Rot spezifiziert. Die hohe Produktivităt dieses Farbfeldes spiegelt sich in einer geringen Anzahl von Komposita wider, die in der Regel der Abdunkelung des entsprechenden Farbtons dienen: „черно-багровы “" (Rauchwolken, „Pozdnij ¿as“, 6: 203), „сумрачно-красный“ (Feuer, „Volki“, 6: 235), „дымнокрасные“ (Feuer, „Тапја“, 6: 259), „воспаленно-красный“ (Feuer, „Genrich“, 6: 298), „.блезло-розовың“ (Bahnhof, „Genrich“, 6: 298), „темно-красның““ (Rose, „Natali“, 6: 310 und 311), „темно-красный“ (Bart, „Dubki““, 6: 346), „бархатисто-пунцовый“ (Lippen, „Čistyj ponedel'nik“, 6:401), „кирпично-кровавыһ““ (Mauer, „Čistyj ponedel'nik", 6: 404).

359 In diesem Zusammenhang soll darauf hingewiesen werden, daß der rote Lampenschirm Bunin als Symbol schlechthin fur das Streben nach gesellschaftlicher Anerkennung galt, das er für sich ablehnte: „Так всю жизнь не понимал я ннкогда, как можно находить смысл жизни в службе, в хозяистве, в политике, в наживе, на семье ... Я с нстинным сртахом смотрел всегда благополучне, прнобретение которого и обладание которым поглошало человеха, а излишество и обычная ннзость этого благополучня вызывали во мне ненависть - даже всякая средняя гостнная $c$ неизбежной ланпой на высокой подставке под грамадным рагатым абахсуром из красного мелка [Hervorhebung H. Reese] выводит меня из себя" (1. Bunin. .Zapisi". In: ders. SS v devjati tomach. 9.Bd. op.cit.: 352). 
Tabelle 3, Farbfeld Rot

\begin{tabular}{|c|c|c|c|}
\hline & Komplex I & Komplex II & Komplex III \\
\hline \multicolumn{4}{|l|}{ Adjektive } \\
\hline алый & 2 & 3 & - \\
\hline багровый & 1 & 2 & 1 \\
\hline вышневый & - & 2 & 1 \\
\hline гранатовы & 1 & 1 & 2 \\
\hline кирпячны & - & 1 & 3 \\
\hline коралловы & 1 & - & 2 \\
\hline кровавый & - & 1 & 1 \\
\hline кровьяной & - & - & 1 \\
\hline красный & 8 & 47 & 25 \\
\hline красноватый & - & 3 & 1 \\
\hline малиновый & - & - & 2 \\
\hline пунцовы & - & 1 & 4 \\
\hline ржавый & 3 & 1 & - \\
\hline rouge [sic] & - & 1 & - \\
\hline розовый & - & 9 & 9 \\
\hline розоватый & - & 1 & - \\
\hline рубиновый & 1 & - & 3 \\
\hline рыжий & - & 5 & 2 \\
\hline рыжеватый & - & 3 & - \\
\hline рыженький & 1 & - & - \\
\hline сангвиновый & - & - & 1 \\
\hline \multicolumn{4}{|l|}{ Verben } \\
\hline алеть & - & 1 & 1 \\
\hline краснеть & 4 & 17 & 4 \\
\hline окрававлеть & - & 2 & - \\
\hline побагроветь & - & 1 & - \\
\hline розоветь & 1 & 2 & 2 \\
\hline румянить (-ся) & - & - & 3 \\
\hline рыжеть & - & 1 & - \\
\hline
\end{tabular}




\begin{tabular}{|l|l|l|l|}
\hline Substantive & & & \\
\hline вишня & - & 2 & - \\
\hline зарево & - & - & - \\
\hline земляника & - & - & 1 \\
\hline йод & - & 1 & - \\
\hline кровь & - & 3 & 4 \\
\hline лафит & 1 & - & - \\
\hline малина & - & 2 & 1 \\
\hline пурпур & - & - & 1 \\
\hline роза & - & 4 & - \\
\hline румянец & - & 2 & 1 \\
\hline свекла & - & 1 & - \\
\hline яхонт & - & 1 & - \\
\hline Summe & 25 & 119 & 76 \\
\hline Frequenz & 0,78 & 1,00 & 0,96 \\
\hline
\end{tabular}

\subsubsection{Das Farbfeld Grün}

Mit 74 Nennungen und einem Anteil von 6,8 Prozent an allen Farbbezeichnungen in den Temnye allei nimmt der Farbton Grün den vierten Platz ein. Seine höchste Frequenz läßt sich im zweiten Komplex nachweisen (0,38). Mit 41 Nennungen des Adjektivs „зеленыи“ und 9 Nennungen des Substantivs, ,зелень“ erweist sich diese Farbpalette als relativ klein, wobei Bunin durchaus auf einige originelle Bezeichnungen wie "Гороховой“ oder „фнсташковый“ zurückgreift. So gibt es denn auch vergleichsweise wenig Komposita, die in der Regel einen unheilverkündenden Beiklang haben: „металлически-зеленый“ (Hahn, „Rusja“, 6: 210), „бледно-зеленые“ (Falter, „Rusja“, 6: 211), „молочно-зеленый“(Flüßchen, „Genrich“, 6: 296), „бледно-зеленый“ (Gesichtsfarbe, „Genrich“, 6: 297).

Die Farbe Grün dient überwiegend der Beschreibung von Naturelementen, seien es nun das Grün der Bäume („зеленью деревьев“, „Parochod ,Saratov““, 6: 372), eine geheimnisvolle grünliche Färbung des Himmels („небо над озером зеленое“, „Kačeli“, 6: 397) oder der besondere Schimmer von Gestirnen, der Bunin zur Edelsteinmetaphorik animierte 
(„Smaragd“). Seltener findet sich der grüne Farbton bei der Beschreibung des Äußeren von Figuren, wie etwa in der Erzăhlung "Rečnoj traktir": „[...] и появилась она, в каком-то картузике цвета хаки, в непромокаемом пальто того же цвета с поясом [...]“ (6: 338). Geradezu skurril mutet die Gesichtsfärbung des eifersüchtigen Liebhabers in der Erzählung „Genrich“ an: „Лицо от газа и от злобы бледно-зеленое, оливковое, фисташковое ...* (6: 297).

Tabelle 4, Farbfeld Grün

\begin{tabular}{|c|c|c|c|}
\hline & Komplex I & Komplex II & Komplex III \\
\hline \multicolumn{4}{|l|}{ Adjektive } \\
\hline горохово & - & 1 & - \\
\hline зеленый & 5 & 24 & 12 \\
\hline зеленоваты & 1 & 6 & - \\
\hline оливковый & - & 1 & 1 \\
\hline фнсташковый & - & 1 & - \\
\hline фосфорическй & - & 1 & - \\
\hline \multicolumn{4}{|l|}{ Verben } \\
\hline зеленеть & - & 1 & - \\
\hline \multicolumn{4}{|l|}{ Substantive } \\
\hline желудь & 1 & 2 & - \\
\hline зелень & - & 5 & 4 \\
\hline смарагд* & - & 4 & - \\
\hline фисташка & - & - & 2 \\
\hline xaku & - & - & 2 \\
\hline Summe & 8 & 46 & 21 \\
\hline Frequenz & 0,21 & 0,38 & 0,26 \\
\hline
\end{tabular}




\subsubsection{Das Farbfeld Blau}

Im Gegensatz zu Bunins Lyrik, in der Blau den Spitzenplatz unter den Farben einnimmt, belegt dieser Farbton in den Temnye allei den fünten Platz. 67 Nennungen oder 6,2 Prozent an der Gesamtsumme entfallen auf blaue Farbtöne, deren Frequenz sich von 0,18 im ersten Komplex auf 0,32 im zweiten steigert, um im dritten Komplex auf 0,27 abzusinken. Die meistverwendeten Nuancen sind „синиһ“ (20 Nennungen), „голубох“ (14) und „сизии“ (11), als ungewöhnlich fallen lediglich das Adjektiv „аквамариновый und das Substantiv „индиго“ auf. Um so mehr Aufmerksamkeit erregt die Zahl der vor allem in den Erzählungen der „schwarzen Sonne“ verwendeten zwölf Komposita, da Blau die meisten Komposita in den Temnye allei stellt und diese sich am Ende des zweiten Komplexes auffallend konzentrieren. Sie spezifizieren ebenfalls hauptsächlich Naturphänomene wie Himmelserscheinungen und Dämmerung: "черно-синий“ (Dunkelheit, „Zojka i Valerija“, 6:252), „темно-синий (Waldlichtung, „Тапја“, 6:257), „темноснзий“ (Rauch, „Тапја“, 6: 259), „мышнно-голубой“ (Mantel, „Genrich“, 6: 297), „дымчато-сизий“ (Himmel, „Genrich“, 6: 301), „зеленовато-голубои““ (Bäume, „Natali“, 6: 307), „зелено-голубои“ (Flamme, „Natali“, 6:321), „зелено-голубо““ (Gewitterleuchten, „Natali“, 6: 322), „густо-синий“ (Wellen, „Parochod ,Saratov““, 6: 376), „темно-синий“ (Samt, „Voron“, 6: 379), „маслянисто-голубои“ (Augen, „Mest'“, 6: 387), „снежно-сизий“ (Moskau, „Čistyj ponedel'nik“, 6: 402).

Blau wird häufig mit dem Tod in Verbindung gebracht: In der Erzählung „Rečnoj traktir" fällt eine interessante mehrteilige Zusammensetzung zur Spezifizierung der sich dramatisch ins Blaue verändernden Gesichtsfarbe eines jungen Mădchens auf („побледнела до гробовой синевы“, 6: 338), die auch charakteristisch ist für den Teint eines musizierenden Zigeuners (,сс сизой мордой утопленника“, 6: 403). Auch die von ihrem Ehemann ermordete junge Frau in ,.Dubki“” weist eine bläuliche Gesichtsfarbung auf („вся снняя с лица“, 6: 349). Darüber hinaus findet Blau Verwendung zur Kennzeichnung der Hautfärbung der kapriziösen Li in „Genrich“ (6: 293), zur Farbgebung eines leichten Flaums über den blauen Lippen der porträtierten Südfranzösin in „Kamarg“ (6: 383) oder zur Beschreibung des bläulichen Schimmerns von Adern durch die Haut auf den Handrücken des Küchenmädchens in „Gost”“ (6: 232). 
Tabelle 5, Farbfeld Blau

\begin{tabular}{|l|l|l|l|}
\hline & Komplex I & Komplex II & Komplex III \\
\hline Adjektive & & & \\
\hline аквамариновы & - & 2 & - \\
\hline голубой & - & 10 & 4 \\
\hline лазоревый & - & - & 1 \\
\hline лазурный & 1 & - & - \\
\hline сизий & - & 7 & 4 \\
\hline синй & 2 & 9 & 9 \\
\hline синеватый & - & 2 & 2 \\
\hline Verben & & & \\
\hline синеть & 1 & 3 & 1 \\
\hline Substantive & & & \\
\hline бирюза* & - & 1 & - \\
\hline индиго & - & 1 & - \\
\hline лазурь & - & 1 & - \\
\hline сизость & - & 1 & - \\
\hline синева & 1 & 2 & 1 \\
\hline Suтmе & 6 & 39 & 22 \\
\hline Frеquепz & 0,18 & 0,32 & 0,27 \\
\hline
\end{tabular}

\subsubsection{Das Farbfeld Braun}

5,9 Prozent aller Farbnennungen gehören dem Farbfeld Braun an; absolut entspricht dies 64 Wörtern und dem sechsten Platz. Im Vergleich zu Grün und Blau sind die Braunabstufungen deutlich nuancierter; am häufigsten verwendet Bunin das Adjektiv „коричневый“ (12 Nennungen), dichtauf gefolgt von „смуглый“(8). Im substantivischen Bereich tritt mit „3arap" der gebräunte Teint gehäuft auf (8). Die Frequenz der Brauntöne nimmt nach dem ersten Komplex auffallend zu, analog zu dem gleichfalls zunehmend auftretenden dunklen Frauengesicht (vgl. Kap. 7.2), das seine Kulmination in der indisch-bernsteinfarbenen Hauttönung der Protagonistin der Erzählung „Cistyj ponedel'nik“ findet („смугло- 
янтарное лицо“, 6: 399). In den Temnye allei bezeichnet Braun fast ausschließlich die Gesichts-, Augen- oder Haarfarbe einer Figur, seltener einmal eine Felltönung („коричневый пойнтер“, „Stepa“, 6: 190) oder die Farbe eines Kleides („в коричневом платье“, "Tanja“, 6: 260). Das Gleiche gilt für die vier verwendeten Komposita: „янтарнокоричневый“ (Augen, „Genrich“, 6: 293), „золотисто-карый“ (Augen, „Kamarg“, 6: 383), „смугло-коричневы й“ (Augenlider, „Kamarg“, 6: 383) und „смугло-янтарный“ (Teint, „Čistyj ponedel'nik“, 6: 399).

Tabelle 6, Farbfeld Braun

\begin{tabular}{|c|c|c|c|}
\hline & Komplex I & Komplex II & Komplex III \\
\hline \multicolumn{4}{|l|}{ Adjektive } \\
\hline brune [sic] & - & - & 1 \\
\hline бурый & - & 2 & - \\
\hline загорелый & - & 4 & 2 \\
\hline карый & - & - & 2 \\
\hline каштановый & - & - & 1 \\
\hline коричневый & 1 & 7 & 4 \\
\hline кофейный & - & 1 & 1 \\
\hline ореховый & - & 3 & 1 \\
\hline русый & - & 1 & 1 \\
\hline смуглый & 1 & 5 & 2 \\
\hline янтарный & - & - & 3 \\
\hline \multicolumn{4}{|l|}{ Verben } \\
\hline загореть & 1 & 3 & 2 \\
\hline \multicolumn{4}{|l|}{ Substantive } \\
\hline брюнет & - & 1 & - \\
\hline брюнетка & - & - & 1 \\
\hline 3агар & 1 & 4 & 3 \\
\hline каurraн & - & 1 & - \\
\hline opex & - & 1 & - \\
\hline смуглость & - & 1 & - \\
\hline gнтraps & - & - & 1 \\
\hline
\end{tabular}




\begin{tabular}{|l|l|l|l|}
\hline янтарность & - & - & 1 \\
\hline Summe & 4 & 34 & 26 \\
\hline Frequenz & 0,12 & 0,28 & 0,32 \\
\hline
\end{tabular}

\subsubsection{Das Farbfeld Grau}

An siebter Stelle liegt die Farbe Grau, die mit 62 Nennungen 5,7 Prozent aller Farbbezeichnungen in den Temnye allei ausmacht. Die Palette der Grautöne ist nicht sonderlich breit gefächert, allein 47 Nennungen entfallen auf das Adjektiv „серый“; zudem nimmt die Frequenz der Grautöne von Komplex zu Komplex deutlich ab. Diesen eher trüben Farbton verwendet Bunin vornehmlich fur Personenbeschreibungen (Kleider-, Haar- und Augenfarbe), seltener fur Landschaftsbeschreibungen, wie beispielsweise Wellen oder ein von einem Dunstschleier umgebener Ort. Diese Praxis zeigt sich auch in den Komposita, bei denen sich lediglich eine einzige Wiederholung konstatieren läßt: „грязно-серый“ (Gamaschen, „Muza“, 6: 196), „темно-серыя“ (Ring, „Rusja“, 6: 216), „молочно-седой“ (Aussehen, „Antigona“, 6: 225), „светло-серый“ (Uniformjacke, „Antigona“, 6: 225), „светлосерый“ (Kleid, „Galja Ganskaja“, 6: 284), „смугло-дымчатый“ (Wolken, „Natali“, 6: 307), „красновато-серый“ (Specht, „Natali“, 6:314). Diesem Neutralität und Ausdruckslosigkeit suggerierenden Farbton kommt neben seiner dämpfenden Wirkung allzu greller Farben eine wichtige Funktion zu: mit seiner ausdrücklichen Verwendung rückt Bunin gezielt scheinbar farblose, nebensăchliche und banale Details ins Zentrum der Aufmerksamkeit.

Tabelle 7, Farbfeld Grau

\begin{tabular}{|l|l|l|l|}
\hline & Komplex I & Komplex II & Komplex III \\
\hline Adjektive & & & \\
\hline дымчатый & - & 1 & - \\
\hline пепельный & - & 2 & - \\
\hline седенький & 1 & - & - \\
\hline серый & 12 & 25 & 10 \\
\hline
\end{tabular}




\begin{tabular}{|l|l|l|l|}
\hline серенький & 1 & - & 1 \\
\hline седой & 2 & 4 & - \\
\hline Verben & & & \\
\hline ceperъ & - & 2 & - \\
\hline Substantive & & & \\
\hline седина & 1 & - & - \\
\hline Summe & 17 & 34 & 11 \\
\hline Frequenz & 0,53 & 0,28 & 0,13 \\
\hline
\end{tabular}

\subsubsection{Das Farbfeld Gelb}

Mit einem kleinen Abstand zu Grau folgt Gelb in dem von Bunin in den Temnye allei verwendeten Farbenspektrum: 55 Nennungen dieses Farbtons ergeben 5,1 Prozent an der Gesamtheit der Farben, mit einer merklichen Frequenzerhöhung im zweiten Komplex. Trotz der überwiegenden Verwendung des Adjektivs „желтый“ (33 Nennungen) erweist sich dieses Farbfeld als erstaunlich produktiv, wobei Verben jedoch nicht vorkommen: interessante Farbbezeichnungen sind etwa kanariengelbe Sonnenblumenblüten („Kavkaz", 6: 182) und der ganz spezielle Blondton der Haare Natalis, den der Protagonist mit der Farbe von reifem Mais vergleicht (,Natali“, 6: 314).

In der Regel bezeichnen die Varianten dieses Farbfeldes die Farben von Kleidung (z.B. der mehrfach erwähnte Sarafan in der Erzählung „Rusja“) und Наaren („желтоволосые половые“, „Reð̌noj traktir“, 6: 336), seltener von Augen (,Natali“, 6: 307, und „Načalo“, 6: 343), verschwindend gering von Landschafts- oder Lichterscheinungen („в свете зимней желтой зари“, „Тапја, 6: 268; „солнце желто светило“, „Теmnуe allei“, 6: 179). Auch wird Gelb ähnlich wie Blau in die Nähe des Todes gerückt:

[...] стоймя прислонена была к стене большая желтая [Hervorhebungen H. Reese] глазетовая крышка гроба. [...] И все же я вошел в сумрак и ладан этой страшной залы, испещренной желтыми свечными огоньками [...] перед гробом [...], чтобы не видеть желтой парчи на гробе [...]. (,Natali“, 6: 325).

In der überraschenden Produktivität dieses Farbfeldes mag auch eine Ursache dafür zu sehen sein, daß sich im gesamten Buch nur drei Komposita finden lassen; eine andere könnte darin liegen, daß Bunin zur Bezeichnung von Licht und Helligkeit speziellere 
Adjektive wie „светлың“ oder "солнечның“ als zutreffender empfunden hat. Das wenig spektakulăre Kompositum „темно-желтың“ („Holztreppe“, „Antigona“, 6: 223) wird ergänzt durch das changierende Aussehen eines Glühwiurmchens („зелено-желтый“, „Zojka i Valerija“, 6: 253) und einer extravaganten Haarfarbe („рыже-лимонный“, „Genrich“, 6: 293).

Tabelle 8, Farbfeld Gelb

\begin{tabular}{|l|l|l|l|}
\hline & Komplex I & Komplex II & Komplex III \\
\hline Adjektive & & & \\
\hline белокурый & - & - & 3 \\
\hline желтый & 2 & 19 & 12 \\
\hline желтенький & 1 & - & - \\
\hline желтоватый & - & 1 & 1 \\
\hline канареечный & 1 & - & - \\
\hline лимонный & - & 1 & - \\
\hline палевый & - & 2 & - \\
\hline пожелтый & - & - & 1 \\
\hline соломенный & - & 1 & 1 \\
\hline Sиьзтпптіле & & & \\
\hline блондинка & - & 2 & - \\
\hline желтизна & - & 1 & - \\
\hline кукуруза, спелая & - & 1 & - \\
\hline подсолнечник & 1 & - & - \\
\hline солома & - & 2 & - \\
\hline шартрез & 1 & 1 & - \\
\hline Sитте & 6 & 31 & 18 \\
\hline Frеqиепz & 0,18 & 0,26 & 0,22 \\
\hline
\end{tabular}




\subsubsection{Das Farbfeld Bunt}

Eine untergeordnete Rolle spielen die nun folgenden restlichen Farbfelder. Mit größerem Abstand auf die bevorzugten Farbtöne folgt das Farbfeld Bunt: 26 Nennungen entsprechen 2,4 Prozent an der Summe aller Farbwörter in den Temnye allei. Die Frequenz nimmt vom ersten zum dritten Komplex hin auffallend ab. Die Kombination mehrerer Farben zu einer bunten Mischung beschränkt sich im wesentlichen auf das Wortfeld um „пестрыи“" und findet sich nur gelegentlich bei Schilderungen der Farbenpracht von Blumensträußen, Feuer oder persönlichen Accessoires, häufiger bei Licht- und Schattenspielen. Komposita entfallen naturgemäß, mit einer Ausnahme: das Kleid der Protagonistin in „Mest”“ weist die auf den ersten Blick irritierende Farbtönung „мрачно-цветисто“ auf (6: 388). Diese restriktive Verwendung eines sammelnden Farbbegriffes unterstreicht nachdrücklich Bunins Beobachtungsgabe sowie sein Vermögen der präzisen, adäquat differenzierenden Beschreibung.

Tabelle 9, Farbfeld Bunt

\begin{tabular}{|l|l|l|l|}
\hline & Komplex I & Komplex II & Komplex III \\
\hline Adjektive & & & \\
\hline пестрый & 4 & 5 & 1 \\
\hline пятнистый & 1 & - & - \\
\hline разноцветный & - & 5 & 2 \\
\hline цветистый & - & - & 1 \\
\hline цветной & - & 1 & 2 \\
\hline Verben & & & \\
\hline пестреть & 2 & - & - \\
\hline Substantive & & & \\
\hline пестрота & - & 2 & - \\
\hline Summe & 7 & 13 & 6 \\
\hline Frequenz & 0,21 & 0,10 & 0,07 \\
\hline
\end{tabular}




\subsubsection{Das Farbfeld Lila}

Dem Farbfeld Lila lassen sich insgesamt 17 Nennungen zuordnen, die einem Anteil von 1,5 Prozent aller Farbattribute in den Temnye allei entsprechen. Die Farbpalette ist nicht sehr umfangreich und enthält keine Verben; die meisten Nennungen entfallen auf das Adjektiv „лиловыћ“ (7 Nennungen), das überwiegend im zweiten Komplex anzutreffen ist. Darüber hinaus ist eine auffällig erhöhte Frequenz des Farbtons im zweiten Komplex festzustellen, in dem sich auch sämtliche Komposita befinden: „сине-лиловый“ (Nachtbeleuchtung im Schlafwagenabteil, „Rusja“, 6: 210 und 216), „серо-сиреневый“ (Hauttönung, „Vizitnye kartoðki“, 6: 240) und „сине-лиловый“ (Augenfarbe, „Natali“, 6: 304).

Die dunkle Lippenfärbung der jungen Frau in "Nacalo" hebt sich erschreckend intensiv von der Blässe ihres Gesichts ab: „гелиотроповые [...] губы“ (6: 344). In der Natur sieht Bunin diesen Farbton in Wolken und Rauhreif und verleiht ihnen auf diese Weise etwas Fernes und Ätherisches.

Tabelle 10, Farbfeld Lila

\begin{tabular}{|l|l|l|l|}
\hline & Komplex I & Komplex II & Komplex III \\
\hline Adjektive & & & \\
\hline гелиотроповый & - & - & 1 \\
\hline лиловый & 1 & 5 & 1 \\
\hline лиловатый & - & 1 & - \\
\hline сиреневый & - & 2 & 1 \\
\hline Substantive & & & \\
\hline фиалка & 1 & 4 & - \\
\hline Summe & 2 & 12 & 3 \\
\hline Frequenz & 0,06 & 0,10 & 0,03 \\
\hline
\end{tabular}

\subsubsection{Das Farbfeld Orange}

Auf das Frische verbreitende Farbfeld Orange entfallen 11 Nennungen, die an der Gesamtheit aller Farbattribute einen verschwindend geringen Anteil von I Prozent haben. Dieses 
unproduktive Farbfeld besteht fast ausschließlich aus dem Adjektiv „оранжевый“ und enthält weder Verben noch Komposita. Bunin verwendet diese Farbe für Kleidungsstücke, wie etwa in „Natali“ („оранжевая распашонка“, 6: 330), aber auch für grell geschminkte Lippen, wie in der Erzählung „Baryšnja Klara“ $(6: 350,353)$ und konterkariert damit das zunächst vermeintlich elegante Aussehen der Protagonistin. Mit dem in den Bereich des Glanzes hinüberspielenden Adjektiv "топазовың" bezeichnet Bunin den Schimmer von Insektenflügeln in der Erzählung „Kavkaz" (6: 18.3).

Tabelle 11, Farbfeld Orange

\begin{tabular}{|l|l|l|l|}
\hline & Komplex I & Komplex II & Komplex III \\
\hline Adjektive & & & \\
\hline оранжевы & - & 5 & 3 \\
\hline топазовы ${ }^{*}$ & 1 & - & - \\
\hline Substantive & & & \\
\hline апельсин & - & 2 & - \\
\hline Summe & 1 & 7 & 3 \\
\hline Frequenz & 0,03 & 0,05 & 0,03 \\
\hline
\end{tabular}

Es überrascht nicht, daß Bunin die Farben Weiß, Schwarz und Rot bevorzugt, entspricht dies doch seiner Neigung zum Stilmittel des Kontrastes. Während die Kontrastfunktion in der Regel Schwarz und Weiß vorbehalten ist, verwendet Bunin die Farbe Rot, um gezielt Akzente zu setzen. Die übrigen Farben der Palette, deren Einsatz mit Abstand folgt, dienen jedoch nicht nur dazu, die entstandenen Kontraste abzumildern, im Gegenteil: Mit ihrer Hilfe zeigt Bunin, daß es neben Schwarz und Weiß noch unzählige Farbabstufungen gibt, und bildet solcherart die Vielfalt des Lebens ab.

Die höchste Farbfrequenz weist mit Ausnahme der Farben Schwarz, Braun, Grau und Bunt der zweite Komplex auf, in dem gleichzeitig die meisten Komposita zu finden sind. Das vermeintlich düstere Zentrum des Buches, die Erzählungen der "schwarzen Sonne“, erweist sich bei einer Analyse somit als erstaunlich farbenfroh und trägt in erheblichem Maße dazu bei, daß die Erzählungen nicht so bedrückend wirken, wie eine Zusammenfassung ihres Inhalts vermuten lassen könnte. Vor dem Hintergrund tragischer Ereignisse 
entfaltet Bunin in den Temnye allei eine leuchtende Farbenpracht, auch mit Hilfe ausgefallener Kombinationen, und verstärkt dadurch ihre Wirkung, so wie auch das Leben und die Liebe im Schatten des Todes intensiver empfunden werden können. Nicht zuletzt unterstreicht die Farbigkeit der Erzählungen die Lebendigkeit der Erinnerung: Die Vergangenheit muß nicht verblassen, und nichts ist verloren, solange nur sich ein Mensch noch erinnem kann.

\subsection{Helligkeit und Dunkelheit; Glanz}

Bunins Neigung zur Darstellung der ihn umgebenden Farbenpracht findet ihre Entsprechung in seinem Interesse an Lichtphănomenen jeder Art, sei es das Strahlen von Himmelskörpern oder künstlichen Lichtquellen, die Reflexion von Licht auf Teichen, in Fenstem und Spiegeln oder der Glanz von Augen, Haaren sowie Stoffen aus Samt, Atlas und Seide. Daß die Temnye allei alles andere als ein düsteres Buch sind, belegen die 1.277 Adjektive (einzeln oder als Komposita), Verben (mit verschiedener Präfigierung) und Substantive, die Licht und Dunkel sowie Glanz bezeichnen und deren Verwendung in der Folge erläutert wird.

\subsubsection{Helligkeit}

Die 591 in den Temnye allei verwendeten Bezeichnungen für Licht entsprechen 46,3 Prozent aller Helligkeitsattribute. Der überwiegend substantivisch geprăgte Bereich der Helligkeitswörter konzentriert sich auf natürliche und künstliche Lichtquellen, die in der Regel spezifiziert werden. Von den 355 Substantiven entfallen nur 51 und somit ein Siebtel auf Licht und Helligkeit im allgemeinen: „свет“ (47), „яркость“ (3) und „ясность“ (1). Anders bei den Verben: knapp die Hälfte aller Lichterscheinungen werden von dem Verb „светить(-ся)“ übermittelt; bei den Adjektiven transportiert „светлый gut ein Viertel der Helligkeitserwăhnungen und stellt mit „закольдованно-светлый“ zur Bezeichnung năchtlichen Dämmerlichts auch das einzige Kompositum (,Muza“, 6: 199). Die mit Abstand höchste Frequenz von Lichterscheinungen weist der erste Komplex auf, gefolgt 
vom zweiten und dritten, so daß es naheläge, eine zunehmende Düsternis zu konstatieren, wäre nicht ein ebensolcher Frequenzverlauf im Bereich der Dunkelheit festzustellen.

In den Temnye allei finden sich zahlreiche Beschreibungen des Morgen- und des Abendhimmels, von Sonnenauf- und -untergängen - und immer wieder des năchtlichen Himmels mit seinen schimmernden Gestimen. Mond (47 Nennungen) und Sterne (26) werden als natürliche Lichtkörper von Bunin klar vor dem hellichten Tag mit Sonnenschein (38) bevorzugt. Mit dem Zwielicht, dem Einbrechen der Dämmerung fallen die Anforderungen des Tages vom Menschen ab, hat er die Muße und innere Bereitschaft, sich seinen Erinnerungen zu stellen oder hinzugeben, wie etwa in den Erzählungen „Rusja“, „V odnoj znakomoj ulice“ oder „Reenoj traktir“. Mit dem Einbruch der Nacht erwacht in ihm zugleich eine Sensibilität für seine Verbundenheit mit dem Kosmos (vgl. Kap. 8.1.3), die Seele öffnet sich und wird empfänglich für prägende Eindrücke, die Dunkelheit schafft Raum, sich tiefer Gefuhle bewußt zu werden, wie etwa in „Pozdnij Cas“, „Cholodnaja osen'"; die Konfrontation mit dem Kosmos löst jedoch auch Unsicherheit und Sprachlosigkeit aus, wie aus dem folgenden Beispiel aus der Erzählung „Tanja“ hervorgeht:

Он постоял на крыльце, пошел по двору ... И ночь какая-то странная [Hervorhebungen H. Reese]. [...] Над головой только легкие белые [облака], и высокая луна алмазно слезится в них, то и дело выходит на темно-синие прогалины, на звездные глубины неба, и будто еше ярqе озаряет крыпи и двор. И все вокруг как-то странно в своем ночном сушествовании, отрешенном от всего человеческого, бесцельно сияющее. И странно еще потому, что будто в первый раз видит он весь зтот ночной, лунный осеннй мир ... (6: 257).

Himmelskörpermetaphern setzt Bunin sehr zurückhaltend ein: Neben der bereits mehrfach erwähnten "schwarzen Sonne“ finden sich noch Vergleiche des Mondes mit einer Eichel („а все вместе напоминало желудь“, „Natali“, 6: 319) bzw. mit einem Schädel („какой-то светящийся череп“, „Čistyj ponedel'nik“, 6: 409). Sterne werden häufig mit dem Attribut Grün belegt („Pozdnij cas“, 6: 205; „Kačeli“, 6: 397; „Cistyj ponedel'nik“, 6: 398) oder gar mit einem Edelstein verglichen (,Smaragd“), lediglich der Planet Jupiter wird direkt benannt (,Natali“, 6: 325). Darüber hinaus wird die nächtliche Dunkelheit von Wetterleuchten und Gewitterblitzen erhellt, doch auch Glühwilrmchen können Lichtpunkte in die Schwärze der Nacht setzen.

Bei den künstlichen Lichtquellen liegen Feuer und Flammen mit 150 Nennungen vorn und bilden damit eine bildliche Entsprechung zu den leidenschaftlichen Gefuhlen im Innern der meisten Protagonisten. Grelles Licht, wie etwa der helle Schein von Lüstern (10 Nennungen), oder elektrisches Licht (2) meidet Bunin; in großem Stile erleuchtete 
Răume sind nur vereinzelt zu finden und öfentlichen Räumen vorbehalten, wie etwa dem Ballsaal in der Erzählung „Natali“ (6: 323) oder dem Restaurant „Praga“ in „Rečnoj traktir" (6: 333). Bunin bevorzugt einzelne kleine Lichtquellen wie die warme und diffuse Leuchtkraft von Lampen und kleineren Zimmerleuchten sowie Lichtquellen vor Ikonen (36) oder das trübe Licht, das Gaslaternen (22) verbreiten. Auch scheint das warme, flackernde Licht von Kerzen (33) oder Streichhölzem (20) einen Reiz auf ihn auszuüben. Elektrisches Licht oder gar Leuchtreklamen spielen eine untergeordnete Rolle.

Bei den Helligkeitswörtern ist eine ganz klare Vorliebe Bunins für überraschend aufblitzende Lichtpunkte zu erkennen: Hierzu gehören ein angerissenes und schnell verlöschendes Streichholz („Stepa“, 6: 193; „Volki“, 6: 234; „Kuma“, 6: 342) ebenso wie die fliegenden Funken eines Kaminfeuers (,„Dubki““, 6:348) oder ein Wetterleuchten bzw. Gewitter (,Natali“, 6:321-322; „Voron“, 6:380) und schnell vorbeifahrende, hell erleuchtete Züge („Rusja“, 6:209) oder auch vorbeigleitende Schiffe (,Pozdnij cas“, 6: 202). Das Halbdunkel, die rasch verfliegende Dämmerung, das kurz aufscheinende Licht entsprechen in ihrer Unbeständigkeit der Kurzlebigkeit des reinen Glücks und der Unwiederbringlichkeit jenes intensiven, zeitlich stark begrenzten Liebeserlebens, das Bunin seinen Protagonisten gewährt (vgl. Kap. 8.1.1).

Tabelle 12, Wortfeld Helligkeit

\begin{tabular}{|l|l|l|l|}
\hline & Komplex I & Komplex II & Komplex III \\
\hline Adjektive & & & \\
\hline звездный & 1 & 1 & - \\
\hline лунный & 2 & 4 & 3 \\
\hline лучистый & 3 & - & - \\
\hline месячный & 3 & - & 2 \\
\hline огненный & 1 & 3 & 3 \\
\hline пламенный & - & - & 1 \\
\hline пожарный & 1 & - & 2 \\
\hline светлый & 5 & 12 & 8 \\
\hline свечный & 2 & 1 & - \\
\hline солнечный & 1 & 6 & 5 \\
\hline фонарный & - & 1 & - \\
\hline
\end{tabular}




\begin{tabular}{|c|c|c|c|}
\hline электрический & - & 1 & 1 \\
\hline яркий & - & 10 & 4 \\
\hline ясный & 5 & 3 & 1 \\
\hline \multicolumn{4}{|l|}{ Verben } \\
\hline Вспьхнуть & - & 2 & - \\
\hline$(3 a-,, 060-) ж е ч ь(-с я)$ & 5 & 13 & 12 \\
\hline (о-)зарить (-ся) & 2 & 7 & 1 \\
\hline ropers & 2 & 17 & 6 \\
\hline мелькать & - & 3 & - \\
\hline просвечивать & - & 1 & - \\
\hline светить $(-$ ся $)$ & 10 & 29 & 20 \\
\hline светлеть & 1 & - & 2 \\
\hline тлеть & - & 3 & - \\
\hline чнркнуть & - & 1 & - \\
\hline яснеть & 1 & & \\
\hline \multicolumn{4}{|l|}{ Substantive } \\
\hline заря & - & 6 & 2 \\
\hline зарница & 1 & 3 & - \\
\hline звезда & 7 & 9 & 6 \\
\hline звездочка & - & - & 1 \\
\hline иллюминатор & 1 & - & - \\
\hline искра & - & 1 & 2 \\
\hline канделябр & - & - & 1 \\
\hline костер & - & 1 & 1 \\
\hline лампа, лампочка & 2 & 14 & 12 \\
\hline лампада, -дка & 2 & 2 & 3 \\
\hline луна & 4 & 7 & 1 \\
\hline лучина & - & - & 3 \\
\hline люстра & 1 & 5 & 4 \\
\hline месяи & 6 & 9 & 6 \\
\hline молния & 2 & 3 & 1 \\
\hline огонь, огонька & 7 & 25 & 10 \\
\hline озарение & 1 & 1 & - \\
\hline
\end{tabular}




\begin{tabular}{|l|l|l|l|}
\hline палироса & 1 & - & - \\
\hline пламя & 3 & 2 & 1 \\
\hline пожар & 1 & 1 & 3 \\
\hline полусвет & 3 & 4 & 2 \\
\hline рассвет & - & 3 & 2 \\
\hline свет & 8 & 22 & 17 \\
\hline светец & - & - & 2 \\
\hline светляк & 1 & 1 & - \\
\hline свеча, свечка & 5 & 21 & 4 \\
\hline солнце & 8 & 13 & 5 \\
\hline спиртовка & - & - & 1 \\
\hline спичка & 5 & 12 & 3 \\
\hline фонарик & - & - & 1 \\
\hline фонарь & 4 & 9 & 8 \\
\hline электричеств & - & 1 & 1 \\
\hline Юпитер & - & 1 & - \\
\hline хркость & - & 2 & 1 \\
\hline ясность & - & 1 & - \\
\hline Sитте & 118 & 298 & 175 \\
\hline Fгеqиепz & 3,68 & 2,50 & 2,21 \\
\hline
\end{tabular}

\subsubsection{Dunkelheit}

Der Bereich der Dunkelheit stellt mit 264 diesbezüglichen Wörtern 20,7 Prozent aller erwähnten Lichtphänomene dar. Die abnehmende Frequenz entspricht den Beobachtungen, die schon beim Wortfeld Helligkeit gemacht wurden. Das dunkle Wortfeld ist bei weitem nicht so produktiv wie das helle; es ist überwiegend adjektivisch geprägt, und über die Hälfte der entsprechenden Termini entstammen der Wortfamilie „темный“. Im einzigen Kompositum mit einem Determinator aus diesem Wortfeld findet sich ebenfalls dieses Adjektiv (.„смугло-темный“), das Bunin in Verbindung mit Farben häufig zum Abtönen des jeweiligen Tons verwendete. Mit 29 Nennungen ist die Wortfamilie „сумрачный“ 
vertreten. Darüber hinaus fällt die Vorliebe Bunins für Schatten und Zwielicht auf, wie etwa in der Erzählung „Pozdnij cas“:

Я шел - большой месяц тоже шел, катясь и сквозя в черноте ветвей зеркальным кругом; широкие улицы лежали в тени - только в домах направо, до которых тень не достигала, освешены были белые стены и траурным глянцем переливались черные стекла; а я шел в тени, ступал по пятнистому тротуару,- он сквозисто устлан был черными шелковыми кружевами. (6: 203).

Tabelle 13, Wortfeld Dunkelheit

\begin{tabular}{|c|c|c|c|}
\hline & Komplex I & Komplex II & Komplex III \\
\hline \multicolumn{4}{|l|}{ Adjektive } \\
\hline мглистый & 1 & 1 & - \\
\hline мрачный & - & 4 & 4 \\
\hline мутның & - & - & 1 \\
\hline пасмурный & - & 1 & - \\
\hline полутемный & - & 3 & - \\
\hline предрассветный & - & 1 & - \\
\hline смутный & - & 2 & 1 \\
\hline сумрачный & 4 & 4 & 1 \\
\hline темный & 22 & 41 & 23 \\
\hline теневой & - & 1 & - \\
\hline тенистый & - & 3 & - \\
\hline \multicolumn{4}{|l|}{ Verben } \\
\hline гасить & - & 2 & - \\
\hline гаснуть & - & 2 & 5 \\
\hline меркнуть & - & 2 & - \\
\hline мрачнеть & 1 & 2 & 1 \\
\hline оттенеть & - & - & 1 \\
\hline темнеть & 5 & 7 & 7 \\
\hline тускнеть & - & 2 & - \\
\hline \multicolumn{4}{|l|}{ Substantive } \\
\hline закат & - & 3 & 2 \\
\hline мрак & - & 3 & - \\
\hline
\end{tabular}




\begin{tabular}{|l|l|l|l|}
\hline полутьма & - & - & 2 \\
\hline сумерки & - & 7 & 3 \\
\hline сумрак & 6 & 10 & 4 \\
\hline темнота & 8 & 23 & 7 \\
\hline тень & 6 & 7 & 4 \\
\hline тьма & 2 & 9 & 3 \\
\hline Summe & 55 & 140 & 69 \\
\hline Frequenz & 1,71 & 1,17 & 0,87 \\
\hline
\end{tabular}

\subsubsection{Glanz}

Die Vielfalt der Glanzträger ist mit 422 Nennungen von einem beachtlichen Umfang, der 33 Prozent aller erwähnten Lichtphänomene entspricht. Das Wortfeld beeindruckt mit 35 verschiedenen Adjektiven, 11 Verben (am hăufigsten verwendet werden „блестеть“ und "сверкать") und 24 Substantiven, von denen einige nur einmal im gesamten Buch vorkommen, wie etwa „глазетовың“, „перламутровый“ und „эмаль“. Im Gegensatz zu den Bereichen Hell und Dunkel ist die Frequenz der glanztragenden Termini in den einzelnen Komplexen vergleichsweise stabil. Auch bezüglich der Komposita erweist sich dieses Wortfeld als deutlich produktiver - in den Komplexen I und II finden sich insgesamt sechs einzigartige Komposita: „серо-серебристый“ (Spiegel, „Мuza“, 6: 197), „хрустальнозолотой“ (Netz von Sonnenstrahlen, „Muza“, 6: 199), „черно-зеркальный“ (Augen, „Rusja“, 6: 217), „белесо-свинцовый“ (Wolken, „Tanja“, 6: 262), „черно-маслянистый“ (kurzer Persianer, „Genrich“, 6:292) und „сухо-золотистый“ (Hauttönung. „Natali“, 6: 310).

Die häufigsten Glanzträger sind die Edelmetalle Gold und Silber, allen voran das Attribut „золотой“ (32 Nennungen), ergänzt um „золотистый“(10). Die Art ihrer Verwendung ist höchst unterschiedlich: Der Leser stößt auf ein goldenes Zigarettenetui („Stepa“, 6: 190), goldene Löffel (,Natali“, 6: 308) und ein goldenes Taufkreuz (,Mest”“, 6: 391) in der Regel verleiht Bunin diesen Farbton edlen oder religiösen Gegenständen, wie den Rahmen von Ikonen; in jedem Fall handelt es sich um Details. Etwas seltener verwendet er .серебряный (20) und „серебристый“ (4); mit ihrer Hilfe gibt Bunin eine kalte Licht- 
spiegelung wieder (,Muza“, 6: 199). Das Edelmetall Silber findet sich aber auch in Kerzenhaltern („Ballada“, 6: 187), einer Kaffeekanne („Natali“, 6: 308) oder manikürten Fingernägeln („Cholodnaja osen’“, 6: 371). Weitere metallische Glanzträger sind Eisen, Bronze, Kupfer und Blech sowie die Schwermetalle Blei und Quecksilber.

Bei der Beschreibung von Protagonisten findet Bunins Neigung zur Darstellung von Lichtspielen ihre Entsprechung in glänzenden, changierenden Stoffen wie Samt, Seide und Atlas, wobei Seide seine besondere Vorliebe gilt. ${ }^{360}$ Das Kleidungsstück kann dabei entweder ein Morgenrock aus Seide (,Rusja“, 6:216), ein Seidenhemd (,Natali“, 6: 306), ein seidener Sarafan („,Dubki““, 6:348) oder ein kostbares Abendkleid aus Atlas sein („Baryšnja Klara“, 6: 350), Bunin kann jedoch dabei seine Aufmerksamkeit auch einem vergleichsweise geringfügigen Detail wie einem seidenen Futterstoff („Gost”“, 6: 232) oder einem seidenbesetzten Kleidersaum widmen (,Rexnoj traktir“. 6: 337). Der Anblick der in ein Kleid aus grünem Atlas gewandeten Natali bleibt dem Protagonisten über Jahre hindurch im Gedăchtnis („Natali“, 6: 330). Eine kostspielige Abendrobe aus schwarzem Atlas oder purpurrotem Samt stellt sich der Vater aus der Erzählung „Voron“ für die junge Gouvernante vor (6: 379). Auch die Protagonistin der Erzählung „Čistyj ponedel'nik“ kleidet sich für ihre abendlichen Unternehmungen in Samt (6: 401), femer wird ihr junger Verehrer von dem Aussehen ihrer Augen und Lippen ebenfalls an Samt erinnert (6: 401). Samtig wirken aber auch das Äußere einer Fledermaus sowie die schleimige Entengrüze auf einer Teichoberfläche (,Natali“, 6: 306 bzw. 308).

Als kostbare Accessoires werden in den Temnye allei Hauben aus Seide (.,Zojka $\mathrm{i}$ Valerija“, 6: 243) oder Atlas (,Naxalo“, 6: 343), seidene Taschentücher („Tanja“, 6: 260), Seidenstrümpfe („Galja Ganskaja“, 6:285), aus Seide bzw. Atlas gefertigte Schuhe („Antigona“. 6: 225; „Baryšnja Klara“, 6: 352), Seidentäschchen („Cholodnaja osen'“. 6: 367) oder gar mit Seide bezogene Sitzmöbel („Parochod ,Saratov““, 6: 373) verwendet.

Daruber hinaus nimmt Bunin Lichtspiegelungen wahr in Augen (menschlichen, aber auch in den Glasaugen eines ausgestopften Bären, „Antigona“, 6: 223), Glas, Edelsteinen. dem saftigen Grün von Bäumen, den Oberflächen von Seen und sogar im glänzenden Gelb einer Holztreppe (,Antigona“, 6: 223).

360 Bei dieser Feststellung ist zudem nicht außer acht zu lassen, daß derartig luxuriose Kleidungsstucke, wie im ubrigen auch Pelze. fur Bunin Symbole einer untergegangenen Welt darstellen mochten (vgl. Kap. 8.2.1). 
Tabelle 14, Wortfeld Glanz

\begin{tabular}{|c|c|c|c|}
\hline & Komplex I & Komplex II & Komplex III \\
\hline \multicolumn{4}{|l|}{ Adjektive } \\
\hline алмазный & - & 2 & 1 \\
\hline атласный & - & - & 5 \\
\hline бархатистый & - & 1 & 2 \\
\hline бархатный & - & 4 & 7 \\
\hline бисерный & - & 1 & - \\
\hline бронзовый & - & 2 & - \\
\hline глазетовый & - & 1 & - \\
\hline глянцевитый & - & 1 & - \\
\hline железный & 2 & 2 & 5 \\
\hline жестяной & - & 2 & 3 \\
\hline зеркальный & 2 & 1 & 2 \\
\hline золотистый & 2 & 6 & 2 \\
\hline золотой & 5 & 13 & 14 \\
\hline золоченый & 2 & 1 & - \\
\hline искристый & - & 1 & - \\
\hline лайковый & - & 1 & $\sqrt{2}$ \\
\hline лакированный & - & 4 & 3 \\
\hline лаковый & 1 & 1 & - \\
\hline масленый & - & 1 & - \\
\hline маслянистый & - & 4 & 1 \\
\hline медный & 1 & 4 & 1 \\
\hline металлический & - & 2 & 2 \\
\hline мраморный & - & 1 & - \\
\hline перламутровый & - & - & 1 \\
\hline полулаковый & - & 1 & - \\
\hline Свинцовый & - & 1 & - \\
\hline серебристый & 1 & 3 & - \\
\hline серебряный & 7 & 8 & 5 \\
\hline стальной & - & 1 & - \\
\hline стеклянный & 1 & 5 & 1 \\
\hline
\end{tabular}




\begin{tabular}{|c|c|c|c|}
\hline хрустальный & - & 1 & - \\
\hline чесучовой & - & 3 & - \\
\hline чугунный & 1 & - & 1 \\
\hline шелковистын & - & 1 & - \\
\hline шелковый & 1 & 15 & 9 \\
\hline \multicolumn{4}{|l|}{ Verben } \\
\hline блеснуть & - & - & 1 \\
\hline блестеть & 8 & 34 & 21 \\
\hline блистать & 1 & 2 & 1 \\
\hline искриться & - & 1 & - \\
\hline мелькнуть & 3 & 10 & 3 \\
\hline мерцать & 1 & 1 & 4 \\
\hline отражать & 1 & 4 & 1 \\
\hline отсветить & 1 & - & - \\
\hline сверкать & - & 9 & 11 \\
\hline серебрить (-ся) & - & 2 & - \\
\hline сиять & 3 & 11 & 1 \\
\hline \multicolumn{4}{|l|}{ Substantive } \\
\hline алмаз & - & 1 & - \\
\hline атлас & - & - & 1 \\
\hline бархат & 1 & 3 & 9 \\
\hline бархатистость & - & 2 & - \\
\hline блеск & 5 & 12 & 6 \\
\hline бриллинант & - & - & 2 \\
\hline витрины & - & - & 1 \\
\hline глянец & 1 & 1 & 2 \\
\hline зеркало & 2 & 3 & 2 \\
\hline золотистость & - & 1 & - \\
\hline золото & 1 & - & 4 \\
\hline мерцание & 1 & - & 1 \\
\hline отблеск & - & 1 & - \\
\hline отражение & 1 & - & 1 \\
\hline Отсвет & - & 2 & - \\
\hline
\end{tabular}




\begin{tabular}{|l|l|l|l|}
\hline ртуть & - & 1 & - \\
\hline самоцвет & 1 & - & - \\
\hline сверкание & - & - & 1 \\
\hline серебро & - & 1 & 2 \\
\hline сияние & 2 & - & - \\
\hline стекло & 3 & 8 & 4 \\
\hline чесуча & - & 2 & - \\
\hline шелк & - & 3 & 3 \\
\hline эмаль & - & - & 1 \\
\hline Summe & 62 & 210 & 150 \\
\hline Frequenz & 1,93 & 1,76 & 1,89 \\
\hline
\end{tabular}

\subsection{Eingefügte Fremdtexte}

Eine nicht zu übersehende Rolle in 19 der 38 in den Temmye allei enthaltenen Erzählungen spielen eingefugte Fremdtexte verschiedener Provenienz. Diese Technik findet sich in jeder Phase von Bunins Schaffen, bei der Auswahl seiner Zitate setzte er jedoch durchaus unterschiedliche Schwerpunkte. In Anlehnung an Julian Connollys aufschlußreiche Untersuchung zu der Art der verwendeten Fremdtexte in Bunins Prosa bis ca. Ende der 1930er Jahre $^{361}$ sollen auch die Temnye allei diesbezüglich analysiert werden. Neben diesem Verfahren, mit dessen Hilfe unter anderem die zeitliche Lokalisierung der Erzählungen erfolgt, verwendet Bunin weiterhin deiktische Verweise (z.B. Roman- und Liedtitel, Namen historischer Personen oder Porträts bekannter Persönlichkeiten), die von den umfangreicheren Zitaten klar unterschieden werden müssen und die in Kap. 8.2.3 eingehender beleuchtet werden. Die eingefugten Fremdtexte sorgen über die zeitliche Lokalisierung hinaus für inhaltliche Tiefe und stellen intertextuelle Bezüge nicht nur zur russischen Vergangenheit her, setzen aber gleichzeitig voraus, daß der Leser mit den Zitaten und Anspielungen vertraut ist. Da Bunin sie jedoch nicht im Übermaß einbindet, sind sie auch bei Unkenntnis nicht störend, obgleich dem unkundigen Rezipienten eine Bedeutungsebene entgeht. Mit der Verwendung derartiger Zitate blieb Bunin unwillkürlich dem

361 J. Connolly. ...Inserted Texts' in Ivan Bunin's Fiction". In: The Short Story in Russia 1900-1917. Hg. N. l.uker. Nottingham, 1991: 129-144. 
Erzăhlverfahren früherer Jahre treu, hinter dem Connolly folgenden Beweggrund sieht, der auch in den Temnye allei immanent ist: „Such quotations underline the all-pervasive power and futility of human desire, thereby locating the character's personal struggle within the larger drama of human existence. “362

Connolly differenziert drei Kategorien von eingefügten Fremdtexten: Zur ersten Gruppe zăhlt er Auszüge aus Volksliedern bzw. Gedichten, der zweiten Gruppe ordnet er Passagen aus religiösen Werken zu, wăhrend die dritte Gruppe fiktive Brief- bzw. Tagebuchauszüge von Protagonisten der Erzăhlungen umfaßt. Diese Kategorisierung kann im wesentlichen auf die Temnye allei übertragen werden, wobei die erste Gruppe um Sprichwörter und Redewendungen, die zweite Gruppe um Zitate aus den Werken anderer Schriftsteller erweitert werden. Der folgende Überblick gibt Aufschluß darüber, welche Textarten bevorzugt in die Temnye allei integriert wurden und worin ihre Funktion besteht.

\subsubsection{Auszüge aus Gedichten und Volksliedern; Redewendungen, Sprichwörter und} Volksweisheiten

Diese Gruppe ist am umfangreichsten, wobei Auszüge aus Gedichten und Volksliedern eine wichtigere Rolle spielen als Redewendungen bzw. Sprichwörter und Volksweisheiten. Allen diesen Zitaten ist gemeinsam, daß sie eine Verbindung zum Unbewußten, zur Gefuhlsebene herstellen und gleichzeitig eine Vorausschau enthalten können. Drei der Erzăhlungen, nămlich „Temnye allei“, „V odnoj znakomoj ulice“ und „Cholodnaja osen"“, basieren auf Gedichten aus dem 19. Jahrhundert, die auszugsweise in den Erzăhlungen zitiert werden und eine leitmotivische Funktion innehaben. Die Bedeutung des Gedichts für die jeweilige Erzăhlung spiegelt sich bereits in der Titelgebung wider, die sich eng an die zitierten Verse anlehnt. Alle drei Titel sind mehrdeutig. Während sie scheinbar konkrete Schauplătze bzw. einen bestimmten Zeitpunkt benennen, offenbaren sie im Laufe der Lektüre die dahinterliegende weitere, metaphorische Ebene: die dunklen, verschlungenen Wege der Liebe bzw. der Erinnerung sowie den Herbst des Lebens.

Am augenfalligsten erfolgt dieses Verfahren in der Erzăhlung „V odnoj znakomoj ulice“, deren Aufbau und Inhalt sich am Gedicht, Zatvornica“363 (1846) von Jakov 
Polonskij orientieren, indem Bunin die jeweils zitierte Strophe als Auslöser für die evozierte Erinnerung des Protagonisten fungieren läßt, die dieser mit dem Inhalt des Gedichts abgleicht, um am Ende die Diskrepanz zu erkennen. In „Temnye allei“ genügen Bunin zwei zitierte Verse aus dem Gedicht „Obyknovennaja istorija“364 (1842) von Nikolaj Ogarev, um an einem unwirtlichen Herbsttag das frühlingshafte Glück der ersten Liebe auferstehen (wenn auch nur in der Erinnerung) und dabei den Kontrast zum verwirkten Leben des alternden Offiziers spürbar werden zu lassen. Die in den genannten Erzăhlungen durch Verwendung der Zitate vertiefte, rein persönliche Dimension wird in „Cholodnaja osen'“ um die historische Dimension erweitert, die jedoch nur dem Rezipienten bewußt ist: Indem Bunin mit Hilfe zweier Verse aus Afanasij Fets Gedicht „Kakaja cholodnaja osen”“365 (1847) die bevorstehenden drohenden Brände des Ersten Weltkriegs andeutet, von denen die Protagonisten zu diesem Zeitpunkt selbstverständlich nichts ahnen können, verleiht er den aus dem Zusammenhang gerissenen Worten Fets prophetischen Klang und über die geschichtliche Einordnung hinaus poetische Tiefe.

Es fallt auf, daß Bunin in keinem dieser Fälle korrekt zitiert. Da es unwahrscheinlich ist, daß Bunins (auch von ihm selbst gerühmtes) phänomenales Wortgedăchtnis in jedem dieser drei Fälle versagt hat, liegt der Schluß nahe, daß er die Zitate bewußt für seine Zwecke leicht verfremdet instrumentalisierte. Am eindrucksvollsten kommt die Änderung in "Cholodnaja osen"“ zum Tragen: Der bedeutungsvolle Austausch von „дремлющих сосен“ gegen „чернеющих сосен“ (6:455) ließe sich auf Bunins Neigung zu sinnlicher Darstellung zurückfuhren, die ihren Ausdruck vor allem in einer überlegten und variantenreichen Farbgebung findet (vgl. Kap. 6.2). Vor allem jedoch tritt durch diese Änderung der Kontrast um so schärfer hervor und unterstreicht mit Hilfe der durch die Verwendung der Verse erzielten doppelten Bedeutungsebenen die bevorstehende Bedrohung kraftvoller, als je ein Prosatext dies vermorhte.

Noch in vier weitere Erzăhlungen integriert Bunin Auszuge aus Gedichten. die jedoch keine derart tragende Rolle spielen wie die oben erwähnten Gedichte. Hierzu gehören drei gleichfalls ungenau zitierte Verse aus der zweiten Strophe der „Čerkesskaja pesnja“ aus Puskkins „Kavkazskij plennik ${ }^{366}$ (1821), die dem Schriftsteller in der Erzählung „Vizitnye kartocki" beim Flirt mit der alleinreisenden Dame gute Dienste leisten: „Так тонут

364 In: N. Ogarev. Stichorvorenija i poemy. op.cit.: 151-152.

365 .Какая холодная осень! / Надень свою шаль н капот ... [...] Смотри - меж чернеющнх [im Original: и3-за дремлющих] сосен / Как будто пожар восстает" (6: 368). In: A. Fet. Polnoe SS. op.cit.: 455.

366 In: A. Puskin. Socinenija v cetyrech romach. 2.Bd. Moskva, 1999: 103-135. Korrekt muß es heißen: .Ках тонут маленькие дети, / Купаясь жаркою порой: / Чеченеи ходит за рекой" (127). 
маленькие дети, / купаясь летнею порой, чеченец ходит за рекой“ (6: 237). Von Aleksej Tolstoj verwendet Bunin gleich zwei Auszüge. Zum einen zitiert er (korrekt) in der Erzăhlung „Zojka i Valerija“ die beiden letzten Verse aus „Il'ja Muromec“367 (1871): „И смолой и земляникой пахнет темный бор“ (6:246), zum anderen verwendet er in der Erzählung „Kuma“ einen leicht abgewandelten Vers aus dem „Epigramma Nr. 1“ (1854) von Koz'ma Prutkov ${ }^{368}$ : „Вы любите ли сыр, спросили раз ханжу“ (6:342). In die Erzählung „Vtoroj kofejnik“ integriert Bunin Verse aus Lermontovs Gedicht „Utes“369 (1841): „Начивала ту-учка, ту-учка золота-ая ... / На груди утеса великана“ sowie die verunglimpfte Variante „Начивала сучка, сучка молодая“ (beide 6:361) und ubermittelt damit illustrativ die frivole Atmosphäre in bestimmten Künstlerkreisen.

Bruchstücke aus Volksliedern bzw. Romanzen finden sich in zahlreichen Erzählungen, wobei diese unterschiedliche Funktionen innehaben: Zum ersten nehmen sie kommende Ereignisse vorweg, zum zweiten liefern sie das passende Lokalkolorit, und zum dritten können sie kontrastierend eingesetzt werden.

Eine Vorwegnahme künftiger Ereignisse erfolgt in den Erzählungen „Ballada“, „Natali“ und „,Dubki““. Die von der alten Maša erwähnten Balladen bzw. Lieder („Boet cыp-6op за горою, / Метет в белом поле, / Стала вьюга-непогода, / Запала дорога ...“ und „Жар любви во всяком царстве, / Любится земной весь круг ...“, beide 6: 188) stimmen den Zuhorrer nicht nur auf ihre Geschichte ein, sondem stellen auch inhaltliche Parallelen her. Darüber hinaus enthält die Erzählung tatsächlich Genremerkmale der Ballade, die sich etwa in dem Eingreifen numinoser Kräfte in Gestalt eines Wolfes zeigen, aber auch in der Exempelbildung zum Ausdruck kommen. Auch läßt Bunin seine Protagonisten den Inhalt der Erzählung selbst als Ballade bezeichnen und verstärkt damit den Eindruck des Folkloristischen $(6: 187,189)$.

In der Erzăhlung „Natali“ scheint die von Sonja angestimmte Romanze von Petr Cajkovskij nach Versen von Aleksej Tolstoj („Средь шумного бала, случайно ...“370 [1851], 6: 309) lediglich der Freude über unbeschwerte Sommertage zu entspringen, antizipiert jedoch die für den Erzähler unheilvolle, zufällige Begegnung mit Natali auf einem Ball anderthalb Jahre später.

367 In: A. Tolstoj. SS v cetyrech tomach. I.Bd. Moskva, 1963: 314

368 Hinter diesem Pseudonym verbergen sich Aleksej Tolstoj und seine zwei Vettern Aleksej und Vladimir Żemcuzzikov. In: A. Tolstoj. SS v cetyrech romach. I.Bd. op.cit.: 451.

369 In: M. Lermontov. SS v cetyrech tomach. 1.Bd. Moskva, 1986: 100.

370 In: A. Tolstoj. SS v cetyrech lomach. I.Bd. op.cit.: 79. 
Ähnlich verhălt es sich in der Erzählung ,„Dubki““: Die aus einer Romanze zitierten Verse „Когда, душа, просилась ты погибнуть иль любить“ (6: 346) werfen einen unheilvollen Schatten der kommenden Ereignisse voraus, in denen die vom Erzähler angebetete junge Frau durch die Hand ihres eifersüchtigen Gatten einen grausamen Tod sterben muß.

Für Lokalkolorit sorgen eingefügte Liedbruchstücke in den Erzählungen „Rečnoj traktir", "Kačeli“" und „Čistyj ponedel'nik“. In „Rečnoj traktir" wird die Atmosphäre in der Pfahlbauschenke mit Hinweisen auf die musikalische Untermalung des dort vorherrschenden schmuddeligen Durcheinanders übermittelt: So kreischt eine Gruppe grell geschminkter leichter Mädchen ein Volks- bzw. Soldatenlied („Ивво рад-нын-и ни узнали-и, спроси-и-ли воин-а [sic], кто-ты-ы ...“, 6: 337); später betritt ein Sänger namens Gračev die kleine Bühne und gibt weitere Volkslieder zum besten: „Я вечор [sic] в л ужках гуляла, грусть хотела разогнать ...“ (6: 337) und weiter: „Я цветочек там искала, чтобы милому послать ...“ (6: 338). Auch in "Cistyj ponedel"nik“ wird die ausgelassene Stimmung auf dem lärmenden .,Kapustnik“ mit einem betrunken gegrölten „Пойдем, пойдем поскорее / С тобой польку танцевать!“ (6: 408) ausgeschmückt. Eine ähnliche Funktion haben die von der männlichen zentralen Figur lauthals geschmetterten Verse in "Kačeli“ („Не завидую богам, / Не завидую царям, / Как увижу очи томны [sic], / Стройный стан и косы темны!“, 6: 396), mit denen der junge Mann seiner unbändigen Lebensfreude Ausdruck verleiht.

Anders verhält es sich in der Erzählung "Tanja“: Das zunächst im Überschwang des Glücks und in Erwartung des nächsten Stelldicheins gesungene Liedchen „Уж как выйду я в сад, / Во зеленый сад, / Во зеленый сад гулять, / Свово милова встречать [sic] ....” (6: 265) hat in seiner textgleichen Wiederholung $(6: 268)$ in einem veränderten Kontext eine gänzlich andere Konnotation - der Liedtext und die Erinnerung an vergangene schöne Stunden machen dem jungen Mädchen die Diskrepanz zum hoffnungslosen Warten in der Gegenwart bewußt und lassen sie in ein verzweifeltes Schluchzen ausbrechen. Als gegen Ende der Erzählung der Protagonist den Vers „Во зеленый сад“ (6: 270) aufgreift und kommende sommerliche Rendezvous in Aussicht stelit, geschieht dies im Sinne einer irreführenden Zukunftsvorausdeutung (vgl. Kap. 5.6.1), denn das Ergrünen des Gartens wird er nicht mehr erleben. Die zitierten Verse setzen auf diese Weise nicht nur einen Kontrapunkt, sondern übernehmen gleichzeitig durch die Wiederholungen eine wichtige strukturbildende Aufgabe. 
Redewendungen, Sprichwörter und Volksweisheiten bilden ebenfalls einen Teil der eingefügten Texte, wobei Bunin auch Anleihen beim Französischen und Lateinischen macht. Im Gegensatz zu den Gedichten und Liederm besteht ihre Funktion vor allem in der Einbettung der Handlung in ein russisches bzw. im Fall von „V Pariže“ in ein französisches Umfeld.

Die in der Erzählung "Temnye allei“ von der leidvoll gereiften Nadežda geäußerte Erkenntnis „... мертвых с погоста не носят“ (6:178) dient dem Beenden des fruchtlosen Gesprăchs mit dem Offizier, dem sehr daran gelegen ist, ihre Verzeihung zu erlangen. In „Genrich“ kommentiert der Kutscher die Reisepläne Glebovs mit den Worten „Охота пуще неволи“ (6: 290). Auch in „Natali“ werden die Weisheiten der Altvorderen bemüht. Zum einen erläutert Sonja ihrem Cousin ihr erwachtes Interesse an ihm und die möglichen angenehmen Implikationen mit den Worten: „И это сулило бы нам много любовных утех, как говорили наши бабушки ...“ (6: 303), zum anderen rügt der Onkel das späte morgendliche Aufstehen seines Neffen folgendermaßen: „Солнце на три дуба поднялось, а ты все еще мордой в подушке, говорят мужики“ (6: 307). In „Madrid““ bekundet die junge Prostituierte ihr Verständnis für einen ehemaligen Freier mit der Redewendung: „волка ноги кормят ...“ (6: 355). In der Erzählung „Parochod ,Saratov““ schließlich ist sich der junge Offizier über den Ernst der Lage noch nicht im klaren, und er versucht, die Trennungsbestrebungen seiner Geliebten ins Lächerliche zu ziehen: „Яка така удруг закавыка, как говорит наш вахмистр?“ (6: 374). Nur allmählich dringt die Bedeutung ihrer Worte in sein Bewußtsein, und er versucht, mit Hilfe einer Platitude die Situation zu entschärfen: „При любви деньги не имеют значения" (6: 374).

Auf das Lateinische greift Bunin lediglich in den Erzählungen „Rusja“ und „Natali“ zurück; beide Zitate stehen hierbei im Kontrast zum zuvor Geschehenen. Die Feststellung des Protagonisten in "Rusja“, „Amata nobis quantum amabitur nulla“ (6: 217), entspricht der Wahrheit, die der Erzähler gleichwohl seine Frau nicht wissen lassen möchte. Ihre Bitte nach einer Übersetzung lehnt er grob ab. In „Natali“ unterstreicht der fröhliche studentische Trinkspruch „Gaudeamus igitur!“ (6: 324) die Diskrepanz zwischen dem frohen Treiben auf dem Ball und der Verzweiflung des Protagonisten, der seine Liebe für immer verloren wähnt.

Daneben verwendet Bunin auch französischsprachige Redewendungen - wenn auch nur in der Erzählung „V Pariže“, die geprägt ist von französischsprachigen Redewendungen. Diese haben, ganz dem Klischee von Paris als Stadt der Liebe entsprechend, allesamt die Frau und die Probleme, die eine Liebesbeziehung mit sich bringen kann, zum Thema: 
„Rien n'est plus difficile que de reconnaitre un bon melon et une femme de bien“ (6: 272); "L'eau gâte le vin comme la charette le chemin et la femme-l'âme" (6: 274); „Le bon Dieu envoie toujours des culottes à ceux qui n'ont pas de derrière ...“ (6: 276); "Qui se marie par amour a bonnes nuits et mauvais jours" (6:277); „Patience - médecine des pauvres“ (6: 278); „L'amour fait danser les ânes“ (6: 280).

Durch die Vielzahl dieser "Locutions" wirkt die Verwendung dieser Zitate bemühter und unpassender und läßt den Verdacht aufkommen, daß Bunin nach einer Möglichkeit suchte, die in seinen Notizbüchern zahlreich vertretenen französischen Redewendungen (im Original) in einer Erzählung unterzubringen. ${ }^{371}$ In „Parochod ,Saratov“" wird zwar auch aus dem Französischen zitiert, aber auf Russisch: „Выбирайте хорошо ваши выражения, как говорят французы“ (6: 375).

Abschließend läßt sich festhalten, daß den Prosazitaten eine weitaus geringere Bedeutung zukommt als den lyrischen, die erheblich dazu beitragen, daß Bunins Prosa als poetisch wahrgenommen wird.

\subsubsection{Zitate aus religiösen und weltlichen Werken}

Im Gegensatz zu seinen früheren Erzählungen, in denen Bunin häufig Passagen aus der Bibel, dem Koran oder buddhistischen Texten verwendete, enthalten die Erzählungen der Temnye allei auffallend wenige religiös geprägte Zitate, die zudem ausschließlich biblischen bzw. liturgischen Ursprungs sind - und das, obwohl seine Weltanschauung eine deutliche buddhistische Prägung aufweist (vgl. Kap. 8.1.3).

Religiöse Zitate finden sich in nur vier Erzăhlungen, die innerhalb des Buches an Schlüsselstellen positioniert wurden. In die Eröffnungserzählung „Temnye allei“ integriert Bunin den biblischen Vers 16 aus Hiob $11^{372}$ : „Как о воде протекшей будешь вспоминать“ (6: 177), den der alternde Offizier als Beleg für die Vergänglichkeit alles Irdischen und somit auch des Schmerzes zitiert. In „Ballada“, der dritten Erzählung des Buches, rezitiert die Pilgerin Maša verschiedene Psalmen (6: 185). Die Erzählung „Pozdnij cas“

371 Es finden sich in keiner weiteren Erzahlung, die in einem franzosischen Umfeld spielt, so viele franzosische Redewendungen. Einzig in der unveroffentlichten Erzahlung "Ivolga", deren Handlung jedoch in Rußland angesiedelt ist, plante Bunin urspranglich, franzosische Redewendungen zu verwenden (vgl. Ergănzungen auf einigen Typoskriptseiten; LRA. MS.1066/124-126).

372 ..Dann wärdest du alle Mahsal vergessen und so wenig daran denken wie an Wasser, das verrinnt" (Hiob 11, Vers 16. In: Die Bibel oder Die ganze heilige Schrift des Alten und Neuen Testaments nach der Übersetzung Martin Luthers. Stuttgart, 1978). 
enthält einen Auszug aus der Totenmesse der römisch-katholischen Kirche: „Requiem aeternam dona eis, Domine, et lux perpetua luceat eis" (6: 206), der dem Protagonisten anläßlich seiner Erinnerung an Pariser Bestattungsgepflogenheiten in den Sinn kommt. Ein Zitat in "Cistyj ponedel'nik" schließlich gemahnt an einen Auszug aus einem Gebet: „Господи Владыко живота моего ...“ (6: 404). In dieser Erzählung, in der weltliche und geistig-religiöse Welt einander gegenübergestellt werden, finden zahlreiche weitere Bücher verschiedener Autoren ohne Einflechtung von Zitaten Erwähnung (vgl. Kap. 8.2.1).

Es ist auffällig, daß die zitierten religiösen Auszüge in Erzählungen am Anfang und am Ende des Buches plaziert wurden; obwohl sie auf den ersten Blick nur eine schmückende Funktion haben, wird ihre strukturelle Aufgabe nach der Lektüre aller Erzählungen offenbar: das Buch erfährt durch diese Zitate eine Umrahmung durch das göttliche Element (Alpha et Omega), das auch in den anderen Erzählungen vorhanden ist, dort jedoch nicht explizit in den biblischen Kontext eingebunden wird (vgl. auch Kap. 4.3.3).

Mehr oder minder ausfuhrliche Zitate aus weltlichen Werken finden sich in den Erzählungen "Genrich“, „Kačeli“ und „Čistyj ponedel'nik“. Der Protagonist in „Genrich“, der sich in einem bedeutungsvollen Zitat aus einem nicht näher bezeichneten "alten Buch" über die ungerechte Kritik beklagt, mit der ein Schriftsteller bei erotischen Darstellungen zu rechnen habe, könnte als Sprachrohr Bunins betrachtet werden, mit dem dieser die zu erwartende Mißbilligung an seinen freimütigen Schilderungen weiblicher Körper (vgl. Kap. 7.2) vorwegnehmend rechtfertigen wollte:

Сочинитель имеет такое же полное право быть смелым в свонх словесных изображениях любви и лиц ее каковое во все времена предоставлено было в этом случае живописцам и ваятелям: только подлые души видят подлое даже в прекрасном или ужасном. (6: 295).

Ein Dante-Zitat, mit dem der verliebte Protagonist in der Erzählung "Kaceli“ seine Begleiterin zu verunsichern beabsichtigt (,Данте говорил о Беатриче: ,В ее глазах начало любви, а конец-в устах““, 6: 397) hat den entgegengesetzten Effekt, so daß letztlich er das Nachsehen hat. Zum Zwecke der Verführung der Ehefrau seines Freundes bedient sich der Protagonist der Erzăhlung „Kuma“ eines Zitats des persischen Autors Sa'dĩ: „,... у одного человека сердце ушло из рук и он сказал уму: прощай“373 (6: 340). 
Um das trügerische Glück, vor allem das in der Liebe, geht es auch in einem Zitat aus Tolstojs Vojna i mir in der Erzăhlung „Cistyj ponedel'nik“: „Счастье наше, дружок, как вода в бредне: тянешь - надулось, а выташишь - ничего нету“374 (6: 403).

Von besonderer Bedeutung sind in "Cistyj ponedel'nik“ ein Zitat aus der altrussischen Chronik („Рече Гюрги ко Святославу, князю Северскому: ,Приди ко мне, брате, в Москову“ и повеле устроить обед силен“, 6: 406) und die Wiedergabe einer märchenhaften Erzählung durch den Protagonisten, die von der Protagonistin aufgegriffen und fortgesetzt wird:

Был в русской земле город, названием Муром, в нем же самодержаствовал благоверны князь, именем Павел. И вселил к жене его диавол летучего змея на блуд. И сей змей являлся ей в естестве человеqеском, зело прекрасном ... (6: 406).

Beide Zitate werden dem Protagonisten der Erzăhlung in den Mund gelegt, der sie ausspricht in dem Bewußtsein, daß seine Freundin ihm entgleitet. Da er sich ihr rätselhaftes Verhalten nicht erklären kann, aber um ihr Interesse an der altrussischen Geschichte weiß, will er ihr vermutlich mit seinen Kenntnissen imponieren - und ubersieht dabei, daß ihre Leidenschaft nicht der weltlichen, sondern der religiösen Vergangenheit Rußlands gilt.

Im Gegensatz zur Bedeutung der religiös orientierten Zitate ist jene der weltlichen Zitate marginal und gleicht in etwa dem Stellenwert der Redewendungen, Sprichwörter und Volksweisheiten im Vergleich zu jenem der Gedichte und Lieder.

\subsubsection{Zitathaft verwendete Äußerungen von Protagonisten der Erzählungen}

Diese Art von Texten unterscheidet sich im wesentlichen von den anderen beiden Kategorien darin, daß sie von Bunin selbst verfaßt wurden, er diese aber zumindest in seinen Erzăhlungen bis etwa 1930 so geschickt einzusetzen versteht, als zitierte er einen Fremdtext. Tagebuchnotizen, wie etwa in den Erzählungen „Legkoe dychanie“ (1916) und „Delo korneta Elagina“ (1925), tragen entscheidend zum Verständnis der Handlung bei, da sie einen Einblick in das Innenleben der jeweiligen Protagonistin gewähren. In den Temnye allei setzt Bunin diesen Kunstgriff ausgesprochen zurückhaltend ein. Es steht zu vermuten, daß ihm nicht mehr an Erklärungen für die Handlungsweisen seiner zentralen Figuren gelegen ist und er als Ursache für vielerlei Geschehnisse das unbarmherzig eingreifende 
Schicksal dafur verantwortlich macht oder die Deutung ausschließlich dem Leser überlassen will.

Eine bedingt erklärende Funktion hat einzig der Brief in der Erzählung „Čistyj ponedel'nik", der den zurückbleibenden Liebhaber über die Wendung im Leben der Protagonistin in Kenntnis setzt, die sich dazu entschlossen hat, den Schleier zu nehmen, und ihn auffordert, den Kontakt abzubrechen und sie nicht weiter zu bedrängen: „В Москву не вернусь, пойду пока на послушание ...“ (6: 410). Doch läßt Bunin sowohl den Empfänger als auch den Leser über die Beweggründe ihres Schrittes im unklaren.

In zwei Erzählungen verwendet Bunin mit dem Fernschreiben ein moderneres Kommunikationsmittel, um die Handlung voranzutreiben: In „Natali“ wird die Familie des Protagonisten durch ein Telegramm vom Tod des Gatten Natalis in Kenntnis gesetzt (Cегодня утром Алексей Николаевич скоропостижно скончался от удара“, 6: 324) - durch die Fahrt des Erzählers zur Beerdigung wird solcherart ein Wiedersehen mit Natali ermöglicht. Mešcerskij seinerseits schickt im Verlauf der weiteren Ereignisse ein Telegramm, um seine Ankunft bei Natali anzukündigen, und leitet damit das dritte Wiedersehen ein: „Еду из Москвы мимо вас, буду на вашей станции в девять вечера, позвольте заехать, узнать, как вы поживаете“" (6: 327).

In zwei Erzählungen findet sich eine besondere Variante dieses Kunstgriffs, indem sich die jeweiligen Protagonisten an früher geäußerte Worte eines nun verstorbenen geliebten Menschen erinnern. In der Erzählung „Pozdnij čas“ ruft sich der Protagonist seine eigenen Worte in Erinnerung, die er an seine junge Geliebte gerichtet hatte: „Если есть будущая жизнь и мы встретимся в ней, я стану там на колени и поцелую твои ноги за все, что ты дала мне на земле“ (6: 205). Diese Worte verbinden ihn nicht nur mit seiner Vergangenheit, sondern verknüpfen darüber hinaus „Pozdnij cas“ mit der Erzăhlung „Cholodnaja osen"“, in der sich die Protagonistin jener Worte entsinnt, mit denen sich ihr Verlobter an ihrem letzten gemeinsamen Abend von ihr verabschiedete und deren tröstlicher Sinn sich ihr erst im Laufe des Lebens erschließt: „Ты поживи, порадуйся на свете, потом приходи ко мне ...“. (6: 369 bzw. 371). Ähnlich wie in der Erzählung „Tanja“ hat dieser zweifach verwendete Satz eine kontrastierende Funktion, indem Abschieds- und Lebensabend einander gegenübergestellt werden.

In den beiden genannten Erzählungen haben die Aussagen im Laufe der Jahre, die seit der unverhofften Trennung verstrichen sind, durch die Unwiederbringlichkeit der Vergangenheit und die in der Zwischenzeit gemachten Erfahrungen eine Wertigkeit erhalten, derer sich die Protagonisten zum Zeitpunkt der Unterhaltung nicht bewußt waren - ihre Vergan- 
genheit erfahrt eine Aufwertung, die das ganze Leben überstrahlt und den Protagonisten verdeutlicht, was wirklich wichtig war in ihrem Leben.

In 11 der 38 veröffentlichten und unveröffentlichten späten Erzählungen, die im gleichen Zeitraum wie die Temnye allei entstanden, lassen sich vergleichbare Beobachtungen machen. Zitierte Verse von Vertinskij bzw. Puskin finden sich in den Erzählungen „Novaja subka“ (unkorrekt zitierte Schlußverse aus dem Lied „O sesti zerkalach“375 [1917]: „И3-3a маленькой, злой и хорошенькой женщины погибаю в шести зеркалах“, 6:600) und „Lizok“ (die letzten Verse aus dem Poem „Bachčisarajskij fontan“376 [1824]: „И зеленеющая влага / Пред ним и блешет и шумит / Вокруг утесов Аю-Дага ...” [LRA. MS.1066/165-167]). Zitate aus der ersten Szene des 5. Aktes des Dramas „The Merchant of Venice" von William Shakespeare ${ }^{377}$ dienen als strukturbildendes Verfahren in der Erzählung „.V takuju noc’ ...““ (6: 577-578). Eine Redewendung - mit Hinweis auf den „Urheber“ Koz'ma Prutkov - enthält lediglich die Erzählung „Lizok“. Biblische Zitate finden sich in „Vesnoj, v ludee“ (Hohelied) und „Otec Nikon“ sowie in der Erzählung „Mistral“, deren Gestaltung an den Gedankenfluß in „Nox"“ erinnert. In der titellosen Erzählung, die postum durch Irina Odoevceva bekannt wurde, verwendet Bunin ein Gogol'-Zitat aus den Vecera na chutore bliz Dikan'ki („Знаете ли вы украннскую ночь ${ }^{4}{ }^{378}$ ), in „Molodost' i starost“" ein altes Gleichnis. Weitere Zitate von Schriftstellern finden sich nicht, in eine Sonderkategorie fallen die Erzählungen „Marija Stjuart“ und „Krem Leodor" mit den in ihnen enthaltenen Auszügen aus einem Werbeplakat bzw. aus Anzeigen. Und lediglich in der Erzählung „Pis'ma“ spielen zitathafte Äußerungen einer Figur eine Rolle: Die Protagonistin liest ihrem neuen Geliebten einen flehenden Brief ihres ehemaligen Liebhabers vor, über den sie sich gemeinsam lustig machen.

Zusammenfassend läßt sich feststellen, daß die Verwendung von Zitaten im Laufe der Jahre in Bunins schriftstellerischem Schaffen rückläufig ist, da sie sich vermutlich mit den zunehmend angestrebten Augenblicksdarstellungen nur schwer in Einklang bringen ließen.

375 In: A. Vertinskij. Pesni i stichi (19/6-1937). Washington, 1962: 73. Die Protagonistin weist ihren Begleiter darauf hin, daß dieser die Verse nicht korrekt wiedergibt. Richtig heißt es: „Н3-за маленькой. злой ограниченнои женщины / Умираю в шестн зеркалах."

376 In: A. Puskin. Socinenija v cetyrech tomach. 2.Bd. Moskva, 1999: 146-163.

377 In: W. Shakespeare. The Merchant of Venice. (1596) http://www.shakespeare.com/FirstFolio/ THE MERCHANT_OF_VENICE/S.l.html.

$378 \mathrm{Vgl}$. die von Lotman zitierte Fassung in: J. Lotman. op.cit.: 173. Das erwahnte Gogol'-Zitat stammt aus der Erzahlung ..Majskaja noc', ili utoplennica“" in Vecera na chutore bliz Dikan 'ki (3. Erzăhlung im 1. Teil). In: N. Gogol'. SS v devjati tomach. I.Bd. Moskva, 1994: 58. 


\subsection{Zusammenfassende Betrachtung}

Ähnlich wie im strukturellen Bereich lassen sich auch bei den stilistischen Gestaltungsmerkmalen Parallelen zwischen den einzelnen Erzählungen feststellen, die in ihrem Zusammenspiel ihre verbindende Funktion ebenso unaufdringlich offenbaren wie analog die strukturellen Gestaltungstechniken. Sie haben keinen geringen Anteil daran, daß beim Rezipienten der Eindruck eines zusammengehörig:n Ganzen entsteht.

Eine tragende Rolle kommt hierbei dem gezielten Einsatz von Epitheta zu, die Bunin keinesfalls rein attributiv verwendet, wie zum Beispiel die häufig anzutreffenden Anthropomorphisienungen von Flora und Fauna mit dem Ziel der Darstellung des Allzusammenhangs der Schöpfung belegen. Vor allem die sensuelle Ausgestaltung der Erzählungen mit Hilfe von Epitheta trägt zu der eindrucksvollen Dichte des Textes bei. Am offensichtlichsten zeigt sich Bunins diesbezügliches Vermögen in seinem virtuosen Umgang mit einer sehr nuancierten und überwiegend adjektivisch geprägten Farbpalette, die für Plastizität, Emotionalität durch Übermittlung innerer Prozesse, Authentizität (in Verbindung mit Erinnerungen) und sprachliche Dichte sorgt. Der überlegte Einsatz von Wörtern zur Bezeichnung von Helligkeit, Dunkelheit und Glanz ergänzt die Verwendung der Farben. Bunins Vorliebe für rasch aufblitzende Lichtpunkte, die die Kürze und Intensităt des Liebesaugenblicks symbolisieren, findet hierbei ihre Entsprechung in der untetstützenden Funktion des Glanzes als Speicher des Lichts und der anhaltenden Strahlkraft der Erinnerung, nachdem das Licht längst verloschen ist.

Die Rhythmisierung des Textes, die Bunins Prosa musikalisch bzw. lyrisch wirken läßt, beruht nicht allein auf strukturellen Gestaltungstechniken wie dem variierenden Erzähltempo. sondern erfolgt auch im lexiko-semantischen Bereich etwa in den Doppelungen und Wiederholungen ganzer Wörter oder einzelner Laute, die eine intensive Emotionalität erzeugen, ohne daß diese forciert wirkt.

Verschiedene Funktionen haben die eingefügten Fremdtexte unterschiedlicher Herkunft. Die gewichtigste Rolle kommt hierbei Auszügen aus Gedichten und Volksliedern zu, denen bei aller Vielfalt gemeinsam ist, daß sie eine Verbindung zum Unbewußten bzw. zur Gefühlsebene der Protagonisten herstellen und das persönliche Ringen der zentralen Figuren in den größeren Zusammenhang der menschlichen Existenz stellen. Die zitierten Sprichwörter und Redewendungen sorgen demgegenüber für l okalkolorit und kontrastive Effekte. Zitate aus religiösen Werken haben einzig in der ersten und der vorletzten Erzählung eine rahmende Funktion, während die Zitate aus weltlichen Werken überwiegend 
dazu dienen, Gesagtes zu untermauern. Darüber hinaus besteht die Aufgabe der eingefügten Fremdtexte zum einen in der zeitlichen Lokalisierung der Erzählungen und zum anderen in der Herstellung intertextueller Bezüge nicht nur zur russischen Vergangenheit. Ihre strukturbildende Funktion schließlich zeigt sich in ihrem teils leitmotivischen, teils prophetischen, teils kontrastierenden Charakter.

An diese Übersicht über die grundlegenden intratextlichen strukturellen und stilistischen Verknüpfungen schließt sich in der Folge eine Analyse des Figurensystems in den Temnye allei an. 
7 DIE ZENTRALEN FIGUREN DER TEMNYE ALLEJ

Die zentralen Figuren der Temnye allei fügen sich zu einem bunten Panorama fiktiver Personen in einem weiten Spektrum von Liebesbeziehungen zusammen. Ein Vergleich der Angaben zur Biographie der einzelnen Handlungsträger ergibt - ähnlich wie bei den Schauplătzen (vgl. Kap. 5.5) - indes nur eine oberflăchlich üppige Vielfalt; innerhalb dieser Verschiedenartigkeit fallen ausgeprägte Parailelen in der Ausgestaltung der Figuren auf, die in diesem Kapitel beleuchtet werden sollen.

Jede Erzählung besitzt ihre eigenen zentralen Figuren, so daß keine der fiktiven Personen innerhalb des Buches zweifach auftritt. Als zentral gelten im Rahmen dieser Analyse nur diejenigen Figuren, die die Handlung bestimmen und ihren Fortgang entscheidend vorantreiben - ihre Anzahl beläuft sich pro Erzählung auf zwei bzw. drei Personen.

Die Einbettung der zentralen Figuren in ein national-kulturelles Umfeld erfolgt zum einen durch die Schilderung einer überwiegend russisch geprägten Umgebung, zum anderen durch die Erwähnung authentischer historischer Persönlichkeiten aus dem künstlerischen oder politischen Bereich des vorrevolutionären Rußland in Gesprächen der Protagonisten oder in Anmerkungen des Erzählers (vgl. Kap. 8.2.1).

Nach einfuhrenden Überlegungen zur Charakterisierung der zentralen Figuren der die Temnye allei konstituierenden Erzählungen wird insbesondere die Darstellung der weiblichen Figuren einer detaillierten Analyse unterzogen. Des weiteren werden die Figurenkonstellationen sowie die Rolle des Nahrungsmittelgenusses als sinnliches Gestaltungsmittel beleuchtet.

\subsection{Zur Charakterisienung der zentralen Figuren}

In den Erzăhlungen der Temnye allei erfolgt die Charakterisienung der zentralen Figuren beiderlei Geschlechts über das von Boris Tomaševskij als "Maske“ bezeichnete Verfahren $^{379}$, das sich nicht allein auf das Äußere einer Figur stützt (das Aussehen bzw. die Kleidung ebenso wie die persönlichen Lebensumstände), sondern auch ihre sprachlichen 
Äußerungen berücksichtigt. ${ }^{380}$ Selbst in Erzählungen mit Ich-Erzählsituation gewăhrt Bunin nur zurückhaltend Einblick in das Seelenleben einer Figur und klammert Handlungsmotive aus, der jeweilige Erzähler ist nur mehr Sprachrohr der Vergangenheit, seiner eigenen Verwicklung zum Trotz ein überwiegend objektiv berichtender Chronist des Geschehens; die Funktion der Übermittlung psychischer Befindlichkeiten übernehmen daher häufig die Naturbeschreibungen (vgl. Kap. 5.5.1).

Biographische Angaben zu Namen, Alter, Herkunft, Familienstand oder Beruf der zentralen Figuren lassen sich zwar nur in geringem Umfang finden, sind aber wesentlich häufiger vorhanden, als es der Eindruck von L. Smirnova suggeriert:

Все, что прямо не касается [любовь], сведено в рассказах к минимуму, нередко герои безымянны, лишены „биографии“. Зато неповторимые реалии их встреч, переживаний, впечатлений настолько выразительны, что опять кажется: автор воспроизвел чъи-то известные ему истории. ${ }^{381}$

Smimovas Wahmehmung verweist auf Bunins Vermögen, beim Leser den Eindruck von Authentizität zu erwecken, ist jedoch trügerisch, denn diese Vorgehensweise beruht nicht auf der Tatsache, daß Bunin selbsterlebte oder ihm bekannt gewordene Liebesgeschichten in anonymisierter Form kolportiert ${ }^{382}$, sondern dient vielmehr dazu, den eigentlichen Interessenmittelpunkt von Ballast freizuhalten und unterstreicht die Austauschbarkeit der Figuren.

Dennoch finden sich in beinahe jeder Erzählung direkte oder indirekte Hinweise auf die Biographie der zentralen Figuren, die bis auf wenige Ausnahmen durch zwei auffällige Gemeinsamkeiten miteinander verbunden sind: die russische Nationalzugehörigkeit sowie ihre Verstrickung in Liebesbeziehungen im weitesten Sinne. Lediglich die fünf folgenden

380 Eine Charakterisierung uber sprachliche Besonderheiten erfolgt allerdings nur bei einigen wenigen Protagonistinnen: $\mathrm{Zu}$ ihnen gehören die beiden Bauernmadchen Stepa und Tanja aus den gleichnamigen Erzahlungen mit ihrer einfachen Diktion sowie die Protagonistinnen der Erzahlungen ...Madrid “.. und „Vtoroj kofejnik“ mit ihren umgangssprachlichen Eigenheiten. Typische Elemente des Skaz finden sich in den Sătzen der alten Maša (.,Ballada“) und des betagten Pilgers aus der Erzăhlung ,Zeleznaja Serst" ". In den abrigen Erzahlungen verwendet Bunin ein hochsprachliches Russisch auch in den Dialogen, allenfalls durchsetzt mit fremdsprachigen Einsprengseln. wie z.B. ukrainische oder franzosische Redewendungen. Im wesentlichen konzentrien sich Bunin darauf, eine Figur bildlich vor dem Auge des Lesers erstehen zu lassen, wobei sein Interesse eindeutig den weiblichen Handlungstragem gilt. Dies laßt sich sogar in dialogisch aufgebauten Erzahlungen wie etwa „Vtoroj kofejnik“ nachweisen, in denen der mănnliche Parn zum reinen Stichwortgeber wird und er der Frau ungleich mehr Rede-Raum gewăhrt.

381 L. Smimova. Ivan Alekseevic Bunin. Zizn' i vorcesrvo. Moskva, 1991: 172.

382 Bunins eigenen Aussagen zufolge entstanden die wenigsten seiner Erzăhlungen als Abbild der Wirklichkeit. In seiner Selbstauskunft „Proischożenie moich rasskazov“ (in: ders. SS v devjati tomach. 9.Bd. op.cit.: $371 \mathrm{ff}$.) erläutert er die zentralen Ausloser, die ihn zum Verfassen einer Erzahlung veranlaBten: zum einen geschah dies im Rahmen von Erinnerungen an Rußland, zum zweiten regten ihn Naturkontemplationen an, und zum dritten standen hin und wieder auch schlicht finanzielle Erwăgungen im Vordergrund. Vgl. auch den eingangs von Kap. 6 zitierten Kommentar Bunins (LRA. MS. 1066/466). 
Figuren in den Temnye allei weisen eine nichtrussische Nationalităt auf: Artur Špigler, der österreichische Liebhaber und Mörder der Protagonistin in „Genrich“ in der gleichnamigen Erzählung; Iraklij Meladze, der grusinische Kaufmannssohn und Mörder der „Baryšnja Klara“; die unbekannte Schönheit aus der Camargue („Kamarg“); die Malaiin, die dem konsternierten Ich-Erzähler von einem ihrer Landsleute für 100 Rupien („Sto rupij“) für ein Schäferstündchen angeboten wird. Die Gesamtheit der russischen Handlungsträger läßt sich untergliedern in die im Anschluß an die Oktoberrevolution 1917 nach Frankreich geflohenen Emigranten und jene Russen, die in ihrer noch nicht von der Revolution erschütterten Heimat leben, wobei letztere die zahlenmäßig größere Gruppe stellen.

Die 92 auftretenden zentralen Figuren unterteilen sich in 52 männliche und 40 weibliche Personen. Nur ein knappes Drittel von ihnen, nămlich 27 weibliche und 14 männliche Figuren, wurden von Bunin mit einem Eigen- bzw. Kosenamen versehen; der größte Teil der handelnden Personen ist namenlos und wird nur mit „on“ bzw. „ona“ bezeichnet. Bei der Vergabe von Namen folgt Bunin den Maximen der Einfachheit und des gefalligen Klangs; am 9. Juni 1940 notiert er in sein Tagebuch: „Вот вдруг подумал сейчас: имена, отчества, фамилия должны звучать в рассказах очень ладно, свободно,- например: Марья Викентьевна, Борис Петрович ... ${ }^{383}$ In seinen undatierten Aufzeichnungen findet sich zudem die folgende Notiz:

Для рассказов надо брать имена и отчества простые, легко произносимые или привычные - царей, известных писателей и т[ак] д[алее]: Алексей Михайлович, Иван Васильевич, Иван Сергеевич ... Фамилии - тоже простые и легко пронзносимые. Сколько несносных фамилий в рассказах и романов даже у хороших писателей, даже иногда у Толстого! ${ }^{384}$

Und so tragen zumindest die Männer klingende, aber nichtssagende Namen wie Vikentij Vikentič („Muza“) und Adam Adamyč ("Gost')) oder erhalten nur einen Vor- oder Kosenamen. Bei der Benennung der weiblichen Figuren hingegen legt Bunin einen weitaus gröBeren Variantenreichtum an den Tag; zudem scheinen die weiblichen Namen ungleich bedeutungsgeladener zu sein. Die Namen „Muza“ oder "Antigona“ beispielsweise deuten bereits die Funktion der Namenträgerinnen an, wohingegen Bezeichnungen wie „Durocka“ oder „Kuma“ auf den gesellschaftlichen Status der jeweiligen Person zielen. Bei der Benennung der weiblichen Figuren bevorzugt Bunin Vor- oder Kosenamen, wobei einige Personen sowohl mit einem Eigen- als auch mit einem Kosenamen versehen sind, wie beispielsweise Katerina Nikolaevna, die als „Antigona“ in der gleichnamigen Erzählung ein- 
gefürt wird. ${ }^{385}$ Mit dieser Verfahrensweise setzt sich auch bei der Namensvergabe die Betonung der weiblichen Figuren fort, die sich bereits bei der Titelwahl abzeichnete.

Hinsichtlich der Altersstufen ist das Verhältnis zwischen den Geschlechtern ausgewogen, da sowohl bei den Männern als auch bei den Frauen nahezu jedes Lebensalter vertreten ist. Vor der Liebe sind alle gleich - gleichberechtigt und gleich hilflos -, oder wie es der besonnene Protagonist mittleren Alters in der Erzählung „V Pariže“ mit einem französischen Sprichwort ausdrückt: „L'amour fait danser les ânes“ (6: 280).

Die jüngste männliche Figur, die mit der Liebe oder vielmehr mit Liebesentzug in Berührung kommt, ist der knapp siebenjährige Stiefsohn der „Schönheit“ („Krasavica“), der älteste Protagonist gibt den Zeitraum des Zurückliegens seines traumatischen Liebeserlebnisses, das ihm als sehr junger Mann widerfuhr und ihm noch im hohen Alter die Seelenruhe raubt, mit mehr als 65 Jahren an; er dürfte somit zum Zeitpunkt seines Berichts ein etwa 85-jähriger Greis sein - es ist der alte Pilger aus der Erzählung ,Železnaja Šerst”“. Zwischen diesen Eckpfeilem greift Bunin alle denkbaren Altersstufen auf, die sich jedoch alle in ihrem von sexueller Leidenschaft geleiteten Blick auf die Frau gleichen: Er zeichnet das Bild der erwachenden Sexualităt eines Jünglings in „Načalo“, skizziert die tödliche Sinnenlust eines jungen Mannes in „Baryšnja Klara“ und läßt in dem gealterten Militär aus "Temnye allei“ die reuevolle Erinnerung an seine lang zurückliegende Liebesaffäre mit einer Leibeigenen erstehen.

Die Spannbreite der Altersstufen bei den weiblichen Figuren ist ähnlich weit gefaßt: Die Jüngste unter ihnen verspürt mit 14 Jahren erste sinnliche Regungen („Zojka i Valerija“), während das hohe Alter der Pilgerin Mašen'ka (,Ballada“) nicht genau beziffert wird. Innerhalb dieses Rahmens bewegen sich die Altersklassen hauptsächlich zwischen 17 (,Tanja“) und 48 Jahren („Temnye allei“), eine Überbetonung erfahren allerdings junge Frauen und Mädchen.

Bei den Protagonisten der Temnye allei hat der Leser es mit Individuen zu tun, deren Familienstand zum Zeitpunkt ihres Aufeinandertreffens in der Regel ledig ist. Doch selbst vorhandene sanktionierte Bindungen wie etwa die Ehen der Protagonistinnen in den Erzählungen „Kavkaz“, „Vizitnye kartocki“, „Kuma“ oder „,Dubki““ stellen kein Bollwerk gegen aufbrandende Gefühle dar, zumal die Frauen diese in der Regel als nicht glücklich

385 Den 9 Eigennamen Muza Graf, Mar'ja Viktorovna, Katerina Nikolaevna, Ksenija Andreevna, Valerija Ostrogradskaja Andreevna. Ol'ga Aleksandrovna, Galja Ganskaja. Elena Genrichovna und Elena Nikolaevna stehen insgesamt 19 Vor- bzw. Kosenamen gegenuber: Nadežda, Masen'ka, Stepa, Durocka, Antigona, Kisa, Sała, Zojka, Tanja, Genrich, Sonja, Natali, Kuma, Anfisa, Klara. Nina, Polja, Kat'ka und Masa. 
empfinden und der Boden fur einen Ausbruch mit teilweise dramatischen Folgen schon bereitet ist. Einzig in der Erzählung „Ballada“ verhindert das Eingreifen numinoser Kräfte das Eindringen eines Dritten in eine bestehende Beziehung. Doch auch die Paare, deren Aufeinandertreffen ein glückliches ist und deren Zukunft bereits gesichert scheint („Natali“, „V Pariže“), sind gemäß Bunins Liebeskonzeption nicht für eine längere Bindung bestimmt (vgl. Kap. 8.1.1) - die Ehe gilt ihm nicht als mögliche Fortsetzung des emotionalen Zusammenpralls zweier Menschen. ${ }^{386}$ Konsequenterweise findet keine der in den Temnye allei geschilderten schicksalhaften Begegnungen zwischen zentralen Figuren ihre Erfullung in Kindern - eine Ausnahme bildet lediglich die Erzăhlung „Durocka“, in der jedoch in der Folge das Kind des Diakonssohns gemeinsam mit seiner Mutter grausam verstoßen wird. ${ }^{387}$ Am eindringlichsten wird die Zukunftslosigkeit der Liebesbeziehungen mit dem Tod der Protagonistin in der Erzählung „Natali“ gezeigt, die während einer Frühgeburt ums Leben kommt, nachdem ihr Leben und das des Protagonisten nach Jahren des Liebesleidens endlich in glücklichere Bahnen zu geraten schien.

Die beruflichen Tätigkeiten der Figuren spielen im Handlungsgefüge eine untergeordnete bis keine Rolle. Auch ihr sozialer Status bzw. ihre Herkunft werden nur selten explizit erläutert; im Falle der verheirateten Frauen (,Kavkaz“, „Krasavica“ oder „,Dubki““) kann er über den des Gatten erschlossen werden, in anderen Fällen ist der Leser auf deiktische Verweise angewiesen, wie etwa den Bemerkungen zu einem Landgut („Dubki“") und Hinweisen auf den văterlichen Reichtum („Baryక̌nja Klara“), oder wird im unklaren gelassen.

386 Folglich sind alle von Bunin dargestellten Ehen auf der Ebene der Hauptfiguren unglucklich: So scheint der Offizier in . Temnye allei" mit einer untreuen Ehefrau und einem verkommenen Sohn baßen zu müssen für sein schmăhliches Beenden der Beziehung zu Nadežda, seiner einzigen wahren Liebe: der Protagonist in ..Krasavica" geht aus Angst vor seiner zweiten Frau so weit, seinen Sohn aus erster Ehe zu verleugnen; die Ehefrau in .Kuma“ langweilt sich und sucht nach Abwechslung: und es darf in Zweifel gezogen werden, daß die junge Gouvernante aus der Erzahlung „Voron" mit dem Vater ihrer ersten Liebe ihr emotionales Gluck gefunden hat, wenngleich sie jetzt materiell abgesichert ist. Vergleichbare Konstellationen finden sich in den folgenden Erzăhlungen: „Kavkaz", „Rusja“, „Vizitnye kantocki“.

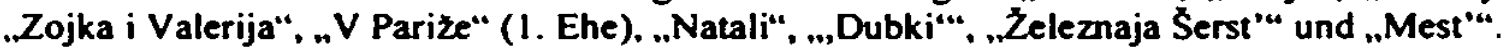

387 Den Kindem, die ohnehin eine untergeordnete Rolle in den Temmye allei spielen, ist in der Regel kein gluckliches Schicksal beschieden: Neben dem bereits enwahnten Kind sind noch der ebenfalls von seinem Vater verleugnete Junge aus .Krasavica“ und das von dem Protagonisten der Erzahlung .Natali“ mit seiner Dienstbotin gezeugte Kind anzufuhren, denen gleichfalls kein Familienleben vergonnt ist. Daruber hinaus werden Kinder nur noch in wenigen weiteren Erzahlungen erwathnt: in ..V Parize" als nicht existent, in ..Kuma", wobei eine Taufe nur den Rahmen fur die Begegnung des zukünftigen Liebespaares bildet, und in ..Cholodnaja osen". - das kleine Madchen, das der Protagonistin als letztes Familienmitglied geblieben ist, will als erwachsene Frau nichts mehr von ihr wissen. Um so bemerkenswerter ist daher die Tatsache, daß ausgerechnet in der Finalerzăhlung ..Casovnja" die einzigen lebenden und handelnden Personen spielende Kinder sind. Dies legt den Schluß nahe, daß Bunin im Angesicht des Todes allgemein auf den Fortgang des Lebens hinweisen wollte, ohne hierfur seine Liebeskonzeption unterlaufen zu mussen. 
Die Hälfte der weiblichen Figuren wird lediglich als „Žena“ bzw. ,ženšina“ bezeichnet. Die andere Hälfte der weiblichen Figuren ist zu 50 Prozent in dienenden Berufen im weitesten Sinne tätig: Hierzu zählen Wirtschafterinnen („Temnye allei“) ebenso wie Köchinnen bzw. Stubenmädchen („Duročka“ bzw. „Tanja“) oder die „Antigona“ genannte Krankenschwester aus der gleichnamigen Erzählung. Die anderen 50 Prozent sind etwas bunter gemischt: Neben Prostituierten („Baryšnja Klara“, ,"Madrid““ und „Sto rupij“) treten eine Malerin (,Rusja“), eine Journalistin („Genrich“), zwei Studentinnen („Muza“ und „Cistyj ponedel'nik“), ein Maler-Modell („Vtoroj kofejnik“) sowie eine Pilgerin (,Ballada“) und die Besitzerin eines Hutsalons (,Mest'“) auf.

Bei den männlichen Personen sind die einzelnen Berufsgruppen gleichmäßiger belegt. Bei etwa einem Drittel der Erzählungen fehlen nähere Angaben zur beruflichen Tätigkeit des Protagonisten gänzlich. Zu etwa gleichen Teilen sind Militărangehörige ("Temnye allei“, „Kavkaz“, „V Pariže“, „Reěnoj traktir“, „Cholodnaja osen”“ und „Parochod ,Saratov“") sowie Schüler bzw. Studenten vertreten (,Antigona“, „Volki“, „Zojka i Valerija“, „Natali“, „Načalo“ und „Voron“). In der Minderheit befinden sich Kaufleute (,Stepa“ und „Baryšnja Klara“), Beamte (,Krasavica“), Schriftsteller („Vizitnye kartoðki“) und - im weitesten Sinne - Geistliche (..Durocka“" und ,Železnaja Šerst “"). Näheres erfährt der Leser nicht; es bleibt unklar, worin diese Beschäftigungen im einzelnen bestehen und was die sie ausübenden Personen vorher taten.

Eine auffällige Parallele besteht jedoch zwischen allen männlichen Figuren: Sie sind gewissermaßen berufsmäßige Liebhaber und zugleich Reisende, deren Reisemotiv in der „Jagd nach einem Ortswechsel“388 besteht, häufig verbunden mit der Hoffnung auf ein Liebesabenteuer. Symptomatisch für die häusliche Situation der männlichen zentralen Figuren ist die Äußerung des Protagonisten in „Tanja“: „У меня нет дома. Таня, я всю жизнь езжу с места на место ...“ (6: 267). Mit Ausnahme der Erzählungen „Krasavica“, „Smaragd“. .,Recnoj traktir”, .,Vtoroj kofejnik“ und „Casovnja“ spielt das Reisen in der Tat für die meisten auftretenden männlichen - aber auch etliche der weiblichen - Figuren eine

388 M. Iofev. Profili iskusstva. Literatura, teatr, Zivopis: estrada. kino. Moskva, 1965: 308. Die Interpretationen der Darstellung der zentralen Figuren fielen in der sowjetischen Literaturwissenschaft hochst unterschiedlich aus. So faßt etwa lof ev die zentralen Figuren in Bunins Spatwerk als letzte literarische Realisierung des ..lišnij celovek“" auf, dem jegliche Idee oder gar soziales Engagement fremd sei, der keinerlei geistige Regung verspüre, sondern im Gegenteil ganz seinen Gefuhlen lebe (S. 309). Nur wenige Jahre spater vermutet A. Acatova die Ursache fur die fehlende Erwăhnung ciner beruflichen Betatigung der Protagonisten in der Zerrissenheit des modernen Menschen, in der Entfremdung der Personlichkeit (Liebe rettet den Menschen nicht vor der Einsamkeit des Lebens) - sie sieht in ihnen bereits die künftigen Emigranten, denen mit dem Verlust ihrer Heimat auch jegliche Basis für eine befriedigende Tatigkeit verlorengegangen sei (vgl. A. Acatova. ..Pozdnjaja liriceskaja novella I. A. Bunina ...". op.cit.: 118). 
bedeutende Rolle (vgl. Kap. 8.1.4). Im übrigen kann diese Feststellung auch im übertragenen Sinne getroffen werden, denn in den Temnye allei ist es mit wenigen Ausnahmen der Mann, der sich auf die Frau zu bewegt, er ist es, der die Initiative ergreift und seinem Verlangen Ausdruck verleiht, während die Frau zunächst passiv bleibt. ${ }^{389}$ In der Erzählung „V Pariže“ kleidet der Protagonist, ein Emigrant in mittleren Jahren, diese unablässige Suche nach der Erfullung geheimer Gefühlssehnsüchte in folgende Worte:

Да, из году в год, изо дня в день, втайне ждешь только одного,- счастливой любовной встречн, живешь, в сущности, только надеждой на эту встречу - и все напрасно ... (6: 274). ${ }^{390}$

Folglich werden im wesentlichen nur die Frauen über ihre Wohnverhältnisse charakterisiert, denn nur sie verfugen über einen festen Wohnsitz, vorausgesetzt, die Paare befinden sich nicht gemeinsam auf Reisen. Einzig der Emigrant aus „V Pariže“ hat in der französischen Hauptstadt ein vorläufiges Zuhause gefunden; die übrigen männlichen zentralen Figuren werden entweder in ihrem Unterwegssein porträtiert, hausen in unpersönlichen Hotelzimmern (z.B. „Kavkaz“, „Muza“ oder ",Madrid“") oder sind zu Gast auf Landsitzen von Freunden bzw. Verwandten (z.B. „Antigona“, „Zojka i Valerija“, „,Dubki““). In der Regel trifft der Mann die Frau in ihrem persönlichen Umfeld an, etwa in ihrer Kammer wie in "Tanja“, in ihrer Gastwirtschaft ("Temnye allei“), ihrem Haus oder ihrer Wohnung (z.B. „,Dubki““, „Parochod ,Saratov““, „Čistyj ponedel'nik“). Die häusliche Umgebung der Frau wird in der Regel durch die Augen des Besuchers geschildert, wie etwa in „Baryšnja Klara“ oder „Dubki““.

Auch im übertragenen Sinne erweisen sich die Frauen als beständiger: So sehr die männlichen Protagonisten auch hingerissen sein mögen im Augenblick der Lust und/oder des Liebesempfindens oder in ihren Projektionen von der Zukunft, als so wenig standfest erweisen sie sich in der Folge. In einigen Erzählungen schütteln sie scheinbar das Erlebte ab (z.B. „Temnye allei“, „Kuma“) und ziehen weiter ihrer Wege. ${ }^{391}$ Besonders kraß zeigt sich dieses Verhalten in den Erzăhlungen, denen reine Begierde und somit kein umfassendes Liebeserlebnis zugrunde liegt (z.B. „Stepa“, „Gost'“). In anderen Erzählungen geben

389 Aktive Frauen finden sich etwa in den Erzahlungen „Muza“ und .Natali“ (Sonja).

390 In diesem Zusammenhang verdient ein Tagebucheintrag Bunins vom 06.07.1941 Erwăhnung, wenige Monate vor der Entstehung dieser Erzahlung: „Ожидания! Жизнь вообще есть почти постоянное ожндание чего-то" (zit. in: UB. 3.Bd. op.cit.: 102).

391 Die Frau setzt sich aktiver mit dem Ende einer Liebesbeziehung auseinander und triff Entscheidungen. wăhrend die Mănner den Weg des geringsten Widerstandes wăhlen und tatenlos verdrăngen: Nadeżda aus der Erzahlung . Temnye allei* bleibt sich selbst treu, bindet sich nicht wieder und macht sich selbstăndig; Rusja entscheidet sich, bei der Mutter zu bleiben; Antigona zieht die Konsequenzen aus der kompromittierenden Situation und reist ab. 
sie sich allzu leicht den Umständen geschlagen, anstatt für ihr Glück zu kämpfen (z.B. „Antigona“, „Dubki““, „Voron“). Vielen Erzählungen ist gemeinsam, daß das Erlebte erst im Rückblick fưr die Männer an Bedeutung gewinnt (z.B. „Temnye allei“, „Rusja“), während sich die Frauen der Tragweite des Geschehens häufig schon im Moment des Erlebens bewußt sind. ${ }^{392}$ Die weiblichen Figuren scheinen der ruhende Pol in der Beziehung zu sein, sie sind weiser, vorausschauender, nüchtemer, pragmatischer und realitätsnäher als zahlreiche der männlichen Figuren und sorgen so manches Mal für eine Ernüchterung der romantischen Vorstellungen ihrer männlichen Gegenparts: In der Erzählung „V Pariže“ etwa weist die Protagonistin ihren Verehrer, der sie zu einem Glas Wein in seine Wohnung einladen will, darauf hin, daß es nicht nötig sei, die hinter der Einladung verborgene Erwartung auf ein sexuelles Beisammensein zu verbrämen („Мы не дети, вы, я думаю, отлнчно знали, что раз я согласилась ехать к вам ...“, 6:280), während die Krankenschwester in "Antigona“ ihren ungestümen jungen Liebhaber auf die Risiken körperlicher Intimität auf dem Divan aufmerksam macht („Нет, нет, нельзя, лежа мы ничего не увидим и услышим ...“, 6: 228). Im Gegensatz zu den Männern sind die Frauen nicht nur in der Lage, die Bedeutung des Liebesaugenblicks im Erleben zu erkennen, sondern wissen zudem um die Unmöglichkeit, diesen in die Zukunft auszudehnen: „Пусть будет только то, что есть ... Лучше уж не будет“ (,Kaхeli“, 6: 396).

Zwischen allen Erzählungen der Temnye allei besteht hinsichtlich der Darstellung der zentralen Figuren eine frappante Ähnlichkeit, die im vorangegangenen Abschnitt bereits anklang: Neben den ausgesprochen plastisch geschilderten komplexen Frauengestalten wirken die männlichen Figuren seltsam blaß und monoton. Dies läßt sich nur zum Teil auf die Tatsache zurückführen. daß die Erzähler mit einer Ausnahme männlichen Geschlechts sind und daher vornehmlich ihr in der Regel weibliches Gegenüber und nicht sich selbst im Blick haben. Denn auch in Erzählungen mit personaler Erzählsituation geraten die männlichen Figuren in den Hintergrund. Während sich die Präsentation der männlichen Handlungsträger nahezu durchgängig in der - meist knapp gefaßten - Schilderung ihres Äußeren und ihres Berufs bzw. sozialen Status erschöpft, wird den weiblichen Figuren durch intensive und detaillierte Beschreibungen vor allem ihres Äußeren, das häufig genug auch eine zeitliche Lokalisierung ermöglicht, Leben eingehaucht. Die Individualisierung der

392 Die Frau bricht unerwartet in das Leben des Mannes ein und hat die Funktion, diesem durch die Erweitenung seines Ich in einer Liebesbeziehung sein Eingebundensein in den Kosmos bewußt zu machen nur uber die Frau fuhn fur ihn der Weg zu einem harmonischen Leben mit der Schopfung (vgl. Kap. 8.1.3). 
Frau, die mit der Namensgebung ihren Anfang nahm, wird hier konsequent weitergefuhrt. Bunins Beweggrinde für diese Vorgehensweise sollen in der Folge im Rahmen einer Analyse der Ausgestaltung der weiblichen Figuren näher beleuchtet werden.

\subsection{Die Darstellung der Frau}

Der Eindruck von Vielfalt bei den zentralen Figuren entsteht den obigen Ausführungen zufolge durch die Vielzahl der porträtierten Frauen, deren jede unverwechselbar individuell ist. Die weiblichen Figuren in den Erzählungen der Temnye allei erscheinen als Objekt eines männlichen Betrachters, der das Wesen des Phänomens „Frau“ durch Studien möglichst zahlreicher Repräsentantinnen dieser Art zu ergründen versucht (vgl. Kap. 3.6), das heißt, es geht Bunin nicht nur um die Darstellung des individuellen Charakters einer einzelnen Frau, sondern auch um allgemeingültige Aussagen zur Frau an sich. W. Lakschin vermutet hinter Bunins auffalliger Bevorzugung der Zeichnung der weiblichen Figuren folgende Ursache:

All diese Rusjas, Natalies und Galjas, die unzugänglichen Schönheiten der großen Welt, die einfaltigen Frauen vom Lande, die jungen Mädchen und frühen Witwen, Prostituierten und Damen von Welt, die Grafinnen und Zimmermädchen - sie alle werden insgeheim von [Bunin] geliebt. ${ }^{393}$

$\mathrm{Ob}$ es Liebe war, sei dahingestellt; zumindest war Bunin schlichtweg fasziniert vom anderen Geschlecht. In einer undatierten Notiz bringt er seine Verwirrung angesichts der offenbaren Unmöglichkeit, das Wesen der Frau zu fassen, zum Ausdruck:

Я по-прежнему чувствовал, что я чужой всем званиям и состояниям (равно как и всем женщинам: ведь это даже как бы и не люди, а какие-то совсем особые существа, живушие рядом с людьми, еще никогда никем точно не определенные, непонятные, хотя от начала веков люди только и делают, что думают о них). ${ }^{394}$

Trotz des hohen Individualisierungsgrads der einzelnen weiblichen Figuren und der daraus entstehenden verblüffenden Vielfalt läßt sich folgende allgemeine Feststellung machen: Es überwiegt ein dunkles Frauenbild, das vor allem im dritten Komplex verstärkt vertreten ist und dessen Bevorzugung unterstrichen wird mit dem Ausruf der Protagonistin

393 W. Lakschin. "Die letzte Begegnung zwischen Bunin und Tschechow". In: Kunst und Literalur 2 (1980): 218.

394 I. Bunin. .Zapisi”. op.cit.: 352. 
der Erzăhlung „Cistyj ponedel'nik“: „И потом, желтоволосую Русь я вообще не люблю“ (6: 401; vgl. auch Kap. 8.2.2). In 28 der 38 Erzählungen wird die Haar- bzw. Hautfarbe präzisiert ${ }^{395}$, in den übrigen 10 Erzählungen $^{396}$ finden sich keine diesbezüglichen Hinweise. Im allgemeinen sind die zentralen weiblichen Figuren entweder dunkelhaarig oder blond, rothaarige Protagonistinnen finden sich nur in den Erzählungen ,Muza“, "Galja Ganskaja“ und „Genrich“ sowie in "Baryšnja Klara“ (orange). Die Dominanz des dunklen Frauenbildes mit seiner ikonenhaften, alterslosen Schönheit führt Igor Karpov zurück auf die Tendenz Bunins, außergewöhnliche Menschen darzustellen, Personen, die in sich Vergangenheit und Gegenwart gleichermaßen vereinigten. ${ }^{397}$ Die These ist zweifelhaft, da sie nur auf wenige Figuren zutrifft; in der Regel stellt Bunin keine Ausnahmeerscheinungen dar, sondem Menschen in Ausnahmesituationen, die allein dadurch, daß sie im Fokus stehen, zu Ausnahmen werden. Der einzige überzeugende Beleg für diese These findet sich in der Erzählung „Cistyj ponedel'nik“: Die rätselhafte namenlose Protagonistin sieht nicht nur östlich-asiatisch aus, sondern hat auch ein starkes Interesse an der russischen Vergangenheit sowie an religiösen Fragestellungen; gleichwohl versteht sie die Freuden des weltlichen Lebens zu genießen: „Не понимаю, как это не надоесть людям всю жизнь, каждый день обедать, ужинать" - но сама и обедала и ужинала с московским пониманием дела“ (6: 399). In ihrem Äußeren wie auch in ihren Äußerungen scheinen sowohl der russische als auch der asiatische Frauentyp zusammenzufließen, in ihr verschmelzen Orient und Okzident, sie verkörpert die Komplexität des alten Rußland mitsamt seinen Widersprüchlichkeiten zwischen exzessivem Feiern und inbrüntiger Religiosität (vgl. Kap. 8.2.2).

Die Individualisierung der einzelnen Frauen erfolgt vor allem über eine reiche farbliche Ausgestaltung ihres Äußeren, aber auch über die Beschreibung unverwechselbarer, scheinbar nebensächlicher physischer Details, die Bunin mit dem Blick eines Malers in den Vordergrund stellt und in denen sich für den Betrachter vor allem die erotische Ausstrahlung

395 Ein heller Frauentyp dominiert in den folgenden Erzahlungen: „Muza“, „Gost"“, "Volki", „Tanja“,

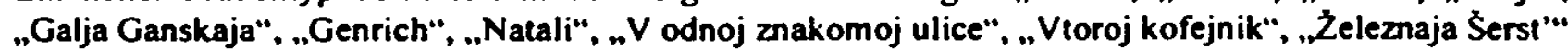
und "Voron". Dunkelhaarige Frauen bzw. Frauen mit einem dunklen Teint finden sich hingegen in diesen Erzahlungen: „Temnye allei“, „Stepa“, ..Pozdnij cas“”, „Rusja“, „Antigona”, .Vizitnye kartocki“, .Zojka i Valerija“, „V Pariže“, „Recnoj traktir“, „Nacalo“, „,Dubki““, „Baryšnja Klara“, „Kamarg”, ..Sto rupij“"...Mest'“. .Kaceli”" und „Cistyj ponedel'nik“".

396 Es handelt sich hierbei um die folgenden Erzahlungen: „Kavkaž, „Ballada“, „Krasavica”, „Durocka”,

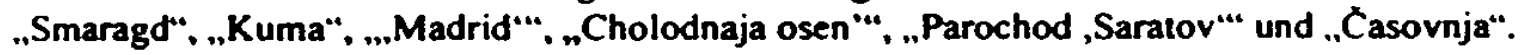

397 I. Karpov. Proza Ivana Bunina (ocerki avtorstva). Moskva, 1996: 58 
der jeweiligen Frau zu konzentrieren scheint. ${ }^{398} \mathrm{Zu}$ diesen Details gehören etwa auffallend lange Wimpern („Sto rupij“, 6:385), ein leichter Flaum über der Oberlippe („Temnye allei“, 6: 176; „Kamarg“, 6: 383), ein mit schwarzen Haaren bewachsener Leberfleck („Natali“, 6: 304), eine kleine Narbe am Mundwinkel („Volki“, 6:235) oder auch ein nacktes Knie, das durch den Spalt eines leicht geöffneten Morgenmantels zu sehen ist (,Parochod ,Saratov““, 6: 373). Offenbar getrieben von dem Wunsch, dem Rätsel „Frau“ auf die Spur zu kommen, porträtierte Bunin die Frauen hăufig in ihrer Nacktheit und setzte sich damit unter anderem dem Vorwurf aus, „sentimentale Alterserotik““399 zu verfassen (vgl. etwa Kap. 10. 2.1).

\subsubsection{Die weibliche Bloße}

Den weiblichen Körper gerade in seiner Nacktheit adäquat zu erfassen, war Bunin seit langem ein künstlerisches Anliegen, dessen Herausforderungen er sich jedoch nicht gewachsen fuhlte, wie eine Tagebuchnotiz vom 3. Februar 1941 bezeugt:

Часто думаю с удивлением и горем, даже ужасом (ибо- не воротишь!) о той тупости, невнимательности, что была у меня в первые годы жизни во Франция (да и раньше), к женщинам.

То дивное, несказанно-прекрасное, нечто совершенно особенное во всем земном, что есть тело женщины, никогда не написано никем. Да и не только тело. Надо, надо попытаться. Пытался - выходит гадость, пошлость. Надо найти какие-то другие слова. ${ }^{400}$

Dem zitierten Eintrag zufolge hat Bunin offenbar weder in der klassischen noch in der zeitgenössischen Literatur Vorbilder für seine Bestrebungen gefunden. Einzig in Maupassant fand er einen Geistesverwandten, der es wiederholt gewagt habe, unverhohlen von der

398 Vgl. hierzu auch J. Woodward. „The Evolution of Bunin's Narrative Technique“. In: Scando-Slovica 16 (1970). Im Rahmen seiner Analyse von Bunins Erzahltechnik stellt Woodward fest, daß "this technique of identifying a character by constant repetition with a specific physical feature was to become [...] a recurrent characteristic of his style" (S. 15).

399 W. Lakschin. „Die letzle Begegnung zwischen Bunin und Tschechow“. op.cit.: 217.

400 Zit. in: UB. 3.Bd. op.cit.: 81. In den Erzahlungen der Temnye allei gelingen ihm hochst differenzierte Frauenportrats, doch fur eine adaquate Beschreibung dieser fremdartigen Geschðpfe fehlen selbst dem Wortkunstler Bunin manchmal die Worte: „Красота, ум, глупость - все зти слова никак не шли $к$ ней, как не шло все человеческое [...] Едннственное, что шло к нея., была бессловесность“” (..Stо rupij”* 6: 385). 
Macht der Frau über den Mann zu schreiben. ${ }^{401}$ Eine Orientierung bei der Umsetzung seiner Bestrebungen, die dieser Macht zugrunde liegenden Ursachen in passende Worte zu fassen, bot ihm das Werk Maupassants jedoch offenbar nicht. Auch furr die naturalistischen Darstellungen der Frau und der körperlichen Liebe in Emile Zolas Roman Nana (1880) fand Bunin laut einer Notiz seiner Frau Vera aus dem Jahr 1939 nur kritische Worte:

Хвалил Зола за ум, за знание жизни - но ни художества, ни поэзии. [...] Ян находит, что в „Nana“ квинт-зссенция женщины известного типа - только желание, больше ничего, отсутствие жалости и какое-то романтическое стремление к бескорыстному чувству. ${ }^{402}$

In einem Gespräch mit Galina Kuznecova äußerte Bunin sich zur Darstellung der Frau in der zeitgenössischen Literatur. In ihrem Tagebuch hielt sie zusammenfassend fest:

И[ван] А[лексеевич] доказывал, что сейчас все стало грубее, что прежде достаточно было „кончика носка из-под женского платья для того, чтобы возбудить соответственные чувства, а теперь для того, чтобы меня возбудить, мне псказывают все - стараются бить в голове.“403

Die angeführten Zitate belegen klar, daß es Bunin keinesfalls um das Verfassen schlüpfriger erotischer Texte mittels anzüglicher Beschreibungen nackter Frauen ging; vielmehr beabsichtigte er zu ergründen, worin das rational nicht faßbare Rätsel Frau besteht und in welchen Formen sich die Anziehungskraft der Frau auf den Mann äußert. ${ }^{404}$ Der maßgebliche Auslöser scheint für Bunin im physischen Bereich zu liegen, denn der Mann in den Temnye allei begehrt in erster Linie den Körper der Frau ${ }^{405}$ und ist im Extremfall gar

$401 \mathrm{Vgl}$. den Tagebucheintrag Bunins vom 03.08.1917: „Продолжаю Мопассана. Места есть превосходные. Он единственный, посмевший без конца говорить, что жнзнь вся под властью женщнны" (zit. in: N. Smimov-Sokol'skij. „Poslednjaja nachodka". In: Novyj mir 10 [1965]: 216). Reverenz erweist Bunin dem bewunderten Schriftsteller in den Erzahlungen „Galja Ganskaja“ und .Antigona": Wahrend sich der Verfuhrer der jungen Galja in jungen Jahren als zweiter Maupassant in Liebesdingen betrachtete (6: 283), was sein Gesprächspartner auf Grund des Gehorten nicht bestätigen mag (6: 287), liest die Krankenschwester Antigona ein Buch des französischen Schriftstellers (6: 227).

402 Tagebucheintrag Vera Buninas vom 08.07.1939. Zit. in: $U B$. 3.Bd. op.cit.: 30 .

403 Tagebucheintrag G. Kuznecovas vom 27.02.1932. Zit. in: dies. Grasskij dnevnik. op.cit.: 241.

404 Auch anhand der noch existierenden Manuskripte (etwa im LRA) låßt sich dokumentieren, daß es Bunin nicht um das Verfassen erotischer Literatur ging (zumindest nicht primar), denn im Zuge des Schreibund Überarbeitungsprozesses einzelner Erzahlungen pflegte er zunachst verwendete eindeutige anatomische Beschreibungen zu streichen bzw. durch minder explizite Formulierungen zu ersetzen.

405 Wird das mannliche Verlangen primär durch optische Reize geweckt, so erfahrt es ein zusatzliches olfaktorisches Stimulans durch den spezifischen Geruch der jeweiligen Frau, der einerseits artifiziellen Ursprungs sein kann, wie beispielsweise in den Erzahlungen „V Pariže" (Pudergeruch, 6: 277 bzw. Seife, 6: 280) und „Baryšnja Klara“ (billiges Eau de Toilette, 6: 353), oder - in der Mehrzahl der Fame naturlich ist, wie etwa in "Muza" (frische Winterluft, 6: 197) und "Zojka i Valerija" (Eigengeruch der Haare, 6: 251). Die Farblosigkeit der männlichen zentralen Figuren setza sich in ihrer Geruchlosigkeit fort. Es finden sich nur wenige Geruche mannlichen Ursprungs in den Erzăhlungen der Temnye allei: For Rusja aus der gleichnamigen Erzahlung ist der Geruch der Mutze ihres Liebhabers ebenso bedeutungsvoll („А я так люблю тебя теперь, что мне нет ничего милее даже вот зтого запаха внутрн картуза. запаха твоей головы н твоего гадкого одеколона!“" 6: 217) wie der Geruch des Sommermantels des Verstorbenen fur die Protagonistin aus der Erzăhlung ..V Parize“" (6: 281). Femer werden der gesunde Schweißgeruch des Ehemanns der ..Kuma" erwahnt " $(6: 340)$ sowie der nach Pelz und

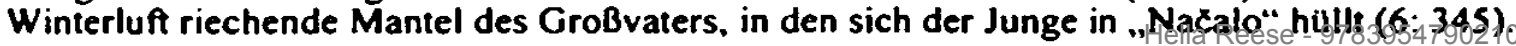


bereit, für die Berührung eines bestimmten Körperteils der Frau zu sterben, wie beispielsweise in der Erzählung „Natali“: „Когда я давеча смотрел на эту зеленую чесучу и на твои колени под нею, я чувствовал, что готов умереть за одно прикосновение $к$ губами, только к неи“ („Natali“, 6: 330). Diese Annahme wird bestătigt durch eine vergleichbare Vorgehensweise in den Erzählungen aus demselben Zeitraum sowie die Existenz zahlreicher Kurz- und Kürzestbeschreibungen von Frauen in Skizzenform (vgl. Kap. 3.6). Wie auch die Erzählungen der Temnyє allei dokumentieren sie das kennzeichnende Prinzip von Bunins Frauendarstellungen: Auf alles seiner Meinung nach Überflüssige sollte verzichtet werden, das Wesen, die Individualităt der jeweiligen Frau sollte mit Hilfe weniger Details skizziert und zum Leben erweckt werden, während Einzelheiten des sexuellen Akts bewußt ausgespart werden und das Nichtausgesprochene der Phantasie des Lesers überlassen wird, da nicht das Geschehen selbst im Mittelpunkt steht, sondern seine Auswirkungen auf die beiden Partner (vgl. Kap. 8.1.2).

Unter Berücksichtigung der angeführten Notizen und Äußerungen låß sich die These aufstellen, daß ein Ziel Bunins während der Arbeit an den Erzählungen der Temnye allei darin bestand, den weiblichen Körper in seinen vielerlei Ausprägungen und gleichermaßen in seiner Ursprungsform angemessen abzubilden. Derart intime Zeichnungen des weiblichen Körpers erscheinen im übrigen erstmals in Bunins Werk ${ }^{406}$ und sind ein Novum in der russischsprachigen Literatur.

Eine besondere Faszination übt die mit ihrer Toilette oder dem Auskleiden beschäftigte Frau auf den sie dabei beobachtenden Mann aus. Dabei neigt Bunin bei den Beschreibungen des weiblichen Körpers keineswegs zu schönenden Darstellungen, wie die eingangs des Kapitels zitierte Notiz vermuten lassen könnte. Sein unbestechlicher Blick nimmt wenn nötig oder gewünscht - jede Einzelheit wahr:

Телом она оказалась лучше, моложе, чем можно было думать. Худые ключицы и ребра выделялись в соответствии с худьм лицом и тонькими голенями. Но бедра были даже крупны. Живот с маленьким глубоким пупком был впалым, выпуклый треугольник темньх красивых волос под ним соответствовал обилию темных волос на голове. („Vizitnye kartoxki“, 6: 240).

Ohne Verschleierung körperlicher Unzulänglichkeiten und mit geradezu erbarmungsloser Genauigkeit wird der gealterte Körper einer Sankt Petersburger Kurtisane gezeichnet. der trotz der unübersehbaren Spuren, die das Leben in ihn geprägt hat. wilde und am Ende mörderische Lust in ihrem Freier weckt: 
Он осмелел и распахнул халат с драконами на большом, полногрудом белом теле с густыми черными волосами ниже широкого волнистого живота. „Она эже старая", подумал он, взглянув на ее пористое меловое лицо, густо засыланное пудрой, на оранжевые губы в трешинках, на страшные налепленные ресницы. на широкий серый пробор среди плоских волос цвета ваксы, но уже совсем жатея от величины и белизны этого голого тела, круглых грудей, красные соски которых были почему-то очень малы, и мягкого зада, тяжело лежащего на его коленях. („Baryšnja Klara“, 6: 353).

Mehr oder minder ausfuhrliche Beschreibungen halbbekleideter Frauen bei der Toilette, beim Baden ${ }^{407}$ oder vor der körperlichen Intimität fimden sich unter anderem auch in den Erzählungen „Rusja“, „V Pariže“, „Galja Ganskaja“, „Genrich“, „Natali“, „Mest”“ und „Cistyj ponedel'nik“. Besondere Beachtung schenkt Bunin dabei dem Lösen der Frisur als einer intimen Geste, die den Übergang vom öffentlichen Raum in die Privatsphäre kennzeichnet und dem Beischlaf vorausgeht, wie sie etwa in den Erzählungen „Vizitnye kartocki“ und „Cistyj ponedel'nik“ beschrieben wird: „Она вынула шпильки, волосы густо упали на ее худую спину в выступающих позвонках“ (6: 240) bzw. „она [...] стояла [...] расчесывая черепаховым гребнем черные нити длинных висевших вдоль лица волос“ (6: 409).

Bereits während der Arbeit an dem Buch scheint Bunin vorausgeahnt zu haben, daß seine freimütigen Schilderungen des weiblichen Körpers auf Kritik bei den Zeitgenossen stoßen würden (vgl. Kap. 10.1), obwohl sie die Schwelle zur Pornographie keinesfalls überschreiten ${ }^{408}$ und auf detaillierte bildhafte Beschreibungen sexueller Kontakte verzichten; als sein Sprachrohr für eine vorwegnehmende Rechtfertigung dient vermutlich der Protagonist der Erzählung "Genrich", der sich darüber empört, daß im Umgang mit der Darstellung weiblicher Nacktheit Maler bzw. Bildhauer und Schriftsteller mit zweierlei $\mathrm{Maß}$ gemessen würden:

[...] „жены человеческие, сеть прельщения человеком“! Эта „сеть“ нечто понстине неизъяснимое, божественное и дьявольское, и когда я пишу об этом,

407 Badende nehmen unter den nackten Frauen eine Sonderstellung ein, denn mit der badenden Frau werden in der russischen Literatur nicht nur Reinheit und Urspronglichkeit in Verbindung gebracht, sondem auch das Motiv der Rusalka assoziiert. In den betreffenden Erzahlungen der Temmye allei steht der erstgenannte Aspekt im Vordergrund: Die badenden Protagonistinnen der Erzahlungen ..Rusja“ und .Natali" wecken positive und erotische Gefuhle beim jeweiligen Erzathler. Das Bild der schaumgeborenen Venus ließe sich am ehesten der Protagonistin der Erzahlung ..Mest'“ zuordnen: Mit ihren täglichen Bădem im Meer scheint sich die betrogene Frau von ihrer Vergangenheit reinwaschen zu wollen. Das Attribut der den Jangling ins Verderben lockemden Sirene kommt einzig Valerija aus der Erzahlung .Zojka i Valerija" zu, die sich zunachst nach einem gemeinsamen Badevergnúgen die Zartlichkeiten des jungen Mannes gefallen laßt, bevor sie ihn zuruckweist und letzalich in den Selbstmord treibt.

408 Auf bemerkenswerte Weise gelingt es Bunin, in seinem Vokabular weder obszorn noch medizinischtechnisch zu werden. Im Gegenteil: Seine prazisen Schilderungen sind in ihrer Farbigkeit, ihrer Konzentration auf Details und durch ihre teils originellen Vergleiche ausgesprochen poetisch 90210 
пытаюсь выразить его, меня упрекают в бесстыдстве, в низких побуждениях ... Подлые души! Хорошо сказано в одной старинной книге: „Сочинитель нмеет такое же право быть смелым в своих словесных изображениях любви н лиц ее, каковое во все времена предоставлено было в этом случае живописцам и ваятелям: только подлые души видят подлое даже в прекрасном или ужасном.“ („Genrich“, 6: 295).

Diese Uberlegungen greift Bunin einige Jahre spăter wieder auf, nachdem er aus dem Freundes- und Bekanntenkreis auf einige Erzählungen der Temnye allei negative Resonanz erhalten hat (vgl. Kap. 10.1.1) und seiner Freundin Tèffi in einem Brief vom 23. Februar 1944 die rhetorische Frage stellt, „[...] почему живописцы и ваятели могут изображать женское тело, например, или всяких сатиров и фавнов с крайней ,натуралистичностью', а мы, писаки, не можем? ${ }^{409}$ Den moralisierenden Einwänden zum Trotz hălt Bunin am bereits eingeschlagenen Weg fest, wobei es ihm gelingt, auch bei naturalistischer Darstellungsweise die Verwirrung der männlichen Protagonisten angesichts des fremdartigen Wesens der Frau zum Ausdruck zu bringen, die gleichsam einer anderen Sphäre als der Mann angehört: „поистине была она как бы с какой-то другой планеты“, „Sto rupij“, 6:385). Diese liegt zwar nicht außerhalb des Universums, gleichwohl unterscheidet sich die Frau durch ihr Eingebundensein in die Natur deutlich vom Mann.

\subsubsection{Die Frau und die Natur}

Alle zentralen Figuren in den Temnye allei sind den elementaren Kräften des Lebens bzw. des Kosmos ausgesetzt (vgl. Kap. 8.1.3); eine besonders enge Beziehung besteht jedoch zwischen den weiblichen Figuren und der Natur. Die bereits erwähnte „Bodenstăndigkeit“ der Frauen und ihre Bindung an die Erde spiegelt sich wider in der Hăufigkeit der Erwăhnungen von Füßen und Beinen zentraler weiblicher Figuren in den Temnye allei und ihrer Funktion als erotisches Signal für die männlichen Protagonisten: „ступни в открытых лаковых туфлях“ (,Muza“, 6: 197); „босые ноги в туфлях“ (,Antigona“, 6: 226); „Он [...] чувствовал ее озябшие босые ноги“ („Tапjа“, 6:266). Die Aufmerksamkeit der männlichen zentralen Figuren wird zudem gefesselt durch den Anblick nackter Fersen („Baryšnja Klara“, 6: 352; „Vtoroj kofejnik“, 6: 363; „Parochod ,Saratov““, 6: 373), zierlicher Knöchel („Nacalo“, 6: 345; ,.Mest’“, 6: 389), auffalligen Schuhwerks (..Kamarg“, 
6: 383; „Sto rupij“, 6: 385) oder lackierter Fußnăgel („Sto rupij“, 6: 385). Die Füße einer Frau zu küssen kann für den Mann entweder von einem nie gekannten Glücksgefuhl begleitet sein wie in der Erzählung „Rusja“ („он кинулся разувать и целовать ее мокрые узкие ступни - подобного счастья не было во всей его жизни“, 6: 210) oder Ausdruck tiefer Dankbarkeit sein wie in der Erzählung „Pozdnij Łas“: „Если есть будущая жизнь и мы встретимся в ней, я стану там на колени и поцелую твои ноги за все, что ты дала мне на земле“ (6: 205).

Die Einbindung der Frau in die Natur verdeutlicht Bunin auch mit der Erwăhnung des weiblichen Zyklus in den drei Erzählungen „Genrich“, „Natali“ und „Cistyj ponedel'nik“ (vgl. Kap. 4.3.3). Mešcerskijs Cousine Sonja macht keinen Hehl aus ihrer Unpäßlichkeit: „Я заболела. У меня зто проходит всегда очень тяжело, дней пять лежу“ („Natali“, 6: 315). In der Erzählung „Genrich“ hat die indirekte Erwähnung der Monatsblutung auf der Ebene der Nebenfiguren eine andere Konnotation: Die Bemerkung der jungen Geliebten des Protagonisten (,Знаешь, я, слава Богу, ночью заболела ...“, 6: 291) kündet von der Erleichterung darüber, nicht schwanger zu sein.

Noch vor der Veröffentlichung der Erzählungen erhielt Bunin von Boris Zajcev ${ }^{410}$ eine negative Reaktion auf dieses literarische Wagnis, der er in seinem Antwortbrief vom 3. Dezember 1943 vehement entgegentritt. Bunin plädiert für einen offenen Umgang mit der Menstruation und zieht die Bibel als Referenzwerk heran:

А что до „менструаций“ [...], думаю, что ты неправ. Что ж тут не эстетично? „И сказала Рахиль Лавану: прости, господин, не могу встать с седел навстречу тебе, ибо у меня обыкновенное женское ..." И подумать только, какую роль играло это „обыкновенное женское“ в любовной жизни каждого из нас и в таковой же у наших женщин! По-моему, про насморк и про то, как „Иван Иваныч шумно высморкался в клетчатый платок“, писать гораздо не жтетичнее. ${ }^{411}$

Auch Natal'ja Ivanovna Kul'man, eine Bekannte Zajcevs, der dieser ohne Bunins Wissen und zu dessem großen Verdruß einige der ihm anvertrauten Erzăhlungen zeigte (vgl. Kap. 10.1.1), äußerte sich empört über die Erwăhnung der Menstruation in der Erzăhlung "Natali", die ihr davon abgesehen sehr gut gefallen hat: „Но зачем Вы портите его тру6онатуралистическими строками, которые решительно ничего не дают для психологии действующих их лиц?“12 Bunin läßt sich durch das Unverständnis seiner Kritiker jedoch nicht beirren und greift das Thema auch in der später entstandenen Erzählung „Cistyj

$410 \mathrm{Vgl}$. Brief Zajcevs an Bunin vom 28.11.1943, auszugsweise zitier in Kap. 8.1.2. Zit. in: „Pis'ma B. Zajceva I. i V. Buninym". In: Nz 146 (1982): 122.

411 Zit. in: „Pis'ma I. Bunina k B. Zajcevu“. In: Nz 137 (1979): 128.

412 Brief Natal'ja Kul'mans an Bunin vom 14.02.1944. LRA. MS.1066/3412. 
ponedel'nik“ wieder auf, deren Protagonistin sich für die Dauer ihrer Menstruation ebenfalls von der Außenwelt zurückzieht: „[...] потому что каждый месяц она дня три-четыре совсем не выходила и не выезжала из дому, лежала и читала [...]“ (6: 401).

Die enge Einbindung der Frau in die Natur spiegelt sich zudem in den zahlreichen Vergleichskonstruktionen wider, deren Konstituenten Bunin der Fauna ${ }^{413}$ entnahm. Die folgende Auswahl an diesbezüglichen Beispielen dokumentiert dies eindrucksvoll:

с тре угольным, как у гусыни, животом (,Temnye allei“, 6: 176); плотная, как рыба, дева („Gost'“, 6: 232); я всегда сплю, как сурок („Vizitnye kartocki“, 6: 237); раскрывала [рот], как галченок („Тапја“, 6: 266); косо разведет в разные стороны углы рук и ног, совсем как лягушка (,Natali“, 6: 308); руку похожей на шею лебеда („Natali“, 6: 323); как серая змея („Parochod ,Saratov““, 6: 373); с обезьяней быстротой и ловкостью („Kamarg“, 6: 383); подобие тех райских бабочек, что так волшебно мерцают на райских индийских иветах („Sto rupij“, 6: 385); ведь и у курица есть сердще! („Mest'“, 6: 394); мягко блестящие, ках черный соболй мех, брови („C'istyj ponedel'nik“, 6: 399-400). ${ }^{414}$

Das körperliche Beisammensein eines Liebespaares erfolgt bemerkenswert oft inmitten der Natur, in der in zahlreichen Erzählungen auf mysteriöse Weise die Fauna präsent ist. In der Erzăhlung „Kavkaz" etwa ist das in nächtliches Dunkel gehüllte Haus des Liebespaares umgeben von den Geräuschen der südländischen Tierwelt - das Brüllen der Panther und das Heulen der Schakale scheinen eine ahnungsvolle, wilde Manifestation männlicher Begierde zu sein: ${ }^{415}$

Тогда в лесах просыпались и мяукали орлята, ревел барс, тявкали чекалки ... Раз к нашему освещенному окну сбежались целая стая их,- они всегда сбегаются в такие ночи к жилью,- мы открыли окно и смотрели на них сверху, а они стояли под блестящим ливнем и тявкали, просились к нам ... (6: 183).

413 Den Vergleich einer Frau mittels der Flora entlehnten Konstituenten nimmt Bunin lediglich „Galja Ganskaja" vor. indem die Protagonistin zum einen mit Blumen (...Вот и вы вся такая же, как эти фналкн““, 6: 285), zum anderen mit einer Pappel (.яk та тополя“, 6: 286) verglichen wird.

414 Es soll nicht unerwahnt bleiben, daß auch fur die mannlichen Figuren Vergleiche aus der Tierwelt gewahlt werden, wobei diese sich im Gegensatz, zu der Vielfalt bei den Frauendarstellungen allerdings auf die Hervorhebung eines wachen Blicks beschrănken. Zu diesen Vergleichen załhlen beispielsweise Levickijs Habichtaugen (.,ястребиные глаза“, „Zojka i Valerija“, 6: 243), die Gazellenaugen eines Hoteldieners in ..Genrich" (.,азельими глазами“, 6: 299), die Bărenăuglein des Wirtes in ..Recnoj traktir" (.медвежьими глазками", 6: 336-337). die gelben Eulenaugen des Begleiters der unbekannten Schønen in ..Nacalo" (.желтыми совиньими глазами". 6: 343) oder die Rabenaugen des Vaters aus der Erzahlung "Voron" (.блестящнмн вороньнми глазамн“", 6: 377), der das Entspinnen zarter Bande zwischen seinem Sohn und der jungen Kinderfrau argwönnisch verfolgt. In diese Rubrik fallt auch die eifersuchtige Wachsamkeit des Starost aus ...Dubki"“ (.,30pok, кak oper", 6: 348).

Diese auffallige Konzentration bei den Vergleichskonstruktionen unterstreicht den visuellen Aspekt der Temnye allei und hebt die Betonung des mannlichen Blicks auf die Frau hervor. Dieses Verfahren findet seine Entsprechung in den detaillierten Schilderungen des weiblichen Korpers durch die Augen der fast ausnahmslos mannlichen Erzahler.

$415 \mathrm{Vgl}$. C. Hauchard. „La Prose de I. A. Bounine ...”. op.cit.: 297. 
Ähnliches ist für die Erzählung „Volki“ zu konstatieren: Die von dem in einer Kutsche sitzenden Liebespaar als Bedrohung empfundene Anwesenheit von Wölfen läßt an die bildliche Umsetzung der machtvollen und dadurch einschüchternd wirkenden Begierde, die aus dem Inneren herauszudrängen trachtet, denken (6: 235).

Mit Betonung des akustischen Elements ist eine Passage in der Erzählung "Rusja“ gestaltet, in der die unsichtbare, aber durchaus vernehmliche Präsenz der tierischen Bewohner eines modrigen Sumpfes geschildert wird:

[...] таннственно, просительно ныли невидимые комары-и летали, летали с тихом треском над лодкой и дальше, над этой по-ночному светящейся водой, страшные, бессонные стрекозы. И все где-то что-то шуршало, ползло, пробиралось ... (6: 215).

In diesem Ausschnitt fält die Anthropomorphisienung der Tierwelt auf, mit deren Hilfe Bunin den Allzusammenhang der Schöpfung verdeutlicht und die auch für weitere Erzählungen charakteristisch ist: In der Erzählung „Muza“ ist das Gezwitscher von Drosseln und Fliegenschnäppern durch menschliche Sprechweisen gekennzeichnet („цокати птички, называемые мухоловками, хрипло трещали дрозды“, 6: 199), der Erzăhler von „Pozdnij cas" fühlt sich beim Anblick eines Schwarms Tauben an weibliche Umtriebigkeit erinnert („женственно“, 6: 206), während in der Erzählung „Natali“ in der Abenddämmerung die Frösche schläfrig murmeln („дремотно журчали лятушки“, 6: 313) und die Zikaden in „Mest”“ höchst eigentümliche Geräusche von sich geben (,цикады [...] пилили, скрежетали все настойчивее, яростней“, 6: 392). Ein Großteil der akustischen Untermalungen aus der Tierwelt, die stets im Zusammenhang mit einer weiblichen Figur auftreten, besteht aus dem Gezwitscher von Vögeln, für die Bunin eine besondere Vorliebe hegte: „Опять думал нынче: прекраснее цветов и птиц в мире ничего нет. Еще бабочек.““16 Getreu seiner Liebe zum Detail beschränkt er sich auch hier nicht auf die Erwăhnung von Vơgeln im allgemeinen, sondern präzisiert die einzelnen Vogelarten: So zwitschern etwa Stare in „Galja Ganskaja“ (6: 284), lärmen Saatkrähen und Pirole in „Natali“ (6: 309 und 314) und krächzen Dohlen im Pensionsgarten in der Erzählung „Mest”“ (6: 388). Ebenfalls nur zu hören ist der schmachtende Gesang der Nachtigallen, der in der Erzăhlung „Antigona“ mit der würzigen Luft aus dem nächtlichen Garten in das Schlafzimmer des schlaflosen jungen Mannes hereinströmt, den die Gedanken an die Krankenschwester seines Onkels keine Ruhe finden lassen (6: 225).

416 Tagebucheintrag Bunins vom 23.05.1942. Zit. in: UB. 3.Bd. op.cit.: 136. Vgl. in diesem Zusammenhang auch den Vergleich der Protagonistin aus der Erzahlung "Sto rupij“ mit einem Schmetterling (6: 385). 
Symbolkraft haben überdies der Hahn in der Erzăhlung „Stepa“ (6: 194), dessen Krăhen an das biblische Motiv des Verrats gemahnt, sowie das scheue Kranichpaar in der Erzählung „Rusja“, das nur das junge Mädchen in ihrer Nähe duldet (6: 216-217): Kraniche gelten als Symbol für Wachsamkeit, die bei dem jungen Liebespaar nicht in ausreichendem Maße vorhanden war und zu ihrer Entdeckung führte.

In den übernatürliche Elemente enthaltenden Erzăhlungen ist die Frau wiederum geradezu komplizenhaft mit wilden Tieren verbunden. In der Erzählung „Ballada“ beispielsweise wird eine junge Frau von einem Wolf gerettet, der ihren lüsternen Verfolger mit einem gezielten $\mathrm{Biß}$ in die Kehle tötet (6:189). In der Erzählung ,Železnaja Šerst”“ hingegen erscheint die Verbindung zwischen den weiblichen Protagonisten und der Tierwelt am gelungensten: Sie enthält Hinweise auf die sexuelle Vereinigung von Frauen mit Waldgeistern bzw. einem Bären, dessen Reaktion auf den Selbstmord einer jungen Frau menschliche Züge trägt.

In zahlreichen Erzählungen sorgt die Erwähnung von Pelzen in jeder denkbaren Form, sei es als Mantel, Mütze oder gar nur als Kragenaufschlag, für die Präsenz einer gewissen animalischen Sinnlichkeit und stellt auf diese Weise auch im großstädtischen Raum eine Verbindung zur Natur her. In der Regel wird die Pelzart präzisiert, und auch hier läßt sich eine unglaubliche Vielfalt konstatieren, denn Bunin vermeidet weitestgehend Wiederholungen und stattet seine Protagonisten - in der Überzahl die weiblichen zentralen Figuren-mit Pelzen aller denkbaren Arten aus, von Biber („бобровый воротник“, „Cistyj ponedel'nik“, 6: 399) und Polarfuchs (.в ночных туфлях, отороченных песцом“, „Genrich“, 6: 295) über Eichhörnchen („поддевку на лисьем меху“, „Тапја“, 6: 262) bis zu Hermelin („горностаевая горжетка“, „Baryšnja Klara“, 6: 350) und Zobel („,соболью шу6ку“, „Kuma“, 6: 341). Die kapriziöse Li aus der Erzählung „Genrich“ etwa erscheint in einer eleganten Persianerausstattung: ,[...] в прямой черно-маслянистой каракулевой шубке [...] держа руки в большой каракулевой муфте [...]“ (6: 292). In der Erzăhlung „Nacalo“, in der keinerlei körperliche Vereinigung stattfindet, ist die erwachende Sexualität des Jungen symbolträchtig sowohl mit einem alten Pelzmantel seines Großvaters, in den er sich während der Schlittenfahrt einhullt, verbunden als auch mit der dabei erwachenden Erinnerung an den scharfen, raubtierhaften Geruch des Fells einer erlegten Wollfin. der ihm im Gedächtnis geblieben ist (6: 345). Tote und lebende Pelztiere haben dieselbe Funktion: In der Erzählung „Antigona“ steht ein ausgestopfter Bär im Vestibül des Anwesens (6: 223), während in „Tanja“ ein gefangener Fuchs in einer Grube im Hof liegt (6: 269). 


\subsection{Die Figurenkonstellationen}

In den Erzăhlungen der Temnye allei ist die Anzahl der handlungstragenden Figuren auf ein Minimum beschränkt: pro Erzählung beläuft sie sich auf höchstens drei Personen, die einander stets nach einem bestimmten Schema zugeordnet sind. Der Grund für diese Reduzierung liegt in der Wahl des dominierenden thematischen Schwerpunkts ,heterosexuelle Liebesbeziehung. ${ }^{417}$

21 Erzählungen haben eine Liebesbeziehung gleich welcher Art zwischen einem Mann und einer Frau zum Thema ${ }^{418}$; die übrigen Erzählungen schildern Dreiecksbeziehungen 14 von ihnen stellen eine Frau zwischen zwei Männer, und lediglich in drei Erzählungen bildet der Mann den Mittelpunkt unterschiedlich gestalteter Dreierbeziehungen: In „Rusja“ fuhlt sich ein Mann mittleren Alters derart lebhaft an seine Jugendliebe erinnert, als er mit seiner Ehefrau auf der Durchreise die Stätte seines ersten Liebeserlebnisses passiert, daß selbst die nur in der Erinnerung präsente Rusja als Konkurrenz für die Gattin angesehen werden muß, da der Mann geradezu aggressiv auf ihre neugierigen Nachfragen reagiert. Der junge Levickij (,Zojka i Valerija“) wiederum wird zwischen höchst unterschiedlichen Gefühlen für die titelgebenden zentralen Figuren hin- und hergerissen, denen er sich letztlich nicht mehr gewachsen fühlt. Unter einem ähnlichen Konflikt leidet auch Mešcerskij in „Natali“: Während er seine ersten sexuellen Erlebnisse mit seiner Cousine Sonja teilt, verliebt er sich gleichzeitig in ihre Freundin Natali.

In der sowjetischen Sekundärliteratur wird mehrfach darauf hingewiesen, daß Bunin die Figurenkonstellation innerhalb eines sozialen Abhängigkeitsverhältnisses zu bevorzugen schien. ${ }^{419}$ Eine intime Beziehung zwischen einem „Barin“ und einer Dienstmagd wird indessen in nur sieben Erzählungen thematisiert. Während man in den Erzählungen „Stepa“, „Durocka“, „Gost”“ und „Vtoroj kofejnik“ nicht umhin kann, die Geschehnisse als Vergewaltigungen zu bezeichnen (und in "Tanja" zumindest den ersten sexuellen Kontakt), sind die Vorkommnisse in den übrigen Erzählungen nicht klar einzuschätzen. Der Gang der weit zurückliegenden Ereignisse in der Erzählung „Temnye allei“ liegt im

417 Eine homoerotische Beziehung zwischen zwei Frauen wird lediglich auf der Ebene der Nebenfiguren in der Erzathlung ....Madrid '." thematisiert (6: 355).

418 Folgende Erzahlungen fallen in diese Kategorie: „Temnye allei“, ..Stepa“. .Pozdnij Cas“, ..Durozka“, „Antigona“, .,Smaragd“, „Gost”“, „Volki“" .,Tanja“, „V Parize”, „Galja Ganskaja”, „V odnoj znakomoj ulice“, „Reěnoj traktir", .Baryšnja Klara“, .,Madrid"“., „Vtoroj kofejnik“, „Cholodnaja osen”“. „Kamarg“" ..Kaceli“, ..Cistyj ponedel'nik“" und .Casovnja“".

419 Vgl. z.B. V. Gejdeko. A. Cechov i Iv. Bunin. Moskva, 1976: 243; M. lofev. Profili iskussiva. op.cit.: 283. 
dunkeln, deutet jedoch auf eine keinesfalls erzwungene Beziehung hin, und in ,"Dubki“c bleibt wegen der überraschenden Rückkehr des mißtrauischen Ehemanns keine Zeit für intime Zärtlichkeiten, die zudem von der Frau initiiert wurden. Da Erzählungen dieses Inhalts somit nur ein knappes Siebtel aller Erzählungen stellen, muß vor allem M. Iofev, der von einer Bunin stăndig interessierenden Beziehung spricht ${ }^{420}$, widersprochen werden. Erzählungen dieses Typs sind weniger als Umsetzung von Allmachtsphantasien eines dünkelhaften Vertreters des verarmten Landadels zu betrachten, denn vielmehr als Varianten möglicher Beziehungskonstellationen zwischen Mann und Frau und tragen überdies zur Schaffung eines russischen, vorrevolutionären Ambientes bei.

Charakteristisch indessen an Bunins Darstellung der Vergewaltigungen ebenso wie der Morde an den Frauen in den Erzählungen „Genrich“, „Dubki“", „Baryšnja Klara“ und „Parochod ,Saratov“” ist die Tatsache, daß er sie vollkommen wertfrei präsentiert. So fühlen sich in seiner Darstellung zum einen die Opfer der Vergewaltigungen - wenn auch teilweise nach anfänglichem Schreck - nicht mißbraucht bzw. söhnen sie sich rasch mit dem Geschehnis aus und scheinen weder Vergewaltiger noch Mörder ein Schuldbewußtsein zu verspüren, treffend versinnbildlicht in dem gleichgültig wirkenden jungen Offizier, der nach dem Mord an seiner Geliebten gemeinsam mit anderen Gefangenen nach Vladivostok verbracht wird: „... он пристально смотрел на горбами летяшую глубоко внизу [...] густо-синюю волну и от времени до времени поплевывал туда“ („Parochod ,Saratov'“, 6: 376).

Durch diese Art der Präsentation erweckt Bunin den Eindruck, als seien die zentralen Figuren allesamt Opfer - Opfer ihrer unterschiedlichen Leidenschaften, denen sie vollkommen machtlos ausgeliefert sind, und somit bar jeder Verantwortung. Auch sind keineswegs stets die Frauen in der offensichtlichen Opferrolle, wenn auch derartige Konstellationen zugegebenermaßen in der Minderzahl sind: So hat die herzlose Stiefmutter aus der Erzählung „Krasavica“ ihren Ehemann fest im Griff, während in der Erzăhlung „Zojka i Valerija" sowohl die minderjährige Zojka als auch die erwachsene Valerija wissen, wie sie Levickij als Objekt ihrer Begierde in ihrem Sinne zu manipulieren haben. Die Protagonistin in „Mest" läßt sich in vollem Bewußtsein der zukünftigen Geschehnisse erneut auf eine Affäre mit mutmaßlich frustrierendem Ausgang ein, und die junge Frau in „Čistyj ponedel'nik" plant mit Bedacht die Liebesnacht mit ihrem jungen Verehrer, ohne daß dieser auch nur ahnt, daß es bei dieser einen intimen Begegnung bleiben wird. Ob in Form reiner Begierde, tief empfundener Liebe oder unvermittelt aufflackernden Hasses - der 
Blitzschlag einer emotionalen Aufwallung triff in den Erzählungen der Temnye allei beide Geschlechter in den unterschiedlichsten Konstellationen gleichermaßen.

\subsection{Speisen und Getränke als Sinnbilder der Lebenslust und des Lebenshungers}

Die Funktion des Nahrungsmittelgenusses in den Temnye allei geht über die bloße Darstellung der Stillung elementarer menschlicher Bedürfnisse hinaus; die einzelnen Genußmittel wurden dabei jedoch nicht unter bestimmten semantischen Gesichtspunkten ausgewăhlt. Festgelegte Essenszeiten greifen als ordnende Instanz in nahezu jeder Erzählung in den Tagesablauf ein, so daß sich eine Erwăhnung von Uhrzeiten erübrigt. Zudem kann eine gemeinsam eingenommene Mahlzeit den Rahmen für eine Binnenerzählung bilden: So erzăhlt ein Maler einem Bekannten anläßlich gemeinsam verbrachter Stunden in einem Pariser Café von einer lang zurückliegenden Romanze („Galja Ganskaja“), wăhrend der Protagonist der Erzăhlung „Rečnoj traktir" nach einem Abendessen in einem Moskauer Restaurant bei Wein und Wodka seiner Erinnerung an eine lang zurückliegende, ihn offensichtlich noch im Rückblick tief bewegende Begegnung mit einem jungen Mädchen freien Lauf läßt.

Wesentlich häufiger jedoch hat der Verzehr von Speisen und Getränken die folgende Funktion: In zahlreichen Erzählungen bilden mehr oder minder opulente Mahlzeiten den Auftakt bzw. das Nachspiel eines sexuellen Beisammenseins, in anderen substituieren sie diese. ${ }^{421}$ Hierbei reicht die Palette von kleineren Imbissen bis hin zu mehrgängigen Menüs. In einigen Erzăhlungen werden zudem typisch russische Gerichte verzehrt (z.B. im russischen Speiserestaurant in „V Pariže“), denen eine nicht zu unterschätzende Funktion der Erinnerung an die verlorene Heimat zukommt (vgl. Kap. 8.2.1).

In einigen Erzählungen werden nur Früchte verzehrt, bei deren Auswahl Bunin stark variiert. Der rätselhaften Protagonistin Muza aus der gleichnamigen Erzählung gelüstet es nach Äpfeln (6: 198), ein Wunsch, dem durch die Ähnlichkeit mit dem Paradiesapfel eine gewisse Symbolhaftigkeit nicht abgesprochen werden kann, zumal der Protagonist durch Muza ins Verderben gestürzt wird. In der Erzählung .,Madrid““ werden ebenfalls Äpfel verspeist (6: 359), während die gealterte Kurtisane aus der Erzählung „Baryšnja Klara“ in Anwesenheit ihres ungeduldigen Freiers ungeruhrt in eine Birne beißt (6: 353). Auch die 
Journalistin Genrich stellt in der gleichnamigen Erzählung einige Birnen an den Rand des Schlafwagenbettes (6:295). In zwei weiteren Erzählungen, „Zojka i Valerija“ und "Kuma“, ist die jeweilige Dame des Hauses in Anwesenheit des begehrten Mannes mit dem Putzen von Kirschen (6: 248) bzw. Beeren (6:340) beschäftigt. Die Verweigerung des Genusses einer Mehlspeise mit Kirschen wiederum, die die kleine Lilja aus der Erzahlung „Voron“ wutentbrannt ablehnt (6: 380), sowie ihre Erkrankung nach dem Verzehr einer zu großen Menge von Himbeeren (6: 381) tragen zu; Annäherung ihres Bruders an die junge Gouvernante bei.

Neben Mahlzeiten, die in größerem Kreise eingenommen werden, wie beispielsweise das Abendessen in der Erzählung „Antigona“ (6:225), in dessen Verlauf der Student unablässig an die attraktive junge Krankenschwester denken muß, sind Mahlzeiten intimeren Charakters, die ein (küntiges) Liebespaar gemeinsam und ungestört zu sich nimmt, ungleich bedeutungsvoller. Hierzu ist etwa das Picknick in der Erzählung "Kavkaz" zu zählen, das unter freiem Himmel genossen wird (6:182). Zwei einander entsprechende Mahlzeiten, die unter jeweils anderen Umständen und Vorzeichen verzehrt werden, sind in der Erzählung „Natali“ zu finden: Das leichte Abendessen, das der Protagonist Mešcerskij am Abend seiner Ankunft im Hause seines Onkels zu sich nimmt, geht einer vielversprechenden Umarmung mit seiner Cousine Sonja voraus (6: 303) und der Verabredung für ein zärtliches Beisammensein am folgenden Tag, während ein anderer Abendimbiß einige Jahre später in Gesellschaft der geliebten Natali, bei dem er jedoch nicht einen Bissen herunterbringt, den Auftakt zur Erfullung seiner Liebesträume bildet (6:328), die nahezu unmittelbar nach jenem ersten Abendessen in ihm erwachsen waren.

Umfang und Bestandteile der kredenzten Mahlzeiten sind stets dem sozialen Status der gastgebenden Frau angepaßt: In der Erzählung „V odnoj znakomoj ulice“ wird der Protagonist von dem ihn liebenden Mädchen mit Käsebroten bewirtet (6: 332); Anfisa erwartet ihren Gast zu einem Rendezvous mit Nüssen und kleinen Pasteten („Dubki““, 6: 348); in der Erzählung „Kuma“ soll das deftige Frühstück im Gefolge der Liebesnacht zugleich Auftakt sein für weitere Treffen, ist aber das Abschiedsessen (6: 342), was allerdings nur dem fortstrebenden Mann klar ist, während die Frau Zukunftspläne schmiedet. In der Erzählung „Galja Ganskaja“ wird eine Einladung zu Gebăck und Portwein gar zu einem Synonym für ein intimes Beisammensein: Der ersten Einladung zu einem kleinen Imbi $\beta$ war Galja bereitwillig gefolgt (6:285) - verzehrt wurde indessen nichts, so daß sich bei der nächsten Einladung dieser Art (6: 287) beide Beteiligten darüber im klaren waren, daß sie nur als Vorwand für den Austausch von Zärtlichkeiten dient. 
Geistige Getränke, vor allem Weine, Wodka und Liköre, bilden einen festen Bestandteil der Mahlzeiten in den Temnye allei; selten jedoch wird der Alkohol bewußt pur getrunken (und nicht unbedingt genossen): In der Erzählung ,Natali“ dient der in Teetassen heruntergestürzte Cognac Mešxerskij dazu, seinen Liebesschmerz zu ertränken (6: 324), in „Genrich" trinkt der ungeduldig auf seine Geliebte wartende Protagonist Cognac, Gin und Whisky in dem hoffnungslosen Unterfangen, seine Eifersucht und Enttäuschung zu dämpfen (6: 300), wăhrend der Protagonist in „Rusja“ versucht, seine Erinnerungen mit Hilfe von Kaffee und Cognac hinwegzuspülen (6: 217).

Die engste Verbindung zwischen körperlicher Sinnlichkeit und Nahrungsmitteln besteht in einigen der Erzählungen, die den sexuellen Mißbrauch eines Dienstmädchens zum Inhalt haben: In der Erzählung „Gost'“ üben Küchengerüche einen beruhigenden Einfluß auf das geschändete Mädchen aus (6: 233), während in „Durocka“ die Vergewaltigung gar in der Küche stattfindet (6: 220). ${ }^{422}$ Ein solcher Bezug zwischen Essendüften und (wenngleich längst vergangener) körperlicher Nähe zwischen einem Barin und einer Untergebenen läßt sich auch in der Erzählung „Temnye allei“ feststellen: „... из-за печной заслонки сладко пахло щами - разварившейся капустой, говядиной и лавровьм листом“ (6: 176).

Ein besonderer Stellenwert kommt in den Temnye allei Restaurantbesuchen zu, die in mehreren Erzählungen eine Rolle spielen, nicht zuletż wegen der bereits erwähnten Mðglichkeit, Angehörige verschiedener sozialer Schichten zusammentreffen zu lassen (vgl. Kap. 5.5.2). Indessen ist auch die Wirkung des in diesem Rahmen transportierbaren Lokalkolorits und der implizite Hinweis auf die jeweiligen Lebensumstände nicht zu unterschätzen. In der Erzăhlung „V Pariže“ macht der Protagonist die Bekanntschaft seiner zukünftigen Lebensgefährtin in einer russischen Speisegaststätte, in der sie als Kellnerin arbeitet und ihn bei der Auswahl seines Menüs berät (6: 273). Den Abend vor ihrer gemeinsamen Nacht verbringen sie in dem bekannten Pariser Café „La Coupole“ bei einem guten Essen (6: 279). Auch in den folgenden Erzählungen gehen Kaffeehaus- oder Restaurantbesuche einem intimen Beisammensein voraus: Galja Ganskaja und ihr Bekannter trinken eine Schokolade, bevor sie sein Atelier aufsuchen (6: 284); Genrich verläßt als erste den Speisewagen des Zuges, um sich für die Nacht zurechtzumachen (6: 295); der Grusinier Meladze macht die Bekanntschaft der „Baryšnja Klara“ in einem Petersburger Restaurant (6: 351); im Speisewagen eines Zuges hängt der Protagonist der Erzählung „Rusja“ seinen

$422 \mathrm{Vgl}$. in diesem Zusammenhang auch die unveroffentlichte Erzahlung .Na postojalom dvore“, in der gleichfalls eine Vergewaltigung in der Kuche dargestellt wird. 
Erinnerungen an zärtliche Stunden mit der jungen gleichnamigen Malerin nach (6: 217); den Intimitäten in der Erzählung „Mest”“ gehen verschiedene Berichte über Mahlzeiten voraus, die ihrerseits in Verbindung mit zwischenmenschlichen Beziehungen stehen: Die Protagonistin der Erzăhlung „Mest”“ schildert, wie sie von ihrem Begleiter nach dem gemeinsamen Verzehr von Kuchen in einem Kasino abrupt verlassen wurde (6: 393), während ihr Ehemann, von dem sie getrennt lebt, vor gastronomischen Einrichtungen auf dem Pariser Montparnasse um Almosen bettelt (6: 392). Das Interesse ihres zukünftigen Liebhabers schließlich wurde geweckt, als er sie beim Frühstück und Mittagessen in der gemeinsam bewohnten Pension beobachtete (6: 387). Die größte Dramatik wohnt allerdings der Schilderung des Frühstücks inne, das der betrogene Ehemann in der Erzählung „Kavkaz“ vor seinem Selbstmord einnimmt, als wolle er ein letztes Mal intensiv genießen (6: 183). Hiermit unterstreicht Bunin besonders nachdrücklich die Nähe von Liebe und Tod, vor allem durch den während der Lektüre unwillkürlich gezogenen Vergleich mit dem zuvor geschilderten Frühstück des ehebrecherischen Liebespaares.

Besonders gehäuft treten Restaurantbesuche in der Erzählung „Cistyj ponedel'nik“ auf. Während der vielen gemeinsamen Abende, die der Protagonist mit seiner Angebeteten in der vergeblichen Hoffnung, ihr näherzukommen, verbringt, beschließen sie ihre abendlichen Unternehmungen häufig mit einem üppigen Mahl in bekannten Restaurants des vorrevolutionären Moskau: „Prag“, „Ermitaž“, „Metropol“, „Jar" und „Strel'na“ (6: 398). Die lukullischen Genüsse müssen dem jungen Mann Ersatz für intimere Wünsche sein, die seine Begleiterin stets aufs Neue zurückweist: „.... совсем близки мы все еще не были; и все это без конца держало меня в неразрешающемся напряжении, и в мучительном ожидании - и вместе с тем был я несказанно счастлив каждым часом, проведенным возле нее" (6: 398). Erst der Besuch der auch vom einfachen Volk besuchten Schenke .Egorov“, in der es dunstig und schwül wie in einem Dampfbad ist, und der Genuß eines, im Vergleich zu den ausgesuchten Spezereien der üblicherweise besuchten Restaurants, bodenständigen Blini-Gerichts (6: 405) scheinen den Weg für das am kommenden Abend erfolgende intime Beisammensein zu ebnen. ${ }^{423}$

Der enge Zusammenhang, der in den Temnye allei zwischen dem sinnlichen Eßvergnugen und körperlicher Sinnlichkeit besteht, spiegelt sich in Nahrungsmittelmetaphern wider, die vornehmlich dazu dienen, das Äußere verschiedener zentraler Figuren (bevorzugt der weiblichen) zu veranschaulichen, wie die folgende Auswahl beispielhaft illustriert: 
молочно-седой королевоһ̆ („Antigona“, 6: 225); колен цвета свекли („Gost”“, 6: 233); вишневыми губами (,Zojka i Valerija“, 6: 245); млечности приподнятых корсетом гр удей („Galja Ganskaja“, 6: 288); рыже-лимонных волос („Genrich“, 6: 293); с длинным шелковом платьем цвета золотистой луковой шелухи („Genrich“, 6: 294); коса немного темнее, цвета спелой кукурузы („Natali“, 6: 314); млечную девичью грудь с твердевшим недозрелой земляникой острием ("V odnoj znakomoj ulice“, 6: 332); еe голые пятки, похожие на белую репу („Baryšnja Klara“, 6: 352); пряный запах еe волос („Ćistyj ponedel'nik“, 6: 403).

Vor allem sind es jedoch die „Apfelbäckchen“ des Stubenmädchens Tanja aus der gleichnamigen Erzăhlung, die zum Anbeißen formlich einladen und nicht nur als Reminiszenz Bunins an die in der Erzählung "Antonovskie jabloki“ (1900) geschilderte untergegangene Welt des Landadels zu sehen sind, sondern auch besonders bildhaft den Hunger nach Leben zeigen: „Ax, этот крестъянский запах ее головы, дыхания, яблочный холодок щеки!“” $(6: 264){ }^{424}$

\subsection{Zusammenfassende Betrachtung}

Bei einer Analyse der Darstellung der zentralen Handlungsträger der Temnye allei fallen zwei eklatante Gemeinsamkeiten auf, die alle 38 Erzählungen miteinander verbinden: Zum einen ist die Vielfalt der zentralen Figuren nur eine scheinbare, da sie nur äußerlich individualisiert sind und sich durch die fehlende Schilderung innerer Prozesse auf ihre Geschlechtszugehörigkeit reduzieren lassen, zum anderen erregt die besondere Betonung der Frau Aufmerksamkeit, während die Männer nicht nur farblich blaß wirken (auch hier tritt also das von Bunin geschătzte Stilmittel des Kontrastes zutage; vgl. Kap. 5.6). Der geringe Individualisierungsgrad des Äußeren der männlichen zentralen Figuren bei gleichzeitiger intensiver ăußerer Ausgestaltung der weiblichen zentralen Figuren deutet darauf

424 Wie bereits im Rahmen der Darstellung der Frau erwahnt, spielen olfaktorische Elemente eine bemerkenswerte Rolle in den Temnye allei, deren unaufdringliche Erwăhnung auch ohne Bezug zu den Protagonisten einen entscheidenden Beitrag zur Authentisierung, Lokalisierung und Sensualisierung der Erzahlungen leistet. Ein solches Detail kann beispielsweise der Geruch von Servietten nach grauer Seife sein, der fur den Sprecher ein typisches Merkmal russischer Flußschenken verkठrpert (..Recnoj traktir". 6: 336) oder als ein intensiver Apfelduft, der im August uber der einstigen Heimatstadt lag, in der Erinnerung erstehen (.,Pozdnij Cas", 6: 204) - stets wird ein als typisch empfundener Duft oder Geruch eingefangen, der fur den jeweiligen Protagonisten eine ganze Welt symbolisiert.

Vgl. hierzu auch die Anmerkung von K. Birkmann: „.Die Rolle des Geruchssinns im literarischen Werk Bunins* - so könnte der Titel einer dickleibigen Abhandlung lauten!" In: ders. Ich schlage langsam ein Kreuz ... Rußland zwischen Bunin und Solschenizyn. Manchen. 1974: 24. 
hin, daß erstere nur Alter ego des Autors sind, der sich dem Phänomen „Frau“ von verschiedenen Seiten zu nähern versucht. In diesem Sinne sind die Temnye allei unter anderem als Experimentierfeld Bunins zu betrachten, der nicht nur auf der künstlerischen Suche ist nach einer adäquaten verbalen Beschreibungsweise des weiblichen Körpers auch und gerade in seiner Nacktheit, sondern auch versucht, das Rätsel der weiblichen Anziehungskraft auf den Mann zu lösen sowie das als fremdartig, teils gar als animalisch empfundene Wesen der Frau zu ergründen. Gleichzeitig verweist bereits die mangelnde Psychologisierung der Figuren darauf, daß ihre Funktion vornehmlich in der plastischen Ausgestaltung der zentralen Themen besteht.

Die in allen Erzählungen anzutreffende Konstellation des Aufeinandertreffens von Mann und Frau wird durch unterschiedliche sinnliche Ausgestaltung vor allem im visuellen Bereich in eine lebendige, vielfaltige Form gebracht; das stets wiederholte Grundmuster der emotionsgeladenen Begegnungen bei weitgehender Anonymität der zentralen Figuren kann als weiterer Beleg dafür gesehen werden, daß es Bunin nicht um die Nachzeichnung inneren Erlebens oder die Ergründung von Motiven für Handlungsweisen ging. Ihre Funktion innerhalb der Kurzprosaverknüpfung besteht daher hauptsächlich darin, die zentralen Themen des Buches - Liebe, Tod, Erinnerung - mit Leben zu erfullen, authentisch wirken zu lassen und durch die dargestellte Vielfalt der überindividuellen Schicksalsträger überzeugend zu illustrieren. 
С тех пор как я понял, что жнзнь - восхождение на Альпы, я все понял. Я понял, что все пустяки. Есть несколько вещей неизменных, органических, с которыми ничего поделать нельзя: смерть, болезнь, любовь, а остальное - пустяки. ${ }^{425}$

Wăhrend die Auseinandersetzung mit der Krankheit als unabdingbarem menschlichem Lebensbestandteil ausschließlich dem privaten Raum vorbehalten blieb, durchziehen die in den literarischen Bereich transferierten universalen Themen Liebe und Tod Bunins gesamtes Werk. In der bereits erwähnten nach Themen gegliederten Aufstellung seiner Erzählungen („Rody moich soxinenij“ ${ }^{426}$ ) übertrifft der Bereich „O ljubvi“ mit 70 Nennungen den Bereich „O smerti“ mit 6 Nennungen jedoch bei weitem und dokumentiert die für Bunin überragende Bedeutung der Darstellung des Lebens angesichts der bedrohlichen Prăsenz des Todes, zumal Liebe und Tod hăufig genug gemeinsam in einer Erzählung vertreten sind ${ }^{427}$ - wie es ja auch charakteristisch ist für die Erzählungen der Temnye allei.

Analog zu dieser Gewichtung verfügt der Themenbereich Liebe über weitaus mehr konstitutive Aspekte als der Themenbereich Tod: Wahrend Bunins in den Temnye allei gestaltete Konzeption eines idealen Liebeserlebnisses gekennzeichnet ist durch die Augenblickhaftigkeit der Emotionen, sexuelle Begegnungen, metaphysisches Erleben und einem Unterwegssein sowohl in räumlicher als auch in geistiger Hinsicht, erscheint der Tod phänomenologisch zwar ähnlich facettenreich wie die verschiedenen Liebesbegegnungen, ist jedoch als unwiderruflicher Endpunkt ungleich einförmiger.

Der Momenthaftigkeit der Liebe und des Todes, die beide im Hinblick auf die Unterbrechung des Gleichmaßes bzw. der Gleichformigkeit des Alltags nicht nur ablenkend, sondern auch zerstörerisch wirken, stellt Bunin die Dauerhaftigkeit der Erinnerung gegenüber, die als Bindeglied zwischen Liebe und Tod, als bewahrende Kraft und Brücke ins Jenseits in Erscheinung tritt. Die Erinnerung verleiht dem Erlebten im wissenden Rückblick Sinn und Glanz und bewahrt es vor dem Vergessen und somit dem Tod - gemäß der von Bunin in der 1925 entstandenen Erzählung "Nox"“ zitierten tröstlichen Erkenntnis buddhistischen Ursprungs „Ничто не гибнет - только видоизменяется.“ ${ }^{428}$

425 Bunin in einem Gespräch mit Galina Kuzzecova: vgl. den entsprechenden Tagebucheintrag G. Kuznecovas vom 02.05.1929. In: dies. Grasskij dnevnik. op.cit.: 101.

426 Brief Bunins an Fedor Stepun vom 12.10.1952. Zit. in: „Pis'ma I. A. Bunina k F. A. Stepunu“. op.cit.: 126. Vgl. auch Kap. 3.3.

427 Fur Bunin sind Liebe und Tod untrennbar miteinander verbunden, wie er in einem Gesprach mit Irina Odoevceva im Jahre 1947 bekannte: „... ведь мысль о смерти всегда присутствует в любвз" (1. Odoevceva. Na beregach Semy. op.cit.: 251).

428 1. Bunin. „Noc”“. In: ders. SS v denjati tomach. S.Bd. Moskau. 1966: 304. 
Lassen sich die Liebeserzählungen der 1920 er Jahre ${ }^{429}$ noch als verständliche Reminiszenz Bunins an seine verlorene Heimat werten und unterstellt man, daß es einiger Jahre bedarf, sich in ein neues Land derart einzuleben, damit dieses seinen Niederschlag auch im schriftstellerischen Werk findet, so kann dies für die 10 bis 20 Jahre später entstandenen Erzählungen der Temnye allei nicht mehr gelten, in denen sich Bunin gedanklich endgültig und unüberlesbar aus der bedrückenden Realität des Zweiten Weltkriegs in die Gefilde seiner verlorenen Heimat zurückzog. Im Gegensatz zur in der Sekundärliteratur genannten Dominanz der beiden Themen Liebe und Tod muß daher als weiteres eigenständiges zentrales Thema des Buches auf einer nachgelagerten Ebene die Erinnerung im allgemeinen und im besonderen an das alte, untergegangene Rußland berücksichtigt werden, das in die Literatur zu transferieren und damit unsterblich zu machen Bunin mit den Temnye allei eindrucksvoll gelungen ist.

\subsection{Liebe und Tod}

Die Temnye allei werden in der Sekundärliteratur häufig als "Enzyklopädie der Liebe“ bezeichnet. $^{430}$ Abgesehen davon, daß diese Bezeichnung die beiden weiteren zentralen Themen Tod und Erinnerung unberücksichtigt läßt, suggeriert sie eine erschöpfende Präsentation verschiedenster Beziehungsformen, die das Buch nicht leistet. Zwar ist das Spektrum der zwischenmenschlichen Beziehungen in den Temnye allei weit gefächert: Es reicht von flüchtigen, sexuell geprägten Reisebekanntschaften ("Vizitnye kartocki“) und unsterblicher Liebe ("Natali“) über käufliche Liebe („Baryšnja Klara“) und Mutterliebe (,Durocka“) bis hin zu homoerotischer Liebe (,..Madrid"“) und ungezügelter Leidenschaft („Parochod ,Saratov“"), um nur einige Beispiele zu nennen. Zwar wird dieser emotionale Grundton differenziert („жалостью и восторгом“, „Kavkaz“, 6: 180; „а вместе с жалостью-нежность и сладострастное желание“, „Vizitnye kartocki“, 6: 239; „любовь до гроба““, „Natali“, 6: 327), und zwar verstand auch Bunin selbst die Temnye allei als ein Buch ausschließlich über die Liebe, „о ее ,темных“ и чаще всего очень

429 Z.B. die in den 1920er Jahren entstandenen Erzahlungen ..Mitina ljubov“” (1924), .Solnečnyj udar“ (1925). „Ida“ (1925), .Mordovskij sarafan“ (1925) und ..Delo kometa Elagina“ (1925). Vgl. hierzu auch J. Woodward. .Eros and Nirvana in the Art of Bunin". In: The Modern Language Review 65 (1970): 576-586.

$430 \mathrm{Vgl}$. z.B. Ju. Mal'cev. Bunin. Frankfurt am Main, 1994: 323 und A. Saakjanc. "'Temnye allei'. Poslednie gody". op.cit.: 514 . 
мрачных и жестоких аллеях““31, deren Auftreten ungeachtet aller möglichen und in der Regel unweigerlich eintretenden tragischen Konsequenzen als positive Erfahrung präsentiert wird. Jedoch geht es in dem Buch nicht um die umfassende Darstellung von Liebesbeziehungen in höchst unterschiedlichen Konstellationen, sondern um das Aufzeigen der Diskrepanz zwischen Liebesmomenten höchster Intensität und dem Alltagsleben sowie der Beschränkung des Liebeserlebnisses auf einen Augenblick, der keinerlei Option auf Fortfuhrung in sich birgt.

Bunins in den Erzählungen der Temnye allei gestaltete Konzeption der Liebe, die er mit derm Titel der 1925 entstandenen Erzăhlung „Solnexnyj udar" treffend definiert hat, ist vor allem durch das plötzliche Aufflammen der Emotionen sowie ihre kurze Dauer gekennzeichnet $^{432}$, geht einher mit einer erhöhten sinnlichen Wahrnehmungsfähigkeit und ist in der Regel gekoppelt mit sexuellem Verlangen. Sie läßt sich weder von gesellschaftichen Konventionen, wie etwa der Ehe, noch von Kontrasten in Alter oder sozialem Status Einhalt gebieten, ja, sie tritt in den Erzăhlungen der Temnye allei sogar überwiegend zwischen höchst unterschiedlichen Partnern auf und demonstriert damit ihre unbeschränkte Macht. Somit begleiten zwei Attribute die Liebe, die sich in mannigfaltigen Variationen im Buch finden: ihr unerwartetes Auftreten („неожиданно“433, „Вдруг “434), gepaart mit einer erhöhten Sensibilisienung für die Umwelt, die als außergewöhnlich („необыкновенно“435) emp-

431 Brief Bunins an Téffi vom 23.02.1944. Zit. in: ${ }_{n}$ Perepiska Teffi s I. A. i V. N. Buninymi 1939-1948“. op.cit.: 506.

432 Eine Ausnahme bilden lediglich die Liebesbeziehungen zwischen russischen Emigranten in den Erzahlungen „V Parize“" „Cholodnaja osen" ${ }^{\prime \prime}$ und „Mest'“: Die durchweg alteren Protagonisten scheinen ihre Liebesbezichungen ahnlich nuchtem als Zweckbondnis zu betrachten wie die Notwendigkeit ihres Aufenthaltes in der Emigration.

$433 \mathrm{Vgl}$. etwa entsprechende Erwahnungen in den Erzahlungen .Zojka i Valerija“ („редким и всегда неожиданным счастьем только поцелуев“, 6:247), "Тапја“ („все вышло и аля него совсем неожиданно“, 6: 256, „3а то неожнданное счастье“, 6:258), „Natali“ („4то так внезапно и нежданно совершилось в моей жизни“, 6:321), "Кита“" (вспоминая подробности своего неожиданного счастья", 6: 342) oder "Voron“ (.В том году встретило меня, однако, дома нечто совсем неожиданное", 6:378).

434 In 25 Erzahlungen kandigt Bunin einen uberraschenden Wechsel im Handlungsverlauf oder eine vom Protagonisten nicht erwartete emotionale Veranderung durch die in der Regel mehrmalige Verwendung dieses Adverbs an; vgl. die folgenden Beispiele: „Bдpуг nослышались мягко бегущие шаги [...]" (.Rusja“, 6: 216), ..[...] в вдруг вспомннл ту мертвенную, но прекрасную бледность [...]" („Nacalo", 6: 344), „[...] все еще не веря той нелепостн, неожиданности, которал вдруг разбила все его радостные надежды на зтот вечер“ (.Parochod ,Saratov““, 6: 375). „А потом, разве не бывает так, что нехоторые мечты вдруг сбываются?“ („Voron“, 6: 379), .[...] она вдруг обернулась, почувствовав это [...]" („C'istyj ponedel'nik“, 6: 405). In diesen plotzlichen Wendungen zeigt sich zudem hăufig das von Bunin geschatzte thythmusgebende Stilmittel des Kontrastes (vgl. Kap. 5.6), etwa als Anzeichen eines Wechsels, der den Übergang von Deskriptionen zu dynamischer Handlung markiert.

$435 \mathrm{Vgl}$. beispielsweise entsprechende Formulierungen in den Erzahlungen „Stepa“ (.взгляд необыкновенно живой“, 6: 194), „Миzа“ (.вкус и форма гу6 необыкновенные“, 6: 198), .Antigona“ (..он успел взглянуть на необыкновенную стройность ее платья, ноге, 6: 223), „Тапја“" (.эта необык-

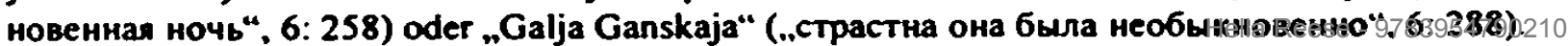


funden wird. Zur Vervollständigung eines den ganzen Menschen ergreifenden Liebeserlebnisses bleibt Bunins Liebeskonzeption zufolge eine intime Begegnung nicht auf die körperliche Lust beschränkt, sondern erfaßt auch den Geist und die Seele des Menschen und offnet ihn den Mysterien des Lebens. Da im Alltag die hierfür nötige Geisteshaltung bzw. Bereitschaft in der Regel nicht gegeben ist, läßt er seine Protagonisten diese Erfahrung häufig auf Reisen bzw. in einem für sie ungewohnten Umfeld machen. Der Preis für dieses Erleben ist hoch: In den Temnye allei haben die Bindungen zwischen Mann und Frau keine Zukunft - der Tod oder eine dramatische Trennung verhindern eine Ausdehnung über einen kurzen Zeitraum hinaus. Als Mittel gegen das Zerstörerische der Zeit dient die Erinnerung, die Erlebtes nicht verlorengehen läßt.

Bunin war sich zeit seines Lebens der Endlichkeit seines irdischen Daseins schmerzlich bewußt und fürchtete den Tod als unwiderruflichen Schlußpunkt. In seinem letzten Lebensjahrzehnt scheint jedoch die Beschäftigung mit dem Tod fast zu einer fixen Idee geworden zu sein. Zahlreiche Tagebuchnotizen zeugen davon, wie Bunin sein Leben im Schatten des Todes lebte und stets der dunklen und ihm unbegreiflich erscheinenden Bedrohung gewahr war:

[...] думаю, - о том своем я, которое живет и сознает себя уже лет 60 - и это я думает, что лет через 5, много 10 , его не будет. И не будет оно ничего видеть и думать. Странно! (29.03.1940); Проснулся ночью, лежал в страхе, что могу умереть (06.03.1941); Нынче записал на бумажке: „сжечь“. Сжечь меня, когда умру. Как это ни страшно, ни гадко, все лучше, чем гнить в могиле. (31.12.1941); Холодная ночь, блеск синего Ориона. И скоро я никогда уже не буду этого видеть. Приговоренный к казни (23.10.1944); А теперь уже ничего впереди калека и смерть почти на пороге (03.10.1949); А ведь вот-вот все, все поглотит могила! (28.01.1953). ${ }^{436}$

Auch in den Erzählungen der Temnye allei ist der Tod allgegenwärtig ${ }^{43}$, sei es in Redewendungen (,мертвых с погоста не носят“, „Temnye allei“, 6:178), Metaphern („Полный месяц [...], какой-то светящийся череп“, „Cistyj ponedel'nik“, 6: 409) oder Beschreibungen des Äußeren einer Person (,с мумийными пальцами“, „Kamarg“, 6: 383). Androhungen, bis zum Äußersten zu gehen (,Я ни перед чем не остановлюсь ...“, „Каvkaz“, 6: 180; „Только через мой труп“, „Rusja“, 6: 216) vervoll-

$436 \mathrm{Vgl}$. die entsprechenden Seiten in UB. 3.Bd. op.cit.: 40, 86, 124, 147, 173, 193 und 207. Am 18.12.1943 findet sich zudem folgende Notiz Bunins zur Vergănglichkeit des Menschen: ..[...] девушкн - и опять: как скоро пройдет их молодость. начнется увяданне, болезни, потом старость, смерть ... До чего несчастны люан! И ннкто еще до сих пор не написал зтого как следует!" (S. 159).

437 Lediglich in den sechs Erzahlungen "Durocka“, .Smaragd“. .Volki". „Kamarg“. ..Sto rupij" und "Kuma" finden sich keinerlei Hinweise auf das Todesmotiv (wohl abelekuf die Verggrightichleit). 
ständigen das Bild ebenso wie ein flehentlicher Wunsch um einen baldigen Tod als Erlösung von Liebesqualen („Царица Небесная, пошли мне смерть!“, „Тапја“, 6: 268), die scherzhafte Ankündigung einer lebenslangen Liebe (,[...] если бы не Натали, в которую ты завтра же утром влюбишься до гроба“, „Natali“, 6: 303) und im Überschwang der Emotionen leicht dahingesagte Sätze (,A за то, чтобы поехать с тобод, х бы, кажется, жизнь отдала!“, „Genrich“, 6: 291).

Zudem werden in diversen Erzählungen - von den Todesfallen unter den zentralen Figuren abgesehen - zahlreiche Hinweise auf tote Personen eingeflochten: Dies geschieht zum einen durch die Integration authentischer Persönlichkeiten, die im Entstehungszeitraum der Temnye allei bereits nicht mehr unter den Lebenden weilten, in den Handlungsverlauf, zum anderen durch die Erwähnung fiktiver verstorbener Figuren. ${ }^{438}$ Während das eine Verfahren der zeitlichen Lokalisierung und der Erzeugung von Lokalkolorit dient, sind die Funktionen des anderen Verfahrens höchst unterschiedlich: Sie können das Motiv zum Antritt einer Reise bilden („Vizitnye kartocki““, 6: 238), den familiären Hintergrund der zentralen Figuren erhellen („Krasavica“, 6: 218; „Tanja“, 6: 258) oder den Anlaß zu einer erzählerischen Rückbesinnung bieten („Ballada“, „Železnaja Šerst”“). Vor allem tragen sie jedoch zu einer Ausdehnung und Verdichtung des Todesthemas bei. Die folgenden Abschnitte veranschaulichen die verschiedenen Konstituenten der in den Erzählungen gestalteten Liebeskonzeption vor der kontrastierenden Folie der Bedrohung durch den Tod, dessen stete Präsenz intensive und sinngebende Erfahrungen erst ermőglicht.

\subsubsection{Der Blitzschlag der Liebe}

In einem Gespräch mit Irina Odoevceva bekannte Bunin, selbst nur kurze Momente des Glücks erfahren zu haben: „A мне иногда до слез жаль, что длительно счастлив я никогда не был. Только вспышками. Минутами. “439 Diese Bemerkung erinnert an die Worte Lev Tolstojs, die dieser dem jungen Bunin bei ihrer ersten Begegnung in Moskau um die Jahreswende 1893/94 ${ }^{440}$ mit auf den Weg gab: „Счастья в жизни нет, есть только

438 Dieses Verfahren laßt sich in den folgenden Erzăhlungen beobachten: „Ballada“, „Pozdnij Cas“. „Krasa-

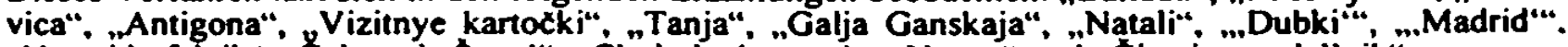

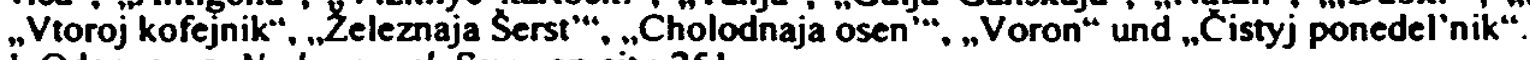

439 i. Odoevceva. Na beregach Seny. op.cit.: 251.

440 Das genaue Datum dieser Begegnung ist unklar. In seiner zusammenfassenden Tagebuchaufzeichnung des Jahres 1893 nennt Bunin Ende Dezember 1893 (vgl. UB. 1.Bd. op.cit.: 24), wahrend er in Osvobo:denie Tolstogo die ersten Januartage des Folgejahres enwahnt (6: 65).

Hella Reese - 9783954790210 
зарницы его-цените их, живите ими ..." (Osvobozdenie Tolstogo, 6: 68). Diese Worte scheinen sich für Bunin im Laufe seines Lebens mit persönlichem Gehalt gefullt zu haben, denn ihr Inhalt liegt auch der Liebeskonzeption in den Erzählungen der Temnye allei zugrunde: Das Liebesglück ist weder planbar noch auf zeitliche Dauer angelegt - den nuhigen, zufriedenen Alltag und die glückliche Ehe oder langfristige vertrauensvolle Beziehung sucht man vergebens. Bunin stellt diese leidenschaftlichen Momente vollkommen wertfrei dar und verurteilt auch Extreme nicht (als einziges Zugestăndnis an gesellschaftliche Konventionen werden Mörder ihrer staatlich sanktionierten Strafe zugeführt), wohl aber jeden Versuch einer Institutionalisierung der Liebe, die Bunin zufolge als elementares Erlebnis keine Ausdehnung in den Alltag zuläßt (vgl. Kap. 7.1). Ein solches Liebeserlebnis gilt ihm als Ausbruch aus dem Alltag; es ergănzt und vervollständigt den Menschen und läßt ihn die wahre Fülle des Seins spüren (vgl. Kap. 8.1.3). Wird die Liebe hingegen in den Alltag transferiert, verliert sie an Glanz und Intensität, wird banal und transformiert sich in Häßlichkeit, wie etwa in den zeitgleich entstandenen, aber nicht zu den Temmye allei gehörenden Erzăhlungen „,Kogda ja vpervye“", "Alupka“, „Krem Leodor“ und „Riv'era“ (vgl. Kap. 3.5). Selbst wenn beide Partner den Wunsch nach einer langfristigen Bindung äußern, ist dieser keine Zukunft beschieden, wie beispielsweise den Paaren in den Erzählungen "Natali“, "Rusja“ oder „Dubki“".

Sofem die zentralen Figuren zum Zeitpunkt ihres Zusammentreffens mit dem anderen Geschlecht nicht ungebunden sind, sind sie bestrebt bzw. bereit, aus ihren aktuellen Bindungen auszubrechen. In den Erzählungen „Temnye allei“, „Kavkaz“, „Vizitnye kartocki“, „V Pariže" und „Kuma“ bricht jeweils eine Frau die Ehe, in „Dubki““ verhindert die vorzeitige Rückkehr des Ehemanns den Seitensprung seiner Frau, in „Zojka i Valerija“ spielt die Dame des Hauses mit dem Gedanken an ein außereheliches Abenteuer. Einen geistigen Betrug an seiner Frau begeht der Protagonist der Erzählung „Rusja“ mit der intensiven Erinnerung an seine viele Jahre zurukckliegende erste Liebesbeziehung.

So sind denn auch die dargestellten Ehen oder eheähnlichen Bindungen dergestalt, daß ein womöglich lebenslanges Verharren in dieser Situation wenig erstrebenswert erscheint. wie etwa in den folgenden Erzählungen: Einen Einblick in die Ehe der jungen Natali aus der gleichnamigen Erzählung erhält der Leser zwar nicht; er kann aber davon ausgehen, daß sie nicht eben glücklich verlief, da sie zum einen bereits vor der Ehe ihrem zukünftigen Mann ablehnend gegenüberstand („Но он ей не нравится“, 6: 305) und zum anderen Mešxerskij ihre Liebe erklärt hat („Да, да, я вас люблю“, 6: 321). Auch die eheähnliche Bindung, die Mešcerskij mit einer Bediensteten eingegangen ist, ist weder glücklich noch 
hat sie Bestand. Die Protagonistin der Erzăhlung „Mest"“ ist zwar noch verheiratet, hat ihren Mann aber verlassen, und die Ehe des Beamten und seiner schonen zweiten Frau ("Krasavica“) ist nicht von Liebe bestimmt, denn er geht so weit, aus Angst vor seiner Frau seinen Sohn aus erster Ehe zu verleugnen („от страха перед ней“, 6: 218). Vernunfgesteuert sind die Ehen in den Erzăhlungen "Cholodnaja osen"“ und „Voron"- und dadurch schon von Haus aus entweder nicht von Dauer oder unglücklich. Unter einem unglücklichen Stern steht die Eheschließung in ,Železnaja Šerst'“, wăhrend die Ehe in "Ballada“ als die die Regel bestătigende Ausnahme auf wundersame Weise gerettet wird. Auch in dieser vergleichsweise kleinen Gruppe ist die Vielfalt nur Illustration der Aussage Bunins, daß intensive, leidenschaftliche und den ganzen Menschen ergreifende Liebe und langfristige, vom Alltag bestimmte Bindung einander ausschließen.

Die Vorliebe Bunins für rasch aufblitzende Lichtpunkte wurde bereits in einem anderen Zusammenhang nachgewiesen (vgl. Kap. 6.3.1) und muß als bildliche Umsetzung seines Konzepts der Liebe als eines unvermittelt aufflammenden Gefuhls verstanden werden. So wie das Licht die Voraussetzung darstellt furr die Wahrnehmung von Farben, so bildet ein intensiver, ekstatischer Liebesaugenblick den Ausgangspunkt fur das Erfahren des alles umfassenden Seins. Es soll daher erneut hingewiesen werden auf die auffallige Präsenz angerissener und rasch verlöschender Streichhölzer in der Dunkelheit (z.B. "Stepa“, 6: 193; „Volki“, 6: 234; „Kuma“, 6: 342), fliegender Funken eines Kaminfeuers („Dubki““, 6: 348) oder Wetterleuchten bzw. Gewitter (z.B. „Natali“, 6: 322; „Voron“, 6: 380). Das Halbdunkel, die schnell verfliegende Dämmerung, das kurz aufscheinende Licht entsprechen in ihrer Unbeständigkeit der Kurzlebigkeit des reinen Glücks, so wie Bunin zufolge die Intensität des Moments des Zusammentreffens zweier in Liebe und/oder Leidenschaft entflammter Menschen kontrăr zur Länge ihrer Beziehung steht - während diese sich indessen der Flüchtigkeit dieses Gefulhls im Moment des Erlebens nicht bewußt sind. Die Liebe erhellt für einen Moment das Leben der Protagonisten; sie läßt sie nicht nur aus ihrer Individualität heraustreten, sondem läßt sie die Existenz von etwas Wesentlichem und Sinngebendem jenseits ihres Alltags spüren, das in dessen Monotonie nicht überlebensfähig wäre und gleich einem Streichholz verlöschen würde.

Die entscheidende Rolle beim Zustandekommen dieses Liebeserlebnisses spielt für die jeweilige männliche zentrale Figur die durch Attraktivität der auserkorenen Partnerin ausgelöste Begierde. Vor allem die rastlos wirkenden männlichen Figuren scheinen jederzeit latent bereit zu sein, ein Liebesabenteuer gleich welcher Art einzugehen (vgl. Kap. 8.1.4). 
In der Regel ist diese Bereitschaft unbewußter Natur und äußert sich lediglich in der raschen Reaktion bei sich bietender Gelegenheit. Selten wird diese Suche so explizit formuliert wie am Beginn der Erzăhlung „Natali“: „... я решил [...] искать любви без романтики“ (6: 302). Die Frauen sind in dieser Hinsicht statischer und werden vom Mann aus ihrer Passivităt gerissen. Zu den wenigen Ausnahmen gehört etwa die flirtfreudige junge Frau in der Erzählung „Vizitnye kartocki“, die auf ein Gedichtzitat schlagfertig und keck erwidert: „Вот чеченца-то я и жду!“ (6: 237). Integraler Bestandteil von Bunins Konzeption der Liebe ist demzufolge die Erotik, so daß man nicht unbedingt von Liebe, aber von „Lust auf den ersten Blick“ sprechen kann, einer Lust, der sich Liebe zugesellen kann, aber nicht zwangsläufig muß.

\subsubsection{Liebe und Erotik}

Zahlreichen Erzählungen der Temnye allei gemeinsam ist der Geist der allumfassenden Liebe im Sinne des Platonschen Eros ${ }^{441}$, des Strebens von der sinnlichen zur geistigen Ebene. Ausgangspunkt ist die Lust an einer schönen körperlichen Gestalt, die Platon als niederste Stufe des Eros gilt. In den Temnye allei ist für die männlichen Protagonisten, aus deren Blickwinkel in der Regel erzählt wird, das Begehren des weiblichen Körpers indessen gleichsam die Voraussetzung für die Erfahrung der metaphysischen Dimension der Liebe. Diese in der Rezeption häufig als Hang Bunins zur Darstellung pornographischer Szenen fehlgedeutete Thematisierung sexueller Begierden (vgl. Kap. 10) geht einher mit einer Öffnung aller Sinne, einer gesteigerten Empfänglichkeit vor allem für visuelle und gustatorische Sinneseindrücke und dem dadurch ausgelösten Verlangen (vgl. Kap. 6.2, 7.2, 7.4). In einigen Erzählungen, wie etwa in "Stepa“, „Gost”“ oder „V odnoj znakomoj ulice“, wird lediglich die körperliche Begierde befriedigt. Das Liebeserlebnis ist jedoch erst dann vollstăndig, wenn nicht nur der Körper, sondern auch die Seele beteiligt ist. wie in der Erzählung „Tanja“: „[...] навеки отдавая ему не только все свое тело, теперь уже полную собственность его, но и всю свою душу“" (6: 261).

In der von Bunin in den Temnye allei präsentierten Liebeskonzeption ist der sexuelle Akt unabdingbarer Bestandteil des Liebeserlebnisses, dessen Bedeutung für die Beteiligten 
seiner Meinung nach vom Menschen häufig nicht ausreichend gewürdigt werde - und verbal auch gar nicht adäquat übermittelt werden könne:

В любви, в любовном акте есть что-то божественное, таинственное и жуткое, а мы не ценим,- говорил он. - Надо дожить до моих лет, чтобы до конца ощутить всю несказанную мистическую прелесть любви. Описать это словами невозможно. Это непередаваемо. Главное ведь всегда ускользает. Сколько я ни пробовал не получается или получается около, где-то рядом, но сути словами не поймать, на крючок не нацепить. Да это не я один - этого еще никто не выразил и не выразит. ${ }^{442}$

Diese allgemein formulierte Bemerkung ließe sich ohne weiteres auch als kritische Bemerkung bezüglich des Verzichts auf Darstellungen körperlicher Liebe in der russischen Literatur des 19. Jahrhunderts verstehen. Im Gegensatz zu den seinerzeit ublichen literarischen Gepflogenheiten ist die offenkundige Betonung körperlicher Sinnlichkeit in vielen Erzählungen der Temnye allei nachgerade erstaunlich progressiv: 19 Erzählungen ${ }^{443}$ (allein 11 davon gehören dem zweiten Komplex an) liefern klare Hinweise auf den Vollzug des Liebesaktes, in den übrigen bleibt es bei Absichtserklärungen oder Referenzen auf zurückliegende Schäferstündchen. Bunin verzichtet auf detaillierte Beschreibungen des Koitus zumindest in den Typoskriptfassungen der Erzăhlungen ${ }^{44}$ - und folgt damit weitgehend den traditionell prüden Moralvorstellungen der russischen Literatur des 19. Jahrhunderts. ${ }^{445}$ Die Modifikationen und Streichungen mögen zum einen Bunins Kapitulation vor dem herrschenden Moralkodex zum Ausdruck bringen, zum anderen dokumentieren

442 A. Bachrach. „Po pamjati, po zapisjam. Razgovory s Buninym“. In: Nż 131 (1978): 132-133.

$443 \mathrm{Zu}$ diesem Kreis gehoren die folgenden Erzahlungen: „Kavkaž”. „Stepa“, „Rusja“, „Durocka”, "Antigona", "Gost" ", „Vizitnye kartocki“, "Zojka i Valerija”, "Tanja“, „V Parize“, "Galja Ganskaja“, "Genrich“, .natali“, . V odnoj znakomoj ulice“, „Kuma“, „Baryšnja Klara“, ..,Madrid““, .ZZeleznaja Serst”“ und "Cistyj ponedel'nik".

$444 \mathrm{Vgl}$. beispielsweise die Manuskriptfassungen der Erzahlungen „Zojka i Valerija“ und „Riv'era“, die den Liebesakt schildern, wenn auch unter Verzicht auf anatomische Bezeichnungen (LRA. MS.1066/306307 und MS.1066/255-258).

$445 \mathrm{Vgl}$. in diesem Zusammenhang eine diesbezugliche Feststellung von Felix Ingold in seinem Aufsatz „Russischer Eros. Frau und Sexualitat in der Literatur des 19. Jahrhunderts“: „.... gleichwohl bleibt festzuhalten, daß die russische Belletristik sich von anderen Literaturen insofem markant unterscheidet, als sie die Liebe ausschließlich in ihrer emotionalen oder ethischen Qualitat, in ihrer Entstehung und ihren Konsequenzen, niemals aber im sexuellen Vollzug, nicht als reale korperliche Erfahrung vorfuhrt" (S. 210). Gleichzeitig hălt er seine Verwunderung daruber fest, „daß eine so bedeutende literarische Kultur wie die russische [...] keine kunstlerisch relevanten oder gar pornographischen Texte [hervorgebracht hat]" (S. 210). In: Annäherungsversuche. Zur Geschichte und Ästhetik des Erotischen in der Literatur. Hg. H. Glaser. Bern u.a., 1993: 209-238.

Auch Elena Tichomirova kommt in ihrer Analyse uber den Umgang mit der Sexualităt in der russischen Literatur des 19. und 20. Jahrhunderts zu dem SchluB, daB eine Sprache fur sexuelle Handlungen erst

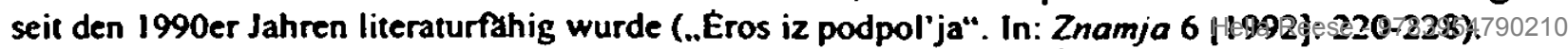


sie, daß er mit dem erzielten Ergebnis nicht zufrieden war. ${ }^{446}$ In jedem Fall belegen sie klar, daß es Bunin zumindest nicht primär um das Verfassen erotischer Texte ging. Anstelle des Koitus zeigt Bunin lediglich das „Davor" und „Danach“ und bleibt somit der literarischen Tradition in gewisser Weise treu-doch selbst diese restriktive Darstellungsform bot Anlaß genug, die Erzählungen ins Kreuzfeuer der Kritik geraten zu lassen (vgl. Kap. 10). Bereits vor der Veröffentlichung erntet Bunin kritische Bemerkungen für erotische bzw. intime Schilderungen in den Erzählungen „Zojka i Valerija“ (Andeutung des Koitus zwischen Levickij und Valerija; Levickijs Kuß auf Zojkas Gesäß, 6: 251), „Galja Ganskaja“ (detaillierte Beschreibung von Galjas Unterwäsche, 6: 288) und „Natali“ (Hinweis auf Sonjas Menstruation, 6: 315) von Boris Zajcev, dem er diese Erzählungen zur Aufbewahrung geschickt hat. In einem Brief vom 28. November 1943 äußert sich der Freund mit Bezug auf die erwähnten Erzählungen indigniert:

Дадечка, скажу правду: все „межножья“, штаны с разрезом, менструации, Зойкины жопы дела не укрепляют. Ты знаешь, я никак не prude [sic] и сам многогрешны человек и много на своем веку „поработавший“-все-таки говорю: литература от этих подробностей не выигрывает. [...] Добабляю только еще, что все сказанное относится к эстетике, а не к морали.

In seiner postwendenden Antwort vom 3. Dezember 1943 verteidigt Bunin seine Vorgehensweise und offenbart seine generell offene Einstellung zu Fragen der Sexualität, die sich in den Temnye allei unüberlesbar widerspiegelt:

А уж про Зойкины ж... [sic] и говорить нечего. Красота и ужас! „Литература от этих подробностей не выигрывает, говоришь ты, - дела они не укрепляют.“ Да дело не в „выигрывании“ и не в „укреплении“-я ничего не хотел этим выигрывать и укреплять (т[о] е[сть] с меркантильной целью) - просто, задача моя была писать именно об этом, понстине „роковом“. Можно, конечно, сказать: плохая задача, ненужна, - да так-ли это? Неужели можно доходить только до „уста их слились в пламенном поцелуе“? Вот „межножье“, может быть, и немножко не в меру ... но опять скажу: эта резкость в соответствии полном, по-моему, со всей хохлацкой ожесточенностью Валерии ... ${ }^{48}$

446 In gewisser Weise kommt diesen Auslassungen sogar unterstutzende Funktion zu bei der Untermauenung der in zahlreichen Erzahlungen impliziten Aussage, daß die intime körperliche Begegnung mit einem anderen Menschen zu einer zeitweisen Ausloschung des Selbst fuhren kann. Im Idealfall ist der Mensch wăhrend eines Liebeserlebnisses vollkommen gegenwartig und zugleich befreit von den Burden des Alltags - er erlebt eine Befreiung, wie sie nur durch den Tod moglich ware und die gleichzeitig die wirksamste Waffe gegen den Tod ist: Am ausdrucksvollsten gelingt Bunin dies mit der Darstellung der Kopulation auf einem Friedhof in „Otec Nikon“ (1944) und einer titellosen Erzahlung, die vermutlich in demselben Zeitraum wie die Erzahlungen der Temmye allei entstanden ist und die er ursprunglich beide in das Buch hatte aufnehmen wollen (vgl. Kap. 3.4.1 und 3.4.2).

447 Zit. in: „Pis'ma B. Zajceva I. i V. Buninym“. In: NE 146 (1982): 123.

448 Zit. in: „Pis'ma B. Zajceva I. i V. Buninym“. In: NE 137 (1979): 128. Wăhrend die Koitus- und die Kußszene in der Endfassung von "Zojka i Valerija“ nicht mehr vorhanden sind, hielt Bunin an den anderen von Zajcer beanstandeten Stellen fest. 
Indem Bunin die Existenz körperlichen Begehrens zu einem literarischen Gegenstand macht und die Liebe als real erfahrbare Emotion zeigt, begeht er einen Tabubruch, den er in einem Brief an Tèffi vom 23. Februar 1944 verteidigt: „[...] это все прочее совершенно необходнмо в своем ,натурализме', то есть ,вещественности“, без которой (то есть ,абстракностью') никак нельзя сказать не только ,трагического', но просто не стоит город городитъ. “449 In demselben Brief räumt Bunin ein, in seinen Manuskriptfassungen einige zu eindeutige Formulierungen verwendet zu haben, die er aber für den Druck gestrichen habe; die übrigen jedoch wolle er bis zum "letzten Blutstropfen“ verteidigen.

Die physische Liebe hat in den Erzählungen der Temnye allei viele Gesichter, aber auch zahlreiche Gemeinsamkeiten: So fühlen sich explizit nur die Männer körperlich von den Frauen angezogen; es bleibt unklar, was eine Frau an einem Mann fasziniert, nicht allein in erotischer Hinsicht. ${ }^{450}$ Der Grund fur diese Unausgewogenheit ist in der Schilderung der Begegnungen aus einem männlichen Blickwinkel zu sehen. Die körperliche Vereinigung ist Ziel vor allem der Männer, jedoch läßt sich in zahlreichen Erzăhlungen die Beobachtung machen, daß zwar die Initiative zum intimen Beisammensein vom Mann ausgeht, während die praktische Umsetzung der Frau obliegt, da diese vergleichsweise nüchtern genug bleibt, um den organisatorischen Part der Begegnung zu übernehmen (vgl. Kap. 7.1). ${ }^{451}$ So hält Antigona in der gleichnamigen Erzählung ihren stürmischen jungen Liebhaber aus Sicherheitsgründen davon ab, sich auf den Divan zu legen, Sonja in der Erzăhlung „Natali“ erteilt Anweisungen, wie die Liebesstunden zu organisieren seien, und die Protagonistin der Erzăhlung „Cistyj ponedel'nik“ bewahrt nicht nur wăhrend zărtlicher Minuten einen kühlen Kopf, sondern bereitet zudem die erste und einzige Liebesnacht von langer Hand vor und führt dabei Regie. Im Gegensatz zu den Männern verlieren die Frauen im Strudel der Gefühle nicht den Kopf, obwohl auch sie sich der Leidenschaft hingeben können, wie die Protagonistin der Erzăhlung „Galja Ganskaja“: „Когда я зверски кинул ее на подушки дивана, глаза у ней [sic] почернели и еще больше расширились, губы

449 Zit. in: „Perepiska Téffi s I. A. i V. N. Buninymi 1939-1948“. op.cit.: 506.

450 Die Ausnahme von dieser Regel bildet Sonja aus der Erzahlung .Natali“, die offensichtlich der erotischen Ausstrahlung ihres Cousins erliegt und sich gleich bei dessen Ankunft unverblumt außert: .Живой взгляд и пошлые черные усикн ... [...] Ты за эти два года, что я не видала тебя, превратился из вечно вспыхиваюшето от застенчнвости мальчншки в очень интересного нахала. И зто сулило бы нам много любовных утех, [...] если бы не Натали $[\ldots]^{*}$ (6: 303).

451 Erzahlungen, die eine Vergewaltigung zum Inhalt haben oder in denen Frauen aus Granden des Lebensunterhalts ihren Korper verkaufen, sind von dieser These selbstverstandlich ausgenommen. Wird in diesen Fallen das sexuelle Geschehen nicht reflektier, wie etwa in der Erzahlung "Tanja", in der die fleischliche Lust in der Folge auf der Gefuhlsebene komplettiert wird, bleibt das Liebeserlebnis unvollstandig. Vgl. hierzu auch L. Smimova. Ivan Alekseevic Bunin. op.cit.: 174, wobei Smimova auch die Erzahlungen .Ballada“ und „Antigona“ als Beispiele anfuhrt, in denen zwar keine Vergewaltigungen stattfinden, aber die korperliche Begierde nicht mit echter Zuneigung fur die begehrte Fraubsinghergeht. 
горячечно раскрылись,- как сейчас все это вижу, страстна она была необыкновенно ...“ (6: 288). Stärker als bei den Mănnern findet sich eine Schicksalsergebenheit der weiblichen Figuren in die sexuelle Begegnung samt ihrer Konsequenzen:

Кто он, она еще не понимала в полусне, но все равно - это было тот, с кем она, в некий срок, впервые должна была соединиться в самой тайной и блаженносмертной близости [...] и вот эта необыкновенная ночь принимает его в свое непостижимое светлое царство вместе с нею, с этой близостью ... („Тапја“, 6: 258).

Eine weitere Gemeinsamkeit der geschilderten Liebeserlebnisse besteht in der teilweise extremen Kürze des Liebesaktes, auf die Spitze getrieben durch die Angabe seiner Dauer in den Erzăhlungen „Gost"“ (,И через минуту исчез“, 6: 233) und „Antigona“ ("Через минуту он упал лицом к ее плечу“, 6: $228^{452}$ ). Der Kürze zum Trotz kann das körperliche Erleben tiefe Spuren bei den Protagonisten hinterlassen. Behauptungen wie etwa der von $M$. Kreps, daß Bunins Liebeskonzeption ausschließlich auf physischem Begehren basiere $^{453}$, muß entschieden widersprochen werden, da er den zentralen Aspekt des Sehnens nach Auflösung der eigenen Grenzen, nach Verschmelzung nicht nur mit einem anderen Menschen, sondern auch mit dem Universum, vollkommen außer acht läßt. Die intensive körperliche Begegnung mit einem anderen Menschen, im Idealfalle im gegenseitigen Einvernehmen und von Zuneigung für den Partner begleitet, verhilft dem Menschen zu einer wertvollen metaphysischen Erfahrung - als Moment der Vereinigung nicht nur mit einem anderen Menschen, sondern mit den Mysterien des Lebens.

\subsubsection{Der metaphysische Aspekt der Liebe}

Zahlreichen Erzăhlungen der Temnye allei gemeinsam sind intensive Naturbeschreibungen (vgl. Kap. 5.5.1) - den Wettererscheinungen ist hierbei eine besondere Aufgabe zugedacht: der Einbruch elementarer Naturkrăfte in das menschliche Dasein oder auch die bewußte

452 Die noch in der Manuskriptfassung dieser Erzahlung angegebene Dauer des Beischlafs mit einer Sekunde abermittelt Bunins Konzept der Augenblickshaftigkeit zwar noch treffender, muß ihm jedoch im nachhinein als ubertrieben erschienen sein, denn in einer Zusammenstellung von Änderungsvorschlagen, die er im Mai 1941 Aldanov zukommen ließ, bittet er darum, die Sekunde durch eine Minute zu ersetzen (vgl. ,Avtorskie varianty pravki“. RGB, fond 429, karton 3, edinica chranenija 21).

453 „Любовь у Бунина - это прежде всего любовь, в основе которой лежит исключительно физнческое влечение, однако это физическое влечение доведено у героев Бунинских рассказов до высшей степени - физическое влеченне - страсть“ (M. Kreps. „Elementy modemizma v rasskazach Bunina o ljubvi“. In: $N \leq 38$ [1979]: 59). 
Wahmehmung der Umgebung veranschaulichen das Eindringen des Transzendenten in das subjektive Empfinden der Protagonisten. Das bei Bunin ausgeweitete Spektrum dieser traditionellen Funktion von Naturerscheinungen in der Literatur umfaßt durch Blitzschläge ausgelöste Großbrände, Unwetter bzw. Gewitter, Regenschauer oder Dauerregen, Schneestürme bzw. starke Schneefalle und sternklare Năchte bzw. Mondschein. ${ }^{454}$

Das bewußte Wahmehmen der Natur durch die jeweilige zentrale Figur, das nach bewegenden Gefühlserlebnissen besonders intensiv erfolgt, steht für ein gesteigertes Empfinden des eigenen Selbst und der Verbindung mit der umgebenden Schöpfung. Das Leben wird mit allen funf Sinnen wahrgenommen, und der Protagonist tritt analog zum Liebeserlebnis aus seiner von den abstumpfenden Wiederholungen des Alltags geprägten Existenz heraus - für einen Augenblick höchsten Glücksempfindens oder tiefster Verzweiflung. Er steht dabei in einem stummen Zwiegespräch mit dem Universum, wie beispielsweise der Protagonist der Erzăhlung ,Zojka i Valerija“, der nach dem verwirrenden nachmittăglichen Zusammentreffen mit Zojka keinen Schlaf finden kann:

Но во дворе остановился: теплый сумрак, сладкая тишина, млечная белизна неба от несметных мелких звезд... Он пошел по двору, опять остановился, поднял голову: уходящая все глубже и глубже ввысь звездность и там какая-то страшная черно-синяя темнота, провалы куда-то ... и спокойствие, молчание, непонятная, великая пустыня, безжизненная и бесцельная красота мира ... безмолвная, вечная религиозность ночи ... и он один, лицом к лицу со всем этим, в бездне между небом и землей ... Он стал внутренне, без слов молиться о какой-то небесной милости, о чьей-то жалости $\mathrm{x}$ себе, с горькой радостью чувствуя свое соединение с небом и уже некоторое отрешение от себя, от своего тела ... (6: 252).

In dieser Zwiesprache mit dem Universum erweisen sich die Temmye allei als fiktionale Einkleidung der existentiellen, von westlichem und ostlichem (biblischem und buddhistischem $^{455}$ ) Gedankengut inspirierten Öberlegungen, die Bunin in seinem 1925 unter dem

454 GroBbrănde: „Pozdnij cas" (6: 203), „Volki“ (6: 235), „Voron“ (6: 380); Unwetter bzw. Gewitter: „Temnye allei“ (6: 175), „Stepa” (6: 191), „Natali“ (6: 321-322); Regengüsse: „Kavkaz" (6: 181), .Muza“ (6: 199), „Rusja“ (6: 210), „Antigona“ (6: 226-227), „V Parize“ (6: 276), „Parochod .Saratov“” (6: 372), .Mest”“ (6: 392); Schneestarme bzw. starke Schneefalle: „Tanja“ (6: 263-265), „V odnoj znakomoj ulice“ (6: 331), „Kuma“ (6: 341), „.Dubki”“ (6: 347-349), „Baryšnja Klara“ (6: 352), „Cistyj ponedel'nik" (6: 398); stemklare Năchte bzw. Mondschein: .Smaragd" (6: 230), „Volki" (6: 234). .Zojka i Valerija“ (6: 252), ..,Madrid““ (6:354), „Cholodnaja osen”“ (6: 367), „Kaceli“" (6: 397).

455 Mit dem Buddhismus beschaftigte sich Bunin, der primar unzweifelhaft von der russischen Kultur gepragt ist, seit den 1890 er Jahren. Seine Weltanschauung wurde davon sparbar beeinfluBt, wie vor allem seine Erzahlungen der 1910er Jahre belegen. In ihnen findet sich noch eine explizite Auseinandersetzung mit der buddhistischen Lehre, wahrend sie in den Erzahlungen der Temmye allei nur im Subtext (oder gar nicht) vorhanden ist. In den zeitgleich entstandenen Erzahlungen lassen sich keine derartigen Spuren mehr finden. 
Titel „Cikady“ (später: „Noz’“456) veröffentlichten philosophischen Monolog darlegt. In einem durch die Betrachtung des nächtlichen Himmels ausgelösten Gedankenstrom verleiht das erzählerische Ich seinen Gedanken zum Werden und Vergehen des Menschen, zur Bedeutung von Zeit und Raum sowie zum Bewußtsein der eigenen Existenz sprachliche Gestalt. Ausgehend von den mahnenden Worten des Predigers Salomo, sich nicht zu sehr im Nachdenken zu verlieren, da alles Irdische vergänglich sei, gelangt der Ich-Erzăhler zu der Erkenntnis, daß sein Wesen unwillkürlich nach Reflexion verlange, während es gleichzeitig darunter leide, den Denkprozeß weder abbrechen noch ihn wirklich verstehen zu können. Die in der Stille der Nacht lebensfroh zirpenden Zikaden gelten ihm als Symbol des-ihm offenkundig beneidenswert erscheinenden-unbewußten Eingebundenseins einer Kreatur in die Schöpfung: „Мир в них и они в нем, а я уже как бы со стороны гляжу на него.“457 Dem Menschen hingegen sei es als einzigem Lebewesen möglich, sich seiner Existenz und seiner Endlichkeit bewußt zu sein, doch nur wenige Menschen wie Dichter und Künstler, die über ein besonders bildhaftes und sinnliches Gedächtnis verfügten („особенно образной [чувственной] Памятью“458), seien in der Lage, die widersprüchlich erscheinende Spannung zwischen dem Lebenshunger und dem gleichzeitigen quälenden Wissen um die Vergänglichkeit desselben sowie den Konflikt zwischen dem Wunsch nach Selbstauslöschung und der Sehnsucht nach dem prallen Leben bewußt auszuhalten.

Bei diesen Überlegungen bezieht sich der Ich-Erzähler auf das buddhistische Konzept der zwölfgliedrigen Kette der „Bedingten Entstehung“ (Paticca-samupadda), die den Kreislauf des Lebens darstellt, und teilt die Menschen in zwei Kategorien ein: Die Angehörigen der einen, größeren Gruppe leben augenblicksbezogen und bleiben durch ihr Festhalten am Konzept einer vom Rest der Schöpfung getrennten Individualität und durch das tătige Streben nach materiellen Gütern nach buddhistischer Auffassung in metaphysischer

456 I. Bunin. „Nox'“. op.cit.: 297-308. Zur Rolle buddhistischen Gedankenguts in Bunins Kurzprosa der 1910er und 1920er Jahre vgl. J. Connolly. „Desire and Renunciation: Buddhist Elements in the Prose of Ivan Bunin“. In: Canadian Slavonic Papers 23 (1981) I: 17-18 sowie O. Solouchina. „O nravstvennofilosofskich vzgljadach I. A. Bunina“. In: Russkaja literatura 4 (1984): 47-59. Vergleichbare Überlegungen finden sich auch in Osvobozdenie Tolstogo, Bunins 1937 verfaßter retrospektiver Auseinandersetzung mit dem Leben und Werk Tolstojs. Obwohl eine Reihe von Erzahlungen Bunins deutliche buddhistische Bezuge aufweisen (2.B. „Brat'ja“, 1914; „Sny Canga“, 1916; „Gorod car'ja carej“, 1924), sollte Bunins Interesse am Buddhismus nicht aberbewertet werden, denn im Lauf seines Lebens hat er sich mit verschiedenen Religionen und Weltanschauungen auseinandergesetz. In den Temmye allei etwa sind Anklänge auch an die christlich-orthodoxe Religion zu finden, obgleich die Bindung an buddhistische Konzepte durch die Betonung des Lebens im Augenblick und dem Ziel der Verschmelzung mit dem Universum von entscheidender Bedeutung für das Verstăndnis der Erzăhlungen ist.

457 1. Bunin. .Nox'”. op.cit.: 299.

458 I. Bunin. .Nox’.. op.cit.: 302. 
Unwissenheit gefangen; in der Kette der Existenz ist diese Unwissenheit die Grundlage für ein weiteres unbewußtes Leben als Glied dieser Kette. Der zweiten, kleineren Gruppe gehören jene Menschen an, die sich der Vergänglichkeit alles Irdischen und damit des in buddhistischem Sinn an sich leidvollen Charakters der Existenz bewußt sind, die Träumer und Nachdenker, die sich danach sehnen, aus der Kette der Existenz auszuscheren und im universellen Sein aufzugehen - und die gleichzeitig darunter leiden, nicht einen Augenblick ihres gegenwärtigen Daseins festhalten zu können. Ihrem Bewußtsein um die Eitelkeit irdischer Freuden zum Trotz seien sie dem Ich-Erzähler zufolge den weltlichen Verlockungen noch stärker ausgeliefert als die Mitglieder der ersten Gruppe und daher hinund hergerissen zwischen dem Wunsch nach dem Genuß der sinnlichen Freuden, die sie an die Erde binden, und der Sehnsucht nach Selbstauslöschung.

Diese Suche nach einer wenn auch nur kurzzeitigen Aufhebung der Grenzen der Individualităt treibt auch zahlreiche Protagonisten der Temnye allei. Als einzige Möglichkeit neben dem Tod kann Bunin zufolge ein intensives, nicht zwangsläufig intimes Liebeserlebnis dem Menschen $\mathrm{zu}$ einem (rasch vorubergehenden) Selbstvergessen und damit einer Transzendenz des eigenen Seins verhelfen, die im Idealfall eine nachhaltige Bewußtseinsveränderung nach sich zieht.

Am deutlichsten wird der metaphysische Aspekt der Liebe in den Temmye allei symbolisiert durch die in den verschiedenen Erzahlungen zahlreich vertretenen Himmelserscheinungen bei Tag und vor allem bei Nacht. Die Gestime sind nicht auf ihre Funktion als Leuchtkörper oder natürliche Kulisse beschränkt, sondern bilden beim jeweiligen Protagonisten den Auslöser für die Entstehung des Bewußtseins des menschlichen Eingebundenseins in den Allzusammenhang. Zudem erfordern sie zum einen den Blick nach oben, gewissermaßen in die geistige Sphäre, um wahrgenommen werden zu können, zum anderen verlassen sowohl Protagonisten als auch Rezipienten zumindest geistig die überwiegend russischen Schauplätze und unterstreichen durch ihren Blick in den die ganze Welt umspannenden Himmel den universalen Charakter der Erzählungen.

Die Sonne galt Bunin bereits in seinem Fruhwerk als Symbol des Lebens und der Lebensfreude. ${ }^{459}$ Diese Funktion kommt ihr auch in den Temnye allei zu, auch wenn sie selten explizit genannt wird, sondern hauptsächlich indirekt über die Erwähnung von Hitze oder die Schilderung von Lichtspielen und Reflexionen in Erscheinung tritt, wie beispielsweise in den Erzählungen „Kavkaz“ („Горячее солнце было уже сильно, чисто и 
радостно“, 6: 182) und „Mest”“ („Солнечный жар тек все ryuе“, 6: 392). In der Regel wird die Sonne als Verkörperung des Lebens kontrastiv in die Năhe des Todes gerückt, am ausdrucksstärksten in den Erzählungen „V Pariže“ („Когда она [...] возврашалась с кладбища, был милый весенный день [...] и все говорило о жизни юной, вечной - и о ее, конченой“, 6: 281) und „Саsovnја“ („И чем жарче и радостней печет солнце, тем холоднее дует из тьмы, из окна“, 6: 412). ${ }^{460}$ Ein metaphorischer Gebrauch der Sonne läßt sich lediglich in der Erzählung "Natali“ nachweisen: die strahlenden dunklen Augen der Protagonistin, die einen Vergleich mit schwarzen Sonnen („черные солнца“, 6: 303) nahelegen, bergen bereits zu Beginn der Erzählung einen ersten Hinweis auf kommende verhängnisvolle Ereignisse.

Eine weitaus größere Rolle als das Tageslicht spielt in den Erzählungen der Temnye allei die Nacht, in der das Alltägliche seinen prägenden Einfluß auf den Menschen verliert und elementare Kräfte die Oberhand gewinnen, die die vertraute Umgebung fremd wirken lassen („заколдованно-светлая ночь“, „Muza“, 6: 199). Jenseits vom Getriebe des Alltags fordem Dunkelheit und Stille die innere Bereitschaft des Menschen, sich existentiellen Fragen und/oder der Unendlichkeit zu öffnen und sich vom rein Irdischen zu lösen:

День есть час делания, час неволи. День во времени, в пространстве. Деньисполнение земного долга, служения земному бытию. [...] Что есть ночь? То, что раб времени и пространства на некий срок свободен, что снято с него его земное назначение, его земное имя, звание. ${ }^{461}$

In der Nacht oder am späten Abend kommt es zu verhängnisvollen Begegnungen („Natali“, „Voron“), zu Liebeserlebnissen („Rusja“, „Antigona“, „Madrid“") oder gar zu Morden („Dubki““, „Baryšnja Klara“); allein oder Seite an Seite stehen die Protagonisten dem Universum gegenüber. Mondschein- und sternenlichterhellte Nächte mit ihrem Gegensatz von Hell und Dunkel haben in den Temnye allei verschiedene Funktionen: Zum einen bilden sie eine lyrische und gleichzeitig kontrastreiche Kulisse, die mit wenigen Ausnahmen in jeder Erzählung eine Rolle spielt ${ }^{462}$, zum anderen übernehmen Mond und Sterne eine wichtige verbindende Funktion zwischen Himmel und Erde bzw. zwischen

460 In seinem Artikel "Les Moirés crépusculaires et le soleil éclatant de l'exil: Les Allées sombres" weist Jacques Catteau darauf hin, daß auch in Bunins Tagebuchnotizen Gedanken zum Tod haufig an sonnigen Tagen auftreten (In: Bounine revisité. op.cit.: 83-89). Diese Feststellung unterstreicht die Bedeutung dieser Bipolaritat in Bunins Weltanschauung.

461 I. Bunin. „Noc'“. op.cit.: 300.

462 Keine Rolle spielt die Nacht lediglich in den Erzahlungen „Galja Ganskaja“, „Vtoroj kofejnik“ sowie in den Skizzen „Kamarg“ und „Sto rupij”. In den Erzahlungen „Temnye allei“" und „Casovnja“ ersetzt die Dunkelheit der Allee bzw. des Grabgewolbes die Nacht und sorgt solcherart fur einen entsprechenden Kontrapunkt. 
Kosmos und Mensch. Dem Mond werden dabei häufig menschliche Eigenschaften zugeschrieben, wie aus den folgenden Beispielen ersichtlich ist:

точно какое-то дивное существо, пристально смотрела поздняя луна („Kavkaz“, 6: 183); „низкой, бедной луной („Мuza“, 6: 200); неподвижным ломтем дыни краснела вдали [...] поздняя луна (,Zojka i Valerija“, 6: 254); молодой месяц, не суливший ничего доброго: блестела одна половина его, но как прозрачная паутина видна была и другая, а все вместе напоминало желудь („Natali“, 6: 319, Bild nochmals aufgegriffen auf 6: 320); Светлый круг месяца [...] как будто замер на одном месте, как будто выржидательно глядел (,Natali“, 6: 329-330); Полный месяц [...], какой-то светящийся череп („Čistyj ponedel'nik“, 6: 409).

Ergänzen lassen sich diese Zitate noch um die zweifache Erwähnung der „Mondscheinsonate" Ludwig van Beethovens in der Erzählung "Čistyj ponedel'nik“ (6: 399 und 407), in der der Mondschein über das Medium Musik in die Stadtwohnung hineingetragen wird.

Die Symbolkraft der Sterne in Bunins Werk wurde in der Sekundărliteratur mehrfach hervorgehoben. ${ }^{463}$ Bereits in "Noc'“ diente ihm der Jupiter, das Symbol fur die innere Sinnfindung, nicht nur als Leitmotiv, sondern als Künder einer anderen Welt: „Он кажется маленькой луной какого-го иного мира." ${ }^{464}$ Auch in den Temnye allei finden sich zahlreiche Beispiele für die Mittlerfunktion der Sterne, und sollten einmal auf Grund der Lichtreflexion am nächtlichen Himmel der Großstadt keine Sterne sichtbar sein, verfăhrt Bunin ebenso wie im Falle der "Mondscheinsonate“ und sorgt durch die Erwăhnung eines Kinos mit dem Namen „Etoile“ („V Pariže", 6: 275) für kosmische Präsenz. Dieser Vorgehensweise vergleichbar sind die Beschreibungen der silberfarbenen Sonnenreflexionen auf dem Meer („крупными серебрянными звездами“, „Mest”“, 6: 388) oder der funkensprühenden Oberleitungen einer Straßenbahn („сыпались с проводов зеленые звезды“, „Сistyj ponedel'nik“, 6: 398). In der Erzählung „Genrich“ sind die Auswirkungen des Alkoholrausches bei dem Protagonisten Ursache für sehr starken Schwindel mit entsprechenden Ausprägungen: „упал навзничь и тотчас головокружительно полетел в бездонную темноту, испещренную огненными звездами“" (6:300). Auch auf dem Baldachin eines Pariser Leichenwagens finden sich Sterne, die von anderen Sphären künden („свидетельствуют о небесах“, 6: 206).

In der Regel bleiben die Sterne namenlos-was angesichts Bunins umfangreicher Kenntnisse der Fauna, Flora und auch der Himmelskörper sowie seiner Neigung zur präzi-

$463 \mathrm{Vgl}$. Z.B. E. Sirina. „Idejno-chudožstvennye funkcii pejzaza ...”. op.cit.: 193; A. Ter-Abramjanc. .Sozvezdija Ivana Bunina (obrazy zvezdnogo neba v tvorcestve Bunina)”. op.cit.: 112: I. Zielke. Text und Metapher. op.cit.: 152ff.

464 I. Bunin. .Noc ”“. Op.cit.: 99. 
sen Benennung auch von Details verwundert ${ }^{465}$-, als einziger Stern wird Jupiter namentlich erwähnt in der Erzăhlung „Natali“ (6: 325): er leuchtet hell am Tag der Beerdigung von Natalis Mann. Für Mešcerskij wird er zu einem Symbol seines Verlusts und schlägt solcherart eine Brücke in die Vergangenheit: „И молодость, красота всего этого, и мысль о ее красоте и молодости и о том, что она любила меня когда-то, вдруг так разорвали мне сердце скорбью, счастьем и потребности любви“ (6: 325). Die Metapher vom weinenden Stern prägt die Erzählung "Smaragd": Nachdem zunächst die angebotene Interpretation als Bezeichnung für einen Edelstein angenommen wird, wandelt sich diese im Laufe der Erzählung - der nächtliche Himmel erhält menschliche Züge und macht so das gesamte Ausmaß der Traurigkeit der jungen Frau deutlich. Das Tränenmotiv findet sich im übrigen auch in Bezug auf den Mond in der Erzählung „Tапја“: „н высокая луна апмазно слезится в них“ (6: 257). In der Erzăhlung „Pozdnij cas“ wird ein ebenfalls grüner Stern für den Ich-Erzähler zum Botschafter aus einer anderen Welt, wăhrend er eine glückselige Nacht mit seiner Geliebten auf einer Bank im Garten verbringt: „... а за ними выглядывавшую из-за какого-то другого сада одинокую зеленую звезду, что-то беззвучно говорившую“ (6: 205). Wăhrend seiner Erinnerungsreise durch Zeit und Raum Jahre später entdeckt er diesen Stern erneut, der nun gleichermaßen zu einer Brücke in die Vergangenheit wie zu einem Symbol der Zeitlosigkeit (aber auch der Sprachlosigkeit) wird im Angesicht der Ewigkeit und des Todes: „Из-за стены же дивным самоцветом глядела невысокая зеленая звезда, лучистая, как та, прежняя, но немая, неподвижная“ (6: 207).

Das Dunkel der Nacht bringt Trennendes zum Verschwinden, die nächtlichen Gestime werden zu Wegbegleitern und Helfern bei der Überwindung scheinbar unüberbrückbarer Distanzen in Zeit und Raum. Besonders eindringlich hat Bunin die kosmische Einbindung des Menschen in der Erzăhlung ,Cholodnaja osen“" umgesetzt: Bevor der Protagonist am folgenden Tag in den Krieg ziehen muß, verbringt er gemeinsam mit seiner Verlobten einen letzten gemeinsamen Abend, den das Paar mit einem Spaziergang durch den nächtlichen herbstlichen Garten beschließt. Unter dem sternenübersäten Himmel und dem roten Schein des Mondes faßt der junge Mann angesichts des drohenden Todes seine Hoffnung auf ein Wiedersehen im Jenseits in folgende Worte, die seiner Braut ihr Leben lang tröstlich im Gedächtnis bleiben werden und einmal mehr die Bedeutung eines einzigen Augen-

$465 \mathrm{Als}$ Beleg fur Bunins Kenntnisse der Astronomie darf nicht zuletza die unveroffentlichte Erzahlung "Lizok" (1943) dienen, die mit ihren Betrachtungen des náchtlichen Himmels ganz im Zeichen der Sterne steht (LRA. MS.1066/165-167). 
blicks für ein Menschenleben illustrieren und ihm historische, gar ewige Dimensionen verleihen: „Ну что-ж, если убьют, я буду ждать тебя там. Ты поживи, порадуйся на свете, потом приходи ко мне“ (6: 369). Der unaufhörlich fließende Zeitstrom wird unterbrochen, ein einzelner Augenblick wird herausgehoben und ist mit dem Strom nur noch über einen Gegensatz verbunden (vgl. auch hier wieder den Einsatz des Stilmittels Kontrast).

So gilt Bunin der Kosmos ${ }^{466}$ vor allem als Synıbol für die Ewigkeit, das nicht nur mahnend auf die Vergänglichkeit irdischer Freuden hinweist, sondern auch ein trơstliches Versprechen gibt hinsichtlich der Unendlichkeit allen Seins und damit dem Tod etwas von seinem Schrecken nimmt. Im Alltag allerdings ist diese Erfahrung der Verbundenheit mit dem Kosmos nicht möglich, es bedarf des besonderen Augenblicks, der besonderen Situation - etwa der des Reisens -, um die Einheit mit der gesamten Schöpfung zu verspüren. Das in diesem Moment erhöhte Bewußtsein des Lebens und der Wunsch nach Auslöschung dieses Bewußtseins kann gewertet werden als Ziel der Suche nach dem Sinn des Lebens oder vielmehr als wert- und sinnverleihende Erfahrung wăhrend der spirituellen Reise des Lebens.

\subsubsection{Eros und Reisen}

Bis zu seiner Emigration nach Frankreich im Jahre 1920 bildeten ausgedehnte Reisen sowohl innerhalb Rußlands als auch in das Ausland (Westeuropa, Naher Osten) einen wichtigen Bestandteil in Bunins Leben, wie er in einem Interview mit einem Journalisten der Zeitung „Golos Moskvy“ aus dem Jahr 1912 bekannte: „Путешествия играли в моей жизни огромную роль.“467 Nach seiner Emigration beschränkte sich seine Reisetätigkeit im wesentlichen auf Fahrten zwischen Paris und Südfrankreich - für einen Emigranten war es bedeutend schwieriger, die erforderlichen Auslandsvisa zu erhalten -, und so reiste

466 Die These Ol'ga Slivickajas, daB der Mensch in Bunins Weltanschauung als Schauplatz des Spiels kosmischer Krafte dient, denen er wehrlos ausgeliefert ist, hat etwas fur sich, vor allem wenn man die abrupten und aberwiegend tragischen Erzahlschlosse betrachtet. Diese Interpretation ist jedoch etwas zu einseitig und wird dem Menschen nicht ganz gerecht, indem sie ihn lediglich zum Spielball macht und rationale bzw. gesellschaftlichen Konventionen geschuldete Entscheidungen, wie die des Protagonisten in der Erzahlung ."Temnye allei“", nicht berucksichtigt. Vgl. O. Slivickaja. .Celovek Bunina kak kosmos i lienost"“. Op.cit:: 70.

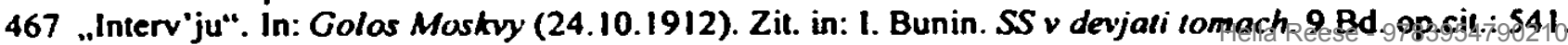


Bunin in den Jahren bis zum Ausbruch des Zweiten Weltkriegs lediglich 1926 auf Einladung des PEN Club nach London ${ }^{468}, 1933$ zur Verleihung des Nobelpreises für Literatur nach Stockholm und im Oktober 1936 in verschiedene deutsche Städte sowie 1937 uber die Schweiz und Italien nach Jugoslawien. Seine letzte Reise vor dem Ausbruch des Zweiten Weltkriegs führte ihn 1938 für einige Wochen nach Estland und Lettland. Abgesehen von der bereits erwähnten „Flucht“" nach Südwestfrankreich (vgl. Kap. 3.1.1), zweier kurzer Reisen nach Paris im Jahre 1940 und gelegentlichen Ausflügen nach Cannes oder Nizza verbrachte Bunin die Kriegsjahre ausschließlich in Grasse, und bereits Ende 1939 äußerte er in einem Brief an Boris Zajcev niedergeschlagen:

А то все солнце и солнце, и я непрерывно томился тайным желанием куда-то ехать, кого-то встретить - и вместе с тем чувством, что нигде ничего и никого не встретишь, - давно, давно знакомым чувством, - и потому по целым дням все читал и читал, - как уже давным давно только это и делаю. ${ }^{469}$

Seine Reiseerfahrungen (nicht zwangsläufig seine Reiseerlebnisse) hat Bunin stets in sein literarisches Werk eingeflochten. Die Reisefreude bzw. Rastlosigkeit, die bereits zentrale Figuren früherer Erzählungen ${ }^{\mathbf{4 7 0}}$ auszeichnet, findet sich auch in den Erzählungen der Temnye allei, überwiegend bei den männlichen Protagonisten (vgl. Kap. 7.1). Der Weg darf somit (neben der Nacht) als ein zentrales Motiv dieses Buches sowohl im konkreten Sinne des Zurucklegens lokaler Entfernungen als auch im übertragenen Sinne des Durchmessens temporärer Distanzen betrachtet werden. Die außergewöhnliche Situation des Reisens ermöglicht es Bunin, sich ganz auf diesen Lebensausschnitt zu konzentrieren und die alltäglichen Lebensumstände und Bindungen des Reisenden außer acht zu lassen. Die Darstellung einer einmaligen Situation im Gegensatz zu dem von Wiederholung geprägten Alltag verstärkt den Effekt des Heraustretens des Protagonisten aus seiner Existenz und ermöglicht es ihm zudem, geistigen Stillstand zu vermeiden. ${ }^{471}$

Unter Berücksichtigung auch kurzer Fahrten etwa von der Stadt zur Datscha, wie beispielsweise in den Erzählungen „Muza“, „Zojka i Valerija“ und „Kuma“, gibt es nur wenige Erzählungen, in denen kein Ortswechsel stattfindet oder nicht zumindest angesprochen wird. Stillstand im wörtlichen und übertragenen Sinne herrscht lediglich in den Momentaufnahmen „Krasavica“, „Smaragd“, „Vtoroj kofejnik“, „Kačeli“ und „Časovnja“.

468 I. Bunin. „Nobelevskie dni“. In: ders. SS v devjati tomach. 9.Bd. op.cit.: 325.

469 Brief vom 12.12.1939. Zit. in: „Pis'ma I. Bunina k B. Zajcevu“. In: Nz 136 (1979): 131.

470 Als Beispiele wăren unter anderem die folgenden E.rzălungen anzufuhren: ..Brat'ja“ (1914), „Gospodin iz San-Francisko“ (1915), .Sny Canga“ (1916), „V nocnom more“" (1923) und .Solnecnyj udar" (1925).

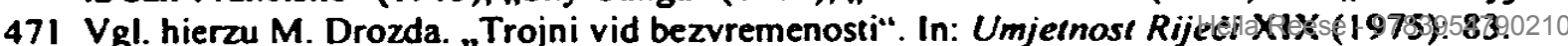


Das in den Temnye allei am hăufigsten genutzte Verkehrsmittel ist die Eisenbahn, für Bunin das Symbol des Unterwegsseins schlechthin, wie er in einem Gespräch mit Irina Odoevceva feststellte: „Рельсы [...] всегда будят во мне мою ненасытную страсть к путешествиям. Ведь больше всего на свете я люблю путешествия. И воспоминания о них. Я объездил чуть ли не весь мир.““72 Die Eisenbahn bringt Menschen zusammen oder auseinander - in 14 Erzählungen findet sie Erwähnung mit unterschiedlichen Funktionen: Während sie in den Erzăhlungen „Temnye allei“, „Stepa“, „Muza“, „Antigona“, "Tanja“, „Natali“, „Kuma“, „Baryšnja Klara“ und „Mest”“ lediglich als Fortbewegungsmittel in Erscheinung tritt, dient sie darüber hinaus in den Erzählungen „Kavkaz", „Rusja“, "Genrich“, „Nacalo“ und „Kamarg“ als Schauplatz und gerät in der Erzăhlung „Zojka i Valerija" gar zum Instrument fur Levickijs Selbstmord. ${ }^{473}$ Andere Verkehrsmittel wie die Kutsche oder das Schiff sowie Reitpferde werden bedeutend seltener benutzt. Moderne Verkehrsmittel wie Metro und Auto verwendet Bunin nur in der Erzählung „V Pariže“.

Für die zentralen Figuren in den Temnye allei bedeutet das Reisen einen Ausbruch aus dem Gewohnten, einen Bruch mit dem Alltäglichen. In diesem Punkt sind die Reisen einem intensiven Liebeserlebnis vergleichbar, das gleichfalls eine Grenzüberschreitung ermöglicht. Die in diesem Buch unternommenen Reisen (und die durch sie ermöglichten Begegnungen) sind in jedem Fall so bedeutungsvoll, daß sie einen scharfen Kontrast sowohl zum Alltag als zum Rest des Lebens darstellen. Eine Reise verspricht interessante, wenn auch möglicherweise flüchtige Begegnungen, die nicht zwangslăufig in ein Liebesabenteuer münden müssen (der Gedanke daran liegt aber auch nicht fern, und ein rein sexuelles Abenteuer scheint grundsätzlich möglich); in jedem Fall wird die Phantasie angeregt und die Bereitschaft für das Schließen von Bekanntschaften geschaffen, wie der Protagonist in "Genrich“ sinniert: „.... а главное, всегда кажется, что где-то там будет что-то особенное счастливое, какая-нибудь встреча ..." (6: 290). Eine Entgegnung auf die Wahrscheinlichkeit einer Erfullung dieser Sehnsucht erhält er gewissermaßen von dem desillusionierten Protagonisten der Erzählung „V Pariže“: „Знаете, на свете так мало счастливых встреч...“ (6: 275). Da diese Begegnungen fern vom Alltag stattfinden,

472 Gesprach mit Irina Odoevceva im Jahre 1947. Zit. in: 1. Odoevceva. Na beregach Serny. op.cit.: 257.

473 Die Eisenbahn verwendete Bunin bereits in seinem Fruhwerk nicht allein als reines Fortbewegungsmittel, sondern schrieb ihr Symbolkraft zu: „... Bunin often utilizes railroads and trains as emblem of the powerful, impersonal forces of change or progress" in the Russian countryside" (J. Connolly. Ivan Bunin. op.cit.: 24). Auch in den Erzahlungen der Temmye allei verwendet Bunin die Eisenbahn als Symbol fur Verănderungen, die jedoch ausschlieBlich das personliche Leben der zentralen Figuren betreffen und keine Technologie- oder Sozialkritik beinhalten. Er hat somit den Funktionsbereich vom gesellschaftlichen in den privaten Raum verlagert. 
ermöglichen sie fundamentale und prägende emotionale Erfahrungen. In den Erzăhlungen der Temnye allei ist der Weg das $\mathrm{Ziel}^{474}$, denn allein die physische Bewegung wie die geistige Beweglichkeit, die erst die Voraussetzung schafft für eine intensive Begegnung, eröffnen dem Menschen die Möglichkeit existentieller Erfahrungen.

Eine Reise birgt vielerlei Möglichkeiten zu Liebesbegegnungen im weitesten Sinne in sich: In den Erzählungen der Temnye allei reicht das Spektrum von stillen Beobachtungen einer unbekannten, für den Protagonisten höchst reizvollen Frau („Načalo“, „Sto rupij“, „Kamarg“) über Reisebekanntschaften intimerer Natur („Vizitnye kartocki“, „Mest”“) und gemeinsame Reisen bzw. Spazierfahrten von Liebespaaren („Kavkaz“, "Genrich“, "Volki") bis zu kurzlebigen Beziehungen im Rahmen eines Ferienaufenthaltes oder einer Geschäftsreise („Zojka i Valerija“, „Antigona“, „Kuma“) und gewaltsamen, rein sexuell orientierten Begegnungen („Stepa“, „Durocka“, „Gost'“). Auch können Reisen zu tatsächlichen oder rein gedanklichen Wiederbegegnungen mit vergangenen Liebesbeziehungen führen („Temnye allei“, „Rusja“). Durch den ephemeren Charakter, der einer Reise innewohnt, erzielt Bunin einen bemerkenswerten Verdopplungseffekt, der die Kürze und Unbeständigkeit der Liebe eindringlich unterstreicht.

Ferner besteht zwischen der Fortbewegung und intimen Begegnungen jenseits der erhöhten Empfindsamkeit eine weitere interessante Parallele: Der Reisende wie der Liebende bewegt sich nicht nur vom Bekannten zum Unbekannten, wobei er sich hăufig einer unruhigen Euphorie nicht erwehren kann; sein Ziel besteht vielmehr darin, dieses Unbekannte bzw. den anderen zu um-, zu erfassen oder sich gar in ihm zu verlieren - er strebt sowohl danach, das Gefühl seiner Individualität im Kontrast zum anderen zu erhöhen als auch nach einer Auflösung seiner eigenen körperlichen und geistigen Grenzen, die es ermöglicht, eine tiefere Verbindung mit dem anderen oder mit der göttlichen Instanz einzugehen (vgl. Kap. 8.1.3). ${ }^{475}$

Die Grenzüberschreitung erschöpft sich Bunin zufolge aber nicht im Durchmessen und Überwinden răumlicher (das heißt auch körperlicher) und geistiger Distanzen. Sie ermöglicht zudem die Erfahrung der Aufhebung zeitlicher Begrenzungen, macht die eigene Vergangenheit ebenso spürbar wie das Wissen um das Eingebundensein in die Vergangenheit der Menschheit:

474 Dies zeigt sich auch in den Liebesbeziehungen der männlichen zentralen Figuren, die sich auf dem Weg zur Frau, zur Liebe befinden; ihre Suche nach Liebe findet jedoch hăufig genug nur fur wenige Momente Erfullung, dann entgleitet ihnen die Frau wieder - so wie sich auch eine Reise nur kurzaeitig unterbrechen laßt, um noch als Reise gelten zu dören.

475 Vgl. D. Richards. .Comprehending the Beauty of the World ... “. op.cittel|s23ese - 9783954790210 
Всю жизнь, сознательно и бессознательно, преодолеваю, разрушаю я пространство, время, формы. Неутомила и безмерна моя жажда жизни, и я живу не только своим настояшим, но и всем своим прошльм, не только своей собственной жизнью, но и тысячами чужих, всем, что современно мне, и тем, что там, в тумане самых дальних веков. ${ }^{476}$

Angesichts dieser Art inhärenter Erinnerung verliert die Bedrohung des Lebens durch den Tod zwar einerseits an Schrecken; andererseits mahnt seine stete Präsenz zum intensiven Wahrnehmen des Lebens.

\subsubsection{Der Tod als Gegenkraft und Gegenspieler der Liebe}

Die untrennbare Verknüpfung von Liebe und Tod zeigt sich auf zweierlei Weise: In rund der Hălfte aller 38 Erzählungen endet die jeweilige Liebesgeschichte mit dem Tod einer der zentralen Figuren bzw. in einem Fall mit einem Mordversuch (,Rusja“) ${ }^{477}$; in etwa ebenso vielen Erzăhlungen bleiben zwar beide Partner am Leben, der Tod ist dennoch stets als dunkler Schatten, als reale Bedrohung oder in Form einer dräuenden Trennung präsent ${ }^{478}$ : Während beispielsweise in den Erzählungen "Temnye allei“ und „Muza“ eine gewisse Todessehnsucht artikuliert wird (,... сколько раз я хотела руки на себя наложить ...“, 6: 177; „Я не могу жить без тебя, за одни эти коленн, за юбку, за валенки готов отдать жизнь!“, 6: 201), haften in verschiedenen anderen Erzählungen dem Liebesakt oder Momenten großer Gefuhlsintensităt tơdliche Züge an:

Она [...] воскликнула в сладком, как бы предсмертном отчаянии: „Aх!““ (,Stepa“, 6: 195); Барин! Я на весь дом закричу! - А я тебя задушу. Смирно! (.Gost”“, 6: 233); Потом он ее, как мертвую, положил на койу („Vizitnye kartoðki“, 6: 241); она побледнела до гробовой синевы („Reغ̌noj traktir", 6: 338); ту мертвенную, но прекрасную бледность („Načalo“, 6: 344); я взял ее безжизненно висевшую вдоль бедра руку („Voron“, 6: 380).

476 I. Bunin. „Noc ${ }^{\cdots \cdots}$. op.cit.: 305.

477 Die Todesursachen in den folgenden 16 Erăhlungen gliedern sich wie folgt: Eingriff ubernaturlicher Krafte (.Ballada"), naturlicher bzw. kriegsinduzierter Tod (.,Pozdnij cas", "Krasavica“. "Tanja“, „V Parize“, „Natali“, „Cholodnaja osen"“), Selbstmord (.Kavkaz", "Zojka i Valerija”, .Galja Ganskaja”. .Zeleznaja Serst"“. „Casovnja“) und Mord (..Genrich“, ...Dubki”“. .Baryšnja Klara“, ..Parochod .Saratov'“).

478 Trennungen bzw. kurzfristige Liebesbeziehungen werden in den folgenden 18 Erzahlungen thematisier: .Temnye allei“, „Stepa“, .Muza“, ..Durocka“, „Antigona“, „Smaragd“”, „Gost”“, „Volki”, .Vizitnye kartoxki", „V odnoj znakomoj ulice". ..Re飞noj traktir". .Kuma". .Nacalo", ...Madrid".. . Vtoroj kofejnik". ."Voron". ..Mest"“ und ..Cistyj ponedel'nik“. Die vier Erzăhlungen „Krasavica“, ..Kamarg". ..Sto rupij" und "Kaceli" schließlich sind derart auf den Augenblick zugeschnitten, daß ihr Ende in dieser Hinsicht offen bleiben muß. 
Sowohl die Todesursachen als auch die Trennungsgründe in den einzelnen Erzählungen sind von unerheblicher Bedeutung und austauschbar, die Berichterstattung der entsprechenden tragischen Ereignisse erfolgt in einem vergleichsweise nüchternen, konstatierenden Tonfall; Erklärungen bietet Bunin nicht an, so daß der Rezipient gezwungen ist, seine eigenen Schlüse zu ziehen. Dem Todesthema in den Temnye allei liegt dasselbe Konzept zugrunde wie dem Liebesthema: Der Tod bzw. das Unglück trifft den Menschen ebenso überraschend wie ein unverhofftes Liebeserlebnis, wie ein Blitz aus heiterem Himmel; warnende Vorzeichen, wie etwa eine Krankheit mit einem prozessualen Verfall, gibt es ebensowenig wie die Möglichkeit, gegen das Unglück zu kämpfen - der Mensch ist dem Schicksal hilflos und unwiderruflich ausgeliefert. Da der Tod unausweichlich, eine Auflehnung sinnlos ist, bleibt dem Menschen lediglich, sich in sein Los zu fügen und der drohenden Gefahr stets gewärtig zu sein, um dem Schrecken die Spitze zu nehmen.

Die künstlerische Umsetzung dieses Konzepts in den Erzählungen der Temnye allei darf als gelungen gewertet werden, da sich bei fortschreitender Lektüre die Todesfälle häufen und der Überraschungseffekt, der beim Lesen der Erzählschlüsse der ersten Erzählungen auftritt, sich abschwächt, bis in der Finalerzăhlung des Buches der potentielle Protagonist schon gar nicht mehr als Lebender präsentiert wird. Eine Verdichtung des Todesthemas låßt sich in den Erzählungen der "schwarzen Sonne“ am Ende des zweiten Komplexes feststellen (inklusive „Natali“, exklusive „Vizitnye kartocki“): In zwei Dreierblöcken folgen die drei möglichen Todesarten Selbstmord, Mord und natülicher Tod in identischer Abfolge aufeinander, verdeutlichen die Relevanz dieses Themas für die Temnye allei und stellen durch ihre Position sicher, daß die Kurzgeschichtenverknüpfung in der Mitte weder an Dichte noch an Spannung verliert.

So wird für den Leser der Tod schon bald ein vertrauter, wenn auch doppelgesichtiger Begleiter der Lektüre, der keinesfalls nur zerstörende, sondern auch schützende Funktion hat: Wahrend er als ungerecht erscheint, wenn er wie in den Erzählungen "Tanja“ und „Natali“ junges Glück zerstört, bewahrt er gleichzeitig die Liebe vor Abschwächung und Abnutzung durch die Routine des Alltags, fordert zu einem bewußten Leben auf und ist Wegbereiter einer nachträglichen, erinnernden Verklärung, die zu einer Überhöhung und Sinngebung des vergangenen Liebeserlebnisses fuhrt. Wird er freiwillig gewählt, so wie in den Erzählungen „Kavkaz“, „Zojka i Valerija“, „Galja Ganskaja“, „Železnaja Šerst”“ und "Časovnja“, so erscheint der Tod nicht als schreckliches Ereignis für die handelnde zentrale Figur, sondern gleichsam als Befreiung von einer schweren Bürde, von der Erdenlast, von den Liebe und Leidenschaft innewohnenden Begierden und Widerspruichen sowie als 
ein Akt der Selbstbestimmung, um dem Leiden zu entgehen, das die Liebe nach buddhistischer Auffassung durch das Klammern an das Leben mit sich bringt. In der Erzählung "Kavkaz" wird er geradezu zelebriert und steht damit in krassem Gegensatz zu dem wenig Sympathie erweckenden Bild, das zuvor von dem eifersüchtigen Offizier gezeichnet wurde:

[...] потом брился, надел чистое белье, белоснежный китель, позавтракал в своей гостинице на террасе ресторана, выпил бутылку шампанского, пил кофе с шартрезом, не спеша выкурил сигару. Возвғатясь в свой номер, он лег на диван и выстрелил себе в виски из двух револьверов. (6: 183).

Dem Tod stellt Bunin jedoch das blühende Leben und eine intensive sinnliche Wahrnehmung der Welt gegenüber, so daß festgehalten werden kann, daß ihm das düstere Thema nicht nur als mahnender Hinweis auf die Endlichkeit allen Daseins, sondern auch als Hintergrund gilt, vor dem sich die bunte Vielfalt des Lebens um so konturierter abhebt. ${ }^{479}$ Besonders eindringlich gelingt ihm dies bei den - angesichts der Vielzahl von Todesfällen - verblüffend seltenen Darstellungen von Beerdigungen oder Aufenthalten auf dem Friedhof. ${ }^{480}$ Als Paradebeispiel ist die Erzăhlung "Casovnja“ zu nennen mit ihrer Gegenüberstellung des eisigen Lufzzugs ${ }^{481}$ aus der Gruft und den brennenden Strahlen der Sonne. Eine ähnliche Kontrastbildung findet sich in den Erzăhlungen „V Pariže" und „Natali“" mit dem Hinweis auf Beerdigungen an wunderschönen Frühlingstagen. So führt das „Memento mori“ zum „Carpe diem“.

\subsubsection{Erinnerung: Reisen in die Vergangenheit}

Als Bindeglied zwischen der Liebe und dem Leben einerseits sowie dem Tod andererseits ist die Erinnerung in der einen oder anderen Form in jeder der 38 Erzählungen der Temnye

$479 \mathrm{Vgl}$. A. Zweers. "The Function of the Theme of Death in the Works of Ivan Bunin". In: Russian Literature 8 (1980): ... [...] it tums out to be the background theme that enables Bunin to bring out the acts of the living" (S. 164).

480. Die Ursache hierfur mag darin zu suchen sein, daß Bunin zwar vom Tod fasziniert war, den nachfolgenden rituellen Zeremonien jedoch auswich: „[Бунин] всегда боялся покойников, никогаа не ходил ни на панихиды, ни на отпевания" (Tagebucheintrag Vera Buninas vom 09.09.1945; zit. in: UB. 3.Bd. op.cit.: 179).

481 Der kalte Hauch ist interpretierbar als physisch spurbar gewordene Transformation der Erinnerung, als unsichtbares Band zwischen den Lebenden und den Toten, das Julian Connolly als Schlusselbegriff im Rahmen seiner Untersuchung der Gedichte und frahen Prosa Bunins identifizierte (vgl. J. Connolly. „Ivan Bunin and the Middle East: A Poetic Encounter". op.cit.: 128). 
allei präsent. Selbst in den Skizzen, die als Augenblicksschilderungen auf den ersten Blick statisch wirken, finden sich Hinweise zur Bedeutung der Erinnerung für den oder die Protagonisten: Während in „Krasavica“ eine Truhe an die verstorbene Mutter des kleinen Jungen erinnert und in „Casovnja“ Särge an den unglücklichen Onkel sowie weitere Vorfahren, verweist der Protagonist in "Smaragd“ auf in der Vergangenheit mehrfach Gesagtes. Ein Großteil der zentralen Figuren der Temnye allei wird mit der eigenen Vergangenheit oder mit der eines anderen Menschen konfrontiert. Allerdings wird dieser Zusammensto $B$ in Form eines Wiedersehens mit einem ehemals wichtigen Menschen nur in der Anfangserzählung „Temnye allei“, der Ankererzählung „Natali“ und einer der beiden Schlußerzählungen, „Čistyj ponedel'nik“, konkret ausgestaltet (vgl. Kap. 4.5). In den anderen Erzählungen wird die Reise in die Vergangenheit in verbaler Form vollzogen: im (auch gedanklichen) Selbstgespräch, in Gegenwart eines Zuhörers oder durch Hinweise des Erzăhlers. Hierbei kann entweder eine persönliche Erinnerung im Mittelpunkt der Erzăhlung stehen (z.B. „Rusja“) oder die Referenz auf die Vergangenheit in einer biographischen Randnotiz bestehen („севастопольский герой“, „Kaceli“, 6: 396).

Wie stark ein viele Jahre zurückliegender Augenblick das Leben eines Menschen prägen kann, zeigt besonders anschaulich die Erzählung „Cholodnaja osen"“. Eine russische Emigrantin mittleren Alters zieht am Ende ihres Rückblicks auf ihr bewegtes Leben die Bilanz, daß in ihrem Leben im Grunde nur der Abschiedsabend mit ihrem in den Krieg ziehenden Verlobten von Bedeutung gewesen sei, dessen Bedeutung sie jedoch im Augenblick des Erlebens nicht zu erfassen vermochte:

Но, вспоминая все то, что я пережила с тех пор, всегда спрашиваю себя: да, а что же все-таки было в моей жизни? И отвечаю себе: только тот холодный осенний вечер. Ужели он был когда-то? И все-таки был. И это все, что было в моей жизни,- остальное ненужный сон. (6: 371).

Der zuvor in aller Ausfuhrlichkeit beschriebene Abend steht hierbei in krassem Gegensatz zu den ubrigen Ereignissen in ihrem Leben, die die Erzählerin in stark gerafter Form präsentiert, obwohl sie viele Jahre mit bewegenden Begebenheiten umschließen (Verlust des gesamten Besitzes, Flucht, Tod des zweiten Ehemanns). Ein Erlebnis, das im Augenblick seines Geschehens weder für die erlebende Person noch für einen außenstehenden Betrachter auf Grund seiner Kürze lebensbestimmend wirkt, kann dem Leben eines Menschen seinen Stempel aufdrücken, im erinnernden und zusammenschauenden Rückblick an Wertigkeit gewinnen und das Vergessen Lügen strafen, so daß die Worte der Protagonistin aus der Titelerzählung als Motto für das gesamte Buch gelten dürfen: „Bce 
проходнт, да не все забывается“ („Temnye allei“, 6: 178 ${ }^{482}$ ). Vor allem Erinnerungen an Liebesbegegnungen hinterlassen ihre Spuren im Gedächtnis und in den Herzen der Menschen, wobei es Bunins in den Temnye allei dargelegten Liebeskonzeption zufolge im Leben nur eine einzige derart tief sich einprägende Begegnung geben kann, wie etwa beim Maler der Erzählung „Galja Ganskaja“: „Вероятно, у каждого из нас наһ̆дется какоенибудь особенно дорогое любовное воспоминание или какой-нибудь особенно тяжкий любовный грех“ (6: 282-283). Diese Feststellung führt zu der paradox anmutenden Erkenntnis des Protagonisten aus der Erzählung „Reěnoj traktir": ,... ведь ото всего остаются в душе жестокие следы, то есть воспоминания, которые особенно жестоки, мучительны, если воспоминается что-нибудь счастливое ...“ (6: 339). Fast ein Jahr nach Entstehung dieser Erzählung notiert Bunin in sein Tagebuch: „Уже давно, давно все мон былые радости стали для меня мукой воспоминаний!“483 Der Prozeß der Erinnerung kann auch Schmerzen bereiten, weil das Ausmaß dessen, was war und was man verloren hat, ins Bewußtsein dringt.

Für Bunin stellt die Erinnerung demzufolge nicht nur ein Phänomen der menschlichen Existenz dar; sie ist vor allem eine unverzichtbare Fähigkeit des Menschen, die bei der Beantwortung der Frage nach der Bedeutung des eigenen Lebens hilfreich sein kann. Die Poetisierung und Erhöhung oder auch die nachträgliche Wertschätzung vergangenen Erlebens, wie es häufig im Rückblick erfolgt (und im Moment des tatsächlichen Erlebens gar nicht möglich ist), erlauben es dem Menschen im nachhinein, die Minuten intensiven Glücks oder Unglücks zurückzuholen und sie dem Vergessen zu entreißen:

482 In der Frage nach dem Zusammenhang zwischen Vergănglichkeit und Vergessen kommunizien diese Erzahlung mit den Erzahlungen „Natali“ und „Cholodnaja osen”“. Die Feststellung „Bедь все на свете проходит" in „Natali" (6: 328) sowie die zweifelnde Überlegung ... [...] и неужели я все-таки забуду его в хакой-то срок-ведь все в хонце концов забывается?'“. der Protagonistin in "Cholodnaja osen" "' (6:369) finden ihre vonwegnehmende Antwort in der Erkenntnis der verlassenen Nadezda in "Temnye allei“: „Bсе проходит, да не все забывается“" („Temnye allei“, 6: 178). Somit ist bereits in der Eroffnungserzahlung des Buches und damit an prominenter Stelle die zentrale Aussage Bunins zum Wert der Erinnerung innerhalb des Lebensstromes plaziert und der Grundton fur alle folgenden Erzathlungen gesetz.

483 Tagebucheintrag Bunins vom 07.10.1944. Zit. in: UB. 3.Bd. op.cit.: 172. Auch am 29.10.1943 und 03.10.1949 finden sich Notizen, die ebenfalls von keiner heilsamen Wirkung der Erinnerung kanden: ,[...] на душе тихо и грустно, воспомннания“ bzw. „Все одни и те же думы, воспомннання. И все то же отчаяние: как невозвратимо, непоправимо!" (zit. in: UB. 3.Bd. op.cit.: 157 bzw. 193). Im September 1942 verzichtet Bunin gar wegen der Moglichkeit des Auslठsens von Erinnerungen auf einen Ausflug nach Cannes oder Nizza: ..[...] и все мысль: все это напрасно, будет только мука автобусамн - и мука воспоминаний монх прежних лет туг" (16.09.1942; zit. in: UB. 3.Bd. op.cit.: 140) Dennoch sei es gerade seine Fathigkeit zur Erinnerung, die den Menschen vom Tier unterscheide und dem Leben einen Sinn gebe und zudem das einzige, was ihm am Ende seines Lebens bleibe: „Кстати. еслн бы Вы знали, как больно и мне все! То есть воспоминания, которые теперь, ках у всех, чья жизнь кончена, единственное, что мне осталось“ (Brief an Teffi vom 21.03.1945. Zit. in: „Perepiska Téffi s I. A. i V. N. Buninymi 1939-1948“". op.cit.: 522). 
Мы живем всем тем, чем живем, лишь в той мере, в какой постигаем цену того, чем живем. Обычно эта цена очень мала: возвышается она лишь в минуты восторга - восторга счастия или несчастия, яркого сознания приобретения или потери; еще - в мннуты поэтического преображения прошлого в памяти. ${ }^{484}$

Die zitierte Aussage läßt keineswegs die Folgerung zu, daß Bunins Denken ausschließlich der Vergangenheit zugewandt war. Es war im Gegenteil sehr gegenwartsbezogen - der Stellenwert sinnlicher Elemente in seinem Werk ist hierfür Beleg genug. Zudem kann die Gegenwart nur dann als sinnvoll erfahren werden, wenn ihr durch die Reflexion der Vergangenheit Tiefe und Bedeutung verliehen wird. Darüber hinaus zeichnet sich die Erinnerung vor allem durch ihre bewahrende Funktion aus, die dem Menschen eine Verteidigungsmöglichkeit gegen das zerstörerische Werk der Zeit und des Todes an die Hand gibt. Unter diesem Aspekt bilden die Temnye allei einen sehr persönlichen, wenn auch teilweise transformierten Fundus von Erinnerungen des Menschen Bunin, der in ihnen das untergegangene alte Rußland wieder zum Leben erweckt und zumindest auf dem Papier unsterblich macht - und der damit belegt, daß er die von ihm in "Noc'“ formulierten Eigenschaften eines Schriftstellers besitzt:

Что это за разряд, что это за люди? Те, которых называют поэтами, художниками. Чем они должны обладать? Способностью особенно сильно чувствовать не только свое время, но и чужое, прошлое, не только свою страну, свое племя, но и другие, чужие, не только самого себя, но и прочих, - то есть, как принято говорить, способностью перевоплощения и, кроме того, особенно живой и особенно образной (чувственной) Памятью [sic].

Im folgenden Kapitel wird diese historische Dimension der Erinnerung nochmals zur Sprache kommen, denn es sind nicht nur die Protagonisten der Temnye allei, die Zeit und Raum durchmessen und Vergangenes zu neuem Leben erwecken, auch Bunin selbst begibt sich mit und durch seine Figuren auf eine Reise in die Vergangenheit.

\subsection{Erinnerung}

Die kulturhistorische Dimension der Erinnerung prägt diesen nachgelagerten zentralen Themenbereich der Temnye allei und kommt in der russischen Prägung des Buches zum 
Ausdruck. Das zeitgenössische Lesepublikum der Erzählungen der Temnye allei (als Einzelveröffentlichungen oder als Buch) bestand in der Mehrzahl aus russischen Emigranten, denen sowohl die Schauplätze als auch der kulturhistorische Hintergrund der Erzählungen aus persönlichem Erleben oder überliefertem Wissen vertraut waren - so gesehen handelt es sich bei den Temnye allei auch um einen Fundus gemeinsamer Erinnerungen einer bestimmten Gesellschaftsschicht, die Bunin in die Literatur transferiert und durch diese teilweise verblüffend detailgenaue Gedächtnisleistung vor dem Vergessen bewahrt hat. ${ }^{486}$

In den Skizzen „Sto rupij“ und „Kamarg“ reicht die Erinnerung zeitlich sogar bis in die Anfänge der Menschheitsgeschichte zurluck und illustriert damit die allein dem Menschen eignende Fähigkeit der historischen Erinnerung: Während in der Erzählung „Kamarg“ zunächst bei der Beschreibung einer Frau aus der Camargue irritierend erscheint, daß ein Bezug zu Asien hergestellt wird („Руки, сухие, индусские с мумийными пальцами [...]“, 6: 383) und die den Erzähler an Affen erinnernde Geschwindigkeit und Geschicklichkeit, mit der sie Pistazien schält (6: 383), betont wird, spielt die Erzählung „Sto rupij“ als einzige der Erzăhlungen der Temnye allei in Asien und stellt durch die Schildenung des Aussehens einer Frau einen Bezug zum Paradies als Wiege der Menschheit her: „[...] ресницы-подобие тех райских бабочек, что так волшебно мерцают на райских индийских цветах ...“ (6: 385). Hiermit ist auch eine weitere wichtige Funktion des Phänomens Erinnerung angesprochen: die des Bewußtmachens des menschlichen Eingebundenseins in den unaufhaltsamen Strom der Zeit. Gleichzeitig dient sie als wichtige Waffe im Kampf gegen den zerstörerischen Lauf der Zeit und die drohende Auslöschung durch den $\operatorname{Tod}^{487}$ und ermöglicht so nicht nur die Umdeutung von vergangenen Ereignissen im Lichte der Gegenwart und auf Grund in der Zwischenzeit gemachter Erfahrungen ${ }^{488}$, sondern lädt auch ein zu Reisen in die Vergangenheit.

486 Auch die jüngere Vergangenheit der Emigranten findet ihren Niederschlag in den Temme allei: In den Erzăhlungen ..V Parize“. .Cholodnaja osen "“ und ,Mest"“ thematisiert Bunin in stark verallgemeinemder, konzentrierter und teils klischeehafter Weise die haufig monatelange Flucht der Emigranten sowie ihr Alltagsleben in der neuen Heimat.

487 .Венец каждой человеческой жизни есть память о ней, - высшее, что обешают человеку над его гробом. зто память вечную“" (1. Bunin. „Noc'“. ор.cit.: 307).

488 D. Richards nennt als weitere wichtige Eigenschaft der Vergangenheit ihre durch die zeitliche Distanz bedingte magische Ausstrahlung. Vgl. ders. „Memory and Time Past: A Theme in the Works of Ivan Bunin“. In: Forum for Modern Language Siudies 7 (1971): 159. 


\subsubsection{Der Tod des alten Rußland - Requiem für eine verlorene Heimat}

Am 20. Januar 1944 notierte Bunin in sein Tagebuch:

„Просмотрел свои заметки о прежней России. Все думаю, если бы дожить, попасть в P[оссию]! А зачем? Старость уцелевших (и женщин, с которыми я когда-то), кладбище всего, чем жил когда-то ...“489

Die Spurensuche Bunins, die zwischen den Zeilen der Erzählungen der Temnye allei durchscheint, wird dem Leser erst nach der Lektüre mehrerer Erzählungen mit ihrer Dominanz russischer Schauplätze bewußt: Die Liebe Bunins zu seiner unwiederbringlich verlorenen Heimat ist mit Ausnahme der Skizzen „Kamarg“ und „Sto rupij“ in allen Erzählungen nicht zuletzt durch die Detailgenauigkeit seiner Erinnerungen spürbar. ${ }^{490}$

Obwohl konkrete Daten lediglich in den Erzählungen "Tanja“, "Cholodnaja osen"“ und "Cistyj ponedel'nik“ genannt werden ${ }^{491}$, fällt eine zeitliche Einordnung des Großteils der erzählten Ereignisse in das vorrevolutionäre Rußland auf Grund zahlreich vorhandener zeitlich und răumlich lokalisierender Verweise ${ }^{492}$ nicht schwer. Der Hinweis auf die Entlassung aus der Leibeigenschaft („Temnye allei“, 6: 177), die berufliche Stellung eines Protagonisten („Чиновник казенной палаты“, „Кrasavica“, 6:218), eine Photographie von Zar Aleksandr III. („Antigona“, 6: 224), der Verweis auf das Zusammentreten der Duma 1906 („Rečnoj traktir“, 6: 333) oder die Anspielung auf die Teilnahme eines alten Herm am Krimkrieg 1854/55 (,Kaceli“, 6: 396) sorgen unaufdringlich, aber um so nachhaltiger für ein spezifisch russisches Kolorit der Erzählungen. Einen authentischen Hintergrund gewähleistet die breite Auswahl russischer Schauplätze in verschiedenen Städten und Provinzen Rußlands (z.B. „имение в Тамбовской губернии“, „Мuza“, 6: 196; „Была в Свияжске“, „Vizitnye kartocki“, 6: 238; .дьячка в Серпухове“, „V odnoj znakomoj ulice“, 6:331) sowie in bekannten Moskauer und Petersburger Restaurants („В Праre“", „Reznoj traktir”, 6: 333; „у Палкина“, „Baryšnja Klara“, 6: 350).

Russisches Lokalkolorit mit hohem Symbolgehalt bieten ferner spezifische Weinsorten („вино князя Голицына“, „Antigona“, 6: 225), eine bekannte russische Kognakmarke („за шустовским“, „Reट̌noj traktir“, 6: 333), typische russische Gerichte („щи флотские.

489 Zit. in: UB. 3.Bd. op.cit.: 161.

490 Die beiden Skizzen haben dennoch eine Verbindung zum Leben Bunins, denn von seiner Heimat Rußland aus trat er Reisen nach Asien an und fuhrte ihn sein Weg in seine zweite Heimat Frankreich.

491 . Это было в феврале страшного семнадиатого года“" (., Тапја“, 6: 271); „Пттнадцатого июня убили в Сараеве Фердинанда“ („Cholodnaja osen”“, 6: 367); „Прошло почти два года с того Чистого понедельника ... В четырнадиатом году, под Новый год“ (.C'istyj poncdel'nik", 6: 410).

492 Gemeint sind die extratextuellen Verweise auf historische Personen, Orte. Ereignisse etc. 
битки по-казацки“, „V Pariž“”, 6: 273), billiges russisches Toilettenwasser („шипром“, „Baryšnja Klara“, 6: 353) oder auch folkloristische Erzählungen („Ballada“, „Železnaja Serst ${ }^{\text {“*993 }}$ ). Gleichzeitig sind derartige Details Ausdruck einer spezifisch russischen Kulturleistung und bilden einen Code furr Eingeweihte, der jedoch von einem Rezipienten keinesfalls beherrscht werden muß, um die Aussagen des Buches zu den Themen Liebe und Tod nachvollziehen zu können. Der metaphysischen Dimension des alten Rußland wird Rechnung getragen mit der Erwähnung von Ikonen in verschiedenen Erzăhlungen: Liebhaber von Ikonen treten in den Erzählungen „Rečnoj traktir“ (6: 334) und „Kuma“ (6: 340) in Erscheinung; Ikonen schmücken die Wände in den Erzählungen „Temnye allei“ (6:175), „Ballada“ (6: 184), „Natali“ (6: 325) und „Cistyj ponedel'nik“ (6: 405); vor allem die Gesichter der weiblichen zentralen Figuren Rusja und Natali aus den gleichnamigen Erzählungen strahlen für den jeweiligen Betrachter eine ikonenhafte Schönheit aus (6: 209 bzw. 399-400); eine besonders mystische Religiosităt wohnt der Beschreibung des betenden Mädchens in der Erzählung „Režnoj traktir" inne (6: 335), die sich in der Erzăhlung "Čistyj ponedel'nik“ auch in der Beschreibung zahlreicher Moskauer Kirchen und Klöster fortsetzt. Die Erwăhnungen von Friedhöfen, Gräbern und Kapellen in den Erzăhlungen „Ballada“, „Pozdnij Cas“, „Natali“, „Čistyj ponedel'nik“ und „Casovnja“ fuhren auf das Todesthema zurick.

Bemerkenswert an den häufig poetisch anmutenden Schilderungen russischen Lebens ist die unkritische Haltung Bunins, vor allem im Vergleich zu seinen gut 30 Jahre zuvor in Rußland publizierten langen Erzählungen Derevnja (1910) und Suchodol (1911), in denen er das triste und schmutzige dörfliche Leben sowie den Niedergang der Gutsbesitzerklasse unnachsichtig nachzeichnet. Nunmehr evoziert Bunin das untergegangene zaristische Rußland auf zweierlei Weise: einerseits über emotional aufgeladene verklärende Schilderungen des Lebens vor der Oktoberrevolution und andererseits durch geschicktes Einflechten bekannter Künstler-Persönlichkeiten des vorrevolutionären Rußland. Hierbei handelt es sich keineswegs um eine reine Ansammlung von Fakten und Details, denn zwischen den Zeilen ersteht in erster Linie Bunins persönliches Rußlandbild, das in seinem widerspruchlichen Facettenreichtum zu erstellen nur aus der zeitlichen und lokalen Distanz heraus möglich war und dessen Inhalt nicht alle Emigranten als kollektive Erinnerung anerkennen wollten (vgl. Kap. 10.1.1).

493 Im 19. Jahrhundert sollen vor allem in Bunins heimatlichem Gouvernement Orel Sagen erzahlt worden sein, die Begegnungen von jungen Madchen mit Waldgeistem zum Inhalt hatten (E. Pomerancevaja. .Predislovie“. In: LN. 84.Bd. [1] op.cit.: 126). 


\subsubsection{Rätselhaftes Rußland - Rußland zwischen Europa und Asien}

Fast jede Erzählung der Temnye allei weist einen russischen Schauplatz auf, den es in der Realităt gegeben haben könnte - aber keinesfalls gegeben haben muß, denn Bunins Rußland ist der Wirklichkeit sowohl zeitlich als auch räumlich entrückt. Ähnlich wie die im Buch dargestellten Frauengestalten entzieht sich Rußland zudem dem Verständnis des Betrachters (dem des Erzăhlers ebenso wie in seinem Gefolge dem des Lesers); das Land ist in seiner Rätselhaftigkeit und Komplexität nicht faßbar. Auf einen Nenner gebracht wird diese Gleichsetzung in der Äußerung des Protagonisten der Erzăhlung „Čistyj ponedel'nik“, der seinem staunenden Unverständnis angesichts der Vielschichtigkeit Moskaus und des widersprüchlichen Verhaltens seiner Freundin mit folgenden Worten Ausdruck verleiht: „Странная любовь!‘ - думал я [...] ,Странный город!““ (6: 402).

Gleichviel, welcher Realitätsgehalt den einzelnen Schauplătzen innewohnt, Bunins persönliches Rußlandbild läßt sich vor allem aus vier Erzählungen mit hohem Symbolgehalt erschließen, die sich an markanten Positionen der Temnye allei befinden. $\mathrm{Zu}$ diesen Schlüsselerzählungen gehören zum einen „Pozdnij cas“ am Ende des ersten Komplexes und „Rusja“ am Beginn des zweiten, zum anderen „Reěnoj traktir" am Beginn des dritten Komplexes und „Čistyj ponedel'nik“ an dessen Ende. Während die beiden erstgenannten Erzählungen als Scharnier den ersten und zweiten Komplex miteinander verbinden, bilden die beiden letztgenannten einen Rahmen um den dritten und größten der drei Komplexe. In jeder dieser Erzăhlungen präsentiert Bunin eine andere Seite seiner verlorenen Heimat: die Kleinstadt, die Provinz und die Großstadt ${ }^{494}$ - und trägt damit zu einer weiteren Verschränkung innerhalb der Kurzprosaverknüpfung bei.

Die Erzählung „Pozdnij čas“ enthält die Erinnerungen eines in Paris ansässigen russischen Emigranten. der sich im Geiste in seine Heimatstadt in der russischen Provinz zurückversetzt, die er 19 Jahre zuvor (und damit 1919, wenn man das Entstehungsdatum der Erzăhlung zugrundelegt) verlassen mußte. Durch Raum und Zeit reist der Ich-Erzähler zurück in seine Kindheit und Jugend, erinnert sich seiner Schulzeit und seiner ersten Liebe. Das inzwischen längst verstorbene namenlose Mädchen gehört einer untergegangenen

494 Das von Claire Hauchard identifizierte diesbezagliche Triptychon, bestehend aus den Erzahlungen .Pozdnij cas", .Rusja“ und .Cistyj ponedel'nik“, muB um die Erzahlung „Rexnoj traktir" erweitert werden, denn diese enthalt einen weiteren wesentlichen Aspekt des Rußlandbilds Bunins (C. Hauchard. .La Prose de I. A. Bounine ...“. op.cit.: 316ff.). Da die mittleren Erzahlungen beide die Provinz zum Inhalt haben, bleibt das Triptychon als Form erhalten. Zudem verbindet die Wahl eines Schauplatzes in der Provinz den zweiten Komplex mit dem dritten, so daß die drei Komplexe keine Lucke in der Mitte aufweisen. 
Welt an, die sich auf der anderen Seite eines Flusses befindet, den der Erzăhler symbolträchtig zu Beginn der Erzăhlung überqueren muß und der eine gedankliche Assoziation zu Lethe, dem Fluß des Vergessens, hervorruft. Eingebettet in die Erinnerungen des Erzählers an verliebte Begegnungen ersteht vor dem Leser ein Rußland der lauschigen Provinzstädtchen, in denen alles seinen geruhsamen Gang geht. Die Erwähnung des Apfelduftes, der im Sommer über der kleinen Stadt lag, läßt zudem an die Erzählung „Antonovskie jabloki“ (1900) denken, in denen der verschwundene Geruch dieser Apfelsorte zum poetischen Symbol für die untergegangene Gutsbesitzerlebensweise wurde.

Im scharfen Kontrast hierzu steht die unvermittelt folgende Schilderung des kaiten und feuchten Paris, das dem Erzähler neue Heimat geworden ist und in dem er sterben muß („В Париже ночи сырые, темные, розовеет мглистое зарево на непроглядным небе, Сена течет под мостами черной смолой [...]", 6: 202). Der düster und emotionslosen anmutenden Darstellung technisch aufwendiger Pariser Beerdigungsgepflogenheiten läßt er die kurze Beschreibung der bescheidenen, aber sehr bewegenden Trauerzeremonie für das junge Mädchen folgen, deren metaphysische Dimension ihm erst im erinnernden Rückblick durch die kosmische Präsenz in Form eines Sternes bewußt wird (vgl. Kap. 8.1.3). Die Gegenüberstellung dieser beiden Rituale stellt nicht nur die Verbindung zum Exilland her, sondern verstärkt den Eindruck des Zusammenbruchs einer ganzen Welt, der sich zu Beginn der Erzählung bereits durch die Beschreibung eines Großbrands (vgl. auch den Feuerschein am Himmel in der Erzählung „Cholodnaja osen"“) angekündigt hatte: „Это во время ночного пожара [...] Горело далеко, за рекой [...]“ (6: 203).

Dem Portrăt des provinziellen Rußland werden in der Erzählung "Rusja“ weitere Züge hinzugefügt. Der Protagonist entsinnt sich anläßlich eines unvorhergesehenen Reiseaufenthaltes einer Romanze, die er 20 Jahre zuvor (bei Zugrundelegung des Entstehungsdatums der Erzăhlung also 1920) in dieser Gegend erlebte. Die Protagonistin mit dem vielsagenden Namen Rusja (als Hypokoristikon für Mar'ja bzw. Marusja) reprăsentiert in dieser Erzählung die russische Natur: in einfachen Sandalen und in einen traditionellen Sarafan gekleidet, bewegt sie sich durch die sumpfige, geheimnisvolle Fauna, als sei sie ein Teil von ihr. Die Natur, die in keiner anderen Erzăhlung derart präsent ist wie hier durch die unsichtbaren, aber umtriebigen animalischen Sumpfbewohner, ist dem jungen Mädchen besonders gewogen - die scheuen Kraniche, die sich hin und wieder am Ufer aufhielten, lassen nur Rusja in ihre Nähe kommen.

Während die Erzählung „Pozdnij cas“ mit dem Tod des geliebten Mădchens schließt. wird die Trennung in „Rusja“ von Menschenhand in Person der hysterischen Mutter Rusjas 
herbeigefuhrt, die den jungen Mann gewaltsam - von Rusjas Passivität gewissermaßen noch unterstützt - aus dem Hause jagt. Der Gedanke, mit dieser Erzählung eine künstlerische Umsetzung von Bunins Flucht aus Rußland vor sich zu haben, liegt nicht fern. Die Ehefrau des Protagonisten, die die Tragweite der Jugenderlebnisse ihres Mannes nicht zu erfassen vermag und sich gar amüsiert dazu äußert, könnte (als konsequente Fortsetzung des Gedankengangs) in dieser Interpretation den Part des Exillandes übernehmen, in dem Bunin trotz seines 33 Jahre währenden dortigen Aufenthaltes ein Fremder blieb. ${ }^{495}$

Ein weiterer Aspekt der russischen Provinz ist der Erzählung "Rečnoj traktir" zu entnehmen. Auch in dieser Erzählung reicht die Erinnerung bezeichnende 20 Jahre zurück, in diesem Falle an einen Abend in einer Pfahlbauschenke an der Wolga, für den Protagonisten ein Fluß, der seinesgleichen sucht: „Русская провинция везде довольно одинакова. Одно только там ни на что не похоже - сама Волта" (6: 336). Die Wolga als ein zentraler Wasserweg des europäischen Rußland ist gleichzeitig Bindeglied zu Asien; assoziierendes Nachdenken über tatarische Wörter und alte Kirchen als Symbole der Koexistenz von Heidentum und Religiosităt entlang des Flusses führen den Ich-Erzähler angesichts dieses Facettenreichtums schließlich zu dem staunenden Ausruf: „[...] до чего в самом деле ни с чем не сравнима эта самая наша Русь!“ (6: 336). In dieser Zusammenschau entsetzt ihn jedoch die andere Seite Rußlands, die Welt der primitiven Schenken mit drittklassigen Unterhaltungskünstlern. Er äußert sich angewidert über das seiner Ansicht nach primitive Ambiente der Pfahlbauschenke, in dem für ihn alle negativen Ausprägungen des russischen Wesens vertreten sind: Unsauberkeit, trunkene, niveaulose Fröhlichkeit, Stillosigkeit. In dieser Umgebung nun trifft er zufällig ein junges Mädchen wieder, deren inbrünstiges Gebet ihn wenige Stunden zuvor sehr bewegt hat und die solcherart die beiden

495 Diese Fremdheit kommt zum Ausdruck in den drei Erzahlungen der Temmye allei, in denen Emigranten portuatiert werden: „V Pariže“. ..Cholodnaja osen“" und „Mest'”. Die verallgemeinernde Darstellung des Fluchtwegs (..Болтарня, Сербия. Чехия, Бельгия, Парнж, Нищиа ....”, 6: 371) wird flankiert von Schilderungen des sozialen Abstiegs sowie der Unmoglichkeit, sich im Exilland einzuleben oder sich dort gar heimisch zu fuhlen: Wahrend in „V Pariže" der ehemalige General der Weißen Armee ein zuruckgezogenes, bescheidenes Dasein fuhrt und seine zukanftige Frau, die Gattin eines in Jugoslawien tătigen ehemaligen WeiBgardisten, ihren Lebensunterhalt als Kellnerin verdienen muB (6: 273), ist die Protagonistin aus "Cholodnaja osen'“ auf die Wohltatigkeit ihrer Mitmenschen oder Gelegenheitsarbeiten angewiesen (6: 371) und arbeitet der Ehemann der Protagonistin aus ..Mest'“, ebenfalls ein ehemaliger WeiBgardist, nach seiner Ankunft in Paris als Chauffeur, bevor er dem Alkohol verfallt und sich bettelnd vor den Kneipen auf dem Montparnasse herumtreibt (6: 392). Durch dic in diesem an Details so reichen Buch auffallende Generalisierung der Vergangenheit und Gegenwart der russischen Emigranten in Frankreich gelingt es Bunin, die Tragweite des Verlusts der Heimat spurbar zu machen.

Eine vergleichende Analyse dieser drei Erzahlungen beschaftigt sich mit Bunins Verfahren, diese Entwurzelung aber die Verdichtung von Zeit und Raum spurbar werden zu lassen: L. Issova. "Prostranstvo

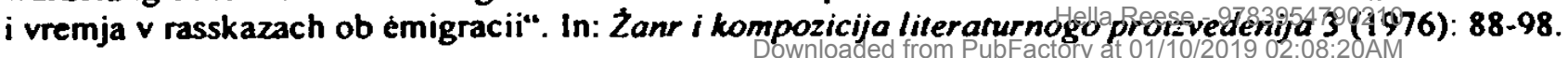


scheinbar widersprüchlichen Seiten seiner Heimat verkörpert. ${ }^{496} \mathrm{Zwar}$ gelingt es ihm, sie von ihrer Begleitung, einem aus dem Dienst entlassenen Husarenoberleutnant und Trunkenbold, zu lösen und fortzubringen; bezeichnenderweise sieht er sie jedoch nicht mehr wieder und weiß nicht, „кто она, что она“ (6: 338). Sowohl der Hinweis auf die Rătselhaftigkeit ihrer Existenz als auch die Darstellung der Rußland inhärenten Mischung aus europäischen und asiatischen Zügen bereitet den Boden für die unzweifelhaft komplexeste Erzăhlung der Temnye allei: „Čistyj ponedel'nik“.

Schauplatz des Gefuhlsdramas des Protagonisten ist die russische Hauptstadt wenige Jahre vor der Oktoberrevolution. Der Ich-Erzähler ruft sich jene glückliche Zeit seiner Liaison mit einer jungen Frau zurück, in der er zwar unter der fehlenden körperlichen Intimităt litt, sich aber mit einem gewissen Fatalismus und Hoffnung auf Hilfe durch die Zeit in sein Schicksal fügte. Im Schmelztiegel Moskau fließen Vergangenheit und Gegenwart seiner russischen Heimat zusammen (alte Bauwerke und moderne Literatur), so wie sich in seiner Freundin scheinbar gegensätzliche Interessen und Neigungen mischen: Die mondäne und modebewußte junge Frau zeigt sich weltlichen Vergnügungen gegenüber durchaus nicht abgeneigt, setzt sich aber auch intensiv mit religiösen Attributen auseinander, begeistert sich für Kirchen, Klöster und liturgische Gesănge. Ihr junger Kavalier vermag diese Passion nicht recht zu teilen. Er ist zu sehr Lebemann, als daß sich seine Bewunderung nicht in einem rein ästhetischen Genuß erschöpfen würde, ohne den tieferen Sinn zu erfassen, was auch von seiner Begleiterin zur Kenntnis genommen wird: „Вы-барнн, вы не можете понимать так, как я, всю эту Москву“ (6: 405). Rätselhaft wie diese Bemerkung bleibt ihm auch ihr Verhalten, nach einer endlich gewährten Liebesnacht ins Kloster zu gehen - für die junge Frau stellt dies jedoch keinen Widerspruch dar, sondern entspricht der konsequenten Handlungsweise, erst durch den bewußten Genuß aller irdischen Freuden ihren Wert zu erkennen, um dann ebenso bewußt auf sie verzichten zu können; erst durch diese Erfahrung ist es ihr möglich, in der Folge ohne Bedauern eine höhere geistige Stufe anzustreben.

Die entscheidende Vermittlerfunktion zum - wenn auch erst in der Erinnerung und damit mit Verspätung erfolgenden-Verständnis des vielschichtigen Wesens Rußlands kommt der zentralen weiblichen Figur der jeweiligen Erzählung zu und geht einher mit der

496 Die beiden Erzahlungen .Pozdnij cas" und „Recnoj traktir" legen durch die Motive des Sterns und des reinen Madchens in einer schmutzigen Kneipe Bezlige zu Aleksandr Bloks Drama Neznakomka (1906) nahe. 
rückwirkenden Erkenntnis der Bedeutung des Liebeserlebnisses: Die Gesichter der Frauen und ihr Wesen sind für die zentralen männlichen Figuren untrennbar mit der jeweiligen Umgebung verbunden. ${ }^{497}$ Mit Ausnahme der Protagonistin der Erzählung „Rexnoj traktir“, die nur über ihre Kleidung beschrieben wird, gehören sie dem dunkelhäutigen und dunkelhaarigen Frauentyp an, der im gesamten Buch dominiert (vgl. Kap. 7.2): So entsteht vor dem Auge des Lesers eine sich (mit Ausnahme von „Rečnoj traktir“) von Erzählung zu Erzählung verdichtende Rußland-Allegorie in der Person eines jungen Mădchens mit der geheimnisvollen Ausstrahlungskraft von Ikonen.

Während die Beschreibung des Äußeren der Protagonistin in der Erzählung „Pozdnij cas" noch ungenau gehalten ist („просто убранные темные волосы, ясный взгляд, легкий загар юного лица, легкое летнее платье“, 6: 204), gelingt es Bunin dennoch, das Wesentliche und schwer Faßbare dieses jungen Mädchens mit einer im Vergleich zu den überwiegend körperbetonten Frauendarstellungen in den Temnye allei geradezu auffallend keuschen Zurückhaltung und Staunen über das Geheimnisvolle ihres Wesens herauszustellen:

У нее было такое вечернее платье, очень нарядное, длинное и стройное. Оно необыкновенно шло к ее тонкому стану и черным молодым глазам. Она в нем была таинственна [Hervorhebungen H. Reese] ... (6: 203).

In der Erzählung „Rusja“ gewinnt dieses vage Frauenbild deutlich an Konturen, die wie von dem Blick eines Malers erfaßt wirken, und wird um religiöse und asiatische Aspekte erweitert:

Да она и сама была живописна, даже иконописиа. Длинная черная коса на спине, смуглое лицо с маленькими темными родинками, узкий правильный нос, черные глаза, черные брови ... [...] Тем более, что лицом была похожа на мать, а мать. родом какая-то княжна с восточной кровью [...] (6: 209).

In der Folge stellt Bunin zudem noch einen Bezug zu Indien her („Она была бледна какой-то индусской бледностью [...]“, 6: 212), sо daß sie schließlich der um eine Dimension erweiterten Realität entrückt wirkt: „В сумраке сказочно были видны ее черные глаза и черные волосы [...]“ (6: 215).

Dieses Bild wird in der Beschreibung der Protagonistin der Erzăhlung „Čistyj ponedel'nik" aufgegriffen und verfeinert. Auch ihre Wurzeln reichen durch ihre Großmutter aus Astrachan, der sie vermutlich einige Züge ihres Aussehens zu verdanken hat, in die ferne östliche Vergangenheit, die indische Weisheit mit persischer Schönheit vereinigt: 
А у нее красота была какая-то индийская, персидская: смугло-янтарное лицо, великолепные и несколько зловешие в своей густой черноте волосы, мягко блестящие, как черный соболй мех, брови, черные, как бархатный уголь, глаза; пленительный бархатисто-пунцовыми губами рот оттенен был темным пушком $[\ldots](6: 400-401)$.

Ihr Äußeres inspiriert ihren jungen Verehrer zu folgender Assoziationskette, die zwar den Facettenreichtum der Wesenszüge seiner Freundin illustriert, sie ihm jedoch dadurch nicht erklärt: „Москва, Астрахан, Перскя, Индия:““ (6: 403).

Analog zu der Anzahl der rußlandspezifischen Schlüsselerzăhlungen kommen in dieser Erzählung kulminativ alle vier Himmelsrichtungen zur Erwähnung und dokumentieren die Unmöglichkeit, das Konglomerat Rußland vollständig und in angemessener Weise erfassen zu können: Der Norden steht für das authentische Rußland, das sich laut der Protagonistin noch in alten Klöstern bewahrt habe (6: 406), und so lenkt der verlassene Liebhaber am Neujahrstag seine Schritte nicht von ungefähr zunächst in die Archangelsker Kathedrale im Kreml (6: 410); während in „Rečnoj traktir“ der Osten zu Assoziationen an den Mongolensturm veranlaßt, wird in "Cistyj ponedel'nik“ unter anderem uber das Äußere der Protagonistin ein Bezug zu Indien hergestellt (6: 399); der Suden spiegelt sich in den kirchlichen Elementen und läßt an Byzanz denken; der Westen schließlich kommt zum Ausdruck etwa in den Büchern westlicher Schriftsteller, die der junge Verehrer seiner Angebeteten bringt (6: 399), in seinem italienischen Aussehen (6: 399) oder einem scherzhaften englischen „Ол райт!“” (6: 407).

Über ihre geheimnisvolle Ausstrahlung hinaus stehen die ikonenartigen Frauengesichter mit ihren indischen Komponenten für eine Kontinuităt, die nicht nur im religiösen Sinne zurück bis nach Byzanz reicht, sondem auch auf die uralte Weisheit der indischen Philosophie Bezug nimmt. ${ }^{498}$ Diese Kontinuităt wird beispielsweise symbolisiert durch in den Himmel ragende Kirchturmspitzen, insbesondere in ihren Glocken, die schon seit altersher läuten und gleichzeitig eine Verbindung zu Europa herstellen, in dieser Erzăhlung insbe-

498 In bezug auf die lllustration der wahmehmbaren asiatischen Einflusse auf Land und Leute erweist sich die Erzathlung .'Cistyj ponedel'nik“" als besonders ergiebig. jedoch finden sich Hinweise auf die asiatischen "Wesenszoge" RuBlands in zahlreichen weiteren Erzahlungen. Am hăufigsten manifestieren sie sich im Äußeren von Personen, wie beispielsweise aus den folgenden Zitaten ersichtlich: „брюнет того восточного типа, что встречается в Москве среди ее старинното торгового люда“" (.Vizitnye kartocki", 6: 236); ,А прнзнаятесь, коллега: ведь есть в вас восточная кровь, жидовская, например, или кавказская? [...] ведь во мне тоже восточная кровь ...“ (,Zojka i Valerija“, 6: 243, 244); „похож на грузина“" (,Natali“, 6: 304); „темноликая красавица-казачка“" (.Natali“, 6: 324); „Грузия Ираклин Меладзе, сын 6огатого купца во Владикавказе [...]" (..Baryšnja Klara“, 6: 350); „Руки сухие, индусские [...]" (..Kamarg“, 6: 383); „малаеи“ („Sto rupij“, 6: 385). Weitere asiatische Einflusse zeigen sich in Details, wie etwa in einem kuhlen Wind aus Asien (."Vizitnye kartocki“", 6: 236), einem Zitat von

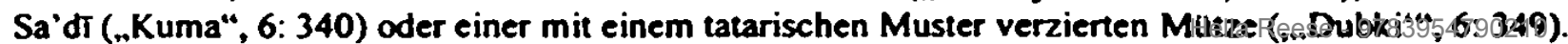


sondere zu Italien (und auch hier einen impliziten Kontrast zu einem anderen kirchlichen und kulturellen Erbe herstellen): „Какой древный звук, что-то жестяное и чугунное. И вот так же, тем же звуком било три часа ночи и в пятнадцатом веке. И во Флоренции [Hervorhebungen H. Reese] совсем такой же бой, он напоминал мне Москву...“ („Čistyj ponedel'nik“, 6: 409).

Dem Protagonisten, der selbst einem Sizilianer ähnelt (6: 399), also europäische Züge trägt (wenn auch ungebildeter als seine Freundin wirkt durch den Vergleich mit seiner provinziellen Herkunft), erscheint Moskau ebenso rătselhaft wie das zwiegespaltene Verhalten seiner Freundin, die ihm zwar zugetan scheint, ihn jedoch körperlich auf Abstand hält:

„Странная любовь!" - думал я [...] ,Странный город! - говорил я себе, думая об Охотном ряде, об Иверской, о Василии Блаженном. - Василии Блаженный и Спас-на-Бору, итальянские соборы - и что-то киргизское в острнях башен на кремлевских стенах ...““” $(6: 402)$.

In Moskau als Verkörperung Rußlands treffen Europa und Asien zusammen und spiegelt sich der ganze Facettenreichtum der russischen Wesensart wider. ${ }^{499}$ Die Verbindung zur östlichen Weisheit wird über die Ikone der Bogorodica Troerucica ${ }^{500}$ hergestellt, die das Paar in der Schenke „Egorov“ entdeckt und deren unerwarteten Anblick inmitten der trunkenen Fröhlichkeit des überwiegend bodenständigen Publikums die Protagonistin mit folgendem enthusiastischen Ausruf kommentiert: „Три руки! Ведь это Индия!“ (6: 405). Während Bunin sich der brutalen asiatischen Primitivität ablehnend gegenüber verhielt, wie sie im Schlagwort des Mongolensturms zum Ausdruck kommt und am treffendsten in der Figur des Lavr in „,Dubki'“ personifiziert wird (,рослого мужика [...] из которого легко мог бы выйти атаман шайки муромский разбойников“, „,Dubki““, 6: 346), zeigte er sich der östlichen Weisheit und ihren Verkörperungen aufgeschlossen.

Am Ende des dritten Komplexes hat sich solcherart ein dunkles und mystisches Rußlandbild Bunins herauskristallisier, das im krassen Gegensatz steht zu der ebenfalls im Buch enthaltenen Allegorie der ,želtovolosaja Rus”“, die einen assoziativen Kontrast zur Ikonenmalerin Rusja aus der gleichnamigen Erzählung nahelegt, insbesondere über ihren Namen. Diese weitere Allegorie setzt sich aus mehreren Elementen zusammen, die wie

499 Eine aufschluBreiche Analyse der Erzăhlung ."Cistyj ponedel'nik“ insbesondere bezuglich der Dualitat RuBland - Asien findet sich in L.. Dolgopolovs Monographie Na rubeze vekov. O russkoj literature konca XIX-nacala XX veka. Leningrad, 1977: „Rasskaz .Cistyj ponedel'nik“ $v$ tvorcestve Bunina emigrantskogo perioda" (S. 333-358).

500 Der Anblick der Gottesmutter mit drei Handen auf dieser Ikone erinnert die Protagonistin offenbar an Shiva, einen Teil der hinduistischen Trinitat Brahma-Vishnu-Shiva, der mit vier Armen dargestellt wird. Nicht unbedeutend ist in diesem Zusammenhang. daß Shiva als zerstorerische Kraft innerhalb dieser gottlichen Einheit gilt. 
Făhrten in verschiedenen Erzăhlungen des dritten Komplexes ausgelegt sind: Da sind zum einen die blonden Kellner in „Rečnoj traktir" („желтоволосые половые“, 6: 336), die ebenfalls blonde Kat'ka aus „Vtoroj kofejnik“ („желтоволосая“, 6: 361) sowie die blonde Puppe, der der Protagonist der Erzăhlung „Parochod ,Saratov““ symboltrăchtig einen Fußtritt versetzt („отшвырнул ногой желтоволосую куклу“, 6: 375). Diese Elemente verbinden sich schließlich in der vorletzten Erzăhlung "Čistyj ponedel'nik“ zu folgender Aussage mit Schlüsselcharakter: „И потом, желтоволосу: Русь я вообще не люблю“ (6: 401). Dieser negativen Attribuierung, die an die blondbezopften Kolchosbäuerinnen stalinistischer Propagandaplakate als Symbole staatlich verordneter Gleichheit denken låßt, stellt Bunin die Vielfalt des vorrevolutionären kulturellen Lebens in Rußland gegenüber.

\subsubsection{Abrechnung und Hommage: Kunst und Literatur im vorrevolutionären Rußland}

Die Erzählungen der Temnye allei spielen überwiegend zu Beginn des 20. Jahrhunderts und somit zu einer Zeit, in der Bunin aktiv am künstlerischen Leben Rußlands teilnahm. Von den Ressentiments, die er seinerzeit vor allem den Symbolisten gegenüber hegte und aus denen er keinen Hehl machte, sind nur mehr Relikte geblieben, ganz als habe die verflossene Zeit frühere Zwistigkeiten verwischt, um einem Rückblick Platz zu machen, dem es vor allem um die Würdigung der Vielfalt des damaligen kulturellen Lebens geht.

Um die Atmosphäre jener Zeit einzufangen und adäquat wiederzugeben, erweckt Bunin das Künstlermilieu der Maler, Schauspieler bzw. Regisseure, Musiker und Schriftsteller vergangener Jahre zu neuem Leben, indem er authentische Persönlichkeiten mit den fiktiven Figuren vermischt. ${ }^{501}$

501 Im Konstlermilieu spielen die folgenden Erzahlungen: „Muza“, „Rusja“, „Vizitnye kartocki“, „Galja Ganskaja“, „Genrich“, , Vtoroj kofejnik", „Mest" „Kaceli“ und „Cistyj ponedel'nik“. Doch auch in verschiedenen anderen Erzăhlungen lassen sich Spuren kunstlerischen Lebens finden, und einige Protagonisten sollen lebenden Vorbildern entlehnt sein: So soll sich hinter Adam Adamyc aus der Erzahlung

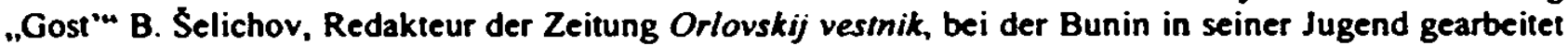
hat, verbergen, wahrend der Protagonist der Erzahlung „Galja Ganskaja“ Zuge des Malers Petr Nilus tragen und die Darstellung der Protagonistin Elena Genrichovna (.,Genrich“) von der unter dem Pseudonym Maks $\mathrm{Li}$ arbeitenden Joumalistin und Schriftstellerin $\mathrm{O}$. Chrennikova inspiriert worden sein sollen (vgl. die entsprechenden Anmerkungen in I. Bunin. SS v vos'mi romach. 6. Bd. Moskva, 1999: 625 bzw. 626).

Als besonders ergiebig erweist sich in dieser Hinsicht die Erzahlung „Cistyj ponedel'nik“, in der es, wie Dolgopolov in seiner Analyse der Erzahlung herausstellt, lediglich eine Person mit einem fiktiven Namen gibt: Fedor, den Kutscher-dies hebt die Erzahlung aus den anderen heraus. Vgl. L. Dolgopolov. Na rubeie vekov. op.cit.: 335. 
Zeitgenössische Maler sind in zwei Erzählungen vertreten: In „Baryšnja Klara“ hängt ein Bild mit dem Titel „Zimnij zakat" von Julius Sergius von Klever (1850-1924) an der Wand (6: 352), und in „Vtoroj kofejnik“ erzählt die Protagonistin ihrem derzeitigen Liebhaber, wie sie einst den Malern G. F. Jarcev (1858-1918), Konstantin A. Korovin (18611939), Sofija P. Kuvšinikova (1847-1907) und Filipp A. Maljavin (1869-1940) Modell gestanden hat (6: 362). In der Erzählung „Gost”“ erweist Bunin der Kunst der niederländischen und flämischen Maler des 16. und 17. Jahrhunderts seine Reverenz („фламандская Eва“, 6: 233), wăhrend er den Protagonisten der Erzăhlung „Genrich“ sich deutlich distanzierter zur italienischen Malerei des 14. Jahrhunderts äußern läßt: „Треченто, кватроченто ... И я возненавидел всех этих Фра Анжелико, Гирляндайо, треченто, кватроченто и даже Беатриче и сухоликого Данте ...“ („Genrich“, 6: 296). Dem 1825 von Sergej G. Stroganov gegründeten „Stroganovskoe učiliše" für Kunstmalerei setzt Bunin in der Erzăhlung „Rusja“ ein Denkmal (6: 209).

Verschiedene Erzăhlungen spielen im Theatermilieu: So erinnert sich etwa der Protagonist der Erzählung "Stepa“ an gemeinsame Frühstückstreffen mit den Akteuren des Moskauer „Malyj teatr" (6:191), während der unglückliche junge Mann der Erzählung „Voron“ im Sankt Petersburger „Mariinskij teatr" (6: 382) sehen muß, wie sein Vater die ehemalige Gouvernante in großer Robe ausführt. In der Erzăhlung "Čistyj ponedel'nik“ triff das mondäne junge Paar auf einem "Kapustnik“, der im 1898 von Stanislavskij (eigentlich K. S. Alekseev; 1863-1938; 6: 408) in Moskau gegründeten „Chudožestvennyj teatr" (6: 407) stattfindet, mit den Schauspielern Moskvin (1874-1946; 6: 408) und V. I. Kaðalov (eigentlich Śverubovix; 1875-1948; 6: 408) sowie dem Regisseur Suleržickij (1872-1916; 6: 408) zusammen.

Im musikalischen Bereich hingegen hălt Bunin sich im Hinblick auf authentische Personen bedeckt: So erblickt zwar die kapriziöse Musikstudentin Muza in der gleichnamigen Erzählung ihren künftigen Liebhaber erstmals auf einem Konzert des Pianisten David Solomonovic Sor (1867-1942) (6: 197), mit dem die Bunins persönlich bekannt waren, und wird in den Erzählungen „Vtoroj kofejnik“ und „Čistyj ponedel'nik“ der Sănger Fedor Saljapin (1873-1938) erwähnt (6: $362^{502}$ bzw. 401). Die übrigen diesbezüglichen Erwähnungen beziehen sich auf Titel oder Texte von Volksliedern (vgl. Kap. 6.4.2) und mehr oder minder professionelle namenlose Restaurantmusiker (portugiesisches Streichorche-

502 Bunins Darstellung Saljapins (.Приехали раз под утро из ,Стрельня' опохмелятьсх Шаляпин ...”, 6: 362) rief vor allem bei den Freunden in Amerika scharfe Kritik hervor, da sie das Andenken des Kunstlers beschmutzi sahen (vgl. Kap. 10.1.1). 
ster, „Rečnoj traktir“, 6: 333; Ballorchester, „Natali“, 6: 323; Streichorchester, „Baryšnja Klara“, 6: 350; Balalaikaspieler, „Madrid““, 6: 360; Zigeunergruppe, „Čistyj ponedel'nik“, 6: 403).

Ein besonders breiter Raum ist allerdings den Schriftstellern vorbehalten: Neben Zitaten aus verschiedenen Werken klassischer Autoren wie Afanasij Fet, Jakov Polonskij, Nikolaj Ogarev, Aleksandr Puskin, Lev und Aleksandr Tolstoj sowie Ivan Gončarov (vgl. Kap. 6.4.2), die den Erzählungen eine spezifisch russische Prägung verleihen, rücken vor allem literarische Zeitgenossen Bunins und ihre Werke ins Bild. Valerij Brjusov (18731924) etwa tritt zweifach in Erscheinung: Zum einen wird in der Erzählung „Rexnoj traktir" seine Sprechweise karikiert („что-то четко, резко и гневно выкрикивал своим картавьм, в нос лающим голосом“, 6: 333), zum anderen ist sein Buch Ognennyj angel (1908) Gegenstand einer Unterhaltung in der Erzăhlung "Čistyj ponedel'nik“ (6: 401), in der sich die Protagonistin abfallig äußert: „До того высокопарно, что совестно читать“ (6: 401). Während ihre Meinung zu einer neuen Erzählung Leonid Andreevs (1871-1919) unbekannt bleibt (6: 403), wird sein ansprechendes Äußeres in der Erzählung „Kaceli“ zu Vergleichszwecken herangezogen: „красив, как Леонид Андреев“ (6: 396), sein Werk hingegen bleibt unkommentiert. Die Erwähnung weiterer Schriftsteller wie Octave Mirbeau (1848-1917; 6: 227), Guy de Maupassant (1850-1893; 6: 227, 283, 287), Hugo von Hofmannsthal (1874-1929), Arthur Schnitzler (1862-1931), Kazimierz Przerwa-Tetmajer (1865-1940) sowie Stanisław Przybyszewski (1868-1927; alle 6: 399) sorgt für die Einordnung in einen größeren europäischen Kontext („Čistyj ponedel'nik“, 6: 399). An den Letztgenannten geht in der Erzählung „Genrich“ allerdings ein Seitenhieb: „А венские пропойцы, вроде Пшибышевского?" (6: 294).

Das junge Paar in der Erzählung „Čistyj ponedel'nik“ lernt sich anläßlich einer vom "Chudožestvennyj kružok" veranstalteten Lesung Andrej Belyjs (1880-1934; 6: 401) kennen. Beide interessieren sich für Kultur und Literatur, und so nimmt es nicht wunder, daß ein Friedhofsbesuch die zwei zu den Gräbern von Aleksandr Ertel (1855-1908) und Anton Čechov (1860-1904) führt (6: 405). Anschließend machen sie sich auf die Suche nach dem ehemaligen Wohnhaus Aleksandr Griboedovs (1795-1829), werden jedoch nicht fündig (6: 405).

Die Erwähnung verschiedener Zeitschriften rundet das Bild ab: Der Protagonist der Erzählung "Antigona“ vertreibt sich die Zeit während seiner Bahnfahrt mit einer Neuerscheinung des Humoristen Arkadij Averčenko (1881-1925), der ab 1908 als Herausgeber der Zeitschrift Satirikon tätig war (6: 222). Zerstreuung und Information bieten darüber 
hinaus die Zeitschriften bzw. Zeitungen Novoe vremja („Genrich“, 6: 301), Istoričeskij vestnik („Natali“, 6: 315) und Niva („Rusja“, 6:215; „Voron“, 6: 377).

Im Hinblick auf diese auffallende Art der Einbettung von bekannten Künstlern und ihren Werken aus der Zeit vor der Revolution wirf Claire Hauchard die Frage auf, ob die Temnye allei nicht eine späte Teilrealisierung eines Buchprojektes seien, das Bunin im Anschluß an Derevnja (1910) über das damalige Intellektuellen- und Künstlermilieu zu schreiben gedachte ${ }^{503}:$ „Что касается меня, то ныне работаю над романом, размером Деревни, посвященным жизни интеллигентных кругов обеих столиц. Когда я закончу это произведение и где я его напечатаю, еще сам не знаю.“504 Die Vermutung, daß Bunin diese Idee in abgewandelter Form in der Emigration wieder aufgriff, um sie in einen nostalgischen, subjektiv geprägten Rückblick einzuflechten, liegt zumindest nahe, muß aber vemeint werden, da es zu wenige Erzählungen sind, die dieses Milieu zum Thema haben, und seine Beschreibung zum damaligen Zeitpunkt sicherlich scharfzüngiger formuliert worden wäre. Zudem würde eine solche Umsetzung höchstens auf die Erzählung "Cistyj ponedel'nik" zutreffen, in der jedoch stellenweise Fakten mitgeteilt werden. die einer näheren Überprufung nicht standhalten, wie Dolgopolov im einzelnen nachweist. ${ }^{505}$ Es läßt sich also folgern, daß es Bunin vornehmlich um die Verstärkung des Eindrucks der Vielfalt des vorrevolutionären Lebens in Rußland (in seiner persönlichen Auswahl) geht im Gegensatz zur staatlich verordneten Gleichheit in der Sowjetunion, wobei nicht verschwiegen werden soll, daß er sich an bestimmte Namen und Ereignisse genau erinnert.

\subsection{Zusammenfassende Betrachtung}

Die vorangegangene Analyse der thematischen Schwerpunkte der die Temnye allei konstituierenden Erzăhlungen macht deutlich, daß das Buch weit mehr ist als еin „калейдоскоп трагических событий ${ }^{506}$. Es stellt in erster Linie die fiktionale Einkleidung

$503 \mathrm{Vgl}$. C. Hauchard. „La Prose de I. A. Bounine ...“. op.cit.: 333.

504 "Interv"ju“". In: Odesskie novosti (15.11.1910). Zit. in: LN. 84.Bd. (1) op.cit.: 366.

505 L. Dolgopolov. Na rubeže vekov. op.cit.: 336. So etwa war Andrej Belyj zum in der Erzahlung genannten Zeitpunkt nicht in Moskau, sondern hielt sich in Deutschland auf.

506 V. Aleksandrova. .Bibliografija“. In: $N \Sigma 15$ (1947): 295. 
Bunins persönlicher Überlegungen zu Liebe, Tod und Erinnerung dar. Gleichzeitig erweisen sich die Temnye allei auf einer zweiten Ebene als persönlicher Erinnerungsfundus Bunins der unterschiedlichsten Details aus der russischen Kulturgeschichte, die er durch ihre Verwendung in den Erzählungen vor dem Vergessen bewahrt. Die Analyse zeigt zudem klar, daß die Erzăhlungen untereinander kommunizieren und erst im Verbund ihr besonderes Profil und Ausdruckskraft erhalten, wobei der - mit Ausnahme der für die Stabilität und Dichte des Buches unentbehrlichen Kernerzählungen - grundsătzlich offene Charakter des Buches diese Erkenntnis keineswegs schmälert, sondern im Gegenteil die Vitalität der Temnye allei unterstreicht.

Den zahlreichen Gesichtern der Liebe in den Erzählungen der Temnye allei gemeinsam ist ihr plötzliches, unerwartetes und kurzlebiges Auftreten, denn die Liebe in Bunins Konzeption ist kein Gefühl, das auf Dauer lebensfähig wäre, und stets von einem jähen Ende bedroht. Hierin vergleichbar ist sie der Bipolarităt zwischen dem Leben und dem Bewußtsein des unvermeidlich eintretenden Todes, die zu einer intensiven Teilnahme am Leben auffordert. Unter diesem Aspekt sind die Temnye allei den zahlreichen geschilderten Todesfällen zum Trotz keinesfalls ein deprimierendes, sondern im Gegenteil ein sehr lebensfrohes und lebensbejahendes Buch - dies spiegelt sich beispielsweise wider in der Bedeutung der Sinnenlust, die nicht allein in der Farbenpracht der Erzählungen und der Bedeutung der Genußmittel zum Ausdruck kommt, sondern auch in der hăufig als Pornographie mißverstandenen Darstellung sexueller Begegnungen. Daß es Bunin nicht primär um das Verfassen erotischer Texte ging, zeigt sich darin, daß ein solches Liebeserlebnis erst dann zu einem ganzheitlichen Erlebnis für den Menschen wird, wenn es durch die Überschreitung der Grenzen der eigenen Individualität um eine metaphysische Komponente erweitert wird, durch das Bewußtsein der Eingebundenheit in die Schöpung, das gleichzeitig ein zeitweiliges Selbstvergessen ermöglicht. Die Bedeutung der Bereitschaft zu einer solchen Grenzüberschreitung kommt auch zum Ausdruck in der Bedeutung des Reisens fur die Protagonisten - zumindest die männlichen Protagonisten befinden sich in der Regel zum Zeitpunkt des Zusammentreffens mit einer Frau nicht in ihrem alltăglichen Lebensumfeld, sofern sie über ein solches verfügen. Von größerer Bedeutung ist jedoch die Bewegung zum Unbekannten, zum anderen, die den Menschen kurzzeitig aus seinen eigenen Grenzen befreit. Begreift man nun Bunins zentrale Figuren als Reisende, die nach Liebe suchen, um aus ihren persönlichen Grenzen heraustreten zu können, so wird man sie gleichzeitig wahrnehmen als Suchende, die unbewußt nach dem Tod als der vollendeten Auflösung streben. Der Tod erscheint in den Temnye allei als Gegenkraf und Gegenspieler 
der Liebe; er zerstört jedoch nicht nur, sondern ist notwendig als Mahner zum bewußten Umgang mit dem Leben. Der Mensch ist jedoch dem Tod nicht hilflos ausgeliefert; gegen seine zerstörerischen Kraft, die nur scheinbar alles auslöscht, kann er sich mit Hilfe der Erinnerung zur Wehr setzen, die eine Poetisierung oder auch die nachträgliche Wertschätzung vergangenen Erlebens ermöglicht und dieses gleichzeitig vor dem Vergessen schützt. Die Erinnerung als spezifisch menschliches Phänomen und als Vehikel für Reisen in die Vergangenheit bildet einen elementaren Bestandteil von Bunins Lebensphilosophie, deren Bedeutung in den Erzăhlungen nicht nur durch ihre Funktion bei der strukturellen Gestaltung der Erzählungen, sondern auch thematisch deutlich zum Tragen kommt. Denn trotz seiner Kürze geht das Liebeserlebnis mit einer unvergleichlichen Intensität einher, die in der Regel jedoch erst im Nachhinein wahrgenommen und für das eigene Leben gedeutet werden kann.

Über das Phänomen der Erinnerung erschließt sich mit zunehmender Kenntnis der Erzählungen die zweite Ebene des Buches: In der überwiegenden Lokalisierung der Erzählungen. deren universelle und zeitlose Thematik keines besonderen Schauplatzes bedarf, im vorrevolutionären Rußland kommen Bunins Liebe zu seiner verlorenen Heimat und seine Trauer über diesen Verlust zum Ausdruck. In Übereinstimmung mit der rückblickenden Bewertung eines intensiven Liebeserlebnisses erhält Rußland für Bunin nun eine andere Wertigkeit, da es unwiderruflich verloren ist. Wie es den Liebenden im Augenblick des Erlebens nicht möglich ist, den Wert dieses Moments einzuschätzen, so war es Bunin in Rußland nicht möglich, den Stellenwert der Heimat für sein Leben zu ermessen. Während er seine Protagonisten nach Liebe und Tod gleichermaßen streben läßt, begibt sich Bunin in den Temnye allei auf die Suche nach seiner verlorenen Heimat und verleiht dem Buch eine kulturgeschichtliche Bedeutung, die keinesfalls zweitrangiger Natur ist.

So finden sich im strukturellen. stilistischen und thematischen Bereich gleichermaßen die von Lundén (vgl. Kap. 2.1.3) definierten, für eine Kurzprosaverknüpfung charakteristischen zentrifugalen und zentripetalen Kräfte: Die auf Grund ihrer grundsătzlichen Autonomie auseinanderstrebenden einzelnen Erzählungen werden strukturell und stilistisch von den zwischen ihnen bestehenden Verbindungen zusammengehalten, während thematisch der Tod als primär zerstörerische und die Erinnerung als bewahrende Kraft um die Liebe kreisen. In welchem Maße die Vielschichtigkeit und Kohärenz des Buches wahrgenommen wurde, wird in den beiden folgenden abschließenden Kapiteln dargelegt, die zum einen die Editions-, zum anderen die Rezeptionsgeschichte beleuchten und höchst widersprüchliche Umgangsweisen mit Bunins „Schwanengesang“ dokumentieren 


\section{DIE EDITIONSGESCHICHTE DER TEMNYE ALLEI}

„В одном месте говорят: „Книги никогда не выходят такими, какими задуманы. Правда, правда.“507 Diese sowohl auf Erfahrungen beruhende als auch hinsichtlich des in der Entstehung befindlichen Manuskripts der Temnye allei prophetisch anmutende Tagebuchnotiz Bunins vom 29. August $1940 \mathrm{kann}$ als Motto furr die Editionsgeschichte des Buches gewählt werden, die gekennzeichnet ist durch unvollständige Publikationen nicht nur in der russischen Sprache. Auf Grund ihrer Komplexität wird die Geschichte der Veröfentlichungen des Originals sowie verschiedener fremdsprachiger Editionen, die genaugenommen Teil der Rezeptionsgeschichte ist, in einem eigenen Kapitel nachgezeichnet.

Für Kürzungen in den Erzählungen und lückenhafte oder gar fragmentarische Veröffentlichungen ohne jeden Hinweis auf das Original sind nicht ausschließlich zur Zensur fürende moralische Bedenken verantwortlich zu machen, da von den Eingriffen auch in dieser Hinsicht untadelige Erzählungen betroffen sind, sondern auch aus Unwissenheit oder Ignoranz erfolgte Modifikationen der von Bunin gewăhlten Reihenfolge. Allen Änderungen zum Trotz wurde bemerkenswert häufig der ursprüngliche Buchtitel beibehalten. Diese Vorgehensweise läßt nur die Folgerung zu, daß die Verleger bzw. Redakteure entweder die innere Kohärenz des Buches nicht erkannten, sich zu zusätzlicher Recherche und weiteren Investitionen angesichts bereits vorliegender Editionen nicht bereit fanden (dies gilt insbesondere für die Übersetzungen) oder unter ökonomischen Aspekten die scheinbar markttauglichsten Erzählungen ausgewăhlt und-zumeist ohne Hinweise auf das Original - in einem Sammelband unter Beibehaltung des Prinzips der Titelvergabe nach der ersten Erzählung vereint haben. Seit jeher verkaufen sich Sammelbände mit Erzählungen schlechter als Romane - zu diesem Hindernis, das sich wie ein roter Faden durch die gesamte Publikationsgeschichte der Temnye allei zieht, kamen für Bunin das Abgeschnittensein vom Buchmarkt seiner ehemaligen Heimat (mit den entsprechenden finanziellen Konsequenzen), seine relative Unbekanntheit trotz des Erhalts des Nobelpreises, die angespannte wirtschaftiche Lage nach dem Ende des Zweiten Weltkriegs (nicht nur im Verlagswesen, sondern auch bei der potentiellen Leserschaft) sowie die Sprachbarriere.

Die isolierte Situation Bunins in den Jahren des Zweiten Weltkriegs und die daraus resultierende umfangreiche Korrespondenz mit einer Vielzahl erhaltener Briefe erlauben es, die Editionsgeschichte der Temnye allei, die von Mißverständnissen ebenso wie von 
Unverständnis geprägt ist, recht genau zu dokumentieren. Deutlich werden dabei die Verdienste Mark Aldanovs, aber auch das Engagement anderer Freunde und Bekannter Bunins, die in unterschiedliche Publikationsprozesse involviert waren bzw. diese gar erst initiiert haben.

In der Folge wird analog zur Entstehungsgeschichte zunächst der lange Weg bis zur ersten Integralveröffentlichung 1946 nachgezeichnet, bevor weitere Editionen in russischer Sprache sowie französisch-, englisch- und deutschsprachige Ausgaben im Hinblick auf ihre Übereinstimmung mit dem Original überprüft werden. ${ }^{508}$ Dabei ist es nicht Aufgabe dieses Kapitels, die editorische Qualităt der einzelnen Ausgaben in bezug auf die Qualităt der Übersetzung zu beurteilen. Im Vordergrund steht vielmehr die Frage nach dem Umgang der Verleger mit dem Original als Gradmesser gleichermaßen für das Ausmaß der Wahmehmung der Kohärenz des Buches wie für präzise Recherchearbeit.

\subsection{Der lange Weg zur Integralveröffentlichung}

Vor dem Ausbruch des Zweiten Weltkriegs wurden lediglich die Erzählungen des ersten Komplexes des späteren Buches Temnye allei-mit Ausnahme der Titelerzählung - einzeln in der russischsprachigen Pariser Tageszeitung Poslednie novosti abgedruckt. Der Einmarsch der deutschen Wehrmacht in Frankreich bedeutete das Ende der Publikationsmöglichkeiten in der Emigrantenpresse für Bunin, sei es weil die entsprechenden Medien ihr Erscheinen einstellten, sei es weil er unter der deutschen Besatzung nichts veröffentlichen wollte. Im März 1941 eröffnet sich ein Ausweg aus dieser Situation: Der in die USA ausgewanderte Mark Aldanov schlägt Bunin vor, ihm ein Exemplar der Temnye allei zu schicken, da er beabsichtigte, die dort enthaltenen Erzählungen in einer noch zu gründenden Zeitschrift zu veröffentlichen; gleichzeitig versăumt er nicht, den Freund nachdrücklich an das puritanisch geprägte Moralempfinden in Übersee $\mathrm{zu}$ erinnern. ${ }^{509}$ Bunin nimmt

508 Die zahlreichen Veroffentlichungen von Einzelerzahlungen in Zeitungen und Zeitschriften oder Anthologien, die von ihrem Alleinstellungswert zeugen, werden in diesem Zusammenhang nicht berilkksichtigt. Der Übersicht Ober die zwischen 1936 und 1949 entstandenen spaten Erzahlungen Bunins im Anhang lassen sich jedoch unter anderem Informationen au Ont und Zeitpunkt ihrer Erstveroffentlichung entnehmen.

$509 \mathrm{Vgl}$. Brief von Aldanov vom 08.03.1941. Zit. in: „Perepiska I. A. Bunina s M. A. Aldanovym“. In: Nz 150 (1983): 160. 
das Angebot an und schickt im April 21 Erzählungen in die USA (vgl. Kap. 3.3). ${ }^{510} \mathrm{Hin}$ sichtlich des Publikationsortes und möglicherweise notwendiger redaktioneller Eingriffe läßt er Aldanov zunächst freie Hand:

А если что-нибудь и где-нибудь можно напечатать по-русски или в переводе, буду рад, конечно. Если некоторые строки или неск[олько] слов (и того и другого очень мало) Вам покажутся резкими, зачеркните их (хотя я-то думаю, что есть несколько таких слов только в „Антигоне“). ${ }^{\text {s11 }}$

Diesen generellen Handlungsspielraum bekräftigt Bunin mit Nachdruck in einem weiteren Brief vom 6. Mai 1941, dem er eine Liste mit Vorschlägen für Änderungen und Kürzungen beilegt. Dennoch bittet er Aldanov angesichts der Sittenstrenge in den USA gleichzeitig um verlegerischen Wagemut, soweit er diesen verantworten könne:

На всякий случай посылаю Вам и список тех поправок и сокращений, смягчений (ежели окажется в них крайняя необходнмость), кон будьте добры внести в мои рассказы, если им будет суждено „появиться в свет“. (Вы мне писали о строгости нравов у Вас,- ужели они, правда, так строги? И даже среди русских читателей? Как же тогда читали у Вас „Любовника Лэди Ч[эттерлей]“?) Если что-нибудь напечатаете, молю Вас о редакторской смелости,-если кто будет меня ругать, черт с ним. Но за всем тем поступайте как хотите, не запраиивая меня, если зта смелость будет для Вас невозможна и ответственность будет падать на Вас.

Die erwähnten Kürzungsvorschlăge und ergänzenden Anmerkungen nicht nur bezüglich erotischer Textstellen betreffen die acht Erzählungen „Rusja“, „Antigona“, „Paša“ (später „Gost'“), „Vizitnye kartocki“, „Volki“, „Zojka i Valerija“, „Tanja“ und „Genrich“. ${ }^{513} \mathrm{Da}$

Bunin ausgesprochen heikel war, was die Redaktion seiner Texte betraf („я идиотичен,

510 Am 07.04.1941 hălt Bunin in seinem Tagebuch fest: „B 4 nоехал в Cannes, отвез Барсухову, едущему в Америку, пакет с рукописями всея своеи новой хниги - кроме ,Натали', для передачи Алданову“ (2it. in: UB. 3.Bd. op.cit.: 91). Zwei Tage spater reichte er "Natali“ nach, die er Barsukovs Frau Marga ubergab (vgl. unveroffentlichten Tagebucheintrag Bunins vom 09.04.1941. LRA. MS.1066/532). Die Erzahlungen hatte Bunin folgendermaßen untergliedert (vgl. Anhang 2, Stand Fruhjahr 1941):

1 (klassifiziert als bereits publiziert): „Temnye allei“, „Kavkaz“, „Ballada“, „Aprel "“, „Stepa“, „Muza“, "Pozdnij Cas" (falschlicherweise gab Bunin die Erzahlung nTemnye allei" als bereits erschienen an; tatsăchlich erschien sie erstmals 1943);

II (klassifiziert als noch unveroffentlicht): „Rusja“, „Antigona“, „Smaragd“, „Pasa“" (spater „Gost'“), "Vizitnye kartocki“, „Volki“, „Zojka i Valerija“, "Tanja“, „V Parize“, „Galja Ganskaja“, "Genrich”, "Tri rublja“", „Natali";

III (klassifiziert als bereits publiziert): „Pro obez'janu“".

Diese Klassifizierung entstammt einem Brief Bunins an Aldanov vom 10.04.1941. Zit. in: "Lettres d'Ivan Bunin a Mark Aldanov". op.cit.: 472.

511 Brief an Aldanov vom 10.04.1941. Zit. in: „Lettres d'Ivan Bunin à Mark Aldanov". op.cit.: 472.

512 Brief an Aldanov vom 06.05.1941. Zit. in: „Perepiska I. A. Bunina s M. A. Aldanovym". In: Nz 150 (1983): 164. Anfang Mai hatte Bunin die Erzahlungen erneut uberarbeitet (vgl. Tagebucheintrag vom 02.05.1941, zit. in: UB. 3.Bd. op.cit.: 92, sowie eine unveroffentlichte Tagebuchnotiz vom 06.05.1941, LRA. MS. 1066/532).

513 „Avtorskie varianty pravki“ (RGB, fond 429, karton 3, edinica chranenija 21). In dieser Box findet sich zudem ein Blatt mit Anmerkungen Aldanovs zur Publizierbarkeit verschiedener Erzahlungen, 
психопатичен насчет свонх текстов“"5/4), ist es nur zu verständlich, daß er neben ihm dringend erforderlich erscheinenden Änderungen auch die Abmilderungen mø̆glicherweise Ansto $B$ erregender Passagen selbst vornehmen wollte. ${ }^{515}$

Eine Veröffentlichung der Erzählungen in einem Einzelband kam jedoch vorerst nicht zustande. Als Aldanov im Jahre 1942 gemeinsam mit Michail Osipovic Cetlin die Zeitschrift Novyj žurnal herauszugeben begann, wurden dort zunăchst einzelne Erzählungen abgedruckt, wobei Bunins Wunsch nach dem Hinweis der Zugehörigkeit zu einem Buch mit dem Titel Temnye allei mißachtet wurde (vgl. Kap. 3.3). In den ersten vier Nummern des Novyj žurnal wurden die bis dahin noch nicht veröffentlichten Erzählungen Bunins aus dem zweiten Komplex publiziert: „Rusja“ und „V Pariže“ (1/1942), "Natali“ (2/1942), "Genrich“ (3/1942) sowie „Tanja“ (4/1943)-die Achtung, die man Bunin entgegenbrachte, zeigt sich darin, daß diese Erzählungen in den jeweiligen Ausgaben sehr weit vorn plaziert wurden. Ebenfalls 1942 erschienen in den USA die Erzählungen "Tri rublja“ in der zweiten Ausgabe der literarischen Monatszeitschrift Novosel'e sowie „Zojka i Valerija“ in dem von Marija Tolstaja und anderen herausgegebenen Sammelband Kov¿eg. ${ }^{516}$

\subsection{Die New Yorker Ausgabe von 1943}

Bevor die postalische Verbindung zwischen Frankreich und den USA abreißt. fragt Aldanov in einem Brief vom 29. Juni 1942, ob Bunin grundsätzlich daran interessiert sei, in einem Verlag für russische Belletristik, den unter anderem der unter dem Pseudonym Andrej Sedych arbeitende Jakov M. Cvibak, Bunins Sekretär aus den Tagen der Nobelpreisverleihung, zu gründen beabsichtigte. die Temnye allei in Buchform zu publizicren. ${ }^{517}$ Bunins Antwort ist unbekannt, aber die erste gebundene kompilative Ausgabe der Temnye allei erschien 1943 in einer Auflage von 600 Exemplaren in dem von Cetlin und Aldanov

514 Brief an Aldanov vom 31.07./01.08.1947. Zit. in: „Perepiska I. A. Bunina s M. A. Aldanovym”. In: Nz 152 (1983): 175.

515 Als Beispiel sei die Erzahlung ..Antigona" angefuhrt: Neben der geringfügig erscheinenden Ergănzung der hervorgehobenen zwei Wörter (.,[...] громко и безразлично говоря под шум дождя [...]", 6: 228). bietet Bunin die Streichung der folgenden Passage an, die der Koitusszene in der Bibliothek entnommen ist: ,[...] она сама крепко схватила пальцами его окаменевшую величнну и силу, напрягшуюся до огненного глянца“" (.Avtorskie varianty pravki“: RGB, fond 429. karton 3, edinica chranenija 21). Beide Vorschlage wurden von Aldanov ubernommen.

516 Kovceg. Sbornik russkoj zarubesnoj literatury. New York, 1942.

517 Edinburgh University Library, Special Collections Department. 
gegründeten Verlag Novaja Zemlja. ${ }^{518}$ Sie enthălt lediglich knapp ein Viertel der die spătere Fassung der Pariser Ausgabe von 1946 konstituierenden Erzăhlungen, folgt aber im wesentlichen der von Bunin vorgeschlagenen Reihenfolge und der Unterteilung in unterschiedliche Komplexe (vgl. Anhang 2):

I: „Temnye allei“, „Kavkaz“, „Ballada“, „Aprel”“, „Stepa“, „Muza“, „Pozdnij cas II: „Rusja“, „Tanja“, „V Pariže, „Natali“.'519

Aldanov macht somit von seiner verlegerischen Freiheit Gebrauch und verzichtet im großen und ganzen entsprechend seinen Notizen zur Publizierbarkeit verschiedener Erzählungen $^{520}$ auf den Abdruck von „Antigona“, „Smaragd“, „Pała“ (spăter „Gost”“), „Vizitnye kartocki“, „Volki“, „Zojka i Valerija“, „Galja Ganskaja“, „Genrich“ und „Tri rublja“. Der Gerechtigkeit halber soll aber darauf hingewiesen werden, daß der Verlag sein Lesepublikum über die Umstănde der Publikation in Kenntnis setzte. In der Vorbemerkung "Ot izdatel'stva“ verweisen die Herausgeber auf die Ausnahmesituation, die eine vollstăndige Ausgabe aller bislang vorliegenden neuen Erzählungen Bunins sowie die Berücksichtigung von Autorkorrekturen vereitelt habe:

„Темные Аллеи“ выходят без авторской корректуры. Издательство не имеет, $\mathrm{x}$ сожалению, возможности снестись с И. А. Буниным. Между тем, оно вынуждено было разделить книгу знаменитого писателя на два тома. Настоящий том заключает в себе лишь половину рассказов, составлящих эту книгу. Автор ее естественно не несет никакой ответственности на раздел и за другие недостатки, которые могут быть у издания. Редакционная коллегия „Новой Земли“ считает себя обязанной довести об этом до сведения читателей, в надежде, что они, как и сам И. А. Бунин, примут во внимание исключительные условия нашего времени. Mă̆, $1943 r^{521}$

Offen bleiben muß die Frage, ob der Verlag die Publikation eines zweiten Bandes ernsthaft in Erwăgung zog, was die Bemerkung zu der notwendigen Unterteilung in zwei Bände suggeriert. Ein zweiter Band mit weiteren Erzăhlungen erschien jedoch nicht.

518 In seinen Erinnerungen an Zeitgenossen kommt Sedych auf ein (moglicherweise anderes?) Manuskript zu sprechen, das Bunin ihm angeblich 1947 geschickt und das er gemeinsam mit Aldanov auf moralisch problematische Textstellen hin durchgesehen habe, bevor es im Verlag Novaja Zemlja veroffentlicht wurde (Dalekie, blizkie. op.cit.: 216). Vermutlich imt sich Sedych in den Jahreszahlen, denn von einer weiteren Edition im Jahre 1947, etwa des noch fehlenden dritten Komplexes, ist nichts bekannt. Hingegen lassen sich 1947 zahlreiche Belege fur Sedychs Engagement bezuglich einer englischsprachigen Edition der Temmye allei fmden (vgl. Kap. 9.3.2).

519 Ivan Bunin. Temmye allei. New York, 1943.

520 "Avtorskie varianty pravki“. RGB, fond 429, karton 3, edinica chranenija 21. Aus diesen Notizen geht hervor, daß Aldanov die drei Erzahlungen „Antigona“, „Pasa“ und „Vizitnye kartocki" fur nicht publizierbar halt, weitere drei Erzăhlungen (.Smaragd“, „Volki“" und „Tanja“) nicht auffuhrt und die obrigen Erzahlungen mit Kurzungen als publizierbar einschatza, wobei er jedoch „Rusja“ und „Galja Ganskaja“ jeweils mit einem Fragezeichen versieht.

521 Ivan Bunin. Temnye allei. New York, 1943. 
Von verschiedenen Einzelveröffentlichungen erfährt Bunin relativ zeitnah, von der Publikation des Buches kann er kriegsbedingt erst mit Verspătung in Kenntnis gesetzt werden. 522 Noch Mitte Dezember 1944 erkundigt er sich bei Aldanov nach dem Schicksal seiner Erzählungen: „Издал ли мою книгу ,Темные аллеи“ Цвибак? Если нет, молебен отслужу! Я написал к это й книге еще немало новых рассказов, из них посылаю Вам авионом три.“ $\$ 23$ Informationen zu den näheren Umständen der Publikation erhält Bunin Ende 1944 offenbar durch Andrej Sedych und äußert sich Aldanov gegenüber höchst unzufrieden über das geringe Honorar:

Reçu votre carte du 10 Oct. et celle de Zwibak du 2. Nov. Il m'écrit: „Votre livre a été publié et a eu beaucoup de succès, mais le tirage ici est très limite“" - et c'est tout à propos de ce pauvre livre! Alors, pas un sou pour moi? Cependant je suis diablement pauvre - et malade: le foie. Reçu votre argent - 4900 frs seulement. Horreur! “524

Im März 1945 setzt Aldanov Bunin persönlich von der gekürzten Ausgabe der Temnye allei in Kenntnis und erläutert ihm die Notwendigkeit der durchgeführten Streichungen:

Они были изданы. Но ... могу Вас уверить-мы спросили адвоката - некоторые Ваши рассказы ке когут быть здесь напечатаны: на издание был бы немедленно наложен арест с преследованием. Поверьте, я не шучу. Здесь „насчет нравственности строго“...525

Er wirbt um Verständnis für die durchgeführte Teilung und schlägt Bunin vor, die später entstandenen Erzählungen in einem zweiten Band in derselben Serie zu publizieren und den ersten Band in Europa und im Fernen Osten emeut herauszugeben: „Не проклинайте нас за раздел,-что же нам было делать?‘\$26 Die Voraussetzungen für einen Fort-

522 In einem Brief an die Dichterin Alla Golovina vom 07.09.1942 schreibt Bunin: „Сам я зтого ничего в печатн не видал - н, думаю, к счастыю: если бы увндал, очень бы мучился - все напечатанное там напечатано по тем не исправленным до конца текстам, что я послал туда наспех, с оказней“ (zit. in: „Iz perepiski I. A. i V. N. Buninych s Alloj Golovinoj [1942-1953]"“. op.cit.: 250).

523 Brief an Aldanov vom 19.12.1944. Zit. in: "Lettres d'Ivan Bunin a Mark Aldanov". op.cit.: 476.

Die Rolle Andrej Sedychs bei diesem Unternehmen bleibi undurchsichtig: In Dalekie, blizkie (op.cit.: 213) berichtet er, daß Bunin ihm vor seiner Überfahrt nach Amerika im Winter 1942 das Manuskript der Temnye allei zur Publikation in den USA abergab, wie bei Aldanov verbunden mit der Erlaubnis, etwaige notige Korrekturen vorzunehmen: „В прошлом году.- продолжал свой монолог Бунин,- напнсал я ,Темные аллен' - книгу о любви. Лежит она на столе. Куда ее девать? Возьмнте с собой в Амернку, может быть, там можно напечатать. Есть в этой кннге несколько очень откровенных страниц. Что же,- Бог с ними, если нужно - вычеркните ...“. Abgesehen davon, daß nur schwer vorstellbar ist, daß Bunin sich so leichtherzig auf Textmodifikationen eingelassen haben sollte, schweigt Sedych sich daruber aus, wie er mit diesem Manuskript verfuhr. Offen bleibt, ob die Publikation in russischer Sprache oder als Übersetzung ins Englische geplant war.

524 Brief an Aldanov vom 17.01.1945. Zit. in: .Perepiska I. A. Bunina S M. A. Aldanovym“. In: Nz 150 (1983): 169.

S25 Brief an Bunin vom 23.03.1945. Zit. in: „Perepiska I. A. Bunina S M. A. Aldanovym“. In: Nz 150 (1983): 171.

S26 Brief an Bunin vom 23.03.1945. Zit. in: „Pis'ma M. A. Aldanova k I. A. i V. N. Buninym“. op.cit.: 136. Diese Passage fehlt im 1983 erschienenen Abdruck des Briefes. 
setzungsband waren indessen denkbar ungünstig und fuhrten im Mai $1945 \mathrm{zu}$ einem abschlägigen Bescheid durch Andrej Sedych:

[...] L'idée d'éditer les livres ici était bonne, mais encore faut-il que le public les achète. Or, la vie[i]lle colonie russe ne lit que le calendrier et le „sonnik"; et les nouveaux, plus cultivés, soit n'ont pas d'argent, soit - s'ils en ont bea[u]coup, n'ont pas l'habitude de lire et d'acheter les livres ... [...] Bref, nous avons rapidement dépensé notre tout petit capital et ne pouvons plus rien éditer. ${ }^{527}$

Erst im Sommer 1945 gelangt Bunin in den Besitz der New Yorker Ausgabe von 1943 und äußert sich in einem Brief vom 16. August gegenüber Aldanov äußerst befremdet:

[...] и мою книжку, составленную очень непонятно для меня. Очень жалею, что решился на это издание! А тут еще „послесловие“ издательства: „остальные рассказы издадим второй книгой“. Избавь Бог, очень боюсь - а вдруг и правда издадут! Ни в каком случае не хочу зтого! ${ }^{528}$

Eine Veröffentlichung der in der Zwischenzeit entstandenen Erzăhlungen in Buchform scheint nicht mehr emsthaft betrieben worden $\mathrm{zu}$ sein; möglicherweise war diese ablehnende Reaktion Bunins der ausschlaggebende Grund für einen Verzicht auf dic Herausgabe einer Fortsetzung der Ausgabe, die Bunin als „6езбожно сокрашенное“529 empfand.

In den Jahren 1945 und 1946 setzt Aldanov jedoch den Abdruck von Erzählungen aus den Temnye allei im Novyj žurnal fort. In vier aufeinanderfolgenden Nummer erscheinen „Ćistyj ponedel'nik“ (10/1945), „Rečnoj traktir“ (11/1945), „Dubki““ (11/1945), „Parochod ,Saratov““ (11/1945), „Mest”“ (12/1945) und „Galja Ganskaja“ (13/1945) ${ }^{530}$; er weist Bunin jedoch darauf hin, daß es schwierig sein würde, die Erzählungen in einem Buch zu versammeln, falls sie schon alle in Zeitschriften erschienen seien. ${ }^{531}$

S27 Brief an Bunin vom 03.05.1945. LRA. MS.1066/5675.

528 Zit. in: „Perepiska I. A. Bunina s M. A. Aldanovym“. In: NZ 150 (1983): 175.

S29 Brief Bunins an Andrej Sedych vom 03.01.1949. Zit. in: Andrej Sedych. Dalekie, blizkie. op.cit.: 226.

530 Vor dem Abdruck dieser Erzahlung bittet Aldanov Bunin um die Erlaubnis, einige Passagen entfernen zu durfen (Brief an Bunin vom 06.05.1946. Zit. in: „Perepiska I. A. Bunina s M. A. Aldanovym“. In: Nz 152 [1983]: 164-165), was Bunin zu folgender postwendender Replik veranlaßte: „.Галя' без ,зротики“ никуда не годнтся, поэтому лучше не печатаяте“" (Brief vom 10.05.1946. Zit. in: „Perepiska 1. A. Bunina s M. A. Aldanovym". In: Nz 152 [1983]: 165). Die Redaktion des Novyj zurnal ignorierte diesen Wunsch und entfernte fur den Abdruck den Part, in der der Maler seinem Freund schildert, wie er Galja entkleidet (von , Я в одну минуту скинул с нее шелковую белую блузку [...]" bis ,[...] панталонах c разрезом в шагу, хах носили в то время", 6: 288).

531 Brief an Bunin vom 27.08.1945. Zit. in: „Perepiska I. A. Bunina s M. A. Aldanovym“. In: Nz 150 (1983): 176. Zu Lebzeiten Bunins erschienen keine Erzahlungen mehr im Novyj turnal, da er sich nach seinem Zerworfnis mit Mar'ja Cetlina anlaßlich seines Austritts aus dem russischen Schriftstellerverband 1947 eine weitere Zusammenarbeit nicht mehr vorstellen konnte. Auch die seit 1947 in Paris erscheinende Zeitschrift Russkaja mysl' blieb Bunin verschlossen, da dort u.a. Boris Zajcev, Nina Berberova und Ivan Śmelev publizierten, die ihm als dem feindlichen Lager angehorrig erschienen. So schränkten sich seine Publikationsmoglichkeiten in der Emigrantenpresse zunelikneng ein? 783954790210 
Ebenfalls 1945 erschien die Erzăhlung „Cholodnaja osen'“ in der prosowjetischen Pariser Tageszeitung Russkie novosti, was Mark Aldanov zu der Frage veranlaßte, ob Bunin dieses Medium gegenüber dem Novyj žurnal bevorzugen würde und letzteren spitz nachfragen ließ, was aus den beiden Aldanov vorliegenden, jedoch noch nicht publizierten Erzăhlungen ",Madrid““ und „Vtoroj kofejnik“ werden solle, ob sie keinen Gefallen fänden; die Publikation sei aus finanzieller Not heraus notwendig gewesen. ${ }^{532}$ Cetlin hatte eine Veröffentlichung dieser beiden Erzählungen im Novyj žurnal abgelehnt, da seiner Ansicht nach in „Vtoroj kofejnik“ Šaljapin und Korovin diffamiert würden (vgl. Kap. 10.1.1), und die beiden Erzählungen an die Verlegerin der Zeitschrift Novosel'e, Sofjia Pregel', weitergereicht, die sie in der Nummer 21 (1945) veröffentlichte. ${ }^{533}$ Auf die Bitte Aldanovs hin, weitere Erzăhlungen zu schicken, reagiert Bunin lediglich mit folgendem Hinweis: „Но мой ,портфель“ уже опустел, а нового я ничего не написал - и, думаю, уже не напишу.“ $\$ 34$ Diese Information entsprach nicht der Wahrheit und mag Ausdruck gekränkter Eitelkeit Bunins gewesen sein, zumal er in demselben Brief auf sich eröffnende Publikationsmöglichkeiten für die Temnye allei in England hinweist, wo man mutiger sei.

Mit dem Ziel der finanziellen Unterstützung Bunins wurde anläßlich seines 75. Geburtstags Ende 1945 in New York eine Sonderausgabe der Erzählung „Rexnoj traktir“ in limitierter numerierter Auflage von 1.000 Exemplaren inklusive des Faksimiles einer Typoskriptseite und der Unterschrift des Autors publiziert. ${ }^{535}$ Ein Festkomitee unter Leitung Mark Aldanovs, dem unter anderem auch Aleksandr Kerenskij, Michail Cetlin und Aleksandra Tolstaja angehörten, veröffentlichte in der in New York erscheinenden Tageszeitung Novoe russkoe slovo einen Aufruf, den notleidenden Schriftsteller durch den Kauf eines Exemplars zu unterstüzen: „Бунин прожнл четыре года под немецкой оккупацией, вел себя с исключительным достоинством и мужеством, укрывал и кормил на послед-ние деньги других писателей. “536 Bunin freut sich zwar über die Bemühungen des Freundes, zeigt sich aber mit der Wahl gerade dieser Erzăhlung nicht ganz zufrieden: „За ,роскошное“ издание ,Речного трактира“ немножко стыжусь-в нем кое-что

532 Brief an Aldanov vom 12.07.1945. Zit. in: „Lettres d'Ivan Bunin a Mark Aldanov“. op.cit.: 480.

533 Brief an Bunin vom 14.10.1945. Zit. in: „Pis'ma M. A. Aldanova k I. A. i V. N. Buninym“. op.cit.: 136.

534 Brief an Aldanov vom 10.05.1946. Zit. in: „Perepiska I. A. Bunina s M. A. Aldanovym“. In: Nz 152 (1983): 166.

535 Ivan Bunin. Recnoj traksir. New York, 1945.

536 M. Aldanov. .Bunin“. In: Novoe russkoe slovo (25.11.1945): 8. 
неплохо насчет Волги, вообще насчет ,святой Руси', но ведь все-таки это не лучший ,перл“ в моей ,короне“ [...]. “537

\subsubsection{Die Pariser Ausgabe von 1946}

Nach der Publikation von 1943 war an eine Integralveröffentlichung in den USA nicht mehr zu denken, so daß sich Bunin zunächst keinen Illusionen bezüglich der Publikation seines Buches hingab: „[...] кому она нужна в такое время? ${ }^{438}$ Seine einzige Hoffnung richtete sich auf Frankreich, doch abgesehen davon, daß sich die wirtschaftliche Infrastruktur erst wieder ausbilden mußte, bereitete den Verlagen auch die Papierknappheit Probleme:

Вообще, на редкость грустна судьба моей последней книги [...]- очевидно, что напечатать ее по-русски мог бы я все-таки только во Франция, если бы была тому материальная возможность; но Вы, верно, знаете, что об этом и мечтать нельзя - на это нужны совершенно дикие деньги! $!^{39}$

Zunächst gelang es ihm, mit den Editions du Pavois einen Verlag für die französische Übersetzung zu gewinnen (vgl. Kap. 9.3.1), bevor sich Ende 1945 der Verleger Orest G. Zeljuk (1888-1951; im Französischen: Oreste Zeluck) ${ }^{540}$ zu diesem verlegerischen Wagnis bereitfand. Am 21. November 1945 schloß Bunin einen Verlagsvertrag über die integrale Erstausgabe der Temnye allei mit Zelucks Verlagshaus La Presse Française et Etrangère. Zur Auswahl der Erzählungen, die im Vertrag nicht namentlich aufgeführt werden, äußerte er sich Aldanov gegenüber: „Кое-что я не ввел в нее, но, на мой взгляд, это оставшееся ,так себе' ...".541 Als Erstauflage waren 3.020 Exemplare (davon 20 Belegexemplare für den Autor) vorgesehen, die binnen anderthalb Jahren erscheinen sollten; das vollständige

537 Brief an Aldanov vom 11.10.1945. Zit. in: „Perepiska I. A. Bunina S M. A. Aldanovym“. In: Nz 150 (1983): 182.

538 Brief an Aldanov vom 12.04.1945. Zit. in: „Lettres d'Ivan Bunin à Mark Aldanov“. op.cit.: 478.

539 Brief an Aldanov vom 03.09.1945. Zit. in "Perepiska I. A. Bunina S M. A. Aldanovym". In: Nz 150 (1983): 179.

540 Mit diesem war er bereits 1919 in Odessa zu Gesprächen aber Publikationen zusammengetroffen. $\mathrm{Vgl}$. Tagebucheintrag Bunins vom 29.07/11.08.1919. Zit. in: UB. I.Bd. op.cit.: 299 .

541 Brief an Aldanov vom 05.07.1946. Zit. in: „Perepiska I. A. Bunina s M. A. Aldanovym“. In: NE 152 (1983): 170. 
Manuskript sollte bis zum 30. November 1945 vorliegen. ${ }^{542}$ Eine Auflage in der genannten Größenordnung erscheint sehr gewagt vor dem Hintergrund der schrumpfenden russischen Leserschaft in Paris ${ }^{543}$ und angesichts einer Mitteilung Aldanovs an Bunin aus dem Mai 1942, daß die aktuelle Auflage des Novyj zurnal 1.000 Exemplare betrage, von denen bis dato lediglich 550 verkauft seien, während zur Kostendeckung der Verkauf von mindestens 1.200 Exemplaren notwendig sei - und das bei unbezahlter Arbeit der beiden Chefredakteure Aldanov und Cetlin. ${ }^{544}$ Auch von den 1.000 Exemplaren der Sonderausgabe der Erzählung „Rečnoj traktir” waren bis Ende Februar 1946 lediglich 200 Stück verkauft. ${ }^{545}$ Über die Tatsache der Publikation freute Bunin sich daher verständlicherweise, aber auch in diesem Fall gab es einen Wermutstropfen: „Книга у Зелюка выйдет по ,новой орфографин“ - я и этим болен!“\$46

Die Veröffentlichung verzögerte sich immer wieder, aber im Dezember 1946 war es soweit: Anfang des Monats erschien das Buch und am 29. Dezember wurde anläßlich der Veröfientlichung und zu Ehren Bunins ein Frühstück gegeben. ${ }^{547}$ Das 325 Seiten umfassende Buch wurde von Bunin in die bereits erwähnten drei unterschiedlich großen Komplexe unterteilt - den bestehenden zwei Abschnitten der Ausgabe von 1943 mit „Natali“ als Finalerzählung wurden die später entstandenen Erzählungen als dritter Komplex (wenn auch nicht in chronologischer Reihenfolge) hinzugefüt. Im Rahmen dieser Publikation erlebten insgesamt zehn Erzählungen ihre Erstveröffentlichung. ${ }^{548}$

Bis heute ist diese Ausgabe als textlich vollständigste der Temnye allei zu betrachten. Die folgenden Kapitel beleuchten russisch-, französisch-, deutsch- und englischsprachige

542 LRA. MS.1066/6043. Andere Autoren sprechen falschlicherweise von einer geringeren Auflage von lediglich 2.000 Exemplaren, jedoch ohne Angabe von Quellen; vgl. u.a. V. Grecaninova. „Primecanija“. In: Ivan Bunin. SS v devjati tomach. 7.Bd. Moskva, 1966: 372.

543 Tausende Emigranten zogen wahrend des Krieges weiter in die USA, und nach Kriegsende kehrten ca. 6.000 Menschen in die Sowjetunion zuruck. Vgl. R. Johnston. ..Paris: Hauptstadt der russischen Diaspora". In: Der große Exodus. Hg. K. Schlogel. München, 1994: 278.

$544 \mathrm{Vgl}$. Brief Aldanovs an Bunin vom 26.05.1942. Edinburgh University Library, Special Collections Department, Gen.565.

545 Brief Aldanovs an Bunin vom 20.02.1946. Zit. in: „Perepiska 1. A. Bunina s M. A. Aldanovym“. In: $N z$ 150 (1983): 159.

546 Brief an Aldanov vom 26.12.1946. Zit. in: „Perepiska I. A. Bunina s M. A. Aldanovym“. In: Nz I50 (1983): 191. Bunin verwendete bis an sein Lebensende die alte Orthographie, in der er auch seine Publikationen gedruckt sehen wollte, was immer wieder zu Streitigkeiten mit Verlegern fuhrte.

$547 \mathrm{Vgl}$. Tagebucheintrage Vera Buninas vom 02.12. und 30.12.1946. Zit. in: UB. 3.Bd. op.cit.: 184 .

548 In einem Exemplar dieser Ausgabe, das von Boris Hoffman, Agence Hoffman, verwahrt wird, findet sich eine von Bunin mit einem roten Kugelschreiber geschriebene undatierte Anmerkung (die Verwendung dieses Stiftes erlaubt eine grobe Datierung der Notiz als in den spaten 1940er oder frühen 1950er Jahren entstanden): „Отмеченное $x$ нигде раньше не было напечатано, появляется в этой книге впервые. Нв. Б.“ Mit einem „x“ kennzeichnet er die folgenden Erzahlungen: „Kuma“, „Načalo“, "Baryšnja Klara”, „Železnaja Šerst'“. „Kamarg" und „Sto rupij“. Übersehen hat er bei seiner Anmerkung, daß auch die Erzâhlungen „Antigona“, „Smaragd“, .,Vizitnye kartocki“ und „Casovnja“ in diesem Buch erstmals publiziert wurden. 
Editionen, die in der Folge dieser autorisierten Erstausgabe erschienen (ohne Anspruch auf Vollständigkeit zu erheben) und beleuchten, soweit möglich, die Beweggründe, die den zahlreichen unvollständigen Ausgaben zugrunde liegen.

\subsection{Weitere russischsprachige Ausgaben der $\underline{\text { Temrye allei }}$}

Unmittelbar nach dem Ende des Zweiten Weltkriegs kam es zu Verhandlungen zwischen Bunin und Vertretern der Sowjetunion bezüglich einer Veröffentlichung der Temnye allei in seiner ehemaligen Heimat. Diese Pläne wurden jedoch zu Bunins Lebzeiten ebensowenig umgesetzt wie weitere diesbezügliche Publikationsvorhaben in den USA. Seit 1955 sind in der Sowjetunion bzw. den Nachfolgestaaten Erzählungen aus den Temnye allei ${ }^{549}$ teils in Zeitschriften ${ }^{550}$, teils in Sammelbänden, teils innerhalb von Werkausgaben, teils in einem Band zusammengefaßt erschienen (vgl. die Ubersicht im Literaturverzeichnis, Kap. 12.2.1). Der erste Integralabdruck erfolgte jedoch erst 1988; in den Jahrzehnten vor der Perestrojka waren selbst die Vollständigkeit suggerierenden Ausgaben gekennzeichnet von dem Fehlen der drei Erzählungen „Gost'“, „Baryšnja Klara“ und „Železnaja Šerst”“. In der Folge werden die relevanten Editionen vorgestellt.

\subsubsection{Publikationsversuche der Temnye allei zu Bunins Lebzeiten}

Mit dem Gedanken an die Möglichkeit der Veröffentlichung von Teilen seines Werkes in seiner ehemaligen Heimat scheint Bunin sich erstmals während des Zweiten Weltkriegs getragen zu haben. Nach Jahren des Schweigens nimmt er 1941 wieder Kontakt zu seinem in der Sowjetunion lebenden Freund Nikolaj Dmitrievič Telešov auf, dem er mitteilt, daß er kürzlich ein ganzes Buch mit neuen Erzăhlungen verfaßt habe, aber nicht wisse, wo er dieses veröffentlichen solle; da er im gleichen Schreiben auf seine desolate finanzielle Lage hinweist, ließe sich hinter diesem Brief die unausgesprochene Hoffnung auf Publika- 
tionsmoglichkeiten in der Sowjetunion vermuten. ${ }^{551}$ Der deutsche Überfall auf die Sowjetunion und der nachfolgende Eintritt derselben in den Zweiten Weltkrieg vereitelte eine Fortsetzung der Korrespondenz, die Bunin im Spätsommer 1945 wieder aufnimmt und den alten Freund wissen läßt, daß er in den Kriegsjahren nicht untătig war (,„...] не помешало мне написать большую книгу рассказов $[\ldots]^{4552}$ ).

Zeitgleich gelangten Gerüchte hinsichtlich geplanter Publikationen Bunins in der Sowjetunion an die Öffentlichkeit; in einem Brief an Aldanov vom 4. September 1945 teilt Bunin diesem seinen diesbezüglichen Kenntnisstand mit, der eine aktive Beteiligung auszuschließen scheint:

О6 издании монх сочинений Академией Наук было в газетах. Правда ли это, не знаю - знаю одно: не покупала у меня, не платила и, если издаст, то, конечно, не заплатит. Ведь не получал же я ничего (и, конечно, ничего не получу) за все то, что было уже издано из моих писаний в России (да еще в каком количестве зкз[емпляров]!) ${ }^{553}$

Ob die Initiative zur Veröffentlichung von Bunin oder sowjetischen Kulturbeauftragten ausging und in welcher Form Telešov involviert war ${ }^{554}$, kann auf Grundlage der vorliegenden Briefwechsel nicht geklärt werden. Bunins Version zufolge, die er in einem Brief an Aldanov vom 26. Dezember $1945^{555}$ schildert, erreichte ihn (seine Angaben legen den Oktober 1945 nahe) uber ein Telegramm an die Schriftstellerin Elsa Triolet die dringende Bitte aus Moskau, unverzüglich seinen letzten Erzählband zu schicken. Bunin will sich daraufhin zum Vorsitzenden des Pariser Sovinformbjuro, Boris Danilovix Michajlov, begeben und diesen gebeten haben, Moskaus Beweggründe zu erhellen, da er ja schließlich die Rechte an den Temnye allei an Oreste Zeluck verkauft habe. Man habe ihm geantwortet, daß man eben jene Erzählungen sowie das ein oder andere aus seinen letzten Publikationen verlegen wolle (ausschließlich in Rußland):

[...] и я попросил Бахраха отвезти Михайлову рукопись моих рассказов (3/4 их), Освобождение Толстого н Жизнь Арсеньева, а также письмо к Телешову ${ }^{556}[\ldots]$ Почти в то же время я получил от А. А.Гузовского, старшего советника

55I Brief an Telesov vom 08.05.1941. Zit. in: „Perepiska s N. D. Telešovym“. In: LN. 84.Bd. (1) op.cit.: 623.

552 Brief an Telesov vom 07.09.1945. Zit. in: „Perepiska s N. D. Telesovym“. op.cit.: 624. Der Brief erreicht Telesov jedoch erst im November 1945.

553 Zit. in: „Perepiska I. A. Bunina s M. A. Aldanovym“. In: Nz 150 (1983): 180.

554 In einem Brief an Telešov vom 08.12.1945 außert Bunin die Vermutung. daß dieser die Information von der Existenz der Temnye allei weitergeleitet habe, da er ihm 1941 von der Arbeit an diesem Buch berichtet hatte (zit. in: „Perepiska s N. D. Telesovym". op.cit.: 627).

S5S Zit. in: „Perepiska I. A. Bunina s M. A. Aldanovym“. In: Nż 150 (1983): 189.

556 Bunin bezieht sich hier auf einen Brief an Telešov vom 08.12.1945. Zit. in: „Perepiska S N. D. Telesovym". op.cit.: 627. 
русского посольства в Париже, извещение, что г[осподин] Посол желает со мной познакомиться $[\ldots]^{557}$

Bunin scheint einem solchen Vorhaben zunächst nicht grundsätzlich abgeneigt: „[...] и я завтра посылаю [...] сборник моих новых рассказов и три из монх последних книг [...] аля ознакомления Москвы со всем зтим [...].“558 $\mathrm{Zu}$ diesen Büchern, die er nach Moskau schickte, gehörte auch das Manuskript „моего последнего сборника (,Темные аллеи' '“559, die New Yorker Ausgabe der Temnye allei (1943) ${ }^{560}$, Žizn' Arsen'eva, Lika und Osvoboždenie Tolstogo. Im November 1945 setzt Telešov Bunin vom Druck eines umfangreichen Buches (25 Druckbögen) in Kenntnis, wobei unklar bleibt, ob sich der Band noch in der Planung oder bereits im Druck befindet. ${ }^{561}$ Diese Nachricht erreicht Bunin offenkundig mit großer zeitlicher Verzögerung, denn er reagiert erst im Januar 1946 auf dieses Schreiben - mit geänderter Meinung, für die er Telešov gegenüber folgende Gründe angibt:

Я называю это дело ужасным для меня потому, что издание, о котором идет речь, есть, очевидно, изборник из всего того, что написано мною за всю мою жизнь, нечто самое существенное из труда и достояния всей моей жизни -и избрано без всякого моего участия в том (не говоря уже об отсутствия моего согласия на такое издание и о том, что оно лишит меня возможности переиздавать собрание монх сочинений на русском языке во Франции или в какойлибо другой стране [...] В конце концов вот моя горячая просьба: если возможно, не печатать совсем этот изборник, пощадить меня $[. . .]^{562}$

Aus Moskau scheint Bunin in der Zwischenzeit keine offizielle Rückmeldung erhalten zu haben, denn im Postskriptum desselben Briefes fragt er Telešov, ob seine Sendung angekommen sei. Danach bricht der Briefwechsel erneut $a b$ und wird erst im November desselben Jahres von Bunin wieder aufgenommen. Zu diesem Zeitpunkt lag das geplante

557 Brief an Aldanov vom 26.12.1945. Zit. in: „Perepiska I. A. Bunina s M. A. Aldanovym“. In: Nz 150 (1983): 189-190.

558 Brief an Telešov vom 08.12.1945. Zit. in: „Perepiska s N. D. Telešovym”. op.cit.: 627.

$559 \mathrm{Vgl}$. Bunins Brief an Konstantin Simonov vom 20.07.1946. Zit. in: $L N$. 84.Bd. (2) op.cit.: 516 . Eigenartigerweise unterscheidet sich der Inhalt des von Bunin geschickten Manuskript-Pakets aus ungeklären Grunden in einigen Punkten von der zu diesem Zeitpunkt bereits vorliegenden Zusammenstellung der in Paris gedruckten Fassung (vgl. Anhang 2, Stand Ende 1945).

560 Außer der Bitte, man moge seine Interpunktion beibehalten, vermerkt Bunin noch folgende Information auf dem Titelblatt: „Эта хннжечка, нзданная в Амернке [...] заключала в себе только одну четвертую часть того, что мною написано под общим заглавнем ,Темные аллен“"” (vgl. Foto des Originals in $L N$. 84.Bd. (1) op.cit.: 47).

$561 \mathrm{Vgl}$. Briefe Telešvs an Bunin vom 11.11.1945: „Твоя кннга листов в 25 печатается в Госнздате“ (zit. in: „Pis'ma N. Telesova $k$ I. Buninu“. In: $N z 85$ [1966]: 132) und nach dem 11.11.1945: „Mexay прочим, очень важно, что Государственнос нздательство печатает твон рассказы, около 20-25 листов"; in demselben Brief bittet er um die Zusendung von Bunins letztem Buch, also den Temmye allei in der New Yorker Edition von 1943 (zit. in: „Perepiska s N. D. Telesovym“. op.cit.: 626).

562 Brief an Telesov vom 30.01.1946. Zit. in: „Perepiska s N. D. Telesovym“. op.chit. 628-629. 
Buch längst im Umbruch vor; Bunin wurde darüber jedoch offensichtlich weder informiert noch erhielt er ein Belegexemplar. ${ }^{563}$ Daher setzt er seine Bemühungen um die Einflußnahme auf den Publikationsprozeß fort.

Im März 1946 spielte er offenbar mit dem Gedanken, auch Konstantin Fedin in die Publikationsverhandlungen einzuschalten. Er läßt ihm zwei Bücher mit Widmungen zukommen, der bereits entworfene Brief hingegen erreicht Konstantin Fedin eigenen Angaben zufolge nicht. ${ }^{564}$ Im LRA befindet sich dieser offenbar versandfertige Brief samt Bunins Unterschrift vom 15. März 1946, in dem Bunin Fedin um seine Unterstützung bei der Einflußnahme auf die Textauswahl des geplanten Sammelbandes bittet, mit dem er sich inzwischen gedanklich ausgesőhnt hat. ${ }^{565} \mathrm{Zu}$ einer Intervention Fedins kommt es somit nicht; statt dessen trifft im März in Paris ein Telegramm von Michail Apletin in seiner Funktion als Vizepräsident der Auslandskommission des sowjetischen Schriftstellerverbands ein, in dem Bunin mitgeteilt wird, daß die Druckvorbereitung des geplanten Buches unterbrochen worden sei. ${ }^{566}$ Daraufhin blieb Bunin offenbar ohne weitere Nachrichten. denn in einem Schreiben vom 20. Juli 1946 wendet er sich an Konstantin Simonov, mit der Bitte, bei Gelegenheit beim Gosudarstvennoe izdatel'stvo ein gutes Wort für ihn einzulegen; diesem Brief zufolge scheint Bunin grundsătzlich an einer Veröffentlichung in der Sowjetunion interessiert, vorausgesetzt man beziehe ihn in den Auswahlproze $B$ der in Frage kommenden Texte ein und orientiere sich etwa an der in den 1930er Jahren im Berliner Verlag Petropolis erschienenen Gesamtausgabe. ${ }^{567}$ Diese Grundhaltung bekräftigt er in zwei weiteren Briefen an Telešov von Anfang 1947: Auch ihm gegenüber erklärt er sich einverstanden mit einer Veröffentlichung unter der Voraussetzung, daß als Grundlage die Petropolis-Gesamtausgabe verwendet werde. ${ }^{568}$

Erklärbar ist Bunins Wankelmut zum einen mit dem Argwohn, mit dem die russischen Emigranten in Paris, aber auch in Amerika, seine Kontakte mit der sowjetischen Macht beobachteten, zum anderen mit dem Teufelskreis seiner prekären gesundheitlichen Lage, die schöpferisches Arbeiten nahezu unmöglich machte, und den daraus resultierenden

563 I. Bunin. „Izbrannye proizvedenija“. Moskva, 1945. Dieser Auswahlband ohne Vor- oder Nachwort bzw. Kommentar enthalt ca. 360 Gedichte und 42 Erzahlungen, darunter Erzăhlungen aus den Emigrationsjahren, u.a. „Mitina ljubov"“, „Delo kometa Elagina“, .,Solnežnyj udar". Vorbereitet und zusammengestellt wurde er von P. Vjaceslavov und An. Tarasenkov auf der Basis der von Bunin als textologisch uberholt angesehenen Polnoe SS. Petrograd, 1915 (Gosudarstvennyj literatumyj muzej, otdel rukopisej. Fond 410, opis' 1, delo Nr. 3).

564 „Pis'mo k K. A. Fedinu. 1946". In: LN. 84.Bd. (1) op.cit.: 691.

S65 LRA. MS.1066/2367.

566 LRA. MS. $1066 / 1639$.

567 Zit. in: „Pis'mo k K. M. Simonovu“. In: LN. 84.Bd. (2) op.cit.: 516-517.

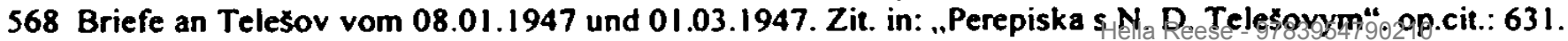


finanziellen Engpässen, aber auch sein heikles Verhältnis seinen Texten gegenüber. Wie groß Telešovs Einfluß in dieser Angelegenheit war, läßt sich nicht mit Genauigkeit feststellen, da er in seinen Briefen häufig darauf hinweist, daß er keine Reaktion vom Verlag erhalten habe. In einem Brief vom 1. April 1947 kündigt Bunin an, dem Freund eine Ausgabe der 1946 in Paris erschienenen Temnye allei zu schicken, und warnt vor: $n[\ldots]$ не смущайся ее некоторыми смельми местами - в общем она говорит о трагичном и о многом нежном и прекрасном [...]. “569 Das Buch trifft allerdings nie bei Telešov ein; Bunin fragt zwar noch mehrfach nach, unternimmt aber offenbar keine weiteren Anstalten, es erneut zu schicken.

Zu Lebzeiten Bunins kommt es nicht mehr zu einer Veröffentlichung von Teilen seines Werkes in der Sowjetunion, dafür gab es Anfang der 1950er Jahre erneute Bestrebungen in den USA: Das sich im Sommer 1951 in Gründung befindliche russische Verlagshaus Izdatel'stvo imeni Cechova beabsichtigte, als eines der ersten Bücher einen Band mit Erzählungen Bunins herauszugeben. Die Verlagsrepräsentantin Vera Aleksandrovna Švarc schlägt in einem Brief vom 29. Juni 1951 an Bunin vor, verschiedene Erzählungen aus der Pariser Ausgabe der Temnye allei auszuwählen, unter Beibehaltung des Titels und mit „Pozdnij Cas" als Eröffnungserzählung. ${ }^{570}$ Eine derartige Zusammenstellung rief bei Bunin höchstes Unbehagen hervor, wie ein Brief an Mark Aldanov vom 1. August 1951 belegt:

[...] предлагающегося какого-то жалкого сборничка, начинающегося „Поздним Часом“, который я очень ценю, но затем состоящего из душеспасительньх кусочков, взятых только из моей книти „Божъе древо“. Это все равно, что взять из Пушкина „Румяной зарею покрылся восток“ и прочее в том же роде с прибавкой „Послания к Декабристам“. Я на это, конечно, никак не согласен. ${ }^{571}$

Die von Bunin herbeigefuhrten Unstimmigkeiten hatten auch noch einen anderen Grund: Er verweigerte die Zustimmung zum Druck seiner Bücher in neuer Orthographie. ${ }^{572}$ Aus materiellen Erwägungen heraus stimmte er jedoch schließlich Veröffentlichungen zu den vom Verlag gestellten Bedingungen zu, so daß 1953 und 1954 insgesamt

569 Brief an Telešr vom 01.04.1947. Zit. in: „Perepiska s N. D. Telesovym“. op.cit.: 634. Selbst wenn Telesov bereits die von Bunin im Jahr zuvor geschickten Fassungen der Temmye allei (New York, 1943, und die Manuskriptfassung) in Augenschein genommen haben sollte, so enthielt die Pariser Fassung zum einen mehr Erzahlungen und zum anderen weniger Kurzungen als die New Yorker Ausgabe von 1943; moglicherweise bezieht sich Bunins Bemerkung auf die im Vergleich zur Edition von 1946 unvollstăndigere Manuskriptzusammenstellung, in der die folgenden Erzahlungen nicht enthalten sind: "Krasavica“, „Durocka“, "Antigona“, „Gost”" und „Baryšnja Klara“.

570 Zit. in: „Perepiska I. A. Bunina S M. A. Aldanovym". In: NZ 155 (1984): 136.

571 Zit. in: „Perepiska I. A. Bunina s M. A. Aldanovym". In: NE 155 (1984): 135.

572 Brief an Vera A. Svarc vom 09.09.1951. Zit. in: „Perepiska 1. A. Bunina s M. A. Aldanovym“. In: Nz 155 (1984): 145. 
drei Sammelbände mit Erzählungen erscheinen ${ }^{573}$, die jedoch keine Erzählungen aus den Temnye allei enthalten.

\subsubsection{Russischsprachige Ausgaben der Temnye allei nach Bunins Tod}

In diesem Kapitel, das keinen Anspruch auf Vollständigkeit erhebt, werden bis einschließlich des Jahres 2000 jene Fassungen der Temnye allei, die wie die rudimentäre Erstausgabe in der Sowjetunion mindestens 17 Erzählungen enthalten, auf ihren Umgang mit der Fassung von 1946 betrachtet. Veröffentlichungen, in denen sich bis zu 17 Erzählungen aus den Temnye allei finden, werden in diesem Kapitel nicht explizit berücksichtigt, aber im Literaturverzeichnis unter Nennung der enthaltenen Erzählungen aufgeführ (vgl. Kap. 12.2.1). Zahlreiche Veröffentlichungen verwenden den Titel des Originals, lösen das damit suggerierte Versprechen auf einen Integralabdruck aber nicht ein.

Die erste Sobranie socinenij mit einer Auswahl aus Bunins Werk erschien 1956 in funf Bänden mit einer umfangreichen Einleitung des sowjetischen Journalisten, Schriftstellers und Literaturkritikers Lev Nikulin. Der vierte Band enthält 17 Erzăhlungen aus den Temnye allei ${ }^{574}$; es fehlt jedoch eine Begründung für diesen unvollständigen Abdruck, der die Unterteilung in die einzelnen Komplexe zwar ignoriert, aber als Textgrundlage die im Moskauer IMLI verwahrte Pariser Ausgabe von 1946 mit Bunins eigenhändig eingetragenen Korrekturen nennt. ${ }^{575}$ Fünf Jahre später werden in etwas anderer Zusammenstellung 18 Erzählungen aus den Temnye allei abgedruckt, ebenfalls ohne Unterteilung, aber mit dem Hinweis „Из книги ,Темные аллеи““. 576

573 Mitina ljubov'. Solnecmyj udar (1953; Erzahlungen der 1910er und 1920er Jahre); Vesnoj, v /udee. Roza lerichona (1953; spatte Erzahlungen); Petlistye usi i drugie rasskazy. (1954; Erzahlungen bis 1930).

574 1. Bunin. SS v pjafi tomach. 4.Bd. Moskva, 1956. Folgende Erzăhlungen aus den Temmye allei sind enthalten: „Temnye allei“, „Kavkaz", „Stepa“, „Muza“, „Rusja“, „Krasavica“, .Durocka“, „Volki“,

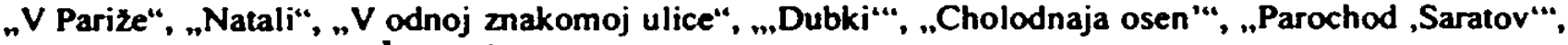
"Voron", „Kaceli“" und „Casovnja“.

575 „Второе, дополненное издание ,Темных аллей“ вышло в 1946 году в Париже. Печатается по этой книге, с исправлениями, сделанными Буниным для перенздания. (Исправленный зкземпляр се находится в Архиве Института мировой литературы им. А. Горького.)" In: I. Bunin. SS v pjati lomach. 4.Bd. Moskva, 1956: 465.

576 I. Bunin. Povesti. Rasskazy. Vospominanija. Moskva, 1961: „Temnye allei“, „Ballada“, "Muza”, „Pozdnij cas", „Rusja“, „Krasavica“, „Durocka“, „Antigona“, „Smaragd”, „Volki“, „Galja Ganskaja“, "V odnoj znakomoj ulice“, „Recnoj traktir", „Dubki““, .Cholodnaja osen"“, "Kaceli“, „Cistyj ponedel'nik“ und "Casovnja“. 
Als nahezu vollständige Fassung wurden die Temmye allei unter Beibehaltung der Unterteilung in drei Komplexe erstmals im Rahmen der neunbändigen Sobranie socinenij herausgegeben, die in den Jahren 1965 bis 1967 unter der Leitung von A. S. Mjasnikov, B. S. Rjurikov und A. T. Tvardovskij zusammengestellt wurde. ${ }^{577}$ Mit einem Verweis auf die erwăhnte Notiz in Bunins persönlichem Exemplar der Temnye allei (1946), das mutmaßlich 1956 in die Sowjetunion gelangt ist ${ }^{578}$, werden die beiden Erzăhlungen „Vesnoj, v Iudee“ und „Noxleg“ in die Edition aufgenommen, während ohne einen diesbezüglichen expliziten Hinweis auf den Abdruck der drei-vermutlich als anstoßßig empfundenenErzählungen „Gost'“, „Baryšnja Klara“ und „Železnaja Šerst”“ verzichtet wurde. Daß Auslassungen vorgenommen wurden, wird dem Leser leicht verklausuliert mitgeteilt:

Что же касается вновь написанного в эмиграции [...] там есть вещи, настолько принижающие талант Бунина, что славное литературное имя его обязывает нас оставить их за бортом даже такого вместительного издания, как нынешнее собрание сочинений. ${ }^{579}$

Auf Basis dieser Ausgabe erschienen 1978 in dem Sammelband Rasskazy 26 Erzahlungen aus den Temnye allei, allerdings ohne Unterteilung in die einzelnen Komplexe. ${ }^{580}$ Eine weitere Variante wird 1979 in Novosibirsk publiziert: Auch dieser Abdruck ohne Voroder Nachwort folgt der Ausgabe von 1966, übernimmt die Dreiteilung der Erzählungen und suggeriert durch Verwendung des Titels Temnye allei eine Integralausgabe, bezieht jedoch ohne Begründung nur 31 Erzählungen in die Auswahl ein. ${ }^{581}$ Der dritte Band der Socinenija v trech tomach, die 1982 (und in zweiter Auflage 1984) in Moskau erscheinen, übernimmt sowohl die Dreiteilung als auch die Erzăhlungen in vollem Umfang auf Grundlage des 1966 erschienenen Bandes. ${ }^{52}$

Ohne einen Hinweis auf die textliche Herkunft erschien 1984 der Titel Temnye allei: Povesti, rasskazy: Umfang und Unterteilung lehnen sich an die Ausgabe von 1966 an; auf

577 I. Bunin. SS v devjati tomach. 7.Bd. Moskva, 1966.

578 In Vera Buninas Nachlaß finden sich verschiedene Quittungen, die mit dem Datum 25.10.1956 unter anderem eine Übergabe der Pariser Ausgabe dokumentieren. LRA. MS.1066/10122.

579 A. Tvardovskij. „O Bunine“. In: I. Bunin. SS v devjati tomach. 1.Bd. Moskva, 1965: 29.

580 1. Bunin. Rasskazy. Moskva, 1978: „Temnye allei“, „Kavkaz“, „Ballada“, „Muza“, „Pozdnij Cas“, „Rusja”. „Antigona“, „Volki“, „Vizitnye kartocki“, "Tanja“, „V Pariž“, „Natali“, „Kuma“, „Recnoj

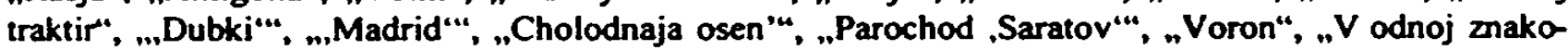
moj ulice“, „Mest”“, .C'istyj ponedel'nik“, „Kaceli“, „Časovnja“, „Vesnoj, v ludee“ und „Nocleg“".

581 1. Bunin. Temnye allei. Novosibirsk, 1979: „Temnye allei“, „Kavkaz", „Ballada“, „Stepa“, „Muza“, „Pozdnij Cas", „Rusja“, „Krasavica“, „Durocka“, „Antigona“, „Volki“, „Tanja“, „V Parize“, „Galja

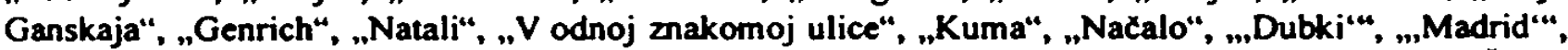

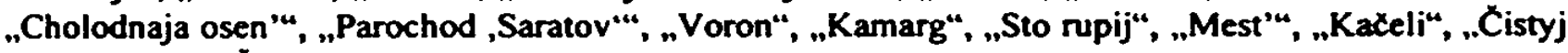
ponedel'nik", "Casovnja" und „Nocleg".

582 I. Bunin. Socinenija v trech tomach. 3.Bd. Moskva, 1982' (1984²). 
den Abdruck der Erzählung „Casovnja“ wird jedoch unerklärlicherweise (und ohne Hinweis) verzichtet. ${ }^{583}$ Ähnlich rätselhaft ist der Abdruck von 35 Erzăhlungen ohne Unterteilung in den Izbrannye socinenija $(1984)^{584}$, die sich vorgeblich an der 37 Erzählungen enthaltenden Ausgabe von 1966 orientiert; für zusätzliche Verwirrung sorgt die Einführung von Oleg Michajlov, in der er suggeriert, daß die New Yorker Ausgabe der Temnye allei 38 Erzählungen enthält. ${ }^{585}$ Von dieser Fehlinformation abgesehen ist es unerklärlich, daß kein Hinweis auf die fehlenden Erzählungen erfolgt. Eine stark verkürzte Fassung auf derselben textlichen Basis mit 28 Erzählungen ohne Unterteilung erschien 1987 unter dem Titel Antonovskie jabloki: Rasskazy. ${ }^{586}$

Im selben Jahr wie die erste Integralausgabe (s.u.) erschien im Rahmen einer Sobranie socinenij $v$ cetyrech tomach die übliche Version, bestehend aus 35 Erzählungen zuzüglich "Vesnoj, v Iudee“ und „Nočleg“. 587 Auch in den 1990er Jahren setzt sich diese Publikationspraxis fort. 588

Der erste Integralabdruck der Temnye allei in der Sowjetunion erfolgte erst 1988 im Rahmen einer in den Jahren 1987 bis 1989 erscheinenden sechsbändigen Sobranie socine$n i j^{589}$ : Die begleitenden Erläuterungen von Anna Saakjanc enthalten jedoch ebensowenig einen Hinweis auf den erstmals erfolgenden vollstăndigen Abdruck des Buches im fünften Band wie die ausführlichen Erläuterungen Aleksandr Baborekos, dafür werden als Textgrundlage genannt die Ausgabe von 1946 samt Bunins Korrekturen sowie für die Erzählungen „Vesnoj, v Iudee“ und „Noxleg“ Typoskripte mit handschriftlichen Korrekturen Bunins, die im Moskauer IMLI verwahrt werden. ${ }^{590}$ Als Einzelausgabe wurde diese Fassung 1990 in die Reihe „Klassiki i sovremenniki“ aufgenommen und mit einem Vorwort

583 I. Bunin. Temnye allei: Povesti, rasskazy. Kemerovo, 1984.

584 I. Bunin. Izbranmye socinenija. Moskva, 1984.

585 ,....] Темные аллеи“ (1943), единственное в своем роде в русской итературе, где все - о любви. Трндиать восемь новелл зтого сборника дают великое разнообразне незабываемых женских типов“ (O. Michajlov. „O Bunine [1890-1953]“" In: I. Bunin. Izbrannye sodinenija. Moskva, 1984: 10).

586 1. Bunin. Antonovskie jabloki: Rasskazy. Murmansk, 1987: „Temnye allei“, "Kavkaz", „Ballada“, .Stepa“, „Muza“, „Rusja“, „Krasavica“, „Antigona“, „Vizitnye kartocki“, „Volki“, „Zojka i Valerija“,

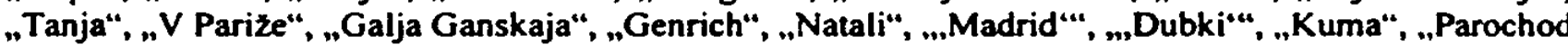
.Saratov“", .Cholodnaja osen”“, . Vtoroj kofejnik“, .Voron", „Mest”“, „Kaceli“, „Sto rupij”, „Cistyj ponedel'nik" und „'Casovnja“.

587 1. Bunin. SS v ceryrech tomach. 4.Bd. Moskva, 1988.

588 Vgl. Z.B. I. Bunin. Izbranmye proizvedenija. Moskva, 1991 (3 Komplexe); ders. SS v jesti tomach. 6.Bd. Moskva, 1994 (3 Komplexe); ders. Povesti, rasskazy. Serija: Russkaja klassika o ljubvi. Moskva, 1994 (ohne Unterteilung); ders. Temnye allei; Mitina ljubov' (Sbornik). Rostov-na-Don, 1994 (ohne Unterteilung); ders. Temmye allei. Sankt-Peterburg, 1994 (3 Komplexe); ders. Temmye allei: Povesti $i$ rasskazy. Ekaterinburg, 1994 (Aufbau unbekannt); ders. Temnye allei. Sankt-Peterburg. 1997 (Aufbau unbekannt); ders. Temnye allei. Moskva, 1998 (3 Komplexe); ders. Temnye allei. Moskva, 2000 (ohne Unterteilung).

589 I. Bunin. SS v J̌esti tomach. S.Bd. Moskva, 1988.

590 A. Baboreko. „Temnye allei“ (Anmerkungen). In: I. Bunin. SS v šesti tomache So Bd] Maskikea. d $988: 611$. 
von Oleg Michajlov versehen. ${ }^{591}$ Verwunderlich ist auch in diesem Falle der Hinweis Michajlovs auf 38 Erzăhlungen, die das Buch enthalte, wăhrend 40 abgedruckt werden. ${ }^{592}$ Seit den 1990er Jahren erscheinen zunehmend Integralausgaben der Temnye allei mit 40 Erzählungen, die jedoch nicht immer in die drei von Bunin vorgesehenen Komplexe unterteilt sind. 593

Für das Jahr 1995 war anläßlich des 125. Geburtstags Bunins das Erscheinen einer 20 Bände umfassenden Akademieausgabe angekundigt, an deren Vorbereitung der Bereich Literatura zarubež'ja des Moskauer IMLI maßgeblich beteiligt ist. ${ }^{594}$ Derzeit scheint dieses Projekt jedoch auf Eis zu liegen. ${ }^{595}$ Eine vollständige bzw. kritische Ausgabe der Temmye allei in russischer Sprache steht demzufolge bis heute aus.

Die sowjetische bzw. russische Publikationspraxis ist kennzeichnend fur den Umgang mit den Temnye allei, der sich auch bei den Öbersetzungen vor allem in Deutschland beobachten läßt: Es werden keine Neuredaktionen vorgenommen, sondern bereits vorliegende Texte übernommen - auf diese Weise können Editionsfehler jahrelang überleben. Während die russischsprachigen Ausgaben (mögen sie noch so unvollstăndig sein) zurmindest die von Bunin gewählte Reihenfolge der Erzählungen und häufig auch die Dreiteilung in verschiedene Komplexe beibehalten, gilt dies nicht für die Übertragungen ins Französische, Englische und Deutsche.

9.3 Französisch-, englisch- und deutschsprachige Ausgaben der Temnye allei

Während die erste Öbersetzung in Frankreich erst gut 40 Jahre nach Erscheinen des Originals publiziert wurde, kam es im deutsch- und englischsprachigen Raum bereits in den 1940er Jahren zu Veroffentlichungen bzw. diesbezüglichen Bestrebungen. Dort erschien

591 I. Bunin. Temnye allei. Moskva, 1990.

592 O. Michajlov. „Pesn’ pesnej Bunina“. In: I. Bunin. Temmye allei. Moskva, 1990: 6.

593 I. Bunin. Solnecmyj udar. Rasskazy. Serija: Russkij éros. Moskva, 1992 (3 Komplexe); ders. Izbrannoe v duch tomach. 1.Bd. Ceboksary, 1993 (3 Komplexe); ders. V takuju noc': Rasskazy. Kaluga, 1993 (ohne Unterteilung); ders. Temmye allei. Paris, 1995 (3 Komplexe); ders. SS v vos 'mi tomach. 6.Bd. Moskva, 1999 (3 Komplexe).

594 O. Michajlov. „Osvobozdenie Bunina“. In: Slovo 7 (1990): 55-57. In diesem Interview weist Michajlov auf die Luckenhaftigkeit der vorliegenden Bunin-Publikationen hin, die man mit der geplanten Ausgabe beheben wolle.

595 In einem Gesprach mit der Verfasserin am 31.05.2000 in Moskau konnte Oleg Michajlov noch keinen Erscheinungszeitpunkt benennen. Auch bis zum Tag der Abgabe der vorliegenden Dissertation lagen keine weiteren Informationen vor. 
auch die erste und bislang einzige fremdsprachige Integralfassung. In den folgenden Kapiteln werden die einzelnen Ausgaben ebenfalls im Hinblick auf ihren Umgang mit dem Original von 1946 betrachtet und die Hintergründe für mangelhafte Editionen - soweit möglich - beleuchtet.

\subsubsection{Französischsprachige Ausgaben}

Es verwundert, daß es in Bunins zweiter Heimat Frankreich erst in den späten 1980er Jahren zu einer französischsprachigen Publikation kam, obwohl erste Veroffentlichungsbestrebungen bereits im Jahr 1941 zu konstatieren sind, zu einem Zeitpunkt also, als die ersten beiden Komplexe des Buches fertiggestellt waren. Kein Geringerer als André Gide wurde vermittelnd tätig und bot nach einem Besuch bei Bunin redaktionelle Unterstutzung an ${ }^{596}$; am 8. Oktober 1941 notiert Bunin Folgendes in sein Tagebuch: „Вчера вечером вернулся из Ниццы Бахр[ax]. A. Gide сейчас там. Какой-то швейц[арский] издатель, по его реком[ендациям], хочет издать на франц[узском] языке мою новую книгу. Вот было-бы счастье!“497 In seinem Buch Bunin v chalate, seinen Erinnerungen an die Jahre in Grasse, erwähnt auch Aleksandr Bachrach dieses Treffen mit André Gide und einem nicht namentlich genannten Schweizer Verleger aus Lausanne. ${ }^{598}$ In der Tat kam es zu einer kurzen Zusammenarbeit, in deren Verlauf Bachrach für die Übersetzungen verantwortlich zeichnete, die Gide redigierte, bis mit der Erzählung „Natali“ sein Interesse erlahmte und die Kooperation ihr Ende fand. ${ }^{599}$

In einem unveröffentlichten Tagebucheintrag Bunins vom 28. Januar 1942 findet sich die Notiz, daß er an den Verleger Oreste Zeluck per Einschreiben folgende Erzählungen geschickt habe: „Temnye allei“, „Stepa“, „Muza“, „Rusja“, „Zojka i Valerija“, „Galja Ganskaja“, „Genrich“, „Tri rublja“ und „Pro obez’janu“. ${ }^{600}$ Konkrete Publikationsabsichten oder gar Vertragsverhandlungen lassen sich jedoch nicht nachweisen, und so bleiben

$596 \mathrm{Vgl}$. Tagebucheintrag Gides vom 28.08.1941: „Il vient, m'a t'il dit, d'achever un nouveau livre, mais ne sait où ni comment le faire éditer.“ In: A. Gide. Journal 1926-1950. Paris, 1997: 780.

597 Zit. in: $U B$. 3.Bd. op.cit.: 114.

598 Rosa Fedoulova nennt in ihrer Dissertation ohne Quellenangabe als Verleger Maurice Blan und halt fest. daß lediglich die Erzahlungen "Natali" und „Tri rublja" ubersetza wurden ("Les Allées sombres d'ivan Bunin“. op.cit.: 39).

599 A. Bachrach. Bunin v chalate. op.cit.: 57-58.

600 LRA. MS. $1066 / 534$. 
die Grunde für diese Sendung unklar. Im Fruhjahr 1942 tritt er zudem in Kontakt mit dem in der Schweiz ansässigen Übersetzer Waldemar (Vladimir) Jollos ${ }^{601}$, vermutlich durch die Vermittlung von Ekaterina Dmitrievna Kuskova-Prokopovic, Frau des Wirtschaftswissenschaftlers Sergej Nikolaevic Prokopovix, die im selben Jahr den Kontakt zu dem in Genf ansässigen François Fosca von den Editions du Milieu du Monde herstellt. In einem Brief vom 3. August 1942 empfiehlt Kuskova-Prokopovic Bunin, sich bezüglich der Veroffentlichung eines Buches mit Erzählungen und insbesondere der Erzăhlung „Natali“ an Fosca zu wenden und gibt ihm folgenden Rat mit auf den Weg, der an Aldanovs mahnende Worte zu den puritanisch geprägten Moralvorstellungen der Amerikaner erinnert: ,[...] выкиньте или переделаете то место, на кот[орое] я Вам указала: страна Кальвина! ${ }^{602}$ Bunin entschließt sich, unverzuglich die Erzăhlung „Natali“ in die Schweiz zu schicken $^{603}$, und erhält im Oktober einen abschlägigen Bescheid von Fosca:

J'ai bien reçu votre lettre du 10 août, et quelques jours après vous ai écrit que nous ne pouvions en aucun cas publier un volume de nouvelles, ayant constaté que le public se montrait très rétif à l'égard de cette sorte d'ouvrages. ${ }^{004}$

Durch seinen in Paris lebenden Freund Boris Zajcev erfuhr Bunin im November 1943 von den verlegerischen Absichten Fernand Sorlots, der in seine Reihe "Les maitres étrangers" auch russische Literatur aufnehmen wollte und sich auf der Suche nach geeigneten Autoren befand. ${ }^{605}$ Bunin reagiert umgehend und schickt die franzosische Fassung von „Natali“, vermutlich in der von Bachrach angefertigten Übersetzung. ${ }^{606}$ Obwohl Zajcev ihm nicht viel Hoffnung macht, da Sorlot Romane herauszugeben beabsichtigte, fahrt Bunin for, ihm Erzăhlungen zu schicken, nunmehr zur Aufbewahrung „für alle Fălle“; weitere Übersetzungen schickt er nicht, da etliche Erzählungen noch nicht ubersetzt

601 Im Marz 1942 hatte Bunin diesem uber Kuskova-Prokopovi飞 verschiedene Erzahlungen geschickt (unveroffentlichter Tagebucheintrag Bunins vom 27.03.1942. LRA. MS.1066/535). Im Mai 1942 schickt er Jollos zudem die folgenden zu den Temmye allei gehorenden Erzahlungen zur Obersetzung: "Temnye allei", .Kavkaz”, „Ballada“, .Stepa“, „Muza“, „Pozdnij Cas", „Tri rublja“, „V Parize“, „Rusja“, „Pro obez'janu" und "Smaragd" (unveroffentlichter Tagebucheintrag vom 26.05.1942. LRA. MS.1066/535). Es muß offen bleiben, warum sich keine Ergebnisse aus dieser Zusammenarbeit finden lassen.

602 LRA. MS. $1066 / 3477$.

$603 \mathrm{Vgl}$. unveroffentlichten Tagebucheintrag Bunins vom 12.08.1942. LRA. MS.1066/535.

604 Brief an Bunin vom 08.10.1942. LRA. MS.1066/2543. Auch Foscas Bruder Robert de Traz proft Publikationsmoglichkeiten in verschiedenen franzosischsprachigen Schweizer Zeitschriften fur "Natali“" kann Bunin jedoch wenig Hoffnung machen. Im LRA befinden sich drei diesbezagliche Briefe aus dem Zeitraum August bis Oktober 1942. LRA. MS.1066/5582-5584.

605 Brief an Bunin vom 02.11.1943. Zit. in: „Pis'ma B. Zajceva I. i V. Buninym”. In: NZ 146 (1982): 118 119.

606 Brief an Zajcev vom 09.11.1943. Zit. in: „Pis'ma I. Bunina k B. Zajcevu“. In: Nz 137 (1979): 124. 
seien. ${ }^{607}$ Am 3. Dezember 1943 traf Zajcev emeut mit Sorlot zusammen und übergab ihm "Nathalie" mit dem Hinweis, daß diese Erzählung nur ein Kapitel eines geplanten romanähnlichen Buches Bunins sei - Sorlot verhielt sich abwartend und wies erneut darauf hin. daß er primăr an Romanen interessiert sei, gab aber noch keine abschließende Antwort. ${ }^{608}$ Mitte Dezember 1943 macht Bunin einen überraschenden Rückzieher bezüglich seiner Publikationsabsichten: „[...] некоторые обстоятельства, довольно неожиданные, заставляют меня твердо решиться не переводить пока и не издавать ,Темные аллеи' “609 Diese Umstände, die Bunin auch in der Folge nicht spezifiziert, stellen nicht nur Zajcev vor ein Rätsel; erklärlich ist Bunins Sinneswandel möglicherweise mit der Angst des Vorwurfs der Kollaboration, falls er unter der deutschen Besatzung publiziert hätte.

Es ist nicht bekannt, ob es in den Kriegsjahren noch zu weiteren Publikationsversuchen gekommen ist, jedoch ist kurz nach Kriegsende und bereits vor der vertraglichen Einigung über das Erscheinen der russischen Originalausgabe (Dezember 1946) ein Verlag für die französische Übersetzung gefunden: Am 11. Juli 1945 schließt Bunin mit den Editions du Pavois einen Vertrag uber die Herausgabe von Les Allées sombres $\mathrm{ab}^{610}$, zweifelt jedoch an einer raschen Umsetzung der Publikationsabsichten, wie er seinem Freund Aldanov anvertraut: „Мой французск[ий] издатель-новый - Le Pavois‘. Книга выйдет, верно, не скоро - переводчик, некто Priel ${ }^{611}$, живет где-то в Бретанин, старик, копун, переводит медленно, плохо ...“612 Sein Gefühl trügt ihn nicht, denn über ein Jahr später ist noch kein Fortschritt in der Sache zu verzeichnen, dennoch schreibt Bunin an Andrej Sedych: „Пофранцузски эти ,Аллеи' выходят вскоре в новом богатом издательстве ,Le Pavois' [...]."613 Diese Aussage ist reines Wunschdenken, da eine entsprechende Nachfrage Bunins beim Verlag eine Antwort nach sich zieht, deren Hinweis auf eine allgemeine Krise

607 Brief an Zajcev vom 19.11.1943. Zit. in: „Pis'ma 1. Bunina k B. Zajcevu“. In: Nz 137 (1979): 126. Insgesamt liegen zu diesem Zeitpunkt vier ubersetzte Erzăhlungen vor, von denen sich bislang nur "Nathalie" in Zajcevs Besitz befindet; Bunin bietet jedoch an, auch die ubrigen zu schicken, falls Sorlot sie einsehen mochte (Brief an Zajcev vom 21.11.1943. Zit. in: „Pis'ma I. Bunina k B. Zajcevu“. In: Nz 137 [1979]: 127).

608 Brief an Bunin vom 03.12.1943. Zit. in: „Pis'ma B. Zajceva I. i V. Buninym“. In: Nz 146 (1982): 124.

609 Brief an Zajcev vom 14.12.1943. Zit. in: „Pis'ma I. Bunina k B. Zajcevu“. In: NŻ 137 (1979): 129.

610 LRA. MS. 1066/2093. Dieser Vertrag umfaßte die Rechte an den folgenden Übersetzungen: Le Monsieur de San-Francisco, Le Calice de la Vie, La [sic] Cornetle Elaguine. complété par d'autres nouvelles sowie Allées sombres. Bis zum Zeitpunkt der Vertragsauflosung waren die beiden letztgenannten Titel bereits fertiggestellt.

611 Jarl Priel, eigentlich Charles Tremel (1885-1965), Obersetzer.

612 Brief an Aldanov vom 26.12.1945. Zit. in: „Perepiska I. A. Bunina s M. A. Aldanovym”. In: Nz 150 (1983): 190.

613 Brief an Sedych vom 23.02 1947. Zit. in: A. Sedych. Dalekie. blizkie. op.cit.: 216. 
am Buchmarkt weitere Verzögerungen erwarten lăßt: „Cette crise se manifeste de plusieures manières et notamment par une mévente presque totale du livre des nouvelles, quelle que soit la célébrité de l'écrivain. “614 Bunin möge sich überlegen, ob er noch warten oder den Vertrag auflösen wolle. Im Oktober 1947 schlägt der Verlag einen Kompromiß vor, den Bunin offenbar akzeptiert: Er wird von seinen vertraglichen Pflichten befreit, unter der Bedingung, daß ein potentieller Verleger der französischen Übersetzung den Editions du Pavois die Übersetzungskosten erstatte. ${ }^{615}$

Den Kontakt zum renommierten Verlagshaus Gallimard bezüglich einer Veroffentlichung der Temnye allei in französischer Sprache scheint Zinaida Sachovskaja hergestellt zu haben, denn in einem Brief vom 15. April 1948 erkundigt Bunin sich nach dem Stand der Dinge und erteilt ihr Handlungsvollmacht: „C Галлимаром поступите, как найдете лучше. Верно, что издательство (дейстительно, очень скупое) уже может дать теперь ответ, берет оно Темн[ые] А[ллеи] или нет - и на каких условиях.“616 Gleichzeitig ist auch der Literaturkritiker Georgij Adamovic in die Verlagssuche involviert und bemüht persönliche Kontakte, um die Temnye allei bei Gallimard unterzubringen. ${ }^{617}$ Doch auch Gallimard erteilt dem Projekt eine Absage - die Begründung hat Standardcharakter:

Malheureusement, comme vous le savez sans doute, les recueils de nouvelles se vendent très mal en France. [...] et comme en ce moment il y a une crise de mévente sur le livre en France, il ne nous a pas paru raisonnable de nous charger de l'édition française de votre livre. „NATHALIE. est un trop petit roman pour que nous puissions espérer qu'avec cet artifice l'ouvrage soit considéré par les libraires et par les lecteurs, comme un recueil de longues nouvelles ou classé dans le genre roman. ${ }^{618}$

Bunin äußerte sich enttäuscht uber dieses offensichtliche Desinteresse: „Bот я налисал лучшую свою книгу ,Темные аллеи', а ее ни один французский издатель брать не желает. “619 $\mathrm{Zu}$ Bunins Lebzeiten gab es weder neue Verhandlungen noch Publikationen in Frankreich. ${ }^{620}$ Im Spätsommer 1958 trat V. A. Mogilevskij als Repräsentant des Verlags La Presse Française et Etrangère an Vera Bunina heran mit der Bitte, dem Haus die Über-

614 Brief von Pierre Caillé an Bunin vom 29.09.1947. LRA. MS. 1066/2094.

615 Brief von Pierre Caillé an Bunin vom 15.10.1947. LRA. MS.1066/2095.

616 Zit. in: Z. Sachovskaja. Otrazenija. Paris, 1975: 147.

$617 \mathrm{Vgl}$. entsprechende Briefe aus den ersten Monaten des Jahres 1948. LRA. MS.1066/1407-1458.

618 Brief von Brice Parain (Librairie Gallimard) an Bunin vom 12.04.1948. LRA. MS.1066/4539.

619 Zit. in: I. Odoevceva. Na beregach Seny. op.cit.: 264 .

620 Nachdem bereits im Juni 1946 die Erzahlungen "L'Heure tardive" und „Le Corbeau" in Henri Troyats Zeitschrift Cavalcade in der Obersetzung von Jarl Priel erschienen waren (Brief Henri Troyats an Bunin vom 06.05.1946. LRA. MS.1066/5597), sind in den Folgejahren weitere Erzahlungen in Zeitungen und Zeitschriften veroffentlicht worden, wie z.B. .A Paris" in der Öbersetzung von Ju. Davydov in den Cahiers du Sud 320 (1953): 92-102. 
setzungsrechte an einigen der Erzählungen der von ihnen verlegten Temnye allei zu ubertragen. $^{621}$ Eine Buchveröffentlichung ging aus dieser Anfrage jedoch nicht hervor.

Erst 40 Jahre nach der Erstveröffentlichung des russischsprachigen Originals in Bunins zweiter Heimat kam eine Übersetzung in französischer Sprache zustande, die jedoch - wie zum Ausgleich für die Verspätung - für sich in Anspruch nehmen darf, die einzige fremdsprachige Integralveröffentlichung zu sein. Die erste Ausgabe erschien 1987 in Lausanne unter dem Titel Les Allées sombres mit einem hymnischen Vorwort von Jacques Catteau:

Il faut lire à haute voix ces nouvelles pour apprécier cette langue à la fois sèche et capiteuse, nerveuse et somptueuse, éclatante de soleil et veloutée d'obscurité et mesurer l'indéniable exploit des deux traducteurs, Jean-Luc Goester et François Laurent, qui nous permettent de goûter pour la première fois en français ce texte flamboyant. ${ }^{622}$

Als bislang einzige feststellbare fremdsprachige Ausgabe enthält die Übertragung ins Französische alle 38 Erzählungen der Pariser Originalausgabe von 1946 und folgt dieser auch in der Anordnung. Um so unverständlicher ist der auch hier zu konstatierende Verzicht auf die vom Autor vorgenommene Unterteilung der Erzählungen in drei Komplexe. Neuauflagen dieses Titels als Taschenbücher in den Jahren 1988 und 1990 zeugen indessen von einem zumindest mäßigen Verkaufserfolg.

\subsubsection{Englischsprachige Ausgaben}

Bunins freundschaftliche Beziehungen zu Personen im angloamerikanischen Sprachraum boten keine Garantie für eine zeitnahe Übersetzung der Temnye allei ins Englische; zudem wurde bis heute keine vollständige Ausgabe publiziert, obwohl von allen fremdsprachigen Ausgaben die erste (rudimentäre) englische Übersetzung dem Erscheinungsdatum der Originalfassung am năchsten ist. Hingegen erschienen einzelne Erzăhlungen in Zeitschriften, Zeitungen oder Anthologien bzw. Sammelbänden ${ }^{623}$; obwohl diese nicht Gegenstand der

621 Brief von V. Mogilevskij an Vera Bunina vom 08.09.1958. LRA. MS.1067/4520.

622 J. Catteau. "Préface”. In: I. Bounine. Les Allées sombres. Ubs. J.-L. Goester, F. Laurent. Lausanne, 1987: 14.

623 Eine Übersicht uber die ins Englische abertragenen Gedichte und Erzahlungen Bunins aus dem Zeitraum von 1916 bis 1983 hat Leland Fetzer zusammengestellt: „Ivan Bunin in English, 1916-1983: A Checklist". In: Russian Literature Triquarterly 21 (1988): 223-232. In diesem hilfreichen Überblick ist Fetzer jedoch ein Fehler unterlaufen: Die als „A Legend“" ubersetze Erzahlung .Ballada” verwechselt er mit der wesentlich spater entstandenen Erzahlung "Legenda" (1949). Bemerkenswert ist in diesem Zusammenhang die Feststellung, daß 1958 mutmaßlich ohne Wissen Vera Buninas im Moskauer Verlag Foreign Language Publishing House eine englischsprachige Publikation der beiden von Olga Shartse ubersetzten Erzahlungen .Shadowed Paths" und "The Raven" in dem Erzahlband Shadowed Paths erfolgte. Beide Erzăhlungen wurden zudem in den Band Srories and Poems aufgenommen (Moskau, 1979). 
Betrachtung der englischsprachigen Editionsgeschichte sind, soll festgehalten werden, daß, wie auch bei den russischsprachigen Auswahlbänden, die Erzăhlungen „Temnye allei“, "Volki“" und „Voron“ am häufigsten publiziert wurden.

In den USA bemühten sich vor allem Mark Aldanov und Andrej Sedych um die Veroffentlichung der Temnye allei in englischer Übersetzung. In einem Brief an Bunin vom 26. Mai 1942 berichtet Aldanov erstmals von seinen bislang gescheiterten Bemühungen, eine englische Übersetzung der Erž̋hlungen zu initiieren: „Устроить англйсское (т[о] е[сть] американское) издание ,Темных аллей“ мне пока не удается,- переводчик Шуб все не может повести дело до конца. “624 Auch in den Kriegsjahren verfolgte Aldanov dieses Vorhaben weiter. Wie er in einem Brief vom 1. Mărz 1947 Vera Bunina mitteilte, war er bereits 1943 an das renommierte Knopf Publishing House herangetreten, hatte aber eine Absage erhalten, die er auf den gewagten Inhalt der Erzählungen zurückführte:

[...] имеете в виду, что „Темные Аллен“ чрезвычайно трудно устроить в С[оеднненньх] Штатах [...] После отзыва своего „ридера“ (чтеца), он ответил отказом, и я смутно чувствую, что мадам, прочитав отзыв, упала в обморок от стыдливости и негодования (у Кнопфа все решает его жена). ${ }^{625}$

Am 30. Mai 1945 berichtet er Bunin von den wenig ermutigenden Ergebnissen seiner bisherigen Bemühungen im Mutterland der Short Story: „Попьтки мои устронть эту книгу у Кнопфа и у Скрибнера ни $\mathrm{x}$ чему не привели: оба издателя ответили, что сборники рассказов никогда в Америке не шли хорошо, а теперь совсем не идут.“626 Trotz dieses negativen Bescheids setzt Aldanov seine Bemühungen fort, die jedoch erfolglos bleiben.

Auch Andrej Sedych war nicht müßig. In einem Brief vom 23. Februar 1947 berichtet Bunin Aldanov von Sedychs Mitteilung, daß der US-amerikanische Verleger Tanko (als Verlagsrepräsentant für die Rockport Press, New York) an den Temnye allei interessiert sei. ${ }^{627}$ Am 22. April 1947 schloß Sedych fur Bunin einen Verlagsvertrag über die Herausgabe der englischen Übersetzung mit dem Titel Veins of Love. ${ }^{628}$ Die Titeländerung versucht er Bunin folgendermaßen schmackhaft zu machen: [...] по-русски это, конечно,

624 Edinburgh University Library, Special Collections Department, Gen.565.

625 Brief Aldanovs an Vera Bunina. LRA. MS.1067/973.

626 Brief an Bunin vom 30.05.1945. Zit. in: „Pis'ma M. A. Aldanova k I. A. i V. N. Buninym“. op.cit.: 136.

627 Zit. in: „Perepiska 1. A. Bunina s M. A. Aldanovym“. In: NZ 152 (1983): 171-172.

628 ,AGREEMENT between Ivan Bunin, author of the work entitled VEINS OF LOVE, published in the Russian language under the title roughly translated as "Dark Alleys", and the ROCKPORT PRESS, INC.. Publisher's for the publication of the said work in the English language in the U.S., to be copyrighted by the Publisher's" (LRA. MS.1066/4770). Im Rahmen einer Rezension der Temmye allei wird dieser Vertragsabschluß umgehend publik gemacht (V. Aleksandrova. ., Temnye allei“ I. A. Bunina“. In: Novoe russkoe slovo [18.05.1947]: 8). 
бессмыслица, но им это понятнее. Вы на это не обращайте внимание. При переводах они всегда меняют название $[. . .]^{629}$ Die beschwichtigenden Worte scheinen ihre Wirkung verfehlt zu haben, denn in einem Brief vom 28. August 1947, in dem Sedych Bunin über Verzögerungen im Übersetzungsprozeß in Kenntnis setzt, versichert er ihm: „Конечно, заглавие будет такое, какое Вы хотите. “630 Die Betitelung war jedoch das geringste Problem, denn die Publikation läßt auf sich warten; im Juni 1948 haben sich nach einem Gesprăch Sedychs mit Tanko alle Hoffnungen auf eine Übersetzung durch die Rockport Press endgültig zerschlagen: „Нашел я человека запуганного, который говорит шепотом и усиленно готовится к банкротству. Из его слов я понял, что денег на переводчика нет [...] и что он не собирается в данное время выпускать ,Гемные Aлnеи“."631 Zeitgleich verkaufte Tanko jedoch die Übersetzung der Erzählung „Vizitnye kartocki" an die Zeitschrift Story, ohne Bunin die anteiligen Erlöse zu überweisen. ${ }^{632}$ Bunin wendet sich ratsuchend an Aldanov, der ihm empfiehlt, die Sache auf sich beruhen zu lassen. ${ }^{633}$ Bunin stimmt ihm zu, bittet aber Aldanov darum, Sedych zu veranlassen, Tanko zum Rücktritt vom Vertrag zu bewegen. ${ }^{634}$ Doch erst im Januar 1949 scheint die Sache zu einem Abschluß zu kommen: Bunin wird aus dem Vertrag entlassen, mit der Auflage, daß der künftige Verleger einer englischsprachigen Übersetzung die bereits gezahlten 300 Dollar Vorschuß an Tanko rückerstatten muß. ${ }^{635}$

Ab 1952 gibt es in den USA neue Bemühungen, etwas aus Bunins Werk in englischer Sprache zu publizieren: Julija Sazonova ist bestrebt, einen US-amerikanischen Verleger für Bunins Erzählungen zu gewinnen. Es scheint jedoch nicht ganz einfach gewesen zu sein, von Bunin eine klare Aussage zur Zusammensetzung des geplanten Buches zu erhalten: „Из первого письма я поняла, что Вы хотите сделать новый выбор рассказов, еще неизвестных английской публике и с этой целью справлялась о переводчиках.

629 Brief an Bunin vom 24.04.1947. LRA. MS.1066/5678. In demselben Brief informiert er Bunin, daß das Erscheinen des Buches bereits im Literaturteil der New York Times fur Oktober angekündigt worden sei. Zuvor hatte er Bunin bereits darauf hingewiesen, daß auch fur die geplante Übersetzung mit Kurzungen zu rechnen sei: „Мы-страна пуританская“" (Brief an Bunin vom 11.04.1947. LRA. MS.1066/5677).

630 LRA. MS. $1066 / 5679$.

631 Brief an Bunin vom 02.06.1948. LRA. MS.1066/5684.

632 Erst am 21.04.1949 trit Whit Burnett, der Herausgeber der Zeitschrift Story, personlich an Bunin heran und bittet um Überlassung der Erzahlung .Visiting Cards" fur eine geplante Anthologie. Bunin stimmt zu, und die Erzahlung erscheint im November desselben Jahres in Story: The Fiction of the Forties (vgl. Brief von Whit Bumett an Bunin. LRA. MS.1066/2059.

633 Brief an Bunin vom 25.06.1948. Zit. in: „Perepiska I. Bunina s M. A. Aldanovym”. In: Nz 153 (1983): 147.

634 Brief an Aldanov vom 01.07.1948. Zit. in: .Perepiska I. Bunina S M. A. Aldanovym“. In: Nż 153 (1983): 147-148.

635 Brief Sedychs an Bunin vom 30.01.1949. LRA. MS.1066/5686. 
Теперь вижу, что Вы хотите переиздать Темные аллеи с добавлением двух новых.“636 Die Kommunikation verlăuft schleppend und ist geprăgt von Unklarheit; Sazonovas Rückfragen nach zu schließen hält Bunin sich bedeckt und gibt nur sehr vage Auskünfte, so daß sich bis zum Sommer 1953 kein Fortschritt in dieser Sache abzeichnet: „Я не поняла, желательно ли Вам издание рассказов, не включенных в Темные аллеи. Вы в первом письме думали о новом подборе рассказов, а не о воспроизведении издания Lehman'a.“637 Zudem gelingt es Sazonova nicht, einen Verleger zu finden, was sicherlich nicht zuletzt daran scheitert, daß Bunin keine Liste mit den Erzählungen schickt, die er publizieren möchte.

Erst über 30 Jahre später werden in den USA im Rahmen einer Sammlung von BuninErzählungen 16 Erzählungen aus den Temnye allei in einer Neuübersetzung von Mark Scott veroffentlicht. ${ }^{638}$ Auch hier sind Auswahl und Reihenfolge offensichtlich vollkommen willkürlich erfolgt, zumal nicht einmal die den Temnye allei entnommenen Erzählungen in einem Block zusammengefaßt wurden.

In England erschien die erste rudimentäre Ausgabe der Temnye allei in der Öbersetzung von Richard Hare im Jahre 1949 unter dem Titel Dark Avenues and Other Stories. ${ }^{639}$ Mit ihrer Auswahl von 20 Erzählungen ${ }^{640}$ ist sie weit entfernt von Vollständigkeit und ignoriert zudem die Unterteilung in drei Komplexe die von Bunin gewăhlte Reihenfolge bleibt hingegen gewahrt. Letzteres verwundert, da das Vorwort auf die Entstehungszeit der Erzăhlungen zwischen 1938 und 1944 hinweist, so daß eine chronologische Anordnung nahe gelegen hätte. Im übrigen wird diese Ausgabe 1987 für den US-amerikanischen Markt unverändert übernommen. ${ }^{641}$

Lediglich zehn Erzählungen aus den Temnye allei (in der Übersetzung von Richard Hare) enthält der Sammelband mit Bunin-Erzählungen The Gentleman from San Fran-

636 Brief an Bunin vom 13.05.1953. LRA. MS.1066/4931.

637 Brief an Bunin vom 03.06.1953. LRA. MS.1066/4932. Beim Londoner Verlag Lehmann erschien 1949 die erste Ausgabe der Temnye allei in englischer Sprache.

638 1. Bunin. Wolfes, \& Other Love Stories. Übs. M. Scott. Santa Barbara, 1989. Dieser Sammelband enthalt u.a.: .Wolfes", "Late at Nighr", "The Caucasus", "Muza“, „Emerald", "Rusya", "The Beauty", "Antigone", A Little Fool", .,Galya Ganskaya", "The Visitor", "A Chapel", "Along a Familiar Street", "The Raven". "A Cold Autumn" und "The Swing".

639 I. Bunin. Dark Avenues and Other Stories. Übs. R. Hare. London, 1949.

640 ..Dark Avenues", „The Caucasus“, „A Legend“, „Styopa“, „Musa“, „Roosya“, „The Beauty", „Tanya”, .In Paris“, „Henry", „Natalya“, „The Riverside Inn", „The Oak Trees“, „Miss Klara“, .Cold Autumn", "The Steamer Saratov", „The Crow". ..Camargue", „One Hundred Rupees" und ..Ash Wednesday".

641 I. Bunin. Dark Avenues and Other Stories. Übs. R. Hare. Westport (Connecticut) 1987 
cisco, and Other Stories, der 1975 in London veröffentlicht wird. ${ }^{642}$ Die Hintergründe für die verănderte Reihenfolge, die sich weder an jener des Originals noch an der Chronologie orientiert, werden in der Ausgabe nicht erlăutert.

Ergänzend soll an dieser Stelle der 1984 in London erschienene Sammelband Long Ago. Selected Stories mit 14 Erzählungen Bunins in der Übersetzung von David Richards und Sophie Lund genannt sein, obwohl er nur 6 Erzählungen aus den Temnye allei enthält, denn in seiner Einleitung weist David Richards darauf hin, daß das Original 38 Erzăhlungen umfaßt. 643

Die mit 31 Erzählungen aus den Temnye allei bislang vollständigste englischsprachige Ausgabe erschien 1988 in Moskau unter dem Titel Light Breathing and Other Stories. ${ }^{644}$ Von den ausgelassenen Erzählungen abgesehen folgt diese Publikation zwar der von Bunin vorgesehenen Anordnung, verzichtet aber auf die Untergliederung in einzelne Komplexe und bleibt eine Erläuterung bezüglich des unvollständigen Abdrucks schuldig, obgleich in den Anmerkungen auf die Temnye allei als eigenständiges Prosawerk hingewiesen wird und man sich gleichzeitig der Zusammengehörigkeit der Erzählungen bewußt war: "Compiled of disconnected short stories which are yet united into a single whole by the theme of love, life, and death, Shadowed Paths held a place apart in Bunin's work."645

Trotz vergleichbarer zeitnaher Publikationsbestrebungen prăsentiert sich im deutschsprachigen Raum eine ähnliche Situation: Auch hier gibt es bis heute keine adăquate Edition der Temnye allei in Übersetzung.

642 I. Bunin. The Gentleman from San Francisco, and Other Stories. Übs. R. Hare. London, 1975. Aus den Temnye allei sind folgende Erzahlungen enthalten: „The Caucasus", „Tanya”, „Roosya“, „Henry", "Natalya", „Miss Klara“, „In Paris“, „Musa“, „The Steamer ,Saratov““ und „Ash Wednesday“.

643 1. Bunin. Long Ago. Selected Stories. Übs. D. Richards. S. Lund. London, 1984. Die sechs Erzahlungen sind: "The Caucasus", "Late Hour", „Visiting Cards", "Zoyka and Valeria", „The Riverside Tavern" und „A Cold Autumn". Der erwahnte Hinwe is findet sich auf Seite 9.

644 I. Bunin. Light Breashing and Other Stories. Übs. O. Shartse. Moskau, 1988. In diesem Buch finden sich aus den Temmye allei folgende Erzahlungen: "Shadowed Paths", "The Caucasus", .Ballad", "Stesha“ [sic], „Muse“, „The Hour Was Late“, „Rusya“, „The Beauty“, „Antigone“, „Smaragd“, "Wolves", „Visiting Cards", „Tania“, „In Paris“, „Galia Ganskaya“, „Heinrich“, „Natalie“. „River Restauranr", „The Beginning", "Young Oaks", „Hotel Madrid", "The Second Coffee Por", "A Cold Autumn Evening“, „SIS Saratov“, "The Raven“, „Camargue“, „A Hundred Rupees”, .,Revenge“. „On the Swing", "Chaste Monday" und "The Chapel".

645 I. Bunin. Light Breathing and Other Stories. Übs. O. Shartse. Moskau, 1988: 418. 


\subsubsection{Deutschsprachige Ausgaben}

Die fruthe Editionsgeschichte der Temnye allei in deutscher Sprache ist gekennzeichnet von fehlendem verlegerischen Wagemut, einer unklaren Rechtelage bezüglich der Übersetzungsrechte und Konzessionen an die (vermeintlichen) Erwartungen des Marktes. Alle drei Komponenten zusammen legten den Grundstein für weitere unvollständige Fassungen in den Folgejahren bis zur vorerst letzten Edition im Jahr 2000.

Erste Bestrebungen, die Temnye allei in deutscher Sprache zu publizieren, gab es bereits in den ersten Jahren nach dem Ende des Zweiten Weltkriegs. So plante der Münchner Ehrenwirth Verlag für das Jahr 1948 die Herausgabe eines Buches mit dem Titel Dunkle Alleen. Im Verlagskatalog vom Juli 1948 wird dieser Titel als in Vorbereitung befindlich angekündigt; es läßt sich zum heutigen Zeitpunkt jedoch nicht mehr nachvollziehen, warum die Veröffentlichung ausgewählter Erzăhlungen, die Galina Kuznecova gemeinsam mit Fedor Stepun festlegen wollte, nicht zustande kam, da sich im Archiv des Verlags keine entsprechenden Dokumente mehr finden. ${ }^{646}$ Die Übertragung ins Deutsche sollte der Literaturwissenschaftler und Übersetzer Arthur Luther $(1876-1955)^{647}$ ubernehmen, mit dessen Übersetzungsleistung sich Galina Kuznecova jedoch nicht zufrieden zeigte und den Verdacht äußerte, er habe aus Zeitmangel eine minder qualifizierte Person damit beauftragt. 648

Auch der Abendlandverlag (später Abendländische Verlagsanstalt) mit Sitz in Innsbruck plante in diesem Zeitraum eine Veröffentlichung von Bunin-Erzählungen: Der damalige Verlagsrepräsentant Eric A. Peschler stattete Bunin 1948 gemeinsam mit Margarita Stepun einen Besuch in Paris ab, um die Modalităten auszuhandeln. ${ }^{649}$ Peschler erhielt das alleinige Verlagsrecht für die deutsche Übersetzung ausgewăhlter Erzăhlungen, die

646 Telefonat der Verfasserin mit Martin Ehrenwirth, Sohn des verstorbenen Verlegers Franz Ehrenwirth, am 14.09.1998. Im LRA befinden sich zudem zwei von Galina Kuznecova fur Bunin unterzeichnete Verlagsvertrăge aus dem November 1947 bzw. dem Oktober 1948, die die Veroffentlichungsmodalitaten eines Bandes ausgewăhlter Erzahlungen Bunins (ohne Spezifizierungen) sowie der deutschsprachigen Ausgabe von Osvobozdenie Tolstogo (mit Begleitbrief) regeln (LRA. MS.1066/2338-2340).

647 Den Kontakt zwischen Bunin und Luther hatte in den 1930er Jahren Fedor Stepun hergestellt. Vgl. R. Guerguel. „I. A. Bunin i F. A. Stepun. Fragmenty tvorદeskoj druzby". In: Bounine revisité. op.cit.: 142.

648 Brief an Bunin vom 02.09.1948. LRA. MS.1066/3498. Wahrend der Jahre, in denen sie in Munchen wohnten, bemohten sich Galina Kuznecova und Margarita Stepun aktiv um die Plazierung deutscher Übersetzungen aus Bunins Prosawerk bei Zeitschriften und Verlagen. Margarita Stepun abersetzte sogar selbst, unter anderem die Erzahlung „Voron", die in der Zeitschrift Story (12 1.Bd. [1947]: 26-28) veroffentlicht wurde (vgl. Anmerkung 3 zum Brief Teffis an Bunin aus dem Juli 1947. Zit. in: „Perepiska Teffi s I. A. i V. N. Buninymi 1939-1948“. op.cit.: S40).

649 Diese Informationen basieren auf einem Gesprach der Verfasserin mit Eric A. Peschler am 03.02.1999. 
1949 unter dem Titel Die Grammatik der Liebe erschienen. Über diese Veröffentlichung hinaus bekundete Peschler Interesse an der Herausgabe deutscher Übersetzungen der geplanten Ausgaben Lika, Osvoboždenie Tolstogo sowie Temnye allei und bemühte sich um den Erwerb der Rechte vom Ehrenwirth Verlag, wie der Übersetzer der beiden Bücher, Arthur Luther, Bunin in einem Brief vom 2. April 1950 mitteilt: ,Далее он сообщает, что переговариваться с издательством Ehrenwirth'a o передаче ему, Освобождения Толстого“ [...] и ,Темньх аллей“ [...], но еще окончательно не договорился. “650 Luther fragt mehrfach bei Peschler nach, wie es um die Umsetzung der Publikationspläne bestellt sei, erhält jedoch widersprüchliche und ausweichende Auskünfte, in denen Peschler einerseits auf die prekäre finanzielle Situation des Verlags hinweist, andererseits sein grundsätzliches Interesse an der Veröffentlichung ,des ganzen Bunin“ bekräftigt. ${ }^{651}$ Im Sommer 1953 scheint die Verbindung zu Peschler abzureißen. Etwa zeitgleich hatte sich der Verleger Karl Rauch aus Bad Salzig an die Redaktion der Zeitschrift Grani gewandt und sich an einer Veröffentlichung der Temmye allei in der Übersetzung Arthur Luthers interessiert gezeigt. Briefe von Karl Rauch befinden sich leider weder im LRA noch im Archiv des Verlags $^{652}$, so daß diesbezügliche Hinweise lediglich den Schreiben des Redakteurs L. RŽevskij an Bunin zu entnehmen sind: So terminiert Rauch eine Veröffentlichung auf den Sommer/Herbst 1954. ${ }^{653}$ Ob das Projekt an der Unzufriedenheit Bunins mit den Bedingungen des Verlags scheiterte oder an der unklaren Rechtelage, muß offen bleiben. ${ }^{654}$

In der Folge versucht Rudolf Karmann, Licht in die unklare Angelegenheit zu bringen. In einem Brief an Vera Bunina vom 5. Januar 1954 teilt Karmann mit, daß Peschler bereits 1949 aus dem Abendlandverlag ausgeschieden sei; da sich die Übersetzungen in der Folge weder beim Verlag noch bei Arthur Luther befinden, geht Karmann davon aus, daß Peschler sie unrechtmäßig an sich genommen habe. ${ }^{655}$ Des weiteren strengt Karmann bei der Oberstaatsanwaltschaft München I ein Verfahren gegen Peschler wegen Unterschlagung des Manuskripts von "Lika“ an. Einem Brief an Vera Bunina vom 11. Juni $1954^{656}$

650 LRA. MS. $1066 / 3718$.

651 Brief Luthers an Bunin vom 27.08.1950. LRA. MS.1066/3719.

652 Bei einem Anruf im Verlag am 14.12.1998 wurde der Verfasserin mitgeteilt, daß keine Korrespondenz aus den 1950er Jahren mehr vorliege.

653 Brief von L. Rzevskij an Bunin vom 24.07.1953. LRA. MS.1066/4876-4892.

654 Richard Davies, Archivar des LRA, wies die Verfasserin darauf hin, daß in privater Sammlung ein Brief Bunins an Arthur Luther vom 07.11.1953 existiert (moglicherweise der letze Brief uberhaupt aus Bunins Hand), in dem er Luther vollständige Freiheit hinsichtlich der Veroffentlichungsmodalitaten der deutschsprachigen Fassung der Temnye allei erteilt, und zwar sowohl bezuglich der Zusammenstellung der Erzahlungen als auch hinsichtlich notwendiger Kurzungen auf Textebene (E-Mail vom 15.05.2002). Luther wurde hingegen nicht nachweislich aktiv; er starb 1955.

655 LRA. MS.1067/3235.

656 LRA. MS. $1067 / 3239$. 
legte er eine Abschrift eines Schreibens der Oberstaatsanwaltschaft München I aus dem Mai $1954^{657}$ bei (der entsprechende Vorgang wurde in der Zwischenzeit allerdings vernich$\operatorname{tet}^{658}$ ), in dem festgestellt wird, daß Peschler das Verlagsrecht von Bunin persönlich übertragen worden und er somit berechtigt sei, auch die Manuskripte der Übersetzungen zu behalten. ${ }^{659}$

Karmann indessen hatte offensichtlich das Empfinden, daß eine Klage Erfolg gehabt hätte, wenn er Unterstützung von Fedor Stepun erfahren hätte. In einem Schreiben an Stepun vom 9. Juni 1954, das er ebenfalls dem oben erwähnten Brief an Vera Bunina beilegt, wirft er diesem sein zögerliches Verhalten vor, das potentielle Publikationen vereitele:

[...] Ihr Schreiben kommt leider viel zu spät! ... Seit dem 16. Januar 1954 hatte ich Tag für Tag, Woche für Woche auf Nachricht von Ihnen gewartet - und jetzt, wo die Sache Peschler an sich schon entschieden ist, wo mir die Oberstaatsanwaltschaft München mitgeteilt hat, daß P[eschler] im Recht sei, kommen Sie daher. Damals, als ich auf Ihren Beistand rechnete, um energisch gegen P[eschler] vorzugehen, hüllten Sie sich in Schweigen. [...]

Die Sache ist umso [sic] ärgerlicher, als sich Karl Rauch sehr für diese Werke interessiert und sie auch gerne herausbringen möchte - was aber niemals realisiert werden kann, wenn P[eschler] die drei MS nicht herausrückt. Da das Interesse der Verleger heutzutage durchaus antirussisch orientiert ist, war ich herzlich froh, in Karl Rauch einen Mann gefunden zu haben, der anders denkt als die stumpfe, breite Masse. ${ }^{660}$

Einen vergleichbaren Schritt hatte Karmann bezuiglich der Manuskripte „Tolstojs Befreiung“ und „Dunkle Alleen“ unternommen, der am 25. Juni 1954 ebenfalls abschlăgig beschieden wurde. Eine Abschrift dieser Nachricht fügte er einem Brief an Vera Bunina vom 21. Juli 1954 bei:

Nach den hiesigen Ermittlungen konnte kein Nachweis dafür erbracht werden, daß Peschler auch die beiden Manuskripte ,Tolstojs Befreiung' und ,Dunkle Alleen' an sich genommen hat. Im ubrigen spricht für die Einlassung Peschlers, daß er die vorbezeichneten Werke nicht in seinen Besitz genommen hat, daß sich in diesem Falle in den Händen der Witwe Bunin ein dahingehender Vertragsentwurf befinden müßte. ${ }^{661}$

Seine vergeblichen Bemühungen, über Peschler an die Manuskripte der Übersetzungen zu gelangen, stellt Rudolf Karmann erst 1957 ein.

657 LRA. MS.1067/3241.

658 Mitteilung der Staatsanwaltschaft Manchen I vom I1.01.1999 an die Verfasserin.

659 Abschrift des Bescheids der Oberstaatsanwaltschaft Manchen 1 vom 06.05.1954. Anlage zum Brief an Vera Bunina vorn 11.06.1954. LRA. MS.1067/3241.

660 Anlage zum Brief an Vera Bunina vom 11.06.1954. LRA. MS.1067/3240.

661 Anlage zum Brief an Vera Bunina vom 21.07.1954. LRA. MS.1067/3244. 
Anfang 1954 trat Anne Bock mit der Frage nach bereits existierenden deutschen Übersetzungen der Bücher Bunins an Vera Bunina heran, offenbar mit der Absicht, ihre Dienste anzubieten. Ihre Bemuhungen, deutsche Verleger für die Übersetzungen zu begeistern, verliefen jedoch auf Grund der ungeklärten Rechtesituation im Sande:

Quant à mes deux maisons d'édition, j'ai eu - et je l'ai encore - un tas de soucis et d'ennuis. [...] les spécialistes trouvent toujours que la situation des droits est tellement compliquée [...] qu'il vaudra beaucoup mieux attendre, du moins attendre le résultat du procès de M. Luther-Karmann [sic] contre ces éditeurs autrichiens. ${ }^{662}$

Im Juni 1955 wendet sich Vera Bunina an Fedor Stepun mit der Bitte um Rat bezilglich der weiteren Vorgehensweise. Dieser schlägt angesichts der Einstellung des Verfahrens gegen Peschler vor, einen anderen deutschen Verleger zu finden bzw. Peschler einen ultimativen Zeitpunkt zu nennen, bis zu dem er die entsprechenden Manuskripte publiziert oder anderenfalls von seinen Rechten zurücktritt. ${ }^{663}$

Am 15. Dezember 1958 ist endlich offiziell ein neuer Verleger für die Temmye allei gefunden: Öber die Literaturagentur Agence Hoffman, die die Rechte Ivan Bunins bis heute vertritt, wird zwischen Vera Bunina und dem Stuttgarter J. F. Steinkopf Verlag ein Vertrag über die Veröffentlichung von Erzăhlungen abgeschlossen, unter der Bedingung, daß die Publikation binnen 18 Monaten nach Vertragsabschluß erfolgen müsse. ${ }^{664}$ In deutscher Übersetzung erschienen somit erstmals 1959 in Buchform einige Erzăhlungen aus den Temnye allei. Unter dem irrefuhrenden Titel Dunkle Alleen ${ }^{665}$, der dem Leser die wortgetreue Öbemahme des russischsprachigen Originals gleichen Titels suggeriert, werden „ausgewählte Meistererzăhlungen [...] aus den Jahren 1903-1944“ vorgestellt, die „einen typischen Querschnitt durch Bunins Schaffen"666 bieten sollen. Tatsächlich enthält dieser Band lediglich 14 Erzählungen aus den Temnye allei, die bis auf zwei Ausnahmen rein chronologisch angeordnet sind und dadurch die von Bunin gewăhlte Reihenfolge durchbrechen. ${ }^{667}$

662 Brief Anne Bocks an Vera Bunina vom 29.12.1954. LRA. MS.1067/1442.

663 Brief Fedor Stepuns an Vera Bunina vom 18.06.1955. LRA. MS.1067/6976.

664 Vertrag vom 15.12.1958. LRA. MS.1067/2400.

665 I. Bunin. Dunkle Alleen. Übs. I. Koenig. Stuttgart, 1959.

666 Anzeige des J.F. Steinkopf Verlags (Stuttgart) im Börsenblatt für den Deutschen Buchhandel (Frankfurter Ausgabe) 87 (30.10.1959).

667 Die folgenden Erzahlungen sind enthalten: „Im Kaukasus“, „Dunkle Alleen", „In spăter Stunde“, „Rusja“, „Die schone Frau", „Der Smaragd“, „Antigone“, „Henrich“ [sic], .Natalie“, „Die Pfahlbauschenke auf der Wolga", „Kuhler Herbst", „Zweimal Kaffee“, „Aus der Camargue“" und „Die Rache“. Den Erzahlungen vorangestellt ist eine Einleitung von Professor Johannes Holthusen. Die Chronologie wird durchbrochen durch Plazierung der Erzahlung "Der Smaragd" vor „Antigone" und „Kahler Herbst" vor ,Zweimal Kaffee“; Uber die Grunde kann nur spekuliert werden. 
Geplant war damals eine Erweiterung des Verlagsprogramms um eine zehn bis zwölf Bände umfassende Reihe mit großen Erzăhlungen der Weltliteratur. ${ }^{668}$ Ursprünglich war offenbar eine Auswahl von Erzählungen aus den beiden in New York veröffentlichten Erzählungssammelbänden Vesnoj, v ludee. Roza lerichona (1953) und Petlistye uši i drugie rasskazy (1954) vorgesehen, in denen keine der Erzählungen aus den Temnye allei enthalten ist. Erst auf Anregung der Übersetzerin Ilona Koenig, die den Verleger Ulrich Weitbrecht auf die Existenz der Ausgabe von i946 aufmerksam machte, stellte dieser gemeinsam mit dem Slavistik-Professor Johannes Holthusen, der eine Einleitung zu dem Sammelband verfaßte, eine Auswahl auf Grundlage der Temnye allei (1946) und Petlistye uši $i$ drugie rasskazy zusammen, die bis zur Drucklegung mehrfach modifiziert wurde. ${ }^{669}$ Im Gegensatz zur erfolgreichen Einflußnahme Ilona Koenigs auf die Auswahl der Erzählungen blieben ihre Bemühungen, eine rein chronologische Anordnung zu verhindern, erfolglos: „Vom künstlerischen Standpunkt aus ist die chronologische Reihenfolge ein Unding. ${ }^{\text {(670 }}$

In der Korrespondenz zwischen Übersetzerin und Verleger fallt auf, daß Ilona Koenig nicht nur Einfluß auf die Auswahl nahm, sondern sich zudem beredt für die Beibehaltung auch erotisch geprägter Textstellen einsetzte, die dem katholischen Verlag als zu heikel erschienen. In einem Brief an Ulrich Weitbrecht vom 7. Januar 1959 schreibt sie:

Heikle Geschichten allerdings. Aber es soll ja kein Kinderbuch werden. Das Eigenartige bei der Erzăhlkunst BUNIN's [sic] ist nämlich, daß er erotische Erlebnisse und Situationen so menschlich sieht und fast mit einer leisen Trauer schildert, so daß man wirklich erschüttert ist. Ganz anders, [sic] als wie die Franzosen, die mit einer wahren Wonne und inneren Beteiligung daruber schreiben. BUNIN ist ein frommer Mensch, das klingt durch, in allen Geschichten steht sein Ethos zwischen den Zeilen. ${ }^{671}$

668 Telefonat der Verfasserin mit Herrn Ulrich Weitbrecht, der Ende der 1950er Jahre fur den J. F. Steinkopf Verlag tatig war, am 17.09.1998. Bei der Frage nach dem Eroffnungsband fiel die Wah! auf Bunin, weil man nach Verleihung des Nobelpreises fur Literatur an Boris Pasternak im Jahre 1958 die gestiegene Aufmerksamkeit fur russischsprachige Literatur nutzen wollte. Aus marketingstrategischen Grunden wirbt der Verlag mit einer sogenannten „Bauchbinde“ mit folgender Beschriftung: „Der erste russische Nobelpreistrager / Zum erstenmal in deutscher Sprache“. In finanzieller Hinsicht entpuppte sich dieses Vorhaben als Mißerfolg; es blieb bei einem Band der geplanten Reihe.

$669 \mathrm{Vgl}$. den diesbezuglichen Briefwechsel zwischen Ilona Koenig, Hamburg, und Ulrich Weitbrecht, Stuttgart, der sich im Nordelbischen Kirchenarchiv in Kiel befindet (NEK-Archiv, 15.05.01 Nr. 16).

670 Brief an Ulrich Weitbrecht vom 11.05.1959. NEK-Archiv, 15.05.01 Nr. 16. Bereits am 14.12.1958 hatte sie sich mit folgender Begrundung gegen eine chronologische Anordnung der Erzăhlungen ausgesprochen: „Ebenso hat Bunin selbst seine Arbeiten nicht nach Jahreszahlen, sondem nach ihrem inneren Zusammenhang angeordnet und zusammengestellt" (NEK-Archiv, 15.05.01 Nr. 16).

671 NEK-Archiv, 15.05.01 Nr. 16. Verschmitzt ergănzt sie in einem Brief am 12.03.1959: „Über die großen Deutlichkeiten und Ungeniertheiten Bunins habe ich mich weitgehend beruhigt. [...] An den kleinen zauberhaften Geschichten wie z.B. [...] Der Smaragd kann der erschrockene Leser sich wieder erholen ... Bunin ist und bleibt ein großer Meister" (NEK-Archiv, 15.05.01 Nr. 16). 
Doch bei dem süddeutschen Verlag steht der Respekt vor den potentiellen moralischen Empfindlichkeiten seiner Leser über dem Wunsch nach einer künstlerisch adäquaten Nachdichtung; die zahlreichen diesbezüglichen Korrekturen und Auslassungen kommentierte Ilona Koenig in einem Schreiben an den Verleger vom 18. September 1959:

Und nun muß ich es erleben, daß aus der glühenden, lebenswahren und lebenswarmen Dichtung BUNIN's [sic] beinahe ein Schulbuch wird, mit einer die Lektüre keineswegs vorbereitenden Literaturstunde davor! [...] Die an sich so bigotten Amerikaner haben Bunin gedruckt, wie er geschrieben hat, die katholischen Franzosen haben es auch fertiggebracht und die deutsche Ausgabe wird „kastriert“. Entschuldigen Sie bitte, aber das Buch ist nicht für Teenager geschrieben. Aber, Sie können als Herausgeber natürlich darüber entscheiden, wie das Buch auf den Markt kommt und wieweit dem Leser der echte und ganze Bunin vorenthalten wird. Obgleich ich weiß, $\mathrm{da} B$ ich es nicht ändern kann, empfinde ich es als meine Pflicht als werktreue Übersetzerin zu dem Dichter und Künstler Bunin zu stehen. ${ }^{672}$

Als Beispiel furr die aus der zurückhaltenden Haltung resultierenden Streichungen - aber auch einer erfolgreichen Intervention der Übersetzerin - sei der Umgang mit der Erzählung „Henrich“ [sic] genannt. In der ursprünglichen Auswahl fehlte sie, was Ilona Koenig nicht nachvollziehen konnte, da sie zu Recht die Bedeutung der Erzählung für das Buch erkannte:

Mir fehlt in der vorgeschlagenen Sammlung sehr die Novelle "HENRICH“, sie stellt den Schlüssel dar zu seiner künstlerischen Forderung, daß ein Dichter mit seinen Worten ebenso den nackten Menschen schildern darf, wie es ein Maler oder Bildhauer in seinem Werk tut. Das darf allerdings nur ein echter Künstler, denn sonst würden diese Schilderungen obszön wirken. Bunin kennt die feine Grenzlinie. Seine erschütternden Schilderungen von Morden, Selbstmorden, Verführungen und kalten Ehebrüchen sind mit einem tiefen Verantwortungsbewußtsein geschrieben und oft aus einer Herzensnot heraus. Ich bin etwas in Sorge, wie ein, wie ich vermute, katholisch orientierter Verlag sich für diese schwere Kost einsetzen will. Und dies harte Anpacken der Probleme zwischen den Geschlechtern zu übersehen oder wegzulassen. hieße den ethischen Wert seiner Novellensammlung zu mindern. ${ }^{673}$

Der Verlag nahm die Erzählung in die endgültige Auswahl auf, aber Koenigs Sorge war nicht unberechtigt, wie sich in der Folge im Umgang mit der Beschreibung der intimen Begegnung zwischen Henrich und Glebov im Zugabteil zeigt. Obwohl es nicht Aufgabe dieses Kapitels ist, auf Diskrepanzen zwischen dem Originaltext und der Endredaktion der deutschen Übersetzung hinzuweisen, soll dieses Beispiel angeführt werden, um zu illustrieren, wie zögerliches Publikationsverhalten noch Jahre später zu unvollständigen Veröffentlichungen führen kann. In der Originalausgabe von 1946 findet sich folgender Satz 
(der im übrigen auch in allen nachfolgenden russischen Ausgaben fehlt): „Он, любуясь, до жнвота, до рыжих волос, открыл ее ноги, их округлую крупность с миндальным блеском колен.“674 Aus der Übersetzung wurde die Schilderung dieses Satzes gestrichen, was Ilona Koenig zu folgenden Protestworten veranlaßte:

Selbstredend muß ich mich mit Ihren Streichungen zufrieden geben, obgleich ich nicht davon überzeugt bin, daß Bunin „die Grenzen des Anstandes“ verletzt hat. Daß „Henrichs“ [sic] Beine den Glanz geschälter Mandeln haben, ist doch ein Dichterwort! Aber ich verstehe Sie auch in der Ablehnung der allerintimsten Schilderungen. Meine erste Reaktion war auch reines Erschrecken, aber es wich der Erkenntnis, daß Bunins Deutlichkeiten oder bis in die letzten Erlebnisphasen reichenden Darstellungen des menschlichen „Miteinander" nie die künstlerische Linie verlassen. Aber Sie als Herausgeber müssen natürlich mit vielfacher Emporung in Leserkreisen rechnen ... Ich glaube, daß Bücher mit der Bunin-gleichen souveränen Offenheit nur auf dem Subskriptionswege verbreitet werden. Diese Tatsache empfinde ich als Konzession an das Muckertum und als Vorsicht aus Geschäftsrïcksichten. Aber ich kann mich darin vielleicht irren, nur subjektiv recht haben. ${ }^{675}$

Weitere Bestrebungen anderer Verlage gab es offenbar in jenen Jahren nicht; nachweisbar ist lediglich ein Raubdruck durch den Münchner W. Goldmann Verlag, der in einem Sammelband mit dem Titel Ein Herr aus San Franzisko und andere Erzählungen unter anderem die Titelerzăhlung „Dunkle Alleen“ sowie die Erzăhlung „Der Rabe“ enthălt. ${ }^{676}$ Als Ulrich Weitbrecht, Verleger des J. F. Steinkopf Verlags, davon Kenntnis erhălt, informiert er umgehend die Agence Hoffman, die wiederum einen Anwalt einschaltet. Abgesehen von der unrechtmäßigen Veröffentlichung spricht sich der Anwalt auch gegen die Publikation als Taschenbuch aus, „denn wird ein Werk zu allererst in einer Taschenausgabe verlegt, so sind damit alle Möglichkeiten, es in einer teureren Ausgabe zu verkaufen, verspielt." ${ }^{677}$ Bestrebt um eine gütliche Einigung fordert er, das Buch sofort vom Markt zurückzuziehen und den Vera Bunina entstandenen Schaden entsprechend zu vergüten. Der Ausgang dieser Sache ist nicht bekannt.

1969 erschien im Zürcher Coron-Verlag eine Neuauflage der bei J. F. Steinkopf publizierten Erzăhlungen in der Übersetzung von Ilona Koenig mit dem Titel Dunkle Alleen, allerdings nur in einer limitierten Auflage für den „Kreis der Nobelpreisfreunde“. ${ }^{678}$ In

674 1. Bunin. Temmye allei. Paris, 1946: 170.

675 Brief an Ulrich Weitbrecht vom 26.09.1959. NEK-Archiv, 15.05.01 Nr. 16.

676 I. Bunin. Ein Herr aus San Franzisko und andere Erzahlungen. Obs. O. Schwechheimer, W. RichterRuhland. Munchen, 1960. Dem Band wurde eine kurze Einleitung von W. Richter-Ruhland vorangestellt.

677 Brief von Dr. Paul Justin Schilling an den Rechtsvertreter des W. Goldmann Verlags vom 30.11.1960. NEK-Archiv, 15.05.01 Nr. 16.

678 I. Bunin. Dunkle Alleen. Übs. I. Koenig. Zurich, 1969. 
Auswahl und Anordnung folgt der Verlag der Fassung des J. F. Steinkopf Verlags und hat demzufolge keine eigenen editorischen Anstrengungen unternommen.

Ein kleiner Sammelband mit Erzählungen Bunins erschien 1973 und in einer Neuauflage 1987 unter dem Titel Dunkle Alleen als Taschenbuch im Münchner Piper-Verlag. ${ }^{679}$ Die von Horst Bienek ausgewählten Erzählungen wurden der Ausgabe des J. F. Steinkopf Verlags entnommen. Die recht willkürlich anmutende Auswahl fält denkbar knapp aus und beinhaltet neben den Erzählungen „Ohren wie Schlingen“ (1916) und „Der Prozeß des Făhnrichs Jelagin“ (1925) lediglich sechs Erzählungen aus den Temnye allei: „Dunkle Alleen“, „In später Stunde“, „Rusja“, „Natali“, „Die Pfahlbauschenke auf der Wolga“ und „Die Rache“; Hinweise auf die Zugehörigkeit in einen größeren Zusammenhang oder gar einfuhhrende Worte fehlen. ${ }^{680}$ Drei weitere Erzählungen in der Übersetzung von Erich Ahrndt (,Der erste Tag der Großen Fasten", „Heinrich" und „Kalter Herbst") wurden in den Erzählband Mitjas Liebe ${ }^{681}$ aufgenommen, der 1992 mit dem Hinweis auf den AufbauVerlag als Lizenzgeber ebenfalls im Piper-Verlag erschien.

In der DDR brachte der Aufbau-Verlag 1985 unter dem Titel Dunkle Alleen. Erzählungen 1920-1953 eine Auswahl aus Bunins in der Emigration entstandenen Erzählungen heraus. Unter den deutschsprachigen Publikationen ist dieser Sammelband mit 23 Erzählungen ${ }^{682}$ aus den Temnye allei, die teils von Erich Ahrndt, teils von Charlotte Kossuth ins Deutsche übertragen wurden, dem Umfang nach der weitaus vollständigste, der darüber hinaus die von Bunin gewählte Anordnung (abgesehen von den Auslassungen) beibehält wenn auch unter Verzicht auf die Unterteilung in die verschiedenen Komplexe. Im Nachwort weist der Herausgeber Karlheinz Kasper zwar darauf hin, daß sich das Original aus 38 Erzählungen zusammensetzt (S. 565), gibt aber keinerlei Erklärung dazu ab, aus welchen Gründen die vorliegende Auswahl sich auf 23 Erzählungen beschränkt. Möglicherweise wurde das Buch von den Herausgebern nicht als zusammengehöriges Ganzes wahrgenommen. Dieser Eindruck wird dadurch gestützt, daß die Übersetzung nicht einer Einzelperson übertragen wurde.

679 I. Bunin. Dunkle Alleen. Übs. I. Koenig. München, 1973' $\left(1987^{2}\right)$.

680 Wie schon die Ausgabe des J. F. Steinkopf Verlags, so verkaufte sich auch diese Auswahl im Taschenbuch denkbar schlecht (Brief von Dr. Uwe Heldt, Piper-Verlag, an die Verfasserin, vom 01.08.1996).

681 I. Bunin. Mitjas Liehe. Übs. E. Ahrndt. Manchen, 1992.

682 Das Buch enthalt die folgenden Erzahlungen: „Dunkle Alleen“, .,Der Kaukasus“, „Stjopa“, „Musa”, „Zu spater Stunde”, „Russja“" [sic]. „Antigone“. „Der Smaragd”, „Visitenkarten“, „Tanja“, „In Paris“, .Galja Ganskaja”, "Heinrich", .Natalie“, „Die Schenke uber dem Fluß", „Die Gevatterin“. "Der Anfang“, ...Madrid“.”. ".Die zweite Kanne Kaffee“. „Kalter Herbst“, „Der Rabe“. ..Die Rache“ und „Der erste Tag der Großen Fasten". 
Die jüngste deutschsprachige Publikation mit Erzăhlungen aus den Temnye allei erschien Ende 2000 im Eichborn Verlag in der Reihe „Die Andere Bibliothek" unter dem Titel Liebe und andere Unglücksfalle. ${ }^{683}$ Sie enthält neben weiteren Erzählungen Bunins 16 Erzählungen ${ }^{684}$ aus den Temnye allei in den Übersetzungen von Erich Ahrndt und Charlotte Kossuth, die für die oben erwähnte Ausgabe des Aufbau-Verlags angefertigt wurden. Von den bereits erwähnten Veröffentlichungen unterscheidet sich dieser Sammelband auf den ersten Blick wohltuend durch die Wahl eines eigenen Titels; Bunins Prinzipien der Zusammenstellung werden allerdings wie so häufig mißachtet, und die Anordnung erfolgte unter chronologischen Gesichtspunkten. Der Herausgeber Hans Magnus Enzensberger orientierte sich bei der Auswahl der Erzählungen an folgenden Leitlinien: „Ein Kriterium der Auswahl war die Konzentration auf die urbane Seite von Bunins Erzählkunst (im Gegensatz zu seinen ländlichen Geschichten); auch hat mich besonders die Erfahrung des Autors als ruheloser dépaysé interessiert.“685 Abgesehen davon, daß mit „Čistyj ponedel'nik" die Stadtgeschichte schlechthin in der Sammlung fehlt, kommt in den ubrigen ausgewăhlten Erzăhlungen die Entwurzelung des Autors nicht uberzeugend zum Ausdruck. Daruber hinaus ließ sich im Zuge des Kontakts mit verschiedenen Verlagsmitarbeitern feststellen, daß die editorische Recherche an Detailgenauigkeit zu wünschen ubrig ließ, denn als Referenztext diente lediglich die Ausgabe des Aufbau-Verlags ${ }^{686}$; die Originalfassung der Temnye allei wurde in keiner Weise berücksichtigt. Von mangelhafter Recherche zeugen zudem verschiedene Fehler im sogenannten Dossier, unter anderem die Angabe des Erscheinungsdatums der Temnye allei mit 1943, ohne die Ausgabe von 1946 mit einem Wort zu erwăhnen; dabei schien es auch keine weitere Irritation hervorzurufen, daß etwa die Erzăhlung „Mest” mit einer Datierung aus dem Jahr 1944 in der 1943er Ausgabe gar nicht hătte berücksichtigt werden können. Dem nicht einschlăgig informierten Leser werden diese Ungereimtheiten vermutlich nicht auffallen; um so bedauerlicher ist, daß eine weitere Möglichkeit vergeben wurde, die Temnye allei in einer adăquaten Edition dem deutschen Lesepublikum nahezubringen, was einen Rezensenten der Eichborn-Ausgabe zu folgender Kritik veranlaßte:

683 Iwan Bunin. Liebe und andere Unglücksfalle. Obs. E. Ahmdt, Ch. Kossuth, G. Schwarz, I. Tschørtner. Die Andere Bibliothek. Frankfurt am Main, 1. Auflage 2000 (2. Auflage 2001).

684 Folgende Erzahlungen wurden aufgenommen: „Der Kaukasus" (Öbs. Ch. Kossuth, CK), "Musa“" (CK), „Dunkle Alleen“ (CK), „Russja” (E. Ahmdt, EA), „Antigone“ (EA), „Visitenkarten“ (EA), "Tanja“ (EA), "In Paris“ (EA), „Galja Ganskaja“ (EA), „Heinrich“ (EA), „Die Gevatterin“ (EA), „Der Anfang“ (EA), „Die Schenke uber dem FluB" (CK), ...Madrid“.” (EA), „Der Rabe“ (EA) und „Die Rache“ (EA).

685 Hans Magnus Enzensberger in einem Schreiben vom 01.04 .2000 an die Verfasserin.

686 E-Mail vom 01.02.2000 von A. Prassel, Lizenzabteilung Eichbom Verlag, an die Verfasserin. 
Die [...] erschienene Auswahl ist eine Kompilation aus der des Aufbau-Verlages. Sie soll wohl als Appetizer fur eine hübsche Kassette aus dem Hause Lunkewitz [Verleger des Aufbau-Verlags] dienen. [...] Aber er bekommt einen merkwürdig reduzierten Bunin zu lesen. Die symphonische Qualităt fehlt ganz. ${ }^{687}$

\subsection{Zusammenfassende Betrachtung}

In ihrer Lückenhaftigkeit gleichen sich die in diesem Kapitel betrachteten original- und fremdsprachigen Ausgaben der Temnye allei bei unterschiedlicher Motivierung der Auslassungen. War die frühe Editionsgeschichte von den zeitgeschichtlichen Umstănden, moralischen Bedenken und mangelnden finanziellen Möglichkeiten beeintrăchtigt, so ist die spätere gekennzeichnet von gekürzten Fassungen entweder aus politischen Erwăgungen (Sowjetunion) oder aus editorischer Nachlässigkeit (Westeuropa, USA, Rußland).

Als nach Bunins Tod die ersten Erzählungen aus den Temnye allei in der Sowjetunion veröffentlicht wurden, wurde als Basis zwar die Ausgabe von 1946 genannt, es wurden jedoch zahlreiche Kürzungen bis hin zu Auslassungen ganzer Erzählungen vorgenommen. Die überwiegende Beibehaltung der von Bunin gewählten Reihenfolge, hăufig unter Wahrung der Einteilung in drei Komplexe, läßt den Schluß zu, daß das Buch grundsätzlich als zusammengehörendes Ganzes anerkannt wurde und die Modifikationen der Zensur geschuldet sind. Doch selbst nach der Lockerung der Publikationsbeschränkungen wurden bereits vorliegende Redaktionen ohne zusätzliche editorische Anstrengungen verwendet und auf diese Weise der Abdruck lückenhafter Fassungen fortgesetzt.

Bei den übersetzten Fassungen hingegen gaben nicht primär zensorische Erwägungen den Ausschlag für Auslassungen (mit Ausnahme der deutschen Ausgabe des J. F. Steinkopf Verlags). sondem mangelhafte Recherche (wie etwa bei der Ausgabe des Eichborn Verlags), editorische Nachlässigkeit (wie etwa bei der französischen Ausgabe, die zwar alle Erzählungen beinhaltet, jedoch die Unterteilung in drei Komplexe außer acht läßt) oder merkantile Bedenken, die aus der im Vergleich mit Romanen schlechteren Verkăuflichkeit von Erzăhlungsbänden resultieren. Dokumentiert wird somit die Dominanz der finanziellen Interessen (bzw. Zwänge) der Verleger über ihren künstlerischen Anspruch nicht nur hinsichtlich eines Integralabdrucks, sondern auch bezüglich notwendiger Investi-

687 A. Widmann. „Hinter jedem Fenster ein Schicksal. Iwan Bunins Erzahlungen in der ,Anderen Bibliothek'" In: Berliner Zeitung (20.03.2001). 
tionen in eine Neuübersetzung, der teilweisen Anerkennung des hohen Niveaus des Buches zum Trotz. Angesichts dieser Randbedingungen ist es nicht verwunderlich, daß bis heute gekürzte Fassungen des Buches gedruckt werden, denn der Entstehungsprozeß der deutschen Übersetzung etwa illustriert höchst anschaulich, daß die Temnye allei jenseits von Sachzwängen wie Absatzzahlen oder den (vermeintlichen) Empfindlichkeiten der lesenden (und kaufenden) Zielgruppe durchaus als kohärente Einheit wahrgenommen werden.

Zahlreichen der übersetzten Fassungen ist somit gemeinsam, daß die Temnye allei vom jeweiligen Verlag nicht als Kurzprosaverknüpfung erkannt bzw. bewußt als solche ignoriert wurden, so daß sich nicht von originärer Ignoranz, sondern von einer Dokumentation eines Sieges des Kommerzes über die Kunst sprechen läßt, während sich in den originalsprachigen Ausgaben bis heute die zensorischen Eingriffe der Vergangenheit erkennen lassen.

Wie sich im folgenden Kapitel zur Rezeptionsgeschichte zeigen wird, wird auch hier die Wahmehmung der Temnye allei als Gesamtkunstwerk von verschiedenen Faktoren beeinflußt, die im wesentlichen den Hindernissen der Editionsgeschichte entsprechen und eine mögliche Perzeption des Buches als Gesamtkunstwerk beeinträchtigen, wenn nicht gar verhindern. 


\section{$W_{4}$

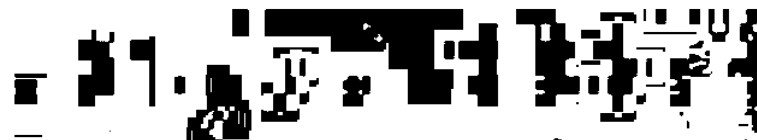

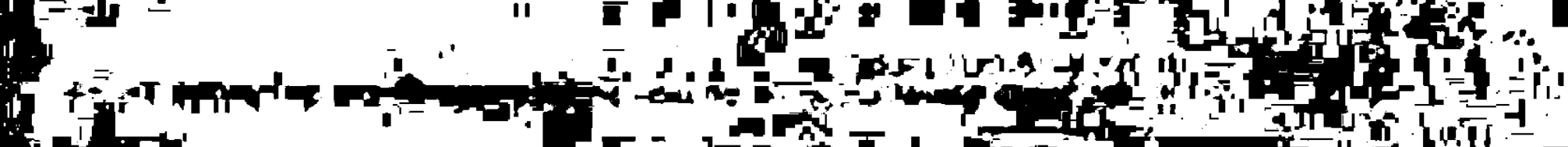

F

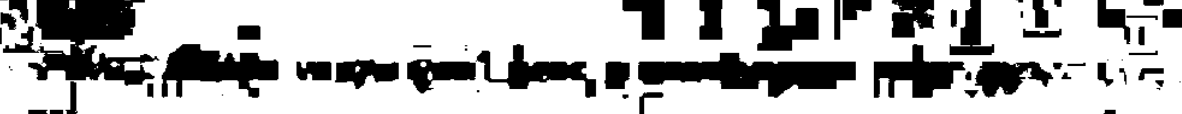

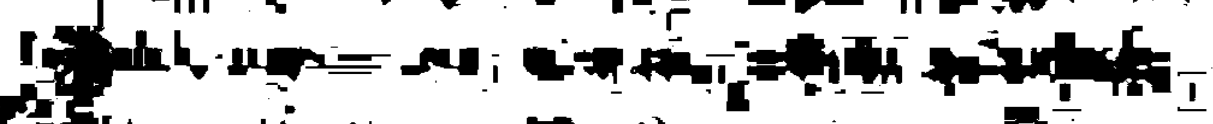

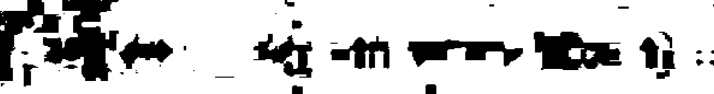

. tadn

. a.

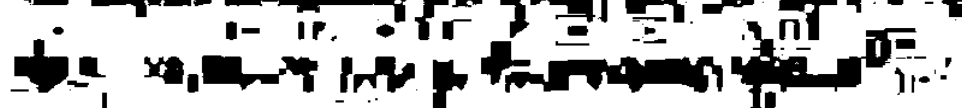

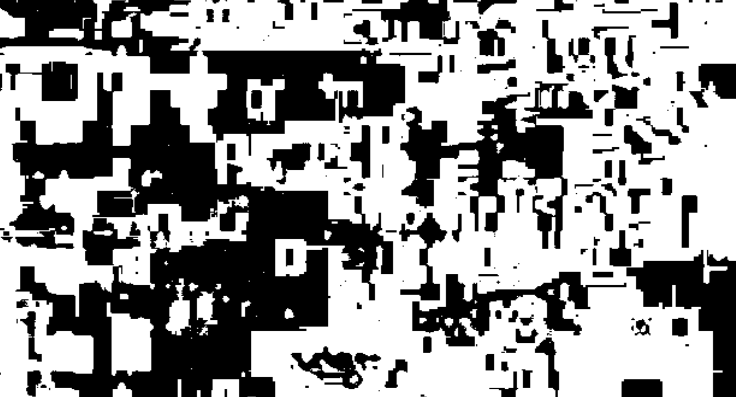

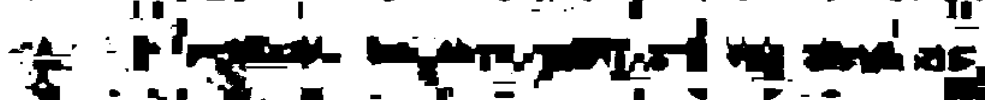

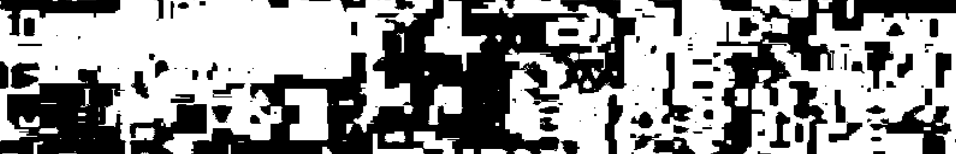
if

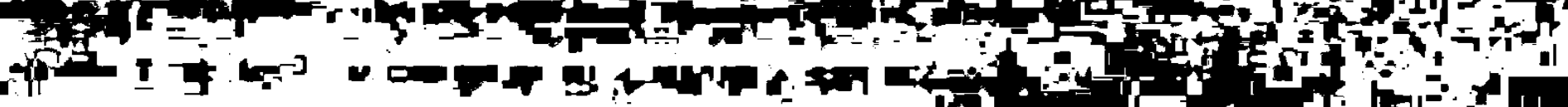

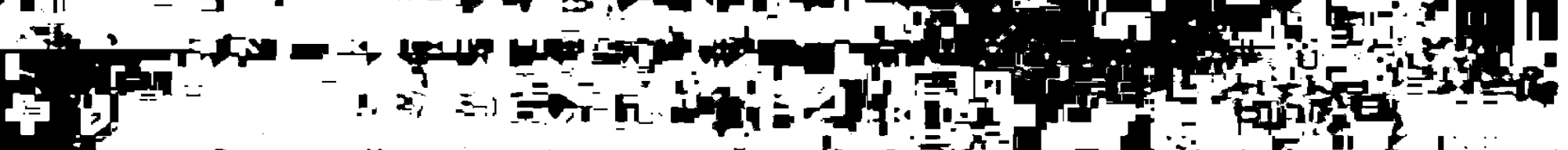

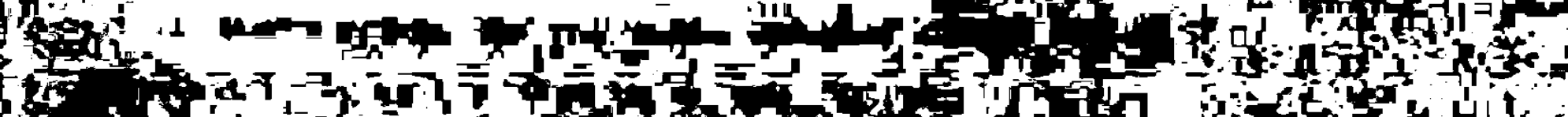
35 , 4.

Iro-

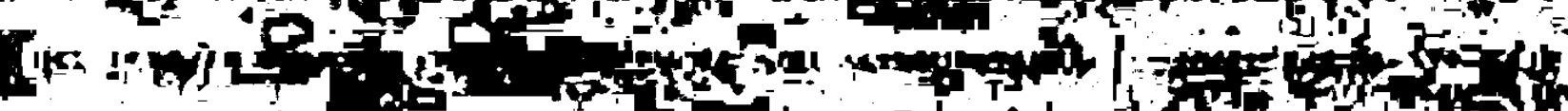
At

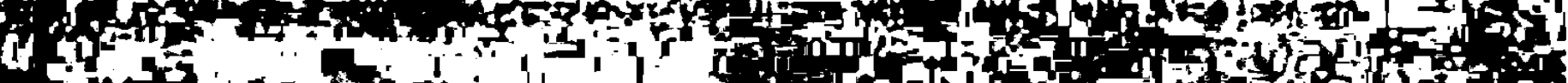
(1)

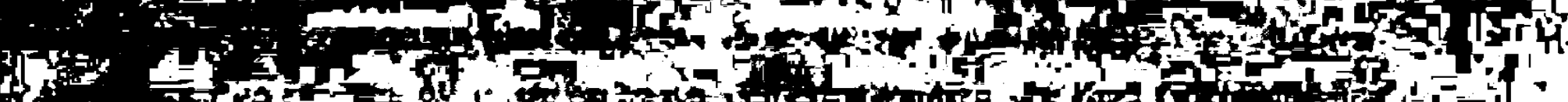

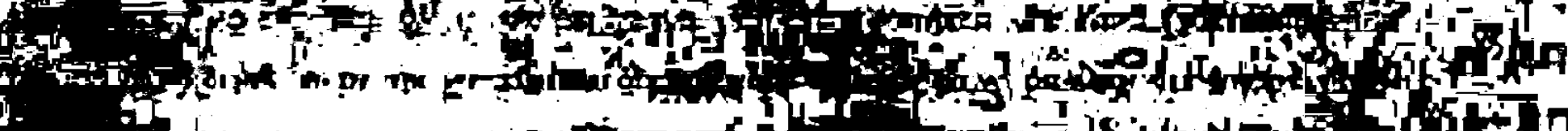

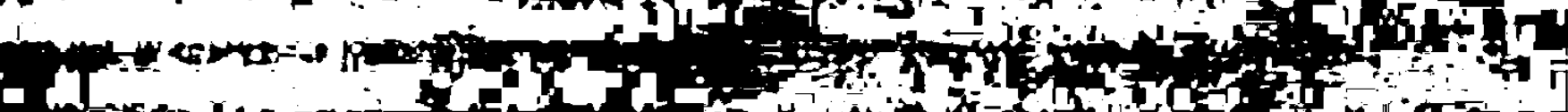
(1)

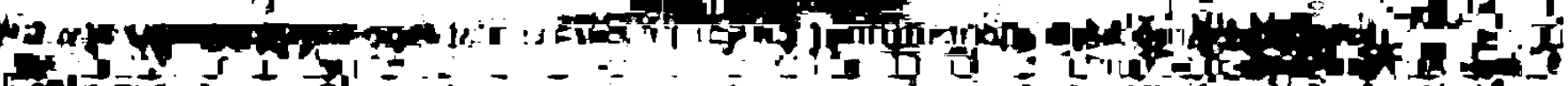

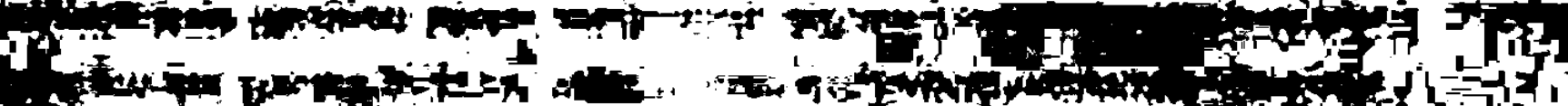

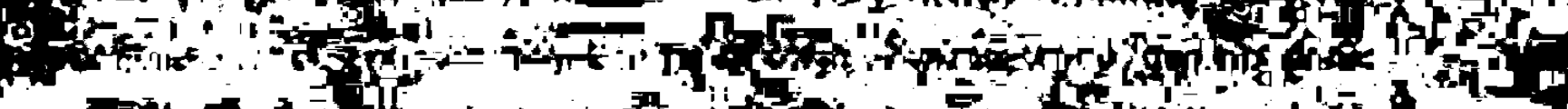

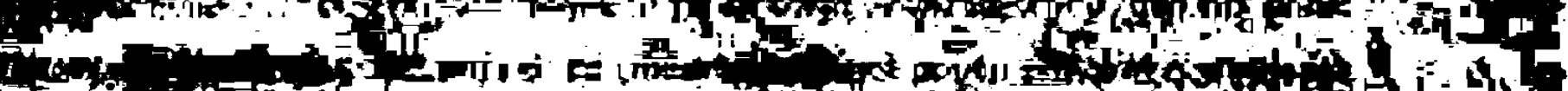
(3) 
10 DIE REZEPTIONSGESCHICHTE - DIE TEMNYE ALLEI IM KREUZFEUER DER KRITIK

In dem in der Einleitung bereits erwähnten Schreiben an den Doktoranden Edward Wasiolek, dem er Material für dessen Dissertation zukommen ließ, zog Bunin wenige Monate vor seinem Tode in der Beurteilung seines Gesamtwerkes folgende Bilanz: „[...] ,Темные Аллеи', которую считаю, может быть, самой лучшей моей книгой в смысле сжатости и вообще литературного мастерства.“688 Auch gegenüber seinem langjährigen Freund Nikolaj Telešov äußerte er sich in einem Brief vom 1. April 1947 in diesem Sinne: „[...] думаю, что это самое лучшее и самое оригинальное, что я написал в жизни,- и не один я так думаю.“689

Es gab indessen eine Reihe von Stimmen, die ihrer Bewertung der Temnye allei nicht die von Bunin genannten Kriterien der inneren Dichte und literarischen Meisterschaft zugrunde legten. So konzentrierten sich die zeitgenössischen Leser bei ihrer Kritik vor allem auf die erotischen Elemente im Buch und verloren durch die Fokussierung auf ein zugegebenermaßen wichtiges Detail den Blick für die kohärente Anlage des Buches. Auch die Funktion der zentralen Figuren als überindividuelle Schicksalsträger konnte unter diesen Voraussetzungen nicht wahrgenommen werden. Wie aus der Editionsgeschichte hervorgeht, fuhrte dieser verengte Blickwinkel, sei es aus moralischen oder auch politischen Erwägungen oder aus Unkenntnis des Originals, nicht selten zu verkürzten Ausgaben, die eine Perzeption der Temnye allei als Kurzprosaverknüpfung erschwerten. In der späteren literaturwissenschaftlichen Forschung, die sich zum Teil auf unvollstăndige Ausgaben stützte (oder stützen mußte), läßt sich hingegen die Tendenz zur Analyse einzelner Erzählungen des Buches ohne Berücksichtigung des Kontextes feststellen.

Inwieweit und in welcher Hinsicht Bunins eigene Einschätzung seines letzten Buches mit Erzählungen abwich von jener seiner zeitgenössischen Leser sowie der späteren Verleger und Literaturwissenschaftler, wird in diesem Kapitel anhand repräsentativer Beispiele der vorhandenen bzw. zugänglichen Resonanz auf die Temnye allei dokumentiert.

688 Brief an E. Wasiolek vom 24.07.1953. Zit. in: E. Wasiolek. „The Fiction of Ivan Bunin ...“. op.cit.: 306. 689 Zit. in: „Perepiska s N. D. Telesovym“. op.cit.: 634. 


\subsection{Zeitgenössische Reaktionen}

Die zeitgenössische Resonanz auf einzelne Erzăhlungen ebenso wie auf das Buch in seinen Fassungen von 1943 und 1946 macht deutlich, daß an Bunins schriftstellerische Produktion feste Erwartungen geknüpft wurden - die Freiheit einer künstlerischen Weiterentwicklung mit modemen Motiven wie der Erotik oder nichttraditionellen erzăhlerischen Mitteln, wie der Verknappung und der bloßen Präsentation von Figuren mit dem Blick eines Malers ohne Erklärungen für die Beweggründe ihrer Handlungen, wollten ihm nur wenige Leser und Kritiker zugestehen. Bunin hingegen hatte offensichtlich vor allem mit Kritik an der Diskrepanz zwischen dem Inhalt seiner Erzählungen mit ihrem Bilderbogen aus dem untergegangenen Rußland und der bedrückenden Realităt des Zweiten Weltkriegs gerechnet, wie vorwegnehmende Erklärungen in Briefen an Boris Zajcev und Tèffi belegen. ${ }^{690}$

Der in der Folge vorgestellte repräsentative Querschnitt durch die zeitgenössischen Reaktionen aus dem privaten und feuilletonistischen Bereich veranschaulicht sowohl die moralischen Empfindlichkeiten als auch das konservative Literaturverständnis der russischen Emigrantenkreise in den 1940er und 1950er Jahren.

10.1.1 Direkte Reaktionen aus dem Freundes- und Bekanntenkreis vor der Buchpublikation

Noch vor der Veröffentlichung der Erzählungen erhielt Bunin positive und negative Resonanz; die maßgeblichen Kritiker waren zugleich seine wichtigsten Korrespondenzpartner in den Jahren der Entstehung der Temnye allei: Mark Aldanov. Boris Zajcev und Tèffi. Diese Reaktionen erreichten Bunin mangels răumlicher Năhe per Brief und lassen sich daher gut dokumentieren. In der Regel beziehen sie sich auf einzelne Erzählungen, da Bunin während des Entstehungsprozesses sukzessive Erzählungen zur Veröffentlichung oder zur bloßen Kenntnisnahme bzw. Aufbewahrung verschickt hat.

690 „Hе хо времени все мон писания, да не все ли равно“ (Brief an Zajcev vom 12.05.1944. Zit. in: .Pis'ma I. Bunina k B. Zajcevu“. In: Nz 137 [1979]: 135); ..[...] возьмите еще 5 из монх последних [...] рассказиков - совершенно диких по своему несоответствню особенно тем последним дням, что дошли до нас [...]" (Brief an Teffi vom 19.05.1944. Zit. in: „Perepiska Teffi s I. A. i V.N. Buninymi 1939-1948". op.cit.: 514). 
Im großen und ganzen finden seine Erzăhlungen Anerkennung oder stoßen sogar auf Begeisterung; zentraler Kritikpunkt ist der als solcher empfundene Überfluß an erotischen Darstellungen, gelegentlich wird die mangelnde Nachvollziehbarkeit der Psychologie der Figuren beanstandet (vgl. Kap. 7.1); nur bezuglich der beiden Erzăhlungen „Vtoroj kofejnik" und "Cistyj ponedel'nik“ wurden Bedenken wegen der möglicherweise verunglimpfenden Darstellung authentischer Personen geäußert.

Die ersten nachweisbaren Reaktionen auf einige der Erzăhlungen des spăteren Buches stammen von Mark Aldanov, dem Bunin sukzessive Erzählungen zur Publikation in den USA schickte und der wohl zu den ersten Lesern überhaupt gehörte (vgl. Kap. 9.1). Bereits vor Erhalt der Erzăhlungen hatte Aldanov Bunin vor den von einer strengen Moral geprägten gesetzlichen Bestimmungen in den USA gewamt: „Но тоже ради Бога: помните о сушествования в С [оединенньх] Штатах законов! (Это относительно сюжета) ....691 Bunin versucht diese Besorgnis zu entkräften durch einen Hinweis auf den 1932 in New York (in gekürzter Fassung) veröffentlichten Roman Lady Chatterley's Lover von D. H. Lawrence (ungekürzte Publikation 1960), der in der zeitgenössischen Rezeption der Temnye allei im ubrigen häufig zu Vergleichszwecken herangezogen wird ${ }^{692}$, und äußert Verwunderung angesichts der Tatsache, daß eine Publikation der Temnye allei problematisch werden könnte, wăhrend Lawrences Buch erscheinen konnte; gleichzeitig spricht er die Hoffnung aus, daß die moralischen Grenzen beim russischen Lesepublikum weniger eng gesteckt seien als bei den US-amerikanischen Lesem - in diesem Punkt sollte er sich jedoch täuschen. ${ }^{693}$

691 Brief an Bunin vom 01.02.1941. Zit. in: „Pis'ma M. Aldanova k I. A. i V. N. Buninym“. In: Nz 81 (1965): 118.

692 Obwohl beide Bucher darin ubereinstimmen, da $B$ in ihnen die Bedeutung des sexuellen Beisammenseins innerhalb der Liebesbeziehung von Mann und Frau thematisiert wird, unterscheiden sie sich doch ganz erheblich in der Darstellung des Geschlechtsaktes, der bei Bunin nur angedeutet, aber nicht beschrieben wird.

Weit verbreitet war jedoch die Ansicht, daß es russischen Schriftstellem nicht gegeben sei, sexuelle Begegnungen in die Literatur zu transferieren. Wahrend Aleksej Remizov sich negativ zur Erzahlung .Zojka i Valerija" geăßert haben soll (.Это надо оставить Селинам и другим, нам, русским, не yдаeтcя ...", zit. in: N. Kodrjanskaja. „Vstreci s Buninym“. In: $L N$. 84.Bd. [2] op.cit.: 346), außerte sich Vladimir Nabokov pauschaler und liefen zugleich eine Begrundung fur das vorbestimmie Scheitem eines solchen Unterfangens: „Aber die Prosa war tugendhaft. Die russische Literatur hatte keine aus der Renaissance stammende Tradition von kraftvoller Offenheit, wie es sie in anderen Literaturen gab, und bis zum heutigen Tag ist der nussische Roman im großen und ganzen der keuscheste aller Romane. Und naturlich ist die russische Literatur der Sowjetepoche die Keuschheit selbst. Ein Russe, der zum Beispiel eine ,Lady Chatterley" schreibt, ist unvorstellbar" (V. Nabokov. Die Kunst des Lesens. Frankfurt am Main, 1991: 29).

$693 \mathrm{Vgl}$. Brief an Aldanov vom 06.05.1941. Zit. in: „Perepiska I. A. Bunina s M. A. Aldanovym“. In: Nz 150 (1983): 164; auszugsweise zitien in Kap. 9.1. 
Nach Kenntnisnahme zahlreicher der die spăteren Temnye allei konstituierenden Erzählungen läßt Aldanov Bunin wissen, welche Erzählungen er persönlich am meisten schätzt:

Мое личное мнение: самое лучшее из всего того, что Вы напечатали в „Новом Журнале“, это „Таня“, потом „Натали“ и „Генрих“. Но все решительно превосходно, никто так не напишет. Описание Волги в „Речном Трактире“ и трактира верх совершенства ... ${ }^{694}$

Mit explizitem Lob für einzelne Erzählungen hält Aldanov sich im Briefwechsel zurück $^{695}$, was möglicherweise auf seine nicht ganz einfache Aufgabe zurückzufuhren ist, bei Bunin um Verständnis für die anstehenden Kürzungen zu werben. So ist denn die folgende Reaktion Aldanovs auf die von Bunin geschickten Erzählungen in einem Brief vom 2. August 1941 ebenso prophetisch wie symptomatisch für die Folgejahre:

Они чудесны, от многих я в полном восторге. Но смелый Вы человек, дорогой Иван Алексеевич! Ведь ругать Вас за вольность некоторых сцен будет всякий, кому не лень: будут говорить: „порнография!“, „лавры автора лэди Чэттерлей“ и $\mathrm{T}\left[\right.$ ак] $д[$ алее $] .^{696}$

Boris Zajcev, dem Bunin Ende 1943 verschiedene Erzăhlungen zur Aufbewahrung schickte (vgl. Kap. 3.3, 9.3.1), kommt zu einer Aldanovs Bewertung verblüffend ähnlichen abschließenden Beurteilung in der Rangfolge der Erzählungen, von denen er zum Zeitpunkt seiner Kritik. dem 28. November 1943, insgesamt acht zur Kenntnis genommen hatte: „Думаю - лучшие из них ,Натали“ и „Руся“. (Мне, по крайней мере, более всех понравились.) [...] В ,Тане‘ прекрасна деревня, зима, да и Таня сама очень жива и мила.“697 In diesem Zusammenhang erlăutert er jedoch auch ausdrücklich am Beispiel der Erzählung „Zojka i Valerija“, daß ihm die erotischen Beigaben ganz und gar mißfallen (vgl. den in Kap. 8.1.2 zitierten Ausschnitt aus Zajcevs Anmerkungen). Daß Bunin diese Kritik nicht so ohne weiteres hinnehmen konnte, zeigt eine Anmerkung in einem Brief an

694 Brief an Bunin vom 26.12.1945. Zit. in: „Perepiska I. A. Bunina S M. A. Aldanovym“. In: Nz 150 (1983): 188. Bemerkenswert ist die Ändenung in Aldanovs „Rangliste“, die vier Jahre zuvor noch von der Erzahlung ..Natali“ angefuhrt wurde: „.[...] зто, по-моему, самый лучшия и просто изумительныи рассказ, одна нз лучшнх Ваших вещей вообще ...“ (Brief an Bunin vom 25.10.1941. Zit. in: „Perepiska I. A. Bunina s M. A. Aldanovym". In: $N z 150$ [1983]: 167).

695 Als reprasentativ kann Aldanovs Resonanz auf die Erzahlung „Mest'“ gelten: „Baw paccka3 „Mectb' получен и ужке набран [für das Novyj zurnal]. Он превосходен, н редакиня (т.е. Карпович) чрезвычайно Вам благодарна“ (Brief an Bunin vom 05.01.1946. Zit. in: „Perepiska I. A. Bunina S M. A. Aldanovym". In: NZ 152 [1983]: 155).

696 Zit. in: „Perepiska I. A. Bunina S M. A. Aldanovym“. In: Nz 150 (1983): 166.

697 Zit. in: „Pis'ma B. Zajceva I. i V. Buninym“. In: NE 146 (1982): 122. Bunin ist hochst interessiert zu erfahren, wie Zajcevs Frau Vera uber die "дерзости" in seinen Erzahlungen denkt; es bleibt unklar, ob Zajcev inm darauf geantwortet hat bzw. ob der entsprechende Brief Bunin erreicht hat (vgl. Brief Bunins vom 03.12.1943. Zit. in: „Pis'ma I. Bunina k B. Zajcevu“. In: Nz 137 [1979]: 129). 
Zajcev mehrere Monate später, in dem er einen Satz aus den Geschichten aus 1001 Nacht zitiert und den Freund zu einem Vergleich mit seinen jüngsten Erzăhlungen auffordert: „Она изумилась красоте его уда и налила себе в шальвары ... А вы говорите похабно пишу!“698

Zajcev äußerte sich nicht nur selbst zu den Erzăhlungen, sondern löste weitere Reaktionen aus, indem er einzelne Erzählungen ohne Wissen Bunins und zu dessen großem Mißfallen zur Lekture an Natal'ja Ivanovna Kul'man, eine gemeinsame Bekannte, weitergab. ${ }^{699}$ Im großen und ganzen äußert auch sie sich in einem Brief vom 14. Februar 1944 positiv zu diesen Erzählungen und wertet sie als Beleg dafür, daß Bunins Talent in der Emigration keinen Schaden genommen habe; ihre zentrale Kritik bezieht sich auf die erotischen Schilderungen, die ihrer Ansicht nach nichts beitragen zur psychologischen Stimmigkeit der handelnden Figuren und zudem Bunins künstlerischer Meisterschaft nicht würdig seien:

Но зачем Вы портите его грубо-натуралистическими строками, которые решигельно ничего не дают для психология действующих лиц? То же в некоторьх цругих рассказах, которые неизмеримо выиграли 6 от отсугствия этих ненужных и даже непонятно зачем вставленных подробностей физнологического характера? Думаю, что освободить от них такие рассказы как Руся, Таня, Галя Ганская, Генрих, в Париже, Вы дали бы тонкие психологические зскизы.

Такие же рассказы, как Смарагд, Зойка и Валерия, а особенно Гость и Антигона повергли бы читателя Вашего в полное недоумение. Борис Конст[антинович Зайцев] говорит, что Вы хотели показать двойственность, какая может случаться в любви: при идеальной любви $\mathrm{K}$,единственной“, грубое чувственное влеченне к другой. Но ведь в этих последних рассказах никакой ЛЮБВИ нет, есть только собачья свадьба, которую описывать так же нельзя, как нельзя в художественном произведении описывать ватер-клоз[ет] с его запахами. Предоставьте зто разным Одоевцевым, Г. Ивановым, Бакуниным с ее „Телами“ / не читала, но знаю, что мерзость / Пусть они описывают развратных подростков с тошнотворными подробностями „собачьей любви“, пусть роются в ватер-клозетах, помойных ямах: они бьют на нездоровные вкусы развратных людей и думают, что своими гадостямн они прнвлекут читателя. Может быть кой-кого и привлекут.

Но Бунин НЕ ДОЛЖЕН снижаться до этой слякоти: он должен уметь сказать то, что ему нужно для ПСИХОЛОГИИ его героев, без унижающих подробностей в описании тела и жестов, как умели это делать и Толстой и Чехов. [...] Любопытно, что сейчас [...] в Ро России среди молодежи очень сильно движение против разврата, грубости ....

698 Brief an Zajcev vom 06.03.1944. Zit. in: „Pis'ma I. Bunina k B. Zajcevu“. In: Nz 137 (1979): 133.

$699 \mathrm{Vgl}$. Brief an Zajcev vom 29.01.1944: „Ты меня зарезал-разве можно было давать Н[аталней] И[вановне] все мои рассказы [...] Я очень огорчен“ (zit. in: „Pis'ma I. Bunina k B. Zajcevu“. In: $N z$ 137 [1979]: 130-131). Zajcev verteidigt sein Vorgehen in einem Brief vom 12.02.1944: ,[...] она сама просила меня дать твои рассказы. Разве я могу отказать? (zit. in: „Pis'ma B. Zajceva I. i V. Buninym*. In: $N Z 146$ [1982]: 128). 
Uneingeschränktes Lob hingegen erhält Bunin von Nadežda Tèffi, die Anfang 1944 von den sich in Boris Zajcevs Obhut befindenden Erzählungen erfährt und Bunin um Einsichtnahme bittet. Im Gegensatz zu Natal'ja Kul'man, die sich berufen fühlte, auch ungefragt ihre Meinung zu dem Buch abzugeben, fordert Bunin Tèffi explizit auf, unumwunden ihre Meinung kundzutun. Diese äußert sie zunächst in einem Brief an Vera Bunina vom 7. April 1944, aus dem bereits hervorgeht, daß sie trotz Kenntnis nur weniger Erzählungen in der Lage ist, diese als Gesamtheit wahrzunehmen, ohne sich an Details aufzuhalten:

Написано великолепно-иного и ожидать нельзя было. Книга трагическая. Автор много в жизни своей писал о смерти, но эта книга ,о любви“ мрачнее и трагичнее его слов о смерти. ${ }^{701}$

Erst im Mai 1944 schickt sie ihren Kommentar an Bunin:

Как я уже писал-впечатление от книги: она очень серьезная, значнтельная, мрачная все от первого до последнего слова! [...] И в этих рассказах чем проще они ведутся, чем циничнее - тем страшнее и трагичнее. ${ }^{702}$

Die insgesamt zwölf Erzählungen, die sie in der Zwischenzeit lesen konnte, sind nicht namentlich bekannt; Tèffi weist jedoch darauf hin, daß sie den gesamten ersten Teil nicht kennenlernen konnte. Es ist bemerkenswert, daß sie gesellschaftlichen Konventionen offenbar nicht verhaftet ist und ohne Umschweife auf die "tragische Ausweglosigkeit" der Protagonisten zu sprechen kommt. In demselben Brief berichtet sie von den unter den Pariser Emigranten umgehenden Gerüchten über die vermeintliche Schamlosigkeit der jüngsten Erzählungen Bunins: „Вы слышали? - сказали они - Бунин написал похабные рассказы. ““703 Tëffis persönliches Urteil zu den bislang gelesenen Erzählungen fällt gänzlich anders aus; in einem Brief vom 2. Juli 1944 hält sie fest:

Сознаю только, что рассказы Ваши, переданные мне Зайцевыми, вошли таким великолепным вагнеровским диссонансом в бездарную симфонию моей жизни, что как будто запомнятся навсегда. ${ }^{704}$

Neben der Kritik an einem Zuviel an Erotik und mangelnder Nachvollziehbarkeit der psychischen Regungen bzw. Beweggründe der Figuren wurden jedoch auch Bedenken

701 Zit. in: „Perepiska Teffi s 1. A. i V. N. Buninymi 1939-1948“. op.cit.: 509.

702 Undatierter Brief an Bunin, laut Poststempel vom 15.05.1944, mit Bunins handschriftlichem Vermerk .Poluceno 19.05.1944 g.“. Zit. in: „Perepiska Tèffi s I. A. i V. N. Buninymi 1939-1948“. op.cit.: 512.

703 Zit. in: „Perepiska Tèffi s I. A. i V. N. Buninymi 1939-1948“. op.cit.: S12.

704 Zit. in: „Perepiska Teffi s I. A. i V. N. Buninymi 1939-1948“. op.cit.: S15, Reese - 9783954790210 
wegen der möglicherweise ehrverletzenden Darstellung authentischer Personen in den Erzăhlungen „Vtoroj kofejnik“ und „Čistyj ponedel'nik“ laut.

Bunin schătzte die beiden im Abstand weniger Tage entstandenen Erzăhlungen „Madrid““ und „Vtoroj kofejnik“ ganz besonders ${ }^{705}$ und wünschte sich einen gemeinsamen Abdruck im Novyj žurnal. Obwohl Bunin bereits Geld für diese Erzählungen erhalten hatte ${ }^{706}$, hielt Aldanov die Publikation im Novyj zurnal nicht für opportun, da er das Schamgefühl zahlreicher Leser ohnehin bereits angegriffen wăhnte und befürchtete, dies durch den Abdruck einer Erzählung mit der Darstellung einer Prostituierten („Madrid“") noch zu verstärken. Zudem hatte er Bedenken, daß die namentliche Nennung Saljapins in der Erzăhlung „Vtoroj kofejnik“ für weiteren Unmut sorgen und sich ein gemeinsamer Abdruck der Erzăhlungen negativ auf die Spendenbereitschaft für Bunin hătte auswirken können. Von diesen Befürchtungen abgesehen konnte sich Cetlin, der Mitherausgeber der Zeitschrift, mit dem Inhalt dieser Erzăhlungen nicht anfreunden. Offenbar wagte Aldanov jedoch nicht, dies Bunin persönlich mitzuteilen und wăhlte den Weg über Vera Bunina - in einem Brief vom 28. August 1945 spricht er die Hoffnung aus, diese möge den Zusammenhang zwischen der Empfindlichkeit des New Yorker Emigrantenpublikums und dem finanziellen Erfolg von Wohltătigkeitsveranstaltungen anläßlich Bunins 75. Geburtstags sehen und Bunin verstăndlich machen:

Но Вы, вероятно, понимаете, что „Мадрид“ и „Второй Кофейник“ в некоторых пуританских кругах НьюЙорка должны были бы вызвать недовольство. Нам это довольно безразлично, однако на успехе банкета это могло бы отразиться: богатые дамы и так гневаются или делают вид, что гневаются: их девичья стыдливость оскорблена Иваном Алексеевичем. [...] Кроме того [...] говорю для примера (конфиденциально), если бы вдова и дочери Шаляпина обнделись из-за „Второго Кофейника“... то на успехе банкета это отразилось бы очень сильно ... ${ }^{707}$

Vera Bunina scheint ihrem Mann diesen Brief nicht vorenthalten zu haben, denn am 3. September 1945 wendet sich Bunin entrustet an Aldanov und bringt sein Unverständnis zum Ausdruck:

705 Boris Zajeev auBerte sich im Mai 1944 lobend zu den beiden Erzahlungen: „Мадрид' И „Второ кофейник' очень милы, девчонки изображены с нежностью. Вообще, зто ,человеколюбивые' рассказы. Иван, ты оказался туманнстом на старости лет, а раньше любил иногда разоблачать" (Brief an Bunin vom 20.05.1944. Zit. in: „Pis'ma B. Zajceva I. i V. Buninym“. In: NE 146 [1982]: 134). Auf diese lobenden Worte antwortet Bunin in einem Schreiben vom 25.05.1944 unter anderem: ..[...] nнша и про девчонку в ,Мадриде' и про „Катьку, молчать!", я то и дело умиленно смеялся, чувствовал нечто вроде прнступа нежных, радостных слез“ (zit. in: „Pis'ma I. Bunina k B. Zajcevu“. In: Nz 137 [1979]: 136).

706 Brief Aldanovs an Bunin vom 27.08.1945. Zit. in: „Perepiska I. A. Bunina s M. A. Aldanovym“. In: Nz 150 (1983): 176.

707 Zit. in: „Perepiska I. A. Bunina s M. A. Aldanorym“. In: Nz 150 (1983): 177. 
Очень огорчен судьбой „Мадрида“ и „Вт[орого] кофейника“,- не понимаю, что в них похабного,- они так чисты, простодушны, „героини“ их, по-моему, просто очаровательны - и что это за „богатые дамы“, кои вообще гневаются на меня? ведь все то, что у Вас было напечатано, так невинно! И уж совсем не понимаю, почему вдова и дочери Шаляпина могут обидеться на мою архиневинную выдумку, что Ш[аляпин] заехал с Коров[иным] в тот извозчичий трактир похмелитъся, где служила „героиня“ „Вт[орого] кофейника“, и там, шутя, кричал?! [...] да что же это за институтские нравы у Вас?! ${ }^{708}$

Bunin zeigt sich gekränkt, daß das Novyj zurnal seine Erzăhlungen ablehnt und sie an die Zeitschrift Novosel'e weitergereicht hat; als Medium ist ihm offenbar das Novyj zurnal näher. ${ }^{709}$ Aldanov hingegen verteidigt seine Vorgehensweise:

Вы не очень довольны тем, что Мих[аил] Ос[ипович Цетлин] отдал „Новоселью“ „Мадрид“ и „Второй Кофейник“. Скажу Вам правду: Миханлу Осиповичу очень не хотелось сохранить имена Шаляпина и Коровина. Он (как и я) не сомневается, что Марья Валентиновна [die Witwe Saljapins] обидится. Между тем Вы написали, что эти рассказы должны идти не иначе, как вместе. ${ }^{710}$

Bunin bleibt nichts übrig, als sich damit abzufinden, obwohl er sich weiterhin darüber wundert, was anstößig sein soll an der Schilderung, „чтобы им подавала чай „Катенька“, а не ,сукин сын половой‘?“711

Auch bezüglich der Erzählung „Cistyj ponedel'nik“ trug sich Aldanov mit Bedenken, da im Rahmen des vom „Chudožestvennyj teatr“ veranstalteten „Kapustnik“ der Schauspieler Kacalov im betrunkenen Zustand gezeigt wird. In einem Brief an Karpovix, einen der Redakteure beim Novyj zurnal, schlägt er folgende Vorgehensweise vor: „Одно неудобство: на мгновение в рассказ появляется пьяный Качалов. Ничего оскорбительного нет, но не совсем приятно. Но заменить ли буквами?“712 Die ursprüngliche Schreibweise wurde letztlich jedoch beibehalten. ${ }^{713}$

Derartige Bedenken scheinen ein Spezifikum der US-amerikanischen Emigrantengemeinde gewesen zu sein, denn von dieser Erzăhlung zeigt sich etwa Boris Zajcev besonders angetan und befindet kurz und bündig: „nросто прелесть.“"714 Auch Bunins in der Schweiz ansăssige Bekannte Ekaterina Kuskova-Prokopovič berichtet in einem Brief vom

708 Zit. in: „Perepiska I. A. Bunina s M. A. Aldanovym“. In: Nz 150 (1983): 178-179.

709 Brief an Aldanov vom 01.10.1945. Zit. in: „Perepiska I. A. Bunina s M. A. Aldanovym“. In: Nz ISO (1983): 181.

710 Brief an Bunin vom 14.10.1945. Zit. in: „Pis'ma M. A. Aldanova k 1. A. i V. N. Buninym“. op.cit.: 136.

711 Brief an Aldanov vom 24.10.1945. Zit. in: „Perepiska I. A. Bunina s M. A. Aldanovym“. In: Nz 150 (1983): 185.

712 Brief an Karpovic vom 17.03.1945. Bakhmeteff Archive (New York), MS Coll. Aldanov.

713 I. Bunin. „Cistyj ponedel'nik“. In: Nz 10 (1945): 17.

714 Brief an Bunin vom 20.05.1944. Zit. in: „Pis'ma B. Zajceva I. i V. Buninym“. In: NE 146 (1982): 134. 
12. November 1945 von dem Umstand, daß den Lesern aus ihrem Umfeld die Erzăhlung "Cistyj ponedel'nik“ am besten gefalle („по блеску и необычайной красотности изображения “715). Ihr selbst hingegen erschließt sich die komplexe Persönlichkeit der Protagonistin nicht, da sie deren Verhalten für unwahrscheinlich hält: „У таких сложных особ одной ночн не бывает.“716 Gänzlich anderer Natur ist Kuskova-Prokopovið̌s Kritik an der Erzählung "Natali“ - nicht ohne Schalk bemängelt sie das plözliche Verschwinden Sonjas: „Автору стало скучно распутываться є двух любях, но читателю все-таки хочется знать, как-же Соня? Или принимает по ночам других черноусых?

\subsubsection{Reaktionen nach Erscheinen des Buches}

In seinen Erinnerungen Odinocestvo isvoboda berichtet der Literaturkritiker Georgij Adamovič von einer vergleichsweise kühlen Aufnahme der Temnye allei durch das Publikum, die den durchaus wohlwollenden Kritiken in der Presse zuwidergelaufen sei: „Ho устная пресса была несколько другая.“.718 In der Tat unterscheiden sich die Briefe, die Bunin als direkte Reaktion auf das Erscheinen seines Buches erhielt, sowie die Korrespondenzen anderer Personen erheblich von der eher unspezifischen, grundsätzlich positiven Beurteilung im Feuilleton (vgl. Kap. 10.1.3).

Die Mundpropaganda scheint sich direkt auf das Kaufverhalten ausgewirkt zu haben, denn in einem Brief vom 23. März 1945 berichtet Aldanov Bunin mit fast schon entschuldigend klingenden Worten von der verhaltenen Resonanz der potentiellen Leser auf die New Yorker Edition aus dem Jahr 1943: „Отзывы в немного-численных русских периодических изданиях были восторженные, но русская колония в Америке книг вообще не читает ...“719 Um die Leser des Novyj žurnal nicht vor den Kopf zu stoßen - so scheint es - und in Anbetracht entsetzter Reaktionen auf die bereits veröffentlichten Erzählungen, die die Redaktion erreicht haben, bittet Aldanov im Zusammenhang mit der anstehenden Veroffentlichung der Erzählung „Galja Ganskaja“ um die Erlaubnis, Kürzungen vornehmen zu dürfen: 
Большое спасибо за „Галю Ганскую“. Рассказ чудесный. Карпович умоляет Вас о разрешении выпустить три строчки (о поцелуях по ножке, вдоль чулочка ...). Не скрою от Вас: редакция „Нового Журнала“ получила письма с протестами против „эротики“ и отдельных слов в Ваших рассказах!! Одно пришло от ученого ... „Как же можно? У меня жена“ и т[ак] д[алее]. Мы не ответили. ${ }^{720}$

Derartigen Reaktionen zum Trotz sei die Redaktion weiterhin am Abdruck von Erzählungen interessiert. Aldanov setzt sich für Bunins Erzählungen ein, wenn er auch immer wieder Zugeständnisse machen muß oder sich nicht durchsetzen kann, wie etwa beim gescheiterten Abdruck der Erzählungen „,Madrid““ und „Vtoroj kofejnik“, die schließlich in der Zeitschrift Novosel'e publiziert wurden. Unterstützung erfährt er hierbei von Andrej Sedych, so etwa durch dessen in der Tageszeitung Novoe russkoe slovo publizierte Würdigung Bunins, an die sich ein Aufruf Aldanovs anschließt, ein Exemplar der Sonderausgabe von „Rečnoj traktir“ zugunsten Bunins zu erwerben:

Вот почему семидесятипяти-летний Бунин может писать о любви так, как не напишет ни один молодой писатель - сколько есть в его „Темных Аллеях“ подлинного темперамента и страсти, сколько есть в этих образах целомудрия,-да целомудрия! - и какой жалостью к всегда обреченному человеку прокинуты его рассказы. $^{721}$

Mit negativer Kritik an Bunins Erzählungen, die Aldanov in seiner Eigenschaft als Mitherausgeber des Novyj zurnal erreicht, setzt er sich höchst diplomatisch auseinander. Eine deutliche Sprache spricht etwa ein Schreiben aus dem Februar 1946, in dem der Schriftsteller Georgij Dmitrievið Grebenščikov seine Kritik an Bunins Rückwärtsgewandtheit. seiner Art der Frauendarstellung sowie seiner vermeintlich arroganten Haltung mit Bezug auf Sedychs anerkennenden Artikel in unmißverständlich klare Worte faßt:

И согласны ли Вы с г[осподином] А. Седых, что все последние Темные Аллеи Бунина переисполнены ,целомудрием“? По этим рассказам-шедеврам Бунина выходит, что потти все русские женщины „блядчонки“, но по моему убогому понятию многих блядчонок сам Бунин превратил в таковых своей барской милостью и кое-кого из них даже литературно изнасиловал и охотно позволял насиловать другим. А. Седых, конечно, понимает в этом деле гораздо больше нанвного автора этих строк, где то он воочию удостверился в случае прнема проституткой сто третьего визитора в один ночь. [...] Bопрос тут не о пятнах на солнце, а о том, что часто по ошибке мы принимаем за солнце давно умершую звезду. Поэтому никто из почитателей и редакторов Бунина не решился написать ему, что последный ряд его рассказов-кокетство дурного тона и документ, нзобличающий всю извращенность сго гордости и благородства? Конечно, нужно было показать, как тысячи барчуков и взрослых развратников из крупного

720 Brief an Bunin vom 06.05.1946. Zit. in: „Perepiska 1. A. Bunina S M. A. Aldanovym“. In: Nz 152 (1983): 165.

721 A. Sedych. .K semidesjatipjati-letniju 1. A. Bunina“. In: Novoe russkoe slovo (23,10.1945) 
и мелкого дворянства учились иностранным языкам на свонх гувернантках и растлевали чнстых крестянских девушек, наполняя ими публичные дома или толкая их на самоубийство, но выставлять это для самолюбования и как классическую добродетель русской литературы по меньшей мере, недостойно в особенности для старика, которому, я понимаю, пора подумать и о покаянии, но только не в такой циничной форме. ${ }^{722}$

Aldanov bleibt in seinem Antwortbrief vom 20. Februar 1946 besonnen und wirbt diplomatisch mit warmherzigen Worten um Verstàndnis für seinen gescholtenen Freund:

Я и сам не сочувствую его „уклону“. Кажется, ему не сочувствует никто приходили письма и из Парижа. Но Вы ведь согласитесь с тем, что порнография в прямом смысле в его рассказах нет. [...] Но он органически не способен писать не о том, что его волнует. Что ж делать, его в особенности волнует физическая любовь - именно теперь, в 75 лет. Вы скажете: это-то и гадко. Я не знаю, гадко ли, не думаю (вспомните толстовского „Дьявола“); но повторяю: тто ж делать? Ни Вам, ни мне еще 75 лет. Вунин по-своему прощается с жизнью. Я его в самом деле очень люблю и как писателя, и как человека. Не преувеличивайте в нем дворянского элемента, „барина“, и т[ак] д[алее]. Ведь этот же „барин“ написал и „Суходол“, и этот „буржуа“ (он всю жизнь, кстатн, был беден, а порою и очень, очень беден) написал „Господин из Сан-Франциско“. 723

Auch Mark Višnjak, eines der Gründungsmitglieder der Zeitschrift Sovremennye zapiski, wendet sich in einem Brief vom 25. Februar $1946 \mathrm{mit}$ kritischen Worten zu den Temnye allei an Aldanov. Višnjak erkennt zwar Bunins künstlerische Meisterschaft im großen und ganzen an, stößt sich jedoch vor allem an der Diskrepanz zwischen dem Zeitgeschehen und dem Inhalt der Erzählungen:

Бунин, конечно, в отделных местах хорош, - но мне несносен; я имел как раз неудачную мысль прочесть его Аллеи и пришел, конечно, в полный раж: изнасилование, растление, опять насилование, и все в 43, 44 и 45 гг.,- самый подходящий сезон для концентрации блудливой мысли на воспоминаниях об очень, очень отдаленном прошлом! ${ }^{724}$

Bunin selbst erreichten nach Erscheinen der Pariser Ausgabe von 1946 verschiedene Reaktionen, die nicht alle von Empörung gekennzeichnet sind, sondern etwa seine Erzăhlkunst in den Mittelpunkt stellen: So schreibt beispielsweise Georgij Govy im Dezember 1946, kurz nach dem Erscheinungstermin des Buches, einen begeisterten Brief an Bunin: „Чудная книга, может быть лучшая из всех, которые я читал в последние 
годы. “725 Auch P. M. Bicilli äußert sich in einem Schreiben an Bunin vom 30. Januar 1947 geradezu hymnisch: „[...] нет ни одного слова, которое можно было бы заменить другим; ни одной фразой, которую можно было бы вычеркнуть." 726 Und Evgenija L'vovna Dechamps teilt Bunin in einem Brief vom 3 . Mai $1949 \mathrm{mit}$, daß sie sich in ihre Jugend zurückversetzt gefühlt habe, und hebt dabei besonders auf Bunins Talent der sinnlichen Beschreibung $a b$, an der sie offenbar nichts Verwerfliches entdecken kann:

Какие захва-тивающие, какие проникновенные Ваши рассказы. [...] Читая „Темныс Аллеи“ я вспомнила слова Goete [sic] в письме посвященной Frau von Stein "Die sehende Hand und das tastende Auge". 727

Auch in den russischen Emigrantenkreisen in den USA wurde das Buch nicht ausschließlich nach seinem erotischen Inhalt beurteilt. Irina Graham, die vor allem in der Erzählung „Čistyj ponedel'nik“ ihr persönliches Rußlandbild wiederfindet, schreibt in einem begeisterten Brief vom 16. Januar 1947 an Bunin: „А я вчера читала ,Темные аллеи' и, в свирепом восторге исчеркала всю книгу. “728 Selbst Mar'ja Cetlina, mit der Bunin nach ihrer Kritik an seinem Austritt aus dem Schriftstellerverband gebrochen hatte, fand lobende Worte, die allem Anschein nach über Galina Kuznecova an Bunin weitergeleitet wurden:

Марья Самойловна [Цетлина] долго говорила со мной о Темных Аллеях, кот[орые] она очень хвалит и утверждает, что немногие рассказы в них возбуждают чувство как великой жалости к девушкам как к Катюше Масловой, жертве так сказать, мужского вожделения. ${ }^{729}$

Julija Sazonova, die sich für eine englischsprachige Übersetzung der Temnye allei in den USA einsetzte (vgl. Kap. 9.3.2), läßt Bunin in einem Brief vom 13. Oktober 1952 wissen: „Но я поистине влюблены в Ваши Темные аллеи, мне они кажутся непревзойденным совершенством и тут нет ни с кем даже параллели. Это граничит с чудом. ${ }^{.730}$ und teilt ihm in einem Schreiben vom 27 . Oktober $1952 \mathrm{mit}$, daß sie ein Buch über ihn und sein Werk verfassen möchte, in dem sie den Temnye allei einen besonderen Platz zubilligen will:

725 LRA. MS. $1066 / 2857$

726 LRA. MS. $1066 / 1908$.

727 LRA. MS. $11665 / 2180$

728 LRA. MS. $1066 / 2860$.

729 Edinburgh University Library, Special Collections Department. Dieser Brief vom 17.07.1950 legt als Absenderin Galina Kuznecova nahe. da er aus ihrem US-amerikanischen Wohnort Flushing abgeschickt wurde. in dem sic seit 1949 mit Margarita Stepun lebte.

730 LRA. MS. $10661 / 4917$. 
[...] так как это поистине явление небывалое. Перебирая в памяти всех лучших мастеров рассказа, я не могу найти ничего схожего в этим даром передачи огромного содержания в сжатых до зкстракта словах. Только в летописи встречается такой творческий лаконизм [...] Но образ ее не достигает личной отчетливости, как в отдельных фигурах Темных Аллей. Это выход из всех перегружений ... Прочтя раз, помнишь навсегда. ${ }^{731}$

Ebenfalls aus den USA erhălt Bunin einen Brief von Il'ja L'vovix Tartak vom 24. Juli 1951, in dem dieser zwar überschwenglich für die Zusendung der Temnye allei dankt, aber gleichzeitig die Dominanz menschlicher Schwächen beanstandet:

Я медленно читал их, рассказу за рассказам - и испытивал знакомые мне наслаждение от Вашей безпоцадной зоркости и веселой, легкой точности слова и фраз. Мне особенно понравились из новьх рассказов „Антигона“ и „Кума“. [...] Но и мучительна у Вас эта власть и навождение хоти (не люблю слова „похоть"),- и слабость и обман. ${ }^{732}$

Nicht alle bemängelten die deutlichen Worte Bunins zur physischen Lust: Jurij Pavlovið Trubeckoj beispielsweise teilte Bunin in einem Brief vom 21. Juni 1949 seinen Eindruck von ten Temmye allei mit, der Bunin durch den darin enthaltenen, zu seinen Gunsten ausfallenden Vergleich mit Maupassant erfreut haben dürfte:

Я уже прочел, вернее проглатил, „Темные аллеи“. [...] Но в этой книге для меня открылось нечто новое, для меня незнакомое, в Вашем творчестве. Вы каким-то крючком выворачиваете наизнанку все внутреннее. [...] Удивительнее всего то, что это хотел когда-то сделать Мопассан, но это ему не удалось. Он сбился вернее сбивался, на пошлость. А у Вас, несмотря не всю нагую откровенность, никогда и нигде я не вижу пошлости, скользности и эротика, В самом скверном пониманием этого слова. $^{733}$

Allgemeiner formulierte seinen Leseeindruck Vladimir Pimenovic Krymov, dem offenbar vor allem daran gelegen war, Bunin angesichts der zahlreichen Anschuldigungen moralische Unterstützung zuzusichern. In einem Brief vom 26. September 1950 schreibt er:

Вот Ваши „Темные Аллен“, пожалуй лучшее произведение Ваше, замечательные есть места и от них остается незабываемое впечатление - а что решают хамрюжки или так называемые литературные критики ровно ничего не стоит. ${ }^{734}$

Von anderer Seite bleibt Bunin derartiger Rückhalt verwehrt: Aus kirchlichen Kreisen erreicht ihn unmittelbar nach dem Erscheinen der Temnye allei Kritik an den freizugigen Beschreibungen. Archimandrit Ioann (Dmitrij A. Sachovskoj), der vor seinem Eintritt ins 
Kloster in den 1920er Jahren selbst eine Zeitschrift herausgegeben hatte, schreibt Bunin am 18. Februar 1947:

[...] с печалью узнаю, что Ваше творчество пошло в сторону возбуждения в читателях полового чувства ... Зная уже тот мир и зная с непреложностью, что надо человечеству уцеломудрнваться, а не развинчивать в себя еше до-нельзя уже в развинченную сферу, я еще более болею за Вашу душу, несомненно близко уже стоящую пред судом Правды и Чистоты Последней ... ${ }^{735}$

Bunins Reaktionen auf diese Briefe sind in der Regel nicht bekannt; eine Ausnahme bildet seine Erwiderung auf die von Fedor Stepun in der Zeitschrift Vozrożdenie ${ }^{736}$ gleichfalls erhobenen Vorwürfe allzu freizügiger Darstellung der weiblichen Figuren in den Erzählungen der Temnye allei, gegen die er sich vehement zur Wehr setzt. In einem Brief vom 10. März 1951 verteidigt er nachdrücklich sein interesse am weiblichen Körper mit dem Hinweis auf die Normalităt männlichen Verhaltens, das aus der Literatur auszuklammern er keine Veranlassung sieht:

Жаль, что Вы написали В „Возрождении“, что „В ,Темных аллеях есть некоторый избыток рассматривания женских прельстительностей“; [...] Какой там „избыток“! Я дал только тысяную долю того, как мужчины всех племен и народов „рассматривают“ всюду, всегда женшин со своего десятилетнего возраста и до 90 лет $^{737}$

(вплоть до всякой даже моды женской): последите-ка, как жадно это делается даже в каждом трамвае особенно когда женцина ставит ногу на подножку трамвая! И есть-ли это только развратность, а не нечто в тысячу раз иное, почти страшное? ${ }^{738}$

Nicht nur Bunin reagiert heftig auf Stepuns kritische Worte. Auch Vladimir Zeeler, Sekretär des Pariser Sojuz russkich pisatelej i žurnalistov, fühlt sich zu einem Kommentar des Artikels herausgefordert. Der emotionale Ton seiner Anmerkungen läßt vermuten, daß es ihm weniger um eine sachliche Auseinandersetzung mit den Temnye allei ging, als vielmehr um die Fortsetzung persönlicher Unstimmigkeiten mit Bunin, die möglicherweise im Rahmen seines Austritts aus dem Schriftstellerverband ungelöst blieben:

И вот странно: Федор Степун, уже не очень молодой человек, все же настолько полон самого неподдельного энтузиазма, что начал искать в этих „Темных аллеях“ не только „какую-то коллекцию эротических ситуаций“ (что находит

735 LRA. MS.1066/5012. Bunins Anmerkung auf diesem Briefbogen spricht Bănde: „Очень rлynо!“

736 F. Stepun. „1. A. Bunin i russkaja literatura". In: Vozrożdenie 13 (1951): 168-175.

737 Bemerkenswert ist, daß Bunin mit dem Hinweis auf diese Altersspanne exakt die Altersstufen der in den Temrye allei dargestellten mannlichen Figuren abdeckt: von „Krasavica“ bis "Zeleznaja Serst”“.

738 Zit. in: „Pis'ma 1. A. Bunina k F. A. Stepunu“. op.cit.: 121. AnlaBlich dieses Artikels erhalt Bunin Schutzenhilfe von L. Gabrilovic: .Даже прннинпиально предающаяся оргиазмом курочка Степун не сомневается, что нельзя свыше меры любоваться женскими прелсстями. Не может немеи жнть без обшего правнла" (Brief an Bunin vom 25.03.195I. LRA. MS.1066/2655). 
большая часть читателей), а русско-филосовское обоснование того, „до чего глубока порученность Бунина-художника в стихию пола [...]" [...] Ведь не и не обо всем даже мать скажет или расскажет своей дочери. Почему? Да потому, что существует некое чувство, правда, не всем доступное. Называется это чувство стыдом. Это и есть то сдерживающее начало, которое не позволяет преступать известной грани во всех ,правдах“ ${ }^{739}$

Stepun antwortet postwendend auf Bunins Brief, distanziert sich von Zeelers Kommentar als vulgär und gesteht Bunin, daß seine persönliche Meinung leicht von seiner im Artikel geäußerten abweiche, er mit dieser jedoch nicht an die Öffentlichkeit habe treten wollen, aus Furcht davor, als subjektiv und voreingenommen beschuldigt zu werden. $^{740}$

\subsubsection{Rezensionen im Feuilleton nach der Veröffentlichung der Pariser Ausgabe von} 1946

Der Öffentlichkeit bekannt gemacht wird die Existenz eines neuen Buches von Bunin mutmaßlich erstmals in einem Artikel, der am 15. Juni 1945 in den Russkie novosti publiziert wurde. Der nur mit „B.“ zeichnende Autor (vermutlich Aleksandr Bachrach) weist die Leserschaft darauf hin, daß die Erzăhlungen auf Grund der Papierknappheit und wirtschaftich problematischen Situation der Verlagsbranche bislang noch nicht erscheinen konnten, macht auf eine wenige Tage später stattfindende Lesung Bunins aufmerksam und charakterisiert die Erzählungen folgendermaßen: „все это рассказы о любви, о любви вечной, о любви жестокой.“741 Eine vergleichbare Notiz von Aleksandr Bachrach findet sich am darauffolgenden Tag im Sovetskij patriot unter dem Titel „Poslednij iz mogikan““ ${ }^{742}$ Bachrach ist es auch, der den erotischen Inhalt der Erzählung ,Zojka i Valerija“ im Hinblick auf ihre Veröffentlichung im Russkij sbornik ${ }^{743}$ verteidigt:

739 V. Zeeler. ...Vozroźdenie'. Tetrad' trinadcataja“. In: Russkaja mysl' (09.03.1951).

$740 \mathrm{Vgl}$. Brief an Bunin vom 16.03.1951: ,Я каждому могу сказать: ,сам вижу, но иначе ошущак. ' [...] Еслн бы у меня было больше времени н главное больше места для статьн, я мог бы и среди того. что многими отрицается как излищества, отделить глубокне наблюдения от простого любопытствования. [...] Я очень хорошо знаю, что хроме мистерин любви есть и мнстерия пола, огненного и страшного, космического и запределенного. Этих вещей сейчас почти никто не чувствует, потому что наш предельно чувственный век почти совершенно утратил дар зротического вдохновения" (LRA. MS.1066/5306).

741 B[achrach?]. „U Bunina“. In: Russkie novosti (15.06.1945).

742 A. Bachrach. „Poslednij iz mogikan“. In: Sovetskij patriot (16.06.1946).

743 Russkij sbornik. Kniga 1. Paris, 1946. 
„Зойка и Валерия“ [...] может кое-кому нравится меньше других рассказов цикла "Темные аллеи“, но отрицать ее чисто художественные достоинства во имя какой-то ханжеской псевдоидеи о засорения нравов, значит отрицать задачи искусства, диктуя ему границы, в которьх рано или поздно оно должно будет увянутъ. ${ }^{744}$

Die fruheste nachweisbare Rezension über die Pariser Ausgabe der Temnye allei erschien Anfang 1947. Der Kritiker Georgij Adamovix sieht sich offenbar zu einer Verteidigung Bunins aufgerufen. In seinem Artikel instrumentalisiert er zum einen Bunin gegen die Vertreter der zeitgenössischen sowjetischen Literatur, zum anderen erweist er sich als weitsichtig, indem er Bunin als seiner Zeit voraus schreibend einschätzt - gleichzeitig kritisiert er solcherart die Engstimigkeit seiner Zeitgenossen, die sich von einem überholten Moralempfinden leiten ließen:

Мало у Бунина книт, о которых было бы труднее говоритъ, qем о „Темных Аллеях". [...] Бунинская книга кажется несбыкновенно смелой и откровенной лишь в литературе русской. Но именно сейчас в русской литературе она нужнее, чем когда бы то ни было,- потому, что русская литература с каждым годом все больше забывает, что человек, это не только общественник, деятель и работник, и что рассказывая о человеке, нельзя игнорировать суцественнейшей стороны его жизни. [...] Когда-нибудь будет смешно - и вместе с тем грустно, и вместе с тем стыдно! - вспоминать, что Бунину, чнстейшему художнику, приходилось оправдыватвся перед современниками, обвинявшими его в потворстве „низким побуждениям“. 745

Auch in der US-amerikanischen Emigrantenpresse wird das Erscheinen der Pariser Ausgabe der Temnye allei registriert. Vera Aleksandrova (eigentlich Vera Aleksandrovna Svarc) weist in ihrem Artikel im Novoe russkoe slovo implizit auf die Eigenständigkeit der einzelnen Erzăhlungen hin, indem sie auf deren Publikationen in den Zeitschriften Novyj žurnal und Novosel'e aufmerksam macht. Auf mögliche Hintergründe der nun erfolgenden Integralveröffentlichung geht sie jedoch nicht ein, sondern stellt statt dessen die Frage nach einem Zuviel an Erotik:

В самой возможности такого вопроса уже есть ответ. Но спешу оговориться: впечатление, что есть иногда какой-то „чересчур“ возникает не от отдельных подробностей, [...], а след от впечатления продолжает жить Дело [sic] не в излишествах подробностей. ${ }^{746}$ 
Ähnliche Worte findet sie in ihrer etwa zeitgleich erschienenen Rezension im Novyj zurnal. ${ }^{747}$ In einem wenige Jahre darauf publizierten Artikel zu Bunin äußert sie sich ihren kritischen Anmerkungen zum Trotz anerkennend zur vergleichsweise höheren künstlerischen Qualität der in den Jahren der Emigration entstandenen Werke gegenüber seinem Frühwerk:

[...] Бунин [...] создал такие произведения, как ,Митина лю6овь', ,Жизнь Арсеньева', ,Божъе древо', ,Темные аллен', которые по своему мастерству превосходят книги его писательской молодости. ${ }^{748}$

In einem 1947 in der Zeitung Novoe russkoe slovo erschienenen Artikel wird eine interessante Verbindung zwischen den Temnye allei und der Erzählung „Krem Leodor" gezogen, die die Erwartungshaltung an Bunins Schaffen veranschaulicht und seine Weiterentwicklung registriert. Ähnlich wie zuvor schon Téffi konstatiert der unbekannte Verfasser satirische Elemente in den Erzählungen des Buches (ohne diese jedoch näher zu bestimmen) und zollt der großen stilistischen Meisterschaft Bunins höchste Anerkennung, anstatt wie andere den Niedergang seines Talents zu beklagen:

Из темного лабиринта „Темных аллей“ не это ли есть, быть может, выход? Прнзнаюсь, по старой косной привычке, мы ждали от Бунина выхода в лирику, ждали каких-то новых „Светлых аллей“. А может быть, именно в сатиру [...] и есть выход? И мучительные тупикн „Темных аллей“ вспыхнут огнем сатиры, а не лирики? Сатира требует абсолютно зрелого мастерства,- им в высокой мере обладает Бунин. ${ }^{749}$

Mark Slonim kritisiert in der Zeitschrift Novosel'e zwar auch überflüssige erotische Details in der Erzählung „Zojka i Valerija“ (vgl. auch die diesbezügliche Kritik Boris Zajcevs, Kap. 8.1.2), äußert sich im großen und ganzen jedoch positiv zu den Temnye allei, wobei er vor allem Bunins Fähigkeit zur Wiedergabe von Sinneseindrücken und zur verschmelzenden Darstellung von Natur und Mensch hervorhebt, die davon zeugt, daß seine schöpferische Kraft auch im Alter nicht versiegt sei. ${ }^{750}$

747 V. Aleksandrova. „Bibliografija“. op.cit.: 295-296. Ergănzend ist hinzuzufugen, daß ihr Hinweis auf die Erstpublikation von zehn Erzahlungen nicht korrekt ist, es sind nur neun.

748 V. Aleksandrova. „Bunin i sovremennost’”. In: Novoe russkoe slovo (01.04.1951): 8.

749 Ohne Verfasserangabe. ...Novosel'e' kniga 31-32“. In: Novoe russkoe slovo (09.02.1947).

750 M. Slonim. .Literatumye zametki (,Russkij sbornik')“.' In: Novosel'e 31 1-32 (1947): 94-96. Angesichts dieser positiven Bewertung uberrascht sein wenige Jahre spater festgehaltenes abschließendes Urteil zu Bunins kunstlerischem Schaffen: ${ }_{n}[\ldots]$ he can be considered only as a mere epigone of the great masters". denn seinem stilistisch vollkommenen Schreiben gebreche es an menschlicher Warme (ders. Modern Russian Literature. From Chekhov to the Present. New York, 1953: 172). 
Diesen positiven Kritiken gegenüber steht die höchst originelle Variante einer tendenziell negativen Literaturkritik, die in der Osterausgabe 1948 der zweimonatlich erscheinenden belgischen Emigrantenzeitschrift Casovoj publiziert wurde. ${ }^{751}$ Der Autor S. Mal'cev bedient sich einer fiktiven Diskussion uber Literatur, um verschiedene Meinungen zu den Temnye allei vorstellen zu können; mehrere Generationen sind an dem Gespräch beteiligt, das von dem Ältesten in der Runde angestoßen wird mit der Bemerkung: „Зачем он выпустил эту книгу ... Ведь почти все рассказы в ней собранные эротический бред старика, да еще с такими подробностьян, которые иначе, как порнографией назвать нельзя ...“ Auch in dieser Diskussion wird wieder der Roman Lady Chatterley's Lover herangezogen, und wieder unterliegt Bunin im direkten Vergleich: „Взять хотя бы нашумевший роман Лоурэнса - „љюбовник лзди Чаттерлэӑ но даже и там не такого цинизма ...“ Bedauerlicherweise läßt der Sprecher offen, was genau er als zynisch empfindet.

Gegen Ende der Diskussion schaltet sich ein bis dahin stummer Anwesender ein, der Bunin verteidigt und eine andere Herangehensweise an das Buch fordert, denn schließlich sei vermutlich jedem unter den älteren Anwesenden schon einmal ein amouröses Zusammentreffen widerfahren, wie Bunin es in der Erzählung "Solnexnyj udar" schildere. Da er in der Folge sein persönliches „Sonnenstich"-Erlebnis erzăhlt, stellt sich zwangsläufig die Frage, ob Mal'cev diese fiktive Diskussionsrunde nur ersonnen hat, um einen publikumswirksamen Aufhănger für seine im Oktober/November 1947 verfaßte Erzählung nutzen zu können. Auf diese Art und Weise vermeidet er zwar eine klare Stellungnahme, illustriert aber die Empfindlichkeiten zahlreicher russischer Leser und fordert dadurch indirekt dazu auf, verschiedene Meinungen gelten zu lassen und Pauschalurteile zu vermeiden.

\subsubsection{Exkurs: Rezensionen der deutschen Ubersetzung: 1959-1961 versus 2001}

Gemeinsam ist den Rezensionen im Gefolge der deutschsprachigen Publikationen Dunkle Alleen (Stuttgart, 1959) sowie Liebe und andere Unglücksfälle (Frankfurt, 2000) die eingeschränkte Auswahl von lediglich 14 bzw. 16 Erzählungen des Originals. Dadurch war es dem deutschen Lesepublikum verständlicherweise nicht möglich, die enge innere Bindung der die Temnye allei konstituierenden Erzählungen zu erkennen. Ein Vergleich der im 
Abstand von 40 Jahren erschienenen Rezensionen erscheint als Exkurs dennoch lohnend im Hinblick auf die Wahrnehmung von Themenbereichen bzw. Motiven wie der Erotik und unterstreicht damit nachdrücklich die Beeinträchtigung der zeitgenössischen Rezeption durch die herrschenden Moralvorstellungen. Die zeitliche Năhe der ersten deutschen Ubersetzung zur Veröffentlichung der Pariser Ausgabe erleichtert die Vergleichbarkeit.

Die 1959 im Stuttgarter J. F. Steinkopf Verlag erschienene Ausgabe Dunkle Alleen fand eine große Resonanz in der zeitgenössischen Presse, die sich jedoch nicht in den Verkaufszahlen niederschlugen (vgl. Kap. 9.3.3). Einig sind sich die Rezensenten darin, daß eine Publikation von Erzählungen Bunins uberfällig war. In zahlreichen Artikeln wird die Qualität erkannt und die Publikation begrußt, so etwa als „ein wertvoller Band, der aber nur einen kleinen Leserkreis finden wird ${ }^{\text {“752 }}$ - die religiöse Prägung des Verlags brachte es dabei mit sich, daß überwiegend kirchliche Medien oder Bücherratgeber eine Besprechung vornahmen. Bei einer Betrachtung der Rezensionen muß zudem berucksichtigt werden, $\mathrm{da}$ die Leser einen vor allem in den erotischen Passagen abgemilderten Text vor sich hatten (vgl. Kap. 9.3.3), der zudem vom Umfang her keine Āhnlichkeit mit dem Original mehr hatte und allein deshalb nicht als zusammengehöriges Ganzes hătte erkannt werden können. Der Tenor der Rezensionen gleicht jenem der Reaktionen auf die Originalausgabe. Die verbindenden Themen Liebe und Tod hingegen wurden ebenso wahrgenommen wie die fehlende psychologische Nachvollziehbarkeit der Handlungen der Figuren, wie beispielsweise in der Reformierten Schweiz:

Es ist darum dem Steinkopf-Verlag hoch anzurechnen, daß er nun eine Reihe ausgewăhlter Erzăhlungen Bunins herausgebracht hat, die verstehen lassen, warum Bunin 1933 als erster russischer Schriftsteller den Nobelpreis fur Literatur erhalten hat. Bunins Thematik kreist um zwei wichtige Motive: den Tod und die Liebe. [...] ... und noch lange schwingt die aufwuhlende Erzählung „Natalie“, die die sinnliche und erotische Liebe ins helle Licht des Bewußtseins ritckt, ohne sie jedoch psychologisierend zu zerfasern, im Leser nach. ${ }^{753}$

Im Gegensatz zur zeitgenössischen russischsprachigen Kritik wird zwar auch die Erotik zur Kenntnis genommen, aber nicht als Selbstzweck aufgefaßt: ,[...] und Bunin schreibt auch uber Einzelheiten, die andere gerne verschweigen“754 oder: „Dabei scheut der Autor auch körperlich-sinnenhafte Streiflichter nicht, soweit es seinen künstlerischen Zwecken dienlich ist.“755 Auch die Stuttgarter Zeitung vermutet hinter den erotischen Beschrei- 
bungen keinen Hang Bunins zu pornographischen Darstellungen, sondem begreift diese als notwendiges erzählerisches Mittel:

Dabei erweist er sich, wie Tolstoj, als ein „Hellseher des Fleisches“, als Künstler einer konkret genauen Realistik, die, nach den damaligen Maßstäben mit ungemein sicheren Griffen ins Körperliche, Sinnenhafte, zumal in die weibliche Natur, das Getriebensein, das Verhängnis und das Wesen der Menschen enthüllt. ${ }^{756}$

Bunins Erzählkunst steht ebenfalls im Fokus: Während die Welt der Bücher konstatiert, daß „Bunin die seltene Gabe [hat], das Lebensgefühl einer bestimmten Stunde in einer Erzählung aufleuchten zu lassen, eine Einzelheit so zu treffen, daß sie den Raum der Schilderung unvergeßlich macht,“"757 überrascht die Tageszeitung Die Welt mit folgender Einschätzung:

Iwan Bunins Novellen und Kurzgeschichten mit ihrem Hauptthema Liebe und Tod, die sich wie von Schnitzler mit einem Schuß amerikanischer Boheme in Europa lesen, uurzeln tief in der russischen Literatur. ${ }^{758}$

Auch 40 Jahre später ist sich die Kritik einig in der Anerkennung der schriftstellerischen Meisterschaft Bunins; bemerkenswert ist jedoch, daß Anmerkungen zu den erotischen Elementen in den Erzählungen keine oder nur eine untergeordnete Rolle spielen zugunsten der trotz der eingeschränkten Auswahl offenbar möglichen Wahmehmung verbindender Themen sowie der hohen Qualität von Bunins Schreibkunst. Angesichts eines relativ kleinen Kreises an russischer Literatur interessierter deutscher Leser ist der große Pressewiderhall auf die 2000 erschienene Ausgabe Liebe und andere Unglücksfälle nachgerade erstaunlich und sicher nicht zuletzt auf umfangreiche Presseaktivitäten seitens des Verlags zurückzuführen. Im Frühjahr 2001 wurde das Buch in allen großen deutschen Medien besprochen, wie ctwa im März in der Süddeutschen Zeitung. Unter dem Titel „Nächte des "Nie mehr - Eine Gelegenheit, den Erzähler Iwan Bunin kennen zu lernen“ hebt Manuela Reichart ab auf die Thematisierung der Vergänglichkeit und des Ausgeliefertseins des Menschen an das Schicksal

Immer wieder begegnen uns in den Novellen von Iwan Bunin Menschen, deren augenblicklicher Affekt, deren momentane Einsicht oder Empfindung ihr ganzes Leben prägen wird, ohne dass sie Einfluss nehmen könnten auf den Lauf ihres Schicksals. ${ }^{799}$

756 hs. „Bunins dunkle [sic] Alleen. ,Ausgewahlte Meistererzahlungen““. In: Stultgarler Zeilung 6 (1960).

757 Ohne Verfasserangabe. In: Well der Bucher 4 (1960).

758 H.-D. Sander. „Viel zuwenig kennen wir von der Literatur der Slawen“. In: Die Welt 218 (1960).

759 M. Reichart. „Năchte des, Nie mehr* - Eine Gelegenheit, den Erzăhler Iwan Bunin kennen zu lernen“. In: Suddeutsche Zeitung (10.03.2001). 
Kurz darauf bemăngelt Amo Widmann in der Berliner Zeitung nach einem Abriß über bisherige deutschsprachige Publikationen aus dem Werk Bunins als einer der wenigen Rezensenten in erster Linie die Auswahl und Ausstattung des Bandes, die die Lektüre spürbar beeintrăchtigten (vgl. Kap. 9.3.3). Zum Inhalt der Erzählungen hingegen äußert er sich nur verhalten und schließt mit folgender, etwas verwirrend klingender Wamung an potentielle Leser: „Aber die Geschichten ähneln einander $\mathrm{zu}$ sehr. Man sollte allenfalls zwei hintereinander lesen. Vielleicht vor dem Einschlafen. Sonst ermudet ihr nahezu immer gleicher Rhythmus. ${ }^{\text {“760 }}$ Eine generelle Leseempfehlung spricht Hellmuth Karasek am 13. Mai 2001 in der Berliner Tageszeitung Der Tagesspiegel aus, wenn auch mit dem Hinweis, daß die Erzählungen ,kalt geschrieben“ seien. ${ }^{761}$

In der Wochenzeitung Die Zeit bespricht Olga Martynova das Buch ausgesprochen positiv und hebt Bunins Fähigkeit zur Wiedergabe von Details hervor: "In diesen wie durch ein Vergrößerungsglas gesehenen Details spiegelt sich jetzt die ganze Welt.“762 Diese Rezension nimmt übrigens als einzige der Besprechungen dieses Buchtitels die erotischen Schilderungen in den Erzählungen explizit zur Kenntnis. Martynova zufolge war Bunin getrieben, „vor allem das Undefinierbare [zu] erfassen, das Unheimliche, Unsichtbare und Allgegenwärtige, das, was in der Antike Eros genannt wurde." Angesichts dieser zutreffenden Feststellung der Erhebung des Eros zur kosmischen Kraft (vgl. auch Kap. 8.1.3) überrascht die mangelhafte Recherche, die Martynova behaupten läßt, daß die Temmye allei ein Erfolg für Bunin gewesen seien.

Den Ritterschlag der populären Literaturkritik erhielt der Titel Liebe und andere Unglücksfälle durch die Aufnahme in den Kreis jener Bücher, die in der Kultursendung „Literarisches Quartett" ${ }^{\text {“763 }}$ vorgestellt und diskutiert wurden. Allen Zweifeln an den Auswahlkriterien des Verlags bezüglich der Erzählungen zum Trotz zog die Runde um Marcel Reich-Ranicki, der Bunins Meisterschaft vor allem in dessen Talent zur Wiedergabe von Stimmungen und zur Darstellung von zwischenmenschlichen Beziehungen sieht, eine positive Bilanz ${ }^{764}$, wobei Bunins relative Unbekanntheit beim deutschen Lesepublikum

760 A. Widmann. „Hinter jedem Fenster ein Schicksal ..... In: Berliner Zeitung (20.03.2001).

761 H. Karasek. „Vorgelesen“. In: Der Tagesspiegel (13.05.2001).

762 O. Martynova. „Russland ist weiblich. Leben auch. Ein literarisches Ereignis: Die Erzahlungen des russischen Nobelpreisträgers Iwan Bunin“. In: Die Zeir 19 (03.05.2001).

763 ZDF, Sendung vom 04.05.2001, Teilnehmer: Marcel Reich-Ranicki, Hellmuth Karasek, Iris Radisch und als Gast Antje Kunstmann.

764 Negative Kritik außerte einzig Iris Radisch: Sie zeigte sich unzufrieden mit den zahlreichen weiblichen Leichen, deren Vorhandensein sie in Anlehnung an Elisabeth Bronfen begreift als Ausdruck der Verunsicherung mânnlicher Kanstler angesichts des Anderen, das sich im Weiblichen verkorpere, und die sie dazu treibe, dieses Andere zu vernichten (vgl. E. Bronfen. Over Her Dead Body. Death. Femininity and the Aesthetic. Manchester, 1992). 
ausdrüklich bedauert wurde. In diesem Punkt besteht eine klare Übereinstimmung mit der Meinung Ulla Hahns, die unter dem Titel „Das abgetrotzte Glück“ in dem Wochenmagazin Der Spiegel Bunin als „Meister der Stimmungen“ bezeichnet, der mit den Augen schreibe. ${ }^{765}$ Hahn weist zudem darauf hin, daß die Liebe bei Bunin das Hindernis brauche, daß Grenzen überschritten würden, für deren Überschreitung gebüßt werden müsse. Und in Anspielung auf den Titel vermeint sie hinter dem Liebesthema Bunins wahres Anliegen zu erkennen:

Und schlimmer selbst als unglückliche Liebe ist nur eines: dass sogar sie vergeht. Wie eben das Leben auch. Und alle ,anderen Unglücksfälle“. Und so wäre denn das einzige wahre Unglück unsere Vergänglichkeit [...] Und so schrieb Bunin nicht nur, um das Vergangene $\mathrm{zu}$ vergegenwärtigen, er schrieb gegen die Vergänglichkeit schlechthin an. ${ }^{766}$

10.2 Vor- bzw. Nachworte von Ausgaben der Temnye allei in der Soujetunion bzw. in Rußland, Frankreich, England und Deutschland

Mit wenigen Ausnahmen spiegeln die Vor- bzw. Nachworte die willkürliche Editionspraxis der Verlage wider - in der Regel finden sich keine Hinweise auf den größeren Zusammenhang der den Temnye allei entnommenen Erzählungen. Dies legt den Schluß nahe, daß, abgesehen von zensorischen Motiven, die Verbindung zwischen den Erzählungen nicht wahrgenommen oder trotz der häufig gemachten Feststellungen der thematischen Ähnlichkeiten für nebensächlich gehalten wurde bzw. keinen Rückschluß auf die Zusammengehörigkeit der Erzăhlungen nahelegte.

Während die Herausgeber der New Yorker Ausgabe der Temnye allei aus dem Jahr 1943 in einer Vorbemerkung auf die den zeitlichen Umständen geschuldeten Kürzungen des Buches hinweisen (vgl. Kap. 9.1.1), fehlen nicht nur den original-, sondern auch den fremdsprachigen Veröffentlichungen in der Regel Anmerkungen zum ursprünglichen Umfang und Inhalt des Buches. Von diesem Manko einmal abgesehen, gibt es jedoch etliche Editionen, die mehr oder weniger umfassende Erläuterungen enthalten und in einem Vor- oder Nachwort den-wie immer wieder betont wird-zu Unrecht unbekannten Schriftsteller und Dichter Bunin in einen biographischen und künstlerischen Kontext stellen. 


\subsubsection{Sowjetunion/Rußland}

Anhand der Vorworte der russischsprachigen Werkausgaben bzw. der Anmerkungen zu den in ihnen enthaltenen Versionen der Temnye allei läßt sich besonders eindrücklich veranschaulichen, wie sich zunächst politisch motivierte zensorische Eingriffe in mangelnde editorische Sorgfalt wandelte. Aufmerksame Leser dürften sich des öfteren über Diskrepanzen zwischen der erwähnten Anzahl der Erzählungen der Originalausgabe und dem vorliegenden Abdruck gewundert haben, wurden aber über die Gründe der Lückenhaftigkeit im unklaren gelassen.

Die erste Werkausgabe Bunins, die 1956 in fünf Bănden (mit 17 Erzählungen aus den Temnye allei) in der Sowjetunion erschien, enthält eine gut 25-seitige Einfuhbrung des Herausgebers Lev Nikulin, von denen Bunins Leben und Schaffen in der Emigration ein unverhăltnismäßig kleiner Anteil gewidmet wird. ${ }^{767}$ Nikulin hebt in diesem Zusammenhang lediglich die Bedeutung des Liebesthemas fur Bunin in der Emigration hervor. Mit Ausnahme des Hinweises auf Bunins Erinnerungen an Cechov verschweigt Nikulin in seiner Einführung die weitere schriftstellerische Tătigkeit Bunins in der Emigration, so daß sein Urteil nur in der Würdigung des bis 1920 entstandenen Werkes bestehen kann: .Долгие годы большой русскнй писатель Иван Бунин прожнл вдали от родины, с которой был связан лучшимн свонми пронзведениями, и умер на чужбине.“" ${ }^{768} \mathrm{Um}$ so mehr überrascht in den Anmerkungen die Nennung der beiden Editionen aus den Jahren 1943 und 1946 (allerdings ohne Angabe der Anzahl der darin enthaltenen Erzählungen), die einen Hinweis zur Verwahrung von Bunins persönlichem Exemplar der Temnye allei im IMLI einschließen. ${ }^{769}$

767 Eine Fußnote wert ist der Hinweis, daß diese Werkausgabe in einer Auflage von 300.000 Exemplaren erschien (V. Aleksandrova. „Sovetskoe izdanie Bunina“. In: Novoe russkoe slovo [09.09.1956]). Zum Vergleich: Von der Pariser Ausgabe der Temmye allei (1946) wurden lediglich 3.020 Exemplare gedruckt (vgl. Kap. 9.1.2).

768 L. Nikulin. „I. A. Bunin“. In: I. Bunin. SS v pjati tomach. I.Bd. Moskva, 1956: 28. Zudem versucht Nikulin eine Abgrenzung zu anderen verfemten Emigrantenschriftstellern und deren Publikationen mit der Begrindung herzustellen, daß Bunins Emigrationswerk kunstlerisch wertvoller sei, da fur ihn die Liebe die horchste Bedeutung habe, wahrend die anderen nur dem verlorenen bequemen Leben im zaristischen Rußland nachtrauerten. In diesem Vorwort findet sich zudem eine Erklarung fur den bevorzugten Abdruck der Erzăhlungen "Temnye allei" und "Voron" in Sammelbănden oder Zeitschriftenpublikationen: Mit der expliziten Enwahnung der beiden Erzăhlungen wurden diese quasi offiziell freigegeben (vgl. Kap. 9.3.2).

769 In: I. Bunin. SS v pjati tomach. 4.Bd. Moskva, 1956: 465. Drei Jahre spater weist er in einem Überblick aber einige der jungst in der Sowjetunion eingetroffenen Manuskripte Bunins erneut auf die Temmye allei hin, hier ergănz um folgende Kritik: „В сборнике ,Темные аллен' есть произведения, написанные с излишными зротическнми подробностями, чуть ли не с утратой чувства меры,- раньше этого нккогда не было у Бунина“ (L. Nikulin. „O cem govorjat rukopisi Bunina“. In: Moskva 7 [1959]: 208). 
Der umfangreicheren neunbăndigen Werkausgabe aus den Jahren 1965-1967 ist ein ausführliches Vorwort von Aleksandr Tvardovskij vorangestellt, in dem er die sozialkritischen Werke Bunins, wie etwa Derevnja (1910), als wirklichkeitsnah wïrdigt, dem Spätwerk jedoch weitgehende Weltfremdheit und Vergangenheitszugewandtheit vorwirft (,[...] на всем у него милый его художническому сердиу элегический отпечаток воспоминания“"779. Vor allem die in der Emigration entstandenen Erzählungen erregen Tvardovskijs Mißfallen durch die einseitige Beschäftigung mit den Themen Liebe und Tod, so daß er nur noch den Niedergang des einstigen Talents, das fern der Heimat einsam und jeglicher frischer Ideen beraubt war, in die Niederungen der fleischlichen Lüste konstatieren kann:

Поздиий Бунин [...] уже нередко с заметной болезненностью и чуждой великим образцам русской литературы натуралистической „пряность“ сосредоточивается на этих неизменных мотивах любви и смерти. Тема любви, при всем мастерстве и отточенности стиля, приобретает порой у Бунина уж очень прямолинейно чувственный характер и выступает в форме эротических мечтаний старости. ${ }^{77}$

Im siebten Band dieser Werkausgabe, der die Temnye allei (mit 37 Erzählungen) enthält, geht Oleg Michajlov gesondert auf die in der Emigration entstandenen Erzählungen ein und stellt das seinen Angaben zufolge 38 Erzählungen umfassende Buch mit Betonung des weiblichen Elements ausführlich vor, allerdings ohne darauf hinzuweisen, daß drei Erzăhlungen im Abdruck fehlen, wăhrend zwei hinzugefügt wurden - die mögliche Verwirmung eines aufmerksamen Lesers wird somit bewußt in Kauf genommen: "Эro единственная в своем роде книга в русской литературе, где все - о любви. Тридцать восемь новелл этого сборника дают великое разнообразие женских типов ... “772 Dabei greift er auch den Vorwurf der im Übermaß vorhandenen erotischen Darstellungen auf und bietet folgendes Erklärungsmodell an:

Правда, взятые сами по себе, некоторые эпизоды „Темных аллей“ могут дать повод для упрека автора в излишнем ,зротизме“. [...] Однако на самом деле все обстоит гораздо сложнее. В бездымном, чистом пламени высокой любви не просто поэтизируются самые „стыдные“ подробности - без них сокращено, урезано путешествие души, громадность ее взлета. [...] Романтика ощущений и осторожный натурализм, по Бунину, всегда уравновешивают друг друга. ${ }^{773}$

770 A. Trardovskij. „O Bunine“. In: I. Bunin. SS v devjati tomach. I.Bd. Moskva, 1965: 19.

771 A. Trardovskij. „O Bunine“. op.cit.: 26.

772 O. Michajlov. (Ohne Titel). In: I. Bunin. SS v devjati tomach. 7.Bd. Moskva, 1966: 355. Leicht verăndert wird Michajlovs Aufsatz auch in den Izbrannye socinenija (1984) gedruckt, Passagen daraus werden zudem im Vorwort zur Einzelveroffentlichung Temmye allei (1990) verwendet, in letzterer trotz der Publikation von $\mathbf{4 0}$ Erzahlungen ohne zusătzlichen Hinweis auf die Hintergrunde der Ergănzung.

773 O. Michajlov. (Ohne Titel). op.cit.: 356. 
In der dreibändigen Werkausgabe von 1982 weist auch Anna Saakjanc in ihrem Nachwort auf das zentrale Thema der Liebe und die Bedeutung der Frau hin, sieht jedoch im Gegensatz zu Michajlov keinen Anlaß, die Relevanz der erotischen Szenen zu verteidigen, sondern stellt lediglich ihr Vorhandensein fest und verbindet dies mit der ausdrücklichen Würdigung, daß Bunin dabei die Grenzen des Künstlerischen keineswegs überschreite:

Предельно откровенно и подробно умеет говорить он об интимейших человеческих отношениях,- однако всегда на том пределе, где большое искусство ни на йоту не снижается даже до намеков с натурализм. [...] И действительно, до Бунина в современной ему русской литературе о любви-страсти не было „никогда не написано никем“ так, как удалось это ему. ${ }^{774}$

Ähnlich äußert sie sich in erweiterter Form in der 1988 publizierten Werkausgabe in sechs Bänden, die den ersten russischsprachigen Integralabdruck enthält (vgl. Kap. 9.2.2). ${ }^{775}$ Das Nachwort zu der gleichfalls 1988 erschienenen Werkausgabe in vier Bănden bietet hingegen kaum Informationen zu den Temmye allei, lediglich die Erzählung "Pozdnij cas" wird etwas ausführlicher vorgestellt. ${ }^{776}$

Während die Werkausgabe, die 1994 in sechs Bänden herausgegeben wurde, keinerlei Erläuterungen oder einführende Worte zum (unvollständigen) Abdruck der Temnye allei enthält, findet sich im sechsten Band der vorerst letzten, achtbändigen Werkausgabe (1999) ein ausfuhrlicher Kommentarteil, zusammengestellt von Aleksandr Baboreko, der schon für den ersten Integralabdruck im Rahmen der Werkausgabe von 1988 verantwortlich zeichnete. Der zwischenzeitlich erfolgte politische Wandel schlägt sich nieder in der weiteren Ausdehnung seiner Anmerkungen sowie nicht zuletzt in seinem Fazit, aus dem sich eine deutliche Befriedigung über die veränderten Publikationsbedingungen herauslesen läßt. Daß auch er nicht frei von politischen Einflüssen ist, zeigt sein Fazit:

„Темные аллеи“- книга о многом высоком и прекрасном, в ней озарения чего-то неземного, [...] она несет людям очищение от того, что породила лжекультура, которой враждебно „живое общение человеческих душ“. ${ }^{777}$

Die Vor- bzw. Nachworte der fremdsprachigen Ausgaben der Temnye allei sind zwar mit Ausnahme der DDR-Ausgabe frei von politischen Einflüssen, aber höchst unterschiedlich in der Wahrnehmung des Buches und der Wahl ihrer Bewertungsschwerpunkte.

774 A. Saakjanc. ... Temnye allei'. Poslednie gody". op.cit.: 516. Es erstaunt, daß Saakjanc in ihrem Aufsatz die Erzahlung ,Zeleznaja Serst'“ enwahnt, obwohl sie in dieser Werkausgabe nicht enthalten ist.

775 A. Saakjanc. (Ohne Titel). In: I. Bunin. SS v Jesti tomach. S.Bd. Moskva, 1988: 582-593.

776 N. Ljubimov „Obraznaja pamjat’. (Iskusstvo Bunina)“. In: I. Bunin. SS v cetyrech tomach. 4.Bd. Moskv2, 1988: 16-39.

777 A. Baboreko. „Temnye allei“. In: 1. Bunin. SS v vos 'mi romach. 6.Bd. Moskva, 1999: 620. 


\subsubsection{Frankreich}

Als einzige der in die Analyse eingeflossenen fremdsprachigen Übertragungen der Temnye allei weist die 1987 erschienene einzige französischsprachige Publikation Les Allées sombres einen Integralabdruck auf (vgl. Kap. 9.3.1). In seinem Vorwort widmet Jacques Catteau den Entstehungsumstănden des Buches großen Raum, bevor er als einziger Verfasser vergleichbarer Anmerkungen auf die innere Geschlossenheit des Buches eingeht:

Ivan Bounine pressentait l'oubli, l'ombre froide et mystérieuse du caveau et pourtant, dans le même temps, il cuvrait à la chaude joumée d'été de la vie. De toute la puissance de sa mémoire, il épiait la note musicale, la première phrase - comme il disait - qui décide et détermine la dimension et le rythme de l'œuvre, et écrivait d'un trait - comme on vide un verre - des nouvelles parfaites dont l'ensemble forme un hymne à l'amour enfui et brisé par la mort venue d'ailleurs. Le recueil se clôt symboliquement sur une image de chapelle qui dit la pensée essentielle de Bounine dans Les Allées sombres: „Et plus la brûlure du soleil est cuisante et radieuse, plus le courant d'air est froid qui s'exhale de la fenêtre obscure."“778

\subsubsection{England}

Den unvollständigen englischsprachigen Ausgaben der Temnye allei fehlen in der Regel Hinweise auf den größeren Zusammenhang der Erzählungen; die jeweiligen Anmerkungen rücken entweder Bunins erstaunliches Erinnerungsvermögen in den Fokus des Lesers oder lenken die Aufmerksamkeit auf die prominente Stellung der Erotik in den Erzählungen.

Richard Hare würdigt Bunin in seinem Vorwort zu dem 1949 in seiner Übersetzung erschienenen Sammelband Dark Avenues, and Other Stories als Meister der Short Story und hebt vor allem Bunins Fahigkeit hervor, auch nach Jahren in der Emigration noch höchst lebendig über das untergegangene Rußland schreiben zu können:

The stories [...] are mainly centered in erotic episodes, which provide vivid and disquieting glimpses into the recent Russian past and into a state of mind which seemed to accept the disintegration of Russian culture as a decree of fate. ${ }^{779}$

Ähnlich prominent wie Hare rückt auch William Sansom in seinem Vorwort für den Sammelband The Gentleman from San Francisco, and Other Stories die Bedeutung der

$778 \mathrm{~J}$. Catteau. „Preface“. op.cit.: 7-14. Ein Übermaß an Erotik kann Catteau nicht registrieren, er stellt lediglich fest: .Cet érotisme, si rare dans la grande littérature russe, est délibéré" (ders. op.cit.: 11).

779 R. Hare. „Preface“. In: J. Bunin. Dark Avemues, and Other Stories. London, 1949: 6. 
Erinnerung furr Bunin in die Aufmerksamkeit des Lesers, macht jedoch auch auf eine ungewöhnliche Parallele aufmerksam: „Bunin is always sensuous, sometimes sensual, in his close evocation of women's flesh and the rural and urban weathers observed by a late Czarist Russian. ${ }^{4780}$

Einzig David Richards weist in seiner Einführung in dem 1984 erschienenen Titel Long Ago. Selected Stories, von dessen 14 Erzählungen lediglich 6 aus den Temnye allei stammen, auf das 38 Erzăhlungen umfassende Originai hin und würdigt Bunins Modernităt vor allem im Hinblick auf seinen Umgang mit Erotik:

[...] his last volume [...] was met with either silence or expressions of dismay at what were regarded as distasteful descriptions of sexual encounters. [...] A special place in Bunin's poetry of live is occupied by sexual love, for although in this realm we may hope to enjoy the highest flights of rapture, we may also be driven as nowhere else to the blackest depths of despair. In many respects Bunin's approach to sex is surprisingly modern. [...] In story after story, sexual entanglements drive Bunin's characters to desolation, madness or self-destruction. An older-fashioned and deeper morality than permissiveness seems to dictate that in this area of poetic experience rapture has to be paid for, and we are reminded, more forcibly than elsewhere, of our fundamental human fragility. ${ }^{781}$

\subsubsection{Deutschland}

Den drei umfangreicheren deutschsprachigen Ausgaben der Temnye allei sind jeweils erläuternde Worte mit höchst unterschiedlichen Schwerpunkten vor- bzw. nachgestellt. Die Ausgabe von 1959 enthält eine umfassende Einfuhrung des Slavisten Johannes Holthusen, der Auskunft zu Bunins Biographie erteilt und vor allem zumindest allgemein auf die Herkunft der Erzählungen hinweist. Damit läßt er implizit erkennen, daß die Erzählungen in einen größeren Zusammenhang gehören. Neben einer allgemeinen Würdigung von Bunins Erzăhlkunst hebt er vor allem dessen „Fähigkeit zu körperlich konkretem Sehen“ hervor und weist auf die Bedeutung der Erotik als Strukturelement in den Erzählungen hin:

Den Charakter der Frau, die in Bunins Novellen eine dominierende, zugleich meist tragische Rolle spielt, läßt der Dichter durch ihren Körper erst in die gesuchte Form eingehen, was der Grund dafür ist, daß Bunin körperliche Details nicht verschweigt, sondern als wichtige Funktion im Aufbau der Erzählung benutzt. ${ }^{782}$

780 W. Sansom. „Introduction“. In: I. Bunin. The Gentleman from San Francisco, and Other Stories. London. 1975: 8.

781 D. Richards. „Introduction“. In: I. Bunin. Long Ago. Selected Stories. London, 1984: 8-13.

782 J. Holthusen. ,Iwan Bunin“. In: I. Bunin. Dunkle Alleen. Stuttgart, 1959: 11. 
Ein ausfuhrliches Nachwort ist der 1985 im Ost-Berliner Aufbau-Verlag erschienenen Ausgabe Dunkle Alleen. Erzählungen 1920-1953 beigegeben. Der Herausgeber Karlheinz Kasper bietet einen ausführlichen, wenngleich von Ansichten der sowjetischen Literaturwissenschaft beeinflußten Überblick über Bunins Leben in der Emigration samt einer literaturwissenschaftlichen Einordnung. Kasper zufolge ist „die Sammlung ,Dunkle Alleen“, achtunddreißig Erzählungen, die zwischen 1937 und 1945 entstanden, [...] solchem ,Wetterleuchten' [des Glücks] gewidmet, kurzen Augenblicken des Glücks und der Liebesfreude. “783 Auch Kasper weist auf die Bedeutung des Weiblichen für Bunin hin, hält sich jedoch bezüglich der Erotik bedeckt: „Bunin erzählt von der Liebe, ohne eine der denkbaren Beziehungen zwischen Mann und Frau auszuklammern." ${ }^{784}$

Der bislang jüngsten deutschsprachigen Publikation mit Erzählungen aus den Temnye allei, dem im Jahr 2000 erschienenen Sammelband Liebe und andere Unglücksfälle, ist weder ein Vor- noch ein Nachwort beigefügt, dafür jedoch gemäß der Konzeption der gesamten Reihe der ,Anderen Bibliothek“ ein von Rainer Wieland erstelltes sogenanntes Dossier, das neben einer Zeittafel unter anderem einige Ausschnitte aus Erinnerungen von Zeitgenossen an Bunin enthält. Der einzige Hinweis auf die Temnye allei besteht in der Angabe des Erscheinungsdatums der New Yorker Ausgabe von 1943, ohne diese als den politischen und finanziellen Umständen geschuldete unvollständige Erstausgabe zu kennzeichnen, während die 1946er Ausgabe hingegen vollständig ignoriert wird.

\subsection{Literaturwissenschaftliche Bewertungen}

Bei der vergleichenden Betrachtung einer Auswahl der Analysen zu den Temnye allei muß berücksichtigt werden, daß die meisten auf unvollständigen Editionen basieren. Möglicherweise ist hierin eine Ursache dafür zu sehen, daß angesichts der Vielzahl untersuchter Teilaspekte des Buches die Genrezugehörigkeit eine untergeordnete Rolle spielt, und zwar unabhängig davon, in welchem der betrachteten Länder die Untersuchung durchgeführt wurde. Ein Zusammenhang zwischen dem steigenden Interesse an Fragestellungen zur Komposition der Temnye allei seit den 1980er Jahren mit der zunehmenden Publikation integraler Ausgaben des Buches kann nicht belegt, aber auch nicht ausgeschlossen werden.

783 K. Kasper. „Nachwort”. In: I. Bunin. Dunkle Alleen. Erzählungen 1920-1953. Berlin und Weimar. 1985: 565-566.

784 K. Kasper. .Nachwor'“. op.cit.: 566. 


\subsubsection{Sowjetunion/Rußland}

Zu Bunins Lebzeiten war es in der Sowjetunion lediglich opportun, sich mit dem vor der Emigration entstandenen Teil seines Werkes zu befassen, sei es als Leser oder als Wissenschaftler. Den offiziellen Impuls zur allmählichen literarischen und wissenschaftichen Rehabilitation Bunins scheint Konstantin Fedins Rede im Rahmen des 2. Kongresses des Schriftstellerverbandes (1954) gegeben zu haben, in der er dazu aufforderte, Bunins Namen nicht länger aus der Geschichte der russischen Literatur auszuklammern, wenngleich er sich mit dem Hinweis auf Bunins Wunsch der Rückkehr in die alte Heimat einer falschen Tatsache bediente, vermutlich um seinem Ansinnen Nachdruck zu verleihen:

Недостало сил вернуться домой Ивану Бунину - русскому классику рубежа двух столетий, который оставался реалистом и в прозе и в поэзии той поры, когда господствовала мода на декаданс. Не следует, по моему мнению, отчуждать Бунина от истории русской литературы, и все ценное из его творчества должкно принадлежать читателю так, как принадлежит лучшее из наследия Куприна. ${ }^{785}$

Durch den Vergleich mit Kuprin, der nur mit Einschränkungen in der Sowjetunion anerkannt wurde, ließ er allerdings offen, welche Teile aus Bunins Schaffen in der Emigration als wertvoll $\mathrm{zu}$ identifizieren waren. Erst die Werkausgabe von 1956 bietet Orientienungspunkte bei der Frage nach der offiziellen Akzeptanz. Mit umfassenderen literaturwissenschaftlichen Studien zu den Temnye allei war jedoch ohnehin nicht vor der Publikation der zweiten Werkausgabe (1965-1967) zu rechnen, da die erste Werkausgabe nicht einmal die Hălfte der das Buch konstituierenden Erzählungen enthălt.

So geht es in den ersten Studien zu Bunins Schaffen in der Emigration vornehmlich darum, Bunins Spätwerk summarisch vorzustellen. Den Anfang machte M. Iofev: Im Rahmen seines 1965 publizierten Buches Profili iskusstva konstatiert er eine Vielfalt von Variationen des Themas und der Protagonisten in den Temnye allei. Bei seiner abschließenden Beurteilung legt er jedoch den Maßstab der sowjetischen Aufbauliteratur an, den Bunin nicht erfullt habe:

Люди и время отжили свой срок. Новеллы позднего Бунина отпели старую Россию, как юношеские его рассказы отпели дворянские гнезда. И потому его творчество - не просто творчество мрачных итогов, оно утверждает закономерность конца. ${ }^{786}$

785 K. Fedin. „Rexi na s" ezdach (1954)“. In: ders. Pisatel: iskusstvo. vremja. Moskva, 19804: 516.

786 M. lofev. Profili iskusstva. op.cit.: 313. 
Einer Beurteilung enthält sich Vladislav Afanas'ev in seiner 1966 erschienenen Studie I. A. Bunin. Ocerk tvorčestva - obwohl er gut 20 Seiten seines Überblicks den Temnye allei widmet: Er konstatiert zwar thematische Verbindungen (Liebe, Verlust der Heimat) des Buches, das er ohne nähere Erläuterung als Zyklus bezeichnet, geht aber nicht auf den Aufbau ein, sondern hebt vielmehr die Verschiedenartigkeit der unterschiedlichen Typen von Erzählungen hervor. ${ }^{787}$ Auch Anatolij Volkov beschränkt sich in seiner 1969 publizierten Monographie zur Prosa Bunins auf Nacherzählungen einzelner Erzählungen aus den Temnye allei und hält als verbindendes Element die konstatierenden Erzählschlüsse fest (vgl. Kap. 5.4). ${ }^{788}$

Um den 100. Geburtstag Bunins herum erschienen in den Jahren 1970 bis 1974 zahlreiche Publikationen, von denen sich einige auch mit den Temnye allei beschäftigen (die meisten haben jedoch das Frühwerk zum Inhalt). Bevorzugter Gegenstand der Analysen ist das politisch wenig angreifbare Gebiet der in den Erzählungen eingesetzten Stilmittel und entspricht gleichzeitig dem wieder einsetzenden Interesse am Formalismus bzw. dem aufstrebenden Strukturalismus. Mit dem inneren Rhythmus der Erzählungen etwa befaßt sich I. Figurovskij 1970 in seinem Aufsatz „O sintaksise prozy Bunina. Sintaksiceskaja dominanta ,Temnych allej"“ - dominierende Syntaxarten gelten ihm als verbindendes Element des von ihm als Zyklus bezeichneten Buches. ${ }^{789}$ Die wesentlichen sprachlichen Stilmittel Bunins in den Temnye allei stehen im Zentrum von A. Koxetkovs 1971 erschienenem Aufsatz. Er macht zwar auf bedeutsam Parallelen aufmerksam, setzt diese aber nicht in Bezug zu einer möglichen globalen Komposition des Buches. ${ }^{790}$ Auch A. Sokolov verläßt 1971 in seinem Artikel zur künstlerischen Meisterschaft Bunins nicht das sichere Terrain, wagt sich jedoch in allgemeinen Worten ein wenig vor: „[...] до рассказов книги ,Темные аллек', которыми как бы завершились искания писателя своей художественной формы." $" 791$

Mit der Komposition des Buches beschäftigt sich 1971 als erste Literaturwissenschaftlerin A. Ačatova. Sie vergleicht es mit einem lyrischen Zyklus; der einzelnen Erzählung spricht sie überraschenderweise gleichzeitig die Eigenständigkeit ab. ${ }^{792}$ Zwei Jahre später

787 V. Afanas'ev. I. A. Bunin. Ocerk rvorcestva. Moskva, 1966: 365.

788 A. Volkov. Proza Ivana Bunina. Moskva, 1969.

789 I. Figurovskij. „O sintaksise prozy Bunina ... “. op.cit.: 63-66.

790 A. Kocetkov. ..Sredstva vyraženija emocional'nosti ... “. op.cit.: 123-130.

791 A. Sokolov. „Zametki o chudozestvennom masterstve I. Bunina“. In: Russkij jazyk za rubezom I (1971): 98.

792 A. Acatova. „Pozdnjaja liriceskaja novella I. A. Bunina ...“. op.cit.: 116. 
setzt sie sich erneut mit den Temnye allei auseinander, diesmal jedoch unter sprachlichen Aspekten. ${ }^{793}$

Nach Erscheinen der neunbändigen Werkausgabe (1965-1967) bildete die Publikation der Bunin gewidmeten zweibăndigen Ausgabe im Rahmen der Reihe Literaturnoe nasledstvo (1973) ein weiteres Signal zur literaturwissenschaftlichen Auseinandersetzung auch mit Bunins Spätwerk. Die beiden umfangreichen Bände enthalten zahlreiche Materialien zu Bunin, wie Erinnerungen, Korrespondenzen, Aufsătze und unveröffentlichte Texte, so unter anderem auch die bislang in der Sowjetunion unveröffentlichte Erzählung „Železnaja Šerst'“. Der zweite Band enthălt zudem eine Auswahl von Antworten auf eine von N. Sedovoj in den Jahren 1968/69 durchgefuhrte Umfrage unter sowjetischen Schriftstellem bezüglich ihrer Ansichten zu Bunin. ${ }^{794}$ Nach seiner Meinung zum Schaffen Bunins in der Emigration befragt, antwortet etwa der Schriftsteller Jurij Markovið Nagibin (1920-1994) folgendes: „Бунин и в эмитрации пнсал изумительно. В ,Темных аллеях есть божественные рассказы, хотя бы такие, как ,В Париже', „Руся', ,Таня'““795 Sergej Alekseevic Voronin (geb. 1913) äußert sich ăhnlich, wenn auch zurückhaltender: „Нельзя согласнться с утверждением, что в эмнграцни Бунин стал писать слабее. ,Темные аллеи' - разве зто слабее раннего Бунина? ${ }^{796}$ Und auch Jurij Valentinovic Trifonov (1925-1981) zeigt sich beeindruckt von Bunins Prosa: „Бунин был для меня открытием: какова может быть сила пластического, живописного слова! [...] Больше всего у Бунина мне нравится рассказ ,В Париже‘.“797

1974 resümiert Valerij Gejdeko in seinem Aufsatz „Opirat'sja na fakty“ verschiedene Forschungsansätze der sowjetischen Literaturwissenschaft zu Bunins Werk und fordert dazu auf, Bunin für die russische Kultur zuruckzuerobern, ohne allerdings die früheren Forschungsergebnisse zu ignorieren. ${ }^{798}$ Sein Hauptargument besteht in der These, daß Bunin trotz der langen Jahre in der Emigration kein westlicher Schriftsteller geworden sei, daß fast sein gesamtes Werk Bezug zu Rußland habe - insofern spielt er implizit auf die Gedächtnisleistung an, die Bunins Emigrationswerk auszeichnet.

793 A. Acatova. „Iz nabljudenij nad liriceskoj prozoj I. A. Bunina“. op.cit.: 83-90.

794 N. Sedovoj. „Iz otzyvov sovetskich pisatelej o Bunine“. In: LN. 84.Bd. (2) op.cit.: 365-374.

795 Ju. Nagibin. Zit. in: N. Sedovoj. „Iz otzyvov sovetskich pisatelej o Bunine". op.cit.: 365.

796 S. Voronin. Zit. in: N. Sedovoj. „lz otzyvov sovetskich pisatelej o Bunine“. op.cit.: 366.

797 Ju. Trifonov. Zit. in: N. Sedovoj. „Iz otzyvov sovetskich pisatelej o Bunine“. op.cit.: 369.

798 V. Gejdeko. .Opirat'sja na fakty". In: Voprosy literatury 3 (1974): 237-246. 
In ihren beiden Aufsătzen „Nekotorye osobennosti struktury novelly I. A. Bunina ,Temnye allei'“ (1974) und „Prostranstvo i vremja $v$ rasskazach ob emigracii iz cikla ,Temnye allei` I. A. Bunina“ (1976) setzte sich L. Issova den eine umfassende Analyse suggerierenden Titeln zum Trotz nur mit einzelnen Erzählungen des Buches auseinander. ${ }^{799}$

Der Bunin-Spezialist Oleg Michajlov legte 1976 seine erste Monographie zu Bunins Leben und Werk vor. Mit den Temnye allei nehme Bunin in der russischen Literatur eine Vorreiterrolle ein:

В нашей отечественной литературе до Бунина, пожалуй, не было писателя, В творчестве которого мотивы любви, страсти, чувства - во всех его оттенках и переходах - играли бы столь значительную роль. ${ }^{800}$

Michajlov bezeichnet das Buch zwar als Zyklus, geht aber mit keinem Wort auf die dahinter liegende Konzeption ein. Er konzentriert sich auf die Parallelen zwischen den Erzăhlungen, die er vor allem an den Protagonisten und am Liebesthema festmacht. Seine hier festgehaltenen Überlegungen finden sich fast textgleich in verschiedenen Vor- bzw. Nachworten sowie in diversen Handbuchartikeln. ${ }^{801}$

Das Interesse an den unveröffentlichten Texten wuchs nach der Perestrojka - so kündigte etwa die Redaktion der Zeitschrift Slovo 1990 den Abdruck weiterer bis dahin in der Sowjetunion unveröffentlichter Texte Bunins an, bis die geplante Akademieausgabe fertiggestellt sei. ${ }^{802}$ In der wissenschaftlichen Forschungsliteratur laß sich etwa zur selben Zeit ein steigendes Interesse an den Kompositionsgrundlagen der Temnye allei sowohl auf thematischer als auch auf struktureller Ebene registrieren. Eine differenziertere Auseinandersetzung mit den Temnye allei wurde zudem durch die veränderten politischen Randbedingungen begünstigt.

Unter strukturellen Aspekten beschäftigt sich beispielsweise Natalija Evstareva in ihrem 1986 publizierten Artikel „Novella i rasskaz-vedušcie żanrovye formy v knige

799 L. Issova. „Nekotorye osobennosti struktury novelly I. A. Bunina ,Temnye allei“”. In: Zanr $i$ kompo zicija literarurnogo proizvedenija 1 (1974): 98-104; dies. „Prostranstvo i vremja v rasskazach ob emigracii iz cikla "Temnye allei* I. A. Bunina". In: Zanr i kompozicija literaturnogo proizvedenija 3 (1976): 88-98.

800 O. Michajlov. Strogij talant. Ivan Bunin. Zizn': sud ba, Norcestvo. Moskva, 1976: 228. Auch elf Jahre spater hat er keine Neubewertung vorgenommen; seine Anmerkungen zu den Temmye allei erscheinen textgleich in seiner Monographie I. A. Bunin. Zizn' i vorčestvo. Tula, 1987. Textahnlich finden sie sich in seiner Bunin-Biographie Zizn' Bunina. Lis' slovu Zizn' dana .... Moskva, 2001.

801 O. Michajlov. „Bunin. 1870-1953“. In: Literatura russkogo zarubes ja. 1920-1940. Moskva, 1993. Textgleich in: ders. Literatura russkogo zarubet ja. Moskva, 1995. Textahnlich in: ders. ..Bunin“. In: Literaturnaja enciklopedija russkogo zarubez ja. 1.Bd. Moskva, 1997: 87-90.

802 Ohne Verfasserangabe. „Bunin, Ivan A. ,Tretij Tolstoj '“. In: Slovo 7 (1990): 47. Vgl. Kap. 9.2.2. 
I. A. Bunina ,Temnye allei“" mit dem Buch, dem sie im Spätwerk Bunins einen besonderen Platz zuweist: Sie faßt die Verwendung verschiedener erzählerischer Genres - Novelle, Erzählung, Miniatur - auf als Resultat und Ausdrucksmittel eines langwierigen ethischphilosophischen Erkenntnisprozesses Bunins zum Verhältnis Welt-Mensch sowie zur Rolle der Liebe im Leben des Menschen. ${ }^{803}$ Die Vielfalt der Erzählformen innerhalb der Temnye allei stellt sie in ihrer Dissertation „Svoeobrazie Zanrovych form $v$ knige I. A. Bunina ,Temnye allei“c (1990) vor, ohne jedoch gleichzeitig auf die Genrezugehörigkeit des Buchès einzugehen. ${ }^{804}$ Dies vermeidet auch L. Smimova in ihrer Monographie Ivan Alekseevic Bunin. Žizn' i tvorčestvo (1991). In ihrem Überblick bezeichnet sie die Temnye allei zwar als Zyklus, läßt aber offen, was sie darunter versteht, und weist lediglich auf Parallelen zwischen den Protagonisten hin. ${ }^{805}$

E. Értner erkennt 1995 in ihrer Studie zur rhythmischen Gestaltung der Temnye allei, die sie als Zyklus (ohne weitere Definition) wahrnimmt, als grundlegendes verbindendes Strukturelement den ähnlichen rhythmischen Aufbau zahlreicher Erzählungen: Diese Gemeinsamkeiten bestehen ihren Ergebnissen zufolge zum einen aus zwei gegenläufigen rhythmischen Linien, die zunăchst in einem Glücks-, dann in einem Katastrophenmoment kulminieren, zum anderen in der Gegenüberstellung der beiden Zeitblocke Gegenwart und Vergangenheit. ${ }^{806}$ Unter thematischen Gesichtspunkten năhert sich V. Grečnev in ihrem 1996 veröffentlichten Aufsatz „Cikl rasskazov I. Bunina ,Temnye allei“ (Psichologiceskie zametki)“ dem Buch. Als verbindendes Element der Erzählungen empfindet sie das Liebesthema, dessen vielfaltige Facetten sie anhand verschiedener Beispiele nachzeichnet, wobei hervorgehoben werden soll, daß sie die erotischen Schilderungen als unabdingbar betrachtet:

Иньми словами, человеческое и духовное в названных рассказах имеет преимущество перед плотским, а точнее говоря - здесь плоть духовна. Как уже отмечалось, такая любовь способна обогатить, пробудить в человеке отзывчивость, уважение, радостное желание отдавать, а не брать. ${ }^{807}$

Diana Myšlova geht in ihrem 1994 publizierten Artikel der Frage nach, ob Bunin ein Realist oder Modemist sei. Ihrer Analyse legt sie die 38 Erzăhlungen der Temnye allei zugrunde und kommt zu dem Schluß, daß Bunins Erzählungen zwar realistisch wirkten, da

803 N. Evstar eva. „Novella i rasskaz ... “. op.cit.: 99.

804 N. Evstafeva. „Svoeobrazie Zanrovych form ... “. Charkov, 1990.

805 L. Smimova. Ivan Alekseevic Bunin. Zizn' i tvorcestvo. Moskva, 1991.

806 E. Ertner. „Ritmiceskaja organizacija cikla I. A. Bunina ,Temnye allei““. In: Tvorceskoe nasledie I. A. Bunina i mirovoj literaturnyj process. Orel. 1995: 43.

807 V. Grěnev. „Cikl rasskazov I. Bunina ,Temnye allei’ ... “. In: Russkaja literatura 3 (1996): 228. 
er die Bestandteile der realen Welt entnommen habe, aber daß er sich wie die Modernisten daraus eine eigene Welt schaffe, in der es nur ein Sujet gebe: das Zusammentreffen von Mann und Frau, das sie als Ur-Situation wertet, mit deren Hilfe Bunin das Ewige und Unverrückbare in der Welt darstelle. ${ }^{808}$

Im Zuge seiner 1996 veröffentlichten Monographie zu Bunin widmet Igor' Karpov ein Kapitel der Darstellung der weiblichen Figuren in den Temnye allei (,Monologizm

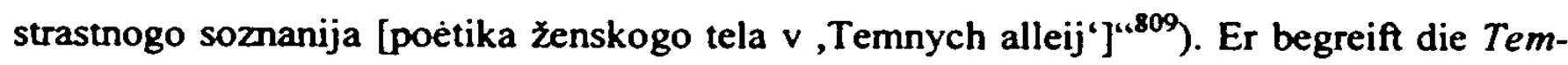
nye allei als phänomenologische Studie Bunins zum typisch männlichen Hingezogensein zur Frau und vor allem zu ihrem Körper. Dabei nimmt wunder, daß er sich nur einem Teilaspekt des Buches widmet und die Komposition vollkommen außer acht läßt.

Ol'ga Slivickaja hingegen verweist in ihrem Artikel „Čelovek Bunina kak kosmos i ličnost'“ (1997), einer Analyse des Verhältnisses Mensch - Kosmos in den Temnye allei, der Berücksichtigung eines Teilbereichs zum Trotz auf den offenen Charakter des Buches. Sie konstatiert ăsthetische Gesetzmäßigkeiten, die die Erzählungen des Buches mit früher entstandenen Erzählungen verbinden würden, aber in dieser Konzentration und Zusammenstellung besonders gut zum Ausdruck kämen. ${ }^{810}$

In einer umfassenden Studie beschäftigt sich M. Štern 1997 mit dem Prosawerk Bunins in den 1930er und 1940er Jahren. In diesem Zusammenhang stellt sie die These auf, daß die Temnye allei ein lyrisches Buch in Prosa seien und weitaus komplexer als ein Zyklus. Die Argumentation wirkt jedoch über weite Strecken unstrukturiert und arbeitet die Besonderheiten eines lyrischen Buches in Prosa im Gegensatz zu einem Zyklus nicht überzeugend heraus, obwohl die Autorin Verbindungen zwischen einzelnen Erzählungen auf verschiedenen Ebenen aufzeigt. Die Gesamtstruktur des Buches bezieht sie jedoch in ihre Analyse nicht ein.

\subsubsection{Westeuropa/USA}

In Westeuropa bzw. den USA setzte die wissenschaftliche Auseinandersetzung mit den Temnye allei bedeutend früher ein, wobei die entscheidenden Impulse von der US-ameri-

808 D. Myšlova. ..Realist li Bunin? O poetike cikla ,Temnye allei'“. In: Grani 171 (1994): 124-130.

809 In: I. Karpov. Proza Ivana Bunina (ocerki avtorsrva). Moskva, 1996: 42-65.

810 O. Slivickaja. „.Celovek Bunina kak kosmos i lienost'”. op.cit.: 74. 
kanischen und der französischen Slavistik ausgingen. In Deutschland dürfe es Fedor Stepun zu verdanken sein, die Temnye allei in der akademischen Welt bekanntgemacht $\mathrm{zu}$ haben. An der Münchener Universităt lehrte er in den Jahren 1946-1959 russische Geistesgeschichte und Philosophie und hielt Vorlesungen und Seminare zur russischen Literatur. In einem Brief an Bunin vom 13. Juni 1951 berichtet er von den Reaktionen der Studenten auf sein Seminarthema, die Erzählung „Pozdnij Cas“:

[...] и был очень обрадован тем, что некоторым студентам была вполне понятна и оценена его стилистически-структурная сложность, двупланность, в которой ведется повествование и, по их мнению, вероятно сознательная стертость границ между обоими планами, русским и французским. ${ }^{811}$

Die ersten Dissertationen, die auch Bunins Spătwerk berücksichtigen, erscheinen jedoch in den USA und in Österreich. Sowohl Edward Wasiolek als auch Otto Peschl haben noch zu Lebzeiten Bunins Kontakt mit diesem aufgenommen, wobei Peschl im Gegensatz zu Wasiolek offenbar keine Antwort mehr erhalten hat. Wasiolek legte 1954 seine großangelegte Analyse „The Fiction of Ivan Bunin: a Critical Study" vor. Den Temmye allei widmet er jedoch keine gesonderte Aufmerksamkeit, sondern kommt auf Grund der darin enthaltenen erotischen Szenen vielmehr zu folgendem Schluß, der kontrår zu Bunins eigener Einschătzung steht:

For the most part, Dark Alleys ist the low water of his artistic achievement. All of the short stories are very brief, and in theme, almost exclusively, treat sex in some way. Whereas earlier a traditional Russian prudery characterized his description of love scenes [...] in the stories which make up the volume Dark Alleys, sex is described almost lasciviously. [...] and in many other stories there are monotonously pornographic descriptions of naked bodies and the acts of seduction. ${ }^{812}$

Auf die erotischen Schilderungen verweist zwar auch Otto Peschl ausdrücklich in seiner ähnlich weit greifenden Dissertation „Die künstlerische Entwicklung von Ivan Bunins

811 LRA. MS. $1066 / 5308$.

812 E. Wasiolek. „The Fiction of Ivan Bunin ... “. op.cit.: 85. Ahnlich empfindet Andrew Guershoon Colin, der 1955 in seinem wordigenden Ruckblick auf Bunins Leben und Werk zu den Temmye allei schreibt: „Here I must say that the erotic element, always present in Bunin's prose, [...] has been the pivot round which revolve practically all of the short stories collected in ,Dark Avenues"." (A. Colin. „Ivan Bunin in Retrospect". In: The Slavonic and East European Review 82 [Dez. 1955]: 172-173).

Wie eine spate Replik auf Wasioleks und Colins Kritik liest sich Gleb Struves Kurzbewertung der Temmye allei in seiner Monographie Russkaja literatura $v$ izgnanii: „K шедевром Буннна прнналлежат и такне небольшне, и столь различные, рассказы о любви как ,Солнечный удар и ,Ида', не говоря улке о мнотих рассказах в ,Темных аллеях', в которых, $\alpha$ сожалению, не одно обывательское мненне, но и некоторые критики увидели не только проявление упадка бунинского таланта, но и какой-то старческий зротизм, чуть ли не порнографню. Между тем некоторые из этих рассказов, в своем сочетании вещественно и плотности, какоя̆-то осязательности пнсьма с лирическоя глубнной и силой, прннадлежат $\mathrm{x}$ лучшимн рассказам о любви-страсти в русскоя литературе" (G. Struve. Russkaja literalura v izgnanii. Paris, 1984: 251). 
Prosastil“ (1954), empfindet diese jedoch als Teil des Facettenreichtums des Liebesthemas. Anlaß zu der Studie bildeten seine Feststellung, daß ,keine bedeutende Abhandlung über den Schriftsteller und sein Werk [existiert] ${ }^{4813}$, und sein Wunsch, einen Teil dieser Lücke mit einem Überblick über das gesamte Prosaschaffen Bunins zu schließen. Die innere Zusammengehörigkeit der Temnye allei, die er als Zyklus begreift, liegt für Peschl ausschließlich im thematischen Bereich:

Die Schaffenspause 1932-1938 kündigt den letzten Abschnitt im Prosawerk Ivan Bunins an. Noch ist seine künstlerische Kraft nicht gebrochen, sie erreicht einen nochmaligen, allerletzten Höhepunkt. [...] Die 38 Erzählungen des folgenden und letzten Bandes "Temnye allei", Paris 1946, zeigen, dass [sic] sich in Bunin eine innere Wandlung vollzogen hat. Das überragende Thema dieser Sammlung heisst [sic]: Liebe. Nichts mehr von dem geheimnisvollen, mystischen Dunkel des Todes, nur sekundär greift er in das Schicksal der Menschen ein. Das vorherrschende Element bleibt die Liebe, die Bunin nun nicht mehr zart poetisch beschreibt oder ihre Sinnlichkeit einem höheren Ganzen unterordnet, sondern der physische Akt steht wiederholt im Vordergrund, dessen banale Schilderung den Dichter manchmal hart an die Grenze der Pornographie geraten läßt. ${ }^{814}$

Bunins Tod löste verschiedene Nachrufe aus, die ihn erneut ins Bewußtsein nicht nur der literarischen Welt rückten. Stellvertretend sei an dieser Stelle William Sansoms im März 1954 erschienener Artikel „Ivan Bunin: The Harpstring Broken“ genannt, in dem er dem in der Emigration entstandenen Werk Bunins großen Raum widmet unter besonderer Betonung der Erzăhlungen aus den Temnye allei (ohne diese jedoch als zusammengehöriges Ganzes wahrzunehmen), die er vergleichsweise hoch bewertet, indem er sie etwa mit „Gospodin iz San-Francisko“ vergleicht:

It ["Gospodin iz San-Francisko"] is a fine work, but as so often happens, overshadows his equally beautiful shorter pieces by the mass of its length. Natalya, Roosya, In Paris, even The Riverside Inn and Henry dig as deeply and move over as many metres of heartground. These stories are involved with great crises, or the most memorable moments of a man's life - yet are told within the economy of the "short story“. But in Bunin's economy there is lavish expenditure with very few coins, coins of the softest and whitest gold. [...] what he is out to express, always, in his art: not a frisson, not a reformation, not anything particular - but always the whole, a nostalgic wonder at the mystery of life in this world, of love, of strangeness of beauty and the beauty of grief, and of death. ${ }^{815}$

813 O. Peschl. „Die kunstlerische Entwicklung von Ivan Bunins Prosastil“. op.cit.: 3. In einem undatierten Brief (mutmaßlich aus dem Jahr 1953), der im LRA verwahrt wird, hatte sich Peschl an Bunin gewandt. unter anderem mit der Bitte, ihm eine persornliche Einschătzung seiner künstlerischen Entwicklung zu geben sowie eine Beurteilung seines Prosaschaffens unter dem Aspekt der küstlerischen Vollkommenheit. Ob er eine Antwort erhielt, muB offen bleiben (LRA. MS.1066/4574).

814 O. Peschl. „Die kunstlerische Entwicklung von Ivan Bunins Prosastil“. op.cit.: 140-141.

815 W. Sansom. .The Harpstring Broken". In: The London Magasine (Marz 1954): 64-65, 68. 
in den 1960er Jahren lassen sich lediglich zwei Dissertationen feststellen, die die Temnye alle $i$ in unterschiedlicher Gewichtung in ihre Analyse einbeziehen: A. de Yackovlevs Stulie „Bunin's Prose Writings in Exile“ (1967) befaßt sich mit den verbindenden Elementen des Spätwerks, wie Themen, Protagonisten, Methoden und Einflüssen, geht jedoch nicıt gesondert auf die Temnye allei ein. ${ }^{816}$ Ein Jahr später erscheint Baldur Kirchners Inaugural-Dissertation, in der er sich zum Ziel setzt, „Die Lebensanschauung Ivan Alekseerix Bunins nach seinem Prosawerk" nachzuvcllziehen. ${ }^{817}$ Den Temnye allei widmet er nur wenige Seiten, wobei er auf die äußere Form des Buches nicht eingeht, sondern sich mil Nacherzählungen einiger Erzăhlungen begnügt und den Fokus auf die im Buch enthalten: Aufforderung zum bewußten Leben richtet, ohne der Erotik einen besonderen Stellenvert beizumessen. ${ }^{818}$

Jie erste westliche Monographie zu Bunins Leben und Werk erschien 1971: In The Woks of Ivan Bunin setzt sich Serge Kryzytski in einem Kapitel auch mit den Dark Alleys ausinander. Nachdem er Wasioleks Kritikpunkte an einem Zuviel an Erotik und einem Nidergang von Bunins Talent entschieden widerlegt hat, befaßt er sich mit der Bedeutung de: Weiblichen und der Liebe in den Erzählungen. Er bleibt jedoch stehen bei der Paraphnsierung einiger Erzählungen und läßt die Konzeption gänzlich unberücksichtigt. ${ }^{819}$

Mit Aspekten der Komposition der Temnye allei befaßte sich als erste Literaturwissenschftlerin im Westen Ljudmila Foster, die 1975 die verschiedenen Kategorien der Handlurysfuhrung in den Erzählungen analysierte (vgl. Kap. 5.3). In diesem Zusammenhang wèdet sie sich gegen die häufig geäußerte Kritik an der Betonung des sexuellen Elements in tem Buch, das keineswegs im Vordergrund stehe, da es in keinem Falle auf der Ebene deıHandlung zu finden sei, sondern stets auf der zweiten Ebene, der des Erzählten. ${ }^{820}$

816 A. de Yackovlev. „Bunin's Prose Writings in Exile“. [Masch.schr.] Diss. Urbana (Illinois), 1967. Auch zwei weitere US-amerikanische Dissertationen gehen aber de Yackovlevs Erkenntnisse nicht hinaus. Der Titel von Kent Sheridan Tiffanys Dissertation („Ivan Bunin: A Poet in Prose“. [Masch.schr.] Diss. Columbia University, 1988) laßt eine intensive Auseinandersetzung mit den Temmye allei erwarten, streift diese jedoch nur am Rande. Sang Ryong Lee widmet den Temmye allei in seiner Dissertation „An Analysis of Thematics, Poetics, and Aesthetics in Ivan Bunin's Prose Narratives" ([Masch.schr.] Diss. Urbana [IIlinois], 1993) ein eigenes Kapitel, bleibt aber bei allgemeinen Feststellungen wie Ähnlichkeiten in Thema und Gestaltung der Erzahlungen stehen - strukturelle Verbindungen laßt er ganzlich unberucksichtigt.

81 i Weitere vier deutschsprachige Dissertationen befassen sich mit Teilaspekten des Werkes (vgl. Kap. 1).

81\&B. Kirchner. "Die Lebensanschauung Ivan Alekseevic Bunins nach seinem Prosawerk“". Inaugural-Diss. Ludwigsburg, 1968: 120.

819S. Kryzytski. „Dark Alleys“. In: The Works of Ivan Bunin. The Hague/Paris, 1971: 204-214.

$82($ L. Foster. „O kompozicii Temmych allej Bunina“. op.cit.: 64. 
1980 erschien mit dem Titel Ivan Bunin. A Study of His Fiction eine weitere Monographie, die Leben und Werk Bunins nachzeichnet. James B. Woodward hat sich bereits in den Jahren zuvor intensiv mit verschiedenen Teilaspekten von Bunins künstlerischem Schaffen auseinandergesetzt und seine Ergebnisse in einigen Artikeln publiziert. In dem Kapitel „The Last Volume“"821 geht es ihm vornehmlich um Bunins Erzählverfahren, vor allem um die Gestaltung der Erzăhlschlüsse, den Einsatz des Kontrastes als Stilmittel sowie die Art und Weise des Spannungsaufbaus. Er begreift die Temnye allei als konsequente Fortsetzung von Bunins Suche nach Konzision, die mit den "Kratkie rasskazy“ ihren Anfang genommen habe. Er stellt aber keinen Zusammenhang her zwischen Komposition und Themen, so als seien die Erzăhlungen eine mehr oder weniger zufälige Zusammenstellung.

Julian Connolly, der sich in mehreren Aufsätzen und einer Monographie unter verschiedenen Aspekten mit Bunins Werk auseinandergesetzt hat, widmet den Temmye allei in seiner Studie Ivan Bunin (1982) ebenfalls ein eigenes Kapitel (,Dark Avenues. The Dimensions of Love، ${ }^{622}$ ), in dem er jedoch weniger der Gesamtstruktur des Buches Aufmerksamkeit schenkt, als vielmehr die thematischen Parallelen in den Vordergrund rückt (, The Power of Passion", "Love and the Passage of Time“) und auf Bunins Kunst des kompakten und konzisen Erzählens hinweist (,The Triumph of Concision“). Connolly wertet das von ihm ohne Definition als Zyklus bezeichnete Buch als Krönung der langen literarischen Tătigkeit Bunins: „On every level, Dark Avenues emerges as a triumphant culmination to an illustrious career. “823

In Bunins Wahlheimat Frankreich, in der 1987 die erste vollständige Übersetzung der Temnye allei publiziert wurde, rückte das Buch in den 1980er Jahren in das Blickfeld der slavistischen Literaturwissenschaft. Vor allem zwei Dissertationen lieferten entscheidende Impulse zur literaturwissenschaftlichen Auseinandersetzung mit den Temnye allei. Die erste monographische Studie legte Rosa Fedoulova 1980 mit ihrer Dissertation „Les Allées sombres d'Ivan Bunin" vor, in der sie sich zum Ziel setzt, anhand der Temnye allei den Stellenwert Bunins in der russischen Literatur zu verdeutlichen. ${ }^{824}$ Die Genrezugehörigkeit des Buches diskutiert sie zwar nicht, aber sie weist auf verbindende Elemente wie etwa die Protagonisten und das Liebesthema hin und wertet das Buch als Meisterwerk, dessen Vergessen den zeitlichen und sozialen Umständen geschuldet sei. Claire Hauchard geht in

821 In: J. Woodward. Ivan Bunin. A Study of His Fiction. Chapel Hill, 1980: 207-226.

822 In: J. Connolly. Ivan Bunin. op.cit.: 124-135.

823 J. Connolly. Ivan Bunin. op.cit.: 134.

824 R. Fedoulova. "Les Allées sombres d'Ivan Bunin“. op.cit.: 17. 
ihrer 1993 erschienenen Dissertation zum schriftstellerischen Schaffen Bunins in der Emigration $^{825}$ einen Schritt weiter als Fedoulova, indem sie die bewußte Anlage des Buches annimmt. Ausgangspunkt ihrer Überlegungen ist jedoch nicht die Frage nach der spezifischen Genrezugehörigkeit der Temnye allei, sondern die Frage nach der inneren Kontinuität und Kohärenz des gesamten Emigrationsschaffens in seinen verschiedenen Ausdrucksformen. Dessen einzige Konstante scheint ihr zufolge eine verwirrende Vielschichtigkeit zu sein wie sie sich ja auch in den Temnye allei zeigt: auf den ersten Blick eine Sammlung von Liebesgeschichten aus dem alten Rußland, enthült erst eine aufmerksame Lektüre die Komplexităt des Buches, das verschiedene Lesarten anbietet und sich somit der Eindeutigkeit entzieht.

1994 legt Jurij Mal'cev im Frankfurter Possev-Verlag die erste russischsprachige Bunin-Biographie ${ }^{826}$ vor, die das Spätwerk qualitativ gleichberechtigt neben das Frühwerk stellt und sich ohne Vorbehalt auch den unveröffentlichten Erzăhlungen nähert. Allerdings räumt er dem Emigrationsschaffen Bunins ungleich weniger Platz in der Analyse ein. In dem Kapitel „Sil'na kak smert'“ beschäftigt er sich mit zahlreichen Erzählungen aus den Temnye allei, zieht aber auch Parallelen zu den zeitgleich entstandenen Erzählungen unter dem Aspekt der verschiedenen phänomenologischen Ausprăgungen der Liebe. Auf die Konzeption des Buches geht Mal'cev zwar nicht ein, würdigt jedoch alle Erzählungen in ihrer Gesamtheit und begreift sie wie vor ihm schon Aldanov als Bunins Abschied vom Leben:

Все рассказы Бунина последнего периода озарены как бы неким закатным светом светом печали прощания с землей. От этого опьянение жизнью становится еще более зкстатичным, чем прежде. ${ }^{827}$

\subsection{Zusammenfassende Betrachtung}

Zusammenfassend läßt sich feststellen, daß seit Erscheinen des Buches ein unvoreingenommener Blick der Rezipienten auf die Temmye allei aus den unterschiedlichsten Gründen und Vorprägungen nicht möglich war. So wurde das Buch über Jahre hinweg nicht als Gesamtkunstwerk mit einer inneren Kohärenz wahrgenommen, sondem als eine

825 C. Hauchard. „La Prose de I. A. Bounine ...“. op.cit.

826 In italienischer Sprache erschien das Buch bereits sieben Jahre zuvor: Ju. Mal'cev. Ivan Bunin. La vira e l'opera: 1870-1953. Milano, 1987.

827 Ju. Mal'cev. Bunin. Frankfurt, 1994: 342. 
Sammlung von „writings full of a senile obsession with sex“ ${ }^{428}$, wie es 1953 der Literaturwissenschaftler Renato Poggioli formulierte.

Vor allem in den zeitgenössischen Reaktionen ist eine Voreingenommenheit der Leser bei der Beurteilung der Erzăhlungen zu spüren, die ihre Ursache in einem verletzten Moralempfinden und in einer konservativen Haltung auf literarischem Gebiet hatte. Bunin enttäuschte ganz offensichtlich die vom Lesepublikum der russischen Emigranten an ihn gestellte Erwartung, die ihnen vertraute Erzählweise der Klassiker des 19. Jahrhunderts fortzufuhren, die mit der Revolution abgerissen war. Eine Weiterentwicklung wurde Bunin nicht zugestanden, die Rezipienten erwarteten offenbar angesichts der Umwälzungen in ihrem Leben zumindest vom literarischen Bereich Kontinuität. Daher sind ihre kritischen Feststellungen im wesentlichen auf die Unterschiede zu dieser Folie zurückzufüren. Lobende Feststellungen der intensiven Naturbeschreibungen oder der Fähigkeit Bunins, die untergegangene Heimat aus und in der Erinnerung wiederauferstehen zu lassen, gehen unter in der Vielzahl kritischer Stimmen, die sich vor allem auf den vermeintlichen Überfluß an erotischen Darstellungen und die mangelnde Nachvollziehbarkeit der Psychologie der Figuren stützen. Zu Bunins Lebzeiten waren derart eingeschränkte Interpretationen an der Tagesordnung und der Beginn einer eindrucksvollen Dokumentation des Einflusses, den der jeweilige Zeitgeist bis heute auf die Rezeption der Temnye allei hat: Während etwa die Resonanz auf die deutsche Übersetzung von 1959 ebenfalls häufig die mangelnde psychologische Nachvollziehbarkeit der Handlungen der Figuren beanstandet, findet sich kein derartiger Hinweis in den Resonanzen auf die deutschsprachige Edition aus dem Jahr 2000, denn hier steht die Schreibkunst Bunins im Vordergrund-ein weiterer Beleg für die Aktualităt bzw. Zeitlosigkeit des Buches.

In den Vor-bzw. Nachworten von Ausgaben der Temnye allei in der Sowjetunion bzw. Rußland, Frankreich, England und Deutschland läßt sich eine vergleichbare Entwicklung feststellen: Dem Liebesthema sowie der für die russische Literatur ungewöhnlich erotischen Darstellung der Frau wird besondere Beachtung geschenkt - in der Sowjetunion zunăchst als realitätsfern und pomographisch kritisient, setże sich seit den 1980er Jahren eine würdigende Sicht der Darstellungskunst Bunins durch. Auch die westeuropäischen Kommentare heben die Betonung des weiblichen Körpers hervor, bewerten diese jedoch nicht negativ, sondern sehen in ihr einen Beweis für Bunins Modernität und seine Fähigkeit zu lebendigem Schreiben.

828 R. Poggioli. „The Ant of Ivan Bunin“. In: Hanvard Slavic Studies I (1953): 251. 
Bei einer Betrachtung der literaturwissenschaftlichen Auseinandersetzung mit den Temnye allei muß berücksichtigt werden, daß den meisten Analysen nur unvollstăndige Editionen zugrunde lagen. Ein Zusammenhang zwischen dem steigenden Interesse an kompositionellen Fragestellungen seit den 1980er Jahren und der zunehmenden Publikation integraler Ausgaben kann zwar nicht belegt, aber auch nicht ausgeschlossen werden. Bis in die 1980er Jahre hinein lassen sich in der Sowjetunion vornehmlich Untersuchungen zu Teilaspekten wie stilistischen Besonderheiten oder der Rolle der Naturbeschreibungen beobachten, die in Monographien zu Bunins Leben und Werk von allgemeinen Feststellungen zu den dominierenden Themen Liebe und Tod flankiert werden. Fragen nach der Konzeption des Buches wurden erst vor etwa 15 Jahren zu einem Gegenstand literaturwissenschaftichen Interesses, konzentrieren sich dabei jedoch entweder auf thematische Teilbereiche oder bleiben unvollständig; in keinem Fall erörtern sie die Genrezugehörigkeit des Buches. In Westeuropa bzw. den USA setzte die literaturwissenschaftliche Auseinandersetzung mit den Temnye allei bedeutend früher ein, doch blieb auch hier die Feststellung von verbindenden Gemeinsamkeiten auf die thematische Ebene beschränkt, bevor Anfang der 1990er Jahre die französische Slavistik auf die mutmaßlich bewußte Anlage des Buches aufmerksam machte. Die zeitliche Distanz zur Erstveröffentlichung ebenso wie die gewandelten Moralvorstellungen und nicht zuletzt der Zugriff auf die Originaltexte ermöglichen heute eine umfassendere Perzeption als in den vergangenen Jahrzehnten und dürten dazu beitragen, die Temnye allei nicht in Vergessenheit geraten zu lassen. 



\section{SCHLUSSBETRACHTUNG}

Bunins persönliche Meinung zu den Temnye allei, seinem letzten zu Lebzeiten veröffentlichten Buch, das er als seine gelungenste Arbeit betrachtete ${ }^{829}$, resultiert sicher nicht zuletzt aus seiner Befriedigung über die geglückte Fusion von Inhalt und Form gemäß seiner Überzeugung: „Ведь у писателя форма неразрывно связана с содержанием и рождается сама собой из содержания. “830 Wie die vorangegangene Analyse belegt, konnte er diese Auffassung im Falle der Temnye allei erfolgreich umsetzen, wenngleich das Buch aus unterschiedlichen Gründen in den seltensten Fällen unter diesem Aspekt rezipiert wurde. Einer der Griunde besteht in der Tatsache, daß es sich einer offenkundigen eindeutigen Genrebestimmung entzieht - wie auch Bunin selbst literarhistorisch schwer einzuordnen ist und sich zeit seines Lebens bewußt abseits jeder literarischen Strömung hielt: „[...] я не принадлежал ни к одной литературной школе, не называл себя ни декадентом, ни символистом, ни романтиком, ни реалистом [...]. “831 Ähnlich vielfaltig wie die Einflüsse, die sich in Bunins literarischem Schaffen konstatieren lassen (Tolstoj, Turgenev, Gogol', Cechov, Impressionismus), sind auch die Temmye allei mit ihren unterschiedlichen Formen von Erzählungen gestaltet - der offene und flexible Charakter einer Kurzprosaverknüpfung entspricht Bunins literarischem Nonkonformismus.

Bunins Vergleich des Buches mit dem Decamerone („Бокачио написал ,Декам[ерон] во время чумы, а я вот ,Темные Аллеи “.832) verweist darauf, daß er sein Buch in der Tradition der großen zyklischen Rahmenerzählung Boccaccios sieht, die sich im Laufe der Jahrhunderte zu einem eigenständigen Genre in den verschiedenartigsten Erscheinungsformen entwickelt hat. In der slavistischen Literaturwissenschaft indes hat das Genre eng miteinander verknüpfter rahmenloser narrativer Kurzprosatexte bislang relativ wenig Beachtung gefunden. Die wichtigsten gattungstheoretischen Impulse stammen aus den USA, der Heimat der Short Story; die Ergebnisse der diesbezüglichen Forschung lassen sich jedoch ohne weiteres auch auf anderssprachige Literaturen übertragen (vgl. Kap. 2). Ausgehend von diesen Überlegungen wurde eingangs der vorliegenden Dissertation die These entwickelt, daß die Temnye allei über alle Merkmale einer Kurzprosaverknüpfung

$829 \mathrm{Vgl}$. u.a. den bereits in Kap. 10 zitierten Brief an Telešov vom 01.04.1947: .....] думаю, что это самое лучшее и самое оригинальное, что я написал в жизни [...]“" (zit. in: „Perepiska s N. D. Teleక̌ovym“. op.cit.: 634 .

830 I. Bunin. „Kak ja pisu“. op.cit.: 374.

831 I. Bunin. "Iz predislovija k francuskomu izdaniju ,Gospodina iz San-Francisko“". In: ders. SS v devjati Iomach. 9.Bd. op.cit.: 268.

832 Brief an Zajcev vom 11.11.1943. Zit. in: „Pis'ma I. Bunina k B. Zajcevu“. In: N 137 (1979): 125. 
verfügen und innerhalb dieses Genres dem Clustertypus mit seiner vergleichsweise offenen Struktur zuzuordnen sind, da die sie konstituierenden Erzählungen weder rein chronologisch angeordnet sind noch auf den ersten Blick offensichtliche Verbindungen wie etwa gemeinsame Protagonisten aufweisen und einige Erzăhlungen sich auf den ersten Blick einer Integration ins Gesamtgefüge zu entziehen scheinen. Der Zusammenhalt des Buches wird im allgemeinen von den Rezipienten über die Themen Liebe und Tod wahrgenommen, weitere Ähnlichkeiten werden mit dem autortypischen Schreibstil begründet, die Anlage des Buches sowie die intratextlichen Verbindungen werden in der Regel außer acht gelassen, so daß zunächst alle Anzeichen für das Vorliegen eines Sammelbandes zu sprechen scheinen. Tatsächlich tragen jedoch zahlreiche Verknüpfungen auf struktureller und stilistischer Ebene zur Kohärenzbildung bei, und nicht zuletzt enthüllt eine aufmerksame Lektüre als weiteres verbindendes Thema die Erinnerung, die auch bei der strukturellen Gestaltung der Erzählungen eine wichtige Rolle spielt. Zum umfassenden Verständnis der Temnye allei müssen zudem extratextliche Faktoren wie die Entstehungs-, Editions- und Rezeptionsgeschichte in die Analyse einbezogen werden.

In den turbulenten Jahren des Entstehungsprozesses der 76 späten Erzählungen (vgl. Kap. 3) findet sich kein Hinweis darauf, daß Bunin einer von vornherein feststehenden globalen Konzeption folgte, zumal die Erzählungen im wesentlichen in drei unterschiedlich langen arbeitsintensiven Phasen entstanden (Herbst 1938, Herbst 1940 sowie Herbst 1943/Frühjahr 1944) und Bunin das Buch im Frühjahr 1942 zunächst abgeschlossen wähnte, bevor er weitere Erzählungen verfaßte, von denen er nur einen Teil in die Temnye allei integrierte. Von Anfang an jedoch intendierte Bunin einen Integralabdruck, obwohl er auf Grund der finanziellen und politischen Verhältnisse eine Reihe von Erzählungen separat publizierte, bevor 1946 in Paris eine von ihm imprimierte Fassung des Buches erschien.

Welchen Leitlinien also folgte Bunin bei der Auswahl und Zusammenstellung der Erzählungen, die letztlich das Korpus der Temnye allei bildeten? Der Formierungsprozeß des Buches ist zwar relativ gut dokumentiert, liefert jedoch nur vage Anhaltspunkte zu den Auswahlkriterien. Während offenbar vor allem das vorliegende Material die Zusammensetzung der beiden ersten Komplexe diktierte, wurden bei der Zusammenstellung des dritten Komplexes andere Motive wirksam. Erst die vergleichende Analyse vor allem der im besonders produktiven Jahr 1944 entstandenen 31 Erzählungen fördert aufschlußreiche Unterschiede zutage: In einem Großteil der 18 nicht für die Temnye allei ausgewählten Erzählungen zeigt sich in ihrer Kürze und mit ihren Unmittelbarkeit suggerierenden 
Momentaufnahmen eine Rückkehr zu den Gestaltungsprinzipien der Anfang der 1930er Jahre verfaßten „Kratkie rasskazy“. In ihrer Betonung des Augenblicks stehen sie den Erzählungen der Temnye allei zwar nahe, thematisieren im Unterschied zu jenen jedoch nicht die Bedeutung, die ein solcher Augenblick auf das Leben eines Menschen haben kann - wenn auch erst im wissenden Rückblick. Im Vergleich zu den Erzählungen der Temmye allei lassen sich zudem weitere Diskrepanzen konstatieren: Eine Reihe der nicht in das Buch integrierten (und teilweise bis heute unveröffentlichten) Erzăhlungen unterscheidet sich von diesen vor allem in ihrer Betonung der physischen Liebe und der Häßlichkeit des Alltags sowie durch den zunehmenden Verzicht auf russische Schauplätze bzw. die Darstellung des Eingebundenseins des Menschen in die Natur.

Nachdem solcherart die Auswahlkriterien Bunins deutlich geworden sind, belegt eine Analyse der extra- und intratextlichen Verknüpfungen der Erzählungen die bewußte Zusammenstellung des Buches unter Wahrung eines offenen Charakters.

\section{Extratextliche Verknüpfungen - der außere Aufbau der Temmye allei}

Das Inhaltsverzeichnis der Temnye allei zeigt drei Komplexe unterschiedlichen Umfangs (6, 14 und 18 Erzählungen); einen ersten Anhaltspunkt zur ordnenden Richtlinie ergibt die Zuordnung der Entstehungsdaten (vgl. Kap. 4). Zunächst suggerieren sie eine Zusammenstellung unter chronologischen Aspekten, entsprechend den oben genannten drei intensiven Schreibphasen. Es fällt jedoch auf, daß Bunin die Chronologie teilweise durchbrochen hat. Dies betrifft vor allem die Positionierung der Eröffnungserzählungen, während die Finalerzählungen gemäß ihren Entstehungsdaten plaziert wurden. Unübersehbare inhaltliche und strukturelle Parallelen zwischen diesen Erzählungen tragen erheblich zu einer Verschränkung der drei Komplexe sowie zur inneren Festigung der Kurzprosaverknüpfung bei. Die Beweggründe für diese Modifikationen und weitere Umstellungen innerhalb der einzelnen Komplexe erschließen sich durch eine gewichtende Klassifizierung der Erzählungen in $19^{833}$ Kernerzählungen einerseits und 19 Satelliten- bzw. Randerzăh-

833 Die Zahl 19 spielt eine tragende Rolle in den 38 Erzahlungen (19 plus 19) der Temnye allei und legt eine Verschlusselung der Jahreszahl 1919 nahe: Die Eroffnungserzahlung .Temnye allei“ entstand 1938 und damit 19 Jahre nach Bunins Entschluß, RuBland zu verlassen; aufgegriffen wird diese Zeitspanne in der Erzăhlung „Pozdnij cas“, die ebenfalls 1938 entstand und als einzige der Erzahlungen des ersten Komplexes die Emigration thematisiert. Die 19. Erzahlung des Buches, „Genrich", nimmt ihren Ausgang in RuBland und findet ihr Ende in Frankreich. Auch im strukturellen Bereich lassen sich Komponenten dieser Verschlusselung ausmachen: die Verwendung je zweier Varianten von Erzahlanfangen und Erzahlschlassen der 38 Erzahlungen (19 plus 19; vgl. Kap. 5) sowie die erwăhnte Klassifizierung der Erzahlungen in $19 \mathrm{Kem}$ - und 19 Satelliten- bzw. Randerzahlungen. Zudem weisen 19 Erzahlungen eingetugte Fremdtexte auf und enthalten 19 Erzahlungen eindeutige Hinweise auf den Koitus. 
lungen andererseits. Während die Kernerzählungen die zentralen Elemente der semantischen Aussage des Buches enthalten und/oder an strategisch bedeutsamen Stellen positioniert wurden, sensibilisieren die Satelliten- und Randerzählungen den Rezipienten für den offenen Charakter der Temnye allei und lassen die Aussagen der Kernerzählungen um so profilierter hervortreten. Diese Erzählungstypen sind proportional auf die drei Komplexe verteilt; dadurch wird sichergestellt, dass die Komplexe trotz ihrer unterschiedlichen Umfänge ausgewogen erscheinen. Eine Analyse der Verteilung hat die Ermittlung verschiedener Eckpfeiler und damit einer stabilen Struktur der Kurzprosaverknüpfung zum Ergebnis: zum ersten drei Binnenrahmen, die die einzelnen Komplexe umschließen, zum zweiten einen alle Erzählungen umfassenden Außenrahmen und zum dritten ein dichtes und strahlkräftiges Zentrum von Kernerzählungen mit einer dominanten sogenannten Ankererzählung. Das Grundprinzip dieser Anordnung veränderte sich trotz der Modifikationen im Laufe des Formierungsprozesses nicht.

Die Funktion des Titels als Motto für alle das Buch konstituierenden Erzählungen ist ein weiteres Indiz für das Vorliegen einer Kurzprosaverknüpfung im Gegensatz zu einem bloßen Sammelband mit Erzählungen. Die Mehrschichtigkeit der ersten Erzählung, die bezeichnenderweise als eine der wenigen Erzählungen nicht einzeln veröffentlicht wurde. sowie die poetische Dimension, die ihr durch das Einbeziehen eines Gedichts verliehen wird, bilden den Grundton, der sich mit seinen zahlreichen Konnotationen durch alle Erzählungen des Buches zieht. Diese extratextlichen Verknüpfungen setzen sich im intratextlichen Bereich mit strukturellen, stilistischen und thematischen Parallelen (vgl. Kap. 5 , 6.7 und 8) zwischen den einzelnen Erzählungen fort.

\section{Intratextliche Verknüpfungen auf struktureller bzw. stilistischer Ebene}

Die Temnye allei zeichnen sich durch zahlreiche Verfahren mit strukturbildender Funktion aus (vgl. Kap. 5): Bereits die prägnanten Titel der Erzählungen, die bei der isolierten Betrachtung einer Erzählung neutral wirken, zeigen in der Gesamtschau aufschlußreiche Gemeinsamkeiten, indem sie die Bedeutung der Frau und der Schauplätze widerspiegeln. Ähnlich richtungweisende Bedeutung haben die Anfangssätze der Erzählungen: Analog zur Anzahl der klassifizierten Erzählungstypen lassen sich je 19 epische und dramatische Anfänge konstatieren. Beide Typen übermitteln gleich zu Beginn Informationen zu Zeit und Ort des Geschehens sowie zu den zentralen Handlungsträgern; die Bedeutung der Zeit wird auch dadurch betont, daß bei der Mehrheit der Erzählungen die Angabe der Zeit vor der des Ortes erfolgt, und kommt noch deutlicher zum Ausdruck in der Gestaltung 
der Handlungsführung unter dem Aspekt des Verhältnisses der dargestellten zeitlichen Ebenen zueinander: Bunin stellt erzăhlerische Gegenwart und erzăhlte Vergangenheit einander kontrastiv gegenüber und macht damit den thematischen Teilbereich der Erinnerung auch über die Struktur sichtbar. Mit Ausnahme der als Momentaufnahmen zu charakterisierenden Skizzen wird dieses Verhăltnis in den vier weiteren Kompositionstypen auf unterschiedliche Weise gestaltet, so daß trotz der Fokussierung auf die Erinnerung in der Umsetzung keine Monotonie aufkommt, sondern vielmehr für weitere Tiefe gesorgt wird. Ein Großteil der Erzählungen ist durch abrupte, in der Regel unerwartete und willkürliche Erzählschlüsse gekennzeichnet, die sich entweder auf Schicksalsschläge oder menschliche Charakterschwăche zurückführen lassen. Ihre unwidermufliche Natur läßt sie geschlossen wirken; die unvorhersehbare Verwendung einer dieser beiden Varianten symbolisiert die blinde und unkalkulierbare Macht des Schicksals, auf die sich der Mensch ebensowenig einstellen kann wie der Leser auf eine bestimmte Art der Schlußgestaltung. Gleichzeitig fordern die abrupten Erzăhlschlüsse zu einem sinnsuchenden Rückblick auf und unterstreichen die Bedeutung der Erinnerung als nicht nur rein thematischen Teilaspekt, sondern auch als höchst bedeutsames strukturbildendes Element.

Eine weitere wichtige strukturbildende Funktion kommt der Schauplatzgestaltung zu. Hier läßt sich beobachten, daß der Fülle von Schauplătzen einheitliche Gestaltungsprinzipien bei gleichbleibender Intention zugrunde liegen, eine Vorgehensweise, die sich auch bei der Gestaltung der zentralen Figuren beobachten läßt. Die Verwendung überwiegend vorrevolutionärer russischer Schauplătze legt die Schlußfolgerung nahe, daß Bunin sich ein imaginăres persönliches Rückzugsgebiet in der Erinnerung geschaffen hat, denn zur Umsetzung der universalen Themen Liebe und Tod wären russische Schauplätze nicht zwingend notwendig gewesen - dieses Vorgehen setzt mit der Erinnerung an die verlorene Heimat eine Facette des thematischen Teilaspekts der Erinnerung unaufdringlich, aber eindrucksvoll um. Bei der Wahl der Schauplătze überwiegen Naturschilderungen, die sich durch Polyfunktionalităt auszeichnen: Sie spiegeln oder opponieren den Seelenzustand des Protagonisten, verbinden unterschiedliche zeitliche Ebenen oder nehmen die Entwicklung eines Sujets vorweg bzw. bereiten es vor. Selbst die Innenräume stehen in einem beständigen Wechselspiel mit dem sie umgebenden endlosen Raum und verdeutlichen auf diese Weise das Eingebundensein des Menschen in eine größere Einheit.

Wie sich bereits in der Gegenüberstellung lăndlicher und stădtischer Schauplătze zeigt, bedient sich Bunin zur Profilierıng seiner Aussagen bevorzugt des Kontrastes als Gestaltungstechnik. Beispielhaft wurde dies anhand der Verfahren der prophetischen bzw. 
irreführenden Zukunftsvorausdeutungen und des kontrastierenden Erzăhltempos illustriert, die zum einen das Ausgeliefertsein des Menschen an Mächte außerhalb seines Einflußbereiches verdeutlichen, zum anderen für Spannung sorgen - und in keinem Fall Monotonie aufkommen lassen.

Letzterer wirkt auch die sinnliche Ausgestaltung der Erzählungen entgegen (vgl. Kap. 6) - Bunins Liebe zum Detail geht einher mit seiner Fähigkeit, komplexe und plastische Bilder zu schaffen. Detailfreude zeichnet auch seinen ausgesprochen bewußten und sensiblen Umgang mit der russischen Sprache aus, bei dem Bunin aus einem großen Wortschatz schöpft. Seine bevorzugt eingesetzten sprachlichen Mittel wie Anaphern, Epiphorä, Alliterationen sowie die Wiederholung einzelner Laute und Wörter werden üblicherweise in der Lyrik verwendet, von Bunin aber in die Prosa transferiert und tragen erheblich zur Musikalität und Emotionalität der Erzählungen bei. Häufig setzt er dabei auch das Verfahren des Einfügens von Fremdtexten in die Erzählungen ein, wie beispielsweise von Auszügen aus Volksliedern bzw. Gedichten oder Zitaten aus Werken anderer Schriftsteller. Über ihre unterschiedlichen Funktionen in den einzelnen Erzählungen hinaus haben sie vor allem strukturbildende Funktion, dienen der zeitlichen Lokalisierung, sorgen für inhaltliche Tiefe sowie Lokalkolorit und stellen intertextuelle Bezüge nicht nur zur russischen Vergangenheit her.

In Bunins sinnlicher Schreibweise dominiert das Visuelle; er bedient sich einer schier unerschöpflich erscheinenden Farbpalette. Vor dem Hintergrund tragischer Ereignisse entfaltet Bunin eine leuchtende Farbenpracht, die zunächst überrascht, aber dann zeigt, daß auch im Schatten des Todes das Leben intensiv empfunden werden kann. Und auch hiermit unterstreicht er die Bedeutung der Erinnerung, denn so lange man sich noch erinnern kann. muß die Vergangenheit nicht verblassen. sondern kann lebendig bleiben. Die Farbenpracht findet ihre Entsprechung in Bunins Faszination von Lichtphänomenen jeder Art, die eine Vorliebe für überraschend aufblitzende Lichtquellen offenbaren, in Umsetzung seiner Konzeption von der Liebe als einem rasch aufflammenden (und ebenso schnell verlöschenden) Gefühl. Analog dazu läßt sich der Einsatz des Glanzes als Speicher des Lichts und der bleibenden Strahlkraft der Erinnerung interpretieren.

Bunt ist auch das Panorama fiktiver Personen, die sich in den Temnye allei in einem weiten Spektrum von Liebesbeziehungen zusammenfinden (vgl. Kap. 7). Diese oberflächliche Vielfalt ist wie bei den Schauplätzen trügerischer Natur, denn die Protagonisten sind über ihre russische Nationalzugehörigkeit hinaus durch vielerlei Gemeinsamkeiten miteinander verbunden, nicht zuletzt durch die Tatsache, daß sie ausschließlich von außen 
geschildert werden, während ihre psychischen Beweggründe und Handlungsmotive keine Rolle spielen - dieses Verfahren trägt dazu bei, daß Einzelschicksale universellen Charakter erhalten. In der Darstellungsweise fallt ein gravierender Unterschied zwischen den männlichen und den weiblichen Figuren auf: Wăhrend die Männer farblos, unprofiliert und austauschbar wirken, beeindruckt die individuelle Gestaltung der weiblichen Figuren, denen Bunin mit dem Blick eines Malers mit wenigen Strichen bzw. uber wenige Details Einzigartigkeit verleiht und damit einer drohenden Schematisierung entgegenwirkt. Diese Vorgehensweise läßt sich nur zum Teil damit begründen, daß die Erzähler mit einer Ausnahme männlichen Geschlechts sind und die Frau als Objekt (ihrer Begierde) wahmehmen und beschreiben. Vielmehr scheint es Bunin um eine Analyse der Spezies Frau mit ihren verschiedenen Phänotypen zu gehen: Einerseits möchte er den Körper in seiner Individualität erfassen, andererseits die Ursprungsform abbilden. In dieser Hinsicht erweisen sich die Temnye allei als Experimentierfeld Bunins, der auf einer persönlich motivierten künstlerischen Suche ist nach einer adäquaten Beschreibungsweise des weiblichen Körpers auch und gerade in seiner Nacktheit sowie zu ergrulnden sucht, worin die weibliche Anziehungskraft besteht.

Das Eingebundensein des Menschen in die Natur, das bereits in der Schauplatzgestaltung zu erkennen war, setzt sich fort in der Darstellungsweise der Protagonisten. In die Nähe der Natur werden vor allem die Frauen gerückt, unter anderem mit Vergleichskonstraktionen aus der Tier- und Pflanzenwelt. Doch findet auch das körperliche Beisammensein eines Liebespaars auffallend hăufig in der Natur statt. Weitere Zeichen der Sinnlichket sind unter anderem schöne Stoffe, Pelze und der Genuß von Nahrungsmitteln und alkoholischen Getränken.

Die Fokussierung auf die Darstellung heterosexueller Liebesbeziehungen bringt es mit sich, caß pro Erzählung zwei bis drei zentrale Figuren vertreten sind, die die Handlung voranteiben. Charakteristisch für die Temnye allei sind die sich in der Gegenüberstellung Mann - Frau ăußernde Bipolarităt wie auch das stets wiederholte Grundmuster der Liebesbegegaungen bei Verzicht auf die Erlăuterung der psychischen Beweggründe und bei weitgehender Anonymităt der Figuren. Dieses Verfahren läßt darauf schließen, daß es Bunin nicht um die Nachzeichnung emotionaler Prozesse ging, sondern er seine Figuren vielmehr als überindividuelle Schicksalsträger einsetzte, die seine Überlegungen zu den universalen Themen Liebe, Tod und Erinnerung einkleiden. 


\section{Intratextliche Verknüpfungen auf thematischer Ebene}

Im thematischen Bereich sind die Temnye allei vielschichtiger, als der erste Eindruck eines durch die Dominanz des Liebesthemas monothematisch wirkenden Buches dies vermuten ließe (vgl. Kap. 8). Inhaltlich sind die Erzählungen der Temmye allei durch die zentralen Themenbereiche Liebe, Tod und Erinnerung miteinander verbunden; diese facettenreichen Stoffkreise lassen sich adäquat nur anhand einer Vielzahl von Beispielen darstellen. Die einzelne Erzahlung ist zwar durchaus autonom rezipierbar, doch erst das Buch als Ganzes gibt bei sukzessiver Lektüre nach und nach den Blick auf Bunins weltanschauliche Überlegungen frei. Den Gegenkräften und Gegenspielern Liebe und Tod, die über das gemeinsame Charakteristikum der Momenthaftigkeit verfügen, stellt Bunin als Bindeglied die Erinnerung an die Seite, die als bewahrende Kraft und Brücke ins Jenseits in Erscheinung tritt. Durch die Einbettung der universellen und zeitlosen Themen Liebe und Tod, deren Darstellung keinen bestimmten Schauplatz erfordert, in ein russisches, vorrevolutionăres Umfeld, erschließt sich eine weitere Ebene des Buches erst mit zunehmender Kenntnis der Erzählungen. Mit den Temnye allei schuf Bunin ein Vexierbild, das seinen weiteren inhaltlichen Schwerpunkt erst nach und nach preisgibt: Die Erinnerungsberichte der fiktiven Figuren entpuppen sich als vorgelagerte Ebene - dahinter verbirgt sich die Liebe Bunins zu Rußland und seine Trauer über den Verlust der Heimat, der ähnlich unvermittelt erfolgte wie die Schicksalsschläge in seinen Erzählungen. Dennoch wirken die Temnye allei keineswegs vergangenheitsorientiert, da sie zeitlose Themen zum Inhalt haben.

Die in den Erzählungen der Temnye allei dargebotene Liebeskonzeption besteht aus verschiedenen Elementen, deren augenfälligstes ihre kurze Dauer ist: Die Liebe bricht vollkommen unvermittelt über die Menschen herein, es gibt keine langsame Annäherung, sie werden getroffen wie von einem Blitzschlag. Ebenso unvermittelt ist dieses Erlebnis wieder vorbei, hinterläßt jedoch trotz seiner Kürze unauslöschbare Spuren in den Beteiligten, deren sie erst im Rückblick gewahr werden, und unterstreicht damit die Bedeutung der Erinnerung. Integraler Bestandteil dieses Liebeserlebnisses ist die Erotik, deren Betonung vielfach (vor allem von seinen Zeitgenossen) als Neigung Bunins zu pornographischen Darstellungen mißverstanden wurde. Wie zahlreiche Kürzungen entsprechender Passagen in den Manu- und Typoskripten belegen, war Bunin zumindest nicht primär an einem Verfassen erotischer Texte interessiert. Vielmehr ging es ihm vor allem darum, einen wichtigen Bereich des zwischenmenschlichen Zusammenlebens auch in der Literatur abzubilden und zu verdeutlichen, daß hinter dem Verlangen nach Stillung der körperlichen Begierde 
auch eine tiefe Sehnsucht nach einer Verschmelzung nicht nur mit einem anderen Menschen, sondern auch mit dem Universum verborgen ist. Bei einem sexuellen Liebeserlebnis in beiderseitigem Einvernehmen kann es dem Menschen (bzw. dem Mann, denn Bunin schildert das Erleben einzig aus männlicher Sicht) gelingen, die Grenzen seiner Individualităt zu überschreiten und ihm über die Physis Zugang zu seiner Psyche gewăhren bzw. ihm zu einer metaphysischen Erfahrung verhelfen. ${ }^{834}$

Symbolisiert wird dieses den ganzen Menschen erfassende Erlebnis durch den engen Bezug, den Bunin zwischen dem jeweiligen Protagonisten und den ihn umgebenden Kosmos mit seinen Gestimen herstellt. Nach einem ekstatischen Liebesaugenblick zieht es die Menschen häufig in die Natur-sie ist ihm gleichermaßen Brücke in die Vergangenheit und Symbol für die Zeitlosigkeit, die Aufhebung von Begrenzungen, das Eingebundensein in die Mysterien des Lebens, in den Kreislauf der Schöpfung - ein Haltepunkt wăhrend der spirituellen Reise des Lebens. Bunin begreift das Leben als eine Reise und weist dem Reisen im Leben eines Menschen besondere Bedeutung zu, denn fern von seinem Alltag ist der Mensch eher fähig und bereit, sich neuen Erfahrungen zu öffnen. Davon abgesehen kann Bunin sich durch die Darstellung reisender Menschen ganz auf diesen besonderen Lebensausschnitt konzentrieren und zudem Menschen zusammenbringen, die sich im Alltag niemals begegnet wären oder nicht offen füreinander gewesen wären.

Der Tod bezeichnet zwar auch in den Temnye allei einen endgültigen und irreversiblen Schlußpunkt, erscheint dennoch nicht ausschließlich negativ. Er triff den Menschen ebenso unverhofft wie die Liebe, der Mensch ist dem Schicksal hilflos ausgeliefert. Durch sein ständiges Wiederauftreten wird er bald zu einem vertrauten Begleiter der Lektüre und vermittelt damit die Botschaft, daß es sinnlos ist, sich gegen sein Schicksal aufzulehnen. Um dem Tod seinen Schrecken zu nehmen, bleibt nur, sich in das Los zu fugen und der drohenden Gefahr stets gewärtig zu sein, mit der Konsequenz, das Leben intensiver zu genießen. Auch kann der Tod Befreiung und Erlossung von drückender Erdenlast sein. Und letztlich ist nicht alles verloren, was tot ist, da mit Hilfe der Erinnerung Reisen in die Vergangenheit unternommen werden können, die auf diese Weise als Bindeglied zwischen Liebe und Tod (wie auch zwischen Thema und Struktur) zutage tritt. Die Erinnerung erweist sich aber auch als zweischneidiges Schwert: Sie kann trösten, weil sie unwiederbringlich verloren Geglaubtes bewahrt, und sie kann schmerzen, weil sie das Ausmaß des

834 Dese Transzendierung gelingt dem mănnlichen Protagonisten nur bei einem Koitus im Einverstandnis mt der begehrten Frau, nicht jedoch bei einer Vergewaltigung (von Bunin im abrigen wertfrei dargestellt), die nach Vollzug nicht reflektiert wird. 
Verlorenen deutlich macht. Gleichzeitig ermöglicht sie eine nachträgliche Wertschätzung vergangenen Erlebens als oftmals einzig wertvollem und hilft dadurch bei der Suche nach einem Sinn des Erlebten; zudem kann die Gegenwart nur als sinnvoll erfahren werden. wenn ihr durch Reflexion der Vergangenheit Bedeutung und Tiefe verliehen wird.

Die bedeutendste Funktion der Erinnerung besteht jedoch in ihrer bewahrenden Kraft, die dem Menschen eine Verteidigungsmöglichkeit gegen den Tod in die Hand gibt - und in ebendieser Funktion enthüllt sich die zweite Ebene des Buches: Die Temnye allei bilden einen sehr persönlichen, wenn auch teilweise transformierten Fundus von Erinnerungen Bunins an seine verlorene Heimat. In den Erzählungen erweckt er das alte Rußland wieder zum Leben und macht es zumindest auf dem Papier unsterblich. Verbürgte historische Ereignisse und Daten verbindet Bunin mit persönlichen Erinnerungen an typisch russische, scheinbar nebensächliche kulturgeschichtliche Details wie etwa Rasierwasser oder religiöse Attribute wie Ikonen und der Erwähnung authentischer Persönlichkeiten und Orte. Dadurch werden trotz der subjektiven Auswahl die Temnye allei zu einem kulturgeschichtlichen Auffangbecken für die kollektiven Erinnerungen einer bestimmten Schicht von Emigranten. Im verklärenden Rückblick verdichten sich die Erzählungen in einer Mischung aus persönlichen Erinnerungen und kulturhistorischem Gedächtnis zu einem Requiem für eine untergegangene Welt, der Bunin auch in der Emigration treu blieb[любовь], что остается где-то в сердие на всю жизнь („Vizitnye kartoðki“, 6: 241).

\section{Editions- und Rezeptionsgeschichte}

$\mathrm{Da}$ Bunins Intentionen häufig mißverstanden wurden, dokumentieren die Editions- und Rezeptionsgeschichte (vgl. Kap. 9 und 10). Die Editionsgeschichte der Temnye allei als Teil der Rezeption gibt beredten Aufschluß über das Zusammenspiel von politischen Randbedingungen, moralischem Zeitgeist und finanziellen Schwierigkeiten, die zu Lebzeiten Bunins zu verschiedenen Einzelveröffentlichungen teilweise gekürzter Erzählungen und einer von ihm nicht imprimierten rudimentären Edition der Temnye allei (New York, 1943) fuhrten (vgl. Kap.9). 1946 wurde das Buch in einer von Bunin imprimierten Fassung in Paris veröffentlicht - jedoch in einer gemessen an den potentiellen Auflagenhöhen in seiner verlorenen Heimat geringen Auflage -, die rasch in Vergessenheit geriet.

Nach Bunins Tod führten politische Erwägungen (Sowjetunion) einerseits sowie verlegerische Nachlässigkeit (Westeuropa, USA, Rußland) andererseits zu gekürzten Fassungen, die eine Wahrnehmung der Kohärenz des Buches verhinderten. In der Sowjetunion wurde erstmals 1956 eine rudimentäre Fassung der Temnye allei publiziert: die erste Inte- 
gralfassung erschien erst 1988. In den dazwischenliegenden Jahren wurden zahlreiche kürzere und lăngere Versionen des Buches veröffentlicht, und selbst nach Erscheinen der ersten Integralausgabe finden sich in den russischsprachigen Ausgaben bis heute die zensorischen Spuren der Vergangenheit. Die fremdsprachigen Übersetzungen des Buches zeichnen sich vor allem durch mangelhafte Recherche bezuglich des Originals sowie eine Scheu vor kostspieligen Neuübersetzungen aus. Auf diese Weise wurde eine Rezeption des Buches als kohărentes Ganzes stark beeintrăchtigt, wenn nicht verhindert (vgl. Kap. 10).

Beeinflußt wurde die Editionspraxis zudem durch negative Reaktionen auf den Inhalt einiger Erzăhlungen. Bereits vor ihrer Publikation sorgte der stellenweise als anstößig, moralisch zweifelhaft oder gar pomographisch empfundene Inhalt einiger Erzählungen fur Mißfallen bei den ersten Lesern - Freunden und Bekannten Bunins - und beeinflußte die Konzeption des Buches in nicht zu unterschätzendem Maße. Bunins für die russische Literatur jener Jahre freimütiger Umgang mit erotischen Darstellungen und seine als respektlos und verunglimpfend empfundene Darstellung einiger authentischer Personen verstellten der zeitgenössischen Leserschaft den Blick für die moderne Struktur der Temnye allei. Femer irritierte die mangelnde psychologische Nachvollziehbarkeit der Handlungen der Figuren die zeitgenössischen Leser; die Funktion der Figuren als überindividuelle Ideenträger wurde daher nicht wahrgenommen.

Auch in den Folgejahrzehnten stand die für die russische Literatur ungewöhnlich erotische Darstellung der Frau in der Regel im Fokus der Rezeption; zudem erfolgten vornehmlich Analysen von Teilaspekten wie etwa der Rolle der Naturbeschreibungen. Fragen nach der Konzeption des Buches wurden erst in den 1980er Jahren zu einem Gegenstand literaturwissenschaftlichen Interesses, konzentrieren sich jedoch in der Regel auf die thematischen Schwerpunkte Liebe und Tod, ignorieren die thematische und strukturelle Bedeutung der Erinnerung und lassen die Frage nach der Genrezugehörigkeit der Temnye allei ungeklärt.

Fazil

Trotz der Vielzahl einzelner Erzăhlungen und der in ihnen enthaltenen Momentaufnahmen bzw. Fragmenten der Vergangenheit wirken die Temnye allei keineswegs bruchstückhaft, sondern sind durch zahlreiche intratextliche Verknüpfungen zu einem kohärenten Ganzen verbunden, basierend auf Bunins Überzeugung von der Existenz einer alles urrschließenden Einheit. Während die Fragmentarisierung und der Zerfall des Gewohnten Bunin mit Fragestellungen des 20. Jahrhunderts verbinden, liegen seine Wurzeln in der 
Erzăhltradition des 19. Jahrhunderts. Zur fiktionalen Auskleidung seiner Öberlegungen zu Liebe, Tod und Erinnerung wählte Bunin mit der Kurzprosaverknüpfung das ideale Medium, in der sich die thematisch kohărierenden zentripetalen mit den in Form der einzelnen Erzăhlungen zentrifugalen narrativen Kräften zu einer höchst vitalen Form verbinden, die Vielfalt in der Einheit bietet.

Die Sinnsuche macht aus Bunins heimatlos umherreisenden Protagonisten mehr als rastlose Hedonisten in steter Erwartung eines unverbindlichen Liebesabenteuers - sie sind gefangen in ihrem Konflikt zwischen dem Wunsch nach Selbstauslöschung und der Sehnsucht nach dem prallen Leben und finden nur kurzzeitige Erfüllung im Liebeserlebnis. Der ständigen Präsenz des Todes und der impliziten Trauer über die verlorene Heimat zum Trotz sind die Temnye allei nicht zuletzt durch die sinnlichen Schilderungen ein Plädoyer für das Leben im Augenblick - und ein Plädoyer für die Bedeutung der Erinnerung, die den Schlüssel darstellt zum Verständnis der Vergangenheit, wie auch analog zur Thematisierung des Rückblicks in den einzelnen Erzăhlungen der Schlüssel zum Verständnis des Buches im Rückblick auf die Gesamtheit der Erzählungen liegt. Eine Erzählung allein ist nicht in der Lage, Bunins lebensphilosophische Überlegungen widerzuspiegeln, erst die Wiederholung illustriert die Facetten, verdeutlicht das Ausgeliefertsein des Menschen ans Schicksal. Die zahlreichen Verbindungen zwischen den einzelnen Erzăhlungen belegen eindrucksvoll die Kohärenz des Buches, das als mehrschichtige Kurzprosaverknüpfung vom vergleichsweise offenen Clustertypus zu klassifizieren ist.

Die kontroversen Reaktionen, die sein von ihm als Meisterwerk empfundenes letztes Buch hervorrief, zeigen Bunin ganz und gar nicht als Epigonen der Erzählkunst des vergangenen Jahrhunderts, sondern als einen höchst modernen Schriftsteller, der sich der traditionellen Erzähltechniken in innovativer Weise bediente, indem er sie im Gewand einer sich erst im 20. Jahrhundert entwickelnden Struktur präsentiert. Der uber 70-jährige Bunin erwies sich somit als ein sich im steten Wandel befindender, geistig unabhängiger Künstler, der zeit seines Lebens auf der Suche war nach den geeigneten Ausdrucksmöglichkeiten für die adäquate künstlerische Umsetzung seiner Lebenswahmehmung und Weltanschauung und sich von den Erwartungshaltungen seiner potentiellen Leser unberührt zeigte. 


\section{QUELLEN- UND LITERATURVERZEICHNIS}

Eine Öbersicht über die Publikationen der einzelnen Erzăhlungen, Entwürfe und Skizzen befindet sich in Anhang 1.

\subsection{Unveröffentlichte Quellen}

\subsubsection{Archive}

Bakhmeteff Archive, Butler Library, Columbia University, New York.

Edinburgh University Library, Special Collections Department.

Ivan Bunin and Vera Bunina Collections, Leeds Russian Archive, University of Leeds.

Institut mirovoj literatury imeni Gor'kogo, Moskau.

Gosudarstvennyj literaturnyj muzej, Moskau.

Nordelbisches Kirchenarchiv, Kiel.

Rossijskaja gosudarstvennaja biblioteka, Moskau.

Rossijskij gosudarstvennyj archiv literatury i iskusstva, Moskau.

\subsubsection{Persönliche Gespräche/Korrespondenz}

Regelmäßiger Kontakt mit Dr. Richard D. Davies, LRA, seit 1996.

Schreiben von Dr. Uwe Heldt, Piper-Verlag, 01.08.1996.

Telefonat mit Martin Ehrenwirth, 14.09.1998.

Telefonat mit Ulrich Weitbrecht, 17.09.1998.

Schreiben der Staatsanwaltschaft München 1, 11.01.1999.

Gesprăch mit Eric A. Peschler, 03.02.1999.

E-Mail von Annette Prassel, Lizenzabteilung Eichborn Verlag, 01.02.2000.

Schreiben von Hans Magnus Enzensberger, 01.04.2000.

Gespräch mit Oleg Michajlov, 31.05.2000. 


\subsection{Primärliteratur Ivan Bunin}

12.2.1 (Integral-)Ausgaben der Temnye allei in russischer Sprache/Ausgewählte Veröffentlichungen einzelner Erzählungen aus den Temnye allei in chronologischer Ordnung

Temnye allei. New York: Novaja zemlja, 1943.

Temnye allei. Paris: La Presse Française et Etrangère, 1946.

Sobranie socinenij v pjati tomach. 4.Bd. Moskva: Pravda, 1956.

Povesti. Rasskazy. Vospominanija. Moskva: Moskovskij raboxij, 1961.

Sobranie socinenij v devjati lomach. 7.Bd. Moskva: Chudožestvennaja literatura, 1966.

Rasskazy. Moskva: Sovetskaja Rossija, 1978.

Temnye allei. Novosibirsk: Zapadno-Sibirskoe izdatel'stvo, 1979.

Socinenija v trech tomach. 3.Bd. Moskva: Chudožestvennaja literatura, $1982^{1}\left(1984^{2}\right)$.

Temnye allei: Povesti, rasskazy. Kemerovo: Knižnoe izdatel'stvo, 1984.

Izbrannye socinenija. Moskva: Chudožestvennaja literatura, 1984.

Antonovskie jabloki: Rasskazy. Murmansk: Murmanskoe knižnoe izdatel'stvo, 1987.

Sobranie socinenij v cetyrech tomach. 4.Bd. Muskva: Pravda, 1988.

Sobranie sočinenij v šesti tomach. 5.Bd. Moskva: Chudožestvennaja literatura, 1988.

Temnye allei. Moskva: Chudožestvennaja literatura, 1990.

Izbrannye proizvedenija. Moskva: Panorama, 1991.

Solnečnyj udar. Rasskazy. Serija: Russkij èros. Moskva: Nadežda, 1992.

Izbrannoe v dvuch lomach. I.Bd. Čeboksary: Čuvašskoe knižnoe izdatel'stvo, 1993.

V takuju noc': Rasskazy. Kaluga: Zolotaja alleja, 1993.

Sobranie sočinenij v sesti tomach. 6.Bd. Moskva: Santaks, 1994.

Povesti, rasskazy. Serija: Russkaja klassika o ljubvi. Moskva: Rusanova, 1994.

Temnye allei; Mitina ljubov' (Sbornik). Rostov-na-Don: Maprekon, 1994.

Temnye allei. Sankt-Peterburg: Liss TOO Biont, 1994. 
Temnye alle:: Povesti i rasskazy. Ekaterinburg: Sredne-Ural'skoe knižnoe izdatel'stvo, 1994.

Temnye allei Paris: Bookking International, 1995.

Temnye allei Sankt-Peterburg: Terra, 1997.

Temmye allei Moskva: EKSMO-Press, 1998.

Sobranie sočnenij v vos 'mi tomach. 6.Bd. Moskva: Moskovskij rabocij, 1999.

Temnye allei Moskva: Terra, 2000.

„Zojka i Vulerija“. In: Kovceg. Sbornik russkoj zarubeżnoj literatury. New York: Association of Writers in New York, 1942.

Rečnoj traktr. Hg. Michail Cetlin. New York: Greenwich Printing Group, 1945.

„Zojka i Valerija“. In: Russkij sbornik. Kniga 1. Paris: Podorožnik, 1946.

Rasskazy. Miskva: Goslitizdat, 1955. ("Temnye allei“ und „Voron“).

"Temnye alli““. In: Novyj mir 6 (1955).

„Voron“. In:Ogonek 30 (1955).

Izbrannye prizvedenija. Moskva: Gosudarstvennoe izdatel'stvo chudožestvennoj literatury, 1556. („Temnye allei“, „Kavkaz“, „Volki“ und „Voron“).

Rasskazy. Kuibyšev: Knižnoe izdanie, 1956. („Temnye allei“ und „Voron“).

Izbrannye pnizvedenija 1892-1944. Celjabinsk: Knižnoe izdanie, 1963. („Temnye allei“, "Kaviaz", „Volki“" und „Voron").

Izbrannoe. Noskva: Chudožestvennaja literatura, 1970. („Temnye allei“, „Pozdnij Cas“, „Rusja“, „Smaragd“, „Cholodnaja osen"“, „Voron“ und „Cistyj ponedel'nik“).

Povesti. Rastazy. Petrozavodsk: Karelija, 1973. („Rusja“ und „Voron“).

Antonovskie abloki. Povesti i rasskazy. Serija: Skol'naja biblioteka. Moskva: Detskaja literaura, 1975. ("Temnye allei“, „Pozdnij Cas“, „Cholodnaja osen"“ und „Voron“).

Izbrannoe. Ksinev: Kartja Moldovenjaske, 1976. („Temnye allei“, „Kavkaz“, „Volki“ und „Voru").

Rasskazy. Moskva: Chudožestvennaja literatura, 1976. („Temnye allei“, „Ballada“ und "Choodnaja osen"“). 
Rasskazy. Moskva: Chudožestvennaja literatura, 1978. (,Kavkaz“, „Stepa“, „Rusja“, „Genrich“, „V odnoj znakomoj ulice“, „,Madrid““, „Voron“ und „Noðleg“).

Poslednee svidanie. Izbrannoe. Minsk: Mastackaja litaratura, 1978. (Kavkaz", „Antigona“, „Vizitnye kartocki“, „Volki“, „Zojka i Valerija“, „Tanja“ und "Voron“).

Antonovskie jabloki. Rasskazy i povesti. Moskva, 1979. („Krasavica“ und „Voron“).

Antonovskie jabloki. Povesti i rasskazy. Krasnodar, 1979. („Temnye allei“)).

Antonovskie jabloki: Povesti i rasskazy. Moskva, 1980 (1981², 1982³, 19854). („Pozdnij cas", "Cholodnaja osen"“ und „Voron").

Povesti $i$ rasskazy. Nal'cik: El'brus, 1983. („Antigona“, „Kuma“, „Nacalo“, „Dubki““, ",Madrid“", „Vtoroj kofejnik“, „Cholodnaja osen"“, „Parochod ,Saratov“" und „Sto rupij“).

Temnye allei. Vladivostok: Dal'nevostočnoe knižnoe izdatel'stvo, 1983. ("Temnye allei“, „Kavkaz", „Pozdnij cas", „Rusja“, „Volki",, „Vizitnye kartocki“, "V Pariže“", "Natali“", „Cholodnaja osen"“, „Voron", „Cistyj ponedel'nik“, „Kaceli“).

Grammatika ljubvi: Povesti i rasskazy. Moskva: Chudožestvennaja literatura, 1985. (,Temnye allei“, „Kavkaz", „Stepa“, „Pozdnij cas“, „Muza“, „Rusja“, „Antigona“, "Smaragd", „Galja Ganskaja“, „Genrich", „Natali“, „Rečnoj traktir", „Voron" und "Cistyj ponedel'nik“).

Temnye allei: Povesti $i$ rasskazy. Moskva: Sovetskaja Rossija, 1986. („Temnye allei“, "Cholodnaja osen" und „Voron").

Legkoe dychanie: Povesti $\mathrm{i}$ rasskazy. Saratov: izdatel'stvo Saratovskogo universiteta, 1986 $\left(1988^{2}\right)$. („Temnye allei“, "Kavkaz", "Ballada“, „Antigona“, „Zojka i Valerija“, "Tanja", „V Pariže“, „Galja Ganskaja“, „Genrich", „Natali“, „Cholodnaja osen”", "Parochod ,Saratov"." und „Cistyj ponedel'nik“).

Antonovskie jabloki: Povesti i rasskazy. Kiev: Veselka, 1988. („Temnye allei“, „Pozdnij cas", "Cholodnaja osen"“ und „Voron“).

Antonovskie jabloki: Povesti i rasskazy. Moskva: Sovetskaja Rossija, 1990. („Temnye allei“", "Krasavica“, „V odnoj znakomoj ulice“, „Rečnoj traktir" und „Cholodnaja osen'").

Legkoe dychanie: Rasskazy. stichorvorenija. Leningrad: Detskoe literaturnoe Leningradskoe otdelenie, 1991. („Pozdnij Cas", „Temnye allei“", "Cholodnaja osen“" und „Kaceli“). 
12.2.2 Integralausgaben der Temnye allei in franzosischer Sprache ${ }^{835} /$ Ausgewählte Veröffentlichungen einzelner Erzählungen aus den Temnye allei in chronologischer Ordnung

Les Allées sombres. Übs. Jean-Luc Goester, François Laurent. Lausanne: L'Age d'Hommes, 1987.

Les Allées sombres. Übs. Jean-Luc Goester, François Laurent. "Classiques slaves". Lausanne: L'Age d'Hommes, 1988.

Les Allées sombres. Obs. Jean-Luc Goester, François Laurent. Lausanne: L'Age d'Hommes. Le Livre de Poche, 1990.

„L'Heure tardive“. Übs. Jarl Priel. In: Cavalcade (Juni 1946).

„Le Corbeau“. Ubs. Jarl Priel. In: Cavalcade (Juni 1946).

„A Paris“. Obs. Ju. Davydov. In: Cahiers du Sud 320 (1953): 92-102.

12.2.3 Ausgaben der Temnye allei in englischer Sprache/Ausgewählie Veröffentlichungen einzelner Erzählungen aus den Temnye allei in chronologischer Ordnung

Shadowed Paths. Hg. Philippa Hentges. Übs. Olga Shartse. Moscow: Foreign Languages Publishing House, 1958.

Stories and Poems. Übs. Olga Shartse. Moscow: Progress Publishers, 1979.

Dark Avenues and Other Stories. Übs. Richard Hare. London: John Lehmann, 1949.

Dark Avenues and Other Stories. Westport (Connecticut): Hyperion, 1987. (Reprint der Ausgabe von 1949).

The Gentleman from San Francisco, and Other Stories. Übs. Richard Hare. London: Chatto and Windus, 1975.

Long Ago. Selected Stories. Übs. David Richards, Sophie Lund. London: Angel Books, 1984.

Light Breathing and Other Stories. Übs. Olga Shartse. Moscow: Raduga, 1988.

Wolfes, \& Other Love Stories. Übs. Mark Scott. Santa Barbara: Capra Press, 1989. 
„Temnye allei“. In: Selected Stories. Hg. Peter Henry. Bristol: British Classical Press, 1993.

12.2.4 Ausgaben der Temnye allei in deutscher Sprache/Ausgewählte Veröffentlichungen einzelner Erzählungen aus den Temnye allei in chronologischer Ordnung

Dunkle Alleen. Übs. Ilona Koenig. Stuttgart: J. F. Steinkopf Verlag, 1959.

Dunkle Alleen. Übs. Ilona Koenig. Zürich: Coron-Verlag, 1969.

Dunkle Alleen. Übs. Ilona Koenig. München: Piper-Verlag, $1973^{1}\left(1987^{2}\right)$.

Dunkle Alleen. Erzählungen 1920-1953. Hg. Karlheinz Kasper. Übs. Erich Ahrndt, Charlotte Kossuth, Ilse Tschörtner. Berlin und Weimar: Aufbau-Verlag, 1985.

Liebe und andere Unglücksfälle. Hg. Hans Magnus Enzensberger. Übs. Erich Ahrndt, Charlotte Kossuth, Georg Schwarz, Ilse Tschörtner. Die Andere Bibliothek. Frankfurt am Main: Eichborn Verlag, 2000' [Erstausgabe] (2001² [Erfolgsausgabe]).

Bunin, Iwan. „Der Rabe“. In: Story 12 1.Bd. (1947): 26-28.

„Dunkle Alleen“, „Der Rabe“. In: Ein Herr aus San Franzisko und andere Erzählungen. Übs. Ottomar Schwechheimer und Walter Richter-Ruhland. München: Wilhelm Goldmann Verlag, 1960.

12.2.5 Autobiographisches, Interviews, weitere Erzählungen bzw. Prosatexte von Ivan Bunin

.Avtobiografičeskaja zametka“ (10.04.1915). In: ders. Sobranie socinenij v devjati tomach. 9.Bd. Moskva: Chudožestvennaja literatura, 1967: 253-266.

„Bunin o sebe i svoem tvorcestve. Archivnye materialy“. $\mathrm{Hg}$. Milica Grin [Greene]. In: Novyj žurnal 107 (1972): 161-170.

„Interv'ju“. In: Odesskie novosti (15.11.1910). Zit. in: Literaturnoe nasledstvo. Ivan Bunin. 84.Bd. (1) Moskva: Nauka, 1973: 364-367.

„Interv'ju“. In: Odesskie novosti (01.03.1912). Zit. in: ders. Sobranie socinenij v devjati tomach. 9.Bd. Moskva: Chudožestvennaja literatura, 1967: 542-545.

„Interv'ju“. In: Golos Moskvy (24.10.1912). Zit. in: ders. Sobranie sodinenij v devjati tomach. 9.Bd. Moskva: Chudožestvennaja literatura, 1967: 540-542. 
"Iwan Boenin in kamerjas. Gesprek met 80-jarige emigrant-schriver". In: Het Parool (28.10.1950).

„1z archiva I. A. Bunina“. Hg. Leonid Zurov. In: Novyj Zurnal 68 (1962): 5-10.

„Izbrannye proizvedenija“. Moskva: Gosudarstvennoe izdatel'stvo chudožestvennoj literatury, 1945 [Umbruchexemplar].

„Iz predislovija k francuskomu izdaniju ,Gospodina iz San-Francisko“" (1921-1934). In: ders. Sobranie sočinenij $v$ devjati tomach. 9.Bd. Moskva: Chudožestvennaja literatura, 1967: 267-269.

„Kak ja pišu“ (1929). In: ders. Sobranie sočinenij v devjati tomach. 9.Bd. Moskva: ChudoZestvennaja literatura, 1967: 374-376.

„Literatumoe zavešanie“. In: Novyj zurnal 66 (1961): 166-172.

Mitina ljubov'. Solnečnyj udar. New York: Izdatel'stvo imeni Cechova, 1953.

„Nadpisi“ (1924) In: ders. Sobranie socinenij v vos'mi tomach. 4.Bd. Moskva: Moskovskij rabocij, 1995: 444-448.

„Neizvestnye rasskazy I. A. Bunina“. Hg. Jurij Mal'cev. In: Novyj žurnal 168-169 (1987): 65-79.

„Neopublikovannye rasskazy I. A. Bunina“. Hg. Milica Grin [Greene]. In: Novyjj žurnal 142 (1981): 5-8.

"Nobelevskie dni“" (undatiert). In: ders. Sobranie socinenij v devjati tomach. 9.Bd. Moskva: Chudožestvennaja literatura, 1967: 323-331.

„Nox"“ (1925). In: ders. Sobranie sočinenij v devjati tomach. 5.Bd. Moskva: Chudožestvennaja literatura, 1966: 297-308.

Okajannye dni (Berlin, 1935) In: ders. Okajannye dni. Moskva: EKSMO-Press, 2001.

Osvoboždenie Tolstogo (1937). In: ders. Sobranie sočinenij v vos'mi tomach. 6.Bd. Moskva: Moskovskij raboxij: 21-172.

Petlistye uši i drugie rasskazy. New York: Izdatel'stvo imeni Cechova, 1954.

Polnoe sobranie socinenij. Petrograd: Izdatel'stvo Marksa, 1915.

„Proischoždenie moich rasskazov“. In: ders. Sobranie sočinenij v devjati tomach. 9.Bd. Moskva: Chudožestvennaja literatura, 1967: 368-373.

Sobranie socinenij v devjati tomach. Moskva: Chudožestvennaja literatura. 1965-1967.

Vesnoj, v Iudee. Roza Ierichona. New York: Izdatel'stvo imeni Cechova, 1953. 
„Zapisi“" (undatiert). In: ders. Sobranie socinenij $v$ devjati tomach. 9.Bd. Moskva: Chudožestvennaja literatura, 1967: 364-366.

12.3 Erinnerungen, Tagebücher, Korrespondenzen, Kritik, Stimmen zu den Temmye allei

Adamovið, Georgij. „Temnye allei“. In: Russkie novosti 86 (03.01.1947).

Ders. „Po povodu ,Temnych allej““. In: Odinočestvo $i$ svoboda. New York: Izdatel'stvo imeni Cechova, 1955.

Aldanov, Mark [Landau]. „Bunin“. In: Novoe russkoe slovo (25.11.1945): 8.

Aleksandrova, Vera [Švarc]. „Temnye allei‘ I. A. Bunina“. In: Novoe russkoe slovo (18.05.1947).

Dies. „Bibliografija“. In: Novyj žurnal 15 (1947): 295-296.

Dies. „Bunin i sovremennost”“. In: Novoe russkoe slovo (01.04.1951): 8.

Dies. „Sovetskoe izdanie Bunina“. In: Novoe russkoe slovo (09.09.1956).

B[achrach, Aleksandr?]. „U Bunina“. In: Russkie novosti (15.06.1945).

Bachrach, Aleksandr. „Poslednij iz mogikan“. In: Sovetskij patriot (16.06.1946).

Ders. „Seroe i korixnevoje“. In: Orion, 1947.

Ders. „Po pamjati, po zapisjam. Razgovory s Buninym“. In: Novyj žurnal 131 (1978): 117 144.

Ders. Bunin v chalate. Bayville: Tovarišcestvo zarubežnych pisatelej, 1979. Nachdruck Moskva: Soglasie, 2000.

„Dva pis'ma I. A. Bunina k A. G. Bloku“. Hg. Andrej Blok. In: Novyj żurnal 120 (1975): 163-166.

„Etomu celoveku ja verju bol’še vsech na zemle“. Hg. Andrej Černyšev. In: Okıjabr' 3 (1996): 115-156.

Gide, André. Journal 1926-1950. Edition établie, présentée et annotée par Martine Sagaert. Bibliothèque de la Pléiade. Paris: Gallimard, 1997.

Grecaninova, V. „Primecanija“. In: Ivan Bunin. Sobranie socinenij v devjati tomach. 7.Bd. Moskva: Chudožestvennaja literatura, 1966: 364-396.

Hahn, Ulla. „Das abgetrotzte Glück“. In: Der Spiegel 24 (11.06.2001): 202-205. 
Hallstrom, Per. „Verleihungsrede“. In: Ivan Bunin. Dunkle Alleen. Zürich: Coron-Verlag, 1969: 9-23.

hs. „Bunins dunkle [sic] Alleen. ,Ausgewăhlte Meistererzählungen““. In: Stuttgarter Zeitung 6 (1960).

„Iz perepiski I. A. i V. N. Buninych s Alloj Golovinoj (1942-1953)“. Hg. A. V. Fomenko. In: I. A. Bunin i russkaja literatura XX veka. Moskva: Nasledie, 1995: 248-253.

Kataev, Valentin. Trava zabvenija. In: ders. Sobranie socinenij v desjati tomach. 6.Bd. Moskva: Chudožestvennaja literatura, 1984.

Kazakov, Jurij. „Beseda v Pariže“. In: Literaturnaja gazeta 30 (1990): 4.

Kodrjanskaja, V. N. „Vstreci s Buninym“. In: Literaturnoe nasledstvo. Ivan Bunin. 84.Bd. (2) Moskva: Nauka, 1973: 341-351.

Kolonickaja, Anna. „Vse cisto dlja cistogo vzora." (Besedy s Irinoj Odoevcevoj). Moskva: Voskresen'e, 2001.

Kuznecova, Galina. Grasskij dnevnik. Washington, 1967. Nachdruck Moskva: Moskovskij raboxij, 1995.

„Lettres d'Ivan Bunin à Mark Aldanov“. Hg. Rosa Fedoulova. In: Cahiers du monde russe et soviétique 4 (1981): 471-488.

Mal'cev, S. „O temnych allejach“. In: Cáavoj 273 (Osterausgabe 1948):16-?.

Müller, Rudolf. „Iwan Bunin: Dunkle Alleen“. In: Wiener Bücherbriefe 4 (1961).

Murav'eva-Loginova, Tat'jana. Pis'ma Buninych (1936-1961) k Murav'evoj-Loginovoj. Paris: YMCA Press, 1982.

Nilus, P. A. „Iv[an] Bunin i ego tvorčestvo“. In: Literaturnoe nasledstvo. Ivan Bunin. 84.Bd. (2) Moskva: Nauka, 1973: 429-435.

.,Novosel'e' kniga 31-32“. In: Novoe russkoe slovo (09.02.1947).

Odoevceva, Irina. Na beregach Seny. Paris, 1983. Nachdruck Moskva: Chudožestvennaja literatura, 1989.

Ohne Verfasserangabe. (Ohne Titel). In: Reformierte Schweiz (Bern) 2 (1960).

Ohne Verfasserangabe. „Iwan Bunin. ,Dunkle Alleen““. In: Offenbach-Post 267 (1959).

Ohne Verfasserangabe. (Ohne Titel). In: Welt der Bücher 4 (1960).

Paustovskij, Konstantin. Naedine s osen'ju. Portrety, vospominanija, ocerki. Moskva: Sovetskij pisatel', 1967. 
„Perepiska I. A. Bunina s M. A. Aldanovym“. Hg. Alexander Zweers. In: Novyj žurnal 150 (1983): 159-191.

„Perepiska I. A. Bunina s M. A. Aldanovym“. Hg. Alexander Zweers. In: Novyj zururnal 152 (1983): 153-191.

„Perepiska I. A. Bunina s M. A. Aldanovym“. Hg. Alexander Zweers. In: Novyj žurnal 154 (1984): 97-108.

„Perepiska I. A. Bunina s M. A. Aldanovym“. Hg. Alexander Zweers. In: Novyj żurnal 155 (1984): 131-146.

„Perepiska s N. D. Telešovym 1897-1947“. Hg. A. Dubovikov. In: Literaturnoe nasledstvo. Ivan Bunin. 84.Bd. (1) Moskva: Nauka, 1973: 471-638.

„Perepiska Teffi s I. A. i V. N. Buninymi 1939-1948“. Hg. Richard Davies und Edythe Haber. In: Diaspora II (2001): 477-584.

„Perepiska Téffi s I. A. i V. N. Buninymi 1948-1952“. Hg. Richard Davies und Edythe Haber. In: Diaspora III (2001): 536-626.

„Pis'ma B. K. Zajceva k I. A. i V. N. Buninym“. Hg. Milica Grin [Greene]. In: Novyj zurnal 140 (1980): 157-181.

„Pis'ma B. Zajceva I. i V. Buninym“. Hg. Milica Grin [Greene]. In: Novyj Zurnal 146 (1982): 115-142.

„Pis'ma I. A. Bunina k M. E. Vejnbaumu“. Hg. Aleksis Rannit. In: Novyj žurnal 133 (1978): 177-188.

„Pis'ma I. Bunina k B. Zajcevu“. Hg. Alexander Zweers. In: Novyj zurnal 136 (1979): 127-140.

„Pis'ma I. Bunina k B. Zajcevu“. Hg. Alexander Zweers. In: Novyj žurnal 137 (1979): 125-141.

„Pis'ma I. Bunina k B. Zajcevu“. Hg. Alexander Zweers. In: Novyj žurnal 138 (1980): 155-175.

„Pis'ma I. A. Bunina k F. A. Stepunu“. Hg. Alexander Zweers. In: Novyj žurnal 118 (1975): 120-128.

„Pis'ma M. A. Aldanova k I. A. i V. N. Buninym“. Hg. Milica Grin [Greene]. In: Novyj Zurnal 81 (1965): 110-147.

„Pis'ma N. Telešova k I. Buninu“. In: Novyj żurnal 85 (1966): 129-140.

„Pis'mo k K. A. Fedinu. 1946“. Hg. Konstantin Fedin. In: Literaturnoe nasledstvo. Ivan Bunin. 84.Bd. (1) Moskva: Nauka, 1973: 690-691. 
„Pis'mo k K. M. Simonovu“. Hg. Konstantin Simonov. In: Literaturnoe nasledstvo. Ivan Bunin. 84.Bd. (2) Moskva: Nauka, 1973: 516-517.

Reichart, Manuela. „Nächte des ,Nie mehr“ - Eine Gelegenheit, den Erzăhler Iwan Bunin kennen zu lemen". In: Süddeutsche Zeitung (10.03.2001).

Sander, Hans-Dietrich. „Viel zuwenig kennen wir von der Literatur der Slawen“. In: Die Welt 218 (1960).

Šachovskaja, Zinaida. „Bunin“. In: Kontinent 3 (1975): 263-287.

Ders. Otraženija. Paris: YMCA Press, 1975.

Sedovoj, N. P. „Iz otzyvov sovetskich pisatelej o Bunine“. In: Literaturnoe nasledstvo. Ivan Bunin. 84.Bd. (2) Moskva: Nauka, 1973: 365-374.

Sedych, Andrej [Cvibak, Jakov M.]. „K semidesjatipjati-letniju I. A. Bunina“. In: Novoe russkoe slovo (23.10.1945).

Ders. Dalekie, blizkie. 3., unveränderte Auflage. New York: Izdanie „Novogo russkogo slova“, 1979.

Slonim, Mark. „Literaturnye zametki (,Russkij sbornik')“. In: Novosel'e 31-32 (1947): 94 96.

Sokolov-Mikitov, I. S. „Slovo o Bunine“. In: Literaturnoe nasledstvo. Ivan Bunin. 84.Bd. (2) Moskva, 1973: 155-158.

Ustami Buninych. Dnevniki v trech tomach. Hg. Milica Grin [Greene]. Frankfurt am Main: Possev-Verlag, 1.Bd. 1977, 2.Bd. 1981, 3.Bd. 1982.

W., H. „Iwan Bunin: ,Dunkle Alleen““. In: Westfälische Zeitung (13.01.1960).

Widmann, Arno. „Hinter jedem Fenster ein Schicksal. Iwan Bunins Erzahlungen in der ,Anderen Bibliothek'“. In: Berliner Zeitung (20.03.2001).

Zeeler, Vladimir. ., Vozroždenie‘. Tetrad' trinadcataja“. In: Russkaja mysl' (09.03.1951).

12.4 Sekundärliteratur zu Ivan Bunin und seinem Werk

Ačatova, A. A. „Pozdnjaja liriceskaja novella I. A. Bunina. (K voprosu o kompozicii)“. In: Izvestija Voronežskogo gosudarstvennogo pedagogiceskogo instituta. 114.Bd. Voronez, 1971: 115-122.

Dies. „Iz nabljudenij nad liriceskoj prozoj I. A. Bunina“. In: Voprosy literatury. Ucenye zapiski. 83.Bd. Tomsk: Izdatel'stvo Tomskogo universiteta, 1973: 83-90. 
Afanas'ev, Vladislav. I. A. Bunin. Ocerk tvorcestva. Moskva: Prosvešcenie, 1966.

Andreeva, A. „Nečego v gosti po plač, esli doma navzryd“. In: Izvestija (01.02.2001).

Antonov, Viktor. „I. A. Bunin vo Francii v gody vojny“. In: Inostrannaja literatura 9 (1956): 250-255.

Anzeige des J. F. Steinkopf Verlags (Stuttgart) im Börsenblatt für den Deutschen Buchhandel (Frankfurter Ausgabe) 87 (30.10.1959).

Baboreko, Aleksandr. „Bunin v gody vojny (1943-1944)“. In: Daugava 10 (1980): 119 122.

Ders. „Temnye allei“. (Anmerkungen). In: Ivan Bunin. Sobranie socinenij v šesti tomach. 5.Bd. Moskva: Chudožestvennaja literatura, 1988: 611-636.

Ders. „Archiv Bunina dol'žen byt' v Rossii“. In: Literaturnaja gazeta 6 (1997): 12.

Ders. „Temnye allei“. (Anmerkungen). In: Ivan Bunin. Sobranie sočinenij v vos'mi tomach. 6.Bd. Moskva: Moskovskij rabocij, 1999: 617-640.

Bažinov, I. D. „Bunin i Nilus“. In: Literaturnoe nasledstvo. Ivan Bunin. 84.Bd. (2) Moskva: Nauka, 1973: 424-428.

Bethea, David. „Ivan Bunin and the Time of Troubles in Russian Emigre Literature“. In: Slavic Review 1 (1984): 1-16.

Birkmann, Karl. Ich schlage langsam ein Kreuz... Rußland zwischen Bunin und Solschenizyn. München: Markus-Verlag, 1974.

Bonami, T. M. „K poetike rasskazov I. A. Bunina. (Funkcional'noe značenie zvukovych i muzykal'nych obrazov)“. In: I. A. Bunin i russkaja literatura XX veka. Po materialam meždunarodnoj naučnoj konferencii, posvjaščennoj 125-letiju so dnja roždenija I. A. Bunina. 23-24 oktjabrja 1995 g. Moskva: Nasledie, 1995: 85-94.

Bounine revisité. Hg. Claire Hauchard. Cahiers de l'émigration russe 4. Paris: Centre d'études slaves et Institut d'études slaves, 1997.

Briker, Boris. „Time, History, and Fairy Tale in Ivan Bunin's ,A Cold Autumn“". In: Canadian Slavonic Papers 1-2 (1998): 125-136.

Catteau, Jacques. „Préface“. In: Ivan Bounine. Les Allées sombres. Übs. Jean-Luc Goester, François Laurent. Lausanne: L'Age d'Hommes, 1987: 7-14.

Ders. „Les Moirés crépusculaires et le soleil éclatant de l'exil: Les Allées sombres“. In: Bounine revisité. Hg. Claire Hauchard. Cahiers de l'émigration russe 4. Paris: Centre d'études slaves et Institut d'études slaves, 1997: 83-89.

Colin, Andrew Guershoon. „Ivan Bunin in Retrospect“. In: The Slavonic and East European Review 82 (Dez. 1955): 156-173. 
Connolly, Julian W. "Desire and Renunciation: Buddhist Elements in the Prose of Ivan Bunin". In: Canadian Slavonic Papers 1 (1981): 11-20.

Ders. Ivan Bunin. Boston: Twayne Publishers, 1982.

Ders. "Ivan Bunin and the Middle East: A Poetic Encounter". In: Russian Language Journal 123-124 (1982): 123-132.

Ders. "Inserted Texts" in Ivan Bunin's Fiction“. In: The Short Story in Russia 1900-1917. Hg. Nicholas Luker. Nottingham: Astra Press, 1991 : 129-144.

Dolgopolov, L. „Rasskaz ,Cistyj ponedel'nik، v tvorčestve Bunina èmigrantskogo perioda“. In: Na rubeže vekov. O russkoj literature konca $X L X$ - načala XX veka. Leningrad: Sovetskij pisatel', 1977: 333-358.

Drozda, Miroslav. „Trojni vid bezvremenosti“. In: Umjetnost Riječi XIX (1975): 3-28.

Elbel, Annette. Die Erzählungen Ivan Bunins 1890-1917. Eine systematische Studie über Form und Gehalt. Osteuropastudien der Hochschulen des Landes Hessen: Reihe II. Marburger Abhandlungen zur Geschichte und Kultur Osteuropas. 10.Bd. Gießen: Wilhelm Schmitz Verlag, 1975.

Értner, E. „Ritmið̌eskaja organizacija cikla I. A. Bunina ,Temnye allei““. In: Tvorceskoe nasledie I. A. Bunina $i$ mirovoj literaturnyj process. Materialy meždunarodnoj naǔ̌noj konferencii, posvjaš̌ennoj 125-letiju so dnja roždenija I. A. Bunina 18.21.10.1995. Orel: Ministerstvo obrazovanija rossijskoj federacii; Orlovskij gosudarstvennyj pedagogiceskij universitet; Muzej I. A. Bunina, 1995: 43.

Evstaf eva, Natalija P. „Novella i rasskaz - veduscie Zanrovye formy v knige I. A. Bunina ,Temnye allei““. In: Voprosy russkoj literatury 1 (1986): 94-100.

Dies. „Svoeobrazie Zanrovych form v knige I. A. Bunina ,Temnye allei"“. Avtoreferat. Charkov, 1990.

Fedoulova, Rosa. „Les Allées sombres d'Ivan Bounin“. [Masch.schr.] Diss. Paris, 1980.

Fedoulova-Touja, Rosa. „O nekotorych osobennostjach jazyka I. Bunina“. In: Revue des érudes slaves 4 (1983): 567-575.

Fetzer, Leland. „Ivan Bunin in English, 1916-1983: A Checklist“. In: Russian Literature Triquarterly 21 (1988): 223-232.

Figurovskij, I. A. „O sintaksise prozy Bunina. Sintaksi飞eskaja dominanta ,Temnych allej"“s. In: Russkaja rec' 5 (1970): 63-66.

Foster, Ljudmila A. "O kompozicii Temnych allej Bunina". In: Russian Literature 9 (1975): 55-65.

Gazer, I. D. „O svoeobrazii lirizma v novellach Bunina“. In: Voprosy russkoj literatury 16 (1971): 59-67. 
Gejdeko, Valerij. „Opirat'sja na fakty“. In: Voprosy literatury 3 (1974): 237-246.

Ders. A. Cechov i Iv. Bunin. Moskva: Sovetskij pisatel', 1976.

Grěnev, V. „Cikl rasskazov I. Bunina ,Temnye allei“ (Psichologiðeskie zametki)“. En: Russkaja literatura 3 (1996): 226-235.

Guerguel, Rostislav. „I. A. Bunin i F. A. Stepun. Fragmenty tvorčeskoj družby“. In: Bounine revisité. Hg. Claire Hauchard. Cahiers de l'émigration russe 4. Paris: Centre d'études slaves et Institut d'études slaves, 1997: 141-146.

Halm, Hans. „Titel und Anfangssatz in Cechovs Erzählungen“. In: Wiener Slavistisches Jahrbuch 10 (1963): 5-10.

Hare, Richard. „Preface“. In: Ivan Bunin. Dark Avenues, and Other Stories. Ubs. Richard Hare. London: John Lehmann, 1949: 5-6.

Hauchard, Claire. „La Prose de I. A. Bunin de 1920 a 1953. La reconstruction d'une cuvre“. [Masch.schr.] Diss. Paris, 1993.

Heywood, Anthony. Catalogue of the I. A. Bunin, V. N. Bunina, L. F. Zurov and E. M. Lopatina Collections. Leeds: Leeds University Press, 2000.

Holthusen, Johannes. „Iwan A. Bunin“. In: Iwan Bunin. Dunkle Alleen. Übs. Ilona Koenig. Stuttgart: J. F. Steinkopf Verlag, 1959.

Hutchings, Stephen. „Myth, Plot Transformation and Iteration in Ivan Bunin's Fiction“. In: Forum for Modern Language Studies 30 (1994): 44-63.

I. A. Bunin i russkaja literatura $X X$ veka. Po materialam meždunarodnoj naučnoj konferencii, posvjašcennoj 125-letiju so dnja roždenija I. A. Bunina. 23-24 oktjabrja 1995 g. Moskva: Nasledie, 1995.

Iezuitova, L. A. „V poiskach vyraženija ,samogo glavnogo, samogo podlinnogo, cto est' $v$ nas' - „šast'ja žizni'. Bunin $v$ rabote nad rasskazami: po materialam russkogo archiva v Lidse (Velikobritanija)“. In: Russkaja literatura 3 (1996): 214-226.

Ingold, Felix Philipp. „Russischer Eros. Frau und Sexualität in der Literatur des 19. Jahrhunderts". In: Annäherungsversuche. Zur Geschichte und Ästhetik des Erotischen in der Literatur. Hg. Horst Albert Glaser. Facetten der Literatur. St. Galler Studien 4. Bern u.a.: Verlag Paul Haupt, 1993: 209-238.

Iofev, M. Profili iskusstva. Literatura, teatr, živopis', estrada, kino. Moskva: Iskusstvo, 1965.

Issova, L. N. „Nekotorye osobennosti struktury novelly I. A. Bunina ,Temnye allei““. In: Żanr $i$ kompozicija literaturnogo proizvedenija 1 (1974): 98-104.

Dies. „Prostranstvo i vremja $v$ rasskazach ob èmigracii“. In: Zanr $i$ kompozicija literaturnogo proizvedenija 3 (1976): 88-98. 
Ivanova-Gladilscikova, $N$. „Detektivnaja istorija s otkrytym finalom. Kak vernut' $v$ Rossiju archiv Ivana Bunina“. In: Izvestija (12.01.2001).

Dies. „Sorok odin recept vmesto archiva“. In: Izvestija (01.02.2001).

Ivask, Jurij. „Bunin“. In: Novyj žurnal 99 (1970): 106-122.

Izvestija Voronežskogo gosudarstvennogo pedagogičeskogo instituta. 114.Bd. Voronež, 1971.

Karasek, Hellmuth. „Vorgelesen“. In: Der Tagesspiegel (13.05.2001).

Karpenko, I. N. „Problemy dinamiceskogo i staticeskogo v proze I. A. Bunina“. In: Izvestija Voronežskogo pedagogičeskogo instituta. 114.Bd. Voronež, 1971: 106-114.

Karpov, Igor. Proza Ivana Bunina (ocerki avtorstva). Moskva: Prometej, 1996.

Kasper, Karlheinz. „Nachwort“. In: Iwan Bunin. Dunkle Alleen. Erzählungen 1920-1953. Obs. Erich Ahmdt, Charlotte Kossuth, Ilse Tschörtner. Berlin und Weimar: Aufbau-Verlag, 1985: 555-575.

Kirchner, Baldur. „Die Lebensanschauung Ivan Alekseevix Bunins nach seinem Prosawerk“. Inaugural-Diss. Tübingen 1968. Ludwigsburg: Druckerei Zinthoffner, 1968.

Klover, Silke. Farbe, Licht und Glanz als dichterische Ausdrucksmittel in der Lyrik Ivan Bunins. Slavistische Beiträge 286. Diss. Münster 1991. München: Verlag Otto Sagner, 1992.

Kocetkov, A. K. „Sredstva vyraženija èmocional'nosti i èkspressivnosti v jazyke I. A. Bunina. (Sb[omik] ,Temnye allei')“. In: Izvestija Voronežskogo pedagogičeskogo instituta. 114.Bd. Voroneż, 1971: 123-130.

Kreps, Michail. „Elementy modernizma v rasskazach Bunina o ljubvi“. In: Novyj žurnal 38 (1979): 55-67.

Kryzytski, Serge. The Works of Ivan Bunin. The Hague/Paris: Mouton, 1971.

Lakschin, W. „Die letzte Begegnung zwischen Bunin und Tschechow". In: Kunst und Literatur 2 (1980): 202-220.

Lavrov, Valentin. ${ }_{m} \mathrm{~V}$ mire kruga zemnogo'. Za strokoj avtografov I. A. Bunina“. In: Al'manach bibliofila 19 (1985): 214-235.

[ers. Cholodnaja osen'. Ivan Bunin v emigracii 1920-1953. Moskva: Molodaja gvardija, 1989.

Lers. Katastrofa. Istoričeskij roman. Moskva: Terra, 1995.

Lee, Sang Ryong. „An Analysis of Thematics, Poetics, and Aesthetics in Ivan Bunin's Prose Narratives". [Masch.schr.] Diss. Urbana (Illinois), 1993. 
Le Guevel, Michel. „Lita et la résurrection d'un mythe“. In: Bounine revisité. Hg. Claire Hauchard. Cahiers de l'émigration russe 4. Paris: Centre d'études slaves et Institut d'études slaves, 1997: 91-98.

"Literarisches Quartett". Teilnehmer an der Sendung: Marcel Reich-Ranicki, Hellmuth Karasek, Iris Radisch und Antje Kunstmann. ZDF (04.05.2001).

Literaturnoe nasledstvo. Ivan Bunin. 84.Bd. (Buch 1 und 2) Moskva: Nauka, 1973.

Ljubimov, N. M. „Obraznaja pamjat'. (Iskusstvo Bunina)“. In: Ivan Bunin. Sobranie socinenij v cetyrech tomach. 4.Bd. Moskva: Pravda, 1988: 16-39.

Makine, Andrei. „La Prose de I. A. Bounine. La Poétique de la nostalgie“. [Masch.schr.] Diss. Paris, 1991.

Mal'cev, Jurij. Bunin. 1870-1953. Frankfurt am Main: Possev-Verlag, 1994. (Erstveroffentlichung unter dem Titel Ivan Bunin. La vita e l'opera: 1870-1953. Milano: La Casa di Matriona, 1987.)

Mamonova, Tatyana. "The Shadowed Paths of Ivan Bunin“. In: dies. Russian Women's Studies. Oxford: Pergamon Press, 1989: 62-69.

Martynova, Olga. „Russland ist weiblich. Leben auch. Ein literarisches Ereignis: Die Erzăhlungen des russischen Nobelpreisträgers Iwan Bunin“. In: Die Zeit (03.05.2001).

Marullo, Thomas Gaiton. Bunin: Twilight of "Emigre" Russia (1934-1953). A Portrait from Diaries, Letters, and Fiction. Chicago (Illinois): Ivan R. Dee Press, 2002.

Meyer, Andrea. Die Sonettdichtung Ivan Bunins. Diss. Göttingen 1989. Opera Slavica. Neue Folge: 20.Bd. Wiesbaden: Otto Harrassowitz, 1990.

Michajlov, Oleg. (Ohne Titel). In: Ivan Bunin. Sobranie socinenij v devjati tomach. 7.Bd. Moskva: Chudozestvennaja literatura, 1966: 351-363.

Ders. Ivan Bunin. Ocerk rvorčestva. Moskva: Nauka, 1967.

Ders. Strogij talant. Ivan Bunin. Żizn', sud'ba. tvorcestvo. Moskva: Sovremennik, 1976.

Ders. „O Bunine (1870-1953)“. In: Ivan Bunin. Izbrannye socinenija. Moskva: Chudožestvennaja literatura, 1984: 5-12.

Ders. I. A. Bunin. Žizn'i tvorčestvo. Tula: Priokskoe knižnoe izdatel'stvo, 1987.

Ders. „Pesn' pesnej Bunina“. In: Ivan Bunin. Temnye allei. Moskva: Chudožestvennaja literatura, 1990: 3-8.

Ders. „Osvobożenie Bunina“. In: Slovo 7 (1990): 55-57. 
Ders. "Mirovoe znacenie Bunina“. I. A. Bunin i russkaja literatura XX veka. Po materialam meždunarodnoj naǔ̌noj konferencii, posvjašcennoj 125-letiju so dnja roždenija I. A. Bunina. 23-24 oktjabrja 1995 g. Moskva: Nasledie, 1995: 3-6.

Ders. Žizn' Bunina. Lis' slovu Żizn' dana .... Moskva: Centroligraf, 2001.

Mysalova Diana. „Realist li Bunin? O poètike cikla ,Temnye allei““. In: Grani 171 (1994): 124-130.

Nagibin, Jurij. Zit. in: „Iz otzyvov sovetskich pisa:elej o Bunine“. Hg. N. Sedovoj. In: Literaturnoe nasledstvo. Ivan Bunin. 84.Bd. (2) Moskva: Nauka, 1973: 365-366.

Nefedov, Valerij. Cudesnyj prizrak Bunin-chudožnik. Minsk: Polymja, 1990.

Nikulin, Lev. „I. A. Bunin“. In: Ivan Bunin. Sobranie sočinenij v pjati tomach. 1.Bd. Biblioteka Ogonek. Moskva: Pravda, 1956: 3-30.

Ders. „O Cem govorjat rukopisi Bunina“. In: Moskva 7 (1959): 200-210.

Oboukhova, Olga. „Moskva - moskovskij tekst u Bunina èmigrantskogo perioda“. In: Bounine revisité. Hg. Claire Hauchard. Cahiers de l'émigration russe 4. Paris: Centre d'études slaves et Institut d'études slaves, 1997: 107-114.

Ohne Verfasserangabe. „Bunin, Ivan A. ,Tretij Tolstoj““. In: Slovo 7 (1990): 47-55.

Peschl, Otto. „Die künstlerische Entwicklung von Ivan Bunins Prosastil“. [Masch.schr.] Diss. Wien, 1954.

Puggioli, Renato. „The Art of Ivan Bunin“. In: Harvard Slavic Studies 1 (1953): 249-277.

Pımerancevaja, E. V. "Predislovie“. In: Literaturnoe nasledstvo. Ivan Bunin. 84.Bd. (1) Moskva: Nauka, 1973: 126-127.

Rukovskij, Leontij. Zit. in: „Iz otzyvov sovetskich pisatelej o Bunine“. Hg. N. Sedovoj. In: Literaturnoe nasledstvo. Ivan Bunin. 84.Bd. (2) Moskva: Nauka, 1973: 371.

Ruzina. A. V. „Kinematografičnost' kak stilevaja osobennost' tvorceskogo pocerka Ivana Bunina“. In: I. A. Bunin i russkaja literatura XX veka. Po materialam meždunarodnoj naučnoj konferencii, posvjašcennoj 125-letiju so dnja roždenija I. A. Bunina. 23-24 oktjabrja 1995 g. Moskva: Nasledie, 1995: 258-267.

Rchards, D. J. „Memory and Time Past: A Theme in the Works of Ivan Bunin“. In: Forum for Modern Language Studies 7 (1971): 158-169.

D.rs. "Comprehending the Beauty of the World: Bunin's Philosophy in Travel". In: The Slavonic and East European Review 52 (1974): 514-532.

Drs. „Introduction“. In: Ivan Bunin. Long Ago. Selected Stories. Obs. David Richards, Sophie Lund. London, 1984: 7-16. 
Rogacevskij, Andrej. „Review Article. Bunin Reincarnate“. In: The Slavonic and East European Review 3 (Juli 2002): 487-496.

Rosxcin, Michail. Ivan Bunin. Žizn' zamexatel'nych ljudej. Serija biografii. Moskva: Molodaja gvardija, 2000.

Roudet, Robert. „Quelques Particularités de la technique d'Ivan Bunin“. In: Revue des études slaves 4 (1995): 665-673.

Saakjanc, Anna. „Temnye allei. Poslednie gody“. In: Ivan Bunin. Socinenija v trech tomach. 3.Bd. Moskva: Chudožestvennaja literatura, 1982: 513-521.

Dies. (Ohne Titel). In: Ivan Bunin. Sobranie sočinenij v sesti tomach. 5.Bd. Moskva: Chudozestvennaja literatura, 1988: 582-593.

Sansom, William. "The Harpstring Broken“. In: The London Magazine (Marz 1954): 6468.

Ders. "Introduction". In: Ivan Bunin. The Gentleman from San Francisco, and Other Stories. Übs. Richard Hare. London: Chatto and Windus, 1975: 7-10.

Sirina, E. A. „Idejno-chudožestvennye funkcii pejzała v cikle rasskazov I. A. Bunina ,Temnye allei"“. In: Tvorčestvo I. A. Bunina $i$ russkaja literatura $X L X-X X$ vekov. Materialy nauCno-praktiðeskoj Vserossijskoj konferencii, posvjašennoj 127 godovsine so dnja roždenija I. A. Bunina 16-17 oktjabrja 1997 goda. Belgorod: Izdatel'stvo Belgorodskogo gosudarstvennogo universiteta, 1998: 190-198.

Scholz, Friedrich. Abbild und Vorbild. Zur Verwendung der Natursymbolik bei Anna Achmatova und Ivan Bunin. Marburger Abhandlungen zur Geschichte und Kultur Osteuropas. 14.Bd. Gießen: Wilhelm Schmitz Verlag, 1977.

Stern, M. S. V poiskach utracennoj garmonii (proza I. A. Bunina 1930-1940-ch gg.): Monografija. Omsk: OmGPU, 1997.

Sedovoj, N. (Hg.). „Iz otzyvov sovetskich pisatelej o Bunine“. In: Literaturnoe nasledstvo. Ivan Bunin. 84.Bd. (2) Moskva: Nauka, 1973: 365-374.

Simonoff, Gabriel. "La Vie des Bounine à Grasse pendant la deuxième guerre mondiale“. In: Bounine revisité. $\mathrm{Hg}$. Claire Hauchard. Cahiers de l'émigration russe 4. Paris: Centre d'études slaves et Institut d'études slaves, 1997: 147-151.

Slivickaja, Ol'ga. „Fabula - kompozicija - detal' buninskoj novelly“. In: Buninskij sbornik. Orel: Orlovskij gosudarstvennyj pedagogiceskij institut, 1974: 90-103.

Dies. „Celovek Bunina kak kosmos i ličnost"“. In: Slavic Almanach. The South African Year Book for Slavic. Central and East European Studies 4 (1997): 69-80.

Slivitskaia [Slivickaja], Olga. „Psichologija kak ontologija. O rasskaze ,V noxnom more““. In: Bounine revisité. $\mathrm{Hg}$. Claire Hauchard. Cahiers de l'émigration russe 4. Paris: Centre d'études slaves et Institut d'études slaves, 1997: 61-69. 
Slonim, Mark. Modern Russian Literature. From Chekhov to the Present. New York: Oxford University Press, 1953.

Smimova, L. Ivan Alekseeviz Bunin. Žizn'i tvorčestvo. Moskva: Prosveščenie, 1991.

Smimov-Sokol'skij, N. P. „Poslednjaja nachodka“. In: Novyj mir 10 (1965): 213-221.

Sokolov, A. G. „Zametki o chudožestvennom masterstve I. Bunina“. In: Russkij jazyk za rubeżom 1 (1971): 95-100.

Solouchina, O. V. „O nravstvenno-filosofskich vzgljadach I. A. Bunina“. In: Russkaja literatura 4 (1984): 47-59.

Stepun, Fedor. „I. A. Bunin i nusskaja literatura“. In: Vozroždenie 13 (1951): 168-175.

Struve, Gleb. Russkaja literatura v izgnanii. Paris: YMCA Press, 1984.

Stulz, Ginette. „Une Approche de Bunin: Etudes des qualificatifs“. In: Cahiers du monde russe et soviétique 3-4 (1987): 347-360.

Ter-Abramjanc, A. P. „Sozvezdija Ivana Bunina (obrazy zvezdnogo neba v tvorčestve Bunina)“. In: I. A. Bunin i russkaja literatura XX veka. Po materialam meždunarodnoj naư̌noj konferencii, posvjašcennoj 125-letiju so dnja roždenija I. A. Bunina. 23-24 oktjabrja 1995 g. Moskva: Nasledie, 1995: 109-116.

Tichomirova, Elena. „Éros iz podpol'ja. Seks-bestsellery 90-ch i russkaja literaturnaja tradicija“. In: Znamja 6 (1992): 220-228.

Tiffany, Kent Sheridan. „Ivan Bunin: A Poet in Prose“. [Masch.schr.] Diss. Columbia University, 1988.

Trifonov, Jurij. Zit. in: „Iz otzyvov sovetskich pisatelej o Bunine“. Hg. N. Sedovoj. In: Literaturnoe nasledstvo. Ivan Bunin. 84.Bd. (2) Moskva: Nauka, 1973: 369.

Troubilova, Elena. „Bunin, Tèffi, Pantelejmonov - istorija družby“. In: Bounine revisité. Hg. Claire Hauchard. Cahiers de l'émigration russe 4. Paris: Centre d'études slaves et Institut d'études slaves, 1997: 129-140.

Tvardovskij, Aleksandr. „O Bunine“. In: Ivan Bunin. Sobranie socinenij v devjati tomach. 1.Bd. Moskva: Chudožestvennaja literatura, 1965: 7-49.

Uxitel', Aleksej (Regie). Dnevnik ego zeny. Spielfilm (104 Min.). Pyramid Home Video, 2000.

Ul'janov, Michail et. al. „Pečal'naja sud'ba archiva Bunina. Otkrytoe pis'mo Prezidentu Rossijskoj Federacii V. V. Putinu“. In: Literaturnaja gazeta 48 (2000): 1.

Vinokur, N. „Novoe o Buninych“. In: Minuv̌̌ee 8 (1989): 282-328.

Volkov, Anatolij. Proza Ivana Bunina. Moskva: Moskovskij rabocij, 1969. 
Voronin, Sergej. Zit. in: „Iz otzyvov sovetskich pisatelej o Bunine“. Hg. N. Sedovoj. In: Literaturnoe nasledstvo. Ivan Bunin. 84.Bd. (2) Moskva: Nauka, 1973: 366-367.

Wasiolek, Edward. „The Fiction of Ivan Bunin: a Critical Study“. [Masch.schr.] Diss. Harvard, 1954.

Woodward, James B. „The Evolution of Bunin's Narrative Technique“. In: Scando-Slavica 16 (1970): 5-21.

Ders. „Eros and Nirvana in the Art of Bunin". In: The Modern Language Review 65 (1970): 576-586.

Ders. „Narrative Tempo in the Later Stories of Bunin“. In: Die Welt der Slaven 16 (1971): 383-396.

Ders. Ivan Bunin A Study of His Fiction. Chapel Hill: The University of North Carolina Press, 1980.

Ders. „The Symphonic Art of Ivan Bunin“. In: The Short Story in Russia. Hg. Nicholas Luker. Nottingham: Astra Press, 1991: 145-158.

Yackovlev, A. de. „Bunin’s Prose Writings in Exile“. [Masch.schr.] Diss. Urbana (Illinois), 1967.

Yashin, Boris (Regie). „The Meshcherskies“. Rußland, 1995.

Zielke, Irina. Text und Metapher. Studien zur Prosa Ivan Bunins. Poetica. Schriften zur Literaturwissenschaft 55. Diss. Münster, 1998. Hamburg: Verlag Dr. Kovac, 2001.

Zweers, Alexander. „The Function of the Theme of Death in the Works of Ivan Bunin“. In: Russian Literature 8 (1980): 151-165.

12.5 Zitierte Primärliteratur anderer Autoren

Alf Laila Wa-laila. Geschichten aus 1001 Nacht. (ca. 8. Jh.). In: Geschichten aus 1001 Nacht. Hg. M. Habicht und H. L. Fleischer. 12 Bd.e. Breslau, 1823-1843.

Babel', Isaak. Konarmija. (1926). In: ders. Socinenija v dvuch tomach. 2.Bd. Moskva: Chudožestvennaja literatura, 1990.

Ders. Odesskie rasskazy. (1921-1924). In: ders. Socinenija v dvuch tomach. 1.Bd. Moskva: Chudožestvennaja literatura, 1990.

Blok, Aleksandr. Neznakomka. (1906). In: ders. Sobranie sočinenij v šesti tomach. Leningrad: Chudožestvennaja literatura, 1981. 
Boccaccio. Decamerone. (1349-1353). Venedig, 1470.

Die Bibel oder Die ganze heilige Schrift des Alten und Neuen Testaments nach der Übersetzung Martin Luthers. Stuttgart: Deutsche Bibelstiftung, 1978.

Dobrodeev, Dmitrij. Archiv i drugie istorii. Moskva: Olim-PPP, 1993.

Fet, Afanasij [Šenšin]. „Kakaja cholodnaja osen'“. (1847). In: ders. Polnoe sobranie socinenij. Leningrad: Sovetskij pisatel', 1959: 455.

Gogol', Nikolaj. Večera na chutore bliz Dikan'ki. (1831). In: ders. Sobranie sočinenij v devjati tomach. 1.Bd. Moskva: Russkaja kniga, 1994.

Goncarov, Ivan. Obyknovennaja istorija. (1847). In: ders. Sobranie socinenij v vos'mi tomach. 1.Bd. Moskva: Chudožestvennaja literatura, 1952.

Ikonnikow, Alexander. Taiga Blues. Öbs. Annelore Nitschke. Berlin: Alexander Fest Verlag, 2002.

Lawrence, D. H. Lady Chatterley. Ohne Angabe des Übersetzers. Hamburg: Rowohlt Taschenbuch Verlag, 1973.

Lermontov, Michail. Geroj našego vremeni. (1840). In: ders. Sobranie sočinenij v četyrech tomach. 4.Bd. Moskva: Pravda, 1986: 100.

Ders. „Utes“. (1841). In: ders. Sobranie socinenij v čtyrech tomach. 1.Bd. Moskva: Pravda, 1986: 100.

Makanin, Vladimir. „Golosa“. (1980). In: ders. Laz. Moskva: Vagrius, 1998.

Nabokov, Vladimir. Die Kunst des Lesens. Frankfurt am Main: Fischer Taschenbuch Verlag, 1991.

Odoevskij, Vladimir. Russkie noci. (1844). In: ders. Sobranie socinenij v dvuch tomach. 1.Bd. Moskva: Chudožestvennaja literatura, 1981.

Ogarev, Nikolaj. „Obyknovennaja povest”“. (1842). In: ders. Stichotvorenija i poèmy. Leningrad: Sovetskij pisatel', 1956: 151-152.

Ovid. Metamorphosen. (1 v. Chr.-10 n. Chr.). In: ders. „Metamorphoseon Libri“. In: Opera. Hg. Franciscus Puteolanus. Bologna, 1471.

Pañcatantra. (1.-6. Jh. n. Chr.). In: Pañcatantra. Hg. F. Kielhorn und G. Bühler. 3 Bd.e. Bombay, 1868.

Polonskij, Jakov. „Zatvornica“. (1846). In: ders. Stichotvorenija. Moskva: Sovetskaja Rossija, 1981: 43-44. 
Prutkov, Koz'ma [Aleksej Tolstoj sowie Aleksej und Vladimir Žemčužnikov]. „Épigramma Nr. 1“. (1854). In: Aleksej Tolstoj. Sobranie socinenij v cetyrech tomach. 1.Bd. Moskva: Chudožestvennaja literatura, 1963: 451.

Puskin, Aleksandr. „Kavkazskij plennik“. (1821). In: ders. Socinenija v četyrech tomach. 2.Bd. Moskva: Chudožestvennaja literatura, 1999: 103-135.

Ders. „Bachcisarajskij fontan“. (1824). In: ders. Socinenija v cetyrech tomach. 2.Bd. Moskva: Chudožestvennaja literatura, 1999: 146-163.

Ders. Pir vo vremja čumy. (1830). In: ders. Sočinenija v četyrech tomach. 3.Bd. Moskva: Chudožestvennaja literatura, 1999.

Ders. Povesti pokojnogo Ivana Petrovica Belkina. (1831). In: ders. Socinenija v cetyrech tomach. 4.Bd. Moskva: Chudožestvennaja literatura, 1999.

Sa'dī, Muslih ad-Dìn. Der Rosengarten. Übs. Karl Heinrich Graf. München: C. H. Beck, 1998.

Shakespeare, William. The Merchant of Venice. (1596). In: www.shakespeare.com FirstFolio/THE_MERCHANT_OF_VENICE/5.1.html.

Tokareva, Viktorija. Korrida. Moskva: ÉKSMO-Press, 1997.

Dies. Gladkoe liciko. Povesti i rasskazy. Moskva: AST, 1999.

Dies. Lilovyj kostjum. Moskva: AST, 1999.

Tolstoj, Aleksej. „Sred’ sumnogo bala, slučajno ...“. (1851). In: ders. Sobranie socinenij v cetyrech tomach. I.Bd. Moskva: Chudožestvennaja literatura, 1963: 79.

Ders. „Il’ja Muromec“. (1871). In: ders. Sobranie sočinenij v četyrech tomach. I.Bd. Moskva: Chudožestvennaja literatura, 1963: 314.

Tolstoj, Lev. Vojna i mir. (1868/69). Moskva: Chudožestvennaja literatura, 1983.

Turgenev, Ivan. Zapiski ochotnika. (1847-1851). In: ders. Sobranie sočinenij v dvadcati tomach. 1.Bd. Moskva: Chudožestvennaja literatura, 1953.

Vertinskij, Aleksandr. „O sesti zerkalach“. (1917). In: Pesni i stichi (1916-1937). Washington: Knigoizdatel'stvo knižnogo magazina Viktora Kamkina, 1962: 73.

Zola, Emile. Nana. In: Les Rougon-Macquart. 9.Bd. Paris, 1880.

Zošcenko, Michail. Rasskazy Nazara Il'ica gospodina Sinebrjuchova. (1921). In: ders. Sobranie socinenij v trech tomach. 1.Bd. Leningrad: Chudožestvennaja literatura, 1986. 
12.6 Nachschlagewerke, Handbücher, Zeitgeschichtliches, Literaturtheorie, Genrestudien

Belova, N. M. „Žanrovoe novatorstvo Turgeneva v ,Zapiskach ochotnika““. In: Učenye zapiski Saratovskogo universiteta 67 (1959): 41-62.

Bronfen, Elisabeth. Over Her Dead Body. Death, Femininity and the Aesthetic. Manchester: Manchester University Press/Routledge, 1992.

Creighton, Joanne V. „Dubliners“ and ,Go Down, Moses“: The Short Story Composite“. [Masch.schr.] Diss. University of Michigan, 1969. Dissertation Abstract Index (DAI) $31: 4$ (1970).

Der große Exodus. Die russische Emigration und ihre Zentren 1917 bis 1941. Hg. Karl Schlögel. München: C. H. Beck, 1994.

Duden. Das Fremdwörterbuch. 5.Bd. 6., verb. und erw. Auflage. Mannheim u.a.: Bibliographisches Institut \& F. A. Brockhaus AG, 1997.

El-Hassan, Karla. Kurzgeschichtenensembles. Formen der Verknüpfung anglokanadischer Short-Stories. Bochum: Universitätsverlag Dr. N. Brockmeyer, 1991.

Enciklopedija dlja detej. 9.Bd. Russkaja literatura. Cast' vtoraja. XX vek. Moskva: Avanta+, 1999.

Enciklopedija mirovoj literatury. Sankt-Peterburg: Nevskaja kniga, 2000.

Fedin, Konstantin. „Reči na s”'ezdach (1954)“. In: ders. Pisatel', iskusstvo, vremja. 4. Auflage. Moskva: Sovetskij pisatel', 1980.

Ingram, Forrest L. Representative Short Story Cycles of the Twentieth Century. Studies in a Literary Genre. The Hague/Paris: Mouton, 1971.

Januškevið, A. S. „Russkij prozaiðeskij cikl kak ,forma vremeni““”. In: Istoričeskie puti i formy chudožestvennoj ciklizacii v poèzii i proze. Hg. M. Darvin. Kemerovo, 1992: 18-35.

Johnston, Robert Harold. „Paris: Die Hauptstadt der russischen Diaspora“. In: Der große Exodus. Die russische Emigration und ihre Zentren 1917 bis 1941. Hg. Karl Schlögel. München: C. H. Beck, 1994: 260-278.

Kasack, Wolfgang. Lexikon der russischen Literatur ab 1917. 1. Auflage. Stuttgart: Alfred Kröner Verlag, 1976.

Ders. Die russische Schriftsteller-Emigration im 20. Jahrhundert. München: Verlag Otto Sagner, 1996.

Kennedy, J. Gerald. „Toward a Poetics of the Short Story Cycle“. Journal of the Short Story in English 11 (Herbst 1988): 9-25. 
Ders. (Hg.) Modern American Short Story Sequences: Composite Fictions, and Fictive Communities. New York: Cambridge University Press, 1995.

Kratkaja literaturnaja énciklopedija. 8.Bd. Moskva: Sovetskaja ènciklopedija, 1975: 398399.

Lauer, Reinhard. Geschichte der russischen Literatur. München: C. H. Beck, 2000.

Lebedev, Ju. V. „Stanovlenie èposa v russkoj literature 1840-1860 gg. (Problemy ciklizacii)". Avtoreferat doktorskoj dissertacii. Jaroslavl, 1975.

Literaturnaja énciklopedija russkogo zarubežja (1918-1940). 1.Bd. Pisateli russkogo zarubež'ja. Moskva: ROSSPEN, 1997.

Ljapina, L. E. Ciklizacija v russkoj literature 1840-60-ch gg. Sankt-Peterburg: Sankt-Peterburgskij Gosudarstvennyj Universitet, 1995.

Dies. Ciklizacija v russkoj literature XIX veka. Sankt-Peterburg: NII Chimii Sankt-Peterburgskij Gosudarstvennyj Universitet, 1999.

Dies. „Puti i principy cikloobrazovanija v lirike, èpike i drame“. In: Zyklusdichtung in den slavischen Literaturen. Beiträge zur internationalen Konferenz. Magdeburg, 18.20. März 1997. Hg. Reinhard Ibler. Frankfurt am Main u.a.: Peter Lang, 2000: 287297.

Lotman, Jurij. Stat'i po istorii russkoj literatury; Teorija i semiotika drugich iskusstv; Mechanizmy kul'tury; Mel'kie zametki. Tallinn: Aleksandra, 1993.

Lubbers, Klaus. Typologie der Kurzgeschichte. Darmstadt: Wissenschaftliche Buchgesellschaft, 1977.

Lundén, Rolf. The United Stories of America. Studies in the Short Story Composite. Amsterdam u.a.: Rodopi, 1999.

Mann, Susan Garland. The Short Story Cycle. A Genre Companion and Reference Guide. WestportConnecticut: Greenwood Press, 1989.

Marti, Roland. „Zyklisierung im älteren kirchenslavischen Schriftum“. In: Zyklusdichtung in den slavischen Literaturen. Beiträge zur internationalen Konferenz, Magdeburg, 18.-20. März 1997. Hg. Reinhard Ibler. Frankfurt am Main u.a.: Peter Lang, 2000: 319-338.

Michajlov, Oleg. „Bunin. 1870-1953“. In: Literatura russkogo zarubež'ja. 1920-1940. Moskva: Nasledie/Nauka, 1993.

Ders. Literatura russkogo zarubež ja. Moskva: Prosvešcenie, 1995.

Ders. „Bunin“. In: Literaturnaja énciklopedija russkogo zarubežja. I.Bd. Moskva: ROSSPEN, 1997: 87-90. 
Neminusxij, A. N. Povesti i rasskazy (1894) v kontekste sbornikov prozy A. P. Cechova. Riga, 1989.

Ohne Verfasserangabe. Russkoe zarubež'e. Zolotaja kniga emigracii. Pervaja tret'XX veka. Enciklopediceskij biograficeskij slovar'. Moskva: ROSSPEN, 1997.

Pospisil, Ivo. "The Cycle as Undercurrent in the Development of Prose: the Example of the $19^{\text {th }}$-Century Russian Novel“". In: Zyklusdichtung in den slavischen Literaturen. Beiträge zur internationalen Konferenz, Magdeburg, 18.-20. März 1997. Hg. Reinhard Ibler. Frankfurt am Main u.a.: Peter Lang, 2000: 419-424.

Reed III, Pleasant Larus. „The Integrated Short-Story Collection: Studies of a Form of Nineteenth- and Twentieth-Century Fiction". [Masch.schr.] Diss. Indiana University. Dissertation Abstract Index (DAI) 35 (1975): 6730A.

Reid, Ian. The Short Story. London: Methuen, 1977.

Schreurs, Marc. Procedures of Montage in Isaak Babel's , Red Cavalry“. Amsterdam u.a.: Rodopi, 1989.

Silverman, Raymond Joel. „The Short Story Composite: Forms, Functions, and Applications". [Masch.schr.] Diss. University of Michigan. Dissertation Abstract Index (DAI) 31: 12 (1970): 6622-A.

Šklovskij, Viktor. „Neskol'ko èmpiriðeskich zamečanij o sposobach soedinenija novell“". In: Povesti o proze. Razmyšlenija i razbory. 1.Bd. Moskva: Chudožestvennaja literatura, 1966: 103-108.

Tomaševskij, Boris. Poetika. 4. Auflage. Moskva: Gosudarstvennoe izdatel'stvo, 1928. Nachdruck New York und London: Johnson Reprint Corporation, 1967.

Vygotskij, Lev. Psichologija iskusstva. Moskva: Iskusstvo, 1968. (darin: „Legkoe dychanie' Bunina“: 187-208).

Ward, D. „The Structure of Pushkin's ,Tales of Belkin““. In: Slavonic and East European Review 14 (1955): 516-517.

Weltz, Friedrich. „Vier amerikanische Erzăhlzyklen“. [Masch.schr.] Diss. München, 1953.

Wilpert, Gero von. Sachwörterbuch der Literatur. 6., verb. und erw. Aufl. Stuttgart: Alfred Kröner, 1979.

Zyklusdichtung in den slavischen Literaturen. Beiträge zur internationalen Konferenz. Magdeburg. 18.-20. März 1997. Hg. Reinhard Ibler. Frankfurt am Main u.a.: Peter Lang, 2000. 


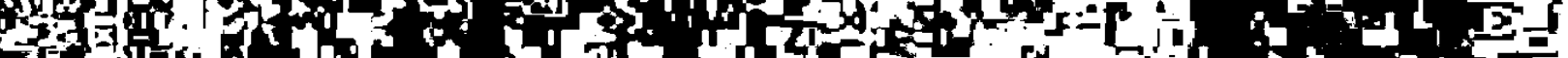




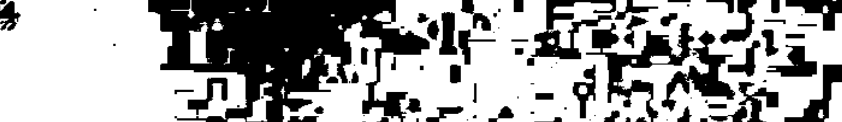

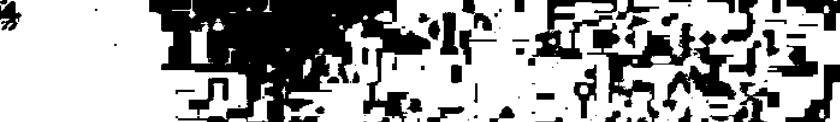

N1) (1) to for

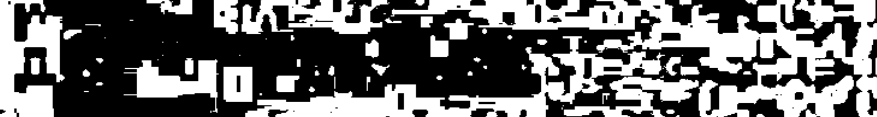

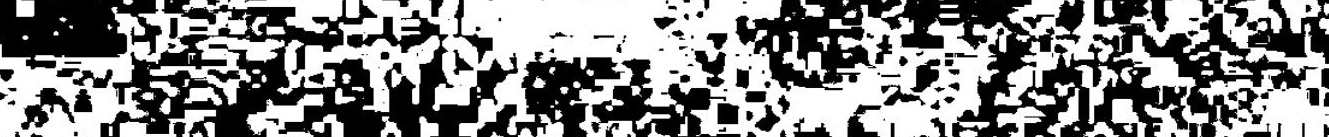

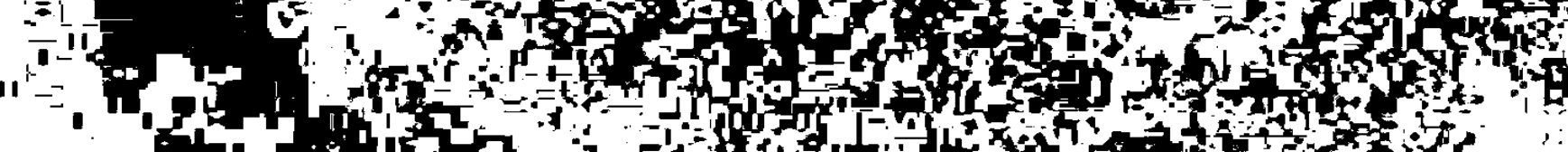

I f

L,

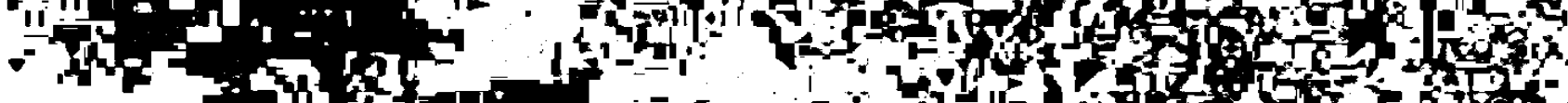

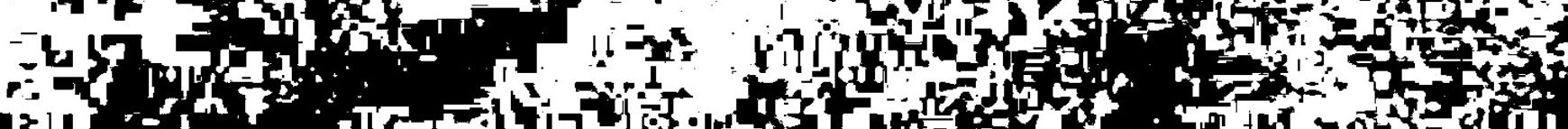
12

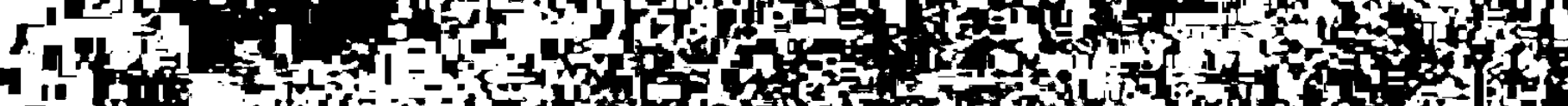
119! II

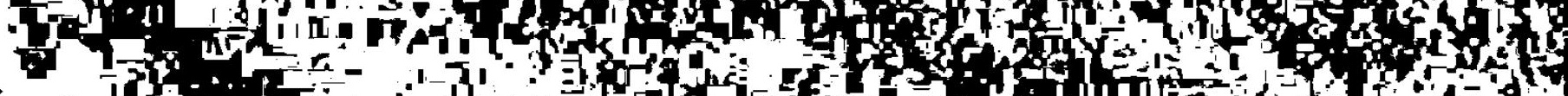
inc

E A - $=1040$

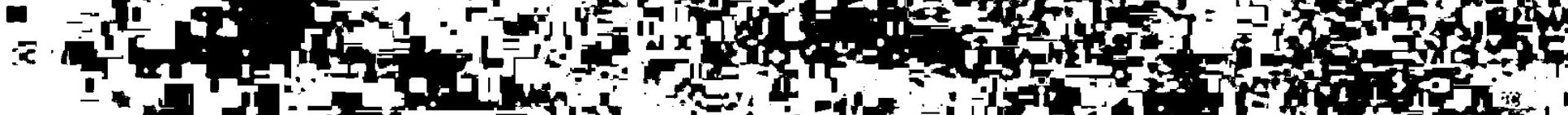
- 1 II n-

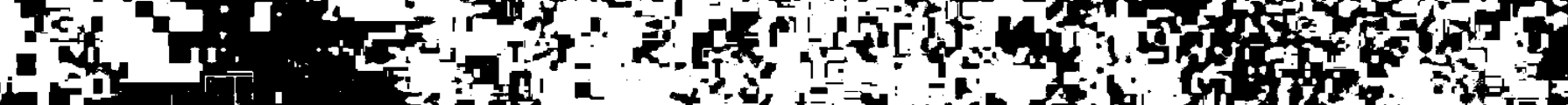
4.

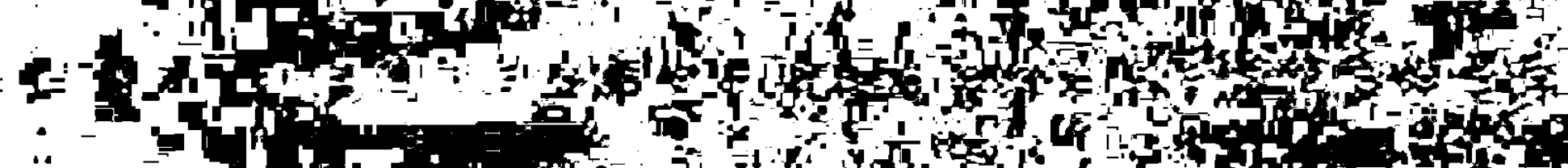

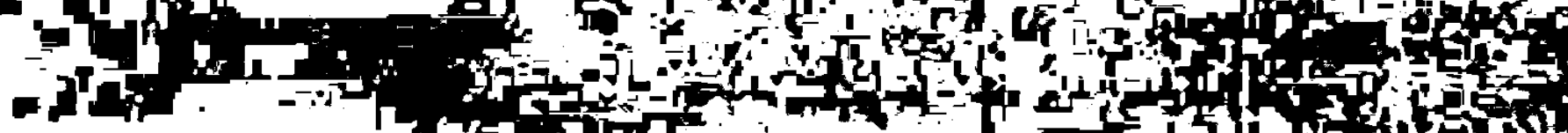

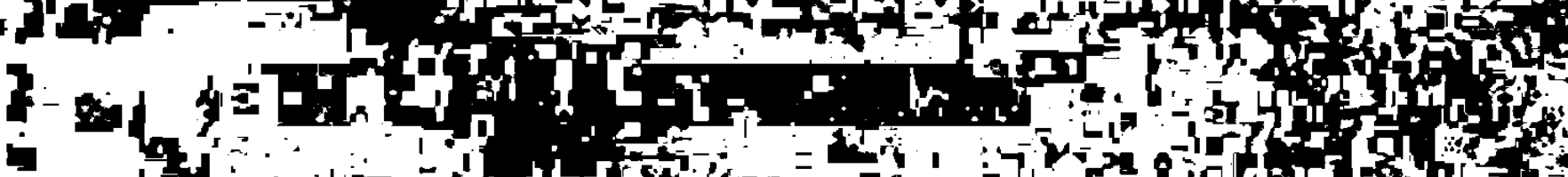

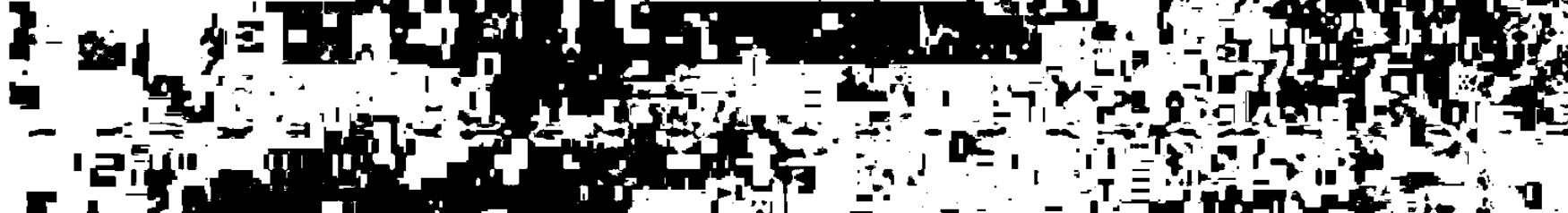

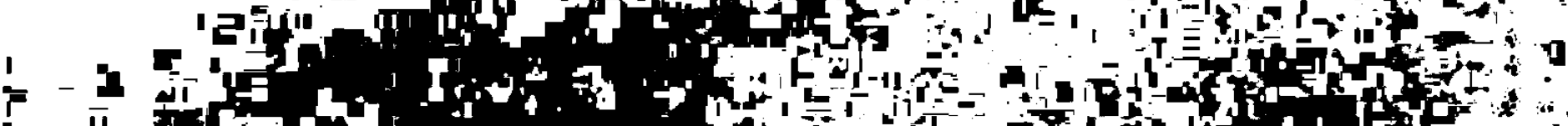

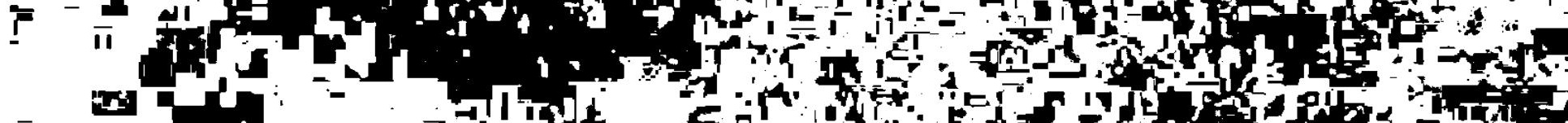
I

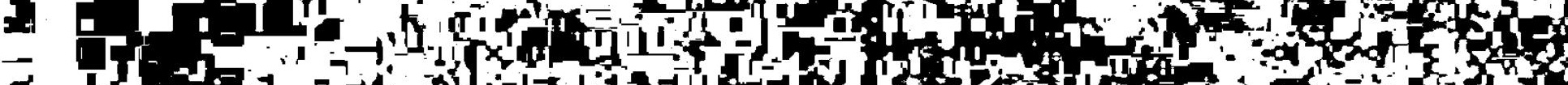

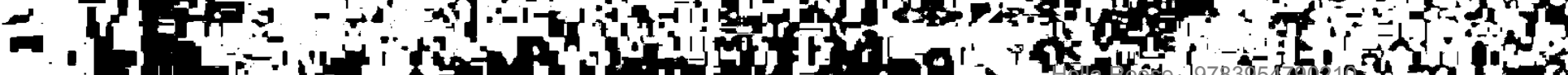
$11=0$ r F, 


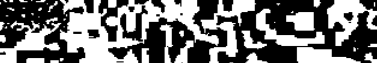

T

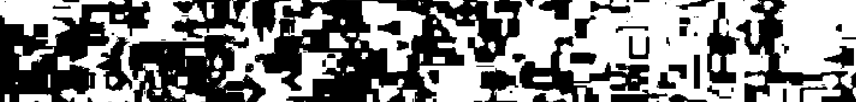

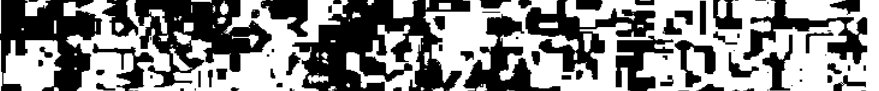

ris

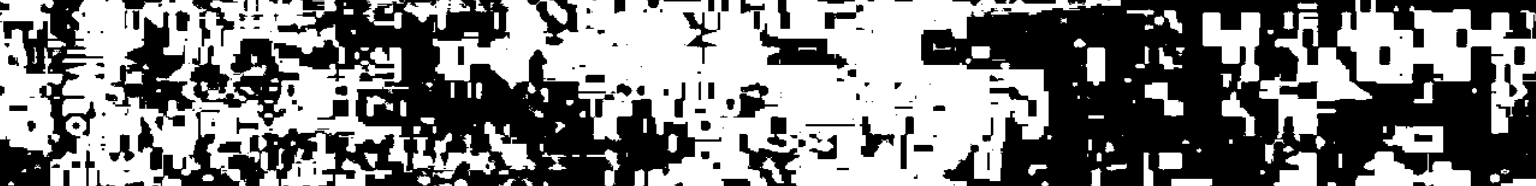

and

a.jot

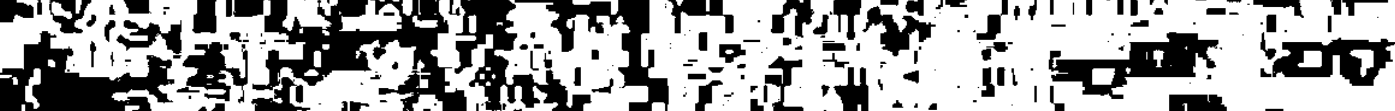

$F_{1} x^{2}$ is

10

fold

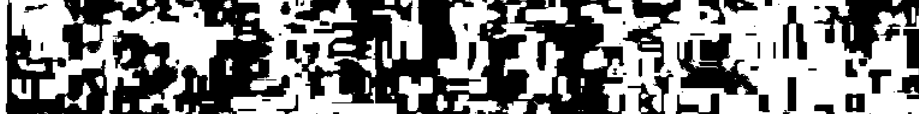

$\geqslant$

$=$

175

trit

of

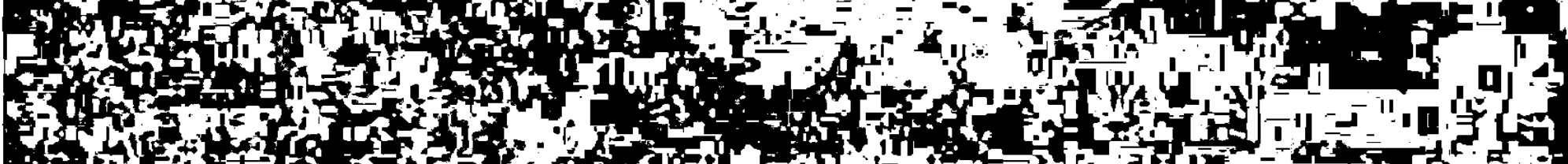

S.

Ste

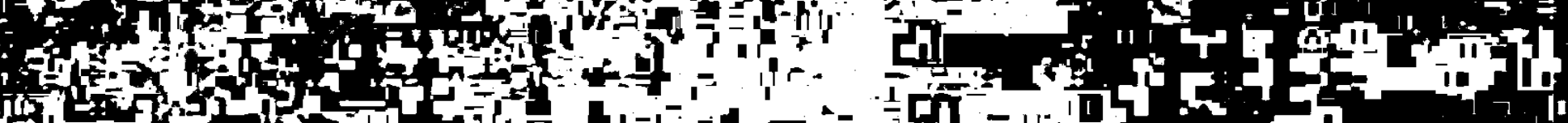
Gin

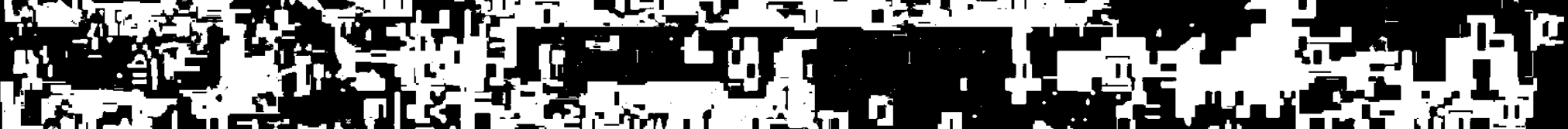
(5)

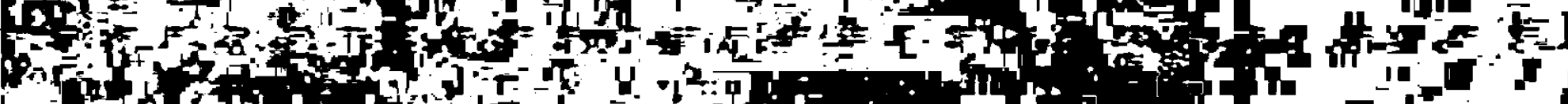
sen \&5

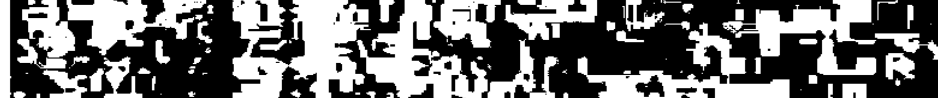

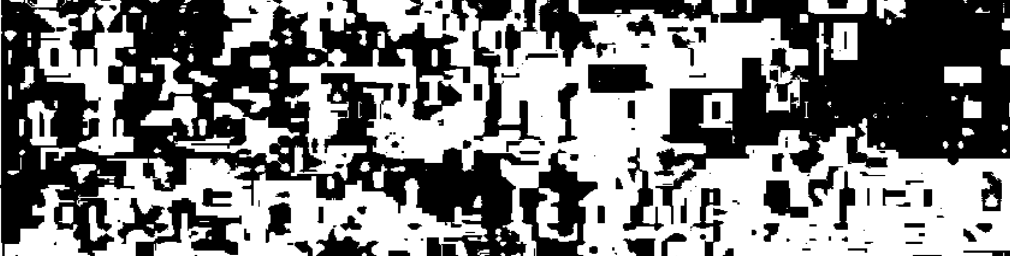

1.

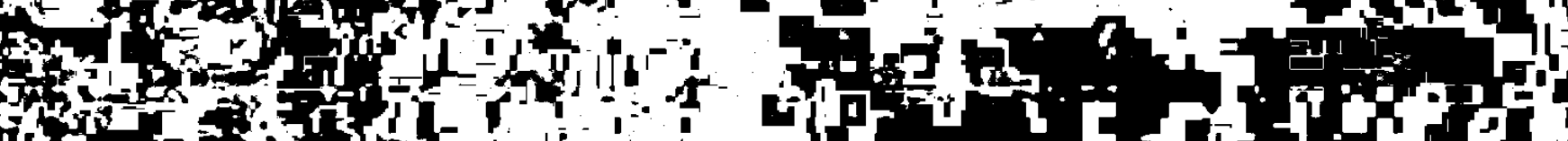

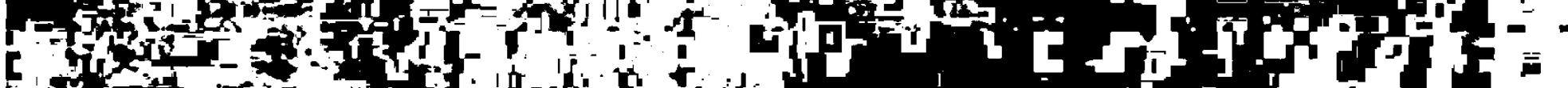
L a

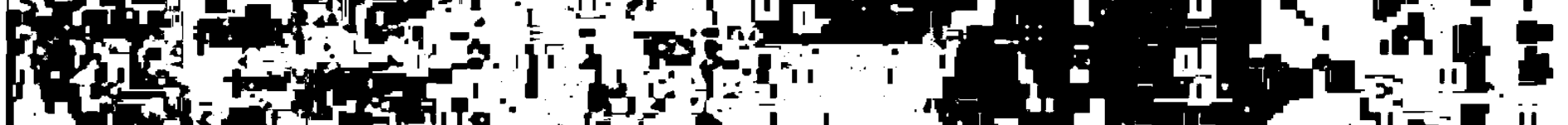
(1) T.4.

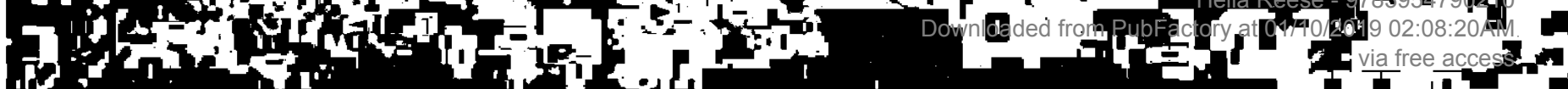


13.1 Anhang 1: Alphabetische Übersicht über alle zwischen 1936 („Molodost' i starost““) und 1949 („Legenda“) entstandenen Erzählungen' sowie über die in der vorliegenden Arbeit erwähnten Entwürfe, Skizzen und Notizen

\section{A: Erzăhlungen}

\begin{tabular}{|c|c|c|c|c|c|c|c|c|}
\hline & Tirel & $\begin{array}{l}\text { Ori der } \\
\text { Entstehung }\end{array}$ & $\begin{array}{l}\text { Datum MS, } \\
\text { Orl der } \\
\text { Archi- } \\
\text { vierung }\end{array}$ & $\begin{array}{l}\text { Datum TS, } \\
\text { Ort der } \\
\text { Archi- } \\
\text { vierung }\end{array}$ & Medium der Erstpublikation & $\begin{array}{l}\text { Ort der } \\
\text { Erst- } \\
\text { publi- } \\
\text { kation }\end{array}$ & $\begin{array}{l}\text { Ent- } \\
\text { halten in } \\
\text { Temmee } \\
\text { allei } \\
\text { von' }\end{array}$ & Erganzende Bemerkungen \\
\hline 1 & "Achmat" & Grasse & $\begin{array}{l}18.04 .1944, \\
\text { LRA } \\
\end{array}$ & $\begin{array}{l}18.04 .1946 \\
\text { LRA }\end{array}$ & Novyj Zurnal 142 (1981): 5-6 & New York & 1 & $\begin{array}{l}1946 \text { oberarbeitete und veranderte Fassung; } \\
\text { Abdruck dieser Fassung im Novyj turnal }\end{array}$ \\
\hline $2 a$ & $\begin{array}{l}\text { "Alja", } \\
\text { 1. Redaktion }\end{array}$ & Grasse & $\begin{array}{l}\text { 16.03.1944, } \\
\text { LRA }\end{array}$ & $\begin{array}{l}\text { Undatien, } \\
\text { LRA }\end{array}$ & Novyj zurnal S7 (1959): 13 & New York & 1 & $\begin{array}{l}\text { Die Erzthlung gehorte zu einem Paket mit } \\
\text { unveroffentlichten Erzahlungen (,Zimnij son } \\
\text { i procee")', das nach Bunins Tod aufgelost } \\
\text { wurde, so daß der Inhalt nicht mehr } \\
\text { ermittelbar ist }\end{array}$ \\
\hline 26 & $\begin{array}{l}\text { "Alja", } \\
\text { 2. Redaktion }\end{array}$ & Grasse & $\begin{array}{l}16.10 .1944 \\
\text { LRA }\end{array}$ & $\begin{array}{l}\text { Undatiert, } \\
\text { LRA }\end{array}$ & $\begin{array}{l}\text { Novyj turnal } 69 \text { (1962): } 15- \\
16\end{array}$ & New York & $\pi$ & $\begin{array}{l}\text { Oberabeitete, leicht gekurate Fassung; } \\
\text { Abdruck der spateren Redaktion in der SSv } \\
\text { vos'mi tomach (1999) unter Angabe des } \\
\text { fruheren Datums (6: 594) }\end{array}$ \\
\hline 3 & "Alupka“ & Grasse & $\begin{array}{l}21.04 .1944 \\
\text { RGALI }\end{array}$ & 1 & $\begin{array}{l}\text { Vesnoj, v Iudee. } \\
\text { Roza lerichona, } 1953\end{array}$ & New York & 1 & $\begin{array}{l}\text { Durch verschiedene Ausgaben zieht sich ein } \\
\text { Druckfehler bei der Datumsangabe: Das } \\
\text { Manuskript belegt den } 21.04 .1944 \text { als } \\
\text { Entstehungsdatum; zudem befindet sich die } \\
\text { Erzahlung in einer Aufstellung aus dem Jahre } \\
\text { 1944, und schließlich hatte Bunin } 1949 \\
\text { massive gesundheitliche Probleme, die ihn an } \\
\text { einer ausgeprägten schopferischen Tatigkeit } \\
\text { hinderten }\end{array}$ \\
\hline 4 & "Antigona" & Grasse & $\begin{array}{l}02.10 .1940, \\
\text { LRA }\end{array}$ & 1 & Temnye allei, 1946 & Paris & $\begin{array}{l}1946, \\
1999 \\
\end{array}$ & $\begin{array}{l}\text { Ursprungliche Titel }{ }^{6} \text { „Anekdor", „Flora“ und } \\
\text { „Flora i fauna“" }\end{array}$ \\
\hline
\end{tabular}




\begin{tabular}{|c|c|c|c|c|c|c|c|c|}
\hline 5 & ..Aprel'” & Grasse & 1 & $\begin{array}{l}09.03 .1938 \\
\text { LRA }\end{array}$ & $\begin{array}{l}\text { Poslednie novosti } 6203 \\
\text { (20.03.1938) und Poslednie } \\
\text { novosti } 6217 \text { (03.04.1938) als } \\
\text { "Varianty gl. I" bzw. } \\
\text { "Varianty gl. II" }\end{array}$ & Paris & 1943 & $\begin{array}{l}\text { Die erste Skizze zu dieser Erzahlung stammt } \\
\text { aus dem Jahr 1926; die Erzahlung entstand } \\
\text { im Gefolge von „Mitina ljubov" (1925) }\end{array}$ \\
\hline $6 a$ & \begin{tabular}{|l} 
Au secours!", \\
1. Redaktion \\
\end{tabular} & Grasse & $\begin{array}{l}\text { 18.04.1944, } \\
\text { LRA }\end{array}$ & 1 & Novyj turnal 168 (1987): 75 & New York & 1 & \\
\hline $6 b$ & $\begin{array}{l}\text { "Au secours!", } \\
\text { 2. Redaktion }\end{array}$ & Grasse & $\begin{array}{l}\text { Undatiert, } \\
\text { LRA }\end{array}$ & 1 & Unveroffentlicht & 1 & 1 & $\begin{array}{l}\text { Erheblich kurzer als die erste Redaktion, } \\
\text { vermutlich spater entstanden; gravierender } \\
\text { Textunterschied: „Je ne l'ai pas blesse!“" in } \\
\text { dieser Version versus „C'est toi que j'ai } \\
\text { blesse!“ in der gedruckten Fassung } \\
\end{array}$ \\
\hline 7 & .Ballada" & Grasse & $\begin{array}{l}03.02 .1938 \\
\text { LRA }\end{array}$ & 1 & $\begin{array}{l}\text { Poslednie novosti } 6175 \\
(20.02 .1938)\end{array}$ & Paris & $\begin{array}{l}1943 \\
1946 \\
1999 \\
\end{array}$ & $\begin{array}{l}\text { Ursprunglicher Titel: „Božij zver'“; im LRA } \\
\text { werden dazugehorige Notizen verwahr, kein } \\
\text { vollstandiges MS }\end{array}$ \\
\hline 8 & . Barysnja Klara" & Grasse & $\begin{array}{l}\text { l7.04.1944, } \\
\text { LRA } \\
\end{array}$ & 1 & Temnye allei, 1946 & Paris & \begin{tabular}{|l|}
1946, \\
1999 \\
\end{tabular} & \\
\hline 9 & ..Casovnja" & Grasse & \begin{tabular}{|l|}
02.07 .1944$, \\
LRA \\
\end{tabular} & 1 & Temnye allei, 1946 & Paris & \begin{tabular}{|l|}
1946, \\
1999 \\
\end{tabular} & \\
\hline 10 & ..Cholodnaja asen'". & Grasse & $\begin{array}{l}03.05 .1944 \\
\text { RGALI }\end{array}$ & $\begin{array}{l}03.05 .1944 \\
\text { RGALI }\end{array}$ & $\begin{array}{l}\text { Russkie novostil } \\
\text { (18.05.1945) }\end{array}$ & Paris & $\begin{array}{l}1946 \\
1999\end{array}$ & \\
\hline 11 & ."Cistyj ponedel 'nik" & Grasse & $\begin{array}{l}\text { 10.05.1944, } \\
\text { LRA }\end{array}$ & $\begin{array}{l}02.07 .1944 \\
\text { LRA }\end{array}$ & Novyj zurnal 10 (1945): 7-21 & New York & $\begin{array}{l}1946, \\
1999\end{array}$ & $\begin{array}{l}\text { Datendiskrepanz: In der Sobranie socinenij v } \\
\text { vos 'mi lomach (1999) wird der } 12.05 .1944 \\
\text { als Entstehungsdatum angegeben }\end{array}$ \\
\hline 12 & .Dalekij pozar" & Grasse & $\begin{array}{l}\text { 04.05.1944, } \\
\text { LRA }\end{array}$ & $\begin{array}{l}\text { Undatier, } \\
\text { LRA } \\
\end{array}$ & Novyj zurnal 142 (1981): 8 & New York & 1 & \\
\hline 13 & ...Dubki ${ }^{\prime \prime}$ & Grasse & 1 & $\begin{array}{l}30.10 .1943, \\
\text { LRA } \\
\end{array}$ & $\begin{array}{l}\text { Novyj zurnal II (1945): } 12 \text {. } \\
16\end{array}$ & New York & \begin{tabular}{|l|}
1946, \\
1999 \\
\end{tabular} & $\begin{array}{l}\text { Laut Tagebucheintrag Bunins wurde diese } \\
\text { Erzathlung am } 29 . / 30.10 .1943 \text { geschrieben }\end{array}$ \\
\hline 14 & "Dura” & Grasse & $\begin{array}{l}21.09 .1943, \\
\text { LRA }\end{array}$ & $\begin{array}{l}21.09 .1943, \\
\text { LRA }\end{array}$ & Unveroffentlicht & I & I & $\begin{array}{l}\text { Ursprungliche Titel: „V rabocuju poru“, } \\
\text { „Sancta Simplicitas“” }\end{array}$ \\
\hline
\end{tabular}




\begin{tabular}{|c|c|c|c|c|c|c|c|c|}
\hline 15 & ..Durocka" & Grasse & $\begin{array}{l}22.09 .1940, \\
\text { LRA }\end{array}$ & $\begin{array}{l}\text { Undatiert, } \\
\text { RGALI }\end{array}$ & $\begin{array}{l}\text { Novosel'e 26 (AprilMai } \\
\text { 1946): 4-6 }\end{array}$ & New York & $\begin{array}{l}1946 \\
1999\end{array}$ & $\begin{array}{l}\text { Ursprunglicher Titel: „Po ulice mostovoj" } \\
\text { RGALI: Undatiertes TS; gemeinsam mit } \\
\text { "Gost'“ und „Krasavica“ unter dem Titel } \\
\text { "Kratkie rasskazy“ zusammengefaßt und als } \\
\text { Gruppe unter diesem Titel in Novosel'e } \\
\text { abgedruckt }\end{array}$ \\
\hline 16 & "Galja Ganskaja" & Grasse & $\begin{array}{l}28.10 .1940, \\
\text { LRA }\end{array}$ & 1 & Novyj turnal 13 (1946): S-13 & New York & $\begin{array}{l}1946 \\
1999\end{array}$ & 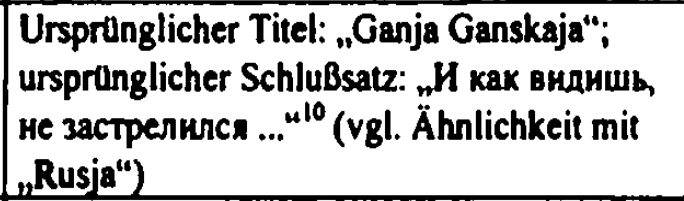 \\
\hline 17 & .Genrich" & Grasse & $\begin{array}{l}\text { l0.11.1940, } \\
\text { LRA }\end{array}$ & 1 & Novyj Eurnal 3 (1942): 5.19 & New York & $\begin{array}{l}1946, \\
1999\end{array}$ & $\begin{array}{l}\text { Ursprunglicher Name der Protagonistin im } \\
\text { MS: Maks bzw. Gans; bemerkenswert ist der } \\
\text { Wechsel zu einem melodischeren zweisilbi- } \\
\text { gen Namen }\end{array}$ \\
\hline 18 & "Gast"." & Grasse & $\begin{array}{l}03.10 .1940, \\
\text { LRA }\end{array}$ & $\begin{array}{l}\text { Undatiert, } \\
\text { RGALI }\end{array}$ & $\begin{array}{l}\text { Novosel'e } 26 \text { (AprilMai } \\
\text { 1946): } 6-8\end{array}$ & New York & $\begin{array}{l}1946 \\
1999\end{array}$ & 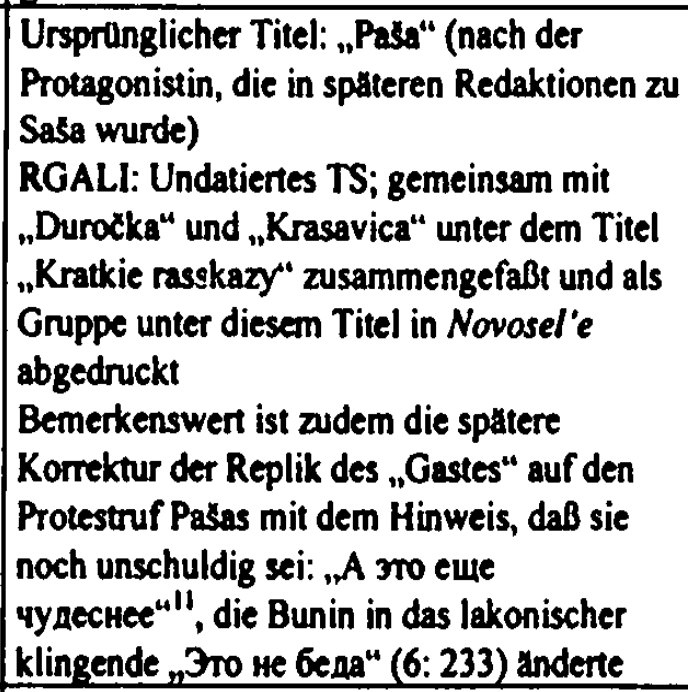 \\
\hline 19 & "Ivolga" & Grasse & $\begin{array}{l}\text { Okt.Nov. } \\
\text { 1943, } \\
\text { LRA }\end{array}$ & $\begin{array}{l}\text { Okt.Nov. } \\
\text { 1943, } \\
\text { LRA }\end{array}$ & Unveroffentlicht & t & 1 & $\begin{array}{l}\text { Bemerkenswert sind eine Reihe } \\
\text { dazugehoriger Notizen franzosischsprachiger } \\
\text { Sprichworter; unklar ist, ob diese in die } \\
\text { Erzthlung aufgenommen werden sollten }\end{array}$ \\
\hline 20 & .Kudeli" & Grasse & $\begin{array}{l}24.09 .1943, \\
\text { RGALI }\end{array}$ & 1 & $\begin{array}{l}\text { Russkie novosti } 26 \\
(09.11 .1945)\end{array}$ & Paris & $\begin{array}{l}1946, \\
1999\end{array}$ & \\
\hline 21 & .Kamarg" & Grasse & $\begin{array}{l}23.05 .1944, \\
\text { LRA }\end{array}$ & 1 & Temnye allei, 1946 & Paris & $\begin{array}{l}1946, \\
1999 \\
\end{array}$ & \\
\hline
\end{tabular}




\begin{tabular}{|c|c|c|c|c|c|c|c|c|}
\hline 22 & .Kavkaz" & Grasse & $\begin{array}{l}04.09 .1937, \\
\text { RGALI } \\
\text { (Fragmente) }\end{array}$ & $\begin{array}{l}\text { 04.09.1937, } \\
\text { RGALI } \\
\text { (Fragmente) }\end{array}$ & $\begin{array}{l}\text { Poslednie novasti } 6077 \\
(14.11 .1937)\end{array}$ & Paris & $\begin{array}{l}1943 \\
1946 \\
1999\end{array}$ & $\begin{array}{l}\text { Fragmente im RGALI: MS und TS mit } \\
\text { Korrekturen, Ende fehlt, Varianten: } \\
\text { 18.09.1937 } \\
\text { Datendiskrepanz: Verschiedene } \\
\text { Publikationen nennen den } 12.11 .1937 \text { als } \\
\text { Entstehungsdatum; Datierung moglich durch } \\
\text { TS des Artikels, „Zloby dnja nusskogo Pariž" } \\
\text { von Andrej Sedych fur das Novoe russkoe } \\
\text { slovo }\end{array}$ \\
\hline 23 & "Kibitka" & Grasse & \begin{tabular}{|l|}
16.10 .1944$, \\
LRA \\
\end{tabular} & \begin{tabular}{|l|}
6.10 .1944$, \\
LRA \\
\end{tabular} & $\begin{array}{l}\text { Novyj zurnal 168-169 (1987): } \\
77-78\end{array}$ & New York & 1 & \\
\hline 24 & "Knjąna Sajtanova“ & Grasse? & $\begin{array}{l}\text { Undatiert, } \\
\text { LRA }\end{array}$ & 1 & Unveroffentlicht & 1 & 1 & \\
\hline 25 & $\begin{array}{l}\text {..'Kogda ja } \\
\text { vpervye ...." }\end{array}$ & Grasse & $\begin{array}{l}\text { Undatien, } \\
\text { LRA }\end{array}$ & $\begin{array}{l}22.04 .1944, \\
\text { LRA }\end{array}$ & Novyj turnal 66 (1961): 6.7 & New York & 1 & $\begin{array}{l}\text { In einem MS wahlte Bunin zunachst einen } \\
\text { deutlich beleidigenderen Schluß: „Позволь } \\
\text { тебе напомннать, что, когда ты вступал в } \\
\text { жнзнь, тебе было уже под тридцать. Кроме } \\
\text { того я уже давно знако про твою связь с } \\
\text { зтнм лысым выродком, который чуть не } \\
\text { на пятнадцать лет моложе тебя.“"13 }\end{array}$ \\
\hline 26 & "Krasavica" & Grasse & $\begin{array}{l}22.09 .1940 \\
\text { LRA }\end{array}$ & $\begin{array}{l}\text { Undatiert, } \\
\text { RGALI }\end{array}$ & $\begin{array}{l}\text { Novosel'e } 26 \text { (April/Mai } \\
\text { 1946): 3-4 }\end{array}$ & New York & $\begin{array}{l}1946, \\
1999\end{array}$ & $\begin{array}{l}\text { Urspringlicher Titel: „Mamin sunduk" } \\
\text { RGALl: Undatiertes TS; gemeinsam mit } \\
\text { "Durocka" und „Gost'" unter dem Titel } \\
\text { "Kratkie rasskazy" zusammengefaßt und als } \\
\text { Gruppe unter diesem Titel in Novosel'e } \\
\text { abgedruckt }\end{array}$ \\
\hline 27 & "Krem Leodor" & Grasse & \begin{tabular}{|l|}
22.04 .1944$, \\
LRA
\end{tabular} & $\begin{array}{l}\text { Undatier, } \\
\text { LRA } \\
\end{array}$ & $\begin{array}{l}\begin{array}{l}\text { Novasel'e } 31.32 \\
\text { (Januar/Februar 1947): } 3\end{array} \\
\end{array}$ & New York & 1 & Ursprunglicher Titel: „Razgovory“ \\
\hline 28 & ..Kuma“ & Grasse & \begin{tabular}{|l|}
25.09 .1943$, \\
LRA
\end{tabular} & 1 & Temmye allei, 1946 & Paris & $\begin{array}{l}1946 \\
1999\end{array}$ & \\
\hline 29 & "Legenda" & Paris? & 1 & 1949 & \begin{tabular}{|l|} 
Vesnoj, v ludee. Roza \\
Ierichona, 1953 \\
\end{tabular} & New York & 1 & \\
\hline 30 & "Lita" & Grasse & \begin{tabular}{|l|}
23.09 .1943$. \\
LRA
\end{tabular} & $\begin{array}{l}23.09 .1943, \\
\text { LRA }\end{array}$ & $\begin{array}{l}\text { Novyj zurnal } 77 \text { (1964): } 41 . \\
42\end{array}$ & New York & 1 & \\
\hline 31 & "Lizok" & Grasse & $\begin{array}{l}\text { Oktober } \\
\text { 1943, } \\
\text { LRA }\end{array}$ & $\begin{array}{l}\text { Undatiert, } \\
\text { LRA }\end{array}$ & Unveroffentlicht & 1 & 1 & Hella Rees \\
\hline
\end{tabular}




\begin{tabular}{|c|c|c|c|c|c|c|c|c|}
\hline 32 & ...Madrid"“ & Grasse & $\begin{array}{l}26.04 .1944, \\
\text { LRA }\end{array}$ & 1 & Novosel'e 21 (1945): 3-10 & New York & $\begin{array}{l}1946, \\
1999 \\
\end{array}$ & \\
\hline $33 \mathrm{a}$ & $\begin{array}{l}\text { "Marija Stjuart", } \\
\text { I. Redaktion }\end{array}$ & Grasse & 1 & 1944, LRA & Unveroffentlicht & 1 & 1 & \\
\hline $33 \mathrm{~b}$ & \begin{tabular}{|l} 
"Marija Stjuart", \\
2. Redaktion \\
\end{tabular} & Paris? & 1 & $\begin{array}{l}\text { 1948, } \\
\text { LRA }\end{array}$ & \begin{tabular}{|l|}
$\begin{array}{l}\text { Novyj Eurnal 168-169 (1987): } \\
76-77\end{array}$ \\
\end{tabular} & New York & 1 & \\
\hline 34 & .Mest"“ & Grasse & $\begin{array}{l}04.06 .1944, \\
\text { LRA }\end{array}$ & 1 & Novyj Zurnal 12 (1946): 5-14 & New York & $\begin{array}{l}1946, \\
1999 \\
\end{array}$ & Urspringlicher Titel: „Nemezida“ \\
\hline 35 & "Mistral'"4 & \begin{tabular}{|l} 
Primorskie \\
Al'py \\
\end{tabular} & 1 & 1944 & Vstreda, Juli 1945 & Paris & 1 & \\
\hline 36 & "Modest" & Grasse & 1 & $\begin{array}{l}16.10 .1944, \\
\text { LRA }\end{array}$ & Novyj Iurnal 67 (1962): 5-6 & New York & 1 & Ursprunglicher Titel: „Na jarmarke“ \\
\hline 37 & .Molodost' i starost”“ & Beausoleil & 1936 & & $\begin{array}{l}\text { Illjustrirovannaja Rassija } 20 \\
\text { (09.05.1936), unter dem Titel } \\
\text { "Pro obez'janu“" }\end{array}$ & Paris & & Urspronglicher Titel: „Pro obez'janu“ \\
\hline 38 & "Muza" & Paris? & $\begin{array}{l}17.10 .1938 \\
\text { RGALI }\end{array}$ & $\begin{array}{l}\text { Undatiert, } \\
\text { LRA } \\
\text { (Fragment) } \\
\end{array}$ & $\begin{array}{l}\text { Paslednie novosti } 6426 \\
(30.10 .1938)\end{array}$ & Paris & $\begin{array}{l}1943 \\
1946 \\
1999 \\
\end{array}$ & \\
\hline 39 & .Nacalo“ & Grasse & \begin{tabular}{|l|}
23.10 .1943$, \\
LRA
\end{tabular} & 1 & Temmye allei, 1946 & Paris & \begin{tabular}{|l|}
1946, \\
1999 \\
\end{tabular} & \begin{tabular}{|l} 
In seinem Tagebuch bezeichnet Bunin diese \\
Erzthlung als ,rasskazik “14 \\
\end{tabular} \\
\hline 40 & .Na izvozcike" & Grasse & $\begin{array}{l}\text { Undatien, } \\
\text { LRA } \\
\end{array}$ & 1 & \begin{tabular}{|l|} 
Novyj Iurnal 168-169 (1987): \\
$68-73$
\end{tabular} & New York & 1 & \\
\hline 41 & \begin{tabular}{|l|} 
Na postojalom \\
dvore" \\
\end{tabular} & Grasse & $\begin{array}{l}27.11 .1942, \\
\text { LRA }\end{array}$ & $\begin{array}{l}\text { Undatiert, } \\
\text { LRA } \\
\end{array}$ & Unveroffentlicht & 1 & 1 & \\
\hline 42 & "Nalali" & Grasse & \begin{tabular}{|l|}
$18.03 .-$ \\
04.04 .1941$, \\
RGALI \\
(Varianten, \\
Fragmente) \\
\end{tabular} & \begin{tabular}{|l|}
04.04 .1941 \\
RGB (2. \\
Variante)
\end{tabular} & Novyj iurnal 2 (1942): 5.37 & New York & $\begin{array}{l}1943 \\
1946 \\
1999\end{array}$ & Ursprunglicher Titel: „Natali Stankevic“ \\
\hline 43 & .Nocleg" & \begin{tabular}{|l} 
Juan-les- \\
Pins \\
\end{tabular} & 23.03 .1949 & 1 & Vozrozdenie 3 (1949) & Paris & 1999 & \\
\hline 44 & "Novaja Subka" & Grasse & $\begin{array}{l}\text { 02.05.1944, } \\
\text { LRA }\end{array}$ & $\begin{array}{l}\text { Undatiert, } \\
\text { LRA } \\
\end{array}$ & Novyj Iurnal 142 (1981): 6-8 & New York & 1 & Abdruck folgt TS \\
\hline 45 & "Otec Nikon" & Grasse & $\begin{array}{l}27.05 .1944, \\
\text { LRA }\end{array}$ & $\begin{array}{l}\text { Undatien, } \\
\text { LRA }\end{array}$ & Unveroffentlicht & 1 & 1 & MS ohne Unterschrift \\
\hline 46 & "Pamjatnyj bal" & Grasse & $\begin{array}{l}\text { 29.04.1944, } \\
\text { RGALI }\end{array}$ & 1 & $\begin{array}{l}\text { Russkie novosti } 86 \\
\text { (03.01.1947) }\end{array}$ & Paris & 1 & $\therefore$ \\
\hline
\end{tabular}




\begin{tabular}{|c|c|c|c|c|c|c|c|c|}
\hline 47 & ."Parochod Saratov"' & Grasse & $\begin{array}{l}\text { 16.05.1944, } \\
\text { RGALI }\end{array}$ & $\begin{array}{l}\text { Undatiert, } \\
\text { LRA } \\
\end{array}$ & $\begin{array}{l}\text { Novyj turnal II (1945): } 16- \\
21\end{array}$ & New York & $\begin{array}{l}1946, \\
1999 \\
\end{array}$ & \\
\hline 48 & "Pis'ma“ & Grasse & 1 & $\begin{array}{l}\text { 15.10.1944, } \\
\text { LRA }\end{array}$ & $\begin{array}{l}\text { Novyj turnal 168-169(1987): } \\
76\end{array}$ & New York & 1 & \\
\hline 49 & ,Poludennyj zar" & Paris & 1947 & 1 & Vozrotdenie l (1949) & Paris & 1 & \\
\hline 50 & .Pozdnij cas" & Grasse & $\begin{array}{l}\text { l9.11.1938, } \\
\text { LRA }\end{array}$ & 1 & $\begin{array}{l}\text { Poslednie novosti } 6467 \\
(11.12 .1938)\end{array}$ & Paris & $\begin{array}{l}1943 \\
1946 \\
1999 \\
\end{array}$ & \\
\hline 51 & ..Raisa“ & Grasse? & \begin{tabular}{|l|} 
Undatiert, \\
LRA \\
\end{tabular} & 1 & Unveroffentlicht & 1 & 1 & $\begin{array}{l}\text { Vermutlich Anfang der 1940er Jahre } \\
\text { entstanden }\end{array}$ \\
\hline 52 & . Recnoj traksir" & Grasse & $\begin{array}{l}28.10 .1943, \\
\text { RGALI } \\
\text { (Entwurf) }\end{array}$ & 1 & Novyj turnal II (1945): 5-11 & New York & $\begin{array}{l}1946 . \\
1999\end{array}$ & $\begin{array}{l}\text { Ursprunglicher Titel: „Rečnoj restoran“; } 1945 \\
\text { auch als Sonderausgabe in limitierter und } \\
\text { numerierter Auflage ( } 1.000 \text { Stuck) in New } \\
\text { York erschienen }\end{array}$ \\
\hline 53 & "Riv'era" & Grasse & $\begin{array}{l}10.01 .1944 \\
\text { LRA }\end{array}$ & $\begin{array}{l}\text { Undatiert, } \\
\text { LRA }\end{array}$ & Novyj turnal 68 (1962): 5-7 & New York & $T$ & 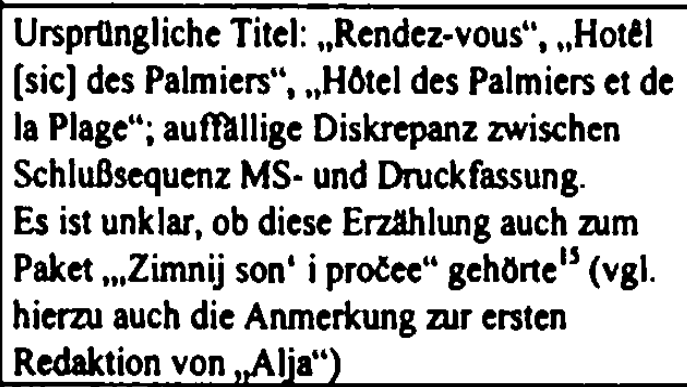 \\
\hline 54 & .Rusja" & Grasse & $\begin{array}{l}20.09 .1940 \\
\text { RGALI }\end{array}$ & 1 & Novyj zurnal I (1942): 8-16 & New York & $\begin{array}{l}1943 \\
1946 \\
1999 \\
\end{array}$ & $\begin{array}{l}\text { Laut Tagebucheintrag Bunins wurde die } \\
\text { Erzashlung am 27.09.1940 fertiggestellt }{ }^{16}\end{array}$ \\
\hline 55 & "Skazka pro soldata“ & Grasse & 1 & $\begin{array}{l}\text { 1943, } \\
\text { LRA }\end{array}$ & Unveroffentlicht & 1 & 1 & \\
\hline 56 & .. Smaragd" & Grasse & $\begin{array}{l}03.10 .1940, \\
\text { LRA }\end{array}$ & 1 & Temnye allei, 1946 & Paris & $\begin{array}{l}1946, \\
1999 \\
\end{array}$ & $\begin{array}{l}\text { Vgl. den ursprunglichen Schlußsatz im MS: } \\
\text { „Myтнar aypa! }\end{array}$ \\
\hline 57 & .Stepa“ & Paris? & $\begin{array}{l}05.10 .1938 \\
\text { RGALI }\end{array}$ & 1 & $\begin{array}{l}\text { Poslednie novosti } 6419 \\
(23.10 .1938)\end{array}$ & Paris & $\begin{array}{l}1943 \\
1946 \\
1999\end{array}$ & \\
\hline 58 & . Slo rupij" & Grasse & $\begin{array}{l}24.05 .1944, \\
\text { LRA } \\
\end{array}$ & 1 & Temmye allei, 1946 & Paris & \begin{tabular}{|l|}
1946, \\
1999 \\
\end{tabular} & \\
\hline 59 & .Tanja" & Grasse & $\begin{array}{l}22.10 .1940 \\
\text { LRA }\end{array}$ & 1 & $\begin{array}{l}\text { Temnye allei, 1943, oder } \\
\text { Novyj Zurnal } 4 \text { (1943): 22-41 }\end{array}$ & New York & $\begin{array}{l}1943, \\
1946, \\
1999\end{array}$ & $\begin{array}{r}\text { Hella Reese - 9783954790210 } \\
\text { doaded from PubEactory at 01/10/2019 02:08:20AM }\end{array}$ \\
\hline
\end{tabular}




\begin{tabular}{|c|c|c|c|c|c|c|c|c|}
\hline 60 & . Temnye allei" & Paris? & $\begin{array}{l}20.10 .1938 \\
\text { RGALI } \\
\text { (Fragment) }\end{array}$ & 1 & Temmye allei, 1943 & New York & $\begin{array}{l}1943, \\
1946, \\
1999\end{array}$ & \\
\hline 61 & .Tri rublja” & Grasse & 09.12 .1940 & 1 & Novosel 'e 2 (Marz 1942): 3-8 & New York & 1 & $\begin{array}{l}\text { Laut eigenem Tagebucheintrag arbeitete } \\
\text { Bunin an dieser Erzallung am 04., 05. und } \\
09.12 .1940^{16} \text {; in verschiedenen Editionen } \\
\text { wird falschlicherweise } 1944 \text { als } \\
\text { Entstehungsdatum angegeben }\end{array}$ \\
\hline 62 & ,.'Un petit accident ${ }^{\prime \prime \prime}$ & Grasse & $\begin{array}{l}\text { 12.01.1944, } \\
\text { LRA }\end{array}$ & $\begin{array}{l}\text { Undatier, } \\
\text { RGB }\end{array}$ & Novosel'e 42-44 (1950): 1-2 & New York & 1 & 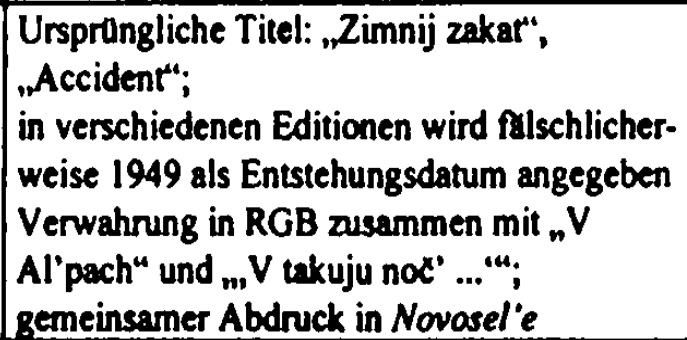 \\
\hline 63 & "V Al'pach" & $?$ & 1 & $\begin{array}{l}\text { Undatient", } \\
\text { RGB }\end{array}$ & Novosel'e 42-44(1950): 2 & New York & t & $\begin{array}{l}\text { Verwahrung in RGB ausammen mit „Un petit } \\
\text { accident“ und „ } V \text { takuju not' ...'“; } \\
\text { gemeinsamer Abdruck in Novosel'e }\end{array}$ \\
\hline 64 & "Vesnoj, v ludee" & Paris? & $\begin{array}{l}\text { 1946, } \\
\text { LRA }\end{array}$ & 1 & $\begin{array}{l}\text { Russkie novosti } 49 \\
(19.04 .1946)\end{array}$ & Paris & 1 & Ursprangliche Titel: „Noc'“4, „Kozyj syr" \\
\hline 65 & .Vizilnye karlocki" & Grasse & 05.10 .1940 & 1 & Temnye allei, 1946 & Paris & $\begin{array}{l}1946, \\
1999\end{array}$ & \\
\hline 66 & "V kanavu!" & Grasse & 1 & $\begin{array}{l}\text { 12.12.1944, } \\
\text { LRA }\end{array}$ & $\begin{array}{l}\text { Novyj turnal 168-169 (1987): } \\
78-79\end{array}$ & New York & 1 & \\
\hline 67 & $\begin{array}{l}\text { "Vodnoj znakomoj } \\
\text { ulice" }\end{array}$ & Grasse & $\begin{array}{l}25.05 .1944, \\
\text { LRA } \\
\text { (Fragment); } \\
19.05 .1944, \\
\text { RGALI } \\
\text { (ohne } \\
\text { Anfang) }\end{array}$ & 1 & $\begin{array}{l}\text { Russkie novosti } 26 \\
(09.11 .1945)\end{array}$ & Paris & $\begin{array}{l}1946, \\
1999\end{array}$ & $\begin{array}{l}\text { In der MS-Fassung ist das Zitat aus Jakov } \\
\text { Polonskijs Gedicht „Zatvornica“ (1846) } \\
\text { umfangreicher }\end{array}$ \\
\hline 68 & ..Volki“ & Grasse & $\begin{array}{l}\text { 07.10.1940, } \\
\text { RGALI }\end{array}$ & 1 & $\begin{array}{l}\text { Novoe russkoe slovo } 10658 \\
(26.04 .1942)\end{array}$ & New York & $\begin{array}{l}1946, \\
1999\end{array}$ & \\
\hline 69 & . Voron" & Grasse & $\begin{array}{l}\text { 19.05.1944, } \\
\text { RGALI }\end{array}$ & I & $\begin{array}{l}\text { Russkie novosti } 33 \\
(28.12 .1945)\end{array}$ & Paris & $\begin{array}{l}1946, \\
1999 \\
\end{array}$ & \\
\hline
\end{tabular}




\begin{tabular}{|c|c|c|c|c|c|c|c|c|}
\hline 70 & .VParize" & Grasse & $\begin{array}{l}26.10 .1940, \\
\text { RGALI } \\
\text { (Fragmente) }\end{array}$ & 1 & Novyj zurnal I (1942): 17-27 & New York & $\begin{array}{l}1943 \\
1946 \\
1999 \\
\end{array}$ & \\
\hline 71 & ".'V takuju noc' ..." & Grasse & ${ }_{20}^{20.09 .1943}$ & $\begin{array}{l}\text { April 1949, } \\
\text { RGB }\end{array}$ & Novosel'e 42-44 (1950): 2-4 & New York & $\pi$ & $\begin{array}{l}\text { Verwahrung in RGB zusammen mit „., Un } \\
\text { petit accident'“" und „V Al'pach"; } \\
\text { gemeinsamer Abdruck in Novosel'e }\end{array}$ \\
\hline 72 & .Vıoroj kofejnik" & Grasse & $\begin{array}{l}30.04 .1944, \\
\text { LRA }\end{array}$ & 1 & Novasel'e 21 (1945): 10-12 & New York & \begin{tabular}{|l}
1946, \\
1999 \\
\end{tabular} & \\
\hline 73 & "Zamuzestvo" & Grasse? & $\begin{array}{l}\text { Undatier, } \\
\text { LRA }\end{array}$ & 1 & Unveroffentlicht & 1 & 1 & \\
\hline 74 & ..Zeleznaja Serst “" & Grasse & $\begin{array}{l}01.05 .1944, \\
\text { LRA } \\
\end{array}$ & 1 & Temmye allei, 1946 & Paris & $\begin{array}{l}1946, \\
1999 \\
\end{array}$ & \\
\hline 75 & .Zojka i Valerija" & Grasse & $\begin{array}{l}13.10 .1940, \\
\text { LRA } \\
\end{array}$ & 1 & Kovceg ${ }^{2}, 1942$ & New York & $\begin{array}{l}1946, \\
1999 \\
\end{array}$ & $\begin{array}{l}\text { Auffallige Diskrepanzen zwischen MS und } \\
\text { Druckfassung }\end{array}$ \\
\hline 76 & Ohne Titel & Grasse? & $1944 ?$ & $T$ & $\begin{array}{l}\text { Abdruck als Zitat in: Irina } \\
\text { Odoevceva. Na beregach } \\
\text { Seny. Op.cit.: 273-276. }\end{array}$ & Paris & 1 & $\begin{array}{l}\text { Die Authentizităt dieser Erzałhlung wurde } \\
\text { auch von Jurij Lotman diskutien, der } \\
\text { Odoevcevas Wiedergabe fur glaubwurdig halt } \\
\text { (vgl. ders. Stat'i po istorii russkoj literarury. } \\
\text { op.cit.: 172) }\end{array}$ \\
\hline
\end{tabular}




\begin{tabular}{|c|c|c|c|c|c|c|c|}
\hline $\begin{array}{l}\text { "Bol' Soe kladbisce v } \\
\text { stenach ..." }\end{array}$ & Grasse? & $\begin{array}{l}\text { Undatien, } \\
\text { LRA }\end{array}$ & 1 & Unveroffentlicht & 1 & 1 & $\begin{array}{l}\text { Diese Sammlung enthalt u.a. die } \\
\text { Beschreibung des Sterbeprozesses } \\
\text { eines an Scharlach erkrankten kleinen } \\
\text { Jungen }\end{array}$ \\
\hline $\begin{array}{l}\text { "Do } 15 \text { let vyros } \\
\text { ocen' nemnogo ..." }\end{array}$ & Grasse? & $\begin{array}{l}\text { Undatiert, } \\
\text { LRA }\end{array}$ & $\begin{array}{l}\text { Undatiert, } \\
\text { LRA }\end{array}$ & Unveroffentlicht & 1 & 1 & \\
\hline \begin{tabular}{|l|} 
"Ee chvatilo tol'ko na \\
menja odnogo ..."
\end{tabular} & Grasse? & $\begin{array}{l}\text { Undatien, } \\
\text { LRA }\end{array}$ & $\pi$ & Unveroffentlicht & 1 & 1 & Unvollstandig \\
\hline "Ego zapiski" & Grasse? & $\begin{array}{l}\text { Undatien, } \\
\text { LRA }\end{array}$ & 1 & Unveroffentlicht & 1 & 1 & $\begin{array}{l}\text { Urspranglicher Titel: „Zapiski } \\
\text { chudožnika“; sechs kurze Skizzen } \\
\text { bzw. Dialoge }\end{array}$ \\
\hline "Jug" & Grasse? & $\begin{array}{l}\text { Undatiert, } \\
\text { LRA }\end{array}$ & 1 & Unveroffentlicht & 1 & 1 & $\begin{array}{l}\text { Beschreibungen von Mahlzeiten und } \\
\text { Gebrăuchen, franzosische } \\
\text { Sprichworter etc. }\end{array}$ \\
\hline "K Parizu" & Grasse? & \begin{tabular}{|l|} 
Undatien, \\
LRA \\
\end{tabular} & 1 & Unveroffentlicht & 1 & 1 & Impressionen aus Paris etc. \\
\hline $\begin{array}{l}\text { "Otel' na Antibskom } \\
\text { mysu" }\end{array}$ & Grasse? & $\begin{array}{l}\text { 10.06.1944, } \\
\text { LRA } \\
\end{array}$ & 1 & Unveroffentlicht & 1 & 1 & $\begin{array}{l}\text { Entwurf bricht ab; gehort zur } \\
\text { Sammlung,Jug" }\end{array}$ \\
\hline $\begin{array}{l}\text { "Spal'nja byla v } \\
\text { uglovoj komnate ..." }\end{array}$ & Grasse? & $\begin{array}{l}\text { Undatien, } \\
\text { LRA }\end{array}$ & 1 & Unveroffentlicht & 1 & 1 & $\begin{array}{l}\text { Auffallig ist die fehlende } \\
\text { Beschreibung des Koitus. die dem } \\
\text { Zustand des Papiers nach zu urteilen } \\
\text { vermutlich nachtraglich } \\
\text { herausgetrennt wurde }\end{array}$ \\
\hline $\begin{array}{l}\text { "Spjat v odnoj } \\
\text { komnate ..." }\end{array}$ & Grasse? & $\begin{array}{l}\text { Undatiert, } \\
\text { LRA }\end{array}$ & 1 & $\begin{array}{l}\text { Novyj turnal 168-169(1987): } \\
74-75\end{array}$ & New York & 1 & \\
\hline $\begin{array}{l}\text { "Stisnuv zuby } v \\
\text { poslednjuju } \\
\text { minutu..." }\end{array}$ & Grasse? & $\begin{array}{l}\text { Undatien, } \\
\text { LRA }\end{array}$ & 1 & Unveroffentlicht & 1 & 1 & $\begin{array}{l}\text { Gehort zur Sammlung "Spjat v odnoj } \\
\text { komnate ..." }\end{array}$ \\
\hline $\begin{array}{l}\text { "V Sestom casu } \\
\text { sentrjabskogo } \\
\text { vecera ..." }\end{array}$ & Grasse? & $\begin{array}{l}\text { Undatiert, } \\
\text { LRA }\end{array}$ & 1 & Unveroffentlicht & 1 & 1 & $\begin{array}{l}\text { Entwurf bricht ab; getort zur } \\
\text { Sammlung „Jug" }\end{array}$ \\
\hline $\begin{array}{l}\text { "Źensciny, devuski, } \\
\text { devocki" }\end{array}$ & Grasse? & $\begin{array}{l}\text { Undatier, } \\
\text { LRA } \\
\end{array}$ & 1 & Unveroffentlicht & 1 & 1 & $\begin{array}{l}\text { Beschreibungen von Frauen jeden } \\
\text { Alters }\end{array}$ \\
\hline $\begin{array}{l}\text { "Zimnjaja nox", ocen' } \\
\text { snežno..." }\end{array}$ & Grasse? & $\begin{array}{l}\text { Undatiert, } \\
\text { LRA } \\
\end{array}$ & 1 & Unveroffentlicht & 1 & 1 & Wetterbeschreibungen \\
\hline
\end{tabular}


'Es gelten Daten und Text der Endredaktion. Die zu den Temmye allei (in der Pariser Edition von 1946) gehorenden Erzahlungen sind kursiviert.

${ }^{2}$ Manuskript; falls vortanden (sofern nachweisbar durch handschriftliche Notiz Bunins nach Fertigstellung der Erzahlung oder durch Erwahnung im Tagebuch); als Entstehungsdatum gilt das spateste Datum, vorausgesetzt, es handelt sich nicht um eine weitere Redaktion mit wesentlichen Ändenungen.

${ }^{3}$ Typoskript; falls vorhanden (sofern nachweisbar durch handschrifliche Notiz Bunins nach Fertigstellung der Erzahlung oder durch Erwathnung im Tagebuch).

"In dieser Kategorie werden die Editionen von 1943 und 1946 sowie die dieser Analyse zugnunde liegende Fassung von 1999 berucksichtigt.

${ }^{3} \mathrm{Vgl}$. Anmerkung Leonid Zurovs anlaBlich der Veroffentlichung der Erzahlung "Alja“" im NZ 69 (1962): 1S. Bunin enwathnt dieses Paket in seinem literarischen Vermächenis aus dem Jahr 1951 ("Literatumoe zavesčanie“". In: Nz 66 [1961]: 170).

${ }^{6}$ Titel der Erzahlung im Manuskript- bzw. Typoskriptstadium, gilt fur alle weiteren Erzahlungen mit einer Anmerkung zum ursprunglichen Titel.

'Vgl. einen Brief Bunins an M. Karamzina vom ca. 31.05 .1938 (genaues Datum nicht bestimmbar): „Когда я писал ,Митину любовь', я делал некоторые заметки - в два, в три слова чаше всего. Tеперь я написал по ним этн ,Bарнанты““” (2it. in: LN. 84.Bd. (1) Moskva, 1973: 668).

Vgl. LRA. MS.1066/86.

$9 \mathrm{Vgl}$. Tagebucheintrag Bunins vom 01.11.1943. Zit. in: UB. 3.Bd. Frankfurt am Main, 1982: 157.

${ }^{10} \mathrm{~V}$ gl. LRA. MS.1066/112.

"VgI. LRA. MS.1066/118.

${ }^{12}$ Undatiertes Typoskript, vermutlich fulr Artikel in Novoe russkoe slovo (1937). In: Gosudarstvennyj literatumyj muzej, Moskau.

${ }^{13} \mathrm{Vgl}$. Varianten der Erzâhlung im LRA. MS.1066/137-142.

i4 Vgl. Tagebucheintrag Bunins vom 23.10.1943. Zit. in: UB. 3.Bd. op.cit.: 157.

is Vgl. die unprazise Anmerkung Leonid Zurovs anlaBlich der Veroffentlichung der Erzahlung: „Рассказ „Рнвьера“ Иван Алексеевич хотел включить в книгу ,Темные аллен', но потом раздумал. Оставил его в пакете с ненапечатаннымн рассказами“" (in: Nz 68 [1962]: 5).

${ }^{16}$ Zit. in: UB. 3.Bd. op.cit.: 71.

"LRA. MS.1066/274.

18 Vgl. UB. 3.Bd. op.cit.: 75 .

${ }^{19}$ In der jungsten Werkausgabe Bunins, der SS v vos'mi tomach (1999), wird das Entstehungsdatum mit 1949 angegeben (6: 582).

${ }^{20}$ In verschiedenen Editionen der Temmye allei, auch im Rahmen der $S S v$ vos'mi tomach (1999), dem Referenzwerk der vorliegenden Dissertation, wird als Entstehungs. datum falschlicherweise der 07.04.1949 angegeben: Zum einen erwăhnt Bunin in einem Brief an Boris Zajcev vom 19.11.1943 diese Erzahlung zusammen mit anderen Erzahlungen, die er dem Freund zur Aurbewahrung schickte (zit. in: „Pis'ma I. Bunina k B. Zajcevu“. In: NZ 137 [1979]: 126), zum anderen fuhrt er die Erzahlung mit dem in der obigen Tabelle genannten Entstehungsdatum in der Liste von Erzahlungen auf, die er im Juli 1944 an Boris Zajcev schickte (vgl. Fotokopie dieser Liste in R. Fedoulova. "Les allees sombres d'Ivan Bounin“. [Masch.schr.] Diss. Paris, 1980: Anhang).

${ }_{21} \mathrm{Vgl}$. Brief Aldanovs an Bunin vom 29.06.1942: „Кроме того в сборнике ,Ковчег“, выпущенном недавно Мансветовым, Марней ТолстоЯ (дочерью Андрея Львовича, женой Мансветова, позтессой) и Кодрянской, появился рассказ ,Зойка и Валерня ““ (zit. in: „Perepiska I. A. Bunina s M. A. Aldanovym”. In: Nz 150 [1983]: 168). 
13.2 Anhang 2: Übersicht über den Formierungs- und Modifikationsprozeß der Temnye allei (1941-1953) ${ }^{1}$

\begin{tabular}{|c|c|c|c|c|c|c|}
\hline $\begin{array}{l}\text { Stand Fruhjahr } \\
\text { 1941, an Aldanov } \\
\text { geschickt }\end{array}$ & $\begin{array}{l}\text { New Yorker Ausgabe } \\
(1943)\end{array}$ & $\begin{array}{l}\text { Stand April 1944, } \\
\text { Brief an Tefri, } \\
11.04 .1944^{3}\end{array}$ & $\begin{array}{l}\text { Stand ca. Mai 1944', } \\
\text { vermutlich als Anlage } \\
\text { eines Briefes im Juli } \\
1944 \text { an Zajcev } \\
\text { geschickt }\end{array}$ & \begin{tabular}{|l|} 
Stand Ende 1945, \\
ergynzte New Yorker \\
Ausgabe (1943)
\end{tabular} & $\begin{array}{l}\text { Pariser Ausgabe von } \\
1946\end{array}$ & $\begin{array}{l}\text { Stand } 1953^{6}, \\
\text { erginzte Pariser } \\
\text { Ausgabe (1946) }\end{array}$ \\
\hline Komplex I & Komplex I & Komplex I & Komplex I & Komplex I & Komplex I & Komplex I \\
\hline "Temnye allei" & .. Temmye allei" & "Temnye allei" & "Temnye allei" & "Temnye allei" & "Temmye allei" & "Temnye allei" \\
\hline "Kavkaz" & .Kavkaz" & "Kavkaz" & "Kavkaz" & "Kavkaz" & "Kavkaz" & "Kavkaz" \\
\hline "Ballada“ & "Ballada" & "Ballada" & "Ballada" & "Ballada" & "Ballada" & "Ballada" \\
\hline .Aprel'" & .Aprel ${ }^{\prime \prime \prime}$ & .Aprel'" & "Aprel"“ & & & \\
\hline ..Stepa" & ..Stepa" & "Stepa" & "Stepa" & "Stepa" & Stepa" & "Stepa" \\
\hline "Muza" &. Muza" & "Muza" & "Muza“ & "Muzs" & "Muza" & "Muza" \\
\hline "Pozdnij Cas" & .Pozdnij cas" & "Pozdnij Cas" & "Pozdnij Cas" & "Pozdnij cas" & "Pozdnij cas" & „Pozdnij cas" \\
\hline \multirow[t]{3}{*}{ Komplex II } & Komplex II & Komplex II & Komplex II & Komplex II & Komplex II & Komplex II \\
\hline & & "Mamin sunduk" & "Mamin sunduk" & "Rusja“" & "Rusja" & "Rusja“ \\
\hline & & $\begin{array}{l}\text { "Po ulice mostovoj" } \\
\text { (später: „Durocka") }\end{array}$ & "Po ulice mostovoj" & & "Krasavica" & "Krasavica" \\
\hline "Rusja" & .Rusja" & "Rusja" & „Rusja“ & & "Durocka" & "Durocka" \\
\hline "Antigona" & & "Antigona" & "Antigona" & & .Antigona" & "Antigona" \\
\hline "Smaragd" & & "Smaragd" & "Sinaragd" & "Smaragd" & .Smaragd" & "Smaragd" \\
\hline $\begin{array}{l}\text { "Pasa“" } \\
\text { (spater „Gost”") }\end{array}$ & & "Gost"“ & "Gost"“ & & "Gost" & "Gost" \\
\hline „Vizitnye kartocki“ & & "Vizitnye kartocki" & "Vizitnye kartocki“ & "Volki" & "Volki" & "Volki" \\
\hline
\end{tabular}




\begin{tabular}{|c|c|c|c|c|c|c|}
\hline "Volki" & & "Volki" & "Volki" & "Vizitnye kartocki" & . Vizilmye kartocki" & "Vizitnye kartocki" \\
\hline "Zojka i Valerija" & & "Zojka i Valerija" & „Zojka i Valerija" & "Zojka i Valerija" & "Zojka i Valerija" & „Zojka i Valerija“ \\
\hline "Tanja“ & .Tanja" & "Tanja" & "Tanja" & „VParize" & "Tanja" & "Tanja" \\
\hline "V Parize" & .VParize" & "V Parize" & "V Parize" & "Tanja“ & "V Parize" & "V Pariže" \\
\hline "Galja Ganskaja“ & & "Galja Ganskaja" & "Galja Ganskaja" & "Galja Ganskaja" & .Galja Ganskaja" & "Galja Ganskaja" \\
\hline "Genrich" & & "Genrich" & "Genrich" & "Genrich" & "Genrich" & "Genrich" \\
\hline "Tri rublja" & & "Tri rublja" & "Tri rublja" & & & \\
\hline $\begin{array}{l}\text { "Natali" (mit Bleistift } \\
\text { hin-zugefugt) }\end{array}$ & .Nasali" & "Natali" & "Natali" & "Natali" & "Natali" & .Natali" \\
\hline Komplex III & Komplex III & Komplex III & Komplex III & Komplex III & Komplex III & Komplex III \\
\hline \multirow[t]{14}{*}{ „Pro obez'janu“ } & & "Na postojalom dvore" & „Na postojalom dvore" & $\begin{array}{l}\text { "V odnoj znakomoj } \\
\text { ulice" }\end{array}$ & $\begin{array}{l}\text { "Vodnoj znakomoj } \\
\text { ulice" }\end{array}$ & $\begin{array}{l}\text { "V odnoj znakomoj } \\
\text { ulice" }\end{array}$ \\
\hline & & „,V takuju noc" ..." & ".V takuju noc" ..." & & & \\
\hline & & "Lita" & "Lita" & & & \\
\hline & & "Nacalo" & "Nacalo" & & & \\
\hline & & "Kaceli" & "Kaceli" & "Recnoj traktir" & "Recnoj traktir" & "Rečnoj traktir" \\
\hline & & "Kuma" & "Kuma" & "Kuma" & .Kuma" & "Kuma" \\
\hline & & "Rečnoj traktir" & "Recnoj traktir" & "Nacalo" & .Nacalo" & "Nacalo" \\
\hline & & "'Dubki"“ & "Dubki"“ & "Dubki"“ & ...Dubki" & ...Dubki"“ \\
\hline & & & "Baryšnja Klara" & & . Baryśnja Klara" & „Baryšnja Klara“ \\
\hline & & & "Achmat" & & & \\
\hline & & & "Au secours!" & & & \\
\hline & & & "Alupka“ & & & \\
\hline & & & ...Kogda ja vpervye" "i" & & & \\
\hline & & & "Krem Leodor" & & & \\
\hline
\end{tabular}




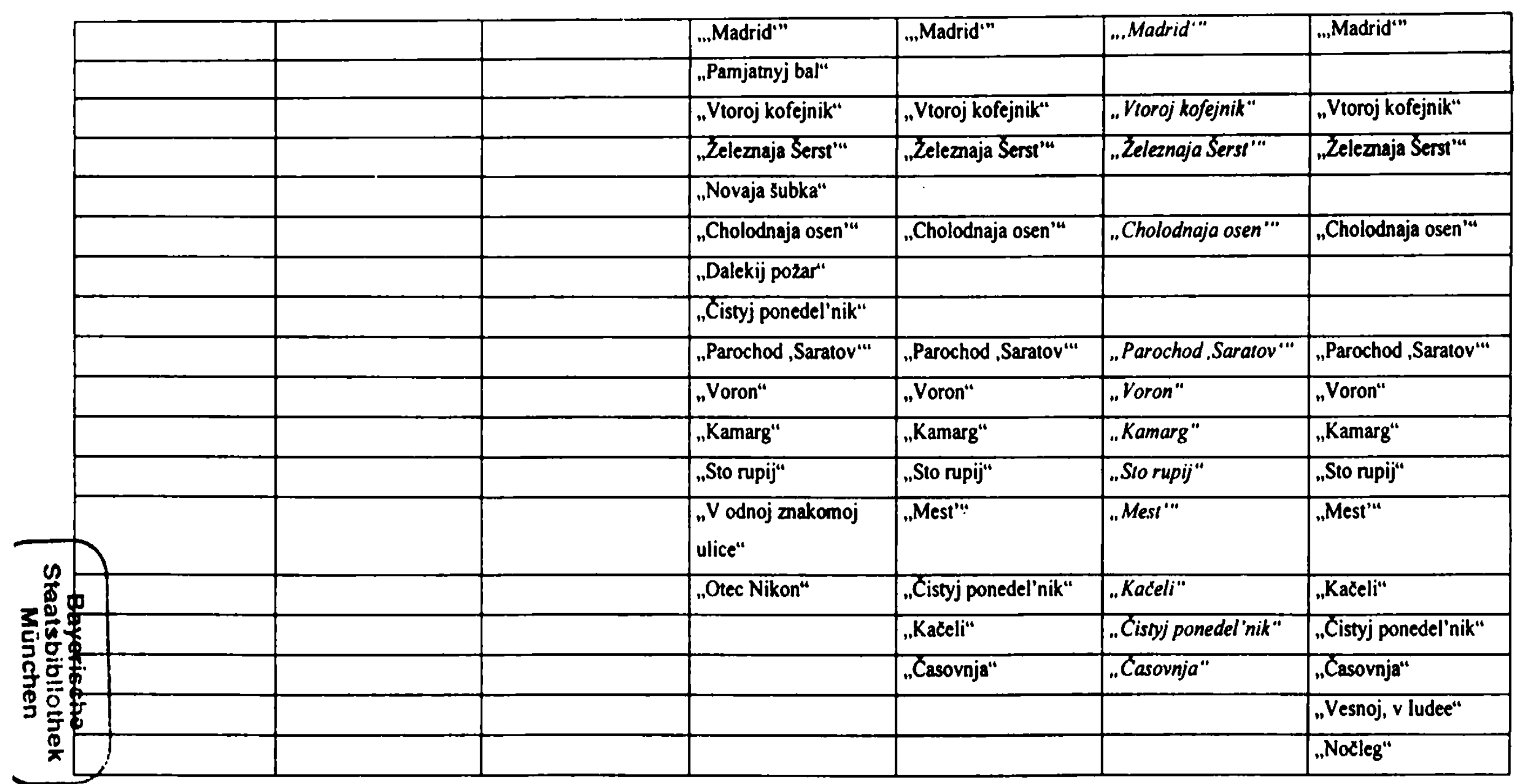

'Zur besseren Vergleichbarkeit wurde der Inhalt der publizierten Fassungen kursiviert.

${ }^{2}$ RGB, fond 429, karton 3, edinica chranenija 21.

${ }^{3}$ Brief an Teffi vom 11.04.1944. Zit. in. „Perepiska Teffi s I. A. i V. N. Buninymi 1939-1948“. In: Diaspora II (2001): 510-511.

"Vermutlich eine Anlage zu einem Brief an Zajcev vom 14.07.1944. Zit. in: „Pis'ma I. Bunina k B. Zajcevu“. In: Nzz 137 (1979): 139.

"Vgl. Erwahnung dieser Liste im Brief an Telesov vom 08.12.1945. Zit. in: „Perepiska s N. D. Telesovym 1897.1947“. In: LN. 84.Bd. (1) Moskau, 1973: 627. Zitiert wird diese Liste nach einer Kopie aus dem LRA; das Original wird im Telesov-Museum in Moskau verwahrt.

${ }^{6} \mathrm{Vgl}$. Bunins personliches Exemplar der Temmye allei (IMLI); die Ergănzungen erfolgten mutmaßlich kurz vor seinem Tode (vgl. Kap. 3.3, 4.5). 


\section{Slavistische Beiträge}

Studienhilfen

Herausgegeben von Peter Rehder

Bd. $264+370$

Nikolaos H. Trunte

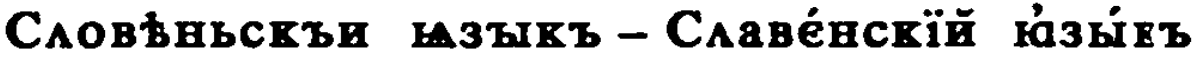

Ein praktisches Lehrbuch des Kirchenslavischen in 30 Lektioien

Band I: Altkirchenslavisch - Band 2: Mittcl- und Neukirchenslarisch

Bd. I: 5., vollig neu bearbeitete Aufl. 2003. XXXIV. 317 S. 20 E. ISBN 3-8769-480-3

Bd. II: Durchges. Nachdr. 2001 der 1. Aun. 1998. XXX. 520 S. 28.63 E. ISBN 3-87,90-716-0

Bd. $308+334$

Alois Schmaus

Lehrbuch der serbischen Sprache, Band I + II

Studienhilfen $2+4$

Vollständig neu bearbeitet von Vera Bojić

Bd. I: 2.. verb. Aun. 1996. 186 S. $15.34 \in$. ISBN 3-87690-568-0

Bd. II: 1. Aufl. 1996. 252 S. 18.41 $€$. ISBN 3-87690-624-5

Bd. 324

Werner Lehfeldt

Studienhilfen 3

Einführung in die Sprachwissenschaft für Slavisen

2.. verb. und erg. Aufl. 1996. 182 S. 15.34 E. ISBN 3-87690-606-7

Bd. 346

Hans Oppermann

Studienhilfen 5

Частное неофициальное тисьмо и тексты-рассуждения

Persönlicher Briefwechsel und Erörterungen auf Russisch

Ein Lehr- und Übungsheft für Fortgeschrittene

1. Aun. 1997. 123 S. 10.23 E. ISBN 3-87690-666-0

Bd. $351+372$

Bohumil Jiří Frei

Studienhilfen $6+10$

Tschechisch gründlich und systematisch

Ein Lehrbuch - Band I + II

Bd. I: 1. Aufl. 1997. 360 S. 18.41 E. ISBN 3-87690-671-7

Bd. II: I. Aufl. 1998. 552 S. 23.52 E. ISBN 3-87690.718-7

Bd. 353

Анна А. Зализняк, Алексей Д. Шмелев

Studienhilfen 7

Лекции по русской аспектологии

1. Aufl. 1997. 151 S 13.29 E. ISBN 3-87690-673-3

Bd. 369

Marija Korom

Studienhilfen 8

Kroatisch für die Mittelstufe

Lese- und Übungstexte

2. uberarb. und erw. Aufn. $2001 . X .275$ S. 17.38 E. ISBN 3-87690-715.2

Bd. 403

Josef Vintr

Studienhilfen II

Das Tschechische

Hauptzüge seiner Sprachstruktur in Gegenwart und Geschicite

1. Aun 2001 1. 240 S. $20.45 €$. ISBN 3-87690-796-9

Bd. 416

Charles E. Townsend, Laura A. Janda

Studienhilfen 12

Gemeinslavisch und Slavisch im Vergleich

Einführung in die Entwicklung von Phonologie und Flexion vom Frühurslavischen über das

Spätgemeinslavische bis in die slavischen Einzelsprachen mit besonderer Berücksichtigung des Russischen, Polnischen. Tschechischen, Serbischen/Kroatischen, Bulgarischen

Übersetzung, Redaktion und Layout Peter Rehder

Durchges. Nachdr. 2003 der I. Aufl. 2002. 237 S. $10 €$. ISBN 3.87690.831.0

Bd. 420

Claudia Hurtig, Taccjana Ramza

Studienhilfen 13

Belarussische Grammatik in Tabellen und Übungen

Граматыка беларускай мовы ў табліцах мдақтықаваннях 